\title{
Cobalt-Catalyzed Aerobic Oxidative Cyclization Reactions of Bisnucleophiles: New Methodologies and the Role of Bisnucleophiles in 02 Activation
}

Jiaqi Liu

West Virginia University, jqliu@mix.wvu.edu

Follow this and additional works at: https://researchrepository.wvu.edu/etd

Part of the Inorganic Chemistry Commons, Medicinal-Pharmaceutical Chemistry Commons, and the Organic Chemistry Commons

\section{Recommended Citation}

Liu, Jiaqi, "Cobalt-Catalyzed Aerobic Oxidative Cyclization Reactions of Bisnucleophiles: New Methodologies and the Role of Bisnucleophiles in 02 Activation" (2020). Graduate Theses, Dissertations, and Problem Reports. 7929.

https://researchrepository.wvu.edu/etd/7929

This Dissertation is protected by copyright and/or related rights. It has been brought to you by the The Research Repository @ WVU with permission from the rights-holder(s). You are free to use this Dissertation in any way that is permitted by the copyright and related rights legislation that applies to your use. For other uses you must obtain permission from the rights-holder(s) directly, unless additional rights are indicated by a Creative Commons license in the record and/ or on the work itself. This Dissertation has been accepted for inclusion in WVU Graduate Theses, Dissertations, and Problem Reports collection by an authorized administrator of The Research Repository @ WVU.

For more information, please contact researchrepository@mail.wvu.edu. 


\title{
Cobalt-Catalyzed Aerobic Oxidative Cyclization Reactions of Bisnucleophiles: New Methodologies and the Role of Bisnucleophiles in $\mathrm{O}_{2}$ Activation
}

\author{
Jiaqi Liu \\ Dissertation submitted to: \\ Eberly College of Arts and Sciences \\ West Virginia University \\ In partial fulfillment of the requirements for the degree of \\ Doctor of Philosophy \\ in \\ Chemistry \\ Jessica Hoover, Ph.D., Committee Chair \\ Brian Popp, Ph.D. \\ Carsten Milsmann, Ph.D. \\ Björn Söderberg, Ph.D. \\ Hanjing Tian, Ph.D. \\ Department of Chemistry \\ Morgantown, West Virginia, 2020
}

Keywords: cobalt, homogenous catalysis, 2-aminophenol, 2-aminoaniline, isonitrile, aerobic oxidation, nitrogen heterocycles, benzoxazoles, benzimidazoles, cyclization, synthetic methods, cobalt complexes

Copyright 2020 Jiaqi Liu 


\section{Abstract \\ Cobalt-Catalyzed Aerobic Oxidative Cyclization Reactions of Bisnucleophiles:}

New Methodologies and the Role of Bisnucleophiles in $\mathrm{O}_{2}$ Activation

\section{Jiaqi Liu}

Over the past few decades, transition metals have found wide applications in the development of selective oxidative transformations mediated by molecular oxygen. Due to the benign nature of molecular oxygen as an oxidant and an increasing awareness of green chemistry practice, tremendous progress has been made towards the development of $\mathrm{Cu}$-and $\mathrm{Pd}$-catalyzed aerobic oxidation reactions. As a first-row transition metal alternative to copper, cobalt has been employed in aerobic catalytic transformations for its cost-efficiency and earth abundance; however, redox-active mediators such as benzoquinone (BQ), N-hydroxyphthalimide (NHPI) or salen-type ligands are usually required. To date, reactions mediated by $\mathrm{Co} / \mathrm{O}_{2}$ catalytic systems in the absence of redox mediators are still limited. In this regard, we developed a highly efficient protocol employing a $\mathrm{Co} / \mathrm{O}_{2}$ catalytic system without acquiring external mediators to turn-over the cycle.

This dissertation offers a brief overview of advancements in cobalt-catalyzed aerobic oxidative reactions in chapter 1 , where three major classes of oxidation reactions mediated by $\mathrm{Co} / \mathrm{O}_{2}$ systems are particularly addressed. Chapterss 2 and 3 describe the development of a series of new cobalt-catalyzed aerobic cyclization reactions of bis-nucleophiles. When isonitriles are employed as coupling partners, a wide variety of functionalized 2-aminobenzoxazoles and 2aminobenzimidazoles are afforded as pharmaceutically valuable structures. These protocols are additive-free, ligand-free, highly efficient, and require no external redox-active mediators. Mechanistic studies point to the dual function of the bis-nucleophile as both a substrate and a redox-active ligand, and its importance in activating molecular oxygen as the stoichiometric oxidant. Additionally, the bis-nucleophile may act as a hydrogen atom donor capable of participating in hydrogen atom transfer (HAT) reactions. Chapter 4 elucidates the synthesis and characterization of two unprecedented $\mathrm{Co}^{\mathrm{II}}$ and $\mathrm{Co}^{\mathrm{III}}$ complexes consisting of the $\mathrm{N}$-unsubstituted aminophenol ligand. As a continuous effort in deepening mechanistic investigations, these metal complexes are regarded as potential active reaction intermediates and have demonstrated success in enabling $\mathrm{O}_{2}$ activation thus mediating oxidative cyclization transformations afterward. 
I have been taught not to use subjective words in my thesis, but I don't care this time.

To my dearest mom and dad,

I could never thank you enough for being the most awesome parents in the world. 


\section{Acknowledgement}

When I look back to seven years ago, the first time I came to the United States, I couldn't imagine the journey I have made so far. With semi-broken English, I even didn't know how to order my first meal at the only open place on a quiet Sunday morning. I was brave and ambitious;

however, I underestimated the challenges along the path I chose. On this journey of studying abroad, I doubted myself hundreds of times and I even wondered if this path towards the Ph.D. is designed for me. Being an international graduate student who switched the major and tackling with stress from improving language proficiency and unexpected cultural shocks, I must admit the whole process was a pain, but it was a good pain. Without experiencing it I would never see my potential, become a stronger person each time from a fall, and stand at the point where I am now telling the story of the past myself as if I am talking about an old friend.

I would like to express my sincere gratitude to my Ph.D. advisor, Dr. Jessica Hoover, who has played an essential role in this journey. Her guidance on my research not only improved the way I visualize science but also impacted many other ways like how I see and solve problems arise in life. She is a serious scientist and a true educator. She cares about the growth of students both academically and mentally. Her high standard in guiding graduate researchers is an awarding experience when a person looks back. I have seen tremendous progress in myself regarding writing and verbal communication skills. What I truly admire is that she is always open to the words and opinions, which created a resilient group culture and made my graduate study enjoyable. I feel fortunate being one of her students in one of the important times of my life.

I sincerely appreciate every member of my committee, Dr. Brian Popp, Dr. Carsten Milsmann, Dr. Björn Söderberg, and Dr. Hanjing Tian for their guidance and active involvement in my 5 years' career in grad school. I also truly appreciate Dr. Novruz Akhmedov for NMR experimental assistance, Dr. Jeffrey Petersen, and Dr. Brian Dolinar for X-ray diffractometry interpretations, Dr. Michael Gunther for EPR measurements, and members from the WVU BioNano Research Facilities (BNRF) for ESI-MS analysis. I am thankful for all the kind help offered by Randy, Allen, Sherman, and Greg for technical work in maintaining instruments. Without their efforts, my research couldn't have been progressed so smoothly. 
I want to show gratitude to all my groupmates for being my colleagues and friends. I am thankful for current group members, Prof. Andreas Baur, Dr. Shannen Lorraine, Rob Crovak, Michael Stanton, Rebekah Krupa, Rabina Basnet, and Karl Golian, their presence makes a great Hoover family. I also want to thank all group alumni who had mentored me, John Riedesel, Dr. Aaron Honeycutt, Dr. Minghao Li, Dr. Anitha Shankara Linge Gowda, Dr. Bhasker Radaram, Dr.

Oliver Mitevski, and Dr. Aaron Honeycutt. Additionally, I would like to thank every undergraduate student I have mentored, these mentorships make me a more responsible individual and I appreciate the input from all of them in their transformation into scientists. I want to thank Dr. Kerry-Ann Green particularly for being an awesome team member and a friend for three years in the Hoover group, I appreciate she is always there for sincere advices and believing in me.

I am deeply grateful to all the lovely persons I have met in the United States. Their friendship and sincerity make me a warm home in this country. I also truly appreciate all the love and the care my families in China have sent along these years. I want to thank a great guy Suhil, my boyfriend. He has shown incredible patience with me and my occasionally occurred irregular temper, and always send me positive vibes even life might be hard for him sometimes. I could never thank my amazing parents enough for their inspiration, drive, and unconditional support. Nothing I do could fully show my gratitude for them. They are not only my parents; they are my teachers. They have guided me so far throughout the journey, and I know their wisdom and support will keep enlightening my future path, no matter where I will be and how far I will go.

Finally, I acknowledge the C. Eugene Bennett Department of Chemistry at West Virginia University for the generous offer and financial support to make the accomplishment of my Ph.D. study true. 


\section{Table of Contents}

Title Page

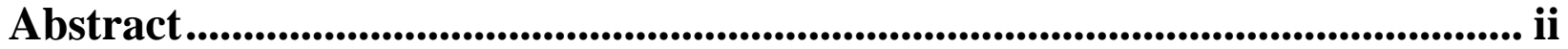

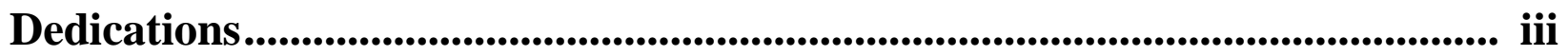

Acknowledgements...................................................................................................... iv

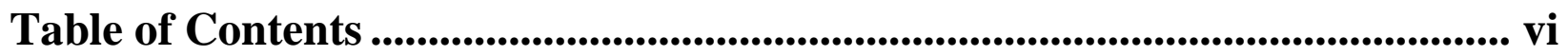

List of Schemes

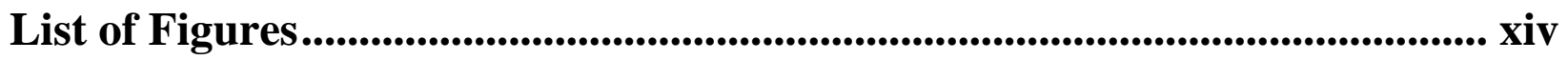

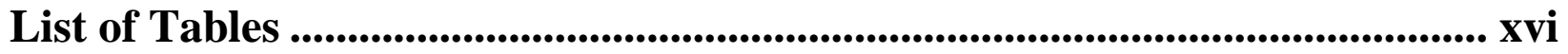

List of Abbreviations ....................................................................................... Xviii

Chapter 1. Cobalt-catalyzed Aerobic Oxidation Reactions: An Overview....... 1

1.1. Transition-Metal Catalyzed Oxidation of Organic Substrates with $\mathrm{O}_{2}$ Oxidant............ 1

1.2. Historic Overview of $\mathrm{Co} / \mathrm{O}_{2}$ Catalysis .............................................................. 3

1.2.1. Mukaiyama Olefin Oxygenation and Oxidative Cyclization of Alkenols.... 3

1.2.2. Co/NHPI-Catalyzed Aerobic Oxidative Reactions ......................................... 6

1.2.3. Cobalt Schiff Base Complexes in Aerobic Oxidation Reactions .................10

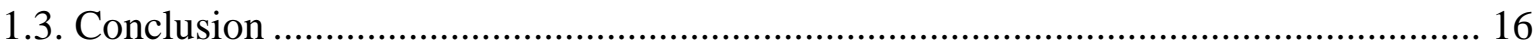

Chapter 2. Cobalt-Catalyzed Aerobic Oxidative Cyclization of 2-Aminophenols with Isonitriles: 2-Aminophenol Enabled $\mathrm{O}_{2}$ Activation by Cobalt(II)........... 17

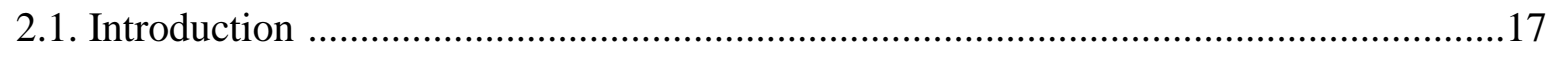

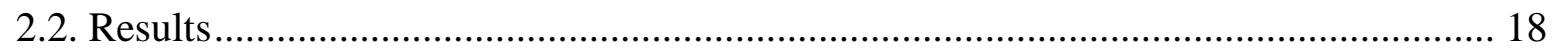

2.2.1. Condition Optimization for Cobalt-Catalyzed Oxidative Cyclization of 2-

Aminophenol with tert-Butyl Isonitrile. 
2.2.2. Substrate Scope of Substituted 2-Aminophenols and Isonitriles 20

2.2.3. Preliminary Mechanistic Investigations .................................................... 22

2.2.3.1. Testing the Presence of Trappable Radical Intermediates. 22

2.2.3.2. The Importance of $\mathrm{O}_{2}$ in Oxidative Cyclization and a Plausible

Path for $\mathrm{O}_{2}$ Activation...

2.2.3.3. Probing the Reaction Mechanism Through UV-Visible Studies .26

2.2.3.4. Other Considerations ...........................................................28

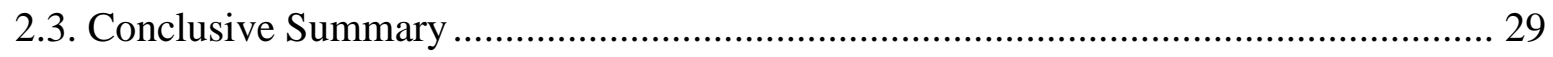

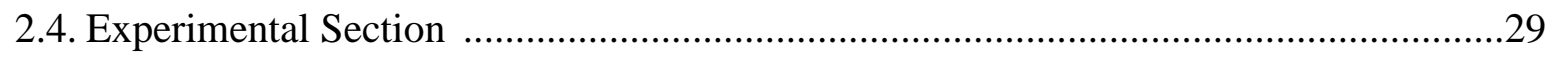

2.4.1. General Considerations ...........................................................................29

2.4.2. Procedure for Screening of the Reaction Conditions ................................29

2.4.3. Synthesis and Characterization of the 2-Aminobenzoxazoles …...................32

2.4.4. Procedures for Control Experiments .......................................................43

2.4.4.1. Control Experiments under a Nitrogen Atmosphere................... 43

2.4.4.2. Control Experiment with a Cobalt(III) Source.............................. 44

2.4.4.3. Control Experiment with a Peroxide Oxidant .............................. 45

2.4.4.4. Control Experiments with Radical Trapping Reagents................ 46

2.4.4.5. Control Experiments in the Absence of Isonitrile ........................ 47

2.4.4.6. Experimental Procedures for UV-Visible Experiments................ 50

\section{Chapter 3. Cobalt-Catalyzed Aerobic Oxidative Cyclization of 2-Aminoanilines with Isonitriles: Facile Access to Substituted 2-Aminobenzimidazoles........... 56}

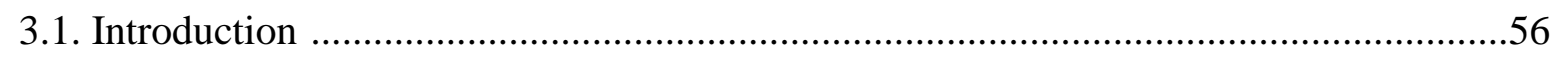

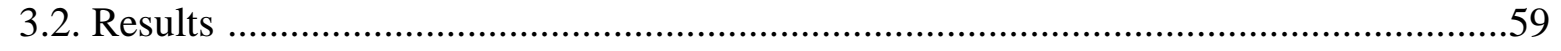

3.2.1. Condition Optimization of Cobalt-Catalyzed Aerobic Oxidative Cyclization of $o$-Phenylenediamine with tert-Butyl Isonitrile ............................................... 59 
3.2.3. Application of the Cobalt-Catalyzed Oxidative Cyclization of $o$ -

Phenylenediamines with Isonitriles

3.2.4. Radical Trapping Experiments for the Standard Reaction 69

3.3. Conclusive Summary 70

3.4. Experiment Section 70

3.4.1. General Considerations. 70

3.4.2. Optimization of the Reaction Condition 71

3.4.3. Reaction Parameter Assessment. 74

3.4.4. Alternative Reaction Setups 79

3.4.5. Synthesis and Characterization of 2-Aminobenzimidazoles (5) and Other Reaction Products (6) 81

3.4.6. Synthesis of 2-Aminobenzimidazoles (5s and $\mathbf{5 t}$ ) 91

3.4.7. Procedures for Control Experiments with Radical Trapping Agents . 94

3.4.8. Attempts in the Synthesis of Mebendazole from 2-Amino-5-Benzoyl Benzimidazole

\section{Chapter 4. Synthesis, Isolation and Characterization of the Well-Defined Co ${ }^{\text {II }}$ and $\mathrm{Co}^{\mathrm{III}}$ Complexes bearing $\mathrm{NH}_{2}$-unsubstituted Aminophenol Ligands and Their Reactivity Studies in the Aerobic Oxidative Cyclization Reactions...... 99}

4.1. Introduction .99

4.2. Results 104

4.2.1. Synthesis of $\mathrm{Co}^{\mathrm{II}}$ complex bearing 2-amino-4,6-di-tert-butylphenol ligands $\mathrm{Co}^{\mathrm{II}}(2 \text {-amino-4,6-tert-butylphenolate })_{2}$ (2-amino-4,6-tert-butylphenol $)_{2}$..... 104

4.2.2. Synthesis of $\mathrm{Co}^{\mathrm{III}}$ complex bearing 2-amino-4,6-di-tert-butyl phenol ligands $\mathrm{Co}_{2}{ }^{\text {III }}$ (2-amino-4,6-tert-butylphenolate) ${ }_{2}$ (2-amino-4,6-tert-butylphenol)( $\mu$-2amido-4,6-tert-butylphenolate) $)_{2}$ 107 
4.2.3. Evaluations of the Electronic Properties of $\mathrm{Co}^{\mathrm{II}}-\mathrm{AP}^{\mathrm{ditBu}}(7)$ and $\mathrm{Co}^{\mathrm{III}}$ $\mathrm{AP}^{\mathrm{ditBu}}(\mathbf{8})$ Complexes

4.2.3.1. UV-Visible Spectroscopy

4.2.3.2. Cyclic Voltammetry

4.2.3.3. EPR Measurements.

4.2.4. Aerobic Oxidation of $\mathrm{Co}^{\mathrm{II}}$ (2-amino-4,6-tert-butylphenolate) ${ }_{2}$ (2-amino-4,6tert-butylphenol $)_{2}$ in Solution

4.2.5. Reactivity of $\mathrm{Co}^{\mathrm{II}}$ and $\mathrm{Co}^{\mathrm{III}}$ Complexes in the Standard Aerobic Oxidative Coupling Systems

4.2.5.1. Catalytic and Stoichiometric Reactivity of $\mathrm{Co}^{\mathrm{II}}$ Complex (7) in the Oxidative Cyclization Reactions

4.2.5.2. Catalytic and Stoichiometric Reactivity of $\mathrm{Co}^{\mathrm{III}}$ Complex $(\mathbf{8})$ in the Oxidative Cyclization Reactions

4.3. Conclusive Summary

4.4. Experimental Section

4.4.1. General Considerations.

4.4.2. Synthesis of 2-amino-4,6-di-tert-butylphenol ligand

4.4.3. Synthesis of 5,7-di-tert-butyl-2-(tert-butylamino)benzoxazole (3w) by Aerobic Oxidative Cyclization Reaction

4.4.4. Synthesis of $\mathrm{Co}^{\mathrm{II}}-\mathrm{AP}^{\mathrm{ditBu}}$ Complex $\mathrm{Co}^{\mathrm{II}}$ (2-amino-4,6-tert-

butylphenolate $)_{2}$ (2-amino-4,6-tert-butylphenol $)_{2}$ and $\mathrm{Co}^{\mathrm{III}}$-AP ${ }^{\mathrm{ditBu}} \mathrm{Complex}$ $\mathrm{Co}_{2}{ }^{\text {III }}$ (2-amino-4,6-tert-butylphenolate) $)_{2}$ (2-amino-4,6-tert-butylphenol)( $\mu$-2amido-4,6-tert-butylphenolate) 2

4.4.5. Reactivity Studies of $\mathrm{Co}^{\mathrm{II}}-\mathrm{AP}^{\mathrm{ditBu}}$ Complex (7) and $\mathrm{Co}^{\mathrm{II}}-\mathrm{AP}^{\mathrm{ditBu}}$ Complex (8)

4.4.6. Crystallography Data 130

4.4.6.1. Description of the X-ray Structural Analysis of $\mathrm{Co}^{\mathrm{II}}-\mathrm{AP}^{\mathrm{ditBu}}$ Complex (7) 
4.4.6.2. Description of the X-ray Structural Analysis of $\mathrm{Co}^{\mathrm{III}}-\mathrm{AP}^{\mathrm{ditBu}}$

Complex (8)

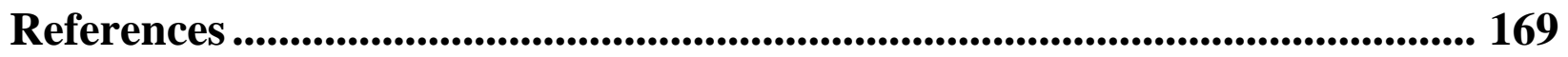

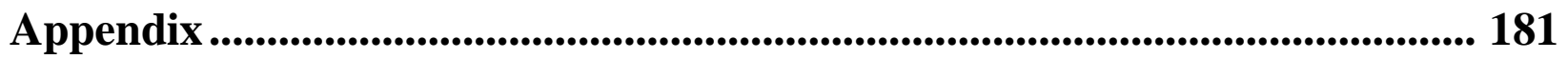




\section{List of Schemes}

Scheme 1.1. Industry Radical Autoxidation Process Employing Transition-Metals and Molecular

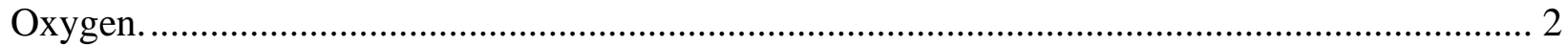

Scheme 1.2. Simplified Mechanism of Metalloenzyme-Catalyzed Aerobic Oxidation. ............. 2

Scheme 1.3. Mukaiyama Olefin Oxygenation with $\mathrm{Co} / \mathrm{O}_{2}$ Catalytic System ............................. 4

Scheme 1.4. First and Second Generations of Cobalt Catalysts in Mukaiyama Oxidative

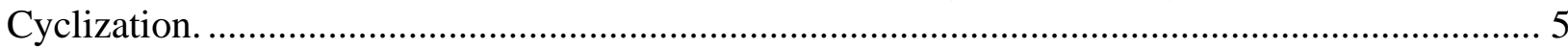

Scheme 1.5. Extension of Mukaiyama Oxidative Cyclization: Reductive and Brominative Alkenol Cyclization.

Scheme 1.6. Pioneer Work by Ishii on Aerobic C-H Oxidation Using Combined Catalytic System of Co and NHPI..

Scheme 1.7. Solvent-Free Aerobic Oxidation of Alkylbenzenes Catalyzed by Co/DDAB/NHPI 8

Scheme 1.8. Oxygenation of Heteroarenes by Co/NHPI Catalytic System (Stahl). 9

Scheme 1.9. Autoxidation of Aryl-Capped Alkynyl $\alpha$-Cyano Alkanones by CoII/NHPI Catalytic System. 10

Scheme 1.10. Two Forms of Co(salen) Complexes with Molecular Oxygen............................ 11

Scheme 1.11. Generalized Mechanism For Co(salen)-Catalyzed Aerobic Oxidation of Lignin-like Phenols to Form Quinones and Aldehydes 12

Scheme 1.12. Simplified Mechanism for the Coupled Redox Cycles Employing Co(salophen) and Hydroquinone Co-catalyst in Pd-Catalyzed Allylic Acetoxylation. 14

Scheme 1.13. Co(salen)-Catalyzed Aerobic Oxidative Cross-Coupling of Phenols in the WasteFree System. 15

Scheme 2.1. Redox-Active Mediators in Cobalt-Mediated Aerobic Oxidative Reactions in Enabling $\mathrm{O}_{2}$ Activation in Prior Studies and This Work...

Scheme 2.2. Aerobic Oxidative Cyclization Conducted in the Presence of Radical Trapping Reagents

Scheme 2.3. Oxidative Cyclization of 2-Aminophenol and tert-Butyl Isonitrile Mediated by Cobalt Under $\mathrm{N}_{2}$

Scheme 2.4. (a) Proposed Pathway for Co-Catalyzed Aerobic Oxidation of Catechol in Literature and (b) Proposed Pathway for Aerobic 2-Aminophenol Oxidation in This Work

Scheme 2.5. (a) The standard reaction conditions and control experiments with (b) 10 mol\% $\mathrm{Co}(\mathrm{OAc})_{2}$ and $(\mathrm{c}) 1$ equiv $\mathrm{Co}(\mathrm{OAc})_{2}$ conducted under a nitrogen atmosphere. 43 
Scheme 2.6. Control experiment with (a) $\mathrm{Co}(\mathrm{acac})_{3}$ as a cobalt(III) source and (b) the

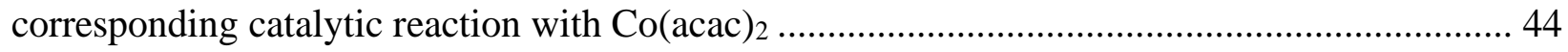

Scheme 2.7. Control experiment with di-tert-butyl peroxide as the oxidant .......................... 45

Scheme 2.8. Control experiment with (a) TEMPO, (b) 9,10-dihydroanthracene (DHA), and (c) 1,1-diphenylethylene included as radical trapping agents 46

Scheme 2.9. Control experiments conducted in the absence of isonitrile both (a) without and (b) with TEMPO

Scheme 3.1. Selected conventional routes for the synthesis of 2-aminobenzimidazoles 57

Scheme 3.2. 2-aminobenzimidazole synthesis via transition-metal catalyzed oxidative cyclization of bisnucleophiles with isonitriles.... 59

Scheme 3.3. Synthesis of $N$-subsittuted diamino quinoxazoline. 64

Scheme 3.4. Synthesis of $N$-substituted 2-aminobenzimidazoles 65

Scheme 3.5. Application of unsubstituted 2-aminobenzimidazoles in pharmaceutical-related synthesis 66

Scheme 3.6. Synthesis of the unsubstituted 2-aminobenzimidazoles $\mathbf{5 s}$ and $\mathbf{5 t}$ via acid-promoted dealkylation.

Scheme 3.7. Attempted synthesis of mebendazole from 2-amino-5-benzoyl-1H-benzimidazole 5t under varied reaction conditions. 68

Scheme 3.8. Synthesis of mebendazole from 2-amino-5-benzoylbenzimidazole in literature .... 69

Scheme 3.9. Control experiments with TEMPO and 1,1-diphenylethylene as radical trapping agents.

Scheme 3.10. Attempts in the synthesis of mebendazole from 2-amino-5-benzoyl benzimidazole and methyl chloroformate. 96

Scheme 4.1. Oxidation states of the bidentate $o$-aminophenol as a redox-active ligand 99

Scheme 4.2. Proposed mechanism for the catalytic oxidation of primary alcohols by dioxygen employing complexes of a tetradentate redox non-innocent ligand

Scheme 4.3. Negishi-type cross-coupling reaction of alkyl halides with organozinc reagents by Co ${ }^{\text {III }}$ bis $(o$-amidophenolato $)$ complex

Scheme 4.4. Proposed mechanism for oxidative ring cleavage of 2-amino-4-tert-butylphenol to the picolinic acid in the presence of $\mathrm{O}_{2}$ 104

Scheme 4.5. Cobalt-catalyzed oxidative coupling of 2-amino-4,6-di-tert-butyl phenol and tertbutyl isonitrile under the standard reaction conditions 105 
Scheme 4.6. Synthesis and condition optimization of $\mathrm{Co}^{\mathrm{II}}-\mathrm{AP}^{\mathrm{ditBu}}$ complex $\mathrm{Co}^{\mathrm{II}}(2$-amino-4,6tert-butylphenolate $)_{2}$ (2-amino-4,6-tert-butylphenol $)_{2}$ by varying metal to ligand ratio

Scheme 4.7. Attempted synthesis of $\mathrm{Co}^{\mathrm{III}}-\mathrm{AP}^{\mathrm{ditBu}}$ complex in the aqueous medium under ambient atmosphere

Scheme 4.8. Solid state oxidation observed by Wieghart group for the oxidation of the Co ${ }^{\mathrm{II}}$ complex $\left[\mathrm{Co}^{\mathrm{II}}\left(\mathrm{LS}_{\mathrm{S}}^{\mathrm{AP}}\right)_{2}\right]_{2} \cdot 2 \mathrm{CH}_{3} \mathrm{CN}$ in the presence of air $\left(\mathrm{LS}_{\mathrm{S}}^{\mathrm{AP}}=2\right.$-amino-4,6-di-tertbutylthiophenol).

Scheme 4.9. Solid-state oxidation of metal complex Co ${ }^{\mathrm{II}}(2$-amino-4,6-tert-butylphenolate) 2 (2amino-4,6-tert-butylphenol $)_{2}$ under air 109

Scheme 4.10. Catalytic control experiments of $\mathrm{Co}^{\mathrm{II}}-\mathrm{AP}^{\mathrm{ditBu}}$ complex (7) in the aerobic oxidative cyclization reactions

Scheme 4.11. Stoichiometric control experiments of $\mathrm{Co}^{\mathrm{II}}-\mathrm{AP}^{\mathrm{ditBu}}$ complex (7) under anaerobic reaction conditions 118

Scheme 4.12. Catalytic control experiments of $\mathrm{Co}^{\mathrm{III}}-\mathrm{AP}^{\mathrm{ditBu}}$ complex (8) under aerobic oxidative cyclization conditions

Scheme 4.13. Stoichiometric control experiments with $\mathrm{Co}^{\mathrm{III}}-\mathrm{AP}^{\mathrm{ditBu}}$ complex (8) under both aerobic and anaerobic atmosphere

Scheme 4.14. Reactivity of $\mathrm{Co}^{\mathrm{III}}-\mathrm{AP}^{\mathrm{ditBu}}$ complex in oxidative cyclization reactions under $\mathrm{N}_{2}$ atmosphere. 


\section{List of figures}

Figure 1.1. Proposed Mechanism for the Co(salophen)-Catalyzed Aerobic Oxidation of $p$ Hydroquinone

Figure 2.1. (a) Absorption spectrum of $\mathrm{Co}(\mathrm{acac})_{2}$ only and $\mathrm{Co}(\mathrm{acac})_{2}$ with $\mathrm{CN} t \mathrm{Bu}$ in $\mathrm{CH}_{3} \mathrm{CN}$ under $\mathrm{N}_{2}$ and after exposed to air overnight. (b) Absorption spectrum of $\mathrm{Co}(\mathrm{acac})_{2}$ and 2aminophenol under $\mathrm{N}_{2}$ and after exposed to air overnight

Figure 2.2. Absorption spectrum of $\mathrm{Co}$ (acac) $)_{2}$ with 2-aminophenol in $\mathrm{CH}_{3} \mathrm{CN}$ under $\mathrm{N}_{2}$ and after exposed to air overnight stacked with the final trace spectrum of $\mathrm{Co}(\mathrm{acac})_{3}$ with 2-aminophenol under air exposure. 28

Figure 2.3. ${ }^{1} \mathrm{H}$ NMR spectrum of the crude reaction mixture of the Co-catalyzed, TEMPOmediated dimerization of 2-aminophenol for the synthesis of 2-aminophenoxazin-3-one (reaction $\mathrm{b}$ in Scheme 2.9) in DMSO- $d_{6}$ at $400 \mathrm{MHz}$.

Figure 2.4. ${ }^{1} \mathrm{H}$ NMR spectrum of standard 2-aminophenozaxin-3-one purchased from AstaTech (95\% pure) in DMSO- $d_{6}$ at $400 \mathrm{MHz}$. 50

Figure 2.5. UV-Visible spectra of $\mathrm{Co}^{\mathrm{II}}(\mathrm{acac})_{2}\left(5.05 \times 10^{-2} \mathrm{mM}\right.$ in $\left.\mathrm{MeCN}\right)$ prepared under $\mathrm{N}_{2}$ (orange trace), and then exposed to air and monitored over the course of $12 \mathrm{~h}$ at room temperature (blue trace)

Figure 2.6. UV-Visible spectra of (a) $\mathrm{Co}^{\mathrm{II}}(\mathrm{acac}) 2\left(5.05 \times 10^{-2} \mathrm{mM}\right.$ in $\left.\mathrm{MeCN}\right)$ prepared under $\mathrm{N} 2$ (red trace), and then tert-butylisonitrile ( 8 equiv) was added (green trace), and final, exposed to air overnight (dark blue trace).

Figure 2.7. UV-Visible spectra of (a) $\mathrm{Co}^{\mathrm{II}}(\mathrm{acac})_{2}\left(5.05 \times 10^{-2} \mathrm{mM}\right.$ in $\left.\mathrm{MeCN}\right)$ prepared under $\mathrm{N}_{2}$ (yellow trace), and then treated with 2-aminophenol to reach a total of 2 equiv added (deep blue trace), and (b) $\mathrm{Co}^{\mathrm{II}}(\mathrm{acac})_{2}\left(5.05 \times 10^{-2} \mathrm{mM}\right.$ in $\left.\mathrm{MeCN}\right)$ and 2 -aminophenol (2 equiv, purple trace) exposed to air and monitored over the course of $12 \mathrm{~h}$ at room temperature (orange trace) .......... 53

Figure 2.8. (a) $\mathrm{Co}(\mathrm{acac})_{2}\left(5.0 \times 10^{-5} \mathrm{M}\right)$ in $\mathrm{MeCN}$ under $\mathrm{N}_{2}$ (red trace) with the addition of 3 equiv of 2-aminophenol (yellow trace), and (b) $\mathrm{Co}(\mathrm{acac})_{2}$ and 2-aminophenol (3 equiv, yellow trace) exposed to air overnight (deep blue trace).

Figure 2.9. (a) $\mathrm{Co}(\mathrm{acac})_{3}\left(2.5 \times 10^{-5} \mathrm{M}\right)$ in $\mathrm{MeCN}$ under $\mathrm{N}_{2}$ (blue trace) with the addition of 3 equiv of 2-aminophenol (yellow trace) and (b) $\mathrm{Co}(\mathrm{acac})_{3}\left(2.5 \times 10^{-5} \mathrm{M}\right)$ and 2-aminophenol (3 equiv, red trace) exposed to air overnight (blue trace) .............................................................. 55

Figure 3.1. Condition-based sensitivity assessment experiment. (a) Four steps involved in sensitivity assessment procedure (b) Sensitivity assessment of key parameters in Co-catalyzed aerobic oxidative cyclization of $o$-phenylenediamine with tert-butyl isonitrile ........................... 62

Figure 3.2. Reaction set up for parameter assessment studies ....................................................... 76 
Figure 3.3. Reaction setup under $\mathrm{N}_{2}$ atmosphere (left side) and $\mathrm{O}_{2}$ atmosphere (right side,

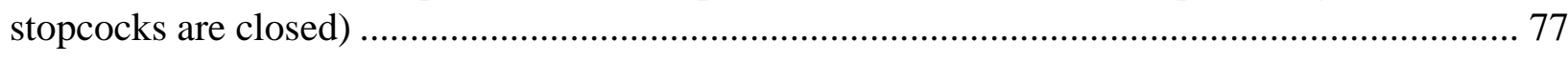

Figure 3.4. Radar diagram generated from parameter assessment data shown in Table 3.9 ..... 78

Figure 3.5. Reaction setup using a pressure tube with a headspace filled with air.................... 80

Figure 3.6. Mixture of the two mebendazole structural isomers from the model transformation ....

Figure 3.7. ${ }^{1} \mathrm{H}$ NMR for structural elucidation of mebendazole isomer with 1-acylation .......... 97

Figure 3.8. ${ }^{1} \mathrm{H}$ NMR for Structural elucidation of mebendazole isomer with 3-acylation .......... 98

Figure 3.9. ${ }^{13} \mathrm{C}$ NMR for the mixture of two mebendazole isomers ........................................ 98

Figure 4.1. Selected Examples for Cobalt Complexes with 3,5-di-tert-butyl-o-aminophenols 100

Figure 4.2. The structure of $\mathrm{Co}(2 \text {-amino-4,6-tert-butylphenolate })_{2}$ (2-amino-4,6-tertbutylphenol $)_{2}$

Figure 4.3. The structure of $\mathrm{Co}_{2}$ (2-amino-4,6-tert-butylphenolate) $)_{2}(2$-amino-4,6-tertbutylphenol $)(\mu \text {-2-amido-4,6-tert-butylphenolate })_{2}$

Figure 4.4. UV-visible spectroscopy of $\mathrm{Co}^{\mathrm{II}}-\mathrm{AP}^{\mathrm{ditBu}}(7)$ and $\mathrm{Co}^{\mathrm{III}}-\mathrm{AP}^{\mathrm{ditBu}}(\mathbf{8}) \ldots \ldots \ldots \ldots \ldots \ldots \ldots . . . . . . . . . . . .112$

Figure 4.5. Cyclic voltammograms of $\mathrm{Co}^{\mathrm{II}}-\mathrm{AP}^{\mathrm{ditBu}}(\mathbf{7})$ and $\mathrm{Co}^{\mathrm{III}}-\mathrm{AP}^{\mathrm{ditBu}}(\mathbf{8})$.......................... 113

Figure 4.6. EPR spectra For $\mathrm{Co}^{\mathrm{II}}-\mathrm{AP}^{\mathrm{ditBu}}$ Complex (7) and $\mathrm{Co}^{\mathrm{III}}$-AP ${ }^{\mathrm{ditBu}}$ Complex (8) ............ 114

Figure 4.7. Aerobic oxidation of the $\mathrm{Co}^{\mathrm{II}}-\mathrm{AP}^{\mathrm{ditBu}}$ complex with dissociation of a ligand monitored by ${ }^{1} \mathrm{H}$ NMR spectroscopy

Figure 4.8. Deuterium Exchange Experiment of the Oxidized Cobalt Intermediate. Standard Spectrum of the Ligand was Included for Reference 


\section{List of Tables}

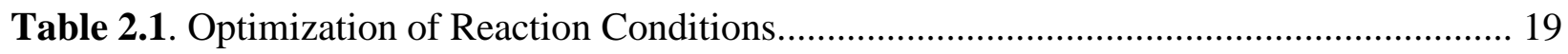

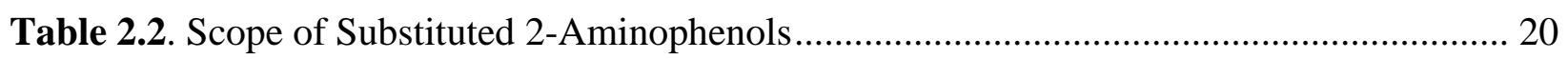

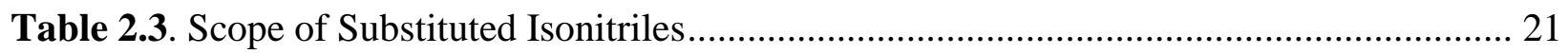

Table 2.4. Optimization of the reaction temperature and base in the oxidative cyclization of 2aminophenol and tert-butylisonitrile...................................................................................... 30

Table 2.5. Optimization of the base in the oxidative cyclization of 2-aminophenol and tert-butylisonitrile

Table 2.6. Optimization of the catalyst loading and reaction time in the oxidative cyclization of

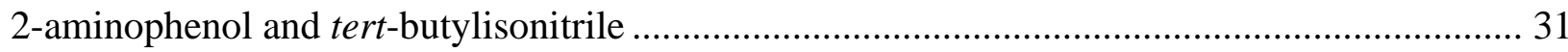

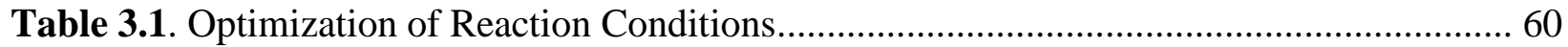

Table 3.2. Scope of ortho-Phenylenediamine and Isonitrile Coupling Partners ............................ 63

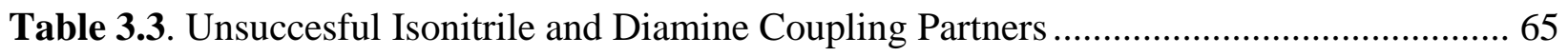

Table 3.4. Optimization of the cobalt source in the oxidative cyclization of ortho-

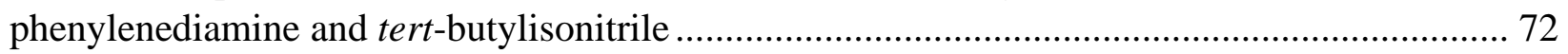

Table 3.5. Optimization of the solvent in the oxidative cyclization of ortho-phenylenediamine and tert-butylisonitrile

Table 3.6. Optimization of the base in the oxidative cyclization of ortho-phenylenediamine and tert-butylisonitrile

Table 3.7. Optimization of the temperature in the oxidative cyclization of ortho-

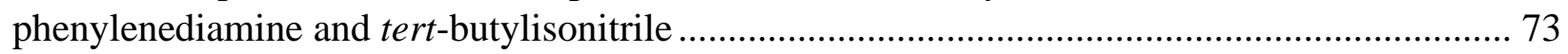

Table 3.8. Conditions used for reaction parameter assessment...................................................... 75

Table 3.9. Results of Parameter Assessment of the Standard Reaction ........................................ 78

Table 4.1. Crystal data and structure refinement for $\mathrm{Co}^{\mathrm{II}}-\mathrm{AP}^{\mathrm{ditBu}}$ Complex (7)........................ 132

Table 4.2. Fractional Atomic Coordinates $\left(\times 10^{4}\right)$ and Equivalent Isotropic Displacement

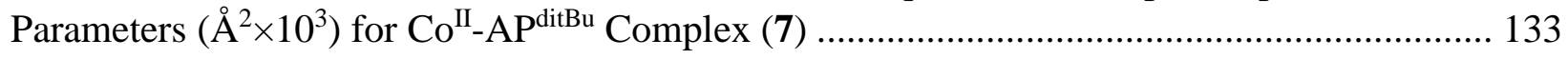

Table 4.3. Anisotropic Displacement Parameters $\left(\AA^{2} \times 10^{3}\right)$ for $\mathrm{Co}^{\mathrm{II}}$-AP ${ }^{\mathrm{ditBu}}$ Complex (7)........ 136

Table 4.4. Bond Lengths for $\mathrm{Co}^{\mathrm{II}}$-AP ${ }^{\mathrm{ditBu}}$ Complex (7) ...................................................... 138

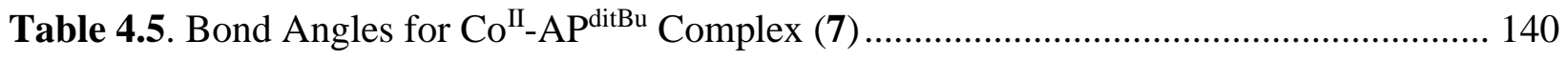


Table 4.6. Hydrogen Atom Coordinates $\left(\AA \times 10^{4}\right)$ and Isotropic Displacement Parameters $\left(\AA^{2} \times 10^{3}\right)$ for $\mathrm{Co}^{\mathrm{II}}-\mathrm{AP}^{\mathrm{ditBu}}$ Complex (7)

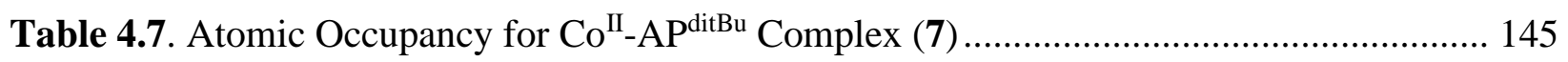

Table 4.8. Crystal data and structure refinement for $\mathrm{Co}^{\mathrm{III}}-\mathrm{AP}^{\mathrm{ditBu}}$ Complex $(8) \ldots \ldots . . . . . . . . . . . . . . . . . .149$

Table 4.9. Fractional Atomic Coordinates $\left(\times 10^{4}\right)$ and Equivalent Isotropic Displacement

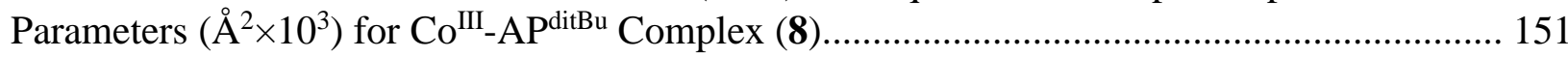

Table 4.10. Anisotropic Displacement Parameters $\left(\AA^{2} \times 10^{3}\right)$ for Co ${ }^{\mathrm{III}}$-AP ${ }^{\mathrm{ditBu}}$ Complex (8) ..... 154

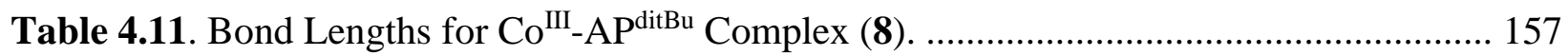

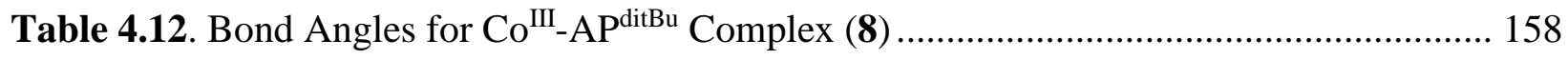

Table 4.13. Torsion Angles for for $\mathrm{Co}^{\mathrm{III}}-\mathrm{AP}^{\mathrm{ditBu}}$ Complex (8)................................................. 161

Table 4.14. Hydrogen Atom Coordinates $\left(\AA \times 10^{4}\right)$ and Isotropic Displacement Parameters

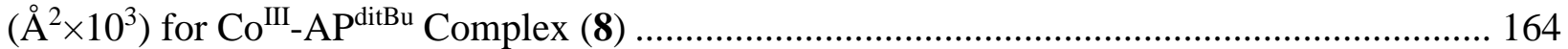

Table 4.15. Atomic Occupancy for $\mathrm{Co}^{\mathrm{III}}$-AP ${ }^{\mathrm{ditBu}}$ Complex (8) .............................................. 168 


\section{List of Abbreviations}

acac: acetylacetonate

AP: abbreviated aminophenol ligand

$\mathrm{AP}^{\mathrm{ditBu}}$ : 2-amino-4,6-di-tert-butylphenol ligand (only used in the context in this dissertation)

BQ: benzoquinone

Co(salen): [N, N'-bis-(salicylidene)-ethane-1,2-diaminato]cobalt

$\mathrm{CV}$ : cyclic voltammetry

DCC: dicyclohexylcarbodiimide

DDAB: di-n-decyl-di-methyl ammonium bromide

DIC: 1,3-diisopropylcarbodiimde

DFT: density functional theory

DHA: 9.10-hydroanthracene

DMSO: dimethyl sulfoxide

DTBP: di-tert-butyl peroxide

EDC: $N$-(3-dimethylaminopropyl)- $N$ '-ethylcarbodiimide hydrochloride

EPR: electron paramagnetic resonance

ESI-MS: electrospray ionization mass spectrometry

FTIR: fourier-transform infrared spectroscopy

HAA: hydrogen atom abstraction

HAT: hydrogen atom transfer

PCET: proton-coupled electron transfer

HFIP: 1,1,1,3,3,3-hexafluoropropan-2-ol

NHPI: $N$-hydroxyl phthalimide

NMR: nuclear magnetic resonance

PINO: phthalimide- $N$-oxyl

DDAB: di-n-decyl-di-methyl ammonium bromide

MLVs: multi-lamellar Vesicles 
$\mathrm{NC}$ : isocyanide group

PTC: phase-transfer conditions

Sq: iminosemiquinoate

tBu: tert-butyl group

THF: tetrahydrofuran

Ts: toluenesulfonyl

OAc: acetate group 


\section{Chapter 1. Cobalt-catalyzed Aerobic Oxidation Reactions: An Overview}

\subsection{Transition-Metal Catalyzed Oxidation of Organic Substrates with $\mathrm{O}_{2}$ Oxidant}

Molecular oxygen is a highly abundant, environmentally benign, and atom economical oxidant, which makes it an ideal choice for oxidation reactions of organic substrates. However, due to the high energy barrier associated with $\mathrm{O}_{2}$ activation, the incorporation of catalysts in the reaction is usually necessary. ${ }^{1}$ With the increasing awareness of green chemistry practice in recent decades, more efforts have been sought towards the development of the new catalytic oxidation reactions to replace the conventional methods involving the use of stoichiometric quantities of toxic inorganic oxidizing reagents, such as dichromate and permanganate. ${ }^{2}$ An ideal system for "Green Oxidation" employs molecular oxygen as the primary oxidant together with recyclable catalysts in a non-toxic solvent to minimize waste disposal. Thus, designing effective catalytic systems that allow the activation of molecular oxygen at ambient conditions for selective oxidation reactions is highly practical. A few applications have been translated to industrial processes and have demonstrated great successes over the past decades (Scheme 1.1), such as the palladiumcatalyzed Wacker oxidation of alkenes to carbonyl compounds, " 3 "KA oil" production via radicalchain autoxidation of cyclohexane to a mixture of cyclohexanone and cyclohexanol, and the synthesis of terephthalic acid from p-xylene in the presence of manganese and cobalt salt, using molecular oxygen as the terminal oxidant. ${ }^{2}$ 
(a) Wacker Oxidation

$$
\mathrm{H}_{2} \mathrm{C}=\mathrm{CH}_{2} \frac{\mathrm{PdCl}_{2} \text { (cat) }}{\mathrm{CuCl}_{2} \text { (cat), } \mathrm{O}_{2}, \mathrm{H}_{2} \mathrm{O}} \mathrm{H}_{3} \mathrm{C} \stackrel{\mathrm{O}}{\stackrel{\mathrm{N}}{\mathrm{H}}}
$$

(b) Cyclohexane Oxidation to "KA oil"

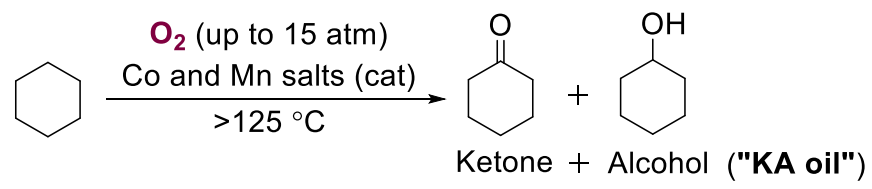

(c) Terephthalic Acid Synthesis

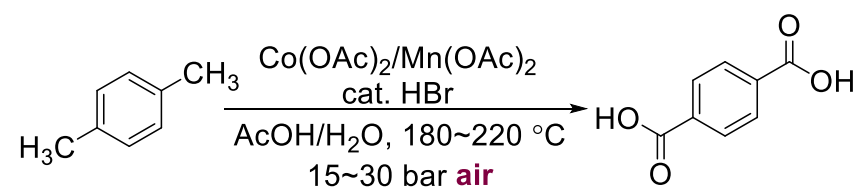

Scheme 1.1. Industry Radical Autoxidation Process Employing Transition-Metals and Molecular Oxygen.

Metalloenzymes that catalyze selective aerobic oxidation reactions have provided valuable frameworks for the design of new catalysts over the century. These enzymes are characterized into two major classes based on the fate of oxygen atom from the molecular oxygen, oxygenase, and oxidase. Oxygenases provide oxygen atom transfer from the molecular oxygen to the substrates, affording the oxygen-incorporated products, while oxidases just use molecular oxygen as the electron or proton acceptor during the oxidation of substrates. ${ }^{4}$ The simplified mechanistic elucidation of these two main categories of metalloenzyme is shown in Scheme 1.2.

(a)

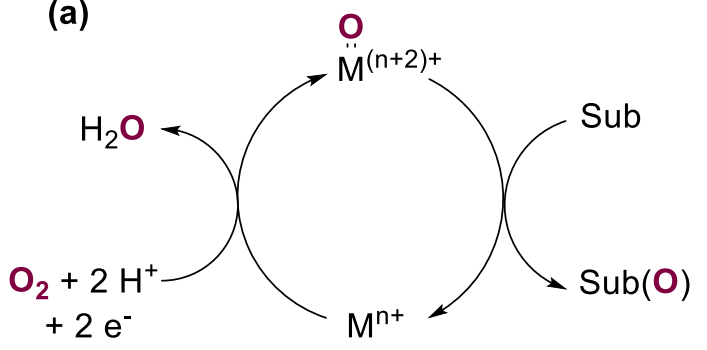

(b)

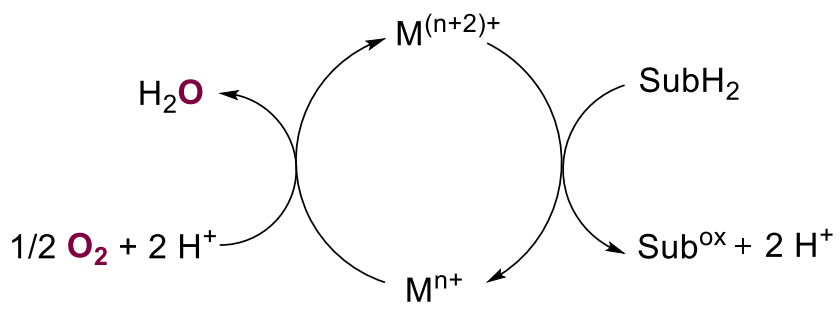

Scheme 1.2. Simplified Mechanism of Metalloenzyme-Catalyzed Aerobic Oxidation. (a) Oxygenase Pathway Featuring Oxygen Atom Transfer from $\mathrm{O}_{2}$ to Substrate. (b) Oxidase Pathway Featuring $\mathrm{O}_{2}$ as a $2 \mathrm{H}^{+} / 2 \mathrm{e}^{-}$Acceptor in Substrate Oxidations. 
Studies on these natural oxidation processes have offered lots of insights and inspirations for chemists aiming to utilize $\mathrm{O}_{2}$ for selective oxidation reactions. "Oxygenase-type" oxidation reactions have demonstrated great successes in asymmetric catalysis, such as Sharpless asymmetric epoxidation, where molecular oxygen or dioxygen surrogates such as amine $\mathrm{N}$-oxides, alkyl peroxides, or hydrogen peroxide are employed. ${ }^{4}$ The "oxidase-type" oxidation reactions allow any oxidation reaction to being coupled to $\mathrm{O}_{2}$ reduction when the catalyst can mediate both redox cycles of substrate oxidation by the oxidized catalyst and re-oxidation of the reduced catalyst by $\mathrm{O}_{2}$. Over the course of seeking effective catalytic oxidation systems, a broad scope of oxidative transformations has been developed using molecular oxygen as the terminal oxidant, catalyzed by a vast range of transition metals. ${ }^{2,-9}$ These transformations include but are not limited to alcohol oxidations, alkene epoxidation, alkene oxidation to alcohols and ketones, benzylic and allylic oxidation, aromatic $\mathrm{C}-\mathrm{H}$ oxidation, sulfoxidation, and Baeyer-Villiger oxidation. While numerous contributions have been made toward this field of study, this chapter will mainly focus on three major categories of aerobic oxidative transformation mediated by cobalt-catalysts, including perspectives from both "oxygenase-type" and "oxidase-type" reactions.

\subsection{Historic Overview of $\mathrm{Co} / \mathrm{O}_{2}$ Catalysis}

\subsubsection{Mukaiyama Olefin Oxygenation and Oxidative Cyclization of Alkenols}

In the late 80 s of the last century, Mukaiyama and co-workers had uncovered a few efficient methods for introducing dioxygen functionality to the carbon-carbon double bond under mild reaction conditions. ${ }^{10}$ The development of these methods made a significant contribution to the selective oxygenation of olefins with molecular oxygen paired with cobalt salts, rather than employing cobalt complexes consisting of Schiff-base ligands or porphyrin ligands. These discoveries built foundations to their later reported olefin activation study, with $\mathrm{O}_{2}$ as the oxidant and $\mathrm{EtSiH}_{3}$ as the reducing agent, the corresponding triethylsilyl peroxide was generated by using a $\mathrm{Co}^{\mathrm{II}}$ catalyst at room temperature. ${ }^{11}$ They also found that the variation of silane agents could produce the alcohol directly from the olefin. When phenyl silane was used in place of triethyl silane, hydration of the olefin proceeded smoothly at room temperature with high efficiency (Scheme 1.3). ${ }^{10}$ 


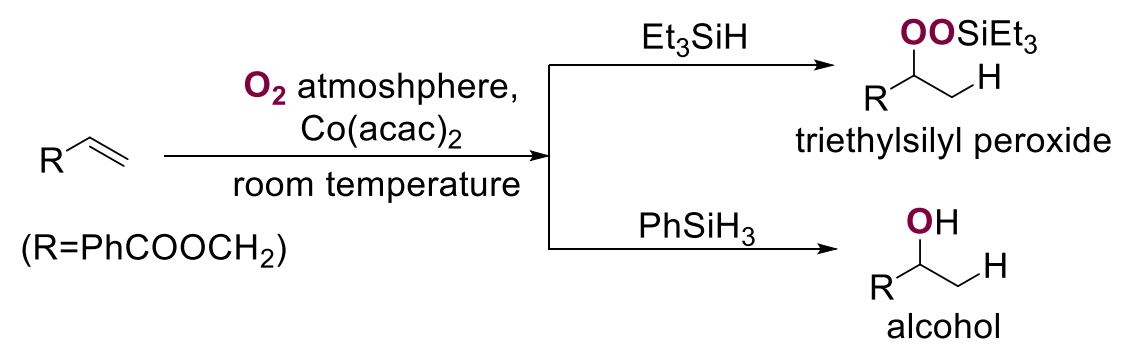

Scheme 1.3. Mukaiyama Olefin Oxygenation with $\mathrm{Co} / \mathrm{O}_{2}$ Catalytic System

In 1990, Mukaiyama reported a Co ${ }^{\text {II }}$-catalyzed oxidative cyclization of 5-hydroxy-1-alkene for the preparation of trans-2-hydroxymethyltetrahydrofurans with molecular oxygen as the oxidant. ${ }^{12}$ Employing a $\mathrm{Co}(\operatorname{modp})_{2}$ catalyst, various 2-hydroxymethyl-tetrahydrofurans were attained with extremely high trans-selectivity (Scheme 1.4a). Though three decades have passed since the discovery of this oxidative cyclization of alkenols, this reaction still interests a lot of researchers as the diastereoselective synthesis of functionalized cyclic ethers is of significant importance. Tetrahydrofurans (THFs) are key structural elements that are naturally occurring in many substances with potent biological activities. ${ }^{13}$ The Mukaiyama oxidation usually proceeds in excellent diastereoselectivity (>99:1 dr) and moderate to good yields, however, the catalyst can be extremely difficult to remove from the THF products when modp ligand is employed, introducing unnecessary challenges to the NMR characterization of the desired product. Also, the difficulties associated with the purification of the products counterbalanced the synthetic advantage of this cobalt catalyst. Later on, Pagenkopf and co-workers developed the second generation of water-soluble cobalt catalyst for Mukaiyama oxidative cyclization reactions. ${ }^{14}$ This catalyst was equipped with a piperazine unit, which was believed to help with the solubility of the cobalt catalyst when the acidic workup is used (Scheme 1.4b). This method retained the efficiency of the Mukaiyama oxidative cyclization while also providing significantly increased polarity of the cobalt catalyst, and was expected to find applications in total synthesis. 
(a) First Generation of Cobalt Catalyst for Oxidative Cyclization of Alkenols (Mukaiyama)

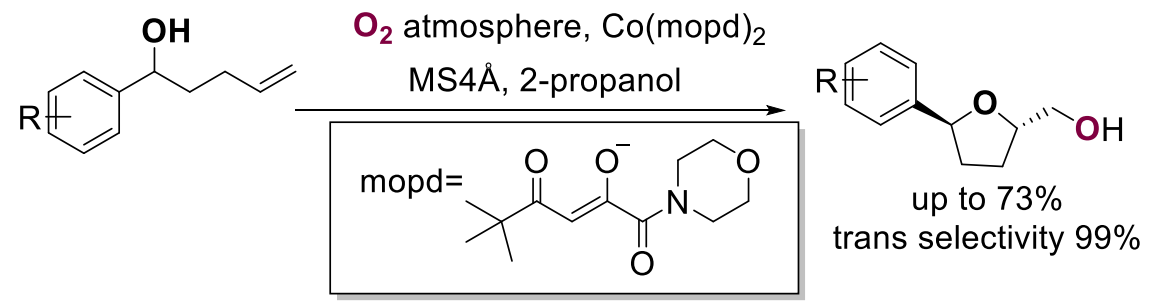

(b) Second Generation of Cobalt Catalyst for Oxidative Cyclization of Alkenols (Pagenkopf)

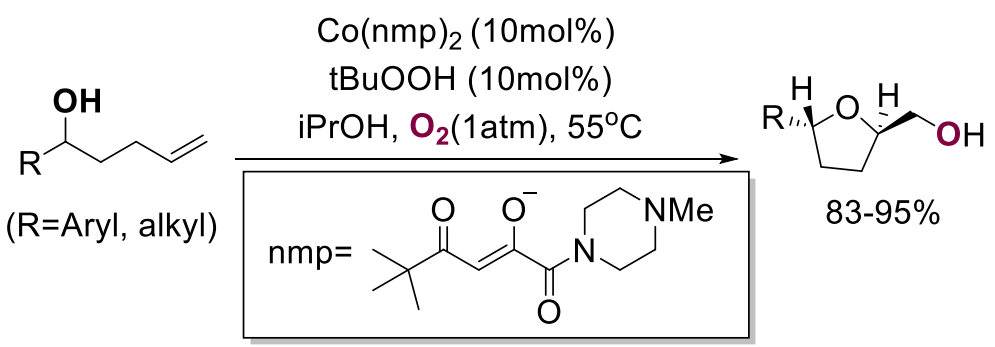

Scheme 1.4. First and Second Generations of Cobalt Catalysts in Mukaiyama Oxidative Cyclization.

Hartung and co-workers further developed a few methods to expand the existing Mukaiyama oxidative cyclization (Scheme 1.5a). ${ }^{15}$ With the retention of the extraordinary diastereoselectivity (> 99:1 dr) of the original oxidative cyclization of alkenols, heterocycles with different functionality can be obtained employing Co catalyst \{4-[3,5-bis(trifluoromethyl)phenyl]-4-oxybut-3-en-2-one -cobalt(II) $\left(\mathrm{CoL}_{2}\right)$ under an $\mathrm{O}_{2}$ atmosphere. In their study, they provided evidence that the intermediates generated during catalysis are free carbon radicals, which can be converted into synthetically valuable functional groups with various chemical reagents (Scheme 1.5b). In this way, they developed methods for reductive and brominative termination of the aerobic oxidative cyclization of alkenols, with the right choice of the reductant and brominating agents. They later expanded the scope to a broader range of acceptor molecules, ${ }^{16}$ such as monosubstituted olefins including methyl acrylate and acrylonitrile; 1,2-disubstituted olefins involving dimethyl fumarate and $\mathrm{N}$-phenylmaleic imide. The protocol can also tolerate ester-substituted alkynes, giving rise to a diastereomerically pure bis-tetrahydrofuran, which was initiated by a cascade process consisting of two aerobic oxidations, an alkyne addition, followed by a hydrogen atom transfer (HAT). 
(a) Reductive and Brominative Alkenol Cyclization (Hartung)

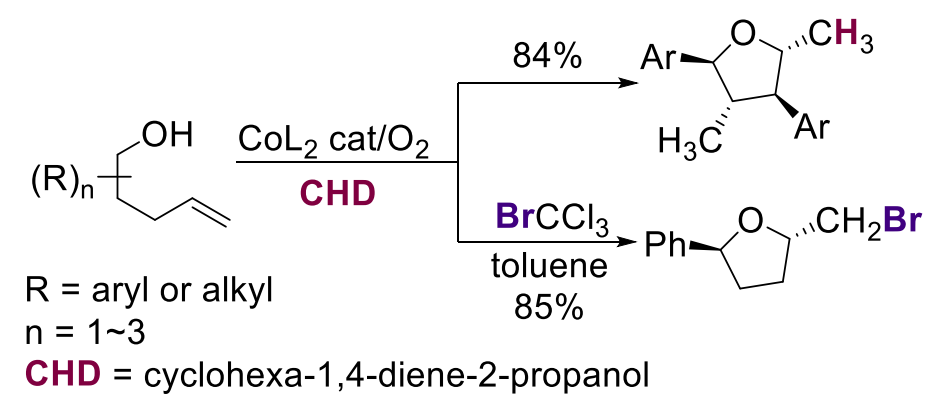

(b) Proposed Mechanism for the Aerobic Oxidation of Alkenols

Step for aerobic oxidation

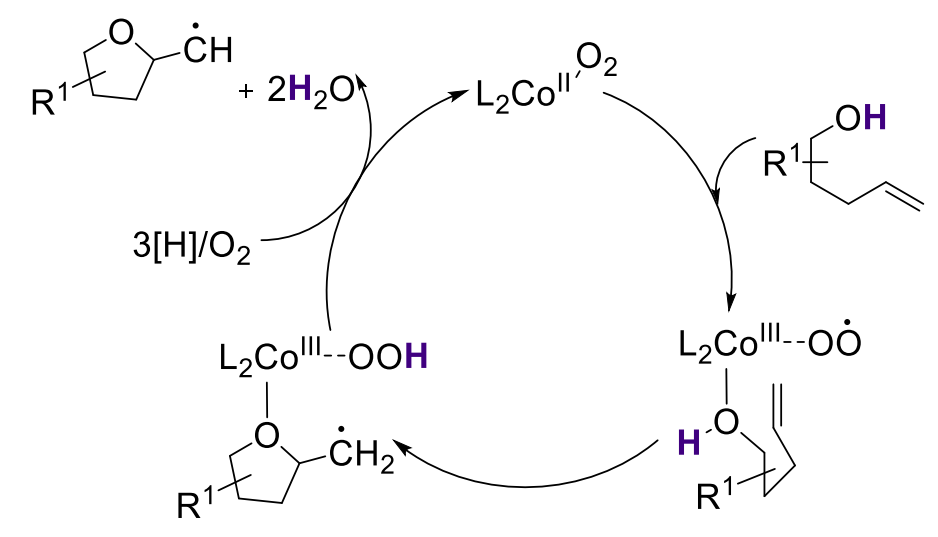

Step for radical functionalization

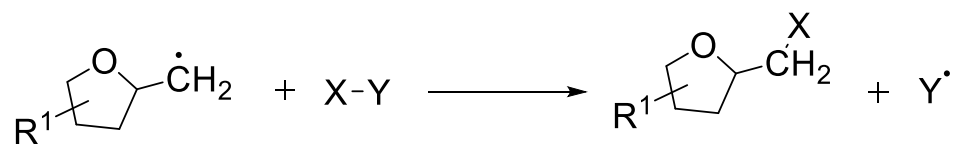

Scheme 1.5. Extension of Mukaiyama Oxidative Cyclization: Reductive and Brominative Alkenol Cyclization.

\subsubsection{Co/NHPI-Catalyzed Aerobic Oxidative Reactions}

While the discovery of Mukaiyama oxidative cyclization reactions has been a milestone in the cobalt-catalyzed oxidations employing $\mathrm{O}_{2}$ as the stoichiometric oxidant, it has limited scope to the oxy-functionality of alkenols to generate diastereomerically pure tetrahydrofurans (THFs). A few years later, a practical method had been introduced by Ishii and co-workers to convert alkanes and alkylbenzenes into the corresponding ketones and carboxylic acids using a combined system consisting of N-hydroxyphthalimide (NHPI) and Co(II) (Scheme 1.6a). ${ }^{17-19}$ This co-catalytic 
system was primarily employed in the $\mathrm{C}-\mathrm{H}$ oxidation of the methylene compounds at ambient pressure. The generalized mechanism shown in Scheme 1.6b suggested the in-situ generated phthalimide-N-oxyl radical (PINO) plays a critical role in the catalytic cycle to abstract a hydrogen atom from the substrate. The resulting carbon-centered radical will participate in the oxygenation with $\mathrm{O}_{2}$, giving rise to the corresponding ketone or carboxylic acid products. Among other transition-metals being investigated, cobalt had shown to be the key promoter to generate the PINO intermediate, other metals demonstrated less efficiency in this aerobic $\mathrm{C}-\mathrm{H}$ oxidation reaction. ${ }^{6,18}$

(a) Selected Work for Aerobic C-H Oxidation by Co/NHPI (Ishii)

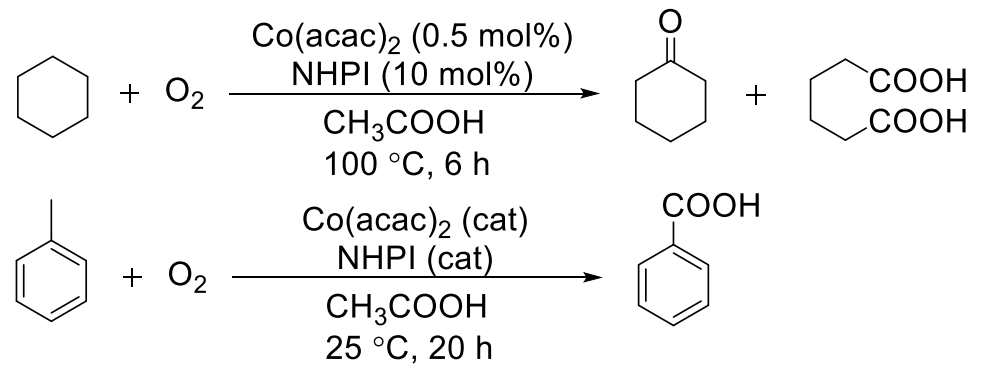

(b) Simplified Mechanism Depicting C-H Abstraction by Phthalimido-N-oxyl (PINO) and Radical Oxygenation by $\mathrm{O}_{2}$

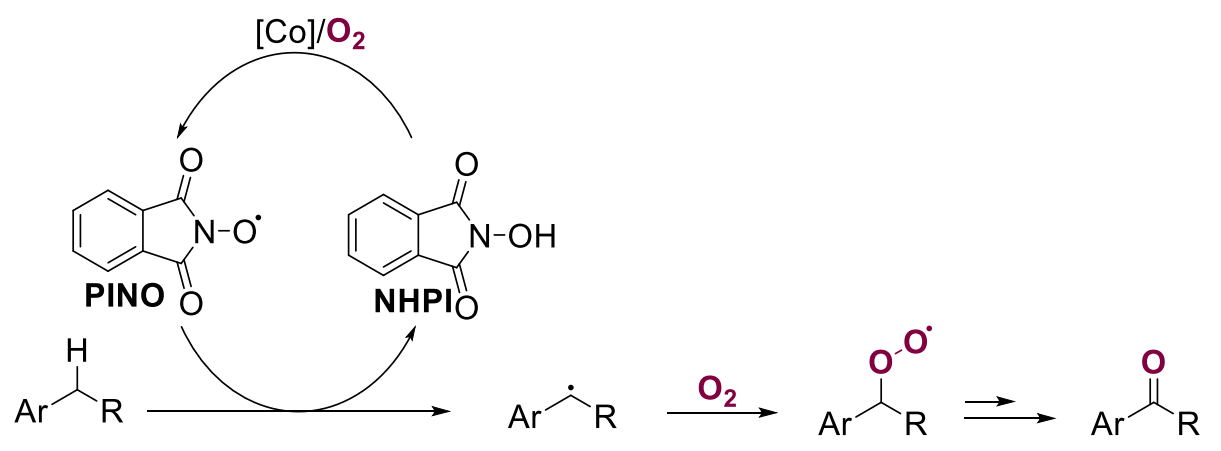

Scheme 1.6. Pioneering Work by Ishii on Aerobic C-H Oxidation Using the Combined Catalytic System of Co and NHPI.

Following these pioneering works, Patil and co-workers later developed a solvent-free, sustainable, and selective reaction for the $\mathrm{C}-\mathrm{H}$ oxidation of alkylbenzenes by $\mathrm{Co} / \mathrm{NHPI}$ under phase-transfer conditions (PTC). ${ }^{20}$ Although NHPI was proved to be highly efficient and versatile in the aerobic oxidation reactions, it has inherited limitations that prevented translation to the industrial process. For example, there are no proper methods for the reuse and recovery of catalysts; NHPI presented poor solubility in non-polar organic phases, and instability of both NHPI and its 
intermediate PINO at the temperature above $80^{\circ} \mathrm{C} .{ }^{21,22}$ The design of this oxidation system aimed at transcending the existing limitations and had demonstrated some success in the preparation of gram scale acetophenone when DDAB (Di-n-decyl-di-methyl ammonium bromide) was used as the phase transfer agent (Scheme 1.7). In this work, a light microscope image demonstrated that the multi-lamellar vesicles (MLVs) structures associated with DDAB protected NHPI at high temperatures. Thus, they speculated an efficient recovery and reuse of this ternary catalytic system (Co-NHPI/DDAB) is practical. However, this method only demonstrated excellent tolerance to ethylbenzene and indane, it didn't show much efficiency for tetralin substrates.

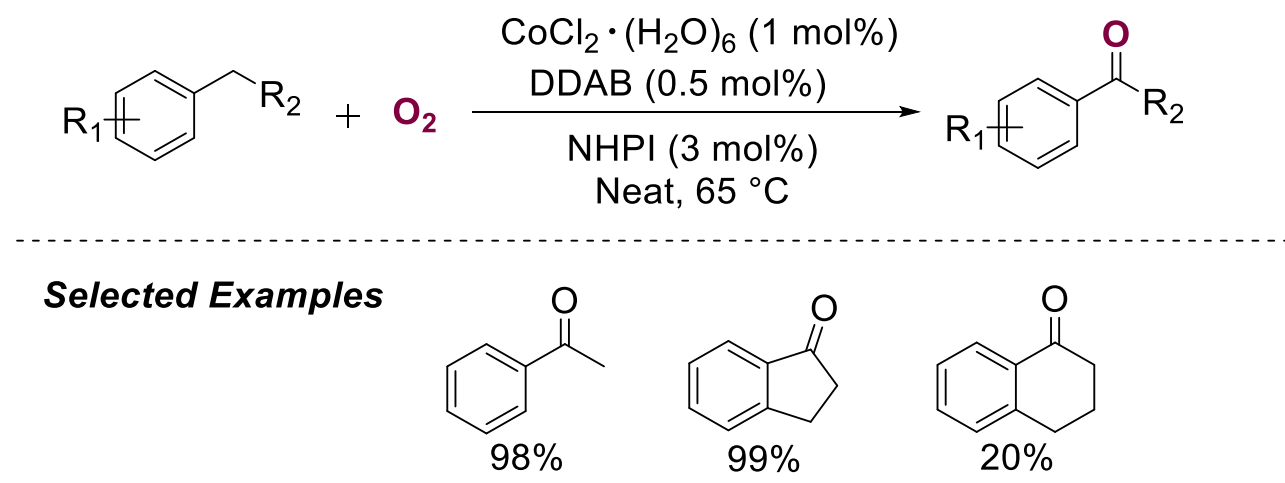

Scheme 1.7. Solvent-Free Aerobic Oxidation of Alkylbenzenes Catalyzed by Co/DDAB/NHPI

In 2017, Stahl and co-workers explored Co/NHPI-catalyzed benzylic oxygenation of heterocyclic substrates including benzimidazoles, thiophenes, and pyridines. ${ }^{23}$ This protocol generated benzylic ketones with good to excellent yields, including a gram-scale synthesis of a pharmacologically active compound from its di(hetero) arylmethane precursor with a modified procedure that comprised the use of $500 \mathrm{psi}$ of a mixture $\left(\mathrm{O}_{2}: \mathrm{N}_{2}\right.$ 9:91) to maintain the limit concentration allowance of molecular oxygen in the solvent BuOAc (Scheme 1.8). It was also suggested in this study that radical oxygen reactions would be inhibited with the presence of certain heterocyclic moieties. They attributed the inhibition of the chelation of heterocycles with the metal catalyst, which can be circumvented by an alternative procedure of a cobalt-free, electrochemical NHPI-mediated method they devised at the same time. 


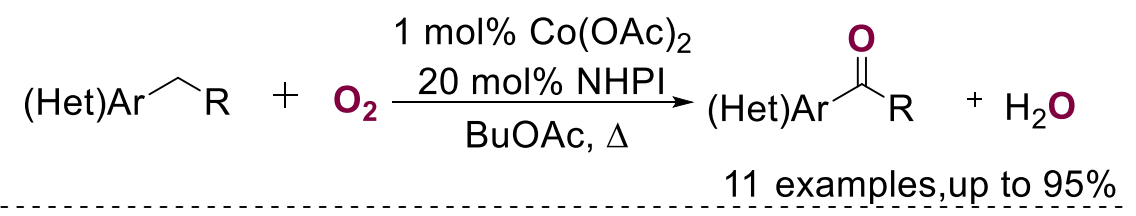

Selected Examples<smiles>O=C(c1ccccc1)c1nc2ccccc2s1</smiles><smiles>CC(=O)c1cccnc1</smiles><smiles>O=C(c1ccc(F)cc1)c1nc2ccccc2[nH]1</smiles>

$2 \mathrm{~g}$ scale, $95 \%$

Scheme 1.8. Oxygenation of Heteroarenes by Co/NHPI Catalytic System (Stahl).

Co/NHPI-catalyzed oxygenation not only established great success in the simple oxygenation of the methylene functionalities, but it also proved to be tolerant with oxygenmediated chain-reactions. The Shia group developed a legitimate protocol of Co/NHPI-catalyzed aerobic oxidation of terminal-capped alkynyl $\alpha$-cyano alkanone systems. ${ }^{24}$ With this method, aryl-, silyl-, and alkyl-capped alkynyl $\alpha$-cyano alkanone systems can be converted to the corresponding highly functionalized bicyclic products in an effective manner (Scheme 1.9). It was also revealed that the substituent capped on the terminal acetylene is structurally variable, although the trialkylsilyl group may play an extraordinary role in inducing the radical chain reaction. According to the proposed mechanism, the chain reaction is initiated by a hydrogen atom abstraction (HAA) at the position $\alpha$ to the cyano group by the in-situ generated phthalimide (PINO) radical, followed by an immediate 5-exo-dig addition to produce a vinyl radical species. Molecular oxygen is then captured by the vinyl radical intermediate to generate a vinyl peroxide species, which undergoes a second hydrogen atom abstraction (HAA) process by NHPI and a 1,4-dehydration to yield the desired product as a highly functionalized bicyclic compound. 


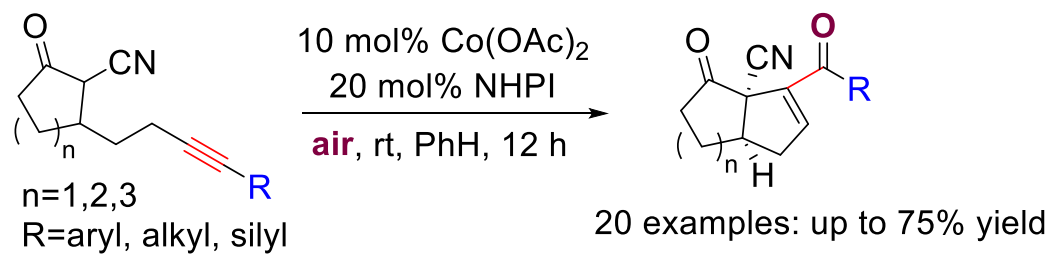

\section{Proposed Mechanism}

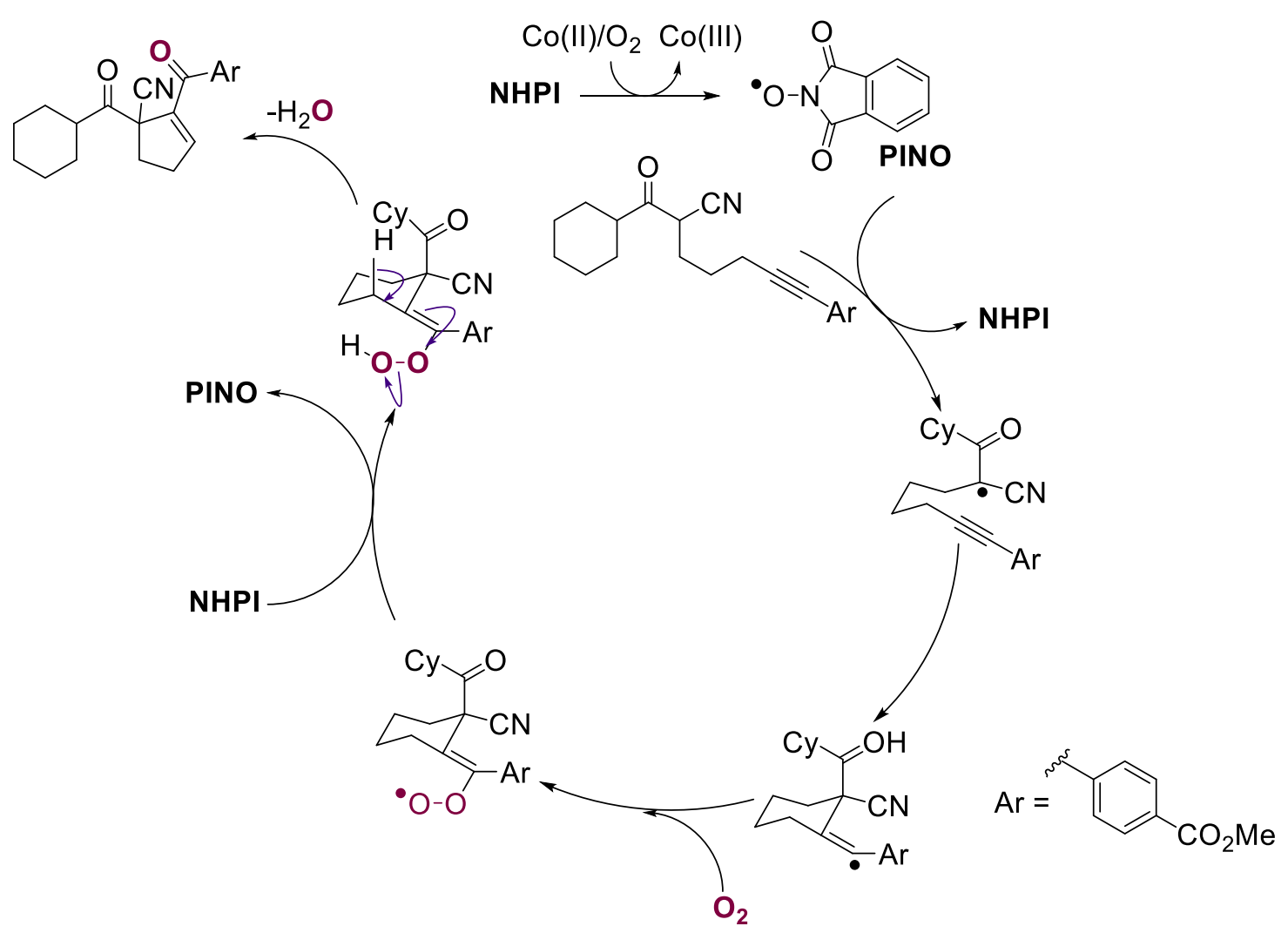

Scheme 1.9. Autoxidation of Aryl-Capped Alkynyl $\alpha$-Cyano Alkanones by $\mathrm{Co}$ II/NHPI Catalytic System.

\subsubsection{Cobalt Schiff Base Complexes in Aerobic Oxidation Reactions}

The tetradentate, square-planar Schiff base cobalt complex is well known for its $\mathrm{O}_{2}$ activation behavior. It was first discovered in the 1930 s by Tsumaki that solid Co ${ }^{\mathrm{II}}(\mathrm{salen})\left(\left[\mathrm{N}, \mathrm{N}^{\prime}\right.\right.$ -bis-(salicylidene)-ethane-1,2-diaminato]cobalt) can reversibly bind molecular oxygen. ${ }^{25}$ This finding spiked tremendous interest among researchers in the oxygen-carrying properties of cobalt complexes with Schiff base ligands. 
The Co(salen) complex adapts a square planar geometry. Upon the coordination of molecular oxygen, it adapts an octahedral geometry with the $\mathrm{O}_{2}$ occupying the axial position. ${ }^{26}$ The other axial position is usually occupied by a base, which is believed to help enhance the binding affinity of molecular oxygen to $\mathrm{Co}$ (salen) species. ${ }^{27,}{ }^{28} \mathrm{Co}$ (salen) complexes typically form either a mononuclear superoxo-complex or a dinuclear complex with a $\mu$-peroxo bridge with molecular oxygen; however, the superoxo complex is assumed to be a radical species and is responsible for aerobic catalytic transformations (Scheme 1.10).

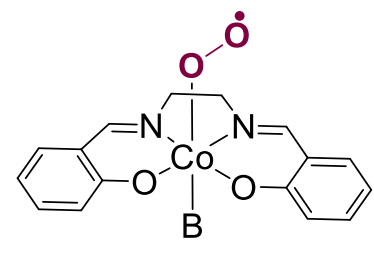

B: base

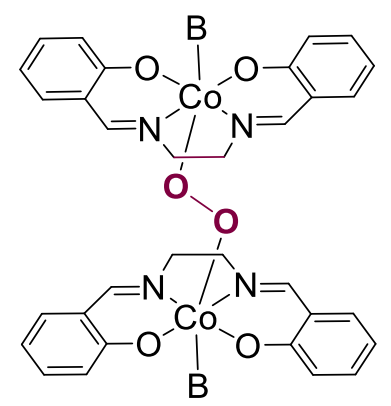

Scheme 1.10. Two Forms of Co(salen) Complexes with Molecular Oxygen. Mononuclear Superoxo Species (Left) and Dinuclear $\mu$-peroxo Species (Right).

Cobalt Schiff base catalysts operate under mild reaction conditions and allow the stoichiometric use of molecular oxygen paired with earth-abundant transition metals. Over the past few decades, it was extensively applied in the phenol oxidations. ${ }^{27,29,30}$ More recently, this aerobic catalytic system has been translated to the deconstruction of lignin biomass and for the conversion to higher value structures such as quinones and aldehydes. The general mechanism of Co(salen)catalyzed oxidation is illustrated in Scheme 1.11 with the $p$-hydroxyphenol lignin model as a substrate. ${ }^{31,32} \mathrm{~A} \mathrm{Co}^{\mathrm{III}}$-superoxide adduct is formed upon activation of molecular oxygen, which readily abstracts a phenolic hydrogen from the substrate to form a phenoxyl radical. This intermediate interacts with the second equivalent of the $\mathrm{Co}^{\mathrm{III}}$-superoxide, giving rise to a peroxo species which immediately undergoes a rearrangement to produce quinone and formaldehyde. Alternatively, the same intermediate could also generate an aldehyde upon hydrogen atom abstraction (HAT) from the $\mathrm{Co}^{\mathrm{III}}$. The presence of a base such as a pyridine at the axial position of $\mathrm{Co}$ (salen) complex has been proved to facilitate the $\mathrm{Co}^{\mathrm{III}}$-superoxide formation by increasing the binding affinity of dioxygen species to the metal center. 


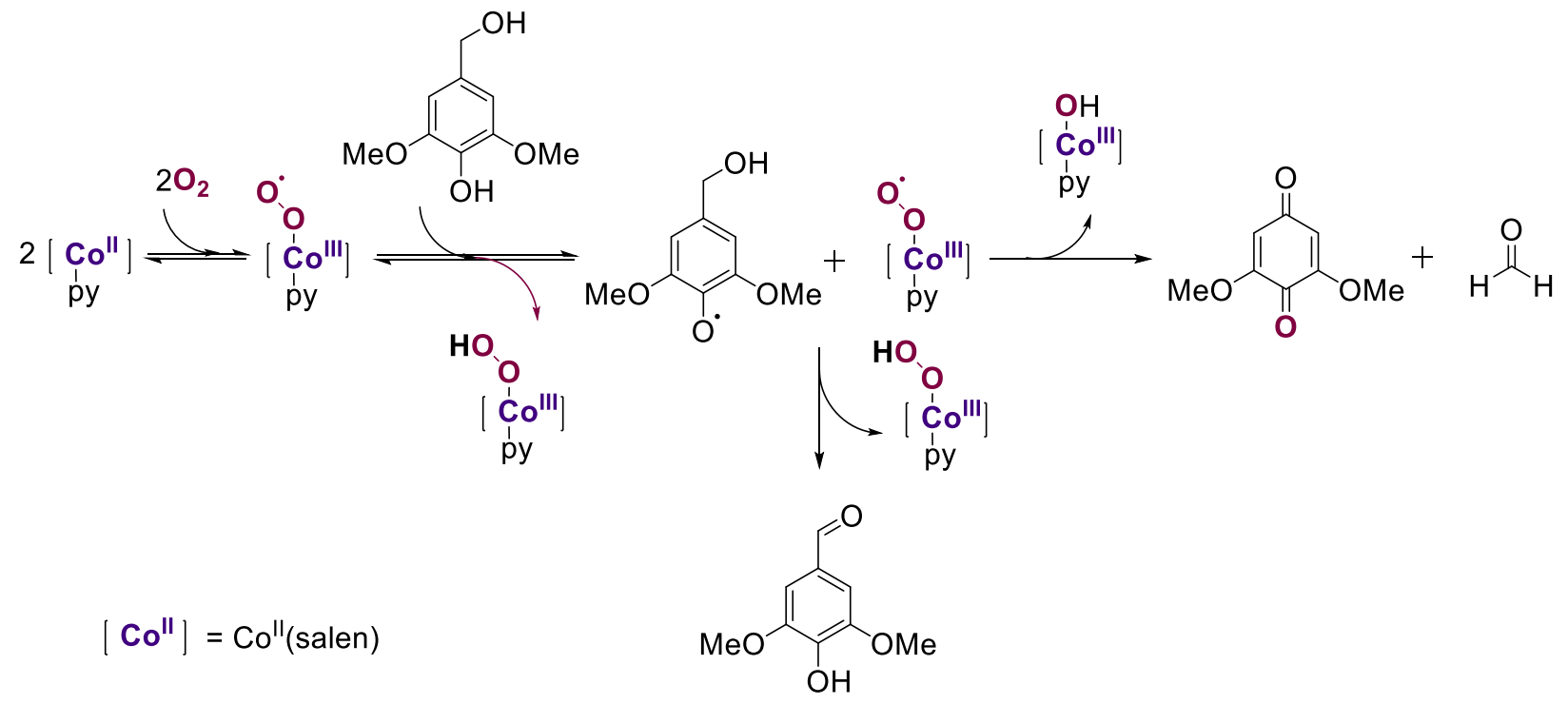

Scheme 1.11. Generalized Mechanism of Co(salen)-Catalyzed Aerobic Oxidation of Lignin-like Phenols to Form Quinones and Aldehydes.

These precedented studies concluded that cobalt Schiff base-catalyzed aerobic phenol oxidations all involve the formation of $\mathrm{Co}^{\mathrm{III}}$-hydroxide and $\mathrm{Co}^{\mathrm{III}}$-hydroperoxide intermediates. In one of the works published, ${ }^{32}$ the proposed $\mathrm{Co}^{\mathrm{III}}-\mathrm{OH}$ intermediate is able to regenerate catalytically active $\mathrm{Co}^{\mathrm{II}}$ species. Upon hydrogen atom transfer (HAT) from phenol to cobalt hydroxy group, the $\mathrm{H}_{2} \mathrm{O}$ can dissociate from the metal center and release the $\mathrm{Co}$ (salen) complex to complete the cycle. In 2016, the Stahl group further investigated the Co(salophen)-catalyzed aerobic oxidation of $p$ hydroquinone (Figure 1.1 left). ${ }^{33}$ The mechanism of this catalytic oxidation was examined with a combination of spectroscopy, kinetic measurements, and density functional theory (DFT) calculations. The study suggested that the catalyst resting-state consists of an equilibrium between a $\mathrm{Co}^{\mathrm{II}}$ (salophen) complex, a Co ${ }^{\mathrm{III}}$-superoxide adduct, and a hydrogen-bonded adduct between the hydroquinone and the $\mathrm{Co}^{\mathrm{III}}-\mathrm{O}_{2}$ intermediate (Figure 1.1 right). The key processes involve a hydrogen atom transfer (HAT) from the $p$-hydroquinone to the $\mathrm{Co}^{\mathrm{III}}$-superoxide species and a proton-coupled electron transfer (PCET) between a semiquinone and $\mathrm{Co}^{\mathrm{III}}$-hydroperoxo intermediate (Figure 1.1 left bottom). The latter is identified as the turn-over limiting step by combined kinetic experiments and DFT calculations. Subsequently, a coordinated $\mathrm{H}_{2} \mathrm{O}_{2}$ intermediate of $\mathrm{Co}^{\mathrm{III}}$ will participate in the oxidation of the second equivalent of $p$-hydroquinone and regenerate the $\mathrm{Co}^{\mathrm{II}}$ catalyst in the cycle. 

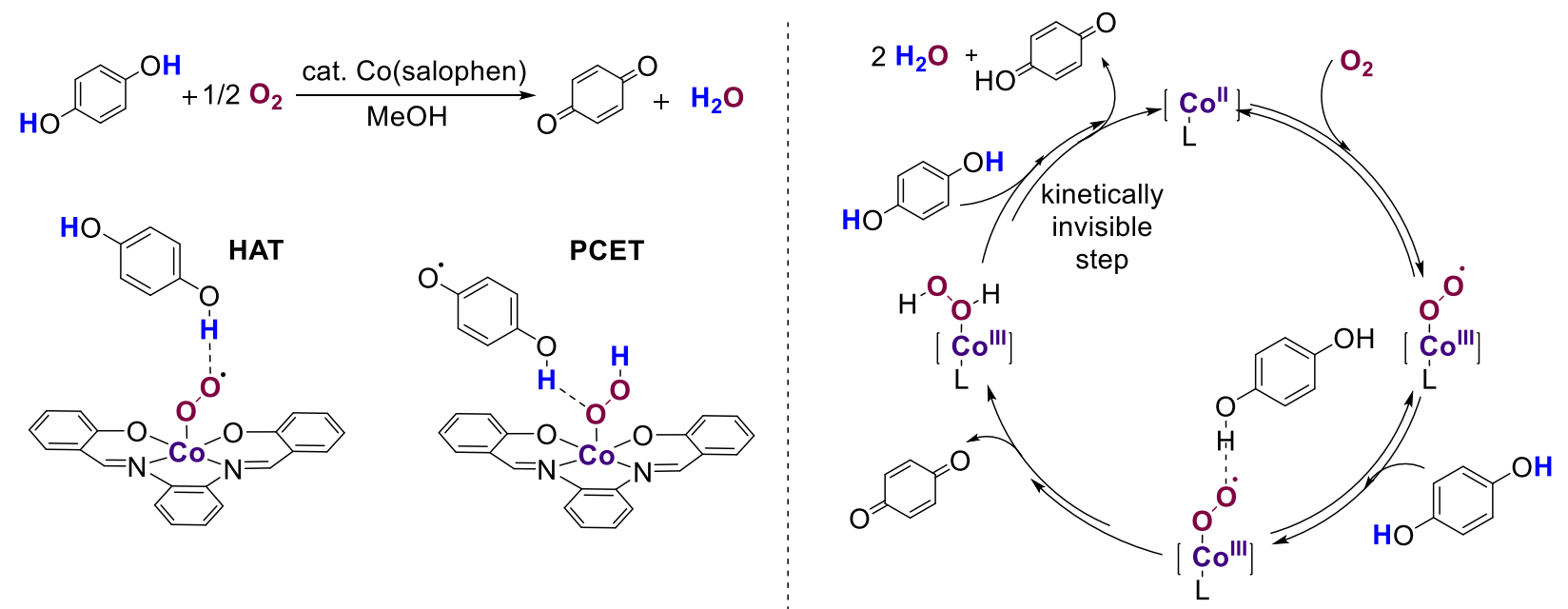

Figure 1.1. Proposed Mechanism for the $\mathrm{Co}($ salophen)-Catalyzed Aerobic Oxidation of $p$ Hydroquinone.

The well-established cycle for aerobic $p$-hydroquinone oxidation by cobalt Schiff base complexes has been widely found in bimetallic-mediated "oxidase" type transformations. These systems all consist of a coupled redox cycle, one cycle for the oxidation of the substrate by the oxidized catalyst, and one cycle for re-oxidation of the reduced catalyst by $\mathrm{O}_{2}$. Particularly featured in palladium-catalyzed oxidations, ${ }^{4}$ benzoquinones and macrocyclic cobalt complexes are usually used as co-catalytic systems in a wide scope of oxidation reactions, such as allylic acetoxylation, ${ }^{34}$ Wacker-type oxidation of the alkenes ${ }^{35}$, and oxidative $\mathrm{C}-\mathrm{C}$ cross-coupling reactions. ${ }^{36}$ Amongst these impressive findings, $\mathrm{Co}$ (salophen) is the most commonly employed co-catalyst in the aerobic oxidative transformations mediated by palladium ${ }^{37}$ and ruthenium. ${ }^{38}$ Scheme 1.12 illustrated an example of Pd-catalyzed acetoxylation with a combined redox cycle employing Co(salophen) and hydroquinone as a co-catalyst system. In this system, $\mathrm{Co}$ (salophen) and $p$-hydroquinone operate synergistically to generate the active benzoquinone as a co-catalyst meanwhile mediate the electron-transfer to the $\mathrm{Pd}$-catalyzed oxidative $\mathrm{C}-\mathrm{H}$ functionalization. 


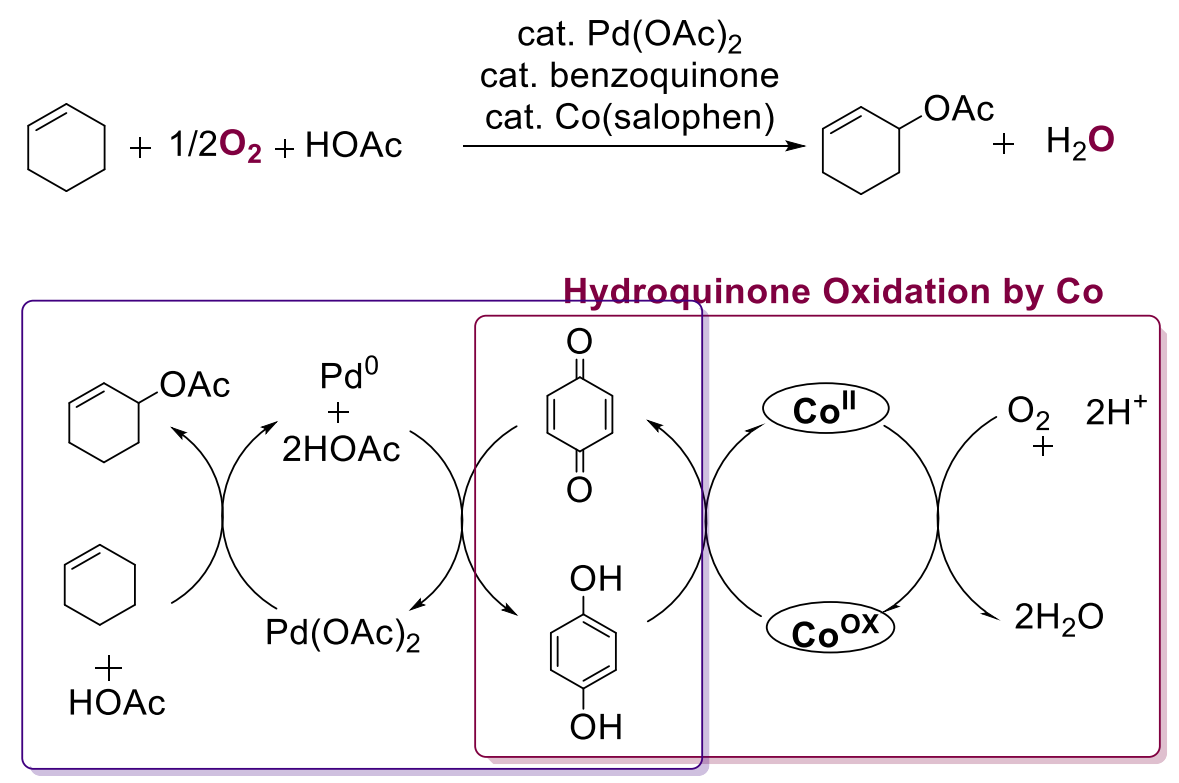

Substrate Oxidation by Pd

Scheme 1.12. Simplified Mechanism for the Coupled Redox Cycles Employing Co(salophen) and Hydroquinone Co-Catalyst in Pd-Catalyzed Allylic Acetoxylation.

Because of the high efficiency of $\mathrm{Co}($ salen) in the bimetallic systems to function as an electron-transfer mediator when it is paired with a benzoquinone co-catalyst, it has found its application in the selective aerobic oxidative cross-coupling reactions. In 2019, the Pappo group reported a waste-free, selectivity-driven oxidative coupling of phenols employing $\mathrm{Co}$ (salen) and air in a recyclable 1,1,1,3,3,3-hexafluoropropan-2-ol (HFIP) solvent (Scheme 1.13). ${ }^{39}$ This protocol offered a sustainable entry to the synthesis of nonsymmetric biphenols from the readily oxidized phenols and 2-naphthols. A combination of control experiments and kinetic studies pointed to the mechanism shown in Scheme 1.13 (bottom). The catalytic cycle starts with the formation of a dinuclear $\mu$-peroxo species of $\mathrm{Co}^{\mathrm{III}}$, which is in equilibrium with the active $\mathrm{Co}^{\text {III }}$ superoxide (a). A ligated intermediate with $\mathrm{Co}^{\mathrm{III}}$-superoxide (b) is formed when the substituted naphthol was introduced, which readily undergoes a hydrogen atom abstraction from a phenol substrate to generate a $\mathrm{Co}^{\mathrm{III}}$-hydrogen peroxide (c) meanwhile liberating a phenoxyl radical. The subsequent steps were kinetically invisible in the proposed cycle, the author suggested a rapid consecutive proton-coupled electron transfer (PCET) from the naphthol to the ligated $\mathrm{Co}^{\mathrm{III}}$ hydrogen peroxide, which released a $\mathrm{Co}^{\mathrm{II}}$-ligated napthoxyl radical intermediate (d). At this stage, the two radical species underwent a coupling reaction and afford biphenol as the product. The 
chemo-selectivity observed in this reaction thus can be attributed to the distinct roles of two phenols during the HAT and PCET processes. Except for aerobic oxidative coupling reactions, $\mathrm{Co}($ salen) has also been used for the aerobic oxidative polymerization of 2,3dihydroxynaphthalene ${ }^{40}$ and polyphenol oxidation. ${ }^{41}$ These studies will not be discussed in this chapter.

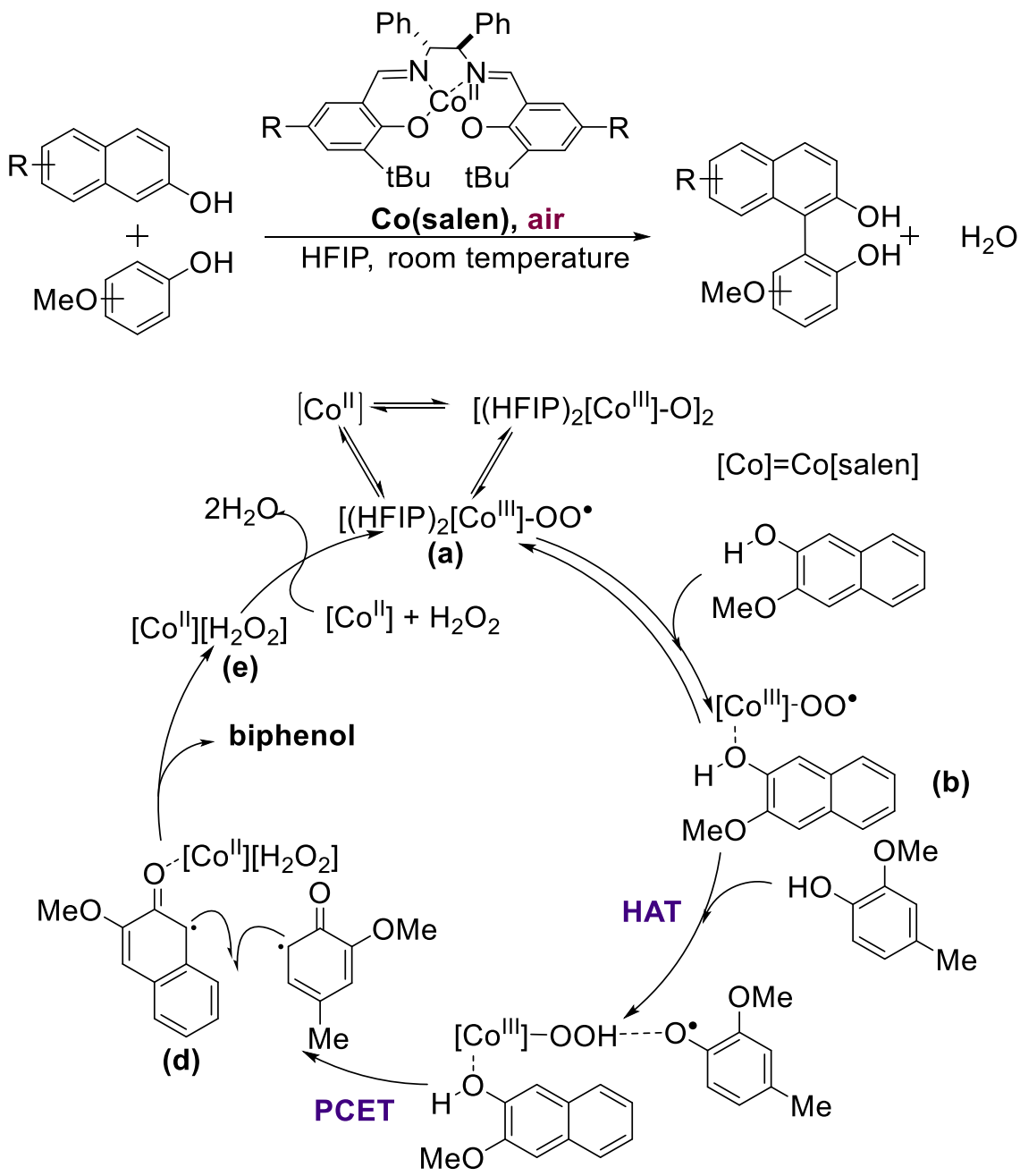

(c)

Scheme 1.13. Co(salen)-Catalyzed Aerobic Oxidative Cross-Coupling of Phenols in the WasteFree System. 


\subsection{Conclusion}

This chapter highlights the significance of developing transition-metal catalyzed oxidative reactions employing molecular oxygen as the stoichiometric oxidant. Two types of metalloenzyme mimic oxidation are introduced, which provide fundamental framework for a vast array of developments of the "oxygenase-type" and "oxidase-type" reactions. Advancements of three major classes of oxidative transformations mediated by $\mathrm{Co} / \mathrm{O}_{2}$ over the past few decades were especially addressed, the Mukaiyama oxidative cyclization, the aerobic oxidation catalyzed by $\mathrm{Co} / \mathrm{NHPI}$ co-catalyst system, and a variety of powerful transformations facilitated by $\mathrm{Co}(\mathrm{salen}) / \mathrm{O}_{2}$ system with and without a $p$-hydroquinone co-mediator. The ideas underlying these brilliant works have inspired the methodology developments and related mechanistic investigations in the next three chapters. A journey towards the development of cobalt-catalyzed aerobic oxidative cyclization reactions with bis-nucleophiles will be uncovered, and the key concepts mentioned in this chapter regarding $\mathrm{O}_{2}$ carrier chemistry, hydrogen atom transfer (HAT) strategies as well as the role of redox-mediators in $\mathrm{Co} / \mathrm{O}_{2}$-catalyzed oxidation will be well-reflected in the following works. 


\section{Chapter 2. Cobalt-Catalyzed Aerobic Oxidative Cyclization of 2- Aminophenols with Isonitriles: 2-Aminophenol Enabled $\mathrm{O}_{2}$ Activation by Cobalt(II)}

\subsection{Introduction}

The recent decade has witnessed tremendous advances in homogeneous transition-metalcatalyzed aerobic oxidation reactions due to the environmentally benign nature of molecular $\mathrm{O}_{2}$ as oxidant. As an alternative of widely explored $\mathrm{Pd}^{42,43}$ and $\mathrm{Cu}^{44,45}$ catalysts in these aerobic oxidation reactions, cobalt has received considerable attention being an earth-abundant first-row transition metal. However, in the cobalt-mediated aerobic oxidative reactions, redox-active comediators, such as benzoquinone (BQ) $)^{33}$, N-hydroxyphthalimide (NHPI) ${ }^{23,24}$ and salen ligands ${ }^{46}$, 47 are often employed to enable the activation of molecular oxygen as the terminal oxidant. There are fewer examples of cobalt-catalyzed aerobic oxidation reactions that operate efficiently in the absence of external redox-active co-mediators, despite a surge of studies in $\mathrm{Co} / \mathrm{O}_{2}$-mediated organic transformations. ${ }^{15,48,49}$

Achieving aerobic oxidative transformations without requiring external redox-comediators may be particularly challenging as these mediators have been shown in a recent study to prevent the accumulation of peroxide and superoxide intermediates which lead to the generation of undesired oxygenation side products. ${ }^{33}$ Inspired by $\mathrm{O}_{2}$ activation routes in oxidation reactions mediated by Co/BQ and Co/NHPI systems (Scheme 2.1a,b), we hypothesized the dual functionality of a substrate also acts as a hydrogen atom donor that is able to activate molecular oxygen via hydrogen atom transfer (HAT) and therefore selectively oxidize the substrate (Scheme 2.1c). We chose 2-aminophenol as a coupling partner to test our hypothesis due to its relevance to metalloenzymes. Cobalt-containing biomimetic catecholase with N,O donor Schiff-base ligands enables oxidation of a catechol derivative to its corresponding quinone with concomitant reduction of $\mathrm{O}_{2}$ to $\mathrm{H}_{2} \mathrm{O} .^{50-52}$ Related N,O-based scaffolds such as $o$-aminophenol derivatives are also commonly explored in cobalt complexes as redox-active ligands. ${ }^{53} \mathrm{We}$ propose a phenoxyl radical generated in situ in the presence of cobalt catalyst and $\mathrm{O}_{2}$, which can be trapped efficiently with the proper choice of a coupling partner. Because isonitriles are versatile chemical entities capable 
of reacting as electrophiles and nucleophiles, directing this tunable reactivity with metal complexes provides a rapid entry to a vast array of pharmaceutically valuable nitrogenous molecular structures. $^{54-56}$ The coupling of 2-aminophenols with isonitriles gives rise to a variety of substituted 2-aminobenzoxazoles; ${ }^{57}$ however, the aerobic routes to access these medicinally and biologically important structures are quite limited. ${ }^{58}$

(a) $\mathrm{H}_{2} \mathrm{Q}$ as the Redox-Active Mediator

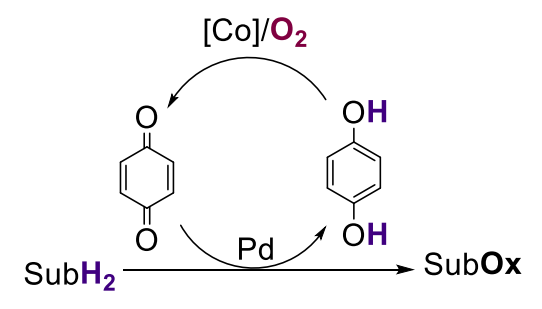

(b) NHPI as the Redox-Active Mediator

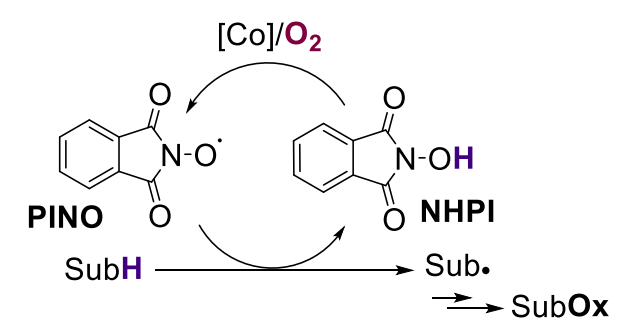

(c) Hypothesis of This Work: Dual Functionality of 2-Aminophenol as Both a Substrate and a Redox-Active Mediator

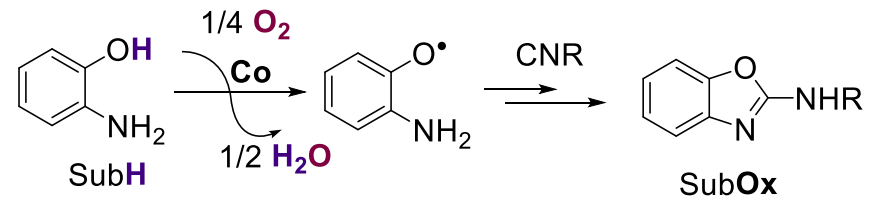

Scheme 2.1. Redox-Active Mediators in Cobalt-Mediated Aerobic Oxidative Reactions in Enabling $\mathrm{O}_{2}$ Activation in Prior Studies and This Work. (a) Hydroquinone $\left(\mathrm{H}_{2} \mathrm{Q}\right)$ as a RedoxActive Mediator. (b) N-Hydroxyphthalimide (NHPI) as a Redox-Active Mediator. (c) Hypothesis of This Work: The Dual Functionality of 2-Aminophenol as Both a Redox-Active Mediator and a Substrate.

\subsection{Results}

\subsubsection{Condition Optimization for Cobalt-Catalyzed Oxidative Cyclization of 2-Aminophenol with tert-Butyl Isonitrile}

We began our studies by evaluating the coupling reaction of 2-aminophenol (1a) and tertbutyl isonitrile (2a) using air as the supply of the terminal oxidant. In our early studies, air efficiently promoted the oxidative cyclization of these two coupling partners in THF solvent. Of 
all $\mathrm{Co}(\mathrm{II})$ catalysts being examined, $\mathrm{Co}(\mathrm{OAc})_{2}$ gave the highest yield of the substituted 2-aminobenzoxazole product 3a. When the solvent is switched to $\mathrm{CH}_{3} \mathrm{CN}, \mathbf{3 a}$ was achieved in $93 \%$ yield. Shorter reaction times led to slightly reduced yields (entry 12 and 13). A variety of bases were also screened in condition optimization. Though in some cases they afforded the target benzoxazole in high yields they were proved to be a non-necessary component for this reaction (See Table 2.5 in the experimental section). The final optimized reaction conditions featured a simple but efficient combination of $\mathrm{Co}(\mathrm{OAc})_{2}$ as the catalyst, $\mathrm{CH}_{3} \mathrm{CN}$ as the solvent, and an air balloon as the source of terminal oxidant. The reaction was carried out at $65{ }^{\circ} \mathrm{C}$ for 24 hours. Control experiments were conducted in the absence of either air or Co(II) (Entry 14 and 15), which afforded the desired product with $0 \%$ and $14 \%$ yields respectively, indicating the importance of both molecular oxygen and the Co(II) source in this oxidative cyclization transformation.

Table 2.1. Optimization of Reaction Conditions ${ }^{\mathrm{a}}$

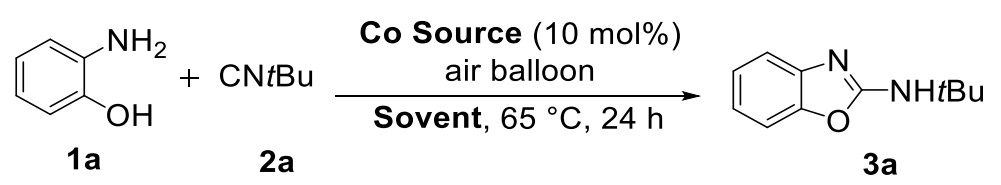

\begin{tabular}{|c|c|c|c|c|}
\hline Entry & Co Source & Solvent & Time (h) & $\%$ Yield $^{\mathrm{b}}$ \\
\hline 1 & $\mathrm{Co}(\mathrm{acac})_{2}$ & $\mathrm{THF}$ & 24 & $58^{c}$ \\
\hline 2 & $\mathrm{Co}(\text { acac })_{2} \bullet \mathrm{H}_{2} \mathrm{O}$ & $\mathrm{THF}$ & 24 & $67^{c}$ \\
\hline 3 & $\mathrm{CoCO}_{3}$ & $\mathrm{THF}$ & 24 & 51 \\
\hline 4 & $\mathrm{CoCO}_{3} \cdot \mathrm{H}_{2} \mathrm{O}$ & THF & 24 & Trace \\
\hline 5 & $\mathrm{CoCl}_{2}$ & $\mathrm{THF}$ & 24 & 46 \\
\hline 6 & $\mathrm{Co}(\mathrm{OAc})_{2}$ & THF & 24 & 86 \\
\hline 7 & $\mathrm{Co}(\mathrm{OAc})_{2}$ & 1,4-dioxane & 24 & 89 \\
\hline 8 & $\mathrm{Co}(\mathrm{OAc})_{2}$ & 2-Me-THF & 24 & 54 \\
\hline 9 & $\mathrm{Co}(\mathrm{OAc})_{2}$ & $\mathrm{DMF}$ & 24 & 86 \\
\hline 10 & $\mathrm{Co}(\mathrm{OAc})_{2}$ & DMSO & 24 & 78 \\
\hline 11 & $\mathrm{Co}(\mathrm{OAc})_{2}$ & $\mathrm{CH}_{3} \mathrm{CN}$ & 24 & $93(90)^{c}$ \\
\hline 12 & $\mathrm{Co}(\mathrm{OAc})_{2}$ & $\mathrm{CH}_{3} \mathrm{CN}$ & 12 & 85 \\
\hline 13 & $\mathrm{Co}(\mathrm{OAc})_{2}$ & $\mathrm{CH}_{3} \mathrm{CN}$ & 6 & 79 \\
\hline 14 & - & $\mathrm{CH}_{3} \mathrm{CN}$ & 24 & 0 \\
\hline
\end{tabular}


$15^{\mathrm{d}} \quad \mathrm{Co}(\mathrm{OAc})_{2} \quad \mathrm{CH}_{3} \mathrm{CN} \quad 24 \quad 14$

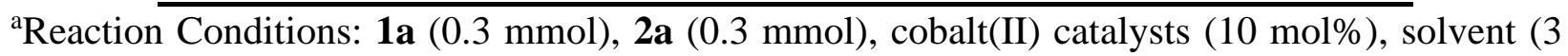
$\mathrm{mL}$ ), at $65{ }^{\circ} \mathrm{C}$ with an air balloon for $24 \mathrm{~h}$. ${ }^{b}$ The yield of 3a was determined by ${ }^{1} \mathrm{H}$ NMR spectroscopy with dimethylsulfone as internal standard $(0.03 \mathrm{mmol}) .{ }^{c}$ Isolated yield. ${ }^{\mathrm{d}}$ The reaction was conducted under $\mathrm{N}_{2}$.

\subsubsection{Substrate Scope of Substituted 2-Aminophenols and Isonitriles}

With optimized reaction condition in hand, we next explored the scope of substituted 2aminophenol coupling partners (1, Table 2.2). This protocol showed good tolerance of a variety of functional groups including both electron-rich (3d, 3e, 3h, and $\mathbf{3 i}$ ) and electron-deficient substituents (3f, 3g, and 3k). The influence of a methyl group in each of the four aromatic positions $(\mathbf{3 b}, \mathbf{3 d}, \mathbf{3 i}$, and $\mathbf{3 l})$ reveals only a small steric effect, as the yield of $\mathbf{3 b}$ bearing the 3-methyl group showed a slightly decreased yield. The 4-, 5-, and 6-methyl aminophenols all resulted in high yields of the corresponding 2-aminobenzoxazoles. Similarly, the large phenyl and tert-butyl groups afforded the desired cyclized products in good yields (3c and $\mathbf{3 h}$ ). Finally, the di-substituted electron-deficient 5-nitro-4-chloro-2-aminophenol $\mathbf{1 m}$ afforded the desired benzoxazole product in $64 \%$ yield.

Table 2.2. Scope of Substituted 2-Aminophenols ${ }^{\mathrm{a}}$

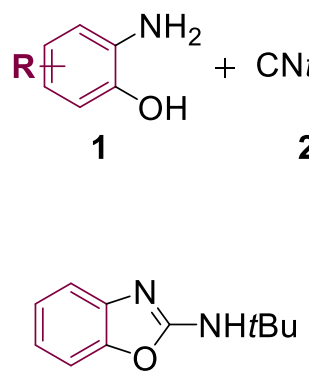

$3 a, 90 \%$

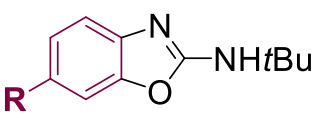

3i, $\mathrm{R}=\mathrm{Me}, \quad 83 \%$

3j, $\mathrm{R}=\mathrm{OMe}, 30 \%$

3k, $\mathrm{R}=\mathrm{NO}_{2}, \quad 73 \%$
$\mathrm{Co}(\mathrm{OAc})_{2}(10 \mathrm{~mol} \%)$
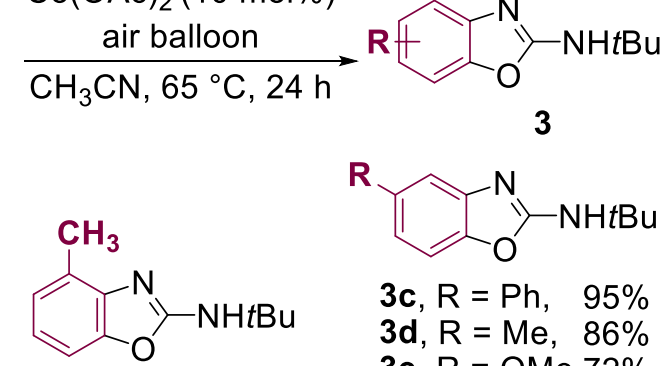

$\mathbf{R}$<smiles></smiles>

3c, $\mathrm{R}=\mathrm{Ph}, \quad 95 \%$

$3 d, R=M e, \quad 86 \%$

3e, $\mathrm{R}=\mathrm{OMe}, 72 \%$

3f, $\mathrm{R}=\mathrm{NO}_{2} \quad 84 \%$

$3 \mathrm{~g}, \mathrm{R}=\mathrm{Br}, \quad 90 \%$

$3 \mathrm{~h}, \mathrm{R}=t \mathrm{Bu}, 93 \%$

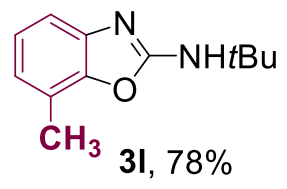

${ }^{a}$ Isolated Yields. Reaction conditions: $1(0.3 \mathrm{mmol}), \mathbf{2 a}(0.3 \mathrm{mmol})$, and $\mathrm{Co}(\mathrm{OAc})_{2}(10 \mathrm{~mol} \%)$ in $3 \mathrm{~mL} \mathrm{CH}{ }_{3} \mathrm{CN}$ at $65^{\circ} \mathrm{C}$ with an air balloon for $24 \mathrm{~h}$. 
To further evaluate the performance of this cyclization reaction, we investigated the scope of isonitriles (2, Table 2.3). While tert-butylisonitrile is the most commonly employed isonitrile in related coupling protocols, ${ }^{54,59}$ other bulky aliphatic isonitriles are also excellent coupling partners under our reaction conditions furnishing the corresponding products in high yields (3n, 3o and 3p). Surprisingly, the isopropyl- and cyclohexyl-substituted isonitriles also generated high yields of the corresponding 2-aminobenzoxazole products (3p and $\mathbf{3 q})$. These products are expected to contain weak $\mathrm{C}-\mathrm{H}$ bonds $\left(\mathrm{BDE}=\sim 86 \mathrm{kcal} \mathrm{mol}^{-1}\right)^{60}$ and are plausible substrates for further oxidation. The benzylic isonitrile $\mathbf{2} \mathbf{u}$, however, did not undergo efficient coupling and instead resulted in only a moderate yield of the coupling product $(3 \mathbf{u}, 32 \%)$. Also observed was the 3-aminobenzoxazine byproduct ( $16 \%$ yield) which results from insertion of 2 equivalents of isontrile. ${ }^{61}$ Surprisingly, no oxygenation byproducts were observed in this reaction, despite the weak $\mathrm{C}-\mathrm{H}$ bond ( 72 $\left.\mathrm{kcal} \cdot \mathrm{mol}^{-1}\right)^{62}$ and the precedent for $\mathrm{Co} / \mathrm{O}_{2}$ enabled benzylic oxygenation. ${ }^{63}$ Finally, aryl isonitriles also underwent coupling to yield the corresponding 2-aminobenzoxazole products, with the bulkier aromatic ring of $\mathbf{1 t}$ resulting in the highest product yield.

Table 2.3. Scope of Substituted Isonitriles ${ }^{a}$
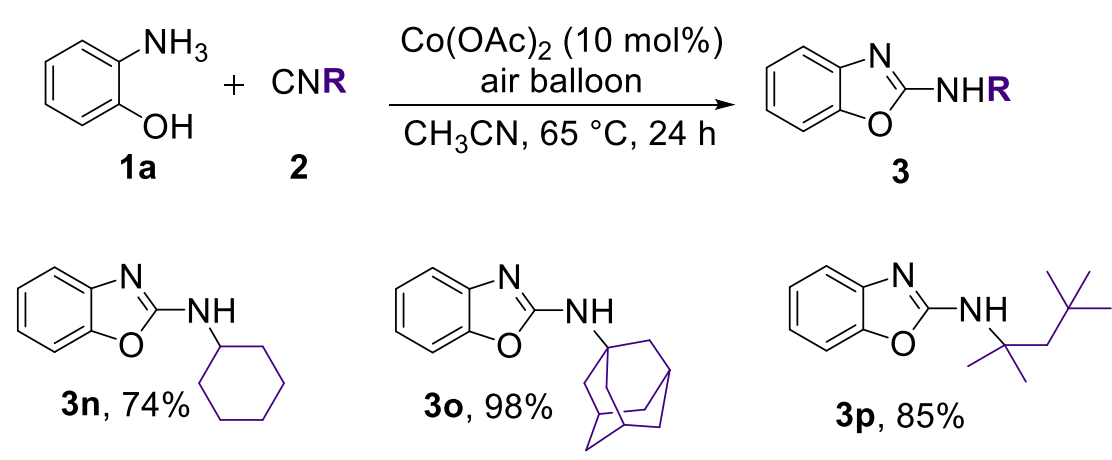

$3 p, 85 \%$
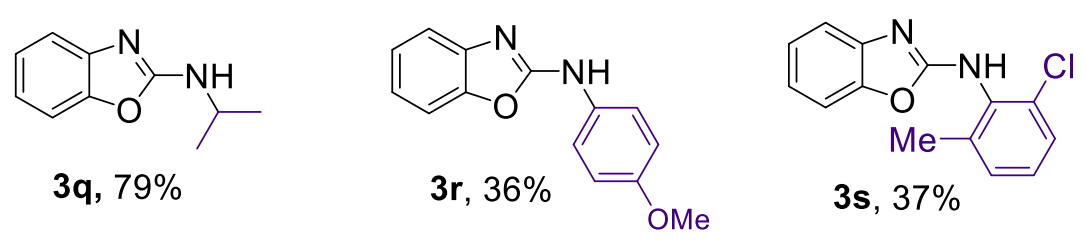

3q, $79 \%$

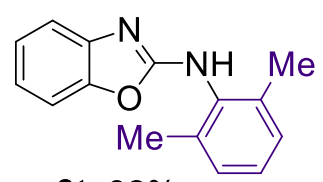

$3 t, 82 \%$

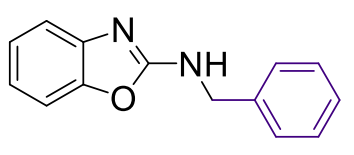

3 u, $32 \%$ 3s, $37 \%$

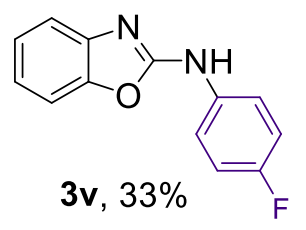

${ }^{a}$ Isolated Yields. Reaction conditions: 1a $(0.3 \mathrm{mmol}), 2(0.3 \mathrm{mmol})$, and $\mathrm{Co}(\mathrm{OAc})_{2}(10 \mathrm{~mol} \%)$ in $3 \mathrm{~mL} \mathrm{MeCN}$ at $65^{\circ} \mathrm{C}$ with an air balloon for $24 \mathrm{~h}$. 
Although a wide variety of functional groups on the 2-aminophenol and isonitrile coupling partners are well tolerated, we observed challenging substrates through our study for which products could not be generated cleanly under the reported reaction conditions (Chart 2.1). This protocol didn't work efficiently for 2-aminophenol substrates bearing a halide in the 5-position. 5-bromo-2-aminophenol and 5-fluoro-2-aminophenol consistently gave the substituted 2aminobenzoxazole isomers with 5:1 ratio. p-Toluenesulfonylmethyl isocyanide underwent competitive oxidation reactions in the presence of $\mathrm{O}_{2}$ probably due to the liable $\mathrm{C}-\mathrm{H}$ bond in combination with the active sulfonyl group, and multiple products were generated. This protocol was also not compatible with isonitriles bearing fused-ring systems. Both $1 H$-indol-5-yl isocyanide and protected indol-5-yl isocyanide went through multiple reaction pathways. Similar challenges were observed when 2-naphthyl isocyanide was subjected to the standard reaction system which resulted in multiple unrecognizable products.

Chart 2.1. Products That Were Not Generated Cleanly Under the Reported Conditions

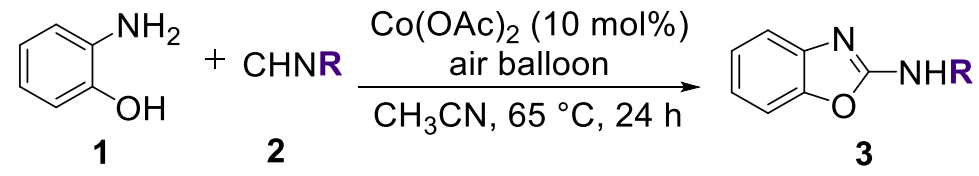<smiles>CC(C)(C)Nc1nc2ccc(Br)cc2o1</smiles><smiles>CC(C)(C)Nc1nc2ccc(F)cc2o1</smiles><smiles>Cc1ccc(S(=O)(=O)CNc2nc3ccccc3o2)cc1</smiles><smiles>c1ccc2oc(Nc3ccc4[nH]ccc4c3)nc2c1</smiles><smiles>CC(C)(C)OC(=O)n1ccc2cc(Nc3nc4ccccc4o3)ccc21</smiles>

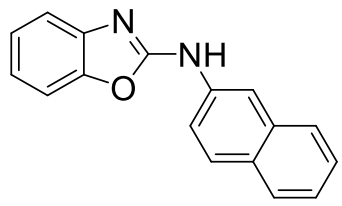

Reaction conditions: 1 (0.3 mmol), $2 \mathbf{a}(0.3 \mathrm{mmol})$, and $\mathrm{Co}(\mathrm{OAc})_{2}(10 \mathrm{~mol} \%)$ in $3 \mathrm{~mL} \mathrm{CH}_{3} \mathrm{CN}$ at $65^{\circ} \mathrm{C}$ with an air balloon for $24 \mathrm{~h}$.

\subsubsection{Preliminary Mechanistic Investigations}

2.2.3.1. Testing the Presence of Trappable Radical Intermediates 
The efficient coupling of isonitriles bearing weak $\mathrm{C}-\mathrm{H}$ bonds suggested that a free-radical intermediate is unlikely. To test our hypothesis, we sought to trap the free-radical intermediates by a careful selection of radical scavengers. The three commonly used radical scavenger $(2,2,6,6-$ tetramethylpiperidin-1-yl)oxyl (TEMPO), 9,10-dihydroanthracene and 1,1-diphenylethylene showed no evidence of trappable intermediates. Instead, high yields of $\mathbf{3 a}$ were still observed when these reagents were included under the standard reaction conditions (Scheme 2.2a), ${ }^{64}$ which were consistent with our hypothesis. When the same reactions are conducted in the absence of isonitrile, oxidative dimerization of 2-aminophenol occurs to form 2-aminophenoxazine-3-one both in the presence and absence of TEMPO (43\% and 10\% yields, respectively) (Scheme 2.2b), ${ }^{65}$ consistent with the presence of aminophenol radicals. ${ }^{52,66,67}$ The elevated yield in the presence of TEMPO could be a result of a TEMPO-mediated $\mathrm{H}$-atom abstraction pathway to form the aminophenol radical, ${ }^{68}$ where TEMPO was acting as a radical initiator rather than a radical-trapping agent.

(a) Control Experiments in the Presence of Radical Scavengers

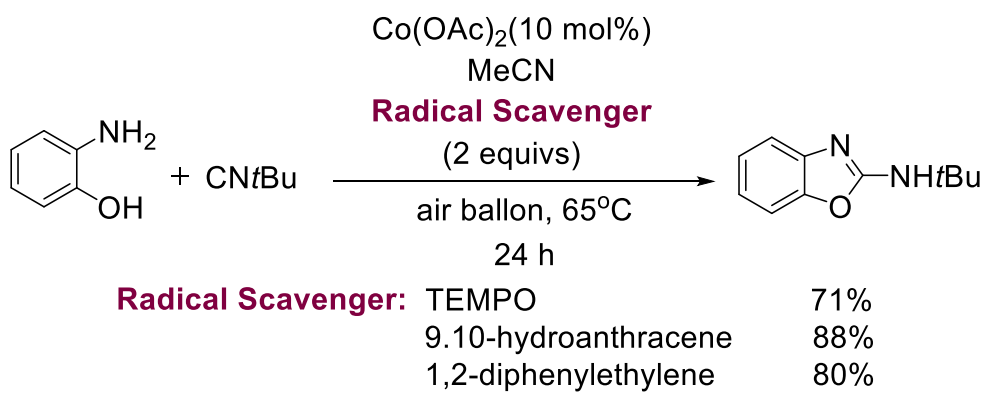

(b) Control Experiments with TEMPO in the Absence of Isonitrile

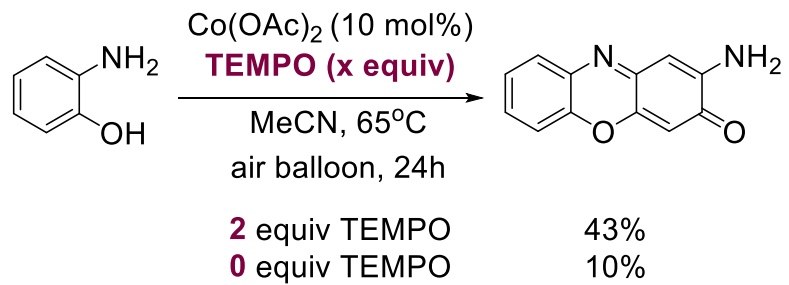

Scheme 2.2. Aerobic Oxidative Cyclization Conducted in the Presence of Radical Trapping Reagents. 


\subsubsection{The Importance of $\mathrm{O}_{2}$ in Oxidative Cyclization and a Plausible Path for $\mathrm{O}_{2}$ Activation}

We attribute the absence of a trappable intermediate to the possibility of a stabilized ligand radical intermediate. A large series of $\mathrm{Co}^{\mathrm{II}}$ complexes of aminophenol-, aminothiophenol- and phenylenediamine-derived ligands have been characterized. ${ }^{53}$, 55, 69-72 Wieghardt and coworkers have shown aerobic oxidation of these species would form stabilized iminobenzosemiquinonatotype species bearing $\pi$-radical ligands $\left(\mathrm{AP}^{\mathrm{SQ}}\right) \cdot{ }^{70} \mathrm{In}$ all of above mentioned cases highly-substituted aminophenols are employed to avoid ligand dimerization and at the same time enable the formation of stable oxidized complexes for isolation purpose. In our case, we believe a similar stabilized ligand radical maybe formed under our reaction conditions from $\mathrm{Co}^{\mathrm{II}}$ catalyst, $\mathrm{O}_{2}$ and 2aminophenol. When isonitrile (CNR) is present, it is a sufficient trap for aminophenol radical while in the absence of isonitrile, dimerization of 2-aminophenol occured and gave rise to 2aminophenoxazinone.

Then we conducted a series of control experiments in the absence of $\mathrm{O}_{2}$ to evaluate if $\mathrm{O}_{2}$ is required for the formation of cyclized benzoxazole products or simply it is responsible for the regeneration of $\mathrm{Co}^{\mathrm{II}}$ after the product formation (Scheme 2.3). When the standard reaction is conducted with stoichiometric amount of $\mathrm{Co}(\mathrm{OAc})_{2}$ under inert atmosphere, only $10 \%$ of product 3a is obtained, suggesting the need for molecular oxygen to efficiently form the cyclized product. The same reaction was conducted with stoichiometric amount of $\mathrm{Co}^{\mathrm{III}}$ salt, $\mathrm{Co}(\mathrm{acac})_{3}$ under $\mathrm{N}_{2}$ atmosphere to test if $\mathrm{Co}^{\mathrm{III}}$ species an active intermediate for this transformation. This time the cyclized product was formed in $63 \%$ yield. The reduced yield obtained with $\mathrm{Co}(\mathrm{acac})_{3}$ related to the standard catalytic conditions was attributed to the slow exchange of the acac ligand. To make a parallel comparison, we set up a control experiment with $\mathrm{Co}^{\mathrm{II}}$ salt but the same acac ligand. Consistent with our hypothesis, when the standard reaction was conducted with catalytic amount of $\mathrm{Co}(\mathrm{acac})_{2}$ under aerobic atmosphere, $58 \%$ of $\mathbf{3 a}$ was obtained. These data combined suggested that $\mathrm{O}_{2}$ is responsible for the oxidation of $\mathrm{Co}^{\mathrm{II}}$ to generate an active $\mathrm{Co}^{\mathrm{III}}$ intermediate or a $\mathrm{Co}^{\mathrm{II}} \mathrm{AP}^{\mathrm{SQ}}$ species with oxidized semiquinonato ligands. 


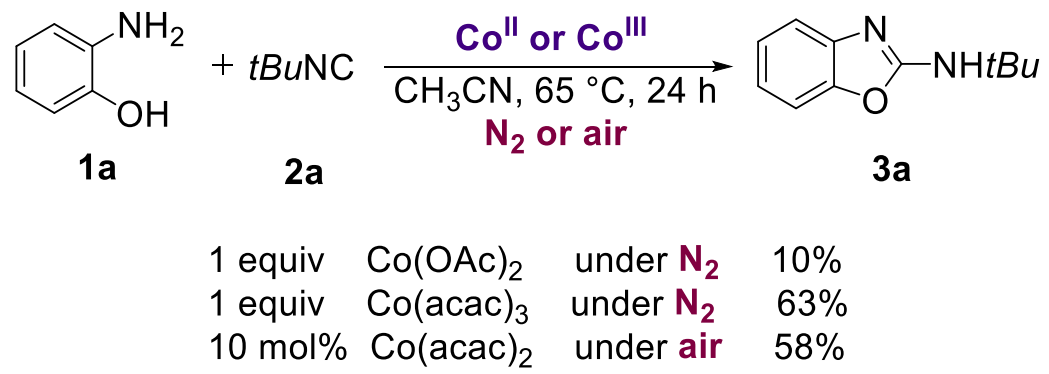

Scheme 2.3. Oxidative Cyclization of 2-Aminophenol and tert-Butyl Isonitrile Mediated by Cobalt Under $\mathrm{N}_{2}$.

Given the importance of oxidation for product formation, we sought to better understand the aerobic oxidation step of this transformation. The oxidation of $\mathrm{Co}^{\mathrm{II}}$ by molecular oxygen is usually proposed to generate a $\mathrm{Co}^{\mathrm{III}}$-superoxide intermediate as demonstrated in a recent study by Stahl, Hammes-Schiffer, and cowokers. ${ }^{33}$ In this study, molecular oxygen is activated by a salophen-ligated $\mathrm{Co}^{\mathrm{II}}$ complex to form a $\mathrm{Co}^{\mathrm{III}}$-superoxide intermediate. This superoxide species is responsible for $\mathrm{H}$-atom transfer (HAT) from $p$-hydroquinone to generate a $\mathrm{Co}^{\mathrm{III}}$-hydroperoxide intermediate. A second HAT sequence then followed to produce $p$-quinone with concomitant release of $\mathrm{H}_{2} \mathrm{O}_{2}$ and regeneration of $\mathrm{Co}^{\mathrm{II}}$ (salophen). Under these reaction conditions, $\mathrm{H}_{2} \mathrm{O}_{2}$ underwent disproportionation to form $\mathrm{H}_{2} \mathrm{O}$ and $\mathrm{O}_{2}$ (Scheme 2.4a). Comparatively, the re-oxidation of N-hydroxyphthalimide (NHPI) was proposed to go through an analogous HAT sequence. ${ }^{73}$ Thus we imagined that a resembling $\mathrm{Co}^{\mathrm{III}}$-superoxide species may be responsible for HAT from 2aminophenol under our oxidative cyclization conditions (Scheme 2.4b). We proposed the molecular oxygen activation by a $\mathrm{Co}^{\mathrm{II}}$ complex with coordination of two equivalents of 2-aminophenol ligands, which leads to the formation of the corresponding $\mathrm{Co}^{\mathrm{III}}$-superoxide as suggested above. $\mathrm{H}_{2} \mathrm{O}_{2}$ is released after two stepwise HAT sequences from 2-aminophenol ligands to peroxide, giving rise to the active $\mathrm{Co}^{\mathrm{II}} \mathrm{AP}^{\mathrm{SQ}}$ intermediate with two oxidized semiquinonato ligands. Consequently, cyclized benzoxazole product is expected in the presence of isonitrile under the aerobic oxidative reaction condition. 
Scheme 2.4. (a) Proposed Pathway for Co-Catalyzed Aerobic Oxidation of Catechol in Literature and (b) Proposed Pathway for Aerobic 2-Aminophenol Oxidation in This Work.

(a) Co-catalyzed aerobic oxidation of catechol

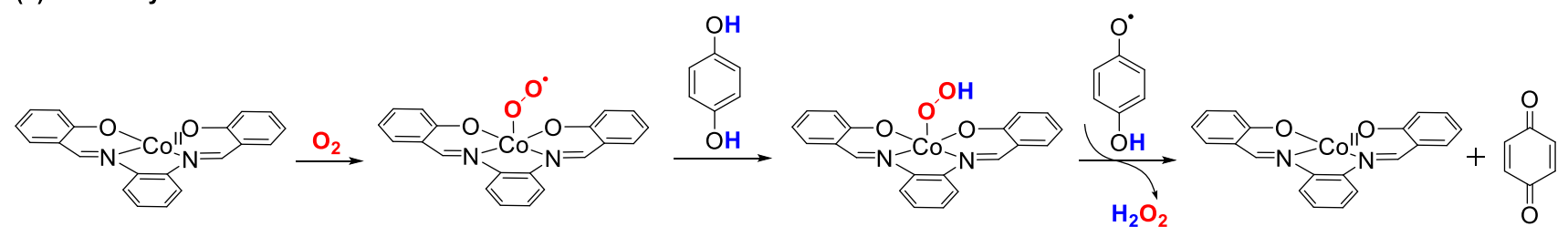

(b) Plausible reaction pathway for Co-catalyzed aerobic oxidation of 2-aminophenol
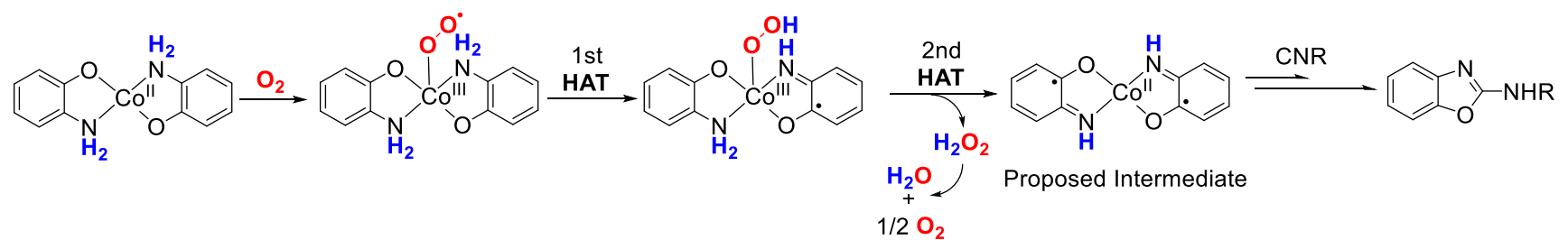

\subsubsection{Probing the Reaction Mechanism Through UV-Visible Studies}

We conducted a series of UV-visible experiments to probe the oxidation step and particularly the ligand environment that enables aerobic oxidation. Three parallel experiments were set up with identical concentration of $\mathrm{Co}(\mathrm{acac})_{2}$ in acetonitrile to investigate potential combination of reaction components that allows the activation of molecular oxygen. Due to the limited solubility of $\mathrm{Co}(\mathrm{OAc})_{2}$ in $\mathrm{CH}_{3} \mathrm{CN}, \mathrm{Co}(\mathrm{acac})_{2}$ was employed for these studies which also showed catalytic competency in previous condition optimization. When $\mathrm{Co}(\mathrm{acac})_{2}$ was exposed to air for 24 hours no changes in the absorption spectrum were observed (Figure 2.1a and Figure 2.5 in the Experimental section). Similarly, a mixture of $1: 2$ equivalents of $\mathrm{Co}(\mathrm{acac})_{2}$ and $\mathrm{CN} t \mathrm{Bu}$ in $\mathrm{CH}_{3} \mathrm{CN}$ showed no significant changes in the spectroscopic features after exposure to air (Figure 2.1a and Figure 2.6 in the Experimental section). The mixture of $\mathrm{Co}(\mathrm{acac})_{2} / \mathrm{CN} t \mathrm{Bu}$ showed identical maximum absorption with $\mathrm{Co}(\mathrm{acac})_{2}$ in $\mathrm{CH}_{3} \mathrm{CN}$ because the absorption of $\mathrm{CN} t \mathrm{Bu}$ can only be detected in the vacuum UV region $\left(\lambda_{\max } \sim 140 \mathrm{~nm}\right)$. In contrast, when a solution of 1:2 ratio of $\mathrm{Co}(\mathrm{acac})_{2}$ and 2-aminophenol was exposed to air a rapid color change was observed from light pink to orange-brown within minutes. This rapid color change was accompanied by an increase in the absorption around $260 \mathrm{~nm}$ (Figure $2.1 \mathrm{~b}$ and Figure 2.7 in the Experimental section). This set 
of preliminary data suggested the activation of molecular oxygen only happen in an environment with 2-aminophenol coordination.

(a)

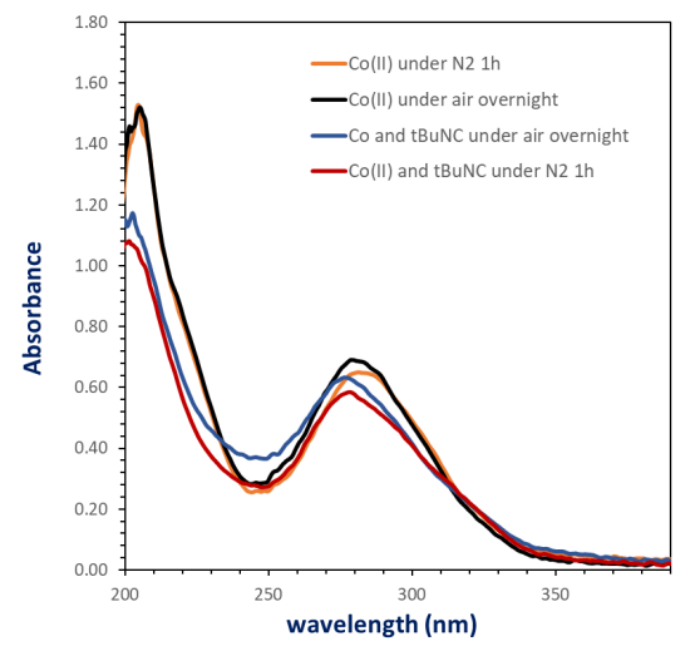

Figure 2.1. (a) Absorption spectrum of $\mathrm{Co}(\mathrm{acac})_{2}$ only and $\mathrm{Co}(\mathrm{acac})_{2}$ with $\mathrm{CN} t \mathrm{Bu}$ in $\mathrm{CH}_{3} \mathrm{CN}$ under $\mathrm{N}_{2}$ and after exposed to air overnight. (b) Absorption spectrum of $\mathrm{Co}(\mathrm{acac})_{2}$ and 2-aminophenol under $\mathrm{N}_{2}$ and after exposed to air overnight. These experiments were conducted at $5.05 \times 10^{-5} \mathrm{M}$ concentration in $\mathrm{CH}_{3} \mathrm{CN}$.

Based on the above observations, we ruled out the possibility of efficient $\mathrm{O}_{2}$ activation mediated by $\mathrm{Co}^{\mathrm{II}}$ only or $\mathrm{Co}^{\mathrm{II}} / \mathrm{CN} t \mathrm{Bu}$. We next investigated if the prolonged exposure of $\mathrm{Co}^{\mathrm{II}}$ and 2-aminophenol mixture under air led to the formation of a $\mathrm{Co}^{\mathrm{III}}$ intermediate. To test our hypothesis, another set of parallel control experiments were conducted. If the absorption maxima of $\mathrm{Co}^{\mathrm{II}} / 2$ aminphenol mixture are analogous to those of $\mathrm{Co}^{\mathrm{III}} / 2$-aminophenol mixture in the presence of $\mathrm{O}_{2}$, a Co ${ }^{\mathrm{III}}$ intermediate may exist in our related catalytic system. In the first experiment, the spectrum of the mixture of 1:3 ratio of $\mathrm{Co}(\mathrm{acac})_{2}$ and 2-aminophenol was taken under anaerobic atmosphere, no spectroscopic changes were observed with extended period of time. When the same solution was exposed to air, we observed a trend of color change comparable to 1:2 ratio mixture and a band around $260 \mathrm{~nm}$ on the absorption spectrum was appeared (Figure 2.2). This spectroscopic feature is similar to that observed when $\mathrm{Co}(\mathrm{acac})_{3}$ is combined with 2-aminophenol $\left(\lambda_{\max }=233 \mathrm{~nm}\right.$, Figure 2.2, Figure 2.8 and Figure 2.9 in the Experimental section). In a related Co system bearing catechol ligands, the semiquinonato species can be obtained when $\mathrm{Co}^{\mathrm{III}}$ starting materials are treated with catechol. ${ }^{74,75}$ A related redox-equilibrium to access $\mathrm{Co}^{\mathrm{II}}\left(\mathrm{AP}^{\mathrm{SQ}}\right)$ from $\mathrm{Co}^{\mathrm{III}}$ may be 
operative in these aminophenol systems. The absorption band around $410 \sim 430 \mathrm{~nm}$ of final trace spectrum of $\mathrm{Co}(\mathrm{acac})_{3}$ and 2-aminphenol mixture demonstrated the presence of 2-aminophenoxazine-3-one, the dimerized product of 2-aminophenol under aerobic condition we had observed in the previous control experiment (Scheme 2.2b). This again might be attributed to the slow exchange of the acac ligand and the rate of aminophenol oxidation exceeded the rate of ligand exchange. Overall, these spectroscopic changes suggest aerobic oxidation of $\mathrm{Co}^{\mathrm{II}}$ is facilitated by the presence of 2 -aminophenol.

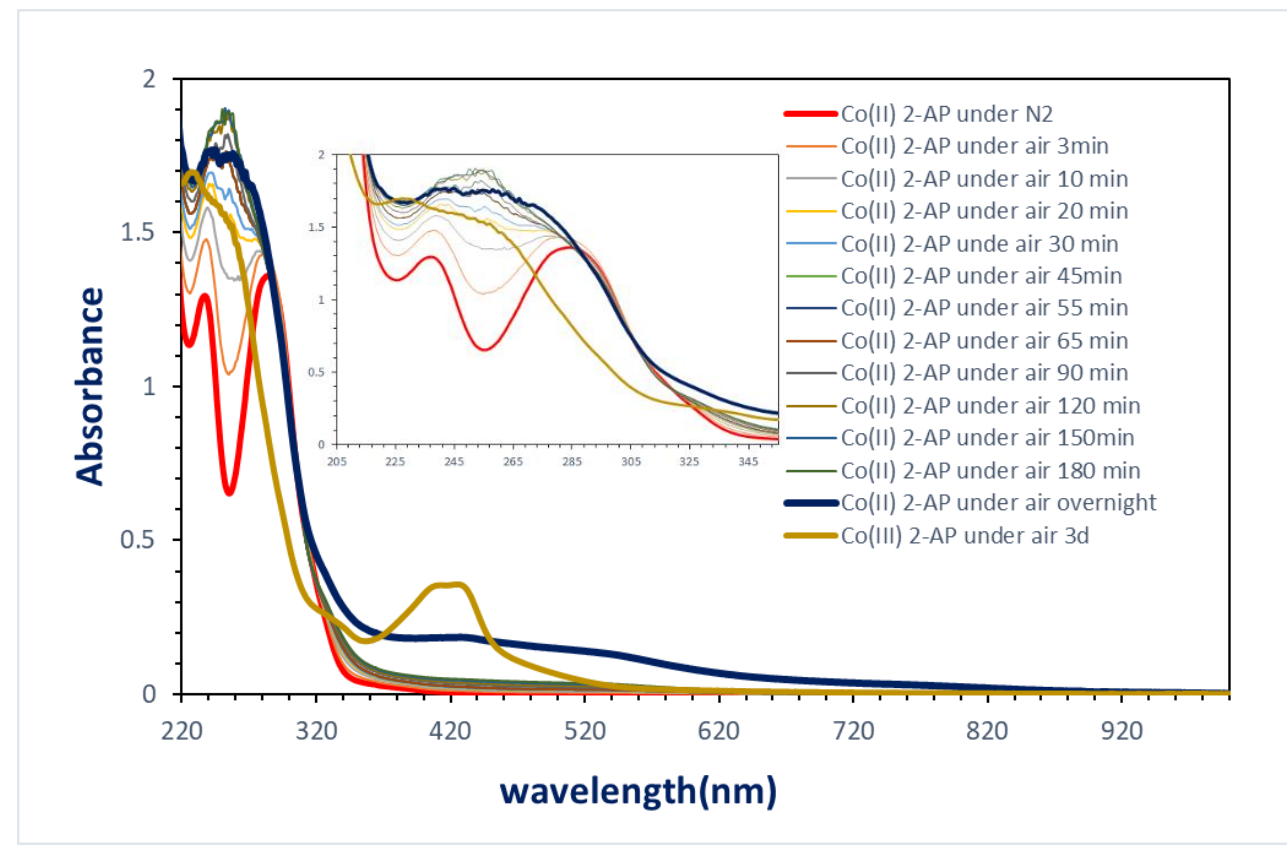

Figure 2.2. Absorption spectrum of $\mathrm{Co}(\mathrm{acac})_{2}$ with 2-aminophenol in $\mathrm{CH}_{3} \mathrm{CN}$ under $\mathrm{N}_{2}$ and after exposed to air overnight stacked with the final trace spectrum of $\mathrm{Co}(\mathrm{acac})_{3}$ with 2-aminophenol under air exposure. These experiments were conducted at $5.05 \times 10^{-5} \mathrm{M}$ concentration in $\mathrm{CH}_{3} \mathrm{CN}$.

\subsubsection{Other Considerations}

In related Pd-catalyzed cyclization reactions of aminophenols with isonitriles, the $\mathrm{C}-\mathrm{N}$ bond-forming step is proposed to proceed via the migratory insertion of the CNR ligand. ${ }^{61}$ Based on our spectroscopic studies and related literature precedence, we have proposed a plausible intermediate resulting from the $\mathrm{O}_{2}$ activation upon the coordination of 2-aminophenol to cobalt center. Although our work here has focused on the step of aerobic oxidation of $\mathrm{Co}^{\mathrm{II}}$, we consider the subsequent coupling of the oxidized intermediate with isonitrile may also interest some researchers. Though the investigation of this particular step is not our primary intention, we expect 
a radical-based addition to CNR may be operative given the presence of the proposed semiquinoate radical intermediates; ${ }^{54,59}$ however, future endeavors are required to gain a deeper insight into this step of interest.

\subsection{Conclusive Summary}

In summary, we have developed a convenient and atom efficient route towards the synthesis of 2-aminobenxazoles utilizing an additive free cobalt catalyst system under aerobic conditions. A broad scope of substituted 2-aminophenols and isonitriles are well tolerated. Finally, the importance of 2-aminophenol acting as a ligand to facilitate the aerobic oxidation of $\mathrm{Co}^{\mathrm{II}}$ was confirmed with a series of UV-visible studies. Future work is directed toward the isolation and characterization of the relevant aminophenol ligated cobalt intermediates.

\subsection{Experimental Section}

\subsubsection{General Considerations}

All synthetic reactions were performed on the benchtop unless otherwise noted. All proteo solvents were taken from a Glass Contours solvent system, in which the solvent is passed through a column of activated alumina with a pressure of Argon. All other commercial reagents and NMR solvents were used without further purification unless otherwise stated.

${ }^{1} \mathrm{H}$ and ${ }^{13} \mathrm{C}\left\{{ }^{1} \mathrm{H}\right\}$ NMR spectra were recorded on an Agilent $400 \mathrm{MHz}$ spectrometer, JEOL $400 \mathrm{MHz}$ spectrometer, or a Varian INOVA $600 \mathrm{MHz}$ spectrometer at room temperature, unless otherwise noted. Chemical shifts $(\delta)$ are given in parts per million and referenced to the residual solvent signal ${ }^{76}$ and all coupling constants $(J)$ are reported in Hz. IR spectra were recorded on a Perkin Elmer (Spectrum 100) FT-IR spectrometer. UV-visible spectra were recorded on a Stellar Net Inc. Black Comet Concave Grating Spectrometer with a SL5 Deuterium/Halogen combination lamp and dip probe or Shimadzu UV 1800. High resolution mass spectra were obtained on a Thermofisher Scientific Q Exactive Mass Spectrometer. 


\subsubsection{Procedure for Screening of the Reaction Conditions}

2-Aminophenol (32.7 mg, $0.300 \mathrm{mmol})$ and cobalt (II) acetate $(5.31 \mathrm{mg}, 0.0300 \mathrm{mmol})$ were combined in a 6-inch test tube in a $\mathrm{N}_{2}$ filled glovebox, and $\mathrm{CH}_{3} \mathrm{CN}(3.00 \mathrm{~mL})$ and tert-butylisonitrile $(35.2 \mu \mathrm{L}, 0.300 \mathrm{mmol})$ were added. The test tube was then sealed with a septum, removed the glovebox, and fitted with an air balloon attached to a needle inserted through the septum. The reaction mixture was then stirred at $65^{\circ} \mathrm{C}$ for $24 \mathrm{~h}$. Upon completion, the mixture was cooled to room temperature and filtered through a Pasteur pipette silica gel plug. Ethyl acetate (15 $\mathrm{mL}$ ) was then passed through the plug and the resulting filtrate was concentrated by rotary evaporation to yield a solid. Dimethylsulfone $(3.00 \mathrm{mg}, 0.0318 \mathrm{mmol})$, used as a ${ }^{1} \mathrm{H}$ NMR standard, was added to the solid residue and the crude mixture was dissolved in $\mathrm{CDCl}_{3}$ for ${ }^{1} \mathrm{H} \mathrm{NMR}$ analysis. All of the optimization reactions in Tables 2.4, 2.5, and 2.6 were conducted following the standard procedure except for those employing $\mathrm{Co}(\mathrm{acac})_{2}$ or $\mathrm{Co}(\mathrm{acac})_{2} \cdot \mathrm{H}_{2} \mathrm{O}$. In these cases, the percent yield of the product was determined by column purification (gradient elution from pure hexane to ethyl acetate: hexanes $=1: 3$ ) due to the difficulties in removing cobalt from the crude mixture.

Table 2.4. Optimization of the reaction temperature and base in the oxidative cyclization of 2aminophenol and tert-butylisonitrile. ${ }^{a}$

\begin{tabular}{|c|c|c|c|}
\hline \multicolumn{3}{|c|}{$\mathrm{CNtBu} \stackrel{\mathrm{Co}(\mathrm{OAc})_{2}(10 \mathrm{~mol} \%)}{\mathrm{CH}_{3} \mathrm{CN}}$} & 32 \\
\hline Entry & Base & $\operatorname{Temp}\left({ }^{\circ} \mathrm{C}\right)$ & $\%$ Yield $^{b}$ \\
\hline 1 & $\mathrm{NaOAc}$ & 65 & 98 \\
\hline 2 & $\mathrm{NaOAc}$ & 80 & 98 \\
\hline 3 & $\mathrm{Na}_{2} \mathrm{CO}_{3}$ & 65 & 78 \\
\hline 4 & $\mathrm{Na}_{2} \mathrm{CO}_{3}$ & 80 & $>99$ \\
\hline 5 & - & 65 & 93 \\
\hline 6 & - & 80 & 91 \\
\hline
\end{tabular}

${ }^{a}$ Reaction conditions: 1a $(0.300 \mathrm{mmol}), \mathbf{2 a}(0.300 \mathrm{mmol}), \mathrm{Co}(\mathrm{OAc})_{2}(0.0300 \mathrm{mmol})$, and base $(0.0600 \mathrm{mmol})$ in $\mathrm{CH}_{3} \mathrm{CN}(3.00 \mathrm{~mL})$ with an air balloon at $65^{\circ} \mathrm{C}$ for $24 \mathrm{~h} .{ }^{b}$ The yield of $3 \mathbf{a}$ was determined by ${ }^{1} \mathrm{H}$ NMR spectroscopy with dimethylsulfone as internal standard $(0.03 \mathrm{mmol})$. 
Table 2.5. Optimization of the base in the oxidative cyclization of 2-aminophenol and tert-butylisonitrile. $^{a}$

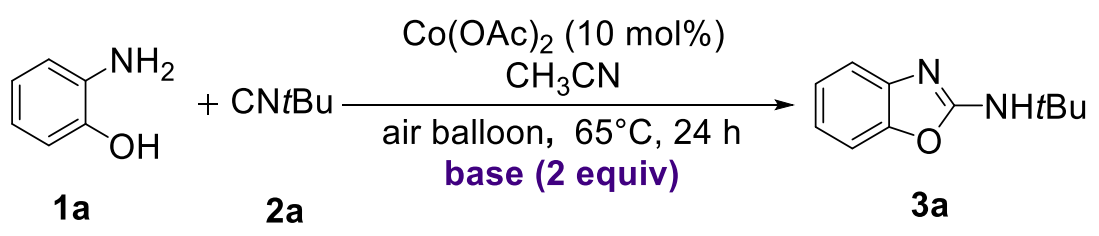

\begin{tabular}{ccc}
\hline Entry & Base & \% Yield $^{b}$ \\
\hline 1 & $\mathrm{Na}_{2} \mathrm{CO}_{3}$ & 78 \\
2 & $\mathrm{NaOAc}$ & 98 \\
3 & $\mathrm{LiOAc}$ & 84 \\
4 & $\mathrm{LiCO}_{2}$ & 87 \\
5 & $\mathrm{KOAc}_{2}$ & 82 \\
6 & $\mathrm{~K}_{2} \mathrm{CO}_{3}$ & 31 \\
7 & $\mathrm{None}$ & 86
\end{tabular}

${ }^{a}$ Reaction conditions: $1 \mathbf{a}(0.300 \mathrm{mmol}), \mathbf{2 a}(0.300 \mathrm{mmol}), \mathrm{Co}(\mathrm{OAc})_{2}(0.0300 \mathrm{mmol})$, and base $(0.0600 \mathrm{mmol})$ in $\mathrm{CH}_{3} \mathrm{CN}(3.00 \mathrm{~mL})$ with an air balloon at $65^{\circ} \mathrm{C}$ for $24 \mathrm{~h} .{ }^{b}$ The yield of $3 \mathrm{a}$ was determined by ${ }^{1} \mathrm{H}$ NMR spectroscopy with dimethylsulfone as internal standard (0.03 mmol).

Base was not incorporated in the final catalytic system because base-free reactions gave comparable yields, while enabling a more straight-forward and reliable workup procedure.

Table 2.6. Optimization of the catalyst loading and reaction time in the oxidative cyclization of 2-aminophenol and tert-butylisonitrile. ${ }^{a}$

\begin{tabular}{|c|c|c|c|}
\hline$\overbrace{1 a}{ }^{\mathrm{NH}_{2}}$ & $\begin{array}{c}\mathrm{Co}(\mathrm{OAc})_{2}(\mathrm{x} \mathrm{mol} \%) \\
\mathrm{CH}_{3} \mathrm{CN}\end{array}$ & $\begin{array}{l}101 \%) \\
5{ }^{\circ} \mathrm{C}\end{array}$ & $3 a$ \\
\hline Entry & $\begin{array}{c}\text { Co loading } \\
(\mathrm{mol} \%)\end{array}$ & Time (h) & $\%$ Yield $^{b}$ \\
\hline 1 & 10 & 6 & 79 \\
\hline 2 & 10 & 12 & 85 \\
\hline 3 & 10 & 24 & 93 \\
\hline 4 & 5 & 24 & 78 \\
\hline
\end{tabular}

${ }^{a}$ Reaction conditions: 1a $(0.300 \mathrm{mmol}), \mathbf{2 a}(0.300 \mathrm{mmol})$ and $\mathrm{Co}(\mathrm{OAc})_{2}(0.0300 \mathrm{mmol})$ in $\mathrm{CH}_{3} \mathrm{CN}$ $(3.00 \mathrm{~mL})$ with an air balloon at $65{ }^{\circ} \mathrm{C}$ for $24 \mathrm{~h}$. ${ }^{b}$ The yield of $\mathbf{3 a}$ was determined by ${ }^{1} \mathrm{H}$ NMR spectroscopy with dimethylsulfone as internal standard $(0.03 \mathrm{mmol})$. 


\subsubsection{Synthesis and Characterization of the 2-Aminobenzoxazoles}

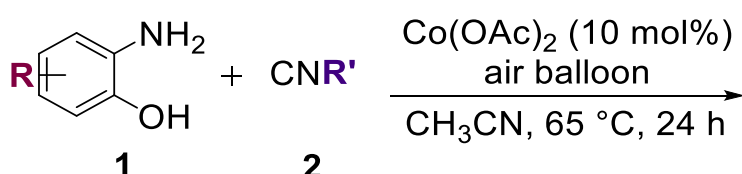

2

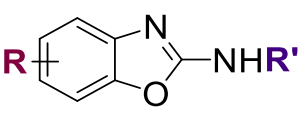

3

$\underline{\text { Representative procedure for the synthesis of 2-aminobenzoxazoles }}$

2-(tert-butylamino) benzoxazole (3a). 2-aminophenol $(32.7 \mathrm{mg}, 0.300 \mathrm{mmol})$ and cobalt(II) acetate $(5.31 \mathrm{mg}, 0.0300 \mathrm{mmol})$ were combined in a 6-inch test tube inside a $\mathrm{N}_{2}$ filled glovebox, and dissolved in dry $\mathrm{CH}_{3} \mathrm{CN}(3 \mathrm{~mL})$. tert-Butyl isocyanide $(35.2 \mu \mathrm{L}, 0.300 \mathrm{mmol})$ was added to the same test tube before it was sealed with a septum and removed from the glovebox. The reaction mixture was then stirred in an oil bath at $65{ }^{\circ} \mathrm{C}$ for 24 hours with an air balloon attached to a syringe with a needle inserted through the septum. Upon completion, the reaction mixture was cooled to room temperature and filtered through a Pasteur pipette silica gel plug and washed with ethyl acetate $(\sim 15 \mathrm{~mL})$. The resulting filtrate was concentrated by rotary evaporation and the resulting solid was purified by silica column flash chromatography (gradient elution from the pure hexanes to $25 \%$ ethyl acetate in hexanes, $R_{\mathrm{f}}=0.5$ in 3:1 hexanes : ethyl acetate), to give the title compound as a brown solid in $90 \%$ yield $(51.3 \mathrm{mg}, 0.270 \mathrm{mmol})$. All 2-aminobenzoxazoles were prepared according the standard procedure unless otherwise noted.

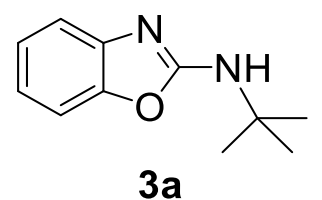

2-(tert-butylamino) benzoxazole (3a). The title compound was synthesized according to the standard procedure and purified by silica column chromatography (25\% ethyl acetate in hexane, $\mathrm{R}_{f}=0.5$ in 3:1 hexanes : ethyl acetate $)$ to yield $51.25 \mathrm{mg}(0.27 \mathrm{mmol}, 90 \%)$ of the title product as a brown solid. ${ }^{1} \mathrm{H}$ NMR (400 MHz, $\left.\mathrm{CDCl}_{3}\right) \delta=7.37$ (dd, $\left.1 \mathrm{H}\right), 7.25$ (dd, 1H), 7.16 (td, $J=7.7,1.1$ $\mathrm{Hz}, 1 \mathrm{H}), 7.02(\mathrm{td}, J=7.8,1.1 \mathrm{~Hz}, 1 \mathrm{H}), 5.75(\mathrm{~s}, 1 \mathrm{H}), 1.51(\mathrm{~s}, 9 \mathrm{H}) .{ }^{13} \mathrm{C} \mathrm{NMR}\left(100 \mathrm{MHz}, \mathrm{CDCl}_{3}\right): \delta$ $=161.43,148.25,143.04,123.75,120.47,116.12,108.62,52.09,29.37$. The spectral data are consistent with those reported in the literature. ${ }^{77,78}$ 


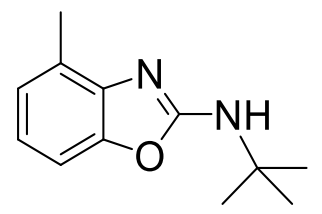

3b

4-methyl-2-(tert-butylamino)benzoxazole (3b). The title compound was synthesized according to the standard procedure and purified by silica column chromatography (25\% ethyl acetate in hexane, $\mathrm{R}_{\mathrm{f}}=0.7$ in $3: 1$ hexanes : ethyl acetate $)$ to yield $27.5 \mathrm{mg}(0.13 \mathrm{mmol}, 45 \%)$ of the title compound as a yellow solid. ${ }^{1} \mathrm{H}$ NMR $\left(400 \mathrm{MHz}, \mathrm{CDCl}_{3}\right){ }^{1} \mathrm{H} \mathrm{NMR}\left(400 \mathrm{MHz}, \mathrm{CDCl}_{3}\right) \delta 7.10$ (dd, $J=7.7,0.6 \mathrm{~Hz}, 1 \mathrm{H}), 6.95(\mathrm{ddd}, J=24.5,8.2,4.1 \mathrm{~Hz}, 2 \mathrm{H}), 4.94$ (s, 1H), 2.48 (s, 3H), 1.49 (s, 9H). ${ }^{13} \mathrm{C}-\mathrm{NMR}\left(100 \mathrm{MHz}, \mathrm{CDCl}_{3}\right): \delta=160.60,147.97,141.58,126.49,124.61,120.32,106.14,52.20$, 29.36, 16.37. HRMS (ESI-MS, m/z) $[\mathrm{M}+\mathrm{H}]^{+}$calcd for $\mathrm{C}_{12} \mathrm{H}_{16} \mathrm{~N}_{2} \mathrm{O}$ 205.1263; found 205.1336. The spectral data are consistent with those reported in the literature. ${ }^{58}$<smiles>CC(C)(C)Nc1nc2cc(-c3ccccc3)ccc2o1</smiles>

5-phenyl-2-(tert-butylamino)benzoxazole. (3c) The title compound was synthesized according to the standard procedure and purified by silica column chromatography ( $20 \%$ ethyl acetate in hexane, $\mathrm{R}_{f}=0.3$ in 3:1 hexanes: ethyl acetate $)$ to yield $75.9 \mathrm{mg}(0.28 \mathrm{mmol}, 95 \%)$ of the title compound as an off-white solid (m.p. $\left.129-131{ }^{\circ} \mathrm{C}\right) .{ }^{1} \mathrm{H}$ NMR $\left(400 \mathrm{MHz}, \mathrm{CDCl}_{3}\right): \delta=7.61(\mathrm{~d}, J=$ $7.7 \mathrm{~Hz}, 3 \mathrm{H}), 7.44(\mathrm{t}, J=7.6 \mathrm{~Hz}, 2 \mathrm{H}), 7.29(\mathrm{dt}, J=18.5,8.0 \mathrm{~Hz}, 3 \mathrm{H}), 5.63(\mathrm{~s}, 1 \mathrm{H}), 1.52(\mathrm{~s}, 9 \mathrm{H}) .{ }^{13} \mathrm{C}$ NMR (400 MHz, $\left.\mathrm{CDCl}_{3}\right): \delta=161.56,147.90,143.88,141.84,137.60,128.80,127.40,126.92$, 120.04, 115.08, 108.58, 52.21, 29.35. HRMS (ESI-MS, m/z) $[\mathrm{M}+\mathrm{H}]^{+}$calcd for $\mathrm{C}_{17} \mathrm{H}_{18} \mathrm{~N}_{2} \mathrm{O}$ 267.1419; found 267.1492. The spectral data are consistent with those reported in the literature. ${ }^{79}$

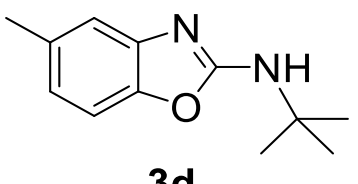

$3 d$

5-methyl-2-(tert-butylamino)benzoxazole (3d). The title compound was synthesized according to the standard procedure and purified by silica column chromatography ( $25 \%$ ethyl acetate in hexane, $\mathrm{R}_{\mathrm{f}}=0.6$ in $3: 1$ hexanes : ethyl acetate $)$ to yield $52.7 \mathrm{mg}(0.26 \mathrm{mmol}, 86 \%)$ of the title 
compound as a yellow solid. ${ }^{1} \mathrm{H}$ NMR $\left(400 \mathrm{MHz}, \mathrm{CDCl}_{3}\right): \delta=7.18(\mathrm{~d}, J=0.6 \mathrm{~Hz}, 1 \mathrm{H}), 7.11(\mathrm{~d}, J$ $=8.1 \mathrm{~Hz}, 1 \mathrm{H}), 6.84-6.79(\mathrm{~m}, 1 \mathrm{H}), 5.24(\mathrm{~s}, 1 \mathrm{H}), 2.39(\mathrm{~s}, 3 \mathrm{H}), 1.49(\mathrm{~s}, 9 \mathrm{H}) .{ }^{13} \mathrm{C}$ NMR $(100 \mathrm{MHz}$, $\left.\mathrm{CDCl}_{3}\right): \delta=161.20,146.42,143.37,133.43,121.32,116.86,108.00,52.12,29.36,21.62$. HRMS (ESI-MS, m/z) $[\mathrm{M}+\mathrm{H}]^{+}$calcd for $\mathrm{C}_{12} \mathrm{H}_{16} \mathrm{~N}_{2} \mathrm{O}$ 205.1263; found 205.1337. The spectral data are consistent with those reported in the literature. ${ }^{61}$

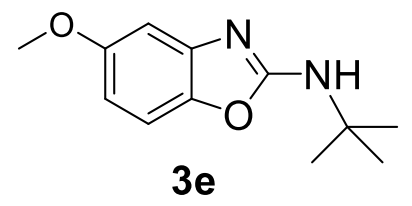

-methoxy-2-(tert-butylamino)benzoxazole (3e). The title compound was synthesized according to the standard procedure and purified by silica column chromatography (gradient elution from pure hexanes to hexanes : ethyl acetate $=3: 1, \mathrm{R}_{\mathrm{f}}=0.4$ in 3:1 hexanes : ethyl acetate) to yield 58.0 $\mathrm{mg}(0.263 \mathrm{mmol}, 74 \%)$ of the title compound as a brown solid (m.p.= $\left.111-113^{\circ} \mathrm{C}\right) .{ }^{1} \mathrm{H}$ NMR $(400$ $\left.\mathrm{MHz}, \mathrm{CDCl}_{3}\right): \delta=7.10(\mathrm{~d}, J=8.7 \mathrm{~Hz}, 1 \mathrm{H}), 6.94(\mathrm{~d}, J=2.4 \mathrm{~Hz}, 1 \mathrm{H}), 6.57(\mathrm{dd}, J=8.6,2.5 \mathrm{~Hz}$, $1 \mathrm{H}), 5.32(\mathrm{~s}, 1 \mathrm{H}), 3.80(\mathrm{~s}, 3 \mathrm{H}), 1.48(\mathrm{~s}, 9 \mathrm{H}) .{ }^{13} \mathrm{C} \mathrm{NMR}\left(100 \mathrm{MHz}, \mathrm{CDCl}_{3}\right): \delta=161.82,156.95$, 144.21, 142.77, 108.45, 107.20, 101.56, 56.02, 52.12, 29.33. HRMS (ESI-MS, m/z) $[\mathrm{M}+\mathrm{H}]^{+}$calcd for $\mathrm{C}_{12} \mathrm{H}_{16} \mathrm{~N}_{2} \mathrm{O}_{2} 221.1212$; found 221.1249. The spectral data are consistent with those reported in the literature. ${ }^{61}$

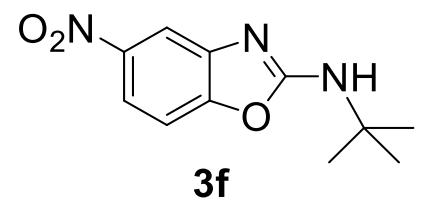

5-nitro-2-(tert-butylamino)benzoxazole (3f). The title compound was synthesized according to the standard procedure and purified by silica column chromatography (gradient elution from pure hexanes to 3:1 hexanes: ethyl acetate, $R_{\mathrm{f}}=0.55$ in $3: 1$ hexanes: ethyl acetate) to yield $56.5 \mathrm{mg}$ ( $0.240 \mathrm{mmol}, 80 \%)$ of the title compound as a yellow solid. ${ }^{1} \mathrm{H}$ NMR $\left(400 \mathrm{MHz}, \mathrm{CDCl}_{3}\right): \delta=$ $8.17(\mathrm{~d}, J=2.2 \mathrm{~Hz}, 1 \mathrm{H}), 7.97(\mathrm{dd}, J=8.7,2.3 \mathrm{~Hz}, 1 \mathrm{H}), 7.25(\mathrm{~d}, J=8.8 \mathrm{~Hz}, 1 \mathrm{H}), 5.36(\mathrm{~s}, 1 \mathrm{H})$, 1.50 (s, 9H). ${ }^{13} \mathrm{C}$ NMR $\left(100 \mathrm{MHz}, \mathrm{CDCl}_{3}\right): \delta=162.57,152.26,145.02,144.26,117.31,111.86$, 108.23, 52.76, 29.08. HRMS (ESI-MS, $\mathrm{m} / \mathrm{z}$ ) $[\mathrm{M}+\mathrm{H}]^{+}$calcd for $\mathrm{C}_{11} \mathrm{H}_{13} \mathrm{~N}_{3} \mathrm{O}_{3} 236.0957$; found 236.1030. The spectral data are consistent with those reported in the literature. ${ }^{58}$ 


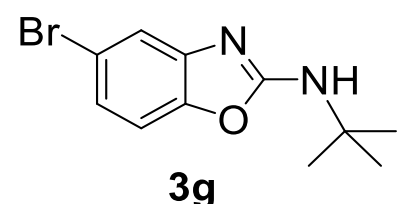

5-bromo-2-(tert-butylamino)benzoxazole (3g). The title compound was synthesized according to the standard procedure and purified by silica column chromatography ( $20 \%$ ethyl acetate in hexane, $R_{f}=0.7$ in 3:1 hexanes: ethyl acetate $)$ to yield $72.6 \mathrm{mg}(0.27 \mathrm{mmol}, 90 \%)$ of the title compound as a yellow solid $\left(\mathrm{mp}=102-104{ }^{\circ} \mathrm{C}\right) .{ }^{1} \mathrm{H}$ NMR $\left(400 \mathrm{MHz}, \mathrm{CDCl}_{3}\right) \delta=7.46(\mathrm{~s}, 1 \mathrm{H})$, $7.16-7.03$ (m, 2H), 5.57 (s, 1H), 1.49 (s, 9H). $\left.{ }^{13} \mathrm{C} \mathrm{NMR} \mathrm{(100} \mathrm{MHz,} \mathrm{CDCl}_{3}\right): \delta=162.50$, 147.87, 145.43, 123.30, 119.46, 116.41, 109.72, 52.42, 29.34. IR (ATR, $\left.\mathrm{cm}^{-1}\right): 162.50,147.87$, 145.43, 123.30, 119.46, 116.41, 109.72, 52.42, 29.34. HRMS (ESI-MS, m/z) $[\mathrm{M}+\mathrm{H}]^{+}$calcd for $\mathrm{C}_{11} \mathrm{H}_{13} \mathrm{BrN}_{2} \mathrm{O}$ 269.0211; found 269.0287. The spectral data are consistent with those reported in the literature. ${ }^{61}$

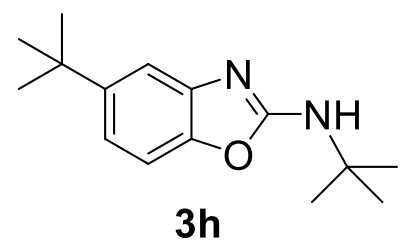

5-tert-butyl-2-(tert-butylamino)benzoxazole (3h). The title compound was synthesized according to the standard procedure and purified by silica column chromatography (20\% ethyl acetate in hexane, $R_{f}=0.7$ in 3:1 hexanes: ethyl acetate) to yield $69.0 \mathrm{mg}(0.28 \mathrm{~mol}, 93 \%)$ of the title compound as a pink solid $\left(\mathrm{mp}=121-123{ }^{\circ} \mathrm{C}\right) .{ }^{1} \mathrm{H} \mathrm{NMR}\left(400 \mathrm{MHz}, \mathrm{CDCl}_{3}\right) \delta=7.44(\mathrm{~d}, J=1.6$ $\mathrm{Hz}, 1 \mathrm{H}), 7.13(\mathrm{~d}, J=8.4 \mathrm{~Hz}, 1 \mathrm{H}), 7.04(\mathrm{dd}, J=8.4,1.9 \mathrm{~Hz}, 1 \mathrm{H}), 5.07$ (s, 1H), 1.48 (s, 9H), 1.33 (s, 9H). ${ }^{13} \mathrm{C} \mathrm{NMR}\left(150 \mathrm{MHz}, \mathrm{CDCl}_{3}\right): \delta=161.09,147.18,146.0,143.05,117.87,113.57,107.69$, 52.04, 34.90, 31.94, 29.26. IR (ATR, $\left.\mathrm{cm}^{-1}\right): 3248$ (w), 2964 (m), 1640 (s), 1582 (s), 1428 (m), 1480 (m), 1216 (s), 912 (w), 801 (m), 653 (m). HRMS (ESI-MS, m/z) [M+H] $]^{+}$calcd for $\mathrm{C}_{15} \mathrm{H}_{22} \mathrm{~N}_{2} \mathrm{O}$ 247.1732; found 247.1805.<smiles>Cc1ccc2nc(NC(C)(C)C)oc2c1</smiles>

$3 \mathbf{i}$ 
6-methyl-2-(tert-butylamino)benzoxazole (3i). The title compound was synthesized according to the standard procedure and purified by silica column chromatography (25\% ethyl acetate in hexane, $\mathrm{R}_{\mathrm{f}}=0.7$ in $3: 1$ hexanes : ethyl acetate $)$ to yield $51.0 \mathrm{mg}(0.25 \mathrm{mmol}, 83 \%)$ of the title compound as a yellow solid $\left(\mathrm{mp}=104-106{ }^{\circ} \mathrm{C}\right) .{ }^{1} \mathrm{H} \mathrm{NMR}\left(400 \mathrm{MHz}, \mathrm{CDCl}_{3}\right): \delta=7.23(\mathrm{~d}, J=7.9 \mathrm{~Hz}, 1 \mathrm{H})$, $7.06(\mathrm{~s}, 1 \mathrm{H}), 6.95(\mathrm{dd}, J=7.9,0.8 \mathrm{~Hz}, 1 \mathrm{H}), 5.44(\mathrm{~s}, 1 \mathrm{H}), 2.38(\mathrm{~s}, 3 \mathrm{H}), 1.47(\mathrm{~s}, 9 \mathrm{H}) .{ }^{13} \mathrm{C}$ NMR $(100$ $\left.\mathrm{MHz}_{\mathrm{CDCl}}\right): \delta=160.87,148.44,140.76,130.58,124.44,115.71,109.24,52.04,29.36,21.53$. HRMS (ESI-MS, m/z) $[\mathrm{M}+\mathrm{H}]^{+}$calcd for $\mathrm{C}_{12} \mathrm{H}_{16} \mathrm{~N}_{2} \mathrm{O} 205.1263$; found 205.1335. The spectral data are consistent with those reported in the literature. ${ }^{80}$

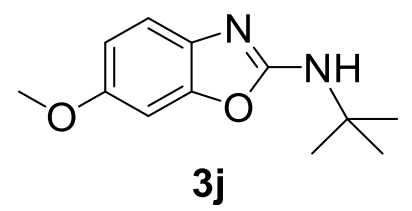

6-methoxy-2-(tert-butylamino) benzoxazole (3j). The title compound was synthesized according to the standard procedure on a larger scale. 2-amino-5-methoxyphenol (83.5 mg, $0.600 \mathrm{mmol})$ and cobalt(II) acetate $(10.6 \mathrm{mg}, 0.0600 \mathrm{mmol})$ were combined in a 6 -inch test tube inside a $\mathrm{N}_{2}$ filled glovebox, and dissolved in dry $\mathrm{CH}_{3} \mathrm{CN}$ (5 mL). tert-Butyl isocyanide (70.4 $\mu \mathrm{L}, 0.600 \mathrm{mmol}$ ) was added to the test tube before it was sealed with a septum and removed from the glovebox. The reaction mixture was then stirred in an oil bath at $65^{\circ} \mathrm{C}$ for 24 hours with an air balloon attached to a syringe and needle inserted through the septum. Upon completion, the reaction mixture was cooled to room temperature and was filtered through a pad of celite. The resulting filtrate was stirred with saturated EDTA solution $(100 \mathrm{~mL})$ for three hours, extracted with ethyl acetate $(50$ $\mathrm{mL})$ and the layers were separated. The aqueous layer was extracted twice with ethyl acetate $(2 \mathrm{x}$ $30 \mathrm{~mL}$ ) and the combined organic layers were washed with saturated sodium chloride solution (80 $\mathrm{mL}$ ), separated, dried over anhydrous sodium sulfate and concentrated by rotary evaporation to 3 $\mathrm{mL}$. The concentrated crude mixture was passed through a silica gel pipette column, which was then washed with ethyl acetate $(10 \mathrm{~mL})$. This step removes any remaining cobalt from the crude mixture. The resulting filtrate was concentrated by rotary evaporation and the resulting solid was purified by silica column flash chromatography (gradient elution from the pure hexanes to hexanes: ethyl acetate $=8: 1, \mathrm{R}_{\mathrm{f}}=0.3$ in 4:1 hexanes $:$ ethyl acetate), to give the title compound as a light brown solid in $31 \%$ yield (40.9 mg, $0.186 \mathrm{mmol})$. m.p. $=82-84{ }^{\circ} \mathrm{C} .{ }^{1} \mathrm{H} \mathrm{NMR}\left(400 \mathrm{MHz}, \mathrm{CDCl}_{3}\right)$ : $\delta 7.23(\mathrm{~d}, J=8.5 \mathrm{~Hz}, 1 \mathrm{H}), 6.86(\mathrm{~s}, 1 \mathrm{H}), 6.73(\mathrm{dd}, J=8.4,1.8 \mathrm{~Hz}, 1 \mathrm{H}), 5.18(\mathrm{~s}, 1 \mathrm{H}), 3.79(\mathrm{~s}, 3 \mathrm{H})$, 
1.47 (s, 9H). ${ }^{13} \mathrm{C} \mathrm{NMR}\left(100 \mathrm{MHz}, \mathrm{CDCl}_{3}\right): \delta=160.34,155.20,148.71,136.88,116.18,109.97$, 95.85, 56.21, 52.09, 29.30. IR (ATR, $\left.\mathrm{cm}^{-1}\right)$ : 3197 (w), 2966 (m), $2834(\mathrm{w}), 1640$ (s), 1584 (s), 1486 (s), 1441 (m), 1362 (m), 1270 (m), 1202 (s), 1138 (s), 1027 (m), 996 (m), 863 (w), 803(w). HRMS (ESI-MS, m/z) $[\mathrm{M}+\mathrm{H}]^{+}$calcd for $\mathrm{C}_{12} \mathrm{H}_{16} \mathrm{~N}_{2} \mathrm{O}_{2} 221.1285$; found 221.1276.

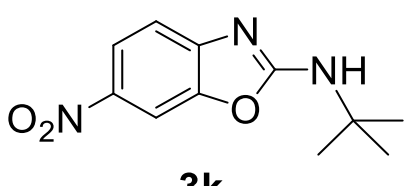

3k

6-nitro-2-(tert-butylamino)benzoxazole (3k). The title compound was synthesized according to the standard procedure and purified by silica column chromatography (25\% ethyl acetate in hexane, $\mathrm{R}_{\mathrm{f}}=0.5$ in $3: 1$ hexanes : ethyl acetate $)$ to yield $51.4 \mathrm{mg}(0.22 \mathrm{mmol}, 73 \%)$ of the title compound as a yellow solid. ${ }^{1} \mathrm{H} \mathrm{NMR}\left(400 \mathrm{MHz}, \mathrm{CDCl}_{3}\right): \delta=8.21-8.07(\mathrm{~m}, 2 \mathrm{H}), 7.33(\mathrm{~d}, J=8.7 \mathrm{~Hz}, 1 \mathrm{H})$, $5.77(\mathrm{~s}, 1 \mathrm{H}), 1.53(\mathrm{~s}, 9 \mathrm{H}) .{ }^{13} \mathrm{C} \mathrm{NMR}\left(100 \mathrm{MHz}, \mathrm{CDCl}_{3}\right): \delta=163.96$ 150.03, 147.32, 141.50, 121.28, 114.95, 104.99, 53.02, 29.13. HRMS (ESI-MS, m/z) $[\mathrm{M}+\mathrm{H}]^{+}$calcd for $\mathrm{C}_{11} \mathrm{H}_{13} \mathrm{~N}_{3} \mathrm{O}_{3} 236.0957$; found 236.1029. The spectral data are consistent with those reported in the literature. ${ }^{80}$<smiles>Cc1cccc2nc(NC(C)(C)C)oc12</smiles>

7-methyl-2-(tert-butylamino)benzoxazole (31). The title compound was synthesized according to the standard procedure and purified by silica column chromatography (20\% ethyl acetate in hexane, $R_{\mathrm{f}}=0.7$ in $3: 1$ hexanes : ethyl acetate $)$ to yield $47.7 \mathrm{mg}(0.23 \mathrm{mmol}, 78 \%)$ of the title compound as a yellow solid. ${ }^{1} \mathrm{H}$ NMR $\left(400 \mathrm{MHz}, \mathrm{CDCl}_{3}\right): \delta=7.10(\mathrm{~d}, J=8.7 \mathrm{~Hz}, 1 \mathrm{H}), 6.94(\mathrm{~d}, J=2.4 \mathrm{~Hz}$, $1 \mathrm{H}), 6.57(\mathrm{dd}, J=8.6,2.5 \mathrm{~Hz}, 1 \mathrm{H}), 5.32(\mathrm{~s}, 1 \mathrm{H}), 3.80$ (s, 3H), 1.48 (s, 9H). ${ }^{13} \mathrm{C} \mathrm{NMR}(100 \mathrm{MHz}$, $\left.\mathrm{CDCl}_{3}\right): \delta=160.96,147.25,142.78,123.63,122.14,118.98,113.85,52.08,29.39$, 15.04. IR $\left(\mathrm{ATR}, \mathrm{cm}^{-1}\right.$ ): 3359 (w), 2977 (w), 1740 (s), 1642 (s), 1580 (s), 1459 (w), 1370 (w), 1270 (m), 1239 (s), 1046 (m), 775 (m), 740 (m). HRMS (ESI-MS, m/z) $[\mathrm{M}+\mathrm{H}]^{+}$calcd for $\mathrm{C}_{12} \mathrm{H}_{16} \mathrm{~N}_{2} \mathrm{O} 205.1263$; found 205.1336 . 


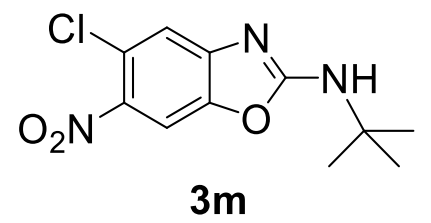

6-nitro-5-chloro-2-(tert-butylamino)benzoxazole $(3 \mathrm{~m})$. The title compound was synthesized according to the standard procedure and purified by silica column chromatography (gradient elution from pure hexanes to $1: 1$ hexanes: ethyl acetate, $R_{f}=0.5$ in 3:1 hexanes : ethyl acetate) to yield $51.8 \mathrm{mg}(0.192 \mathrm{mmol}, 64 \%)$ of the title compound as a fluffy yellow solid (m.p. $=165-$ $\left.167{ }^{\circ} \mathrm{C}\right) .{ }^{1} \mathrm{H}$ NMR $\left(400 \mathrm{MHz}, \mathrm{CDCl}_{3}\right): \delta=7.90(\mathrm{~s}, 1 \mathrm{H}), 7.37$ (s, 1H), $5.80(\mathrm{~s}, 1 \mathrm{H}), 1.52(\mathrm{~s}, 9 \mathrm{H})$. ${ }^{13} \mathrm{C}$ NMR (100MHz, $\left.\mathrm{CDCl}_{3}\right): \delta=164.44,149.04,145.97,140.20,124.61,118.00,106.94,53.23$, 29.05. IR (ATR, $\mathrm{cm}^{-1}$ ): 3203 (w), 2980 (w), 1655 (s), 1575 (s), 1454 (s), 1313 (s), 1263 (s), 1213 (s), $1011(\mathrm{~m}), 906$ (m), $872(\mathrm{~m}), 832(\mathrm{~m}), 729$ (m), 669 (w). HRMS (ESI-MS, m/z) [M+H] ${ }^{+}$calcd for $\mathrm{C}_{11} \mathrm{H}_{12} \mathrm{ClN}_{3} \mathrm{O}_{3} 270.0567$; found 270.0640 .<smiles>c1ccc2oc(NC3CCCCC3)nc2c1</smiles>

2-(cyclohexylamino)benzoxazole (3n). The title compound was synthesized according to the standard procedure and purified by silica column chromatography (20\% ethyl acetate in hexane, $\mathrm{R}_{\mathrm{f}}=0.3$ in hexanes: ethyl acetate) to yield $47.3 \mathrm{mg}(0.22 \mathrm{mmol}, 73 \%)$ of the title compound as a white solid. ${ }^{1} \mathrm{H}$ NMR $\left(600 \mathrm{MHz}, \mathrm{CDCl}_{3}\right) \delta=7.35(\mathrm{~d}, J=7.7 \mathrm{~Hz}, 1 \mathrm{H}), 7.23(\mathrm{~d}, \mathrm{~J}=7.7 \mathrm{~Hz}, 1 \mathrm{H}), 7.15$ (td, $J=7.7,0.9 \mathrm{~Hz}, 1 \mathrm{H}), 7.01(\mathrm{t}, J=7.7 \mathrm{~Hz}, 1 \mathrm{H}), 5.14$ (s, 1H), 3.76 (s, 1H), 2.13 (dd, $J=12.4,3.1$ $\mathrm{Hz}, 2 \mathrm{H}), 1.85-1.71(\mathrm{~m}, 2 \mathrm{H}), 1.70-1.60(\mathrm{~m}, 1 \mathrm{H}), 1.51-1.38(\mathrm{~m}, 2 \mathrm{H}), 1.26$ (dddd, $J=24.9,15.5$, 9.9, $3.4 \mathrm{~Hz}, 3 \mathrm{H}) .{ }^{13} \mathrm{C} \mathrm{NMR}\left(150 \mathrm{MHz}, \mathrm{CDCl}_{3}\right): \delta=161.50,148.47,143.08,123.98,120.81,116.29$, 108.76, 52.17, 33.57, 25.63, 24.87. HRMS (ESI-MS, m/z) $[\mathrm{M}+\mathrm{H}]^{+}$calcd for $\mathrm{C}_{13} \mathrm{H}_{16} \mathrm{~N}_{2} \mathrm{O} 217.1263$; found 217.1335. The spectral data are consistent with those reported in the literature. ${ }^{81}$

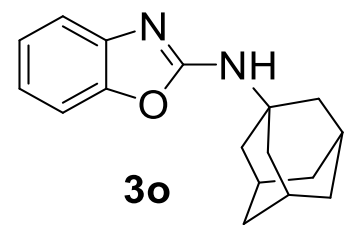


2-(1-admantylamino)benzoxazole (3o). The title compound was synthesized according to the standard procedure and purified by silica column chromatography (25\% ethyl acetate in hexanes, $\mathrm{R}_{f}=0.7$ in 3:1 hexanes: ethyl acetate) to yield $78.9 \mathrm{mg}(0.29 \mathrm{mmol}, 98.0 \%)$ of the title compound as a pink solid (m.p. $\left.=160-162{ }^{\circ} \mathrm{C}\right) .{ }^{1} \mathrm{H}$ NMR $\left(400 \mathrm{MHz}, \mathrm{CDCl}_{3}\right): \delta=7.36(\mathrm{~d}, J=7.8 \mathrm{~Hz}, 1 \mathrm{H})$, $7.26-7.21(\mathrm{~d}, J=7.8 \mathrm{~Hz}, 1 \mathrm{H}), 7.14(\mathrm{t}, J=7.7 \mathrm{~Hz}, 1 \mathrm{H}), 7.01(\mathrm{t}, J=7.7 \mathrm{~Hz}, 1 \mathrm{H}), 5.20(\mathrm{~s}, 1 \mathrm{H}), 2.13$ $(\mathrm{d}, J=21.4 \mathrm{~Hz}, 9 \mathrm{H}), 1.79-1.67(\mathrm{~m}, 6 \mathrm{H}) .{ }^{13} \mathrm{C} \mathrm{NMR}\left(100 \mathrm{MHz}, \mathrm{CDCl}_{3}\right): \delta=160.67,148.15$, 143.21, 123.78, 120.65, 116.34, 108.60, 52.47, 42.18, 36.29, 29.63. IR (ATR, $\mathrm{cm}^{-1}$ ): 3243 (w), 2903 (m), 2851 (w), 1635 (s), 1576 (s), 1460 (m), 1357 (w), 1233 (m), 1011 (w), 813 (w), 740 (m). HRMS (ESI-MS, m/z) $[\mathrm{M}+\mathrm{H}]^{+}$calcd for $\mathrm{C}_{17} \mathrm{H}_{20} \mathrm{~N}_{2} \mathrm{O}$ 269.1576; found 269.1648 .

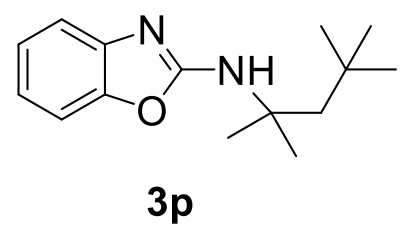

2-(1,1,3,3-tetramethylbutylamino)benzoxazole (3p). The title compound was synthesized according to the standard procedure and purified by silica column chromatography (gradient elution from pure hexanes to 4:1 hexanes: ethyl acetate, $R_{f}=0.30$ in 3:1 hexanes : ethyl acetate) to yield $62.8 \mathrm{mg}(0.255 \mathrm{mmol}, 85 \%)$ of the title compound as a light yellow solid (m.p. $=109-110^{\circ}$ C). ${ }^{1} \mathrm{H} \mathrm{NMR}\left(400 \mathrm{MHz}, \mathrm{CDCl}_{3}\right): \delta=7.36(\mathrm{~d}, J=7.7 \mathrm{~Hz}, 1 \mathrm{H}), 7.23(\mathrm{~d}, J=8.0 \mathrm{~Hz}, 1 \mathrm{H}), 7.14(\mathrm{td}, J$ = 7.7, $1.0 \mathrm{~Hz}, 1 \mathrm{H}), 7.00(\mathrm{td}, J=7.7,1.1 \mathrm{~Hz}, 1 \mathrm{H}), 5.54(\mathrm{~s}, 1 \mathrm{H}), 1.84(\mathrm{~s}, 2 \mathrm{H}), 1.53(\mathrm{~s}, 6 \mathrm{H}), 1.00(\mathrm{~s}$, 9H). ${ }^{13} \mathrm{C}$ NMR (100 MHz, $\left.\mathrm{CDCl}_{3}\right): \delta=160.99,148.21,143.33,123.76,120.48,116.30,108.59$, 55.81, 51.90, 31.82, 31.59, 28.85. IR (ATR, $\mathrm{cm}^{-1}$ ): 3239 (w), 2950 (m), 1655 (s), 1640 (s), 1579 (s), 1459 (s), 1149 (w), 1009 (w), 927 (w), 847 (w), 754 (m), 740 (s). HRMS (ESI-MS, m/z) $[\mathrm{M}+\mathrm{H}]^{+}$calcd for $\mathrm{C}_{15} \mathrm{H}_{22} \mathrm{~N}_{2} \mathrm{O} 247.1732$; found 247.1806.

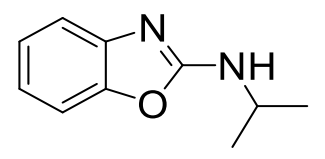

$3 q$

2-(isopropylamino)benzoxazole (3q). The title compound was synthesized according to the standard procedure and purified by silica column chromatography (gradient elution from pure hexanes to 4:1 hexanes : ethyl acetate, $R_{f}=0.30$ in $3: 1$ hexanes : ethyl acetate) to yield $41.7 \mathrm{mg}$ 
$(0.237 \mathrm{mmol}, 79 \%)$ of the title compound as a light yellow solid. ${ }^{1} \mathrm{H} \mathrm{NMR}\left(400 \mathrm{MHz}, \mathrm{CDCl}_{3}\right): \delta$ $=7.35(\mathrm{~d}, J=7.8 \mathrm{~Hz}, 1 \mathrm{H}), 7.28-7.20(\mathrm{~m}, 1 \mathrm{H}), 7.15(\mathrm{dd}, J=11.3,4.0 \mathrm{~Hz}, 1 \mathrm{H}), 7.06-6.97(\mathrm{~m}$, 1H), $5.44(\mathrm{~s}, 1 \mathrm{H}), 4.08(\mathrm{~s}, 1 \mathrm{H}) 1.33(\mathrm{~d}, J=6.5 \mathrm{~Hz}, 7 \mathrm{H}) .{ }^{13} \mathrm{C} \mathrm{NMR}\left(100 \mathrm{MHz}, \mathrm{CDCl}_{3}\right): \delta=161.63$, $148.47,143.09,123.95,120.73,116.19,108.78,45.45,23.25$. HRMS (ESI-MS, m/z) [M+H] ${ }^{+}$ calcd for $\mathrm{C}_{10} \mathrm{H}_{12} \mathrm{~N}_{2} \mathrm{O}$ 177.0950; found 177.1023. The spectral data are consistent with those reported in the literature. ${ }^{82}$

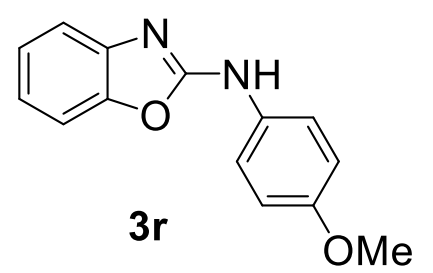

2-(4-methoxyphenylamino)benzoxazole (3r). The title compound was synthesized according to the standard procedure and purified by silica column chromatography (gradient elution from pure hexanes to $1: 1$ hexanes: ethyl acetate, $R_{\mathrm{f}}=0.55$ in $3: 1$ hexanes : ethyl acetate) to yield $25.6 \mathrm{mg}$ $(0.107 \mathrm{mmol}, 36 \%)$ of the title compound as a light yellow solid (m.p.=137-139 $\left.{ }^{\circ} \mathrm{C}\right) .{ }^{1} \mathrm{H} \mathrm{NMR}$ $\left(400 \mathrm{MHz}, \mathrm{CDCl}_{3}\right): \delta=8.77(\mathrm{~s}, 1 \mathrm{H}), 7.52-7.45(\mathrm{~m}, 2 \mathrm{H}), 7.40(\mathrm{~d}, J=7.8 \mathrm{~Hz}, 1 \mathrm{H}), 7.31(\mathrm{~d}, J=$ $8.0 \mathrm{~Hz}, 1 \mathrm{H}), 7.20(\mathrm{td}, J=7.7,1.0 \mathrm{~Hz}, 1 \mathrm{H}), 7.08(\mathrm{td}, J=7.8,1.1 \mathrm{~Hz}, 1 \mathrm{H}), 6.96-6.89(\mathrm{~m}, 2 \mathrm{H}), 3.80$ (s, 3H). ${ }^{13} \mathrm{C}$ NMR $\left(100 \mathrm{MHz}, \mathrm{CDCl}_{3}\right): \delta=156.26,142.36,131.16,124.4,121.55,121.19,116.73$, 114.72, 109.21, 55.70. HRMS (ESI-MS, m/z) $[\mathrm{M}+\mathrm{H}]^{+}$calcd for $\mathrm{C}_{14} \mathrm{H}_{12} \mathrm{~N}_{2} \mathrm{O}_{2}$ 241.0972; found 241.0965. The spectral data are consistent with those reported in the literature. ${ }^{83}$

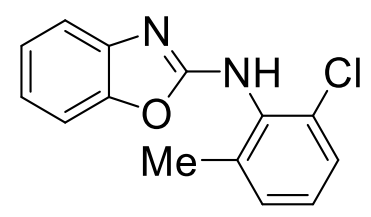

$3 s$

2-(6-chloro-2-methylphenylamino)benzoxazole (3s). The title compound was synthesized according to the standard procedure and purified by silica column chromatography (gradient elution from pure hexanes to 4:1 hexanes : ethyl acetate, $R_{\mathrm{f}}=0.40$ in 3:1 hexanes : ethyl acetate) to yield $28.5 \mathrm{mg}(0.110 \mathrm{mmol}, 37 \%)$ of the title compound as a light yellow solid (m.p.=166$\left.168{ }^{\circ} \mathrm{C}\right) .{ }^{1} \mathrm{H}$ NMR $\left(600 \mathrm{MHz}, \mathrm{CDCl}_{3}\right): \delta=7.83(\mathrm{~s}, 1 \mathrm{H}), 7.34(\mathrm{~d}, J=8.0 \mathrm{~Hz}, 2 \mathrm{H}), 7.28(\mathrm{~d}, J=6.9$ $\mathrm{Hz}, 1 \mathrm{H}), 7.26-7.13(\mathrm{~m}, 3 \mathrm{H}), 7.07(\mathrm{t}, J=7.7 \mathrm{~Hz}, 1 \mathrm{H}), 2.39(\mathrm{~s}, 3 \mathrm{H}) .{ }^{13} \mathrm{C} \mathrm{NMR}\left(100 \mathrm{MHz}, \mathrm{CDCl}_{3}\right)$ : 
$\delta=138.14,133.21,132.00,129.82,129.63,128.08,127.63,124.24,121.70,117.16,109.33,19.01$. IR (ATR, cm ${ }^{-1}$ ): 2984 (w), 1639 (m), 1582 (m), 1460 (m), 1372 (m), 1238 (s), 1045 (s), 938 (w), 847 (w), 744 (w), 672 (w). HRMS (ESI-MS, m/z) [M+H] ${ }^{+}$calcd for $\mathrm{C}_{14} \mathrm{H}_{11} \mathrm{ClN}_{2} \mathrm{O} 259.0560$; found 259.0632 .

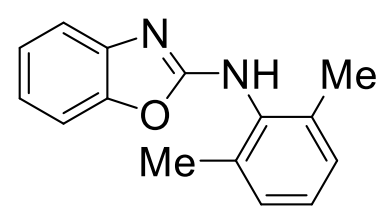

3t

2-(2,6-dimethylphenylamino)benzoxazole (3t). The title compound was synthesized according to the standard procedure and purified by silica column chromatography (gradient elution from pure hexanes to 4:1 hexanes: ethyl acetate, $R_{f}=0.40$ in 3:1 hexanes : ethyl acetate) to yield 58.9 $\mathrm{mg}(0.247 \mathrm{mmol}, 82 \%)$ of the title compound as a light yellow solid. ${ }^{1} \mathrm{H} \mathrm{NMR}\left(400 \mathrm{MHz}, \mathrm{CDCl}_{3}\right)$ : $\delta=8.78(\mathrm{~s}, 1 \mathrm{H}), 7.28-7.21(\mathrm{~m}, 2 \mathrm{H}), 7.20-7.10(\mathrm{~m}, 4 \mathrm{H}), 7.03(\mathrm{dd}, J=11.3,4.2 \mathrm{~Hz}, 1 \mathrm{H}), 2.36(\mathrm{~s}$, $6 \mathrm{H}) .{ }^{13} \mathrm{C} \mathrm{NMR}\left(400 \mathrm{MHz}, \mathrm{CDCl}_{3}\right): \delta=161.12,148.49,142.57,136.05,134.33,128.56,127.45$, 124.03, 120.88, 116.20, 109.09, 18.44. HRMS (ESI-MS, m/z) $[\mathrm{M}+\mathrm{H}]^{+}$calcd for $\mathrm{C}_{15} \mathrm{H}_{14} \mathrm{~N}_{2} \mathrm{O}$ 239.1106; found 239.1177. The spectral data are consistent with those reported in the literature. ${ }^{58}$

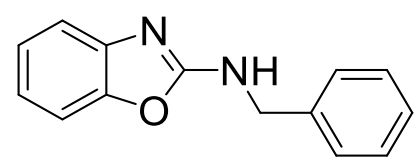

$3 \mathbf{u}$

N-(phenylmethyl)-2-benzoxazolamine (3u). The title compound was synthesized according to the standard procedure and purified by silica column chromatography (gradient elution from pure hexanes to 4:1 hexanes : ethyl acetate, $R_{\mathrm{f}}=0.3$ in 3:1 hexanes : ethyl acetate) to yield $21.8 \mathrm{mg}$ $(0.0972 \mathrm{mmol}, 32.4 \%)$ of the title compound as a light yellow solid (m.p.=122-124 $\left.{ }^{\circ} \mathrm{C}\right) .{ }^{1} \mathrm{H} \mathrm{NMR}$ $\left(400 \mathrm{MHz} \mathrm{CDCl}_{3}\right): \delta=7.43-7.33(\mathrm{~m}, 4 \mathrm{H}), 7.32-7.27(\mathrm{~m}, 2 \mathrm{H}), 7.28-7.21(\mathrm{~m}, 1 \mathrm{H}), 7.16(\mathrm{t}, J$ $=7.6 \mathrm{~Hz}, 1 \mathrm{H}), 7.03(\mathrm{t}, J=7.7 \mathrm{~Hz}, 1 \mathrm{H}), 5.63(\mathrm{~s}, 1 \mathrm{H}), 4.68(\mathrm{~s}, 2 \mathrm{H}) \cdot{ }^{13} \mathrm{C} \mathrm{NMR}\left(100 \mathrm{MHz}, \mathrm{CDCl}_{3}\right): \delta$ $=162.09,148.75,143.04,137.83,128.98,128.01,127.77,124.09,121.14,116.67,108.96,47.29$. HRMS (ESI-MS, m/z) $[\mathrm{M}+\mathrm{H}]^{+}$calcd for $\mathrm{C}_{14} \mathrm{H}_{12} \mathrm{~N}_{2} \mathrm{O} 225.1022$; found 225.1013. The spectral data are consistent with those reported in the literature. ${ }^{83}$ 


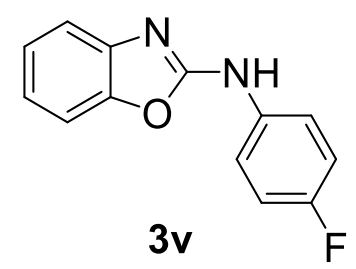

2-(4-fluorophenylamino)benzoxazole (3v) The title compound was synthesized according to the standard procedure on a doubled scale. Cobalt (II) acetate (10.6 mg, $0.0600 \mathrm{mmol})$, 2-aminophenol (65.4 mg, $0.600 \mathrm{mmol})$ and 4-fluorophenyl isocyanide $(72.7 \mathrm{mg}, 0.600 \mathrm{mmol})$ were combined in a 6-inch test tube inside a $\mathrm{N}_{2}$ filled glovebox and dissolved in dry $\mathrm{CH}_{3} \mathrm{CN}(5 \mathrm{~mL})$. The test tube was sealed with a septum and removed from the glovebox. The reaction mixture was then stirred in an oil bath at $65{ }^{\circ} \mathrm{C}$ for 24 hours with an air balloon attached to a syringe and needle inserted through the septum. Upon completion, the reaction mixture was cooled to room temperature and filtered through a Pasteur pipette silica gel plug and washed with ethyl acetate $(\sim 15 \mathrm{~mL})$. The resulting filtrate was concentrated by rotary evaporation and the solid was purified by silica column chromatography (gradient elution from pure hexanes to 10:1 hexanes : ethyl acetate, $R_{\mathrm{f}}=$ 0.65 in 3:1 hexanes : ethyl acetate) to yield $26.8 \mathrm{mg}(0.180 \mathrm{mmol}, 19.6 \%)$ of the title compound as a yellow solid (m.p. $\left.=167-169^{\circ} \mathrm{C}\right) .{ }^{1} \mathrm{H}$ NMR $\left(400 \mathrm{MHz}, \mathrm{CDCl}_{3}\right): \delta=7.80(\mathrm{~s}, 1 \mathrm{H}), \delta 7.63-7.53$ (m, 2H), $7.47(\mathrm{~d}, J=7.8 \mathrm{~Hz}, 1 \mathrm{H}), 7.35(\mathrm{~d}, J=8.0 \mathrm{~Hz}, 1 \mathrm{H}), 7.27-7.21(\mathrm{~m}, 2 \mathrm{H}), 7.17-7.05(\mathrm{~m}$, 3H). ${ }^{13} \mathrm{C}$ NMR (100 MHz, $\mathrm{CDCl}_{3}$ ): $\delta=159.97$ (s), 158.36 (s), 147.99 (s), 142.31 (s), 133.94 (d, $J$ = 2.7 Hz), 124.49 (s), 122.14 (s), $120.43(\mathrm{~d}, J=7.9 \mathrm{~Hz}), 117.32$ (s), 116.19 (d, $J=22.9 \mathrm{~Hz}), 109.27$ (s). HRMS (ESI-MS, m/z) $[\mathrm{M}+\mathrm{H}]^{+}$calcd for $\mathrm{C}_{13} \mathrm{H}_{9} \mathrm{FN}_{2} \mathrm{O}$ 229.0699; found 229.0772. The spectral data are consistent with those reported in the literature. ${ }^{84}$ 


\subsubsection{Procedures for Control Experiments}

2.4.4.1. Control Experiments under a Nitrogen Atmosphere

(a)

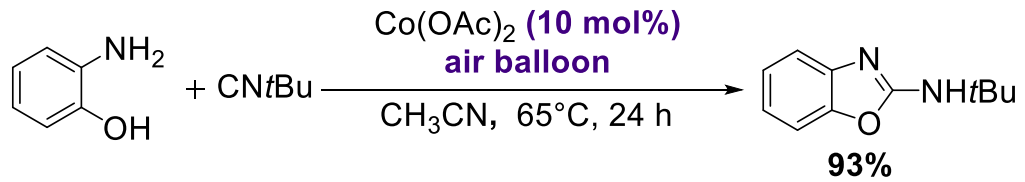

(b)

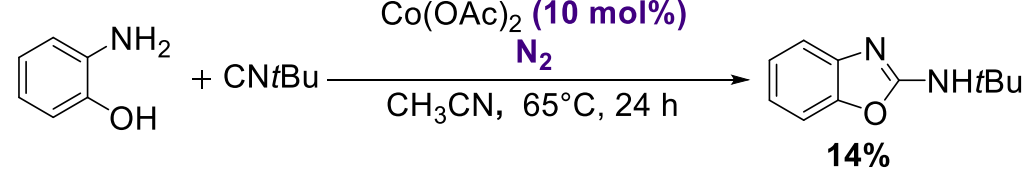

(c)

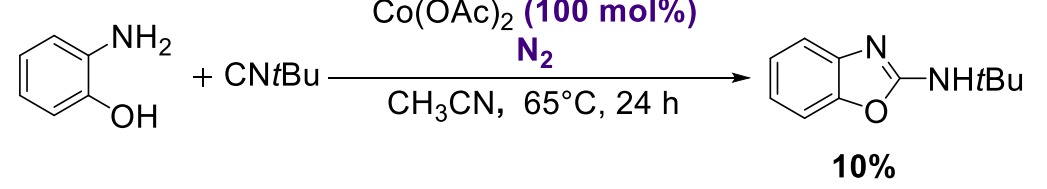

Scheme 2.5. (a) The standard reaction conditions and control experiments with (b) 10 mol\% $\mathrm{Co}(\mathrm{OAc})_{2}$ and (c) 1 equiv $\mathrm{Co}(\mathrm{OAc})_{2}$ conducted under a nitrogen atmosphere. Yields are determined by ${ }^{1} \mathrm{H}$ NMR spectroscopy using dimethylsulfone internal standard.

2-Aminophenol (32.7 mg, $0.300 \mathrm{mmol}$ ) and cobalt (II) acetate (either $5.31 \mathrm{mg}, 0.0300$ mmol or $53.1 \mathrm{mg}, 0.300 \mathrm{mmol}$ ) were combined in a $25 \mathrm{~mL}$ Schlenk tube in a $\mathrm{N}_{2}$ filled glovebox. $\mathrm{CH}_{3} \mathrm{CN}(3.00 \mathrm{~mL})$ and tert-butylisonitrile $(35.2 \mu \mathrm{L}, 0.300 \mathrm{mmol})$ were then added. The Schlenk tube was then sealed with a septum, removed from the glovebox, connected to a Schlenk line and the mixture stirred under $\mathrm{N}_{2}$ for 24 hours at $65^{\circ} \mathrm{C}$. At the end of this period, the reaction mixture was cooled to room temperature and filtered through a Pasteur pipette silica gel plug. Ethyl acetate $(15 \mathrm{~mL})$ was then passed through the plug and the resulting filtrate was concentrated by rotary evaporation to yield a dark brown solid. Dimethylsulfone $(3.00 \mathrm{mg}, 0.0318 \mathrm{mmol})$, used as a ${ }^{1} \mathrm{H}$ NMR standard, was added to the solid residue and the crude mixture was dissolved in $\mathrm{CDCl}_{3}$ for ${ }^{1} \mathrm{H}$ NMR analysis. 
2.4.4.2. Control Experiment with a Cobalt(III) Source

(a)

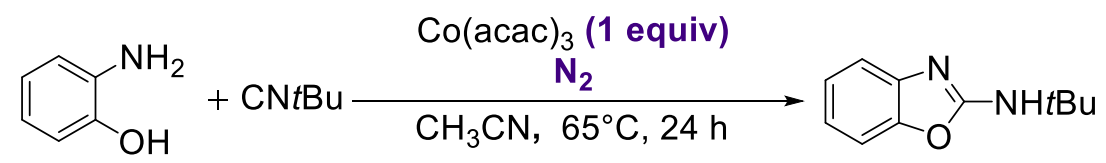

$63 \%^{\mathrm{a}}$

(b)

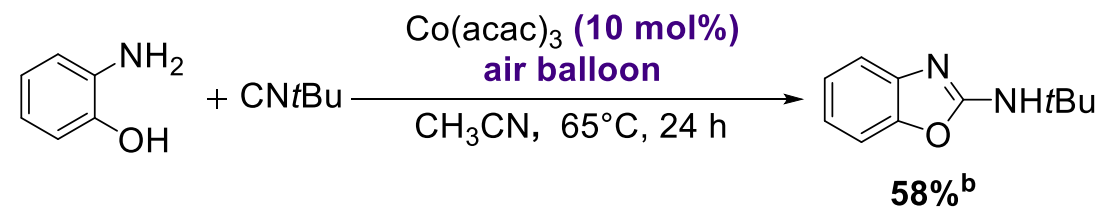

Scheme 2.6. Control experiment with (a) $\mathrm{Co}(\mathrm{acac})_{3}$ as a cobalt(III) source and (b) the corresponding catalytic reaction with $\mathrm{Co}(\mathrm{acac})_{2}$. ${ }^{a}$ Isolated yield. ${ }^{b}$ Yield determined by ${ }^{1} \mathrm{H} \mathrm{NMR}$ spectroscopy using dimethylsulfone as internal standard.

Procedure for Stoichiometric Co ${ }^{\mathrm{III}}(\mathrm{acac})_{3}$ Control Experiment:

2-Aminophenol (32.7 mg, $0.300 \mathrm{mmol})$ and cobalt(III) acetylacetonate (106.8 mg, $0.3000 \mathrm{mmol})$ were combined in a $25 \mathrm{~mL}$ Schlenk tube in a $\mathrm{N}_{2}$ filled glovebox, and $\mathrm{CH}_{3} \mathrm{CN}$ ( $3 \mathrm{~mL}$ ) and tert-butyl isonitrile $(35.2 \mu \mathrm{L}, 0.300 \mathrm{mmol})$ were added. The Schlenk tube was then sealed with a septum, removed from the glovebox and stirred under $\mathrm{N}_{2}$ on a Schlenk line for 24 hours in a $65^{\circ} \mathrm{C}$ oil bath. Upon completion, the reaction mixture was cooled to room temperature and filtered through a pad of Celite via vacuum filtration. The filtrate was then concentrated by rotary evaporation to yield the crude product as a dark brown solid. The crude material was then purified by silica column chromatography (6:1 hexanes: ethyl acetate, $R_{\mathrm{f}}=0.3$ in 5:1 hexanes : ethyl acetate) to generate $35.9 \mathrm{mg}(0.189 \mathrm{mmol}, 63 \%)$ of the desired product as brown solid.

Procedure for Catalytic $\mathrm{Co}^{\mathrm{II}}(\mathrm{acac})_{2}$ Control Experiment:

2-Aminophenol (32.7 mg, $0.300 \mathrm{mmol})$ and cobalt(II) acetylacetonate $(7.71 \mathrm{mg}, 0.0300 \mathrm{mmol})$ were combined in a $25 \mathrm{~mL}$ Schlenk tube in a $\mathrm{N}_{2}$ filled glovebox, and $\mathrm{CH}_{3} \mathrm{CN}$ ( $3 \mathrm{~mL}$ ) and tert-butyl isonitrile $(35.2 \mu \mathrm{L}, 0.300 \mathrm{mmol})$ were added. The Schlenk tube was then sealed with a septum, removed from the glovebox, fitted with an air balloon attached to a needle inserted through the septum and stirred under this aerobic atmosphere for 24 hours in a $65^{\circ} \mathrm{C}$ oil bath. Upon completion, the reaction mixture was cooled to room temperature and filtered through a pad of Celite via vacuum filtration. The filtrate was then concentrated by rotary evaporation to yield the crude 
product as a dark brown solid. The crude material was then purified by silica column chromatography (6:1 hexanes: ethyl acetate, $R_{f}=0.3$ in 5:1 hexanes : ethyl acetate) to generate $33.1 \mathrm{mg}(0.174 \mathrm{mmol}, 58 \%)$ of the desired product as brown solid.

\subsubsection{Control Experiment with a Peroxide Oxidant}

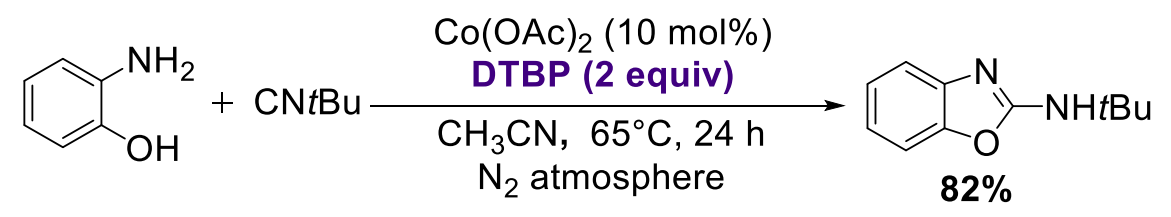

Scheme 2.7. Control experiment with di-tert-butyl peroxide as the oxidant. Yield determined by ${ }^{1} \mathrm{H}$ NMR spectroscopy using dimethylsulfone as internal standard.

2-Aminophenol (32.7 mg, $0.300 \mathrm{mmol})$, di-tert-butyl peroxide $(87.7 \mathrm{mg}, 0.600 \mathrm{mmol})$ and cobalt (II) acetate $\left(5.31 \mathrm{mg}, 0.0300 \mathrm{mmol}\right.$ ) were combined in a $25 \mathrm{~mL}$ Schlenk tube in a $\mathrm{N}_{2}$ filled glovebox. $\mathrm{CH}_{3} \mathrm{CN}(3 \mathrm{~mL})$ and tert-butyl isonitrile $(35.2 \mu \mathrm{L}, 0.300 \mathrm{mmol})$ were added. The Schlenk tube was then sealed with a septum, removed from the glovebox and the reaction stirred under $\mathrm{N}_{2}$ on a Schlenk line for 24 hours at $65^{\circ} \mathrm{C}$. Upon completion, the reaction mixture was cooled to room temperature and filtered through a Pasteur pipette silica gel plug. Ethyl acetate $(15 \mathrm{~mL})$ was passed through the silica plug and the resulting filtrate was concentrated via rotary evaporation to yield the crude product as a dark brown solid. The yield of the reaction was determined by ${ }^{1} \mathrm{H}$ NMR spectroscopy with dimethylsulfone $(3.00 \mathrm{mg}, 0.0318 \mathrm{mmol})$ as the internal standard. 
2.4.4.4. Control Experiments with Radical Trapping Reagents

(a)

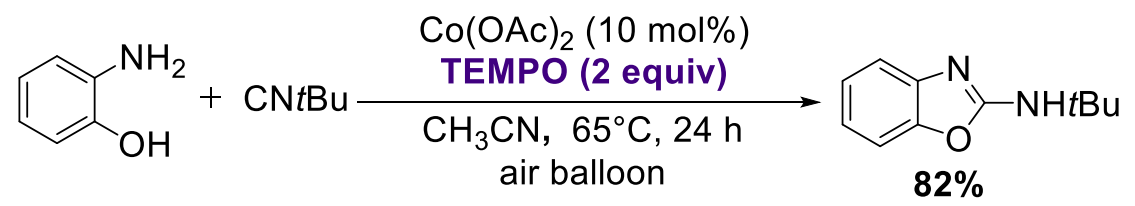

(b)

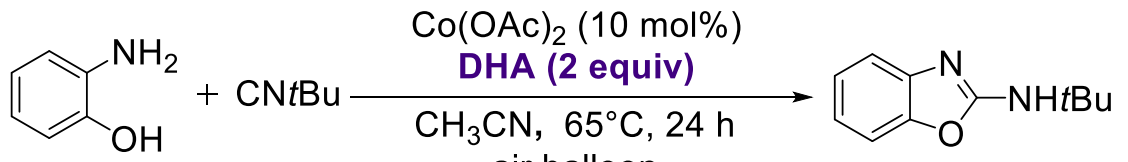
air balloon

$\mathrm{Co}(\mathrm{OAc})_{2}(10 \mathrm{~mol} \%)$

(c)

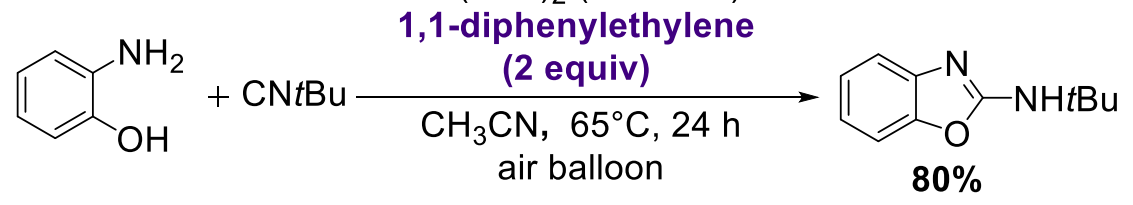

Scheme 2.8. Control experiment with (a) TEMPO, (b) 9,10-dihydroanthracene (DHA), and (c) 1,1-diphenylethylene included as radical trapping agents. Yields determined by ${ }^{1} \mathrm{H}$ NMR spectroscopy using dimethylsulfone as internal standard.

Standard procedure for radical trap experiments. 2-Aminophenol $(32.7 \mathrm{mg}, 0.300 \mathrm{mmol})$, radical scavengers $(0.6 \mathrm{mmol})$, and cobalt (II) acetate $(5.31 \mathrm{mg}, 0.0300 \mathrm{mmol})$ were combined in a 6 inch test tube in a $\mathrm{N}_{2}$ filled glovebox, $\mathrm{CH}_{3} \mathrm{CN}(3 \mathrm{~mL})$ and tert-butylisonitrile $(35.2 \mu \mathrm{L}, 0.300$ mmol) were added. The test tube was then sealed with a septum, removed from the glovebox, and fitted with an air balloon attached to a needle inserted through the septum. The reaction mixture was stirred in an oil bath at $65^{\circ} \mathrm{C}$ for 24 hours.

Work up method for control experiment with TEMPO as the radical scavenger. Upon completion of the reaction, the reaction mixture was cooled to room temperature and was diluted with ethyl acetate $(20 \mathrm{~mL})$. The resulting mixture was extracted with a saturated solution of $\mathrm{Na}_{2} \mathrm{~S}_{2} \mathrm{O}_{3}(3 \times 20 \mathrm{~mL})$ until the organic layer changed from dark red to light yellow. The organic layer was then washed with saturated sodium chloride solution, separated, dried over anhydrous magnesium sulfate, filtered, and finally concentrated via rotary evaporation to $\sim 3 \mathrm{~mL}$ then passed through a Pasteur pipette silica gel plug to remove residue cobalt. The filter plug was flushed with extra $10 \mathrm{~mL}$ of ethyl acetate and further concentrated by rotary evaporation to provide the crude 
product as a brownish-red solid. The crude yield was determined by ${ }^{1} \mathrm{H}$ NMR spectroscopy with dimethylsulfone $(0.0300 \mathrm{mg}, 0.0318 \mathrm{mmol})$ as the internal standard.

Work up method for control experiment with all other radical scavengers. Upon completion, the reaction mixture was cooled to room temperature, filtered through a pad of silica gel with ethyl acetate $(20 \mathrm{~mL})$ by vacuum filtration, and the resulting filtrate was concentrated by rotary evaporation to $\sim 3 \mathrm{~mL}$ then passed through a Pasteur pipette silica gel plug (to further remove any remaining cobalt). The filter plug was flushed with an extra $10 \mathrm{~mL}$ of ethyl acetate and eventually, the solvent was removed by rotary evaporation to generate the crude product as a brownish solid. The crude yield was determined by ${ }^{1} \mathrm{H}$ NMR spectroscopy with dimethylsulfone $(0.03 \mathrm{mg}, 0.0318$ mmol) as the internal standard.

2.4.4.5. Control Experiments in the Absence of Isonitrile

(a)

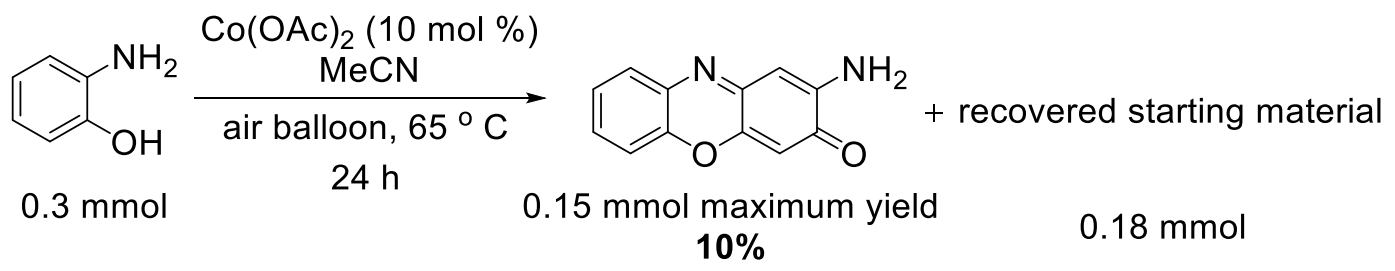

(b)

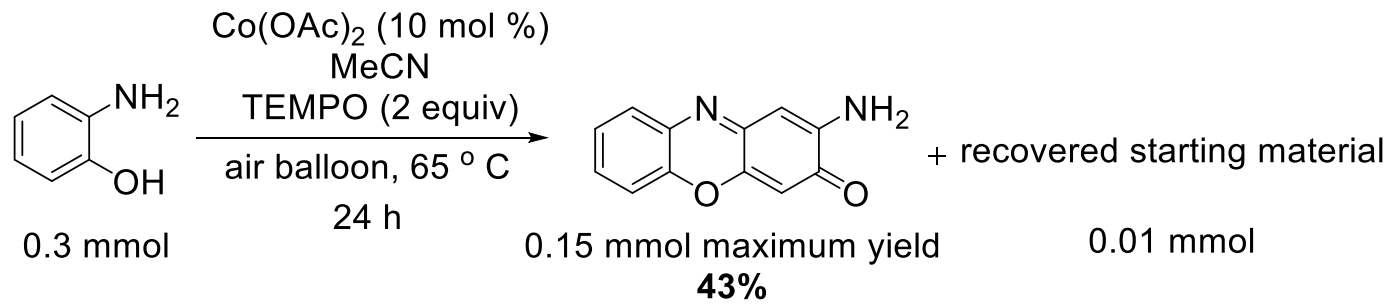

Scheme 2.9. Control experiments conducted in the absence of isonitrile both (a) without and (b) with TEMPO. Yields determined by ${ }^{1} \mathrm{H}$ NMR spectroscopy using a dimethylsulfone internal standard.

Procedure for (a): 2-Aminophenol $(32.7 \mathrm{mg}, 0.300 \mathrm{mmol})$ and cobalt(II) acetate $(5.31 \mathrm{mg}, 0.0300$ mmol) were combined in a $25 \mathrm{~mL}$ Schlenk tube, and the tube was evacuated and back-filled with air three times. $\mathrm{CH}_{3} \mathrm{CN}(3.00 \mathrm{~mL})$ was added and the reaction mixture was stirred at $65^{\circ} \mathrm{C}$ for 24 h. Upon completion, the reaction mixture was cooled to room temperature, filtered through Celite, 
and washed with excess amount of ethyl acetate $(50 \mathrm{~mL})$. The filtrate was then concentrated to 3 $\mathrm{mL}$ by a rotary evaporation and the resulting mixture was filtered through a silica gel plug to further remove cobalt residues. Then, the plug was rinsed with ethyl acetate $(10 \mathrm{~mL})$ and the combined filtrate was concentrated under vacuum to yield the crude product as a brownish solid. Dimethylsulfone (3.00 mg, $0.0318 \mathrm{mmol}$ ), used as a ${ }^{1} \mathrm{H}$ NMR standard, was added to the solid residue and the crude mixture was dissolved in DMSO- $d_{6}$ for ${ }^{1} \mathrm{H}$ NMR analysis.

Procedure for (b): 2-Aminophenol $(32.7 \mathrm{mg}, 0.300 \mathrm{mmol})$, TEMPO (93.4 mg, $0.6 \mathrm{mmol})$ and cobalt(II) acetate $(5.31 \mathrm{mg}, 0.0300 \mathrm{mmol})$ were combined in a $25 \mathrm{~mL}$ Schlenk tube, and the tube was evacuated and back-filled with air three times. $\mathrm{CH}_{3} \mathrm{CN}(3.00 \mathrm{~mL})$ was added and the reaction mixture was stirred at $65^{\circ} \mathrm{C}$ for $24 \mathrm{~h}$. Upon completion, the reaction mixture was cooled to room temperature, filtered through Celite, and washed with ethyl acetate $(\sim 50 \mathrm{~mL})$. The filtrate was then extracted with a saturated solution of $\mathrm{Na}_{2} \mathrm{~S}_{2} \mathrm{O}_{3}(3 \times 20 \mathrm{~mL})$ until the organic layer changed from dark red to light yellow. This step removes any remaining TEMPO. The organic layer was then washed with saturated sodium chloride solution, dried over anhydrous magnesium sulfate, filtered, and finally concentrated via rotary evaporation to $\sim 3 \mathrm{~mL}$. The resulting mixture was filtered through a silica gel plug to further remove cobalt residues. Then, the plug was rinsed with ethyl acetate $(10 \mathrm{~mL})$ and the combined filtrate was concentrated under vacuum to yield the crude product as a brownish solid. Dimethylsulfone (3.00 mg, $0.0318 \mathrm{mmol}$ ), used as a ${ }^{1} \mathrm{H}$ NMR standard, was added to the solid residue and the crude mixture was dissolved in DMSO- $\mathrm{d}_{6}$ for ${ }^{1} \mathrm{H}$ NMR analysis.

In both cases, the reaction yields were determined by ${ }^{1} \mathrm{H}$ NMR spectroscopy with a dimethylsulfone $(0.0300 \mathrm{mg}, 0.0318 \mathrm{mmol})$ internal standard. The assignment of the product as 2aminophenoxazin-3-one was confirmed by both literature evidence ${ }^{85}$ as well as comparison with the standard purchased from Asta Tech (95\% pure). ${ }^{1} \mathrm{H}-\mathrm{NMR}\left(400 \mathrm{MHz}, \mathrm{DMSO}-\mathrm{d}_{6}\right) \delta 7.70(\mathrm{~d}, J$ $=7.7 \mathrm{~Hz}, 1 \mathrm{H}), 7.47(\mathrm{dd}, J=18.8,8.0 \mathrm{~Hz}, 2 \mathrm{H}), 7.38(\mathrm{t}, J=7.2 \mathrm{~Hz}, 1 \mathrm{H}), 6.80(\mathrm{~s}, 2 \mathrm{H}), 6.36(\mathrm{~d}, J=$ $2.6 \mathrm{~Hz}, 2 \mathrm{H})$. 


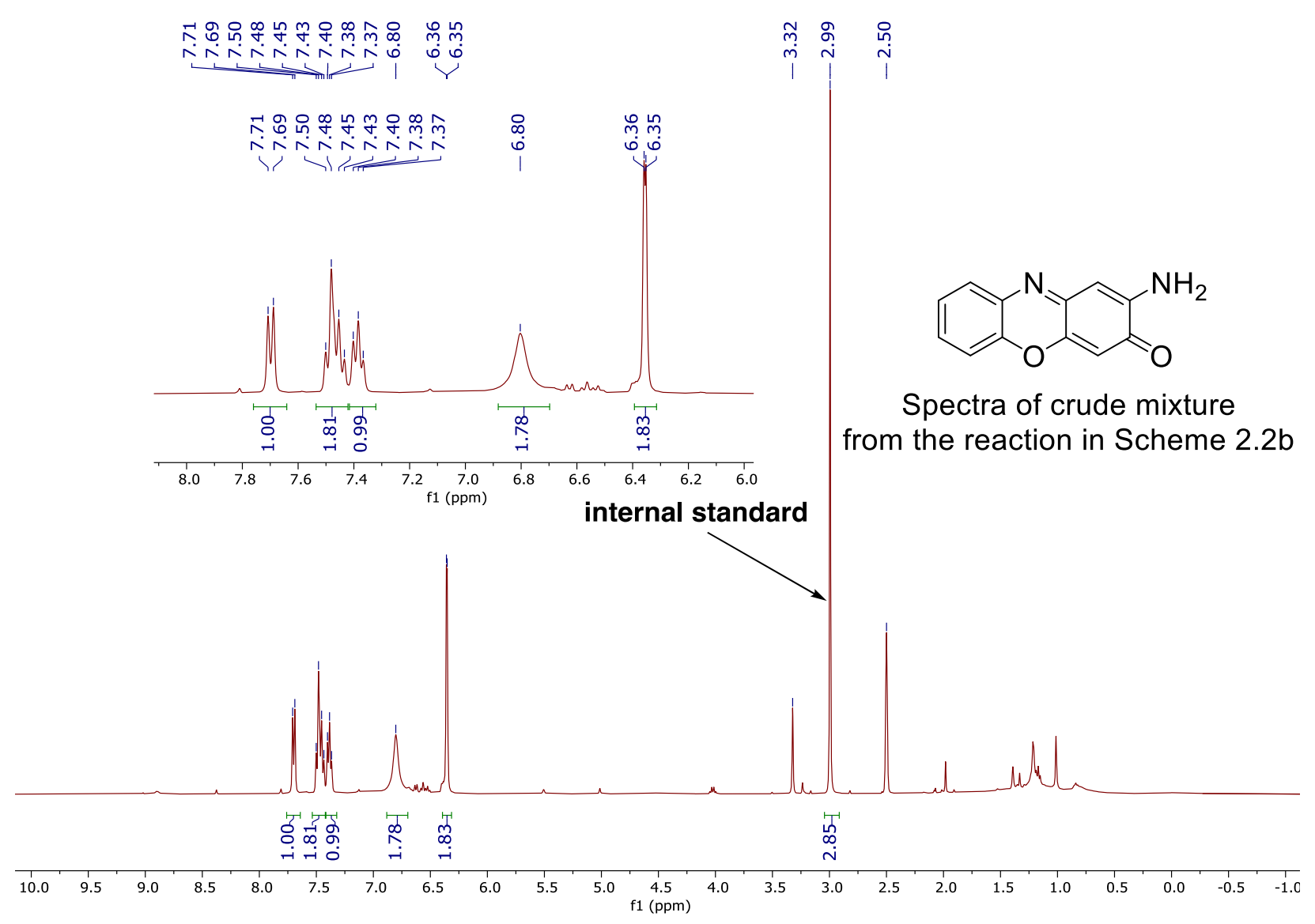

Figure 2.3. ${ }^{1} \mathrm{H}$ NMR spectrum of the crude reaction mixture of the Co-catalyzed, TEMPOmediated dimerization of 2-aminophenol for the synthesis of 2-aminophenoxazin-3-one (reaction b in Scheme 2.9) in DMSO- $d_{6}$ at $400 \mathrm{MHz}$. 


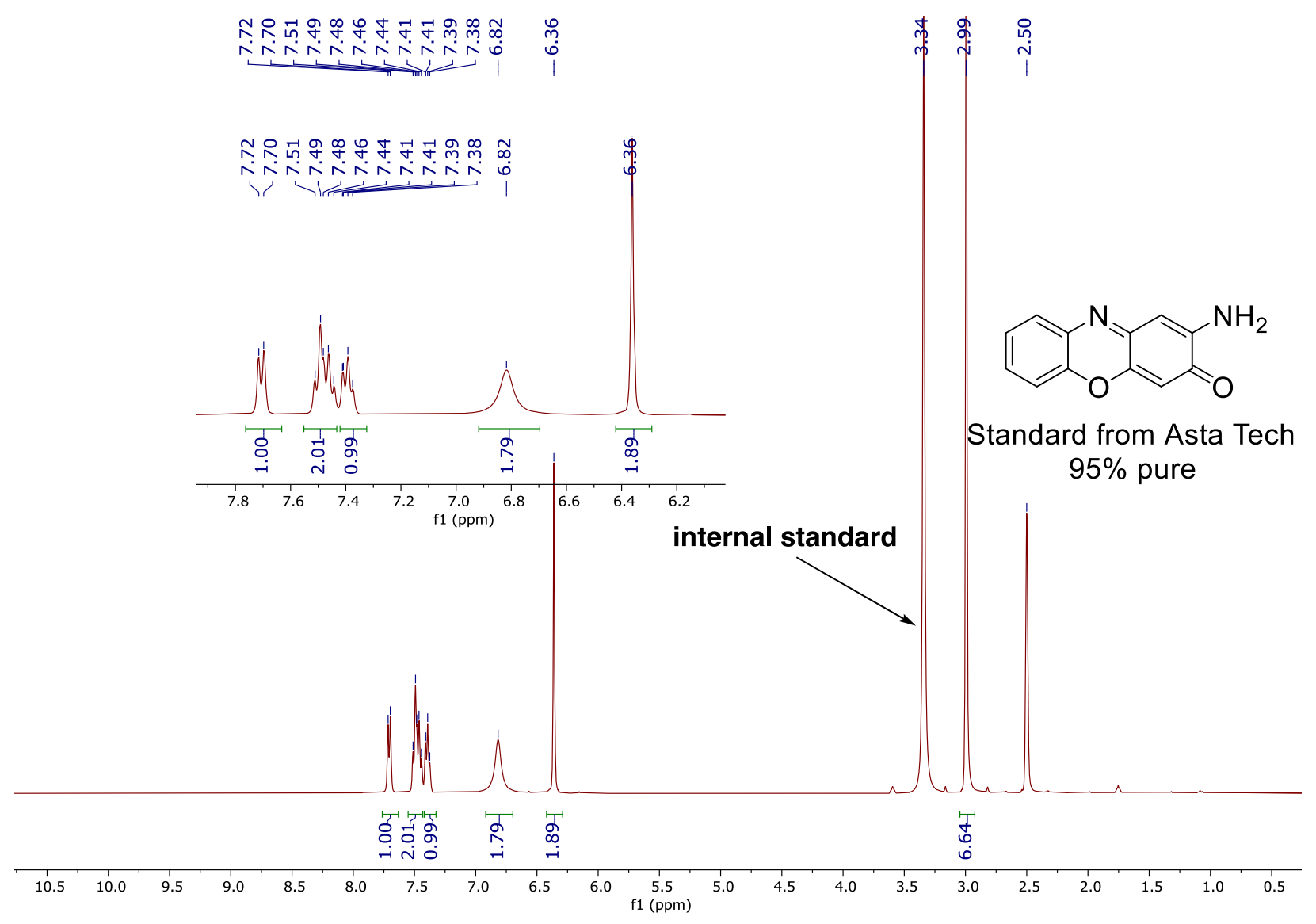

Figure 2.4. ${ }^{1} \mathrm{H}$ NMR spectrum of standard 2-aminophenozaxin-3-one purchased from AstaTech (95\% pure) in DMSO- $d_{6}$ at $400 \mathrm{MHz}$.

\subsubsection{Experimental Procedures for UV-Visible Experiments}

The following three experiments (A-C) were conducted with a Stellar Net UV-Vis dip probe.

All cobalt salt and 2-aminphenol solutions for these experiments were prepared by serial dilution under nitrogen using standard Schlenk techniques. The general procedure for preparing $\mathrm{Co}^{\mathrm{II}}(\mathrm{acac})_{2}$ and 2-aminophenol solutions in acetonitrile are described below:

\section{Preparation of $\mathrm{Co}^{\mathrm{II}}(\mathbf{a c a c})_{2}$ solution in $\mathrm{CH}_{3} \underline{\mathrm{CN}}$ :}

To a $25 \mathrm{~mL}$ Schlenk tube equipped with a stir bar and a dip probe inserted through the septum, was added $\mathrm{Co}^{\mathrm{II}}(\mathrm{acac})_{2}\left(1.3 \mathrm{mg}, 5.05 \times 10^{-3} \mathrm{mmol}\right)$. The tube was evacuated and backfilled with $\mathrm{N}_{2}$ three times via the side arm and dry acetonitrile $(10 \mathrm{~mL})$ was added by syringe. For dilution purposes, $9 \mathrm{~mL}$ of the resulting $10 \mathrm{~mL}$ solution was removed. To the remaining $1 \mathrm{~mL}$ of solution, 
was added an additional $9 \mathrm{~mL}$ of fresh dry acetonitrile to yield a final $10 \mathrm{~mL}$ solution with a concentration of $5.05 \times 10^{-5} \mathrm{M}$.

\section{Preparation of 2-aminophenol solution in $\mathrm{CH}_{3} \mathrm{CN}$ :}

To a $25 \mathrm{~mL}$ Schlenk tube equipped with a stir bar and septum, 2-aminophenol (6.5mg, $0.060 \mathrm{mmol})$ was added and the tube was evacuated and backfilled with $\mathrm{N}_{2}$ three times via the side arm. Dry acetonitrile $(3 \mathrm{~mL})$ was added to yield a final solution with a concentration of $2.0 \times 10^{-2} \mathrm{M}$.

\section{A. Co ${ }^{\mathrm{II}}\left(\right.$ acac) 2 control experiment under $\mathrm{N}_{2}$ and air atmosphere}

During the experiment, the standard spectrum of $\mathrm{Co}^{\mathrm{II}}(\mathrm{acac})_{2}\left(5.05 \times 10^{-2} \mathrm{mM}\right.$ in $\left.10 \mathrm{~mL} \mathrm{MeCN}\right)$ was taken first under the protection of $\mathrm{N}_{2}$ atmosphere, then the headspace was exposed to air by inserting an air balloon through the septum. The spectroscopic changes were monitored overnight with stirring. No significant changes were observed upon exposure to air and the spectrum of the cobalt species showed two absorbance maxima at $202 \mathrm{~nm}$ and $272 \mathrm{~nm}$ under both aerobic and anaerobic conditions (Figure 2.5 below).

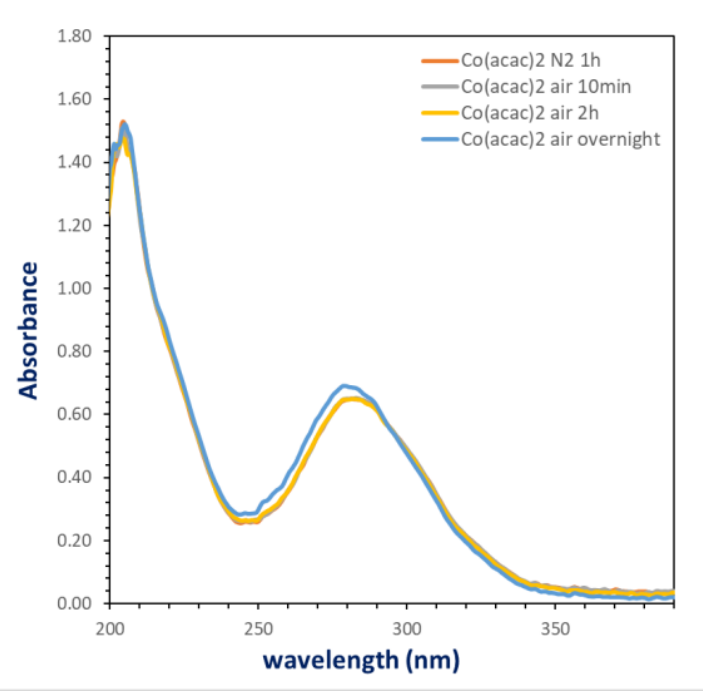

Figure 2.5. UV-visible spectra of $\mathrm{Co}^{\mathrm{II}}(\mathrm{acac})_{2}\left(5.05 \times 10^{-2} \mathrm{mM}\right.$ in $\mathrm{MeCN}$ ) prepared under $\mathrm{N}_{2}$ (orange trace), and then exposed to air and monitored over the course of $12 \mathrm{~h}$ at room temperature (blue trace).

\section{B. Co ${ }^{\mathrm{II}}(\text { acac })_{2}$ control experiment with tBuNC}

The standard spectrum of $\mathrm{Co}^{\mathrm{II}}(\mathrm{acac})_{2}$ in acetonitrile $\left(5.05 \times 10^{-2} \mathrm{mM}\right.$ in $\left.10 \mathrm{~mL} \mathrm{MeCN}\right)$ was taken first under a $\mathrm{N}_{2}$ atmosphere, then tert-butylisonitrile $(5 \mu \mathrm{L}, 3.65 \mathrm{mg}, 0.044 \mathrm{mmol}, 8$ equiv) was 
added by syringe. The mixture was then exposed to air by inserting an air balloon through the septum and the reaction mixture was stirred under the air atmosphere overnight. No new band were observed and instead only the two absorbance maxima characteristic of $\mathrm{Co}^{\mathrm{II}}(\mathrm{acac})_{2}$ were present (202 nm and $272 \mathrm{~nm}$, Figure S4 below).

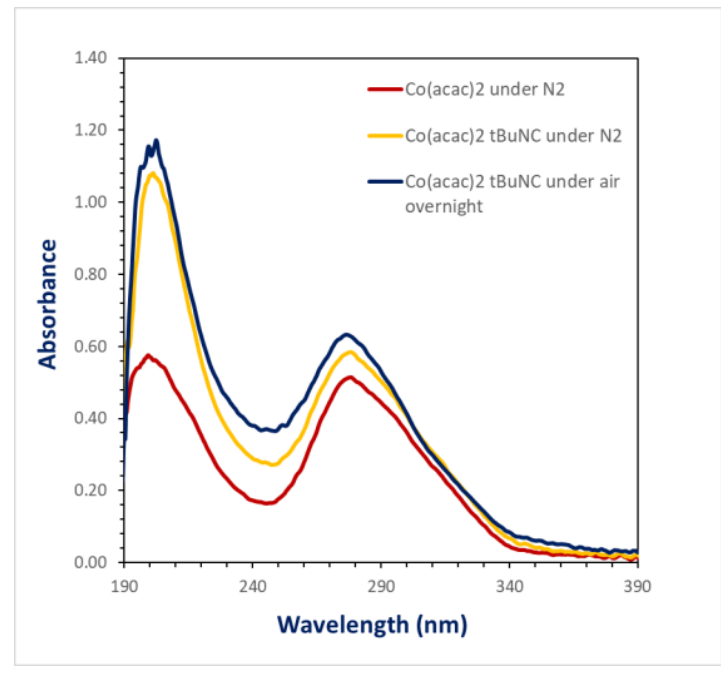

Figure 2.6. UV-Visible spectra of (a) $\mathrm{Co}^{\mathrm{II}}(\mathrm{acac})_{2}\left(5.05 \times 10^{-2} \mathrm{mM}\right.$ in $\left.\mathrm{MeCN}\right)$ prepared under $\mathrm{N}_{2}$ (red trace), and then tert-butylisonitrile ( 8 equiv) was added (green trace), and final, exposed to air overnight (dark blue trace).

\section{C. $\mathrm{Co}^{\mathrm{II}}(\mathrm{acac})_{2}$ control experiment with 2 equivalents of 2 -aminophenol}

First, a UV-visible spectrum of $\mathrm{Co}^{\mathrm{II}}$ (acac $)_{2}\left(5.05 \times 10^{-2} \mathrm{mM}\right.$ in $\left.10 \mathrm{~mL} \mathrm{MeCN}\right)$ was taken under a $\mathrm{N}_{2}$ atmosphere. Then 2-aminophenol was added by syringe in 1 equivalent increments ( $25 \mu \mathrm{L}$ of the $2.0 \times 10^{-2} \mathrm{M}$ aminophenol stock solution in $\mathrm{MeCN}$, described above) until a total of 2 equivalents had been added. Spectra were recorded after each addition. The mixture was then stirred under an inert atmosphere for $2.5 \mathrm{~h}$, then exposed to air by inserting an air balloon through the septum. The resulting mixture was stirred in the closed aerobic system overnight. UV-visible spectra were taken throughout the reaction. Under anaerobic condition, $\mathrm{Co}^{\mathrm{II}}(\mathrm{acac})_{2}$ showed absorbance maxima at 202 and $272 \mathrm{~nm}$. Upon the injection of the 2-aminophenol solution in MeCN, accumulation of 2-aminophneol was observed. Changes of absorbance maxima were observed only when the mixture was exposed to air, which was observed as the slow growth of the peak around $270 \mathrm{~nm}$ (Figure 2.7, below). 

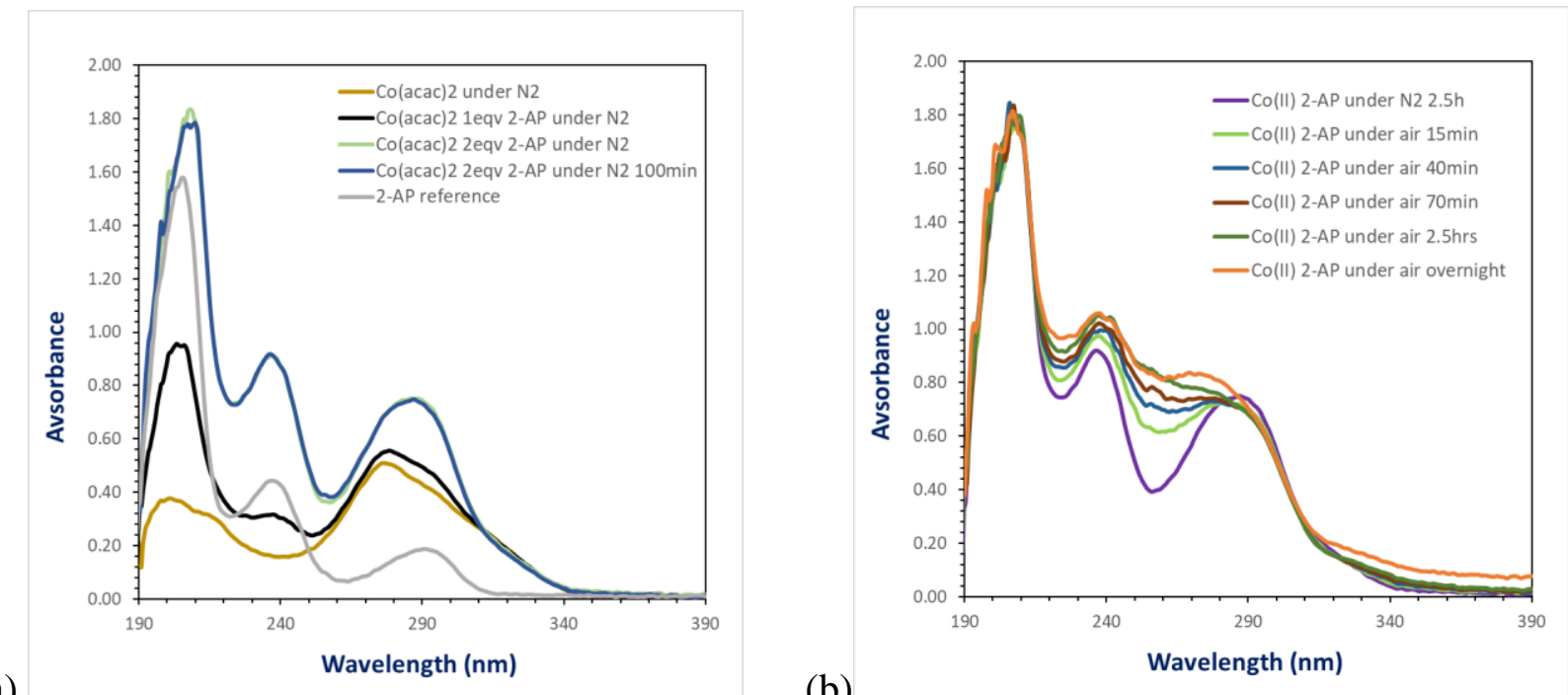

(a)

(b)

Figure 2.7. UV-visible spectra of (a) $\mathrm{Co}^{\mathrm{II}}(\mathrm{acac})_{2}\left(5.05 \times 10^{-2} \mathrm{mM}\right.$ in $\left.\mathrm{MeCN}\right)$ prepared under $\mathrm{N}_{2}$ (yellow trace), and then treated with 2 -aminophenol to reach a total of 2 equiv added (deep blue trace), and (b) $\mathrm{Co}^{\mathrm{II}}(\mathrm{acac})_{2}\left(5.05 \times 10^{-2} \mathrm{mM}\right.$ in $\left.\mathrm{MeCN}\right)$ and 2-aminophenol (2 equiv, purple trace) exposed to air and monitored over the course of $12 \mathrm{~h}$ at room temperature (orange trace).

\section{The following two experiments (D and E) were conducted with a Shimadzu UV 1800 instrument}

All cobalt salt and 2-aminophenol solutions for these experiments were prepared by serial dilution in a nitrogen-filled glovebox or using standard Schlenk techniques. The general procedure for preparing $\mathrm{Co}^{\mathrm{II}}(\mathrm{acac})_{2}$ and 2-aminophenol solutions in acetonitrile are described below:

$\underline{\text { General procedure for preparing } \mathbf{C o}^{\mathrm{II}}(\mathbf{a c a c})_{2} \text { solution: }}$

To a $20 \mathrm{~mL}$ scintillation vial inside the glovebox, $\mathrm{Co}(\mathrm{acac})_{2}\left(1.3 \mathrm{mg}, 5.0 \times 10^{-3} \mathrm{mmol}\right)$ was first dissolved in dry $\mathrm{CH}_{3} \mathrm{CN}(10 \mathrm{~mL})$. For dilution purposes, $1 \mathrm{~mL}$ of the resulting $10 \mathrm{~mL}$ solution was transferred to a new clean $20 \mathrm{~mL}$ scintillation vial. To this $1 \mathrm{~mL}$ of solution was added $19 \mathrm{~mL}$ of fresh $\mathrm{CH}_{3} \mathrm{CN}$ to yield a final $20 \mathrm{~mL}$ solution with concentration of $2.5 \times 10^{-5} \mathrm{M}$.

General procedure for preparing $\mathbf{C o}^{\text {III }}(\mathbf{a c a c}) 3$ solution:

To a $20 \mathrm{~mL}$ scintillation vial inside the glovebox, Co(acac) $3\left(1.8 \mathrm{mg}, 2.5 \times 10^{-3} \mathrm{mmol}\right)$ was first dissolved in dry $\mathrm{CH}_{3} \mathrm{CN}(10 \mathrm{~mL})$. For dilution purposes, $1 \mathrm{~mL}$ of the resulting $10 \mathrm{~mL}$ solution was transferred to a new clean $20 \mathrm{~mL}$ scintillation vial. To this $1 \mathrm{~mL}$ of solution was added $19 \mathrm{~mL}$ of fresh $\mathrm{CH}_{3} \mathrm{CN}$ to yield a final $20 \mathrm{~mL}$ solution with concentration of $2.5 \times 10^{-5} \mathrm{M}$. 
General procedure for preparing 2-aminophenol solution

To a $25 \mathrm{~mL}$ Schlenk tube equipped with a stir bar and septum, 2-aminophenol (8.2 mg, 0.075 mmol) was added and the tube was evacuated and backfilled with $\mathrm{N}_{2}$ three times. Dry acetonitrile $(3 \mathrm{~mL})$ was added via syringe to make a final solution with a concentration of $2.5 \times 10^{-2} \mathrm{M}$.

\section{D. $\mathrm{Co}^{\mathrm{II}}(\mathrm{acac})_{2}$ control experiment with 3 equivalents of 2-aminophenol}

Inside a $\mathrm{N}_{2}$ filled glovebox, a $3 \mathrm{~mL}$ aliquot of the standard solution of $\mathrm{Co}$ (acac) $)_{2}\left(2.5 \times 10^{-5} \mathrm{M}\right.$, described above) was transferred to a cuvette. The cuvette was then sealed, removed from the glovebox and an initial spectrum recorded. Then 2-aminophenol was added by syringe in 1 equivalent increments ( $3 \mu \mathrm{L}$ of the $2.5 \times 10^{-2} \mathrm{M}$ aminophenol stock solution in $\mathrm{CH}_{3} \mathrm{CN}$, described above) until a total of 3 equivalents had been added. Spectra were recorded after each addition and for 1 hour further under $\mathrm{N}_{2}$. Under a $\mathrm{N}_{2}$ atmosphere, no significant changes in the spectra were observed upon addition of 2-aminophenol except for the accumulation of 2-aminophenol in the mixture. Air was then bubbled into the mixture for $3 \mathrm{~min}$ by inserting an air balloon through the septum of the cuvette and UV-visible spectra were recorded under this aerobic atmosphere for over 12 hours. Upon exposure of the mixture to air, spectral changes were seen with a rapid growth of the absorbance around $260 \mathrm{~nm}$. (Figure 2.8, below).

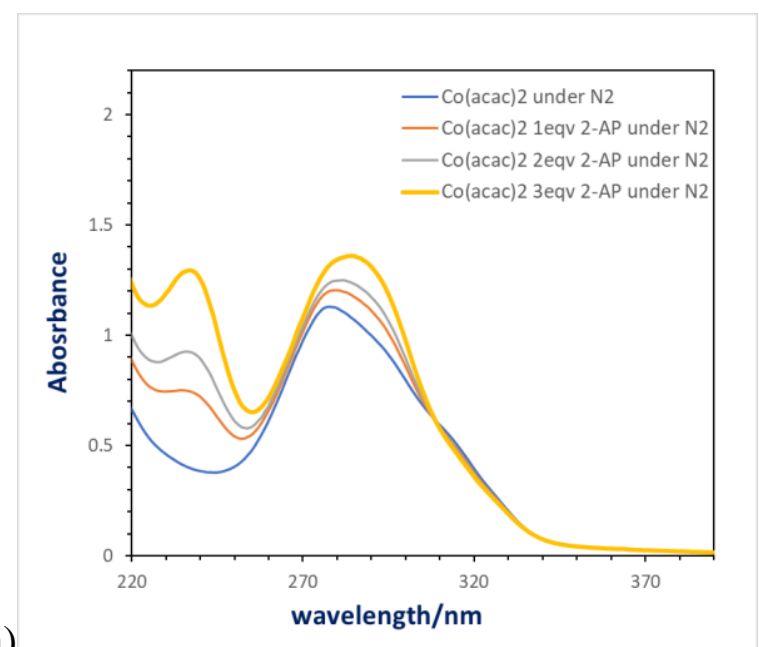

(a)

(b)

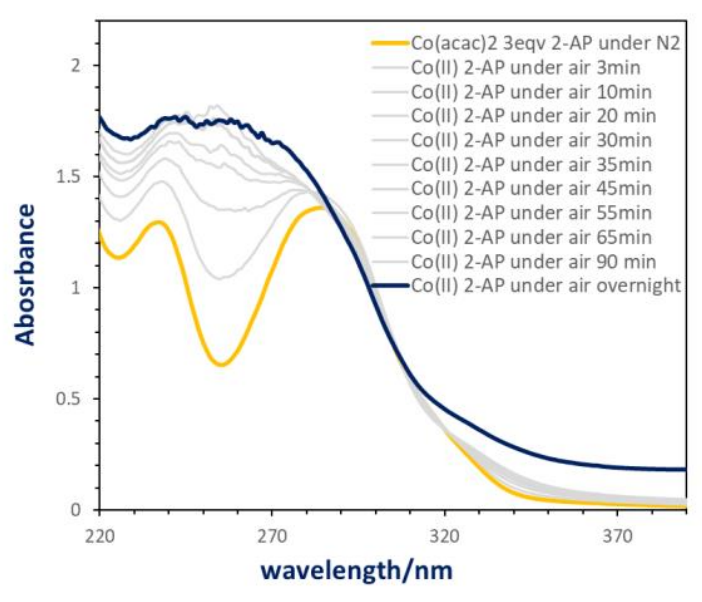

Figure 2.8. (a) $\mathrm{Co}(\mathrm{acac})_{2}\left(5.0 \times 10^{-5} \mathrm{M}\right)$ in $\mathrm{MeCN}$ under $\mathrm{N}_{2}$ (red trace) with the addition of 3 equiv of 2-aminophenol (yellow trace), and (b) $\mathrm{Co}$ (acac) 2 and 2-aminophenol (3 equiv, yellow trace) exposed to air overnight (deep blue trace). 


\section{E. $\mathrm{Co}^{\mathrm{III}}(\mathrm{acac})_{3}$ control experiment with 3 equivalents of 2-aminophenol}

Inside a $\mathrm{N}_{2}$ filled glovebox, a $3 \mathrm{~mL}$ aliquot of the standard solution of $\mathrm{Co}(\mathrm{acac})_{3}\left(2.5 \times 10^{-5} \mathrm{M}\right.$, described above) was transferred to a cuvette. The cuvette was then sealed, removed from the glovebox and an initial spectrum recorded. Then 2-aminophenol was added by syringe in 1 equivalent increments ( $3 \mu \mathrm{L}$ of the $2.5 \times 10^{-2} \mathrm{M}$ aminophenol stock solution in $\mathrm{CH}_{3} \mathrm{CN}$, described above) until a total of 3 equivalents had been added. Spectra were recorded after each addition and for 2 hours further under $\mathrm{N}_{2}$. Air was then bubbled into the mixture by inserting an air balloon through the septum of the cuvette and UV-visible spectra were recorded under this aerobic atmosphere for over 12 hours (Figure 2.9 below).

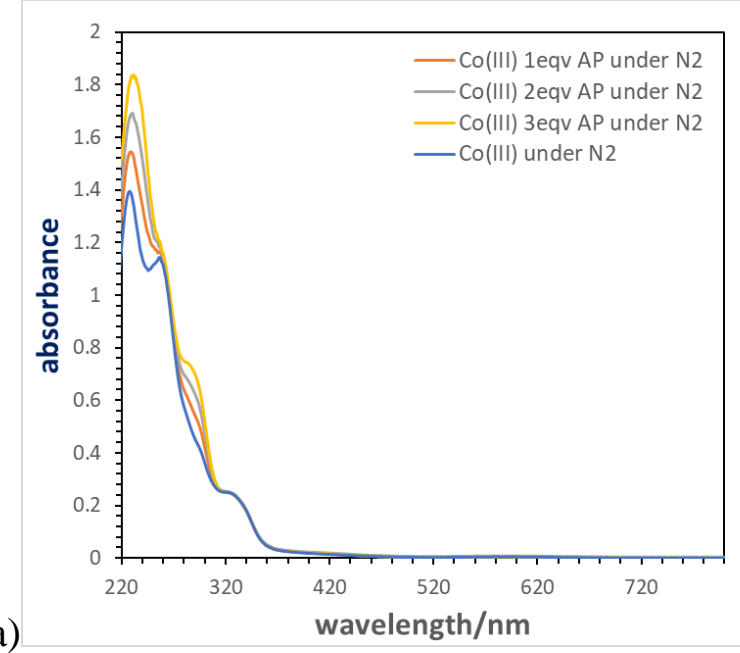

(b)

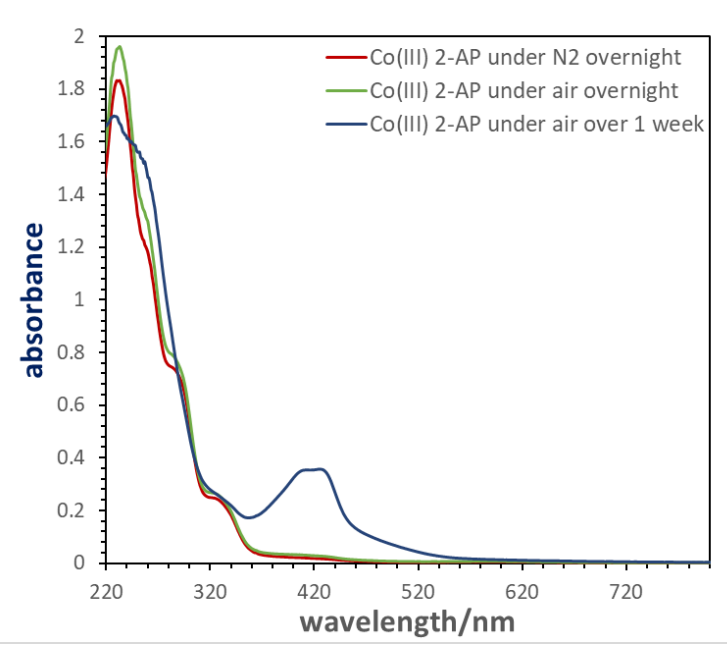

Figure 2.9. (a) $\mathrm{Co}(\mathrm{acac})_{3}\left(2.5 \times 10^{-5} \mathrm{M}\right)$ in $\mathrm{MeCN}$ under $\mathrm{N}_{2}$ (blue trace) with the addition of 3 equiv of 2-aminophenol (yellow trace) and (b) $\mathrm{Co}(\mathrm{acac})_{3}\left(2.5 \times 10^{-5} \mathrm{M}\right)$ and 2 -aminophenol (3 equiv, red trace) exposed to air overnight (blue trace). 


\section{Chapter 3. Cobalt-Catalyzed Aerobic Oxidative Cyclization of 2-Aminoanilines with Isonitriles: Facile Access to Substituted 2-Aminobenzimidazoles}

\subsection{Introduction}

Benzimidazoles are structurally important heterocyclic compounds that are key targets or the intermediates in the synthesis of pharmaceutically valuable and biologically active molecules. ${ }^{86-90}$ Specifically, the 2-aminobenzimidazole scaffold is a common substructure in this category that existing widely in a variety of antihistamines (norastemizole and astemizole), ${ }^{91}$ antihelmitics (mebendazole), ${ }^{92}$ kinase inhibitors, ${ }^{93}, 94$ and integrin $\alpha v \beta_{3}$ antagonists. ${ }^{95}$ These structures have also demonstrated anticancer ${ }^{96}$ and antimalarial ${ }^{97}$ activities among others in related research (Chart 3.1)..$^{98,99}$
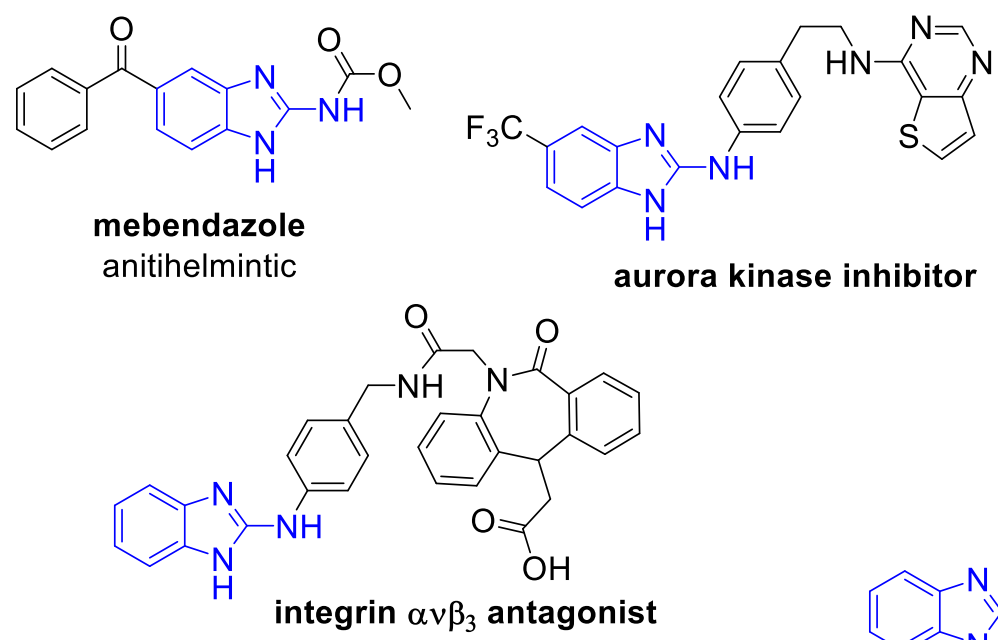

aurora kinase inhibitor
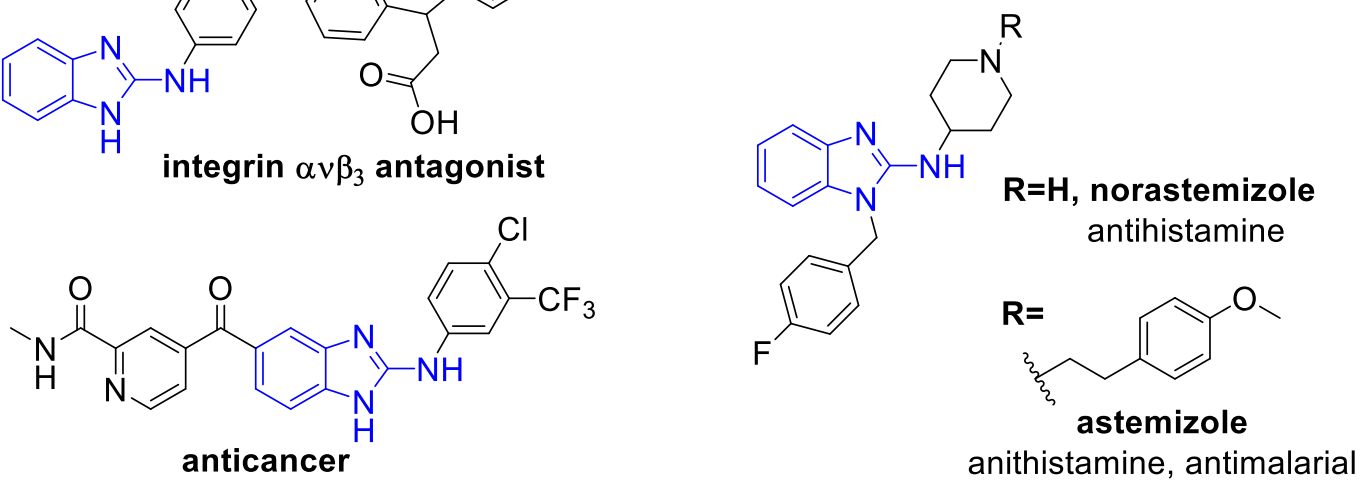

Chart 3.1. Selected biologically active small molecules containing 2-aminobenzimidazole substructure. 
One of the most conventional routes to access these heterocyclic structures relies on the desulfurization of a preformed thiourea that can be prepared from either the reduction of the appropriate ortho-nitroaryl thiourea ${ }^{100-104}$ or the coupling of ortho-phenylenediamine with the corresponding isothiocyanate ${ }^{81,}{ }^{105-111}$ (Scheme 3.1 Route a). Unfortunately, the prefunctionalization of these starting materials has disadvantages like low yields, poor atom efficiency and the reduction of nitro-group was not always efficient. Also, these reactions require the use of super stoichiometric mercury salts for the ring-closure of thiourea derivatives and toxic/or hazardous desulfurizing agents such as MeI among others. ${ }^{81,112}$ Alternatively, TsCl has been employed under basic conditions ${ }^{113}$ and coupling agents such as 1,3-diisopropylcarbodiimde (DIC) or N-(3-dimethylaminopropyl)-N'-ethylcarbodiimide hydrochloride (EDC) or dicyclohexylcarbodiimide (DCC) have also been shown to be efficient in this category of transformations. ${ }^{102,114}$ Whilst effective, these methods suffer from low atom economy and the employment of toxic reagents renders a doubtful feasibility for large scale synthesis and limited industrial applications. Furthermore, the 1,2-diamine substitutions on the arene substrates prior to desulfurization often require a fresh preparation due to the poor stability of these compounds. ${ }^{115}$

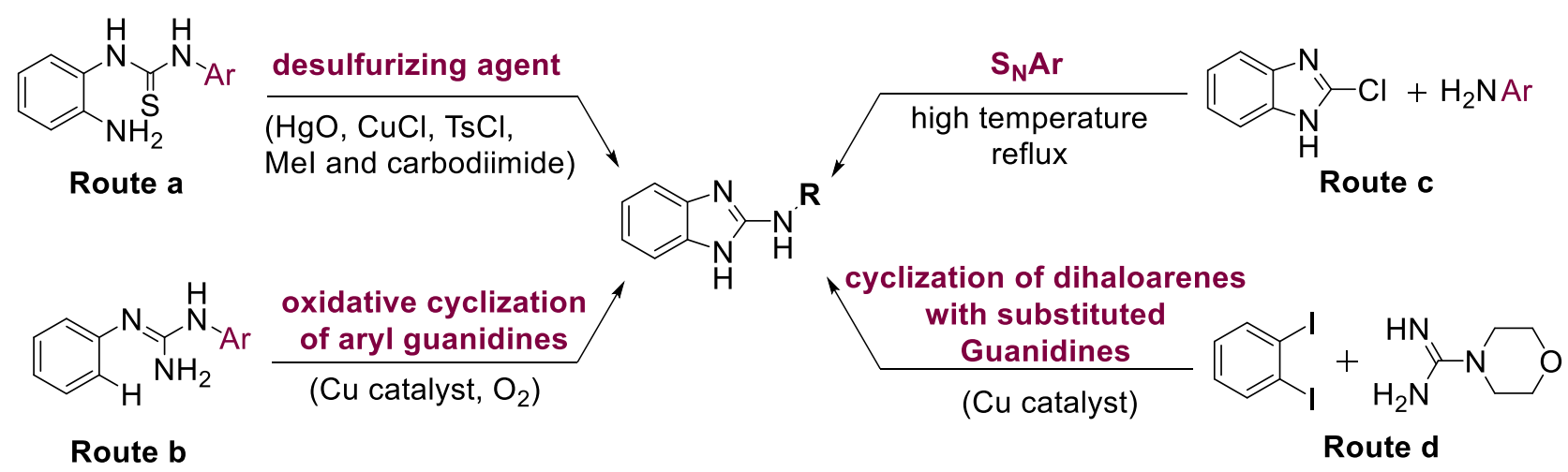

Scheme 3.1. Selected conventional routes for the synthesis of 2-aminobenzimidazoles. Reaction Conditions: (Route a) desulfurization agents such as $\mathrm{HgO}$, carbodiimide or $\mathrm{Cu}$ catalyst and base. (Route b) $\mathrm{Cu}$ catalyst and O2. (Route c) reflux at high temperature or Pd catalyst. (Route d) $\mathrm{Cu}$ catalyst and base.

More recently, transition metal-catalyzed cyclization reactions have provided attractive alternatives to access 2-(N-substituted)-aminobenzimidazoles. The copper-catalyzed intramolecular cyclization reactions of thioureas ${ }^{116}$ or guanidines (Scheme 3.1 Route b) ${ }^{115}$ help 
eliminate the requirement of stoichiometric desulfurizing agents. Other approaches enable arylamination of 2-chlorobenzimidazole either by $\mathrm{Pd}$ catalysis ${ }^{117,} 118$ or $\mathrm{S}_{\mathrm{N}} \mathrm{Ar}$ transformation mediated either by high temperature ${ }^{119,120}$ or high pressure (Scheme 3.1 Route c) ${ }^{121}$ Cyclization of dihaloarenes with substituted guanidines mediated by a $\mathrm{Cu}$ catalyst also provided an alternative path to achieve 2-aminobenzimidazoles (Scheme 3.1 Route d), ${ }^{122,}{ }^{123}$ however, this protocol is restricted by its inherent limitation that only dihaloarenes can be used and availability of guanidines is another challenge. Finally, transition-metal-free cyclization reactions using $\mathrm{I}_{2}{ }^{110,111}$ or hypervalent iodine-based oxidants ${ }^{124}$ have also been developed. To circumvent additional nontrivial synthetic challenges that most methodologies suffer, the ability to utilize readily available coupling partners in combination with environmentally benign oxidants, such as $\mathrm{O}_{2}$ and air, and abundant first-row transition-metal catalysts would represent a significant advance toward the facile synthesis of substituted 2-aminobenzimidazoles ${ }^{57} \mathrm{~A}$ variety of cobalt-catalyzed cyclization reactions of isonitriles have been developed. Specifically, Wang and coworkers have reported cyclization reactions with bisnucleophiles employing persulfate-based oxidants ${ }^{125}$ and in the last chapter we have revealed an aerobic cobalt-catalyzed oxidative cyclization of aminophenols and isonitriles to generate substituted 2-aminobenzoxazoles. ${ }^{126}$ Thus, we wondered if we can expand our aerobic cobalt catalyst system to the efficient synthesis of other heterocycles. In this chapter, we will disclose the cobalt-catalyzed aerobic oxidative cyclization reactions of orthophenylenediamines with isonitriles to generate substituted 2-aminobenzimidazoles (Scheme 3.2). 
(a) Oxidative cyclization of bisnucleophiles with isonitriles mediated by Pd catalyst and $\mathrm{O}_{2}$

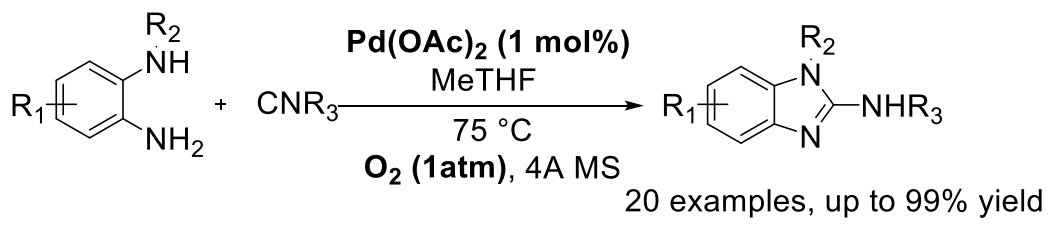

(b) Oxidative cyclization of bisnucleophiles with isonitriles mediated by Co catalyst and persulfate oxidant

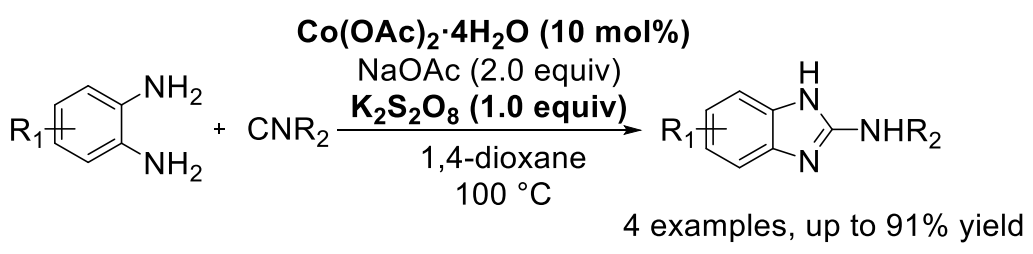

(c) Our approach: Efficient transformation under simple and mild reaction conditons<smiles>[R2]Nc1nc2c[nH+]ccc2[nH]1</smiles>

Scheme 3.2. 2-aminobenzimidazole synthesis via transition-metal catalyzed oxidative cyclization of bisnucleophiles with isonitriles. (a) $\mathrm{Pd} / \mathrm{O}_{2}$ mediated oxidative cyclization reactions. (b) Oxidative cyclization reactions mediated by Co catalyst pairing with a persulfate oxidant. (c) Approach of our work in this chapter.

\subsection{Results}

\subsubsection{Condition Optimization of Cobalt-Catalyzed Aerobic Oxidative Cyclization of o- Phenylenediamine with tert-Butyl Isonitrile}

We started our condition optimization with the model coupling reaction of orthophenylenediamine (4a) and tert-butyl isonitrile (2a) under the aerobic cobalt-catalyzed conditions. Of all cobalt salts investigated, $\mathrm{Co}(\mathrm{OAc})_{2}$ was found to provide the highest yield of $\mathbf{5 a}$ in $69 \%$ of yield when $\mathrm{CH}_{3} \mathrm{CN}$ was employed as a solvent at $65{ }^{\circ} \mathrm{C}$ (entries 1-5). Reactions run in $\mathrm{CH}_{3} \mathrm{CN}$ provided higher yields of 5a than other commonly utilized solvents such as dioxane, THF and DMF (entries 5-9). The incorporation of base additives improved the reaction yield, with two equivalents of $\mathrm{K}_{2} \mathrm{CO}_{3}$ showing the greatest improvement of product in $85 \%$ of yield (entries 10-15). Finally, we have found that the increase of the reaction temperature plays a critical role in this 
aerobic oxidative cyclization reaction. The yield of $\mathbf{5 a}$ was increased to $95 \%$ when the reaction temperature was raised to $80{ }^{\circ} \mathrm{C}$ (entry 16). Thus, the optimized reaction conditions employ 10 mol\% of $\mathrm{Co}(\mathrm{OAc})_{2}$ with two equivalents of $\mathrm{K}_{2} \mathrm{CO}_{3}$ and an air balloon in $\mathrm{CH}_{3} \mathrm{CN}$ at $80{ }^{\circ} \mathrm{C}$ for 24 hours.

Table 3.1 Optimization of Reaction Conditions ${ }^{\mathrm{a}}$

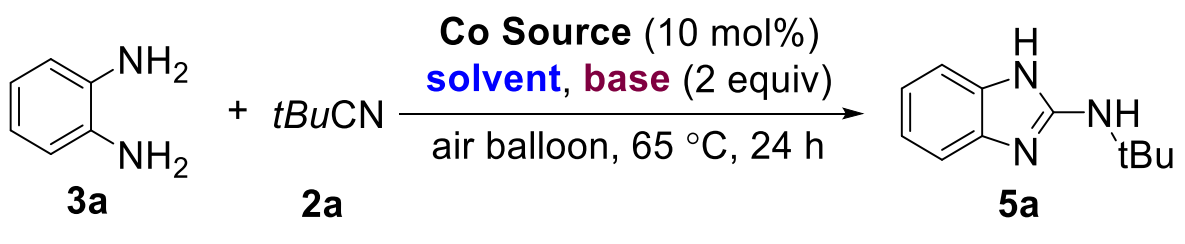

\begin{tabular}{ccccc}
\hline Entry & $\mathrm{Co}$ Source & Solvent & Base & \% Yield \\
\hline 1 & $\mathrm{CoCO}_{3}$ & $\mathrm{CH}_{3} \mathrm{CN}$ & -- & Trace \\
2 & $\mathrm{CoCO}_{3} \cdot \mathrm{H}_{2} \mathrm{O}$ & $\mathrm{CH}_{3} \mathrm{CN}$ & -- & Trace \\
3 & $\mathrm{CoCl}_{2}$ & $\mathrm{CH}_{3} \mathrm{CN}$ & -- & Trace \\
4 & $\mathrm{Co}(\mathrm{acac})_{2}$ & $\mathrm{CH}_{3} \mathrm{CN}$ & -- & 41 \\
5 & $\mathrm{Co}(\mathrm{OAc})_{2}$ & $\mathrm{CH}_{3} \mathrm{CN}$ & -- & 69 \\
6 & $\mathrm{Co}(\mathrm{OAc})_{2}$ & $1,4-\mathrm{dioxane}$ & -- & 61 \\
7 & $\mathrm{Co}(\mathrm{OAc})_{2}$ & $2-\mathrm{Me}-\mathrm{THF}$ & -- & 69 \\
8 & $\mathrm{Co}(\mathrm{OAc})_{2}$ & $\mathrm{THF}$ & -- & 54 \\
9 & $\mathrm{Co}(\mathrm{OAc})_{2}$ & $\mathrm{DMF}$ & -- & 23 \\
10 & $\mathrm{Co}(\mathrm{OAc})_{2}$ & $\mathrm{CH}_{3} \mathrm{CN}$ & $\mathrm{K}_{2} \mathrm{CO}_{3}$ & 85 \\
11 & $\mathrm{Co}(\mathrm{OAc})_{2}$ & $\mathrm{CH}_{3} \mathrm{CN}$ & $\mathrm{Na}_{2} \mathrm{CO}_{3}$ & 79 \\
12 & $\mathrm{Co}(\mathrm{OAc})_{2}$ & $\mathrm{CH}_{3} \mathrm{CN}$ & $\mathrm{Li}_{2} \mathrm{CO}_{3}$ & 67 \\
13 & $\mathrm{Co}(\mathrm{OAc})_{2}$ & $\mathrm{CH}_{3} \mathrm{CN}$ & $\mathrm{KOAc}^{2}$ & 82 \\
14 & $\mathrm{Co}(\mathrm{OAc})_{2}$ & $\mathrm{CH}_{3} \mathrm{CN}$ & $\mathrm{NaOAc}_{3}$ & 62 \\
15 & $\mathrm{Co}(\mathrm{OAc})_{2}$ & $\mathrm{CH}_{3} \mathrm{CN}$ & $\mathrm{LiOAc}_{3}$ & 65 \\
$\mathbf{1 6}{ }^{[\mathbf{c}]}$ & $\mathbf{C o}(\mathrm{OAc})_{2}$ & $\mathbf{C H}_{3} \mathrm{CN}$ & $\mathbf{K}_{2} \mathbf{C O}_{3}$ & $\mathbf{9 5}$ \\
\hline
\end{tabular}

${ }^{a}$ Reaction Conditions: $\mathbf{4 a}(0.3 \mathrm{mmol}), \mathbf{2 a}(0.3 \mathrm{mmol})$, cobalt(II) catalysts $(10 \mathrm{~mol} \%)$, solvent (3 $\mathrm{mL}$ ), at $65{ }^{\circ} \mathrm{C}$ with an air balloon for $24 \mathrm{~h} .{ }^{b}$ The yield of 5a was determined by ${ }^{1} \mathrm{H}$ NMR spectroscopy with dimethylsulfone as internal standard $(0.03 \mathrm{mmol}) .^{c}$ The reaction was conducted at $80{ }^{\circ} \mathrm{C}$. 
Last year Glorious and co-workers developed an user-friendly assessment tool that enabled the sensitivity to different variants of a protocol to be rapidly assessed. ${ }^{127}$ This tool delivers a straightforward overview of the sensitivity of reactions to key parameters by the standardized presentation of the results in a radar diagram. This diagram provides a direct visualization of the general sensitivity of a reaction based on the shape of the black line generated. The round shape around the " $0 \%$ deviation line" indicates low sensitivity, while any section deflecting from that to the red zone refers to high sensitivity. Specifically, the sharp "arrow-like" deflections immediately demonstrate the most influential parameters. As we aimed to develop a highly efficient but simple transformation delivering the scaffolds of critical pharmaceutical importance, we applied this tool to our standard cobalt-catalyzed aerobic cyclization reaction to test the robustness of the condition screening and reproducibility of this protocol.

In this assessment, $\mathrm{O}_{2}$ concentration, base stoichiometry, catalyst loading, concentration of reaction mixture and reaction temperature were chosen as key parameters in the standard cyclization reaction. These parameters were evaluated by carefully setting up five sets of experiments with single variation for each, following the systematic four-step procedure reported by Glorious (experimentation, data analysis, calculation and data plotting) (Figure 3.1a). From the radar diagram generated upon using this methodology, we realized the almost neglectable influence of reaction mixture concentration and small impact of catalyst loading on the overall performance of this transformation. Also confirmed was the strong dependence of this reaction on the base loading as well as the reaction temperature and $\mathrm{O}_{2}$ concentration, as indicated by the black "arrow-like" deflections shown in the diagram (Figure 3.1b) (See the details of reaction set up and results of these assessment experiments in the Experimental Section 3.4.3/Tables 3.8 \& 3.9/Figures 3.2-3.4). By knowing the highly sensitive parameters associated with a chemical transformation, the implementation of this condition-based assessment in our cobalt aerobic cyclization system could help us facilitate higher reproducibility in the later stage substrate scope investigations, and allow the fast application of the new developed protocol in further structural functionalization. 
(a) Sensitivity Assessment Procedure

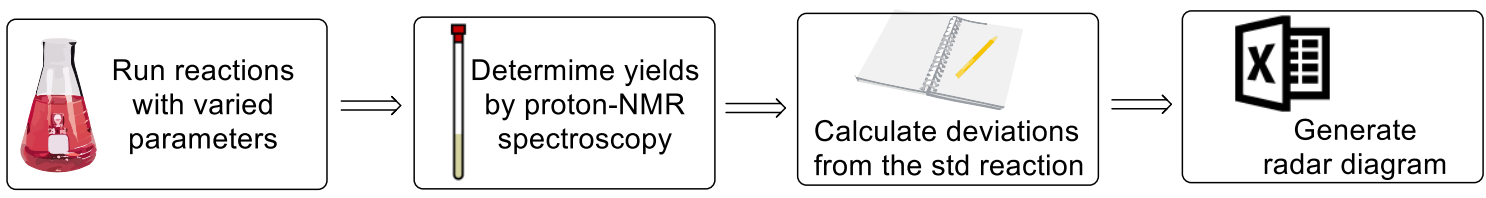

(b) Key Parameter Assessment for the Standard Co-Catalyzed Aerobic Oxidative Cyclization of o-Phenylenediamine with tert-Butyl Isonitrile

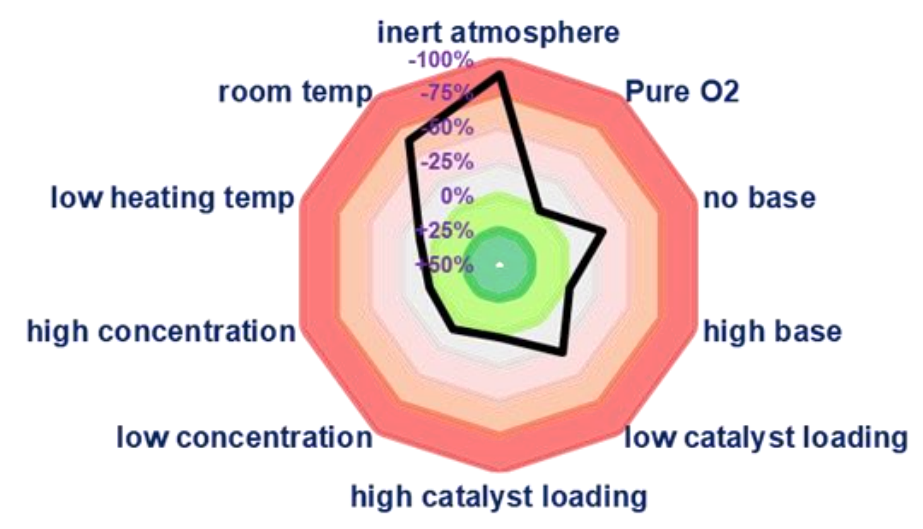

Figure 3.1. Condition-based sensitivity assessment experiment. (a) Four steps involved in sensitivity assessment procedure (b) Sensitivity assessment of key parameters in Co-catalyzed aerobic oxidative cyclization of $o$-phenylenediamine with tert-butyl isonitrile.

\subsubsection{Substrate Scope of $o$-Phenylenediamines and Isonitriles}

With the optimized reaction conditions, we move on to investigate a variety of substituted ortho-phenylenediamine coupling partners (4, Table 3.2). This protocol is broadly tolerant of a wide range functional groups including both electron-rich and electron-deficient substrates. Of the ortho-phenylenediamines being explored, the reaction didn't show preference for either electronMHYHHHHdonating or withdrawing substituents. Electron-withdrawing (4e-4j), electron-neutral $\mathrm{H}(\mathbf{4 a}, \mathbf{4 b})$ and electron-donating (4c and 4d) groups all leads to high yields of the benzimidazole products. Similarly, steric influences on the reaction yield are minimal. For example, high yields of benzimidazoles are obtained in the presence of methyl-substitution in both the 3- and 4positions of ortho-phenylenediamine. Furthermore, functional groups such as a 4-tert-butyl (4c) or naphthalene $\mathbf{( 4 m )}$ are also well tolerated. 
Table 3.2. Scope of ortho-Phenylenediamine and Isonitrile Coupling Partners ${ }^{\mathrm{a}}$

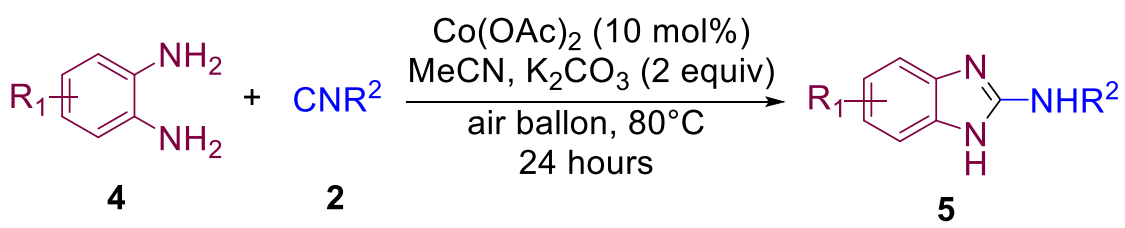<smiles>CC(C)(C)Nc1nc2ccccc2[nH]1</smiles>

5 a, $95 \%$<smiles>COc1ccc2nc(NC(C)(C)C)[nH]c2c1</smiles>

$5 d, 63 \%$<smiles>CC(C)(C)Nc1nc2ccc(F)cc2[nH]1</smiles>

$5 g, 80 \%$<smiles>CC(C)(C)Nc1nc2ccc(C#N)cc2[nH]1</smiles>

5j, $34 \%(63 \%)^{b}$<smiles>Cc1ccc2nc(NC(C)(C)C)[nH]c2c1</smiles>

5b, $96 \%$<smiles>CC(C)(C)Nc1nc2ccc(Br)cc2[nH]1</smiles>

5e, $75 \%$<smiles>CC(C)(C)Nc1nc2ccc(C(F)(F)F)cc2[nH]1</smiles>

5h, $52 \%$<smiles>Cc1cccc2[nH]c(NC(C)(C)C)nc12</smiles>

5k, $75 \%$<smiles>CC(C)(C)c1ccc2nc(N[13C](C)(C)C(C)(C)C)[nH]c2c1</smiles>

5c, $93 \%$

5f, $81 \%$<smiles>CC(C)(C)Nc1nc2ccc([N+](=O)[O-])cc2[nH]1</smiles>

5i, $67 \%$<smiles>CC(C)(C)Nc1nc2c(Br)cccc2[nH]1</smiles>

5I, $87 \%$<smiles>CC(C)(C)NC(=O)c1nc2cc3ccccc3cc2[nH]1</smiles>

5m, $63 \%$<smiles>c1ccc2[nH]c(NC34CC5CC(CC(C5)C3)C4)nc2c1</smiles>

5o, $78 \%$<smiles>CC(C)(C)CC(C)(C)Nc1nc2ccccc2[nH]1</smiles>

5n, $84 \%$

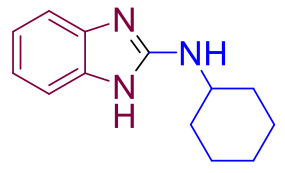

$5 p, 62 \%$

${ }^{a}$ Isolated Yields. Reaction conditions: 4 (0.3 mmol), 5 (0.3 mmol), $\mathrm{K}_{2} \mathrm{CO}_{3}(0.6 \mathrm{mmol}), \mathrm{Co}(\mathrm{OAc})_{2}$ $(10 \mathrm{~mol} \%)$ in $\mathrm{MeCN}(3 \mathrm{~mL})$, at $80{ }^{\circ} \mathrm{C}$ with an air balloon for $24 \mathrm{~h} .{ }^{b}$ Yield in parentheses determined by ${ }^{1} \mathrm{H}$ NMR spectroscopy.

In addition to substituted ortho-phenylenediamine coupling partners, various isonitirle coupling partners (2) were also explored. Bulky aliphatic substituents, such as tert-butyl, 
neopenthyl and admantyl groups delivered the most efficient product formation (5a, 5n. 5o). In contrast, less bulky n-pentyl isonitirle undergoes multiple isonitrile insertion steps to generate the corresponding diamino quinoxazoline product (6) in 25\% yield (Scheme 3.3).
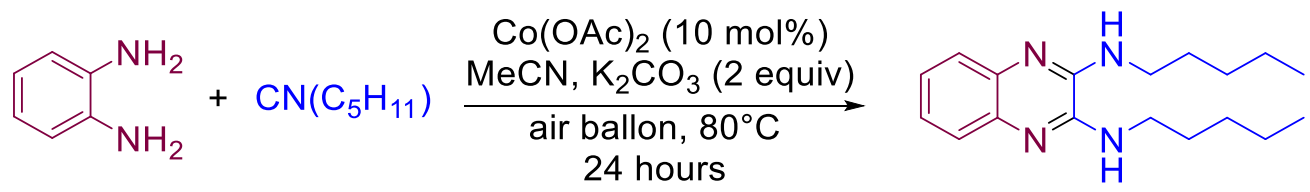

6, $25 \%$

Scheme 3.3. Synthesis of $N$-subsittuted diamino quinoxazoline.

A similar behavior was observed when 2,6-di-methyl phenyl isonitrile was employed as a coupling partner. Different from the case above where the product was generated exclusively from double insertion of isonitrile in this reaction, a complicated compound resulting from tripleinsertion of the isonitrile was also found to be one of the major products (Table 3.3c). We also explored other isonitrile and diamine coupling partners for this chemical transformation (Table 3.3). Isonitirles that had proceeded smoothly with ortho-aminophenol coupling partners in our previous study unfortunately revealed to be ineffective in this aerobic cyclization reaction. For example, the oxidative cyclization product was not observed when isopropyl isonitrile was employed as the coupling partner. Interestingly, a product resulting from benzylic oxidation was detected as the major product in the reaction where benzyl isonitirle was used; however, this oxygenation was not observed in the aerobic oxidative cyclization of ortho-aminophenol with benzyl isonitrile, indicating the reaction might be operating via a distinct oxidation pathway (Table 3.3c). Additionally, we also included a fused-ring system and a heteroaromatic ring in our substrate scope investigation. Unfortunately we found that our system is not tolerant of the fused 2-naphthyl isocyanide. Heterocyclic-based diamines were also shown to be unsuccessful in delievering the desired products in our aerobic system. Both 2,3-diamopyridine and 3,4-diaminopyridine didn't undergo oxidative cyclization with tert-butyl isonitrile under our standard reaction conditions (Table 3.3b), probably due to the irreversible binding of pyridine substrates to the cobalt catalyst, leading to catalyst deactivation. 
Table 3.3. Unsuccesful Isonitrile and Diamine Coupling Partners

(a) Unsuccessful Isonitriles<smiles>CC(C)Nc1nc2ccccc2[nH]1</smiles><smiles>c1ccc(CNc2nc3ccccc3[nH]2)cc1</smiles><smiles>Cc1cccc(C)c1Nc1nc2ccccc2[nH]1</smiles><smiles>c1ccc2cc(Nc3nc4ccccc4[nH]3)ccc2c1</smiles>

(b) Unsuccessful Diamines<smiles>CC(C)(C)Nc1nc2cccnc2[nH]1</smiles><smiles>CC(C)(C)Nc1nc2ccncc2[nH]1</smiles>

(c) Observed Products for Unsuccessful Substrates
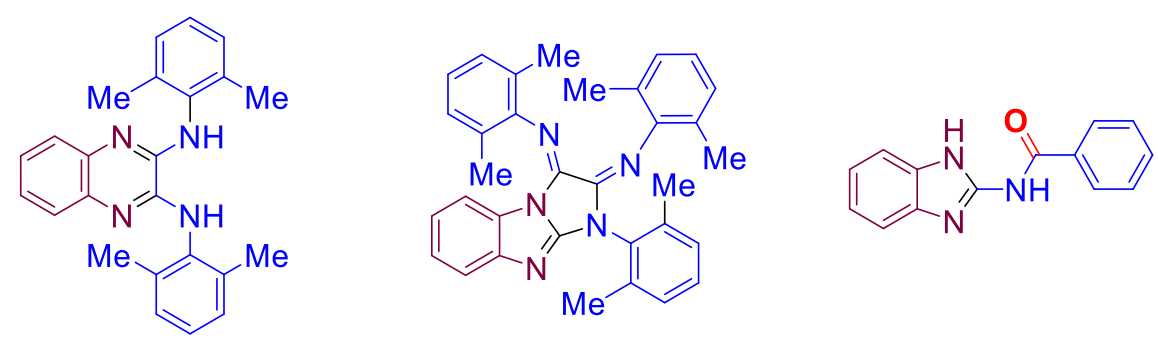

We also explored the reactivity of $\mathrm{N}$-substituted ortho-phenylenediamine coupling partners, the reaction of $N$-methyl- and $N$-phenyl-substituted ortho-phenylenediamines (5q and $\mathbf{5 r}$ ) allow access to the corresponding $N$-subsituted 2-aminobenzimidazoles in moderate yields (Scheme 3.4).

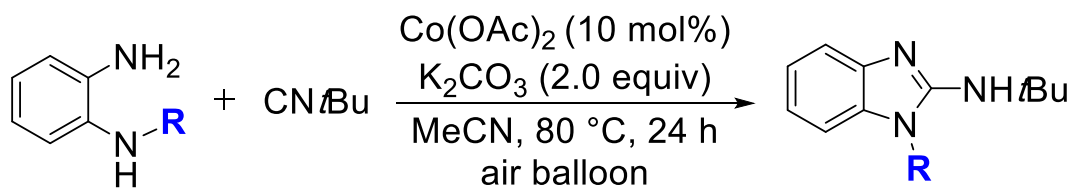

$$
\begin{aligned}
& \mathbf{R}=\operatorname{Me} 5 \mathrm{q}, 44 \% \\
& \mathrm{Ph} \text { 5r, 27\% }
\end{aligned}
$$

Scheme 3.4. Synthesis of $N$-substituted 2-aminobenzimidazoles.

\subsubsection{Application of the Cobalt-Catalyzed Oxidative Cyclization of o-Phenylenediamines with Isonitriles}

Next, we sought to explore the utilization of this cobalt-catalyzed method to access the unsubstituted 2-aminobenzimidazoles. These compounds are convenient precursors to access a 
variety of substituted benzimidazoles readily available as synthetic intermediates or pharmaceutically important drug targets. For example, studies have shown this compound to be an intermediate in the synthesis of biologically active small molecules such as mebendazole (Scheme 3.5a) ${ }^{128}$ and enviroxime (Scheme 3.5b). ${ }^{129}$ It also allows access to unique fused heterocyclic structures when treated with aryl sulfonyl chlorides (Scheme 3.5c) ${ }^{130}$ or oximes (Scheme 3.5d). ${ }^{131}$ Finally, treating unsubstituted 2-aminobenzimidazole with triphenylphosphine dibromide generates iminophosphoranes, a versatile structure for heterocyclic synthesis (Scheme 3.5e). ${ }^{132}$

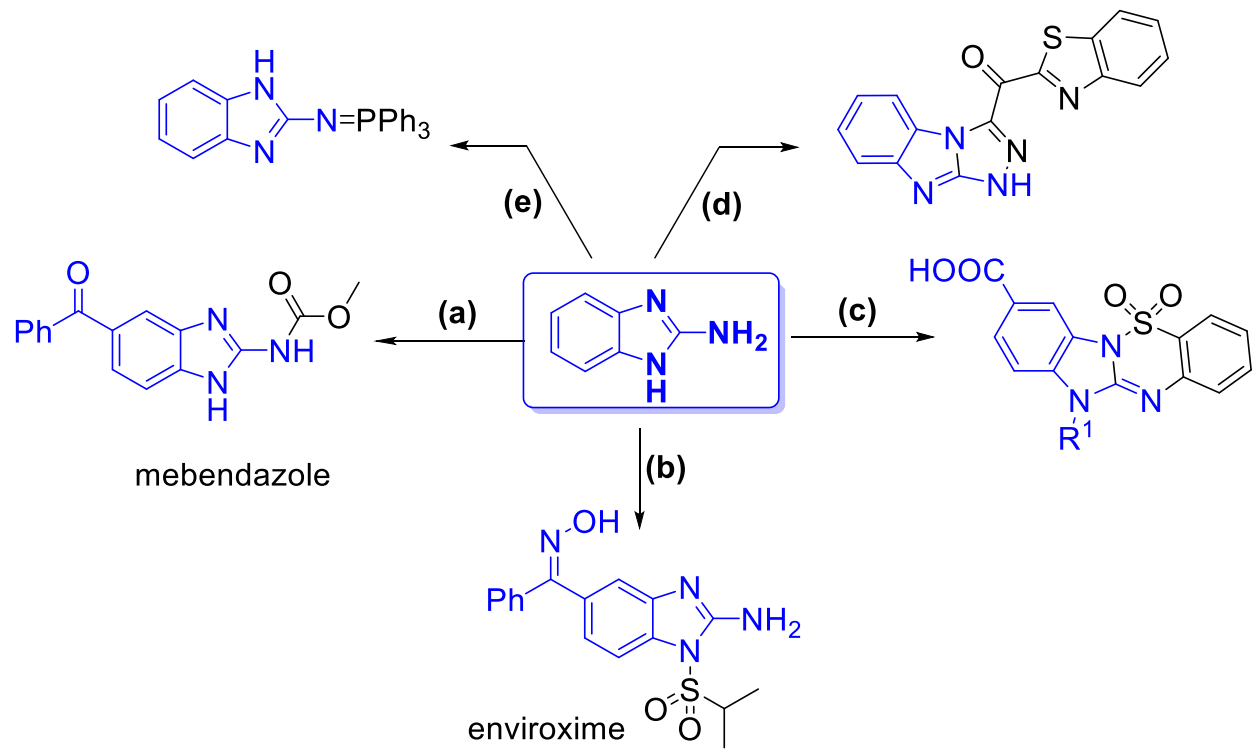

Scheme 3.5. Application of unsubstituted 2-aminobenzimidazoles in pharmaceutical-related synthesis. (a) methyl chloroformate and base ${ }^{128}$ (b) isopropylsulfonyl chloride, base and reflux ${ }^{132}$ (c) sulfonyl chloride/Cu catalyst then Pd catalyst ${ }^{130}$ (d) hydroximoyl chloride and reflux ${ }^{131}$ (e) $\mathrm{Ph}_{3} \mathrm{PBr}_{2}$ and base ${ }^{132}$

Thus, we sought to enable the efficient access to the unsubstituted 2-aminobenzimidazole 5s. Researchers in other groups have shown the N-tert-butyl benzimidazole to undergo selective dealkylation upon treatment with a strong acid. ${ }^{57}$ Based on this precedent, we designed a convenient sequence for facile access to 2-aminobenzimidazole from ortho-phenylenediamine and the readily available tert-butyl isonitrile. Upon accomplishment of the reaction under standard condition, the resulting crude product 5a was treated directly with a strong acid under reflux conditions, giving rise to the unsubstituted 2-aminobenzimidazole $5 \mathrm{~s}$ in $82 \%$ yield (Scheme 3.6). 


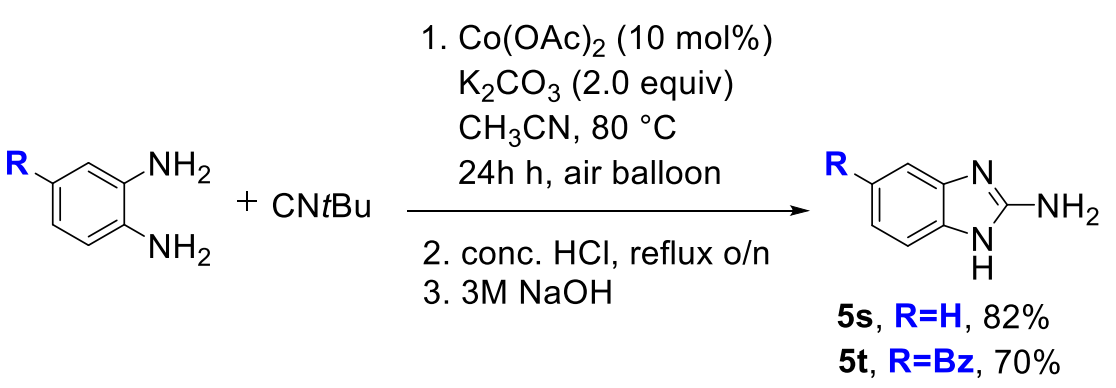

Scheme 3.6. Synthesis of the unsubstituted 2-aminobenzimidazoles $5 \mathrm{~s}$ and $5 \mathrm{t}$ via acid-promoted dealkylation.

Finally, we applied this sequence to the synthesis of 5t (Scheme 3.6), an important precursor for accessing antiparasitic small molecule mebendazole and antivirus drug enviroxime. Our method allows access to $\mathbf{5 t}$ in a convenient two-step synthesis from orthodiaminobenzophenone and tert-butyl isonitrile in $70 \%$ yield. Then we attempted to convert this intermediate to mebendazole by selective acylation of amino group. However, the journey towards this small molecule synthesis led to unexpected challenges. When $\mathbf{5 t}$ was treated with dimethyl dicarbonate and triethylamine under the conventional amino group protection conditions, we didn't observe the generation of mebendazole resulting from the $\mathrm{NH}_{2}$-functionalization (Scheme 3.7). We also attempted the $\mathrm{Cu}$-mediated cross-coupling reaction between 2-amino-5-benzoyl benzimidazole and methyl-chloroformate, ${ }^{133}$ and no desired product was detected under the referred reaction condition. More interestingly, when chloroformate was acting as a coupling partner under varied reaction conditions, ${ }^{134}$ it consistently generated a mixture of compounds from two distinct $\mathrm{N}$-substitutions (For more details regarding this reaction, see the Experimental Section 3.4.8), demonstrating these structural isomers are more thermodynamically favorable under these reaction conditions. 


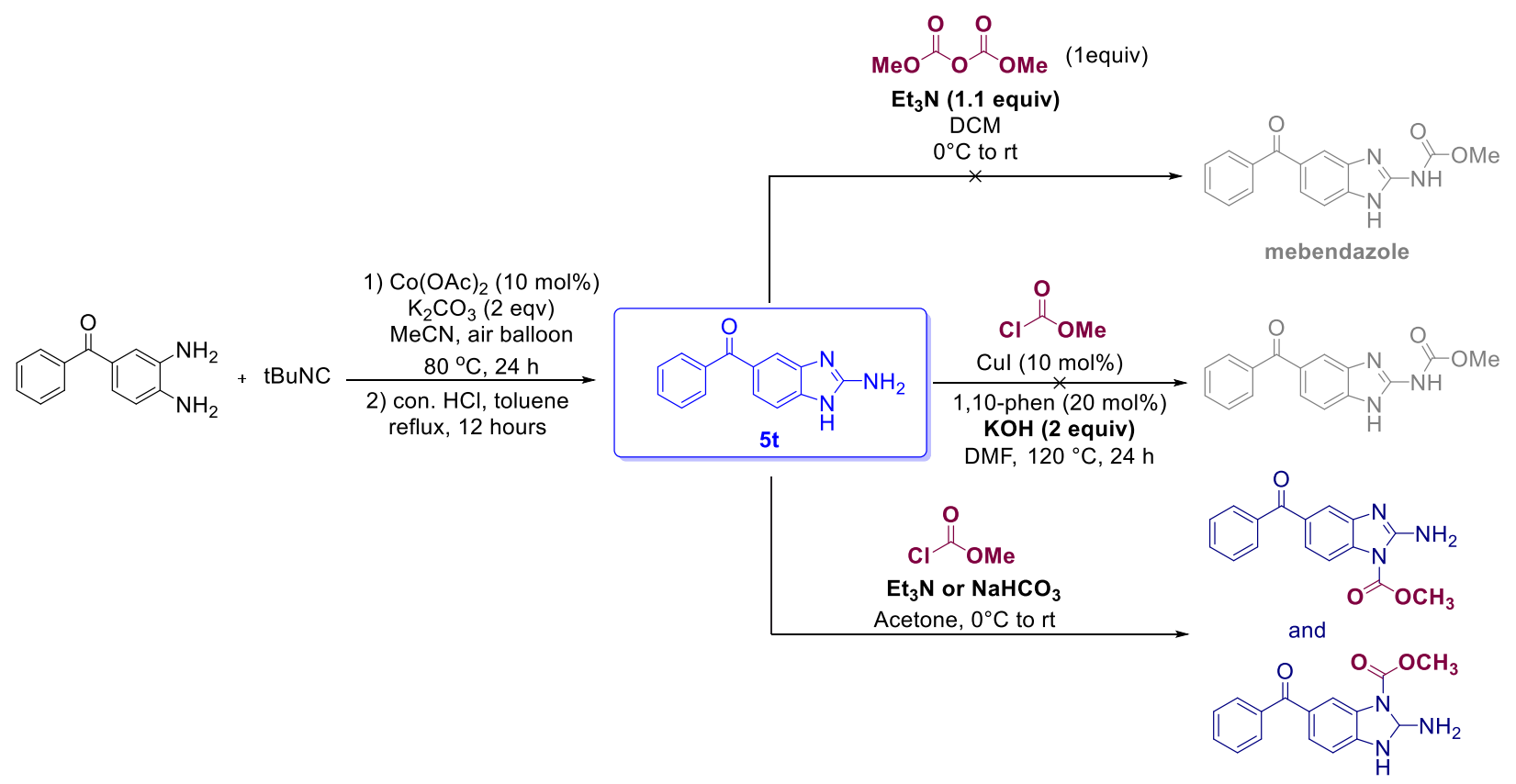

Scheme 3.7. Attempted synthesis of mebendazole from 2 -amino-5-benzoyl-1H-benzimidazole $\mathbf{5 t}$ under varied reaction conditions.

More endeavors have been made towards a forced base-promoted rearrangement for mebendazole synthesis from the mixture of the structural isomers; however, only starting materials were recovered under the reflux condition for a few hours, suggesting mebendazole isomers are thermodynamically stable and harsher reaction conditions might be required. To track the poor regioselectivity of this transformation, we found support from the literature that the transformation of 2-amino-5-benzoyl benzimidazole to mebendazole can be quite complicated (Scheme 3.8). ${ }^{128}$ The reaction effectiveness is highly dependent on the choice of solvent and $\mathrm{pH}$ value of the reaction mixture. With methyl chloroformate as a coupling partner, the reaction generated exclusively mono-acylated or di-acylated product when acetone or chloroform were employed as a solvent. When the reaction was performed in $\mathrm{pH} 7.8$ environment, a distinct di-acylated product was formed. Although it is suggested mebendazole could be eventually generated through methanolysis (for di-acylated regio-isomer) or base promoted rearrangement (for mono-acylated isomer), we unfortunately didn't generate mebendazole successfully following these protocols. However, we are optimistic that through a thorough tuning of reaction conditions or broad screening, an ideal regioselectivity could be expected, and our protocol of generating 2-aminobenzimidazoles though two-step sequence will provide access to a variety of other 2-aminobenzimidazole substructures that are biologically important. 


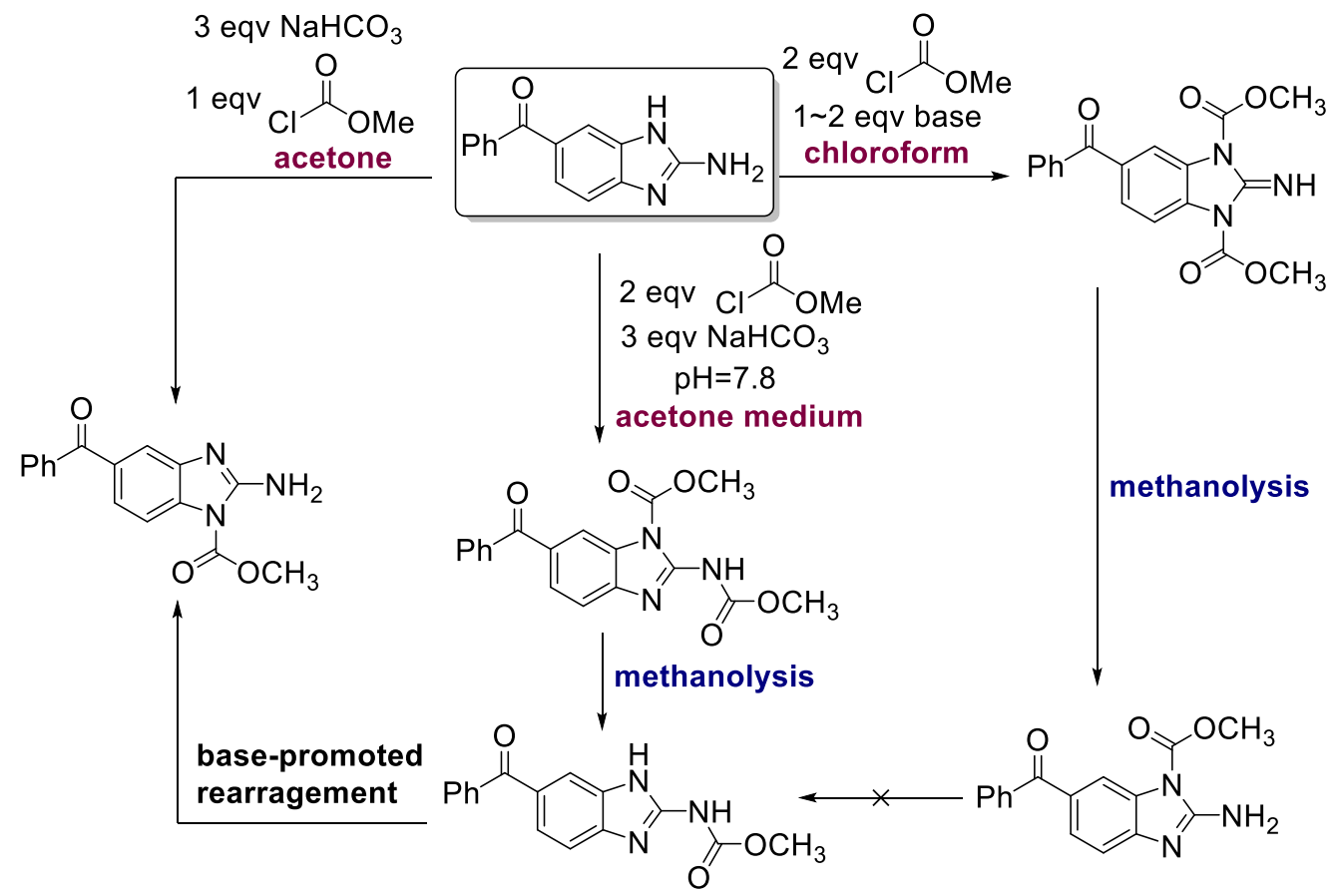

Scheme 3.8. Synthesis of mebendazole from the 2-amino-5-benzoyl benzimidazole in literature.

\subsubsection{Radical Trapping Experiments for the Standard Reaction}

In our previous studies on the oxidative cyclization of ortho-aminophenols with isonitriles, ${ }^{126}$ we found the reaction to proceed through a pathway involving initial oxidation of an aminophenol-coordinated cobalt(II) species by $\mathrm{O}_{2}$ to generate a semiquinoato-type intermediate. ${ }^{70}$ Due to the ligand stabilization, these radical intermediates were not trappable with common radical trapping agents. In this study, similarly, no trappable free radicals are observed under the current reaction conditions. When the standard reaction was conducted in the presence of TEMPO, no radical trapped products were obtained, and we observed no significant decrease in the yield of benzimidazole product. Similarly, the incorporation of 1,1-diphenylethylene into the reaction system led to no observation of the radical trapped intermediates. Except for $24 \%$ recovery of the starting material, there was no drastic changes in the yield of benzimidazole (Scheme 3.9). 


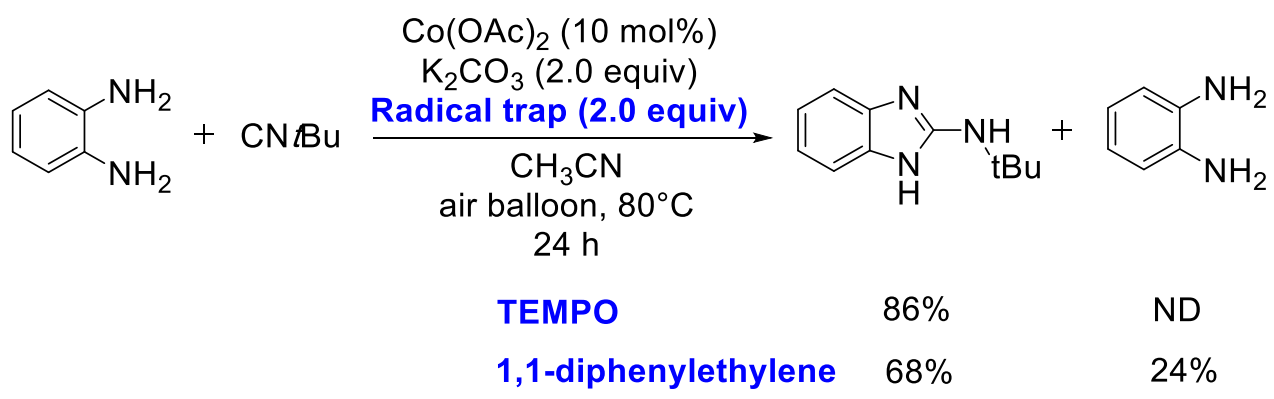

Scheme 3.9. Control experiments with TEMPO and 1,1-diphenylethylene as radical trapping agents.

\subsection{Conclusive Summary}

In summary, we have described a new cobalt-catalyzed oxidative cyclization of orthophenylenediamines with isonitriles to generate the substituted 2-aminobenzimidazoles. This catalytic reaction is efficient under simple and mild ligand-free conditions. It also provides access to the unsubstituted 2-aminobenzimidazoles from an acid-promoted dealkylation of the 2-(tertbutylamino)-benzimidazoles. This route affords structures that can serve as important intermediates in the synthesis of pharmaceutically valuable small molecules.

\subsection{Experimental Section}

\subsubsection{General Considerations}

${ }^{1} \mathrm{H}$, and ${ }^{13} \mathrm{C}\left\{{ }^{1} \mathrm{H}\right\}$ NMR spectra were recorded on an Agilent $400 \mathrm{MHz}$ spectrometer or a JEOL $400 \mathrm{MHz}$ spectrometer. Chemical shifts are given in parts per million and referenced to the residual solvent signal, ${ }^{135}$ all coupling constants are reported in Hz. High resolution mass spectra were obtained on a Thermo Finnigan Linear Trapping Quadrupole mass spectrometer. IR spectra were recorded on a PerkinElmer (Spectrum 100) FT-IR spectrometer. Column chromatography was performed using Silicycle SiliaFlash P60 silica gel.

Dry solvents were taken from a solvent system which passes the solvent through a column of activated molecular sieves. All deuterated solvents were purchased from Cambridge Isotope 
Laboratories. All other chemicals were purchased from commercial sources and used without further purification unless otherwise noted. Air to fill air balloons was obtained from a house compressed air system. $\mathrm{O}_{2}$ used in control reactions was purchased from Airgas. Both air and $\mathrm{O}_{2}$ sources were used as received without drying tubes or additional precautions to remove trace water.

\subsubsection{Optimization of the Reaction Condition}

General Procedure for Screening of Reaction Conditions. ortho-Phenylenediamine (32.4 mg, $0.300 \mathrm{mmol})$ and a cobalt(II) source $(0.03 \mathrm{mmol}, 10 \mathrm{~mol} \%)$ were combined in a 6-inch test tube in a $\mathrm{N}_{2}$ filled glovebox. A base ( 2 equiv, $0.6 \mathrm{mmol}$ ) was added in some instances. Solvent ( $3 \mathrm{~mL}$ ) and tert-butylisonitrile $(35.2 \mu \mathrm{L}, 0.3 \mathrm{mmol}$ ) were added and the test tube was sealed with a septum before being removed from the glovebox. Upon removal, an air balloon attached to a needle was inserted through the septum and the reaction mixture was then stirred for 24 hours at 65 or $80{ }^{\circ} \mathrm{C}$ in an oil bath. Upon completion, the reaction mixture was cooled to room temperature and passed through a pad of Celite via vacuum filtration. The resulting Celite cake was washed with ethyl acetate $(\sim 50 \mathrm{~mL})$, the filtrate was collected and concentrated by rotary evaporation to $3 \mathrm{~mL}$, then

passed through a silica gel plug Pasteur pipette and rinsed with ethyl acetate $(\sim 10 \mathrm{~mL})$. The filtrate was collected and the solvent was removed by rotary evaporation. Dimethyl sulfone (3.00 mg, $0.0318 \mathrm{mmol}$ ) was added as an internal standard and the crude mixture was dissolved in DMSO$d_{6}$ for ${ }^{1} \mathrm{H}$ NMR analysis. The reaction yield was determined by ${ }^{1} \mathrm{H}$ NMR spectroscopy. 
Table 3.4. Optimization of the cobalt source in the oxidative cyclization of orthophenylenediamine and tert-butylisonitrile. ${ }^{a}$

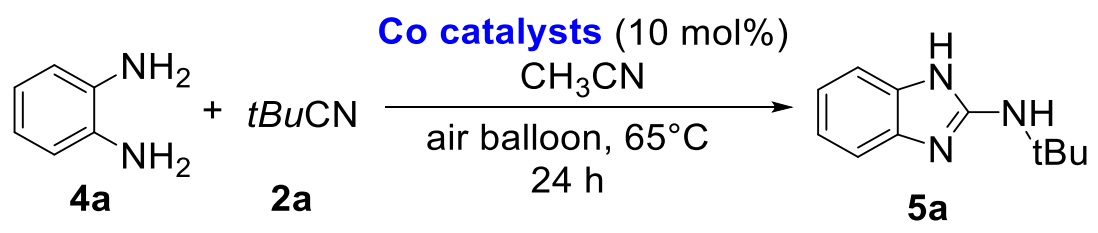

\begin{tabular}{ccc}
\hline Entry & Co Catalyst & \% Yield \\
\hline 1 & $\mathrm{CoCO}_{3}$ & $<5$ \\
2 & $\mathrm{Co}(\mathrm{acac})_{2}$ & 41 \\
3 & $\mathrm{Co}(\mathrm{OAc})_{2}$ & 69 \\
4 & $\mathrm{CoCl}_{2}$ & $<5$ \\
5 & $\mathrm{CoCO}_{3} \cdot \mathrm{H}_{2} \mathrm{O}$ & $<5$ \\
\hline
\end{tabular}

${ }^{a}$ Reaction conditions: $4 \mathbf{a}(0.300 \mathrm{mmol}), \mathbf{2 a}(0.300 \mathrm{mmol})$, cobalt catalyst $(0.030 \mathrm{mmol}), \mathrm{CH}_{3} \mathrm{CN}$ $(3.00 \mathrm{~mL})$, with an air balloon at $65{ }^{\circ} \mathrm{C}$ for $24 \mathrm{~h}$. The yields of $\mathbf{5 a}$ were determined by ${ }^{1} \mathrm{H} \mathrm{NMR}$ spectroscopy with dimethyl sulfone as internal standard $(0.0300 \mathrm{mmol})$.

Table 3.5. Optimization of the solvent in the oxidative cyclization of ortho-phenylenediamine and tert-butylisonitrile. ${ }^{a}$
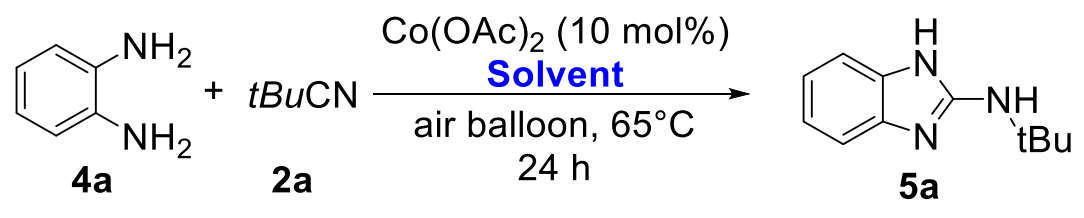

\begin{tabular}{ccc}
\hline Entry & Solvent & \% Yield \\
\hline 1 & $\mathrm{CH}_{3} \mathrm{CN}$ & 69 \\
2 & 1,4-dioxane & 61 \\
3 & $\mathrm{Me}-\mathrm{THF}$ & 69 \\
4 & $\mathrm{THF}$ & 54 \\
5 & $\mathrm{DMF}$ & 23 \\
\hline
\end{tabular}

${ }^{a}$ Reaction conditions: $4 \frac{5}{4}(0.300 \mathrm{mmol}), \mathbf{2 a}(0.300 \mathrm{mmol}), \mathrm{Co}(\mathrm{OAc})_{2}(0.030 \mathrm{mmol})$, solvent $(3.00$ $\mathrm{mL}$ ), with an air balloon at $65{ }^{\circ} \mathrm{C}$ for $24 \mathrm{~h}$. The yields of $\mathbf{5 a}$ were determined by ${ }^{1} \mathrm{H}$ NMR spectroscopy with dimethyl sulfone as internal standard $(0.0300 \mathrm{mmol})$. 
Table 3.6. Optimization of the base in the oxidative cyclization of ortho-phenylenediamine and tert-butylisonitrile. $^{a}$

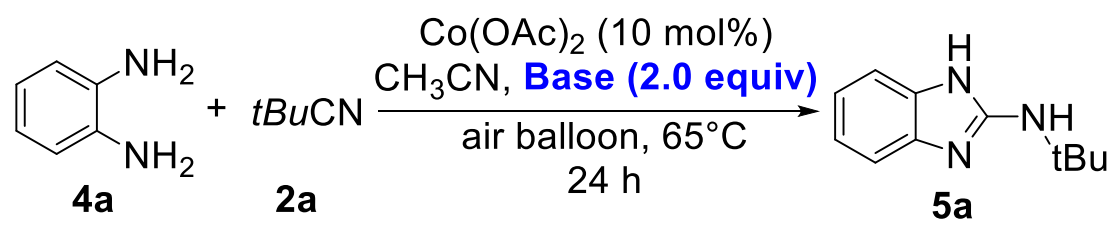

\begin{tabular}{ccc}
\hline Entry & Base & \% Yield \\
\hline 1 & $\mathrm{LiOAc}$ & 65 \\
2 & $\mathrm{NaOAc}$ & 62 \\
3 & $\mathrm{KOAc}$ & 82 \\
4 & $\mathrm{Li}_{2} \mathrm{CO}_{3}$ & 67 \\
5 & $\mathrm{Na}_{2} \mathrm{CO}_{3}$ & 79 \\
6 & $\mathrm{~K}_{2} \mathrm{CO}_{3}$ & 85 \\
\hline
\end{tabular}

${ }^{a}$ Reaction conditions: $\mathbf{4 a}(0.300 \mathrm{mmol}), \mathbf{2 a}(0.300 \mathrm{mmol}), \mathrm{Co}(\mathrm{OAc})_{2}(0.030 \mathrm{mmol}), \mathrm{CH}_{3} \mathrm{CN}(3.00$ $\mathrm{mL})$, base $(0.600 \mathrm{mmol})$ with an air balloon at $65{ }^{\circ} \mathrm{C}$ for $24 \mathrm{~h}$. The yields of $5 \mathrm{a}$ were determined by ${ }^{1} \mathrm{H}$ NMR spectroscopy with dimethyl sulfone as internal standard $(0.0300 \mathrm{mmol})$.

Table 3.7. Optimization of the temperature in the oxidative cyclization of ortho-phenylenediamine and tert-butylisonitrile. ${ }^{a}$

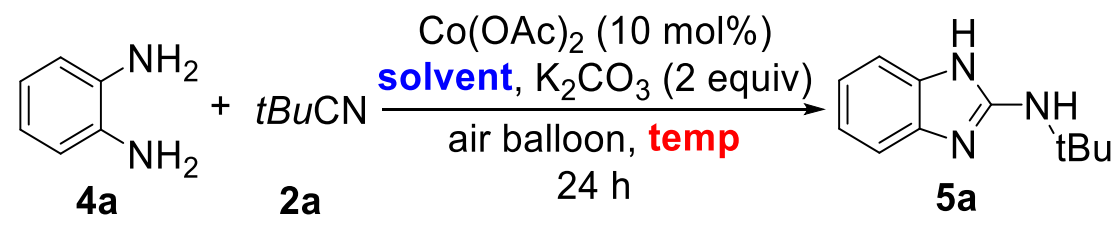

\begin{tabular}{cccc}
\hline Entry & Solvent & Temp $\left({ }^{\circ} \mathbf{C}\right)$ & \% Yield \\
\hline 1 & $\mathrm{CH}_{3} \mathrm{CN}$ & 65 & 85 \\
2 & $\mathrm{CH}_{3} \mathrm{CN}$ & 80 & 95 \\
3 & $\mathrm{Me}-\mathrm{THF}$ & 80 & 78 \\
\hline
\end{tabular}

${ }^{a}$ Reaction conditions: $4 \mathbf{a}(0.300 \mathrm{mmol}), \mathbf{2 a}(0.300 \mathrm{mmol}), \mathrm{Co}(\mathrm{OAc})_{2}(0.030 \mathrm{mmol})$, solvent $(3.00$ $\mathrm{mL}$ ), $\mathrm{K}_{2} \mathrm{CO}_{3}$ (2 equiv) with an air balloon at $65{ }^{\circ} \mathrm{C}$ or $80^{\circ} \mathrm{C}$ for $24 \mathrm{~h}$. The yields of $5 \mathbf{a}$ were determined by ${ }^{1} \mathrm{H}$ NMR spectroscopy with dimethyl sulfone as internal standard $(0.0300 \mathrm{mmol})$. 


\subsubsection{Reaction Parameter Assessment}

To assess the sensitivity of the reaction to different parameters, a set of control experiments were conducted according to the work reported by Glorius and coworkers. ${ }^{127}$ In each experiment only a single parameter is varied while all others are held constant. In our study, the following parameters were varied: oxygen concentration, base loading, catalyst loading, reaction concentration and reaction temperature as described in Table 3.8 below. Each reaction was conducted according to the standard procedure described below with the exception of the parameter being tested. For each reaction the yield of 5a was quantified by ${ }^{1} \mathrm{H}$ NMR spectroscopy. The deviation from the standard conditions was calculated in order to provide the visual colorcoded radar diagram shown in Figure 3.4. For a given parameter, the proximity of the line to the perimeter indicates the significance of the parameter, or the reactions sensitivity to the parameter.

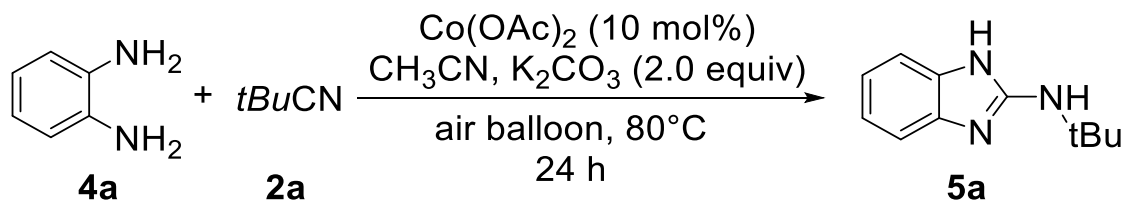

Conditions for reaction parameter assessment. $o$-phenylenediamine $(0.3 \mathrm{mmol})$, tert-butyl isocyanide (0.3 mmol), $\mathrm{Co}(\mathrm{OAc})_{2}(0.03 \mathrm{mmol}), \mathrm{K}_{2} \mathrm{CO}_{3}(0.6 \mathrm{mmol}), \mathrm{MeCN}(3 \mathrm{~mL}), 80^{\circ} \mathrm{C}, 24$ hours. Due to the limited solubility of $\mathrm{Co}(\mathrm{OAc})_{2}$ and $\mathrm{K}_{2} \mathrm{CO}_{3}$ in $\mathrm{MeCN}$, and volatility of the isonitrile, stock solutions were not prepared. All components of the reaction mixtures with varied parameters were independently weighed. All experiments were set up according to the standard procedure unless otherwise indicated. 
Table 3.8. Conditions used for reaction parameter assessment.

\begin{tabular}{|c|c|c|c|}
\hline Entry & \multicolumn{2}{|c|}{ Evaluated Parameter } & Reaction prep and setup \\
\hline 1 & \multirow{2}{*}{$\mathrm{O}_{2}$ content } & inert atmosphere & $\mathrm{N}_{2}$ atmosphere $^{1}$ \\
\hline 2 & & pure $\mathrm{O}_{2}$ atmosphere & $\mathrm{O}_{2}$ balloon $^{2}$ \\
\hline 3 & \multirow{2}{*}{ base } & base free & 0 equiv of base \\
\hline 4 & & high base loading & 4 equiv of base \\
\hline 5 & \multirow{2}{*}{ catalyst } & low catalyst loading & $5 \mathrm{~mol} \%$ of $\mathrm{Co}(\mathrm{OAc})_{2}$ \\
\hline 6 & & high catalyst loading & $20 \mathrm{~mol} \%$ of $\mathrm{Co}(\mathrm{OAc})_{2}$ \\
\hline 7 & \multirow{2}{*}{ concentration } & low concentration & with $6.0 \mathrm{~mL} \mathrm{MeCN}$ \\
\hline 8 & & high concentration & with $1.5 \mathrm{~mL} \mathrm{MeCN}$ \\
\hline 9 & \multirow{2}{*}{ temperature } & low heating temperature & $65^{\circ} \mathrm{C}$ \\
\hline 10 & & room temperature & room temperature \\
\hline 11 & control & standard rea & $\mathrm{n}$ conditions \\
\hline
\end{tabular}

${ }^{1}$ The reaction was set up in a $25 \mathrm{~mL}$ Schlenk tube with Schlenk line technique. See the inert atmosphere procedure below for the detailed description. ${ }^{2}$ The reaction was set up in a $25 \mathrm{~mL}$ Schlenk tube with an $\mathrm{O}_{2}$ balloon attached to a needle inserted through the septum. See the $\mathrm{O}_{2}$ atmosphere procedure below for the detailed description.

Procedure for reaction parameter assessment ortho-Phenylenediamine ( $32.4 \mathrm{mg}, 0.300 \mathrm{mmol})$ and a cobalt(II) acetate $(5 \mathrm{~mol} \%, 10 \mathrm{~mol} \%$ or $20 \mathrm{~mol} \%$ ) were combined in a 6 -inch test tube in a $\mathrm{N}_{2}$ filled glovebox. $\mathrm{K}_{2} \mathrm{CO}_{3}$ ( 0 equiv, 2 equiv, or 4 equiv) was added to the same test tube. $\mathrm{CH}_{3} \mathrm{CN}$ $(1.5 \mathrm{~mL}, 3 \mathrm{~mL}$ or $6 \mathrm{~mL})$ and tert-butylisonitrile $(35.2 \mu \mathrm{L}, 0.300 \mathrm{mmol})$ were added and the test tube was sealed with a septum before being removed from the glovebox. Upon removal, an air balloon attached to a needle was inserted through the septum and the reaction mixture was then stirred for 24 hours at room temperature, 65 or $80^{\circ} \mathrm{C}$ in an oil bath. Upon completion, the reaction mixture was cooled to room temperature and passed through a pad of Celite via vacuum filtration. The resulting Celite cake was washed with ethyl acetate $(\sim 50 \mathrm{~mL})$, the filtrate was collected and concentrated by rotary evaporation to $3 \mathrm{~mL}$, then passed through a silica gel plug Pasteur pipette and rinsed with ethyl acetate $(\sim 10 \mathrm{~mL})$. The filtrate was collected and the solvent was removed by rotary evaporation. Dimethyl sulfone $(3.00 \mathrm{mg}, 0.0318 \mathrm{mmol})$ was added as an internal standard and the crude mixture was dissolved in DMSO- $d_{6}$ for ${ }^{1} \mathrm{H}$ NMR analysis. The reaction yield was determined by ${ }^{1} \mathrm{H}$ NMR spectroscopy. 


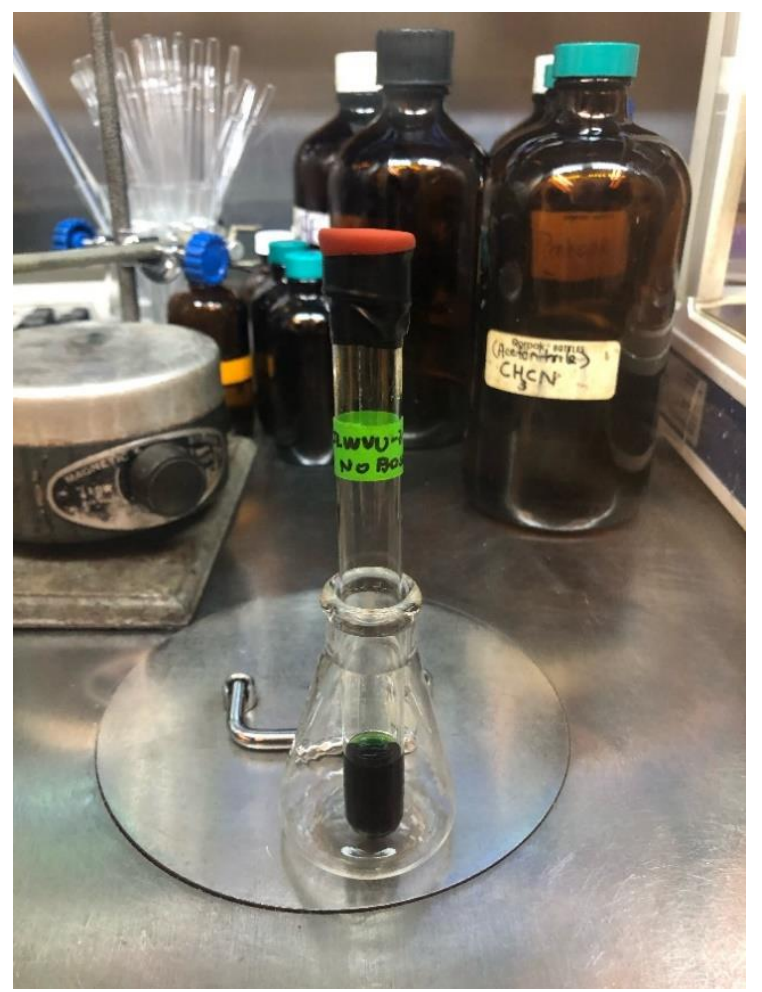

(a)

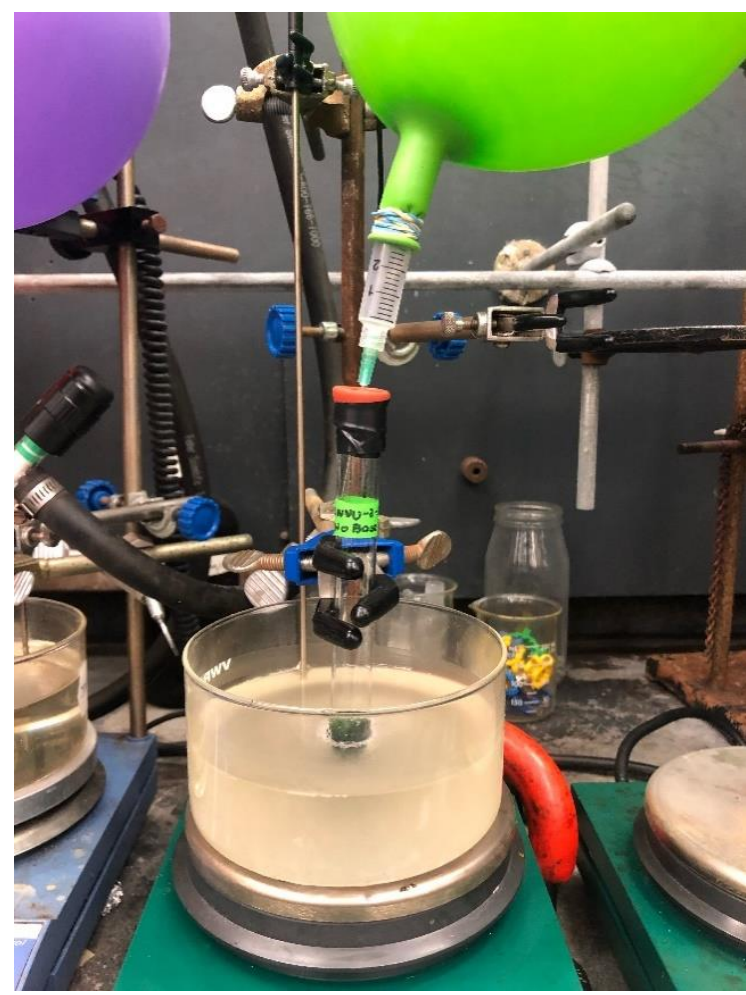

(b)

Figure 3.2. Reaction set up for parameter assessment studies. (a) Preparation of the reaction mixture inside the glovebox. (b) Final reaction setup inside a fume hood with an air balloon.

Procedure for inert atmosphere reaction (Entry 1 in Table 3.8). To a $25 \mathrm{~mL}$ Schlenk tube equipped with a stir bar, ortho-phenylenediamine $(32.4 \mathrm{mg}, 0.300 \mathrm{mmol}), \mathrm{Co}(\mathrm{OAc})_{2}(5.31 \mathrm{mg}$, $0.0300 \mathrm{mmol}), \mathrm{K}_{2} \mathrm{CO}_{3}(82.9 \mathrm{mg}, 0.600 \mathrm{mmol})$ were combined. The tube was then evacuated and backfilled with $\mathrm{N}_{2}$ three times. Dry $\mathrm{CH}_{3} \mathrm{CN}(3 \mathrm{~mL})$ and tert-butylisonitrile $(35.2 \mu \mathrm{L}, 0.300 \mathrm{mmol})$ were added under $\mathrm{N}_{2}$ atmosphere and the reaction mixture was stirred in a $80{ }^{\circ} \mathrm{C}$ oil bath for 24 hours. Upon completion, the reaction mixture was cooled to room temperature and passed through a pad of Celite via vacuum filtration. The resulting Celite cake was washed with ethyl acetate $(\sim$ $50 \mathrm{~mL}$ ), the filtrate was collected and concentrated by rotary evaporation to $3 \mathrm{~mL}$, then passed through a silica gel plug Pasteur pipette and rinsed with ethyl acetate $(\sim 10 \mathrm{~mL})$. The filtrate was collected and the solvent was removed by rotary evaporation. Dimethyl sulfone $(3.00 \mathrm{mg}, 0.0318$ mmol) was added as an internal standard and the crude mixture was dissolved in DMSO- $d_{6}$ for ${ }^{1} \mathrm{H}$ NMR analysis. The reaction yield was determined by ${ }^{1} \mathrm{H}$ NMR spectroscopy. 
Procedure for the $\mathrm{O}_{2}$ atmosphere reaction (Entry 2 in Table 3.8). To a $25 \mathrm{~mL}$ Schlenk tube equipped with a stir bar, ortho-phenylenediamine $(32.4 \mathrm{mg}, 0.300 \mathrm{mmol}), \mathrm{Co}(\mathrm{OAc})_{2}(5.31 \mathrm{mg}$, $0.0300 \mathrm{mmol}), \mathrm{K}_{2} \mathrm{CO}_{3}(82.9 \mathrm{mg}, 0.600 \mathrm{mmol})$ were combined. The tube was then evacuated and backfilled with $\mathrm{O}_{2}$ three times using a $\mathrm{O}_{2}$ balloon. The side arm of the Schlenk tube was sealed and an $\mathrm{O}_{2}$ balloon attached to a needled was balloon inserted through the septum. Dry $\mathrm{CH}_{3} \mathrm{CN}$ (3 $\mathrm{mL})$ and tert-butylisonitrile $(35.2 \mu \mathrm{L}, 0.300 \mathrm{mmol})$ were then added and the reaction mixture was stirred in an $80{ }^{\circ} \mathrm{C}$ oil bath for 24 hours. Upon completion, the reaction mixture was cooled to room temperature and passed through a pad of Celite via vacuum filtration. The resulting Celite cake was washed with ethyl acetate $(\sim 50 \mathrm{~mL})$, the filtrate was collected and concentrated by rotary evaporation to $3 \mathrm{~mL}$, then passed through a silica gel plug Pasteur pipette and rinsed with ethyl acetate $(\sim 10 \mathrm{~mL})$. The filtrate was collected and the solvent was removed by rotary evaporation. Dimethyl sulfone $(3.00 \mathrm{mg}, 0.0318 \mathrm{mmol})$ was added as an internal standard and the crude mixture was dissolved in DMSO- $d_{6}$ for ${ }^{1} \mathrm{H}$ NMR analysis. The reaction yield was determined by ${ }^{1} \mathrm{H}$ NMR spectroscopy.

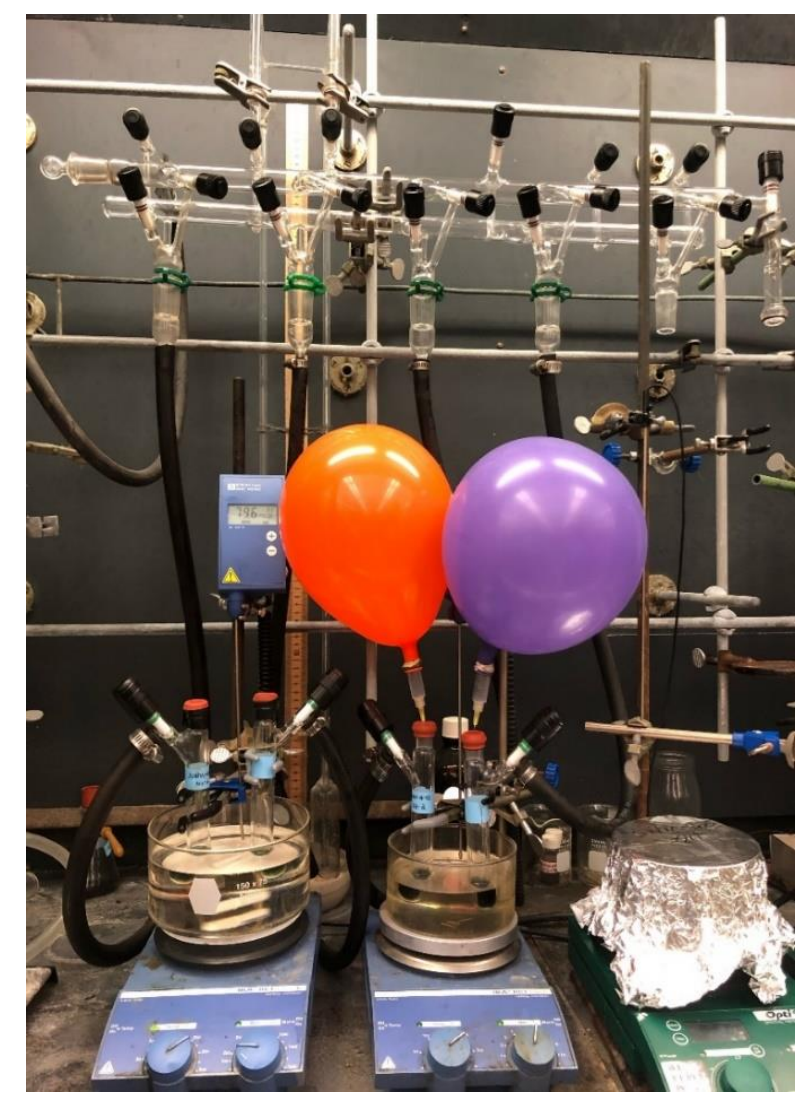

Figure 3.3. Reaction setup under $\mathrm{N}_{2}$ atmosphere (left side) and $\mathrm{O}_{2}$ atmosphere (right side, stopcocks are closed). 
Table 3.9. Results of Parameter Assessment of the Standard Reaction.

\begin{tabular}{|c|c|c|c|c|c|c|}
\hline Entry & \multicolumn{2}{|c|}{ Evaluated Parameter } & $\underset{(\%)}{\operatorname{Run} 1}$ & $\underset{(\%)}{\operatorname{Run} 2}$ & $\begin{array}{l}\text { Average } \\
\% \text { Yield }\end{array}$ & $\begin{array}{c}\% \\
\text { Deviation }\end{array}$ \\
\hline 1 & \multirow{2}{*}{$\mathrm{O}_{2}$ content } & inert atmosphere & 9 & 11 & 10 & -89 \\
\hline 2 & & pure $\mathrm{O}_{2}$ atmosphere & 94 & 97 & 96 & 1 \\
\hline 3 & \multirow{2}{*}{ base } & Base free & 67 & 67 & 67 & -29 \\
\hline 4 & & high base loading & 92 & 90 & 91 & -4 \\
\hline 5 & \multirow{2}{*}{ catalyst } & low catalyst loading & 67 & 66 & 67 & -29 \\
\hline 6 & & high catalyst loading & 92 & 92 & 92 & -3 \\
\hline 7 & \multirow{2}{*}{ concentration } & low concentration & 86 & 87 & 87 & -8 \\
\hline 8 & & high concentration & 93 & 89 & 91 & -4 \\
\hline 9 & \multirow[t]{2}{*}{ temperature } & $\begin{array}{l}\text { low heating } \\
\text { temperature }\end{array}$ & 83 & 86 & 85 & -11 \\
\hline 10 & & room temperature & 37 & 37 & 37 & -62 \\
\hline 11 & control & $\begin{array}{c}\text { standard reaction } \\
\text { condition }\end{array}$ & 95 & 95 & 95 & $\mathbf{0}$ \\
\hline
\end{tabular}

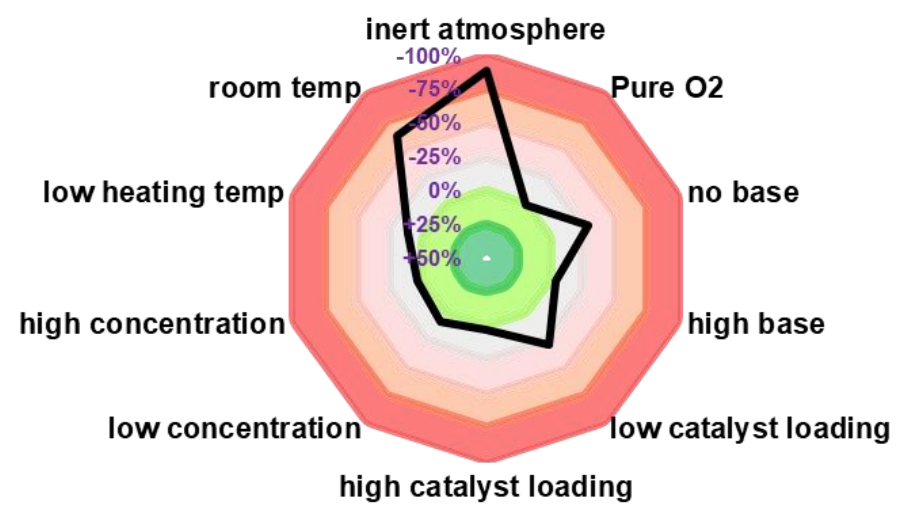

Figure 3.4. Radar diagram generated from parameter assessment data shown in Table 3.9.

The radar diagram indicates the high sensitivity of the standard reaction to an inert atmosphere. Base loading and reaction temperature are also critical factors in influencing the yield of the product $\mathbf{5 a}$. 


\subsubsection{Alternative Reaction Setups}

Our parameter assessment studies revealed that the standard reaction proceeds efficiently in the presence of a sufficient supply of oxygen. For example, with air as the source of oxygen the reaction yields $95 \%$ of $\mathbf{5 a}$, while with an $\mathrm{O}_{2}$ balloon $96 \%$ yield of $\mathbf{5 a}$ is obtained. Thus, it is possible that the transformation proceeds smoothly in the absence of an air balloon with a headspace filled with air. To test the efficacy of this protocol, we used a sealed $125 \mathrm{~mL}$ pressure tube as the vessel for the reaction instead of using our standard 6-inch test tube fitted with an air balloon.

Sealed Reaction Vessel. To a $125 \mathrm{~mL}$ pressure tube equipped with a stir bar, orthophenylenediamine ( $32.4 \mathrm{mg}, 0.300 \mathrm{mmol}), \mathrm{Co}(\mathrm{OAc})_{2}(5.31 \mathrm{mg}, 0.0300 \mathrm{mmol}), \mathrm{K}_{2} \mathrm{CO}_{3}(82.9 \mathrm{mg}$, $0.600 \mathrm{mmol})$ were combined in the open air. Dry $\mathrm{CH}_{3} \mathrm{CN}(3 \mathrm{~mL})$ and tert-butylisonitrile $(35.2 \mu \mathrm{L}$, $0.300 \mathrm{mmol}$ ) were added, the pressure tube was sealed and the reaction mixture was stirred in an $80^{\circ} \mathrm{C}$ oil bath for 24 hours. Upon completion, the reaction mixture was cooled to room temperature and passed through a pad of Celite via vacuum filtration. The resulting Celite cake was washed with ethyl acetate $(\sim 50 \mathrm{~mL})$, the filtrate was collected and concentrated by rotary evaporation to $3 \mathrm{~mL}$, then passed through a silica gel plug Pasteur pipette and rinsed with ethyl acetate $(\sim 10 \mathrm{~mL})$. The filtrate was collected, and the solvent was removed by rotary evaporation. Dimethyl sulfone (3.00 $\mathrm{mg}, 0.0318 \mathrm{mmol}$ ) was added as an internal standard and the crude mixture was dissolved in DMSO- $d_{6}$ for ${ }^{1} \mathrm{H}$ NMR analysis. The reaction gave $95.9 \%$ of the desired product indicating the efficiency of the transformation in a sealed vessel with only a headspace of air. 


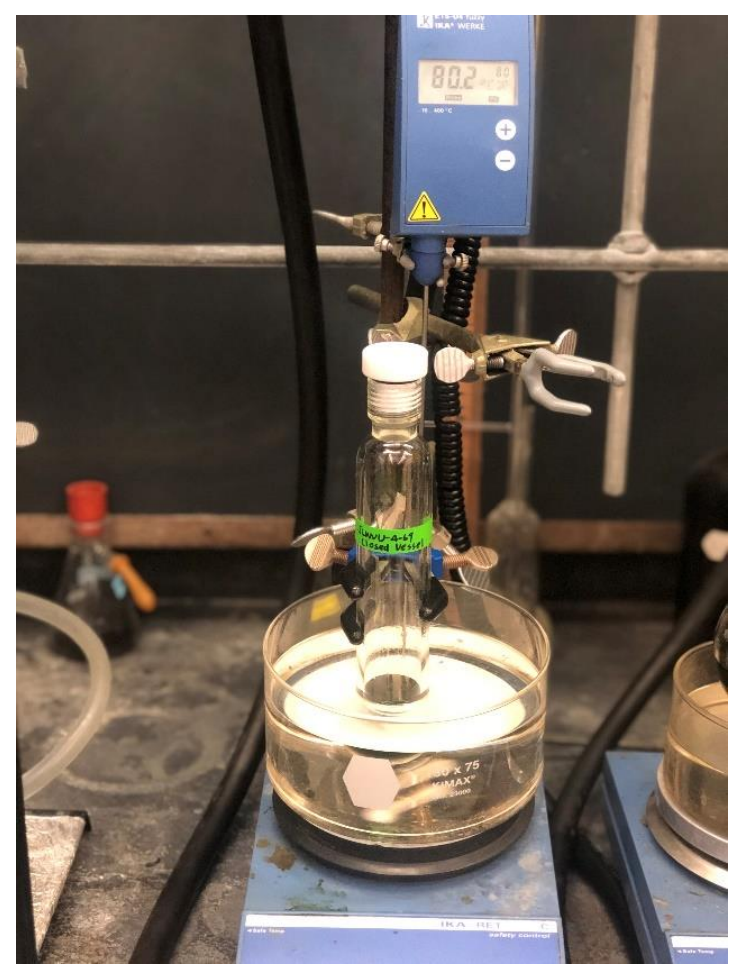

Figure 3.5. Reaction setup using a pressure tube with a headspace filled with air.

The reaction also proceeds smoothly using standard Schlenk technique with reagents stores in a benchtop dessicator without need for a glovebox.

Benchtop Procedure. To an oven-dried $25 \mathrm{~mL}$ Schlenk tube equipped with a stir bar, orthophenylenediamine (32.4 mg, $0.300 \mathrm{mmol}), \mathrm{Co}(\mathrm{OAc})_{2}(5.31 \mathrm{mg}, 0.0300 \mathrm{mmol}), \mathrm{K}_{2} \mathrm{CO}_{3}(82.9 \mathrm{mg}$, $0.600 \mathrm{mmol}$ ) were combined. The tube was connected to the Schlenk line via the sidearm and was evacuated and backfilled with an air balloon three times. The side arm valve was then closed and an air balloon attached to a needle was inserted through the septum. Dry $\mathrm{CH}_{3} \mathrm{CN}(3 \mathrm{~mL})$ and tertbutylisonitrile $(35.2 \mathrm{~mL}, 0.300 \mathrm{mmol})$ were added and the reaction mixture was stirred in an $80{ }^{\circ} \mathrm{C}$ oil bath for 24 hours. Upon completion, the reaction mixture was cooled to room temperature and passed through a pad of Celite via vacuum filtration. The resulting Celite cake was washed with ethyl acetate $(\sim 50 \mathrm{~mL})$, the filtrate was collected and concentrated by rotary evaporation to $3 \mathrm{~mL}$, then passed through a silica gel plug Pasteur pipette and rinsed with ethyl acetate $(\sim 10 \mathrm{~mL})$. The filtrate was collected and the solvent was removed by rotary evaporation. Dimethyl sulfone (3.00 $\mathrm{mg}, 0.0318 \mathrm{mmol}$ ) was added as an internal standard and the crude mixture was dissolved in 
DMSO- $d_{6}$ for ${ }^{1} \mathrm{H}$ NMR analysis. The reaction yield was determined by ${ }^{1} \mathrm{H}$ NMR spectroscopy to be $95.9 \%$ (average of two independent reaction yields).

\subsubsection{Synthesis and Characterization of 2-Aminobenzimidazoles (5) and Other Reaction Products (6)}

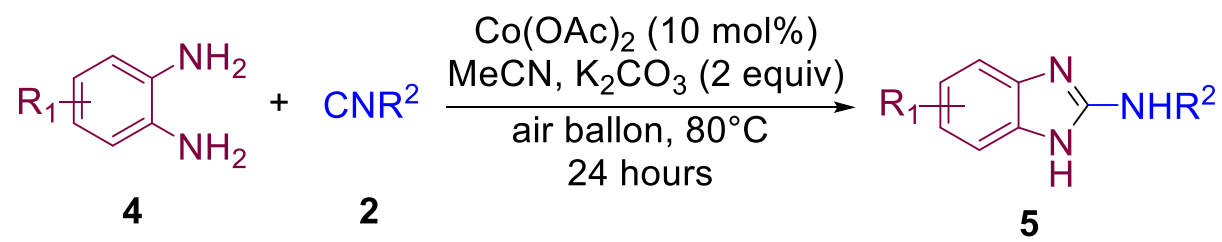

\section{Representative Procedure for the Synthesis of 2-Aminobenzimidazoles (5)}

Ortho-phenylenediamine (32.4 mg, $0.300 \mathrm{mmol}), \mathrm{Co}(\mathrm{OAc})_{2}(5.31 \mathrm{mg}, 0.0300 \mathrm{mmol}, 10$ mol \%), and $\mathrm{K}_{2} \mathrm{CO}_{3}(82.9 \mathrm{mg}, 0.600 \mathrm{mmol})$ were combined in a 6-inch test tube in an $\mathrm{N}_{2}$ filled glovebox. $\mathrm{CH}_{3} \mathrm{CN}(3 \mathrm{~mL})$ and tert-butylisonitrile $(34.2 \mathrm{~mL}, 0.300 \mathrm{mmol})$ were added and the test tube was sealed with a septum before being removed from the glovebox. Upon removal, an air balloon attached to a needle was inserted through the septum and the reaction mixture was then stirred for 24 hours at 65 or $80^{\circ} \mathrm{C}$ in an oil bath. Upon completion, the reaction mixture was cooled to room temperature and passed through a pad of Celite via vacuum filtration. The resulting Celite cake was washed with ethyl acetate $(\sim 50 \mathrm{~mL})$, the filtrate was collected and concentrated by rotary evaporation to $3 \mathrm{~mL}$, then passed through a silica gel plug Pasteur pipette and rinsed with ethyl acetate $(\sim 10 \mathrm{~mL})$. The solvent was removed by rotary evaporation again. The residue was purified by silica column chromatography (98:2 EtOAc:MeOH). All 2-aminobenzimidazole compounds (5) were prepared following the standard procedure unless otherwise noted.<smiles>CC(C)(C)Nc1nc2ccccc2[nH]1</smiles>

$5 a$

2-(tert-butylamino)-benzimidazole (5a). The title compound was synthesized according to the standard procedure and purified by silica column chromatography (98:2 EtOAc: $\mathrm{MeOH}, \mathrm{R}_{f}=0.20$ in 80:15:5 $\mathrm{CHCl}_{3}$ : EtOAc: $\left.\mathrm{MeOH}\right)$ to yield $52.6 \mathrm{mg}(0.278 \mathrm{mmol}, 92.8 \%$ yield $)$ of the title compound as a light-yellow solid $\left(\mathrm{mp}=217-220{ }^{\circ} \mathrm{C}\right) .{ }^{1} \mathrm{H}$ NMR $\left(400 \mathrm{MHz}, \mathrm{DMSO}-d_{6}\right): \delta=10.19$ (s, 1H), $7.15(\mathrm{dd}, \mathrm{J}=5.7,3.2 \mathrm{~Hz}, 2 \mathrm{H}), 6.85$ (dd, J = 5.7, $3.2 \mathrm{~Hz}, 2 \mathrm{H}), 6.18(\mathrm{~s}, 1 \mathrm{H}), 1.42(\mathrm{~s}, 9 \mathrm{H})$. 
${ }^{13} \mathrm{C}$ NMR (100 MHz, DMSO- $\left.d_{6}\right): \delta=154.11,119.05,111.77,50.69,29.09$. FTIR (ATR, $\mathrm{cm}^{-1}$ ): 3428 (w), 3058 (w), 2960 (w), 2868 (w), 2673 (w), 1554 (s), 1481 (m), 1465 (m), 1455 (m), 1414 (m), 1391 (m), 1362 (m), 1265 (m), 1204 (s), 1069 (m), 1008 (m), 923 (m), 865 (m), 839 (m), 760 (m), 734 (s). HRMS (ESI-MS, m/z) $[\mathrm{M}+\mathrm{H}]^{+}$calcd for $\mathrm{C}_{11} \mathrm{H}_{16} \mathrm{~N}_{3}$ 190.1337; found 190.1339. The spectral data are consistent with those reported in the literature. ${ }^{57}$

1.0 Gram Scale Reaction. Upon scaling the reaction, the product yield is reduced, likely due to inefficient gas-liquid mixing. Due to the limited solubility of $\mathrm{Co}(\mathrm{OAc})_{2}$ in $\mathrm{CH}_{3} \mathrm{CN}$ under the large scale reaction conditions, a mixed solvent system was used to enhance the solubility of $\mathrm{Co}(\mathrm{OAc})_{2}$. To an oven-dried $250 \mathrm{~mL}$ round-bottom flask equipped with a stir bar, $o$-phenylenediamine $(1.00 \mathrm{~g}$, $9.25 \mathrm{mmol}), \mathrm{Co}(\mathrm{OAc})_{2}(163.7 \mathrm{mg}, 0.925 \mathrm{mmol})$ and $\mathrm{K}_{2} \mathrm{CO}_{3}(2.56 \mathrm{~g}, 18.5 \mathrm{mmol})$ were combined.

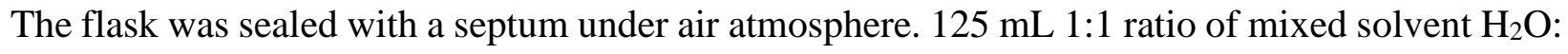
$\mathrm{CH}_{3} \mathrm{CN}$ was added. With stirring, tert-butyl isocyanide $(1.05 \mathrm{~mL}, 9.25 \mathrm{mmol})$ was added dropwise. The reaction mixture was allowed to stir in an $80^{\circ} \mathrm{C}$ oil bath for 48 hours under aerobic atmosphere with two air balloons inserted through the septum. Upon completion of the reaction, the reaction mixture was cooled down to room temperature and $\mathrm{CH}_{3} \mathrm{CN}$ were removed via rotary evaporation. The remaining mixture was partitioned in $100 \mathrm{~mL}$ ethyl acetate and stirred with 3 M EDTA (100 $\mathrm{mL})$ up to 12 hours. The aqueous layer was separated and extracted with ethyl acetate $(2 \times 50 \mathrm{~mL})$. The combined organic phase was washed with brine, separated, dried over anhydrous $\mathrm{MgSO}_{4}$, filtered and concentrated via rotary evaporation to generate the crude product as a dark brown solid. The product was purified by column chromatography (gradient elution from pure chloroform to 97:3 $\left.\mathrm{CHCl}_{3}: \mathrm{MeOH}\right)$ to yield $377 \mathrm{mg}(1.99 \mathrm{mmol}, 21.5 \%)$ of the desired product as a brown solid.<smiles>Cc1ccc2nc(NC(C)(C)C)[nH]c2c1</smiles>

$5 \mathbf{b}$

2-(tert-butylamino)-5-methylbenzimidazole (5b). The title compound was synthesized according to the standard procedure and purified by silica column chromatography $\left(97: 1: 2 \mathrm{CHCl}_{3}\right.$ : $\mathrm{MeOH}: \mathrm{Et}_{3} \mathrm{~N}, \mathrm{R}_{f}=0.2$ in the same solvent) to yield $58.8 \mathrm{mg}(0.289 \mathrm{mmol}, 96.4 \%$ yield $)$ of the title compound as a brown oil. ${ }^{1} \mathrm{H}$ NMR $\left(400 \mathrm{MHz}, \mathrm{CDCl}_{3}\right): \delta=10.64(\mathrm{~s}, 1 \mathrm{H}), 7.17(\mathrm{~d}, J=7.9 \mathrm{~Hz}$, 1H), $7.10(\mathrm{~s}, 1 \mathrm{H}), 6.84(\mathrm{~d}, J=7.9 \mathrm{~Hz}, 1 \mathrm{H}), 5.64$ (s, 1H), 2.35 (s, 3H), 1.37 (s, 9H). ${ }^{13} \mathrm{C}$ NMR (100 
$\left.\mathrm{MHz}, \mathrm{CDCl}_{3}\right): \delta=153.81,136.91,134.85,130.50,121.82,112.40,111.75,51.78,29.58,21.61$. FTIR (ATR, cm ${ }^{-1}$ ): 3277 (w), 2969 (w), 1634 (m), 1596 (m), 1568 (s), 1488 (m), 1459 (m), 1392 (m), 1364 (m), 1273 (m), 1215 (s), 1143 (w), 1034 (w), 956 (w), 938 (w), 861 (w), 802 (m), 750 (s), 665 (s). HRMS (ESI-MS, m/z) $[\mathrm{M}+\mathrm{H}]^{+}$calcd for $\mathrm{C}_{12} \mathrm{H}_{18} \mathrm{~N}_{3}$ 204.1494; found 204.1495. The spectral data are consistent with those reported in the literature. ${ }^{57}$<smiles>CC(C)(C)Nc1nc2ccc(C(C)(C)C)cc2[nH]1</smiles>

2-(tert-butylamino)-5-tert-butylbenzimidazole $(\mathbf{5 c})$. The title compound was synthesized according to the standard procedure and purified by silica column chromatography (95:2:3 EtOAc: MeOH: $\mathrm{Et}_{3} \mathrm{~N}, \mathrm{R}_{f}=0.5$ in 98:2 EtOAc: $\left.\mathrm{MeOH}\right)$ to yield $68.3 \mathrm{mg}(0.278 \mathrm{mmol}, 92.6 \%$ yield $)$ of the title compound as a dark brown oil. ${ }^{1} \mathrm{H}$ NMR $\left(400 \mathrm{MHz}, \mathrm{CDCl}_{3}\right): \delta=8.76(\mathrm{~s}, 1 \mathrm{H}), 7.35(\mathrm{~s}, 1 \mathrm{H})$, $7.22(\mathrm{~d}, J=7.9 \mathrm{~Hz}, 1 \mathrm{H}), 7.08(\mathrm{~d}, J=7.4 \mathrm{~Hz}, 1 \mathrm{H}), 5.29(\mathrm{~s}, 1 \mathrm{H}), 1.40(\mathrm{~s}, 9 \mathrm{H}), 1.32(\mathrm{~s}, 9 \mathrm{H}) .{ }^{13} \mathrm{C}$ NMR $\left(100 \mathrm{MHz}, \mathrm{CDCl}_{3}\right): \delta=154.57,143.75,137.61,135.61,117.80,111.45,109.01,51.51,34.68$, 32.01, 29.61. FTIR (ATR, $\mathrm{cm}^{-1}$ ): 3393 (w), 3310 (w), 3086 (w), 2961 (m), 2867 (m), 1636 (m), 1596 (m), 1567 (s), 1486 (m), 1435 (m), 1391 (m), 1273 (m), 1216 (s), 1134 (w), 1086 (w), 1050 (w), 1024 (m), 934 (w), 870 (w), 811 (m), 752 (s). HRMS (ESI-MS, m/z) [M+H] ${ }^{+}$calcd for $\mathrm{C}_{15} \mathrm{H}_{24} \mathrm{~N}_{3}$ 246.1964; found 246.1965.<smiles>COc1ccc2nc(NC(C)(C)C)[nH]c2c1</smiles>

2-(tert-butylamino)-5-methoxybenzimidazole (5d). The title compound was synthesized according to the standard procedure and purified by silica column chromatography (100:20:10 $\mathrm{CHCl}_{3}$ : EtOAc: $\mathrm{MeOH}, \mathrm{R}_{f}=0.15$ in the same solvent system) to yield $41.3 \mathrm{mg}(0.188 \mathrm{mmol}, 62.8 \%$ yield) of the title compound as a brown oil. ${ }^{1} \mathrm{H}$ NMR $\left(400 \mathrm{MHz}, \mathrm{CDCl}_{3}\right): \delta=8.85(\mathrm{~s}, 1 \mathrm{H}), 7.16(\mathrm{~d}$, $J=7.7 \mathrm{~Hz}, 1 \mathrm{H}), 6.87(\mathrm{~s}, 1 \mathrm{H}), 6.63(\mathrm{~d}, J=7.6 \mathrm{~Hz}, 1 \mathrm{H}), 6.17(\mathrm{~s}, 1 \mathrm{H}), 3.72(\mathrm{~s}, 3 \mathrm{H}), 1.39(\mathrm{~s}, 9 \mathrm{H}) .{ }^{13} \mathrm{C}$ $\operatorname{NMR}\left(100 \mathrm{MHz}, \mathrm{CDCl}_{3}\right): \delta=155.58,153.08,136.61,129.61,112.09,108.63,97.69,56.03,52.06$, 29.52. FTIR (ATR, $\mathrm{cm}^{-1}$ ): 3299 (w), 3085 (w), 2964 (m), 1636 (m), 1601 (m), 1567 (s), 1486 (s), 1446 (s), 1391 (m), 1364 (m), 1302 (m), 1261 (m), 1194 (s), 1152 (s), 1024 (s), 958 (m), 788 (s). 
HRMS (ESI-MS, m/z) [M+H] $]^{+}$calcd for $\mathrm{C}_{12} \mathrm{H}_{18} \mathrm{~N}_{3} \mathrm{O} 220.1443$; found 220.1444. The spectral data are consistent with those reported in the literature. ${ }^{57}$<smiles>CC(C)(C)Nc1nc2ccc(Br)cc2[nH]1</smiles>

$5 e$

2-(tert-butylamino)-5-bromobenzimidazole (5e). The title compound was synthesized according to the standard procedure and purified by silica column chromatography (95:2:3 EtOAc: $\mathrm{MeOH}: \mathrm{Et}_{3} \mathrm{~N}, \mathrm{R}_{f}=0.7$ in 98:2 EtOAc: $\mathrm{MeOH})$ to yield $63.0 \mathrm{mg}(0.226 \mathrm{mmol}, 75.4 \%$ yield $)$ of the title compound as a yellow brown solid $\left(\mathrm{mp}=152-155{ }^{\circ} \mathrm{C}\right) .{ }^{1} \mathrm{H}$ NMR $\left(400 \mathrm{MHz}, \mathrm{CDCl}_{3}\right): \delta=8.73(\mathrm{~s}, 1 \mathrm{H}), 7.37(\mathrm{~s}, 1 \mathrm{H}), 7.08(\mathrm{~s}, 2 \mathrm{H})$, $5.26(\mathrm{~s}, 1 \mathrm{H}), 1.41(\mathrm{~s}, 9 \mathrm{H}) .{ }^{13} \mathrm{C} \mathrm{NMR}\left(100 \mathrm{MHz}, \mathrm{CDCl}_{3}\right): \delta=154.72,139.63,136.62,123.07,115.24,112.95$, 51.71, 29.55. FTIR (ATR, cm ): 3322 (w), 3073 (w), 2967 (m), 1630 (m), 1592 (m), 1565 (s), 1462 (s), 1392 (m), 1365 (m), 1341 (w), 1267 (m), 1215 (s), 1048 (m), 1023 (m), 1006 (m), 950 (m), 908 (m), 852 (w), $801(\mathrm{~m}), 753$ (m), 677 (m). HRMS (ESI-MS, m/z) [M+H] $]^{+}$calcd for $\mathrm{C}_{11} \mathrm{H}_{15} \mathrm{~N}_{3} \mathrm{Br}$ 268.0452; found 268.0444. The spectral data are consistent with those reported in the literature. ${ }^{57}$<smiles>CC(C)(C)Nc1nc2ccc(Cl)cc2[nH]1</smiles>

2-(tert-butylamino)-5-chlorobenzimidazole (5f). The title compound was synthesized according to the standard procedure and purified by silica column chromatography $\left(98: 2: 0.3 \mathrm{CHCl}_{3}: \mathrm{MeOH}\right.$ : $\mathrm{Et}_{3} \mathrm{~N}, \mathrm{R}_{f}=0.5$ in 96:4:0.3 $\left.\mathrm{CHCl}_{3}: \mathrm{MeOH}: \mathrm{Et}_{3} \mathrm{~N}\right)$ to yield $54.5 \mathrm{mg}(0.244 \mathrm{mmol}, 81.2 \%$ yield $)$ of the title compound as a dark yellow solid $\left(\mathrm{mp}=178-181{ }^{\circ} \mathrm{C}\right) .{ }^{1} \mathrm{H}$ NMR $\left(400 \mathrm{MHz}\right.$, DMSO- $\left.d_{6}\right): \delta$ $=7.17(\mathrm{~s}, 1 \mathrm{H}), 7.12(\mathrm{~d}, J=8.2 \mathrm{~Hz}, 1 \mathrm{H}), 6.85(\mathrm{~d}, J=8.1 \mathrm{~Hz}, 1 \mathrm{H}), 6.47(\mathrm{~s}, 1 \mathrm{H}), 1.40(\mathrm{~s}, 9 \mathrm{H}) .{ }^{13} \mathrm{C}$ NMR (100 MHz, DMSO- $\left.d_{6}\right): \delta=154.92,123.30,118.63,111.90,50.77,28.94$. FTIR (ATR, $\mathrm{cm}^{-}$ 1): 3441 (w), 3074 (w), 2975 (w), 1634 (m), 1595 (s), 1567 (s), 1467 (s), 1441 (s), 1392 (m), 1364 (m), 1269 (m), 1213 (s), 1060 (s), 953 (m), 924 (m), 859 (m), 792 (s), 696 (s). HRMS (ESI-MS, $\mathrm{m} / \mathrm{z})[\mathrm{M}+\mathrm{H}]^{+}$calcd for $\mathrm{C}_{11} \mathrm{H}_{15} \mathrm{ClN}_{3} 226.0920$, found 226.0922. The spectral data are consistent with those reported in the literature. ${ }^{57}$ 
$\overbrace{\mathrm{H}}^{\mathrm{NH}}$

$5 \mathrm{~g}$

2-(tert-butylamino)-5-fluorobenzimidazole (5g). The title compound was synthesized according to the standard procedure and purified by silica column chromatography $\left(98: 2: 0.3 \mathrm{CHCl}_{3}: \mathrm{MeOH}\right.$ : $\mathrm{Et}_{3} \mathrm{~N}, \mathrm{R}_{f}=0.5$ in 96:4:0.3 $\left.\mathrm{CHCl}_{3}: \mathrm{MeOH}: \mathrm{Et}_{3} \mathrm{~N}\right)$ to yield $50.0 \mathrm{mg}(0.241 \mathrm{mmol}, 80.4 \%$ yield $)$ of the title compound as a beige solid $\left(\mathrm{mp}=203-205{ }^{\circ} \mathrm{C}\right) .{ }^{1} \mathrm{H}$ NMR $\left(400 \mathrm{MHz}, \mathrm{DMSO}-d_{6}\right): \delta=7.05$ $(\mathrm{dd}, J=8.2,5.0 \mathrm{~Hz}, 1 \mathrm{H}), 6.92(\mathrm{~d}, J=9.8 \mathrm{~Hz}, 1 \mathrm{H}), 6.61(\mathrm{t}, J=9.2 \mathrm{~Hz}, 1 \mathrm{H}), 6.39(\mathrm{~s}, 1 \mathrm{H}), 1.37$ (s, 9H). ${ }^{13} \mathrm{C}$ NMR (100 MHz, DMSO- $\left.d_{6}\right): \delta=158.55,156.26,155.03,110.65,105.47,105.23,99.36$, 50.75, 28.97. ${ }^{19} \mathrm{~F}$ NMR (376 MHz, DMSO- $\left.d_{6}\right): \delta=-124.51(\mathrm{~s}, 1 \mathrm{~F})$. FTIR (ATR, $\left.\mathrm{cm}^{-1}\right): 3439(\mathrm{w})$, 3066 (w), 2979 (w), 2928 (w), 2856 (w), 1637 (m), 1581 (s), 1562 (s), $1486(\mathrm{~s}), 1452$ (s), 1403 (s), 1284 (m), 1254 (m), 1206 (s), 1139 (s), 1105 (m), 1068 (m), 968 (m), 947 (m), 836 (s), 791 (s), 714 (s). HRMS (ESI-MS, m/z) $[\mathrm{M}+\mathrm{H}]^{+}$calcd for $\mathrm{C}_{11} \mathrm{H}_{15} \mathrm{FN}_{3} 209.1278$, found 209.1273. The spectral data are consistent with those reported in the literature. ${ }^{57}$<smiles>CC(C)(C)Nc1nc2ccc(C(F)(F)F)cc2[nH]1</smiles>

$5 \mathrm{~h}$

2-(tert-butylamino)-5-trifluoromethylbenzimidazole $(\mathbf{5 h})$. The title compound was synthesized according to the standard procedure and purified by silica column chromatography (98:2:0.3 $\mathrm{CHCl}_{3}: \mathrm{MeOH}: \mathrm{Et}_{3} \mathrm{~N}, \mathrm{R}_{f}=0.4$ in 96:4:0.3 $\left.\mathrm{CHCl}_{3}: \mathrm{MeOH}: \mathrm{Et}_{3} \mathrm{~N}\right)$ to yield $40.2 \mathrm{mg}(0.156 \mathrm{mmol}$, $52.1 \%$ yield $)$ of the title compound as a dark yellow solid $\left(\mathrm{mp}=166-168{ }^{\circ} \mathrm{C}\right) .{ }^{1} \mathrm{H} \mathrm{NMR}(400 \mathrm{MHz}$, $\left.\mathrm{CD}_{3} \mathrm{OD}\right): \delta=7.44(\mathrm{~s}, 1 \mathrm{H}), 7.27(\mathrm{~d}, J=8.2 \mathrm{~Hz}, 1 \mathrm{H}), 7.21(\mathrm{~d}, J=8.3 \mathrm{~Hz}, 1 \mathrm{H}), 1.45(\mathrm{~s}, 9 \mathrm{H}) .{ }^{13} \mathrm{C}$ NMR (100 MHz, Methanol- $\left.d_{4}\right): \delta=156.85,126.79$ (q, $\left.J=269 \mathrm{~Hz}\right), 123.14$ (q, $\left.J=32 \mathrm{~Hz}\right), 118.18$ $(\mathrm{q}, J=4.0 \mathrm{~Hz}), 115.71,112.38,109.77,52.15,29.52 .{ }^{19} \mathrm{~F}$ NMR $\left(376 \mathrm{MHz}\right.$, Methanol- $\left.d_{4}\right): \delta=-$ 61.82 (s, 3F). FTIR (ATR, cm): 3405 (w), 3082 (w), 2974 (w), 2936 (w), 1637 (m), 1575 (s), 1447 (m), 1366 (m), 1325 (s), 1217 (m), 1159 (m), 1112 (s), 1051 (m), 953 (w), 929 (w), 873 (w), $815(\mathrm{w}), 729 \mathrm{w}), 666(\mathrm{w})$. HRMS (ESI-MS, m/z) $[\mathrm{M}+\mathrm{H}]^{+}$calcd for $\mathrm{C}_{12} \mathrm{H}_{15} \mathrm{~F}_{3} \mathrm{~N}_{3}$ calcd for 259.1246, found 259.1239 . 
<smiles>CC(C)(C)Nc1nc2ccc([N+](=O)[O-])cc2[nH]1</smiles>

$5 \mathbf{i}$

2-(tert-butylamino)-5-nitrobenzimidazole (5i). The title compound was synthesized according to the standard procedure and purified by silica column chromatography $\left(96: 4: 0.3 \mathrm{CHCl}_{3}: \mathrm{MeOH}\right.$ : $\mathrm{Et}_{3} \mathrm{~N}, \mathrm{R}_{f}=0.10$ in the same solvent system) to yield $47.1 \mathrm{mg}(0.201 \mathrm{mmol}, 67.0 \%$ yield $)$ of the title compound as a bright yellow solid $\left(\mathrm{mp}=147-149{ }^{\circ} \mathrm{C}\right) .{ }^{1} \mathrm{H}$ NMR $\left(400 \mathrm{MHz}, \mathrm{CD}_{3} \mathrm{OD}\right): \delta=$ 8.05 (s, 1H), $7.98-7.90(\mathrm{~m}, 1 \mathrm{H}), 7.88(\mathrm{~s}, 1 \mathrm{H}), 7.24(\mathrm{~d}, J=8.7 \mathrm{~Hz}, 1 \mathrm{H}), 1.48(\mathrm{~s}, 9 \mathrm{H}) .{ }^{13} \mathrm{C} \mathrm{NMR}$ $\left(100 \mathrm{MHz}, \mathrm{CD}_{3} \mathrm{OD}\right): \delta=158.24,142.63,118.12,112.17,107.87,52.39,29.42$. FTIR (ATR, $\mathrm{cm}^{-}$ 1): 3362 (m), 2968 (m), 2214 (w), 1635 (s), 1602 (s), 1572 (s), 1504 (m), 1470 (s), 1437 (m), 1416 (m), 1392 (m), 1360 (m), 1280 (s), 1258 (s), 1211 (s), 1121 (s), 1048 (s), 932 (s), 871 (s), 809 (m), 729 (s), 687 (s), 662 (s). HRMS (ESI-MS, m/z) [M+H] ${ }^{+}$calcd for $\mathrm{C}_{11} \mathrm{H}_{15} \mathrm{~N}_{4} \mathrm{O}_{2}$ 235.1191; found 235.1190. The spectral data are consistent with those reported in the literature. ${ }^{57}$<smiles>CC(C)(C)Nc1nc2ccc(C#N)cc2[nH]1</smiles>

5j

2-(tert-butylamino)-5-cyanobenzimidazole $(\mathbf{5 j})$. The title compound was synthesized according to the standard procedure and purified by silica column chromatography (100:2:0.3 $\mathrm{CHCl}_{3}: \mathrm{MeOH}$ : $\mathrm{Et}_{3} \mathrm{~N}, \mathrm{R}_{f}=0.1$ in $\left.\mathrm{CHCl}_{3}: \mathrm{MeOH}: \mathrm{Et}_{3} \mathrm{~N}=96: 4: 0.3\right)$ to yield $22.1 \mathrm{mg}(0.103 \mathrm{mmol}, 34.3 \%$ yield) of the title compound as a light brown solid $\left(\mathrm{mp}=185-188{ }^{\circ} \mathrm{C}\right) .{ }^{1} \mathrm{H}$ NMR $\left(400 \mathrm{MHz}, \mathrm{CD}_{3} \mathrm{OD}\right): \delta=$ 7.50 (s, 1H), 7.31 (d, $J=0.8 \mathrm{~Hz}, 2 \mathrm{H}), 1.48$ (s, 9H). ${ }^{13} \mathrm{C}$ NMR (100 MHz, CD $\left.3 \mathrm{OD}\right): \delta=157.06$, 143.21, 138.58, 125.91, 121.56, 115.93, 113.49, 103.08, 52.38, 29.43. FTIR (ATR, $\left.\mathrm{cm}^{-1}\right): 3331(\mathrm{~m})$, 2969 (m), 2931 (m), 2216 (m), 1632 (s), 1591 (s), 1566 (s), 1467 (s), 1445 (s), 1392 (m), 1364 (m), 1281 (s), 1216 (s), 1120 (m), 1055 (m), 959 (m), 938 (m), 866 (m), 811 (s), 755 (m). HRMS (ESIMS, m/z) $[\mathrm{M}+\mathrm{H}]^{+}$calcd for $\mathrm{C}_{12} \mathrm{H}_{15} \mathrm{~N}_{4}$ 215.1292; found 215.1291. The spectral data are consistent with those reported in the literature. ${ }^{57}$ 
<smiles>Cc1cccc2[nH]c(NC(C)(C)C)nc12</smiles>

2-(tert-butylamino)-4-methylbenzimidazole (5k). The title compound was synthesized according to the standard procedure and purified by silica column chromatography $\left(97: 1: 2 \mathrm{CHCl}_{3}\right.$ : $\mathrm{MeOH}: \mathrm{Et}_{3} \mathrm{~N}, \mathrm{R}_{f}=0.15$ in the same solvent system) to yield $45.7 \mathrm{mg}(0.225 \mathrm{mmol}, 74.9 \%$ yield $)$ of the title compound as a dark brown solid $\left(\mathrm{mp}=146-148{ }^{\circ} \mathrm{C}\right) .{ }^{1} \mathrm{H} \mathrm{NMR}\left(400 \mathrm{MHz}, \mathrm{CDCl}_{3}\right): \delta=$ $9.69(\mathrm{~s}, 1 \mathrm{H}), 7.21(\mathrm{~d}, J=7.7 \mathrm{~Hz}, 1 \mathrm{H}), 6.95(\mathrm{t}, J=7.6 \mathrm{~Hz}, 1 \mathrm{H}), 6.86(\mathrm{~d}, J=7.4 \mathrm{~Hz}, 1 \mathrm{H}), 5.38$ (s, 1H), 2.41 (s, 3H), 1.40 (s, 9H). ${ }^{13} \mathrm{C}$ NMR (100 MHz, $\left.\mathrm{CDCl}_{3}\right): \delta=154.02,139.55,134.15,121.56$, 120.87, 120.59, 111.28, 51.69, 29.73, 17.00. FTIR (ATR, $\mathrm{cm}^{-1}$ ): 3386 (w), 3060 (w), 2968 (m), 2163 (w), 2050 (w), 1981 (w), 1627 (s), 1610 (s), 1563 (s), 1491 (m), 1457 (s), 1391 (m), 1363 (s), 1273 (s), 1216 (s), 1160 (m), 1085 (m), 1033 (m), 948 (m), 866 (w), 776 (s), 739 (s). HRMS (ESIMS, m/z) $[\mathrm{M}+\mathrm{H}]^{+}$calcd for $\mathrm{C}_{12} \mathrm{H}_{18} \mathrm{~N}_{3}$ 204.1495; found 204.1495. The spectral data are consistent with those reported in the literature. ${ }^{57}$<smiles>CC(C)(C)Nc1nc2c(Br)cccc2[nH]1</smiles>

5I

2-(tert-butylamino)-7-bromobenzimidazole (5l). The title compound was synthesized according to the standard procedure and purified by silica column chromatography (96: $4: 0.3 \mathrm{CHCl}_{3}: \mathrm{MeOH}$ : $\mathrm{Et}_{3} \mathrm{~N}, \mathrm{R}_{f}=0.15$ in the same solvent system) to yield $70.3 \mathrm{mg}(0.262 \mathrm{mmol}, 87.4 \%$ yield $)$ of the title compound as a dark brown solid $\left(\mathrm{mp}=158-160{ }^{\circ} \mathrm{C}\right) .{ }^{1} \mathrm{H} \mathrm{NMR}\left(400 \mathrm{MHz}, \mathrm{CDCl}_{3}\right): \delta=9.57$ (s, 1H), $7.25(\mathrm{~d}, J=7.2 \mathrm{~Hz}, 1 \mathrm{H}), 7.16(\mathrm{~d}, J=7.8 \mathrm{~Hz}, 1 \mathrm{H}), 6.90$ (t, $J=7.8 \mathrm{~Hz}, 1 \mathrm{H}), 5.22(\mathrm{~s}, 1 \mathrm{H})$, 1.40 (s, 9H). ${ }^{13} \mathrm{C} \mathrm{NMR}\left(100 \mathrm{MHz}, \mathrm{CDCl}_{3}\right): \delta=154.11,140.10,135.88,123.22,121.93,112.40$, 103.94, 51.95, 29.78. FTIR (ATR, cm ${ }^{-1}$ ): 3394 (w), 2968 (m), 1628 (m), 1586 (s), 1565 (s), 1459 (m), 1433 (s), 1392 (m), 1364 (s), 1268 (s), 1214 (s), 1182 (s), 1138 (m), 1044 (m), 930 (m), 77 (s), 730 (s). HRMS (ESI-MS, m/z) $[\mathrm{M}+\mathrm{H}]^{+}$calcd for $\mathrm{C}_{11} \mathrm{H}_{15} \mathrm{~N}_{3} \mathrm{Br} 268.0448$; found 268.0444. 


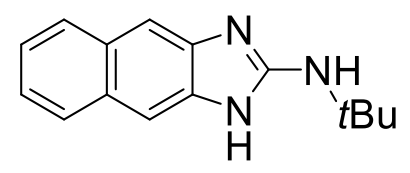

$5 m$

2-(tert-butylamino)-naphtho[2,3-d]imidazole $\mathbf{( 5 m )}$. The title compound was synthesized according to the standard procedure and purified by silica column chromatography $\left(80: 15: 5 \mathrm{CHCl}_{3}\right.$ : EtOAc: $\mathrm{MeOH}, \mathrm{R}_{f}=0.15$ in the same solvent system) to yield $45.3 \mathrm{mg}(0.189 \mathrm{mmol}, 63.1 \%$ yield $)$ of the title compound as a dark brown solid $\left(\mathrm{mp}=100-102{ }^{\circ} \mathrm{C}\right) .{ }^{1} \mathrm{H}$ NMR $\left(400 \mathrm{MHz}, \mathrm{CDCl}_{3}\right): \delta=$ $9.76(\mathrm{~s}, 1 \mathrm{H}), 7.73(\mathrm{~d}, J=2.4 \mathrm{~Hz}, 2 \mathrm{H}), 7.63(\mathrm{~s}, 2 \mathrm{H}), 7.29$ (d, $J=2.9 \mathrm{~Hz}, 2 \mathrm{H}), 6.31(\mathrm{~s}, 1 \mathrm{H}), 1.42$ (s, 9H). $\left.{ }^{13} \mathrm{C} \mathrm{NMR} \mathrm{(100} \mathrm{MHz,} \mathrm{CDCl}_{3}\right): \delta=155.83,137.49,130.04,127.39,123.54,107.57,52.10$, 29.50. FTIR (ATR, cm ${ }^{-1}$ ): 3386 (w), 3054 (w), 2968 (m), 2930 (w), 1651 (m), 1601 (s), 1567 (s), 1463 (m), 1447 (s), 1425 (s), 1392 (m), 1334 (m), 1260 (s), 1207 (s), 1113 (m), 1058 (w), 1034 (w), 944 (m), 852 (s), 783 (m), 742 (s). HRMS (ESI-MS, m/z) [M+H] $]^{+}$calcd for $\mathrm{C}_{15} \mathrm{H}_{18} \mathrm{~N}_{3}$ 240.1494; found 240.1495 .

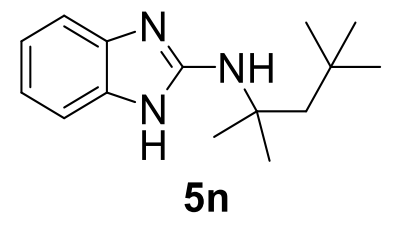

2-(1,1,3,3-tetramethylbutylamino)benzimidazole (5n). The title compound was synthesized according to the standard procedure and purified by silica column chromatography (96: 4: 0.3 $\mathrm{CHCl}_{3}$ : $\mathrm{MeOH}: \mathrm{Et}_{3} \mathrm{~N}, \mathrm{R}_{f}=0.15$ in the same solvent system to yield $61.8 \mathrm{mg}(0.252 \mathrm{mmol}, 84.0 \%$ yield) of the title compound as a dark brown solid ( $\left.\mathrm{mp}=143-146{ }^{\circ} \mathrm{C}\right) .{ }^{1} \mathrm{H} \mathrm{NMR}\left(400 \mathrm{MHz}, \mathrm{CDCl}_{3}\right)$ : $\delta=10.71=(\mathrm{s}, 1 \mathrm{H}), 7.31(\mathrm{~s}, 2 \mathrm{H}), 7.04(\mathrm{~s}, 2 \mathrm{H}), 5.47(\mathrm{~s}, 1 \mathrm{H}), 1.73(\mathrm{~s}, 2 \mathrm{H}), 1.48(\mathrm{~s}, 6 \mathrm{H}), 0.90(\mathrm{~s}, 9 \mathrm{H})$. ${ }^{13} \mathrm{C}$ NMR $\left(100 \mathrm{MHz}, \mathrm{CDCl}_{3}\right): \delta=153.61,136.83,120.85,112.09,55.66,52.67,31.69,31.56$, 29.82. FTIR (ATR, cm): 3394 (w), 3060 (w), 2951 (m), 1629 (m), 1599 (m), 1564 (s), 1462 (s), 1421 (m), 1386 (m), 1364 (m), 1271 (m), 1247 (m), 1222 (s), 1150 (m), 1060 (w), 1008 (m), 955 (w), 800 (w), 735 (s). HRMS (ESI-MS, m/z) [M+H] $]^{+}$calcd for $\mathrm{C}_{15} \mathrm{H}_{24} \mathrm{~N}_{3}$ 246.1964; found 246.1965 . 


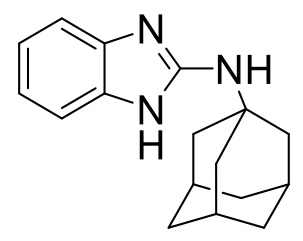

50

2-(1-admantylamino)benzimidazole (5o). The title compound was synthesized according to the standard procedure and purified by silica column chromatography (95:2:3 EtOAc: $\mathrm{MeOH}: \mathrm{Et}_{3} \mathrm{~N}$, $\mathrm{R}_{f}=0.4$ in $98: 2$ EtOAc: $\left.\mathrm{MeOH}\right)$ to yield $58.3 \mathrm{mg}(0.235 \mathrm{mmol}, 78.2 \%$ yield $)$ of the title compound as a dark reddish-maroon solid $\left(\mathrm{mp}=220-222{ }^{\circ} \mathrm{C}\right) .{ }^{1} \mathrm{H}$ NMR $\left(400 \mathrm{MHz}\right.$, DMSO- $\left.d_{6}\right): \delta=10.13(\mathrm{~s}$, 1H), 7.13 (s, 2H), 6.83 (s, 2H), 6.05 (s, 1H), 2.07 (s, 9H), 1.66 (s, 6H). ${ }^{13} \mathrm{C}$ NMR (100 MHz, DMSO): $\delta=153.57,118.97,111.71,50.82,41.61,36.09,29.05$. FTIR $\left(\right.$ ATR, $\left.\mathrm{cm}^{-1}\right): 3386(\mathrm{w}), 3059(\mathrm{w})$, 2904 (s), 2850 (m), 1627 (m), 1600 (m), 1567 (s), 1462 (s), 1398 (w), 1358 (s), 1342 (m), 1264 (s), 1139 (m), 1049 (m), 935 (m), 815 (m), 756 (s), 665 (m). HRMS (ESI-MS, m/z) [M+H] calcd for $\mathrm{C}_{17} \mathrm{H}_{22} \mathrm{~N}_{3} 268.1807$; found 268.1808 . The spectral data are consistent with those reported in the literature. ${ }^{136}$

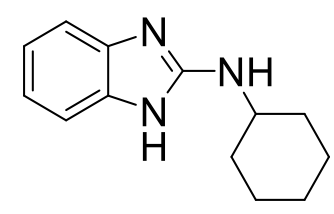

$5 p$

2-(cyclohexylamino)benzimidazole (5p). The title compound was synthesized according to the standard procedure and purified by silica column chromatography $\left(97: 1: 2 \mathrm{CHCl}_{3}: \mathrm{MeOH}: \mathrm{Et}_{3} \mathrm{~N}\right.$, $\mathrm{Rf}=0.15$ in the same solvent system) to yield $40.0 \mathrm{mg}(0.186 \mathrm{mmol}, 61.9 \%$ yield $)$ of the title compound as a yellow oil. ${ }^{1} \mathrm{H}$ NMR (400 MHz, DMSO- $\left.d_{6}\right): \delta=10.62(\mathrm{~s}, 1 \mathrm{H}), 7.10(\mathrm{~s}, 2 \mathrm{H}), 6.84$ $(\mathrm{dd}, J=5.3,2.9 \mathrm{~Hz}, 2 \mathrm{H}), 6.56(\mathrm{~d}, J=5.7 \mathrm{~Hz}, 1 \mathrm{H}), 3.51(\mathrm{~m}, 1 \mathrm{H}), 1.94(\mathrm{~d}, \mathrm{~J}=11.1 \mathrm{~Hz}, 2 \mathrm{H}), 1.71$ $(\mathrm{d}, J=12.3 \mathrm{~Hz}, 2 \mathrm{H}), 1.59(\mathrm{~d}, J=12.6 \mathrm{~Hz}, 1 \mathrm{H}), 1.24(\mathrm{qd}, J=23.6,11.8 \mathrm{~Hz}, 5 \mathrm{H}) \cdot{ }^{13} \mathrm{C}$ NMR $(100$ MHz, DMSO- $\left.d_{6}\right): \delta=154.58,119.06,111.38,50.92,32.96,25.37,24.73$. FTIR (ATR, $\left.\mathrm{cm}^{-1}\right): 3265$ (w), 3056 (w), 2926 (s), 2853 (m), 1665 (m), 1631 (s), 1602 (s), 1577 (s), 1464 (s), 1450 (s), 1402 (m), 1358 (m), 1266 (s), 1213 (m), 1148 (m), 1106 (m), 1024 (m), 890 (m), 810 (m), 738 (s). HRMS (ESI-MS, $\mathrm{m} / \mathrm{z}$ ) $[\mathrm{M}+\mathrm{H}]^{+}$calcd for $\mathrm{C}_{13} \mathrm{H}_{18} \mathrm{~N}_{3}$ 216.1495; found 216.1495. The spectral data are consistent with those reported in the literature. ${ }^{137}$ 


\section{Synthesis of $N$-Substituted 2-Aminobenzimidazoles (3q and 3r)}

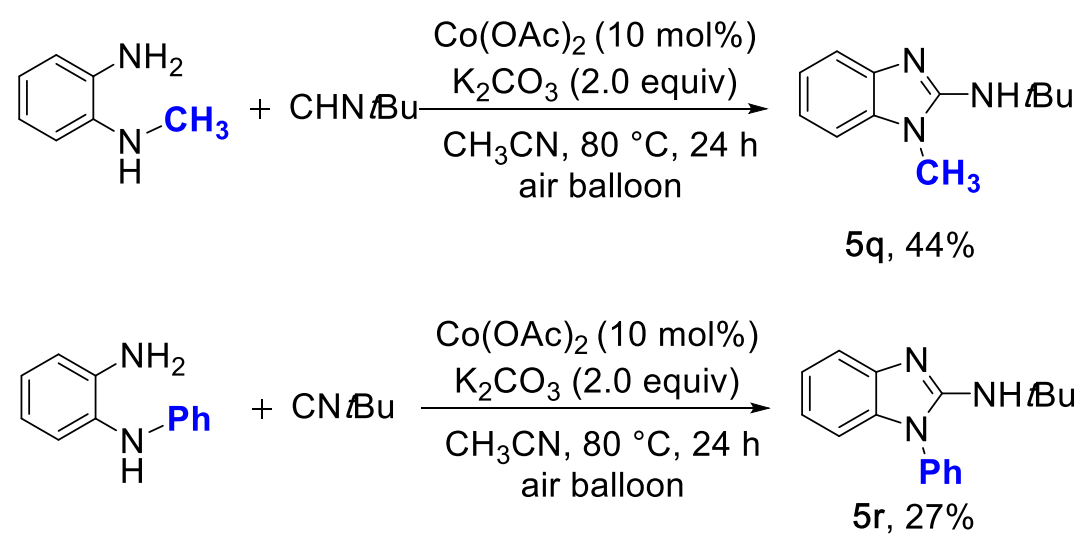

To a 6-inch test tube in an $\mathrm{N}_{2}$ filled glovebox, $N$-substituted ortho-phenylenediamine $(0.300 \mathrm{mmol})$, $\mathrm{Co}(\mathrm{OAc})_{2}(5.31 \mathrm{mg}, 0.0300 \mathrm{mmol}), \mathrm{K}_{2} \mathrm{CO}_{3}(82.9 \mathrm{mg}, 0.600 \mathrm{mmol})$ were combined. $\mathrm{CH}_{3} \mathrm{CN}(3 \mathrm{~mL})$ and tert-butylisonitrile $(35.2 \square \mathrm{L}, 0.300 \mathrm{mmol})$ was added and the test tube was sealed with a septum before being removed from the glovebox. The reaction mixture was then stirred for 24 hours in an $80{ }^{\circ} \mathrm{C}$ oil bath with an air balloon attached to a needle inserted through the septum. Upon completion, the reaction mixture was cooled to room temperature, diluted with $10 \mathrm{~mL}$ ethyl acetate and filtered through a pad of Celite. An additional $20 \mathrm{~mL}$ of ethyl acetate was used to flush the Celite and the filtrate was concentrated to $\sim 3 \mathrm{~mL}$ under vacuum. The resulting concentrate was then passed through a silica gel plug Pasteur pipette and rinsed with $\sim 10 \mathrm{~mL}$ ethyl acetate. The solvent was removed by rotary evaporation to generate the crude product as a dark brown solid. Dimethyl sulfone $(2.90 \mathrm{mg}, 0.03 \mathrm{mmol}$ ) was added as an internal standard and the crude mixture was dissolved in DMSO- $d_{6}$ for ${ }^{1} \mathrm{H}$ NMR analysis.

$N$-tert-butyl-1-methyl-1H-benzimidazol-2-amine (5q). ${ }^{1} \mathrm{H}$ NMR (400 MHz, DMSO-d6): $\delta=$ $7.22(\mathrm{~d}, J=7.4 \mathrm{~Hz}, 1 \mathrm{H}), 7.11$ (d, $J=7.4 \mathrm{~Hz}, 1 \mathrm{H}), 6.91$ (p, $J=7.5 \mathrm{~Hz}, 2 \mathrm{H}), 5.90$ (s, 1H), 3.48 (s, $3 \mathrm{H}), 1.46(\mathrm{~s}, 9 \mathrm{H})$. The spectral data is consistent with those reported in the literature. ${ }^{80}$

$\boldsymbol{N}$-tert-butyl-1-phenyl-1H-benzimidazol-2-amine (5r). ${ }^{1} \mathrm{H}$ NMR $\left(400 \mathrm{MHz}, \mathrm{CDCl}_{3}\right): \delta=7.65-$ $7.46(\mathrm{~m}, 4 \mathrm{H}), 7.41(\mathrm{~d}, J=7.9 \mathrm{~Hz}, 2 \mathrm{H}), 7.13(\mathrm{t}, J=7.6 \mathrm{~Hz}, 1 \mathrm{H}), 6.98(\mathrm{t}, J=7.6 \mathrm{~Hz}, 1 \mathrm{H}), 6.91(\mathrm{~d}, J$ $=7.8 \mathrm{~Hz}, 1 \mathrm{H}), 4.15(\mathrm{~s}, 1 \mathrm{H}), 1.50(\mathrm{~s}, 9 \mathrm{H})$. The spectral data are consistent with those reported in the literature. ${ }^{138}$ 
<smiles>CCCCCNc1nc2ccccc2nc1NCCCCC</smiles>

6

$N^{2}, N^{3}$-dipentylquinoxaline-2,3-diamine (6). The title compound was synthesized according to the standard procedure and purified by silica column chromatography (gradient elution from pure hexanes to 6:1 hexanes: ethyl acetate, $\mathrm{R}_{f}=0.55$ in 6:1 hexanes: ethyl acetate) to yield $11.5 \mathrm{mg}$ (0.0383 mmol, $25.5 \%$ yield) of the title compound as a light brown oil. ${ }^{1} \mathrm{H}$ NMR (400 MHz, $\left.\mathrm{CDCl}_{3}\right): \delta=7.67(\mathrm{dd}, J=5.9,3.5 \mathrm{~Hz}, 2 \mathrm{H}), 7.30(\mathrm{dd}, J=6.1,3.5 \mathrm{~Hz}, 2 \mathrm{H}), 4.91(\mathrm{~s}, 2 \mathrm{H}), 3.56(\mathrm{t}, J$ = 7.2 Hz, 4H), $1.84-1.56(\mathrm{~m}, 4 \mathrm{H}), 1.49-1.29(\mathrm{~m}, 9 \mathrm{H}), 1.26(\mathrm{~s}, 2 \mathrm{H}), 0.91(\mathrm{t}, J=6.8 \mathrm{~Hz}, 7 \mathrm{H})$, 0.07 (s, 2H). ${ }^{13} \mathrm{C} \mathrm{NMR}\left(100 \mathrm{MHz}, \mathrm{CDCl}_{3}\right): \delta=144.45,136.46,125.35,124.90,42.80,29.49,29.13$, 22.61, 14.15. FTIR (ATR, $\left.\mathrm{cm}^{-1}\right): 3341(\mathrm{w}), 2956$ (m), 2928 (m), 2858 (m), 1649 (w), 1598 (m), 1556 (s), 1505 (s), 1460 (s), 1352 (m), 1330 (m), 1259 (m), 1259 (m), 1214 (s), 1144 (m), 1022 (m), 936 (w), $801(\mathrm{~m}), 750$ (s), 666 (m). HRMS (ESI-MS, m/z) [M+H] ${ }^{+}$calcd for $\mathrm{C}_{18} \mathrm{H}_{29} \mathrm{~N}_{4}$ 301.2387; found 301.2384 .

\subsubsection{Synthesis of 2-Aminobenzimidazoles ( $5 \mathrm{~s}$ and $5 \mathrm{t}$ )}

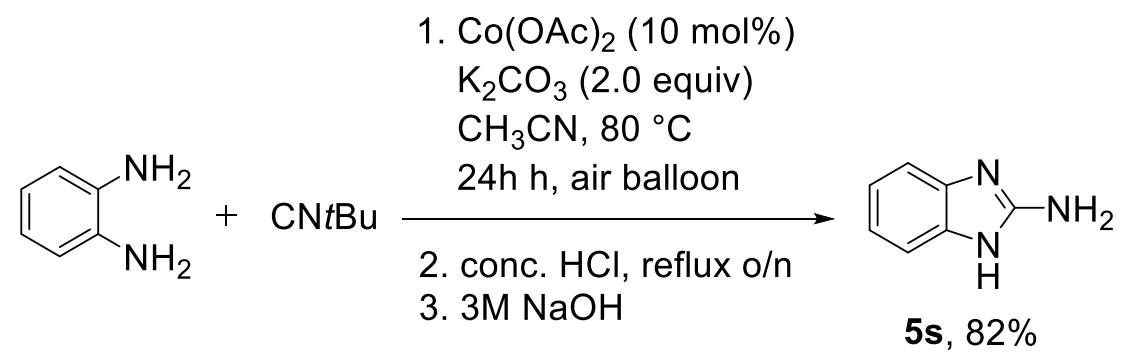

2-aminobenzimidazole (5s). ortho-phenylenediamine $(32.4 \mathrm{mg}, 0.300 \mathrm{mmol}), \mathrm{Co}(\mathrm{OAc})_{2}(5.31 \mathrm{mg}$, $0.0300 \mathrm{mmol}), \mathrm{K}_{2} \mathrm{CO}_{3}(82.9 \mathrm{mg}, 0.600 \mathrm{mmol})$ were combined in a 6-inch test tube in an $\mathrm{N}_{2}$ filled glovebox. $\mathrm{CH}_{3} \mathrm{CN}(3 \mathrm{~mL})$ and tert-butylisonitrile $(35.2 \square \mathrm{L}, 0.300 \mathrm{mmol})$ were added and the test tube was sealed with a septum before being removed from the glovebox. The reaction mixture was then stirred for 24 hours in an $80{ }^{\circ} \mathrm{C}$ oil bath with an air balloon attached to a needled inserted through the septum. Upon completion, the reaction mixture was cooled to room temperature, diluted with ethyl acetate $(10 \mathrm{~mL})$ and filtered through a pad of Celite. Additional ethyl acetate 
$(20 \mathrm{~mL})$ was used to flush the Celite and the resulting filtrate was transferred in a $100 \mathrm{~mL}$ twoneck flask and the solvent was removed by rotary evaporation. The flask was then connected to the Schlenk line and evacuated and backfilled with nitrogen three times. Under a $\mathrm{N}_{2}$ atmosphere, dry toluene $(20 \mathrm{~mL})$ was added by syringe followed by a solution of concentrated $\mathrm{HCl}(1 \mathrm{~mL})$ in toluene $(5 \mathrm{~mL})$. The resulting reaction mixture was placed in a $120{ }^{\circ} \mathrm{C}$ oil bath and allowed to reflux overnight. Upon completion, the reaction mixture was cooled to room temperature, basified with $3 \mathrm{M} \mathrm{NaOH}$ until the aqueous layer reached a $\mathrm{pH}$ of $\sim 13$ (monitored by $\mathrm{pH}$ paper) and turned from a black goo to a dark brown suspension. The aqueous layer was extracted with ethyl acetate $(3 \times 50 \mathrm{~mL})$ and the combined organic layers were washed with brine $(50 \mathrm{~mL})$, separated, dried over anhydrous sodium sulfate, filtered, and the solvent removed under vacuum to yield the crude product as a light yellow solid. Dimethyl sulfone $(3.00 \mathrm{mg}, 0.0318 \mathrm{mmol})$ was added as an internal standard and the crude mixture was dissolved in DMSO- $d_{6}$ for ${ }^{1} \mathrm{H}$ NMR analysis. The reaction yield was determined by ${ }^{1} \mathrm{H}$ NMR spectroscopy to be $82 \%$.

${ }^{1} \mathrm{H}$ NMR $\left(400 \mathrm{MHz}, \mathrm{DMSO}-d_{6}\right): \delta=7.09(\mathrm{~s}, 2 \mathrm{H}), 6.84(\mathrm{~s}, 2 \mathrm{H}), 6.18(\mathrm{~s}, 2 \mathrm{H})$. The spectral data are consistent with those reported in the literature. ${ }^{57}$

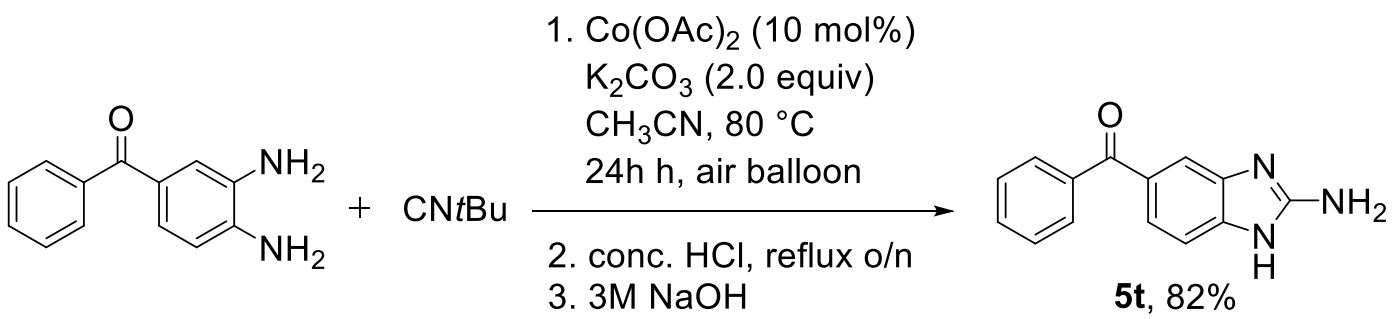

2-Amino-5-benzoyl-1H-benzimidazole (5t). In a $\mathrm{N}_{2}$-filled glovebox, a 6-inch test tube equipped with a stir bar was loaded with 3,4-diaminobenzophenone (63.7 mg, $0.300 \mathrm{mmol}), \mathrm{Co}(\mathrm{OAc})_{2}(5.31$ $\mathrm{mg}, 0.0300 \mathrm{mmol})$, and $\mathrm{K}_{2} \mathrm{CO}_{3}(82.9 \mathrm{mg}, 0.600 \mathrm{mmol})$. Dry $\mathrm{CH}_{3} \mathrm{CN}$ (5 mL) was added to the test tube followed by tert-butylisonitrile $(34.2 \mathrm{~mL}, 0.300 \mathrm{mmol})$. The test tube was then removed from the glovebox and the reaction mixture was stirred in an $80{ }^{\circ} \mathrm{C}$ oil bath for 24 hours. Upon completion, the reaction mixture was cooled to room temperature, filtered through a pad of Celite, and the Celite was rinsed with $30 \mathrm{~mL}$ of ethyl acetate. The filtrate was then transferred to a 100 $\mathrm{mL}$ two-neck flask and the solvent was removed under vacuum. The flask was then connected to the Schlenk line, fitted with a water condenser and evacuated and backfilled with $\mathrm{N}_{2}$ three times. Under a $\mathrm{N}_{2}$ atmosphere, dry toluene $(20 \mathrm{~mL})$ was added via syringe, followed by a mixture of 
concentrated $\mathrm{HCl}(1 \mathrm{~mL})$ in toluene $(5 \mathrm{~mL})$. The reaction mixture was heated at $120{ }^{\circ} \mathrm{C}$ with stirring overnight to enable complete dealkylation. Upon completion, the reaction mixture was cooled to room temperature, basified with $3 \mathrm{M} \mathrm{NaOH}$ until the aqueous layer reached a $\mathrm{pH}$ of $\sim 13$ (monitored by $\mathrm{pH}$ paper) and turned from a black goo to a dark brown suspension. The aqueous layer was then extracted with ethyl acetate $(3 \times 50 \mathrm{~mL})$ and the combined organic layers were washed with brine, separated, dried over anhydrous sodium sulfate, filtered, and concentrated via rotary evaporation to generate the crude product as a dark yellow solid. The product was purified by silica column chromatography (EtOAc: $\mathrm{MeOH}: \mathrm{Et}_{3} \mathrm{~N}=90: 10: 5, \mathrm{R}_{\mathrm{f}}=0.1$ in the same solvent system) to yield the title compound. Due to the presence of triethylamine in the isolated compound, an aqueous extraction was applied to remove remaining triethylamine. The isolated compound was dissolved in $30 \mathrm{~mL}$ ethyl acetate and partitioned into $100 \mathrm{~mL}$ water. The water layer was extracted ethyl acetate $(2 \times 20 \mathrm{~mL})$ and the combined organic layers were washed with brine, dried over anhydrous sodium sulfate, filtered, and concentrated via rotary evaporation to provide $49.9 \mathrm{mg}$ of the titled compound $(0.210 \mathrm{mmol}, 70.1 \%)$ as a yellow solid (m.p.=169-174 $\left.{ }^{\circ} \mathrm{C}\right) .{ }^{1} \mathrm{H}$ NMR $(400$ MHz, DMSO-d6): $\delta=7.71-7.64(\mathrm{~m}, 2 \mathrm{H}), 7.64-7.48(\mathrm{~m}, 4 \mathrm{H}), 7.40(\mathrm{~d}, J=1.7 \mathrm{~Hz}, 1 \mathrm{H}), 7.20(\mathrm{~d}$, $J=8.2 \mathrm{~Hz}, 1 \mathrm{H}), 6.74(\mathrm{~s}, 2 \mathrm{H}) .{ }^{13} \mathrm{C} \mathrm{NMR}\left(100 \mathrm{MHz}, \mathrm{DMSO}-d_{6}\right): \delta=195.47,157.68,145.25,139.03$, 136.62, 131.51, 129.22, 128.32, 127.78, 123.56, 112.64, 111.92. FTIR (ATR, cm $\left.{ }^{-1}\right)$ : 3320 (w), 3171 (w), 3060 (w), 2923 (w), 2853 (w), 1598 (s), 1565 (s), 1519 (s), 1466 (m), 1433 (s), 1344 (m), 1318 (s), 1283 (s), 1177 (w), 1071 (m), 1026 (m), 975 (w), 930 (w), 873 (m), 851 (m), 825 (m), 790 (s), 709 (s), 695 (s). HRMS (ESI-MS, m/z) $[\mathrm{M}+\mathrm{H}]^{+}$calcd for $\mathrm{C}_{14} \mathrm{H}_{12} \mathrm{~N}_{3} \mathrm{O}$ 238.0975; found 238.0974 . 


\subsubsection{Procedures for Control Experiments with Radical Trapping Agents}

(a)

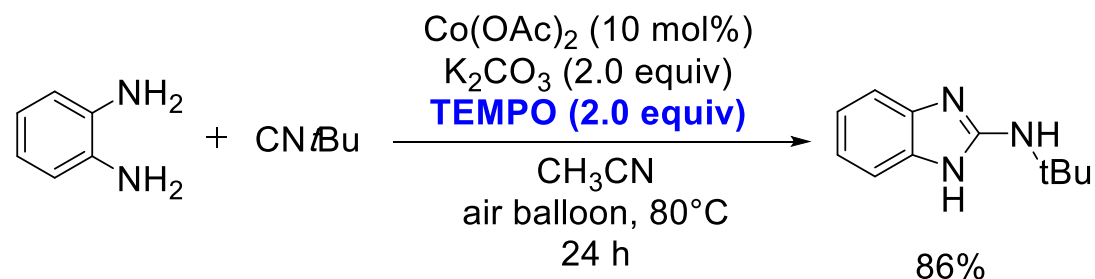

$\mathrm{Co}(\mathrm{OAc})_{2}(10 \mathrm{~mol} \%)$

$\mathrm{K}_{2} \mathrm{CO}_{3}$ (2.0 equiv)

(b)

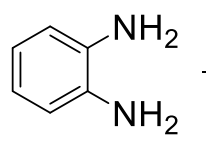

$+\mathrm{CHN} / \mathrm{Bu}$

1,1-diphenylethylene

$24 \%$ Starting Material

Recovery

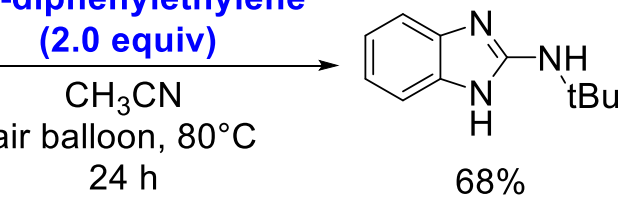

Standard procedure for radical trap experiments. ortho-phenylenediamine $(32.4 \mathrm{mg}, 0.300$ $\mathrm{mmol}), \mathrm{Co}(\mathrm{OAc})_{2}(5.31 \mathrm{mg}, 0.0300 \mathrm{mmol}), \mathrm{K}_{2} \mathrm{CO}_{3}(82.9 \mathrm{mg}, 0.600 \mathrm{mmol})$ and radical scavenger (2.0 equiv, $0.600 \mathrm{mmol}$ ) were combined in a 6-inch test tube in an $\mathrm{N}_{2}$ filled glovebox. $\mathrm{CH}_{3} \mathrm{CN}$ (3 $\mathrm{mL})$ and tert-butylisonitrile $(35.2 \mathrm{~mL}, 0.300 \mathrm{mmol})$ were added and the test tube was sealed with a septum before being removed from the glovebox. The reaction mixture was then stirred for 24 hours in an $80{ }^{\circ} \mathrm{C}$ oil bath with an air balloon inserted through the septum.

Work up method for control experiment with 1,1-diphenylethylene as the radical scavenger. Upon completion, the reaction mixture was cooled to room temperature, diluted with $10 \mathrm{~mL}$ ethyl acetate and filtered through a pad of Celite. An additional $20 \mathrm{~mL}$ ethyl acetate was used to wash the Celite and the resulting filtrate was concentrated to $\sim 3 \mathrm{~mL}$ on the rotary evaporator. The resulting solution was then passed through a silica gel Pasteur pipette to remove any remaining cobalt and the pipette was flushed with additional $10 \mathrm{~mL}$ of ethyl acetate. The filtrate was collected and the solvent was removed via rotary evaporation to generate the crude product. Dimethyl sulfone $(3.00 \mathrm{mg}, 0.0318 \mathrm{mmol})$ was added as an internal standard and the crude mixture was dissolved in DMSO- $d_{6}$ for ${ }^{1} \mathrm{H}$ NMR analysis. The reaction yield was determined by ${ }^{1} \mathrm{H}$ NMR spectroscopy.

Work up method for control experiment with TEMPO as the radical scavenger. After cooling to room temperature, the reaction mixture was diluted with ethyl acetate $(20 \mathrm{~mL})$ and the resulting mixture was extracted with a saturated solution of $\mathrm{Na}_{2} \mathrm{~S}_{2} \mathrm{O}_{3}(3 \times 20 \mathrm{~mL})$ until the organic layer 
changed from dark red to light yellow. The organic layer was then washed with brine, and the resulting organic layer was dried over anhydrous sodium sulfate, filtered, and finally concentrated via rotary evaporation to $\sim 3 \mathrm{~mL}$. The concentrated sample was then passed through a Pasteur pipette silica gel plug to remove any remaining cobalt and the pipette was flushed with additional $10 \mathrm{~mL}$ of ethyl acetate. The filtrate was collected and the solvent was removed via rotary evaporation to generate the crude product as a brownish-red solid. Dimethyl sulfone (3.00 mg, $0.0318 \mathrm{mmol}$ ) was added as an internal standard and the crude mixture was dissolved in DMSO$d_{6}$ for ${ }^{1} \mathrm{H}$ NMR analysis. The reaction yield was determined by ${ }^{1} \mathrm{H}$ NMR spectroscopy.

\subsubsection{Attempts in the Synthesis of Mebendazole from 2-Amino-5-Benzoyl Benzimidazole}

As we stated previously, the formation of mebendazole from 2-amino-5-benzoyl benzimidazole (5t) was quite challenging due to the presence of exchangeable NH protons in the starting material. Aside from the methodologies applied in Scheme 3.8 we especially extended our exploration in this transformation using methyl chloroformate as a coupling partner, but with varied reaction conditions (Scheme 3.10). We realized a fully conversion of the starting material in these related reaction conditions; however, these transformations yielded almost 1:1 mixture of mebendazole isomers exclusively regardless of the varied bases and reaction stoichiometry. Suggesting a thermodynamic preference of the following structural isomers over mebendazole under these reaction conditions. 
(a) 2 equiv of methyl chloroformate<smiles>CCN(CC)C(=O)OC(=O)OC(=O)c1ccc2c(c1)nc(N)n2C(=O)OC(=O)c1ccccc1</smiles>

(b) 1 equiv of methyl chloroformate with different bases

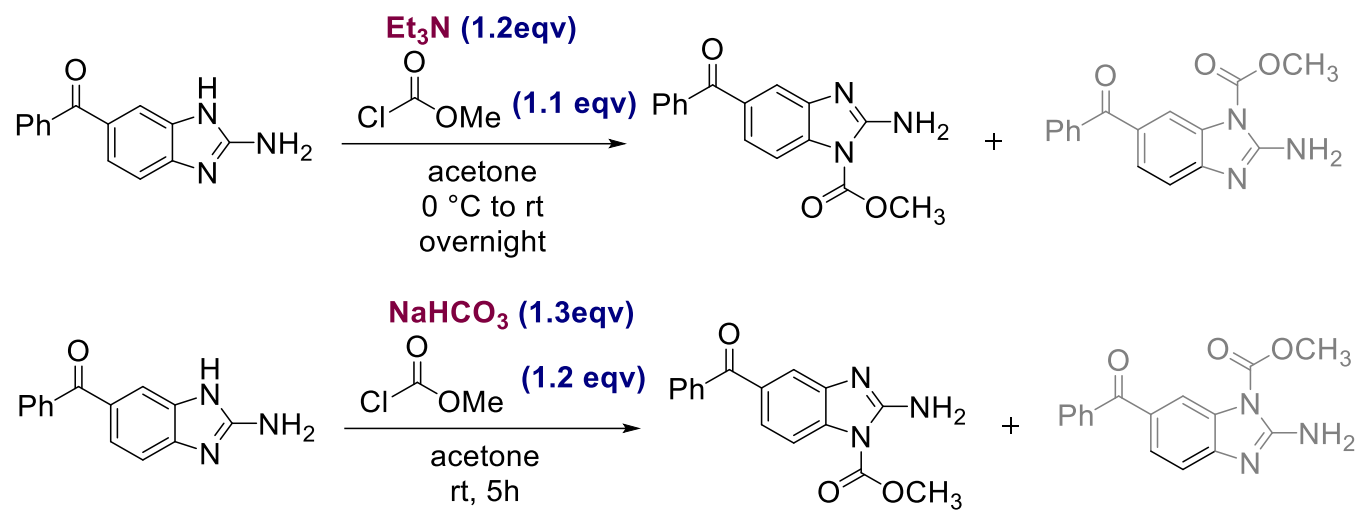

Scheme 3.10. Attempts in the synthesis of mebendazole from 2-amino-5-benzoyl benzimidazole and methyl chloroformate.

Structures of mebendazole isomers are elucidated by ${ }^{1} \mathrm{H}-\mathrm{NMR}$ using one of the model reactions from Scheme 3.10, where $\mathrm{NaHCO}_{3}$ was employed as a base. Characteristic protons on the benzimidazole ring are highlighted in each structure of the mebendazole isomers. Due to the extreme similarity of the physical properties these two isomers presented, the isolation proved to be impractical. Therefore the structure elucidation here is provided by the sample with mixed isomers (Figure 3.6-3.9). 


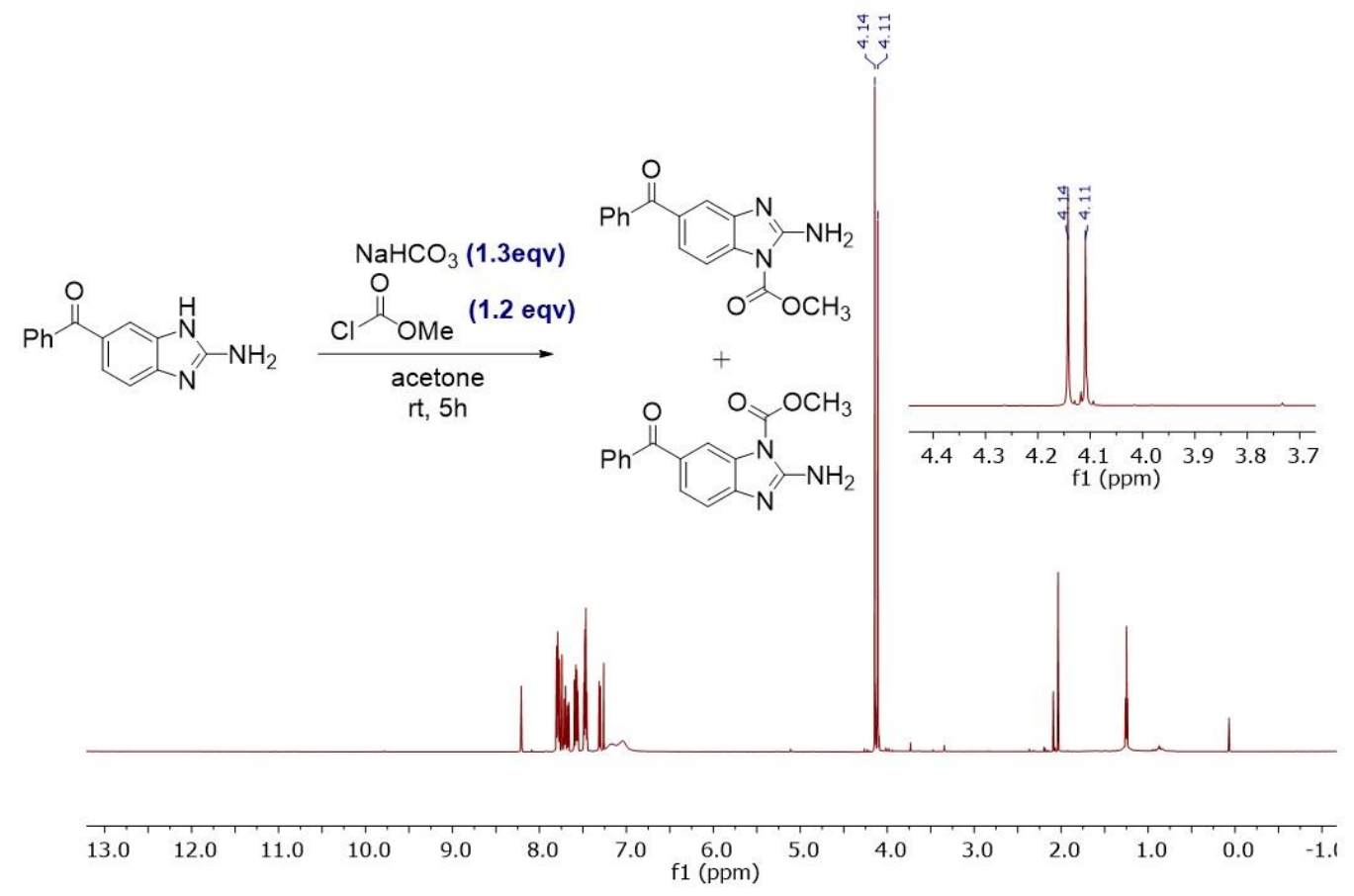

Figure 3.6. Mixture of the two mebendazole structural isomers from the model transformation.
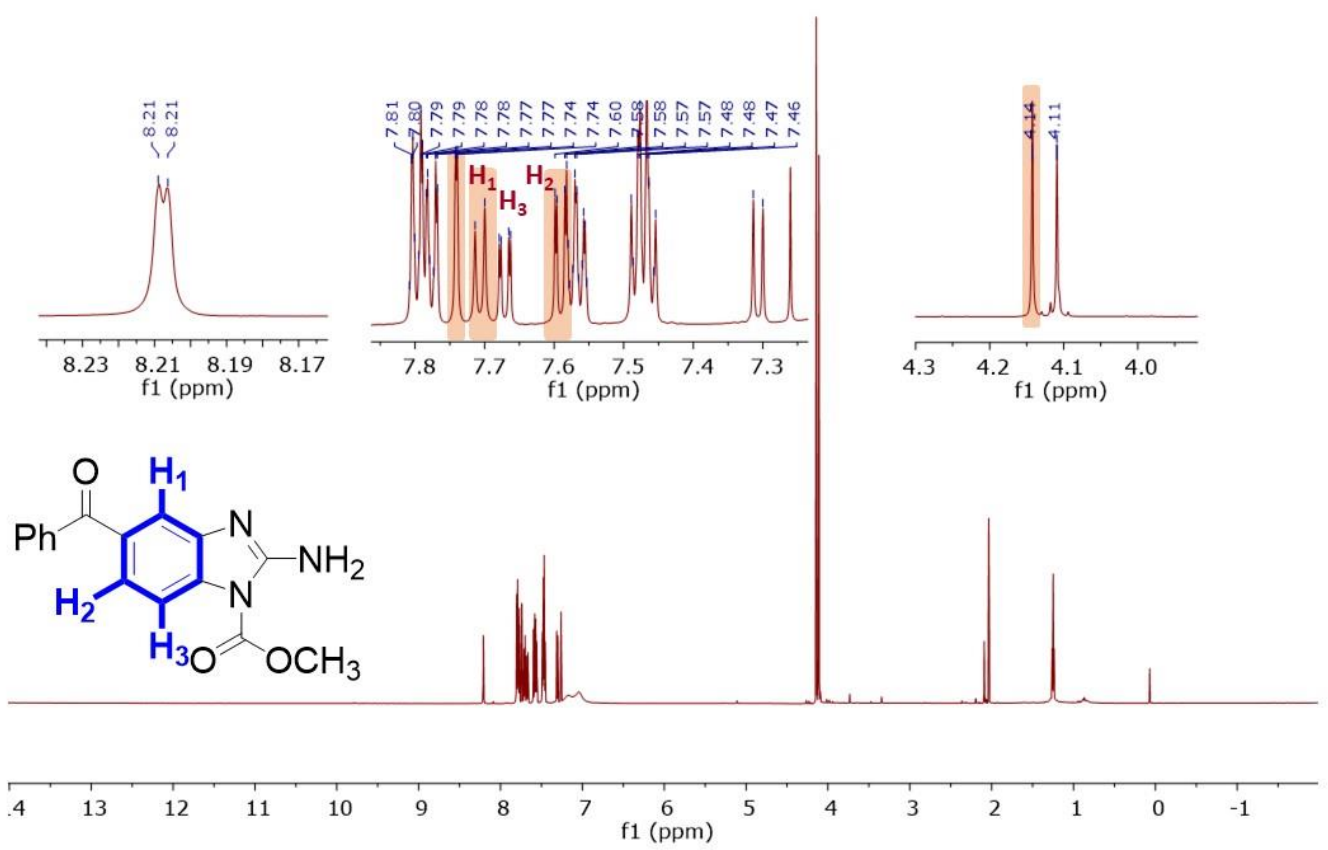

Figure 3.7. ${ }^{1} \mathrm{H}$ NMR for structural elucidation of mebendazole isomer with 1-acylation. 

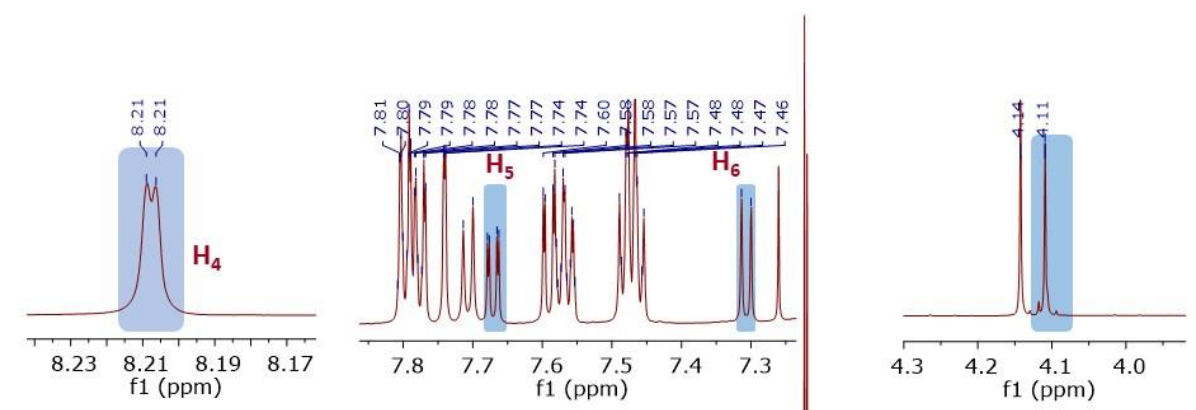<smiles>COC(=O)n1c(N)nc2c(C)c(C)c(C(=O)c3ccccc3)c(C)c21</smiles>
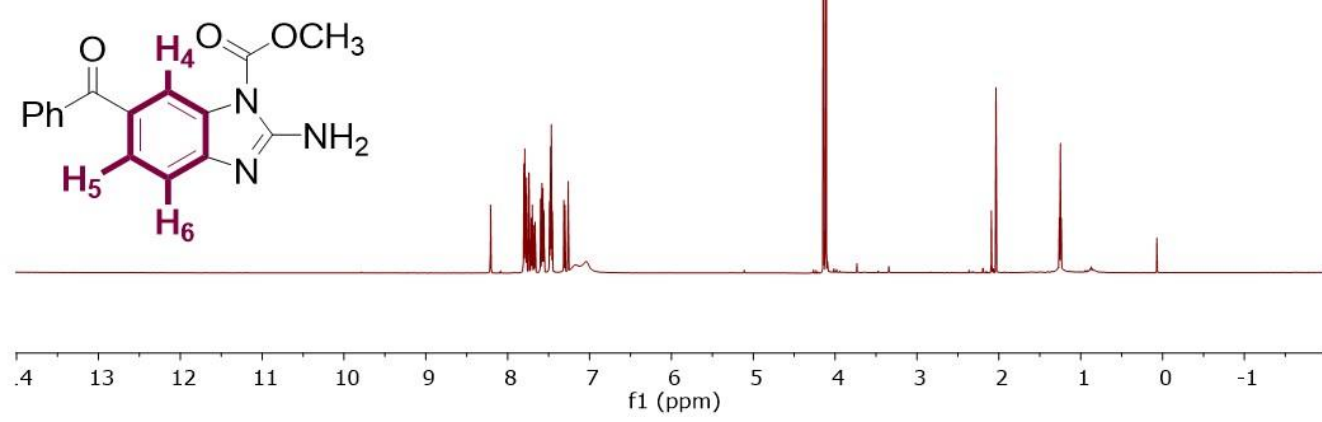

Figure 3.8. ${ }^{1} \mathrm{H}$ NMR for Structural elucidation of mebendazole isomer with 3-acylation.

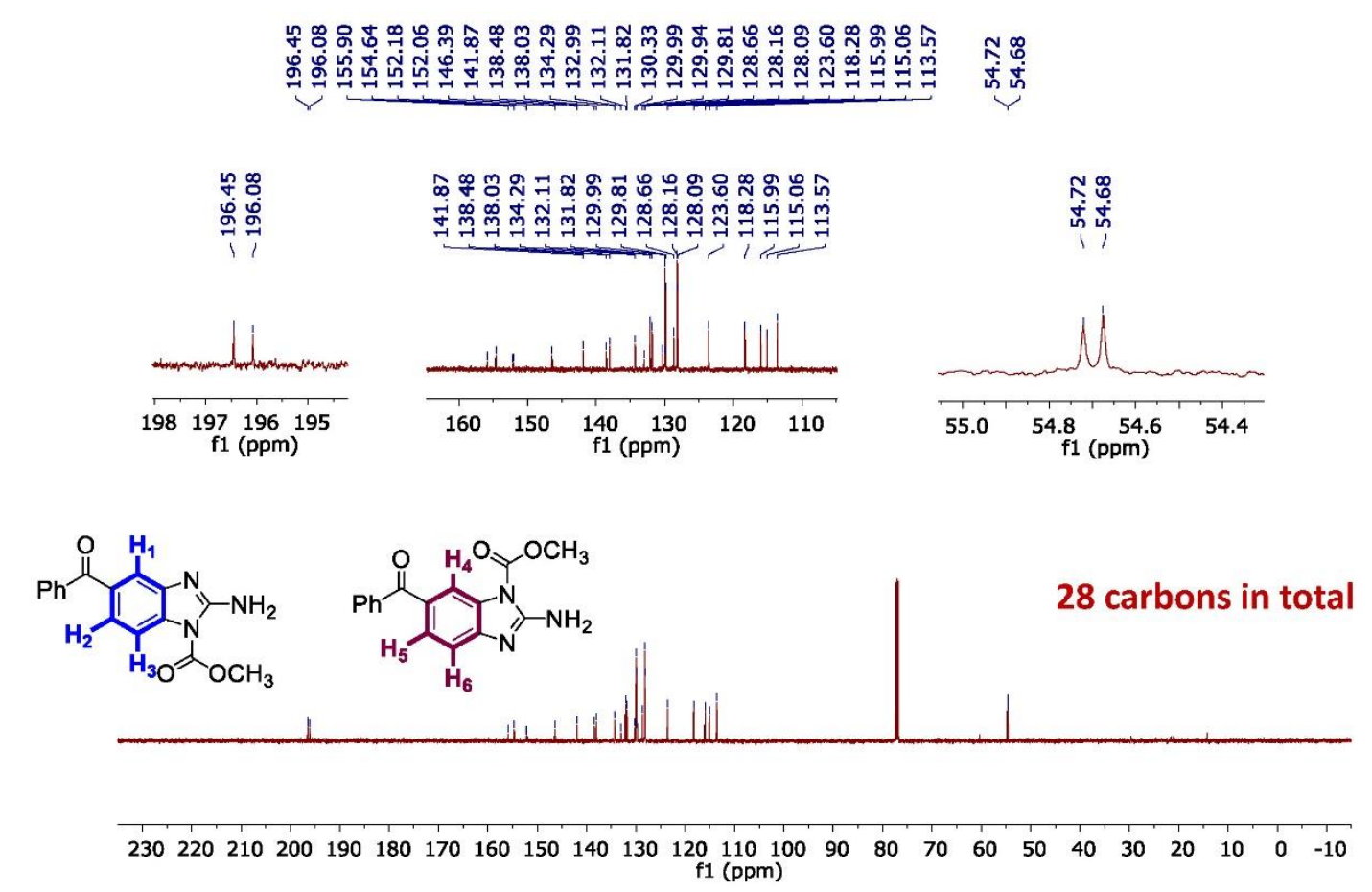

Figure 3.9. ${ }^{13} \mathrm{C}$ NMR for the mixture of two mebendazole isomers. 


\section{Chapter 4. Synthesis, Isolation and Characterization of the Well-Defined $\mathrm{Co}^{\mathrm{II}}$ and $\mathrm{Co}^{\mathrm{III}}$ Complexes bearing $\mathrm{NH}_{2}$-unsubstituted Aminophenol Ligands and Their Reactivity Studies in the Aerobic Oxidative Cyclization Reactions}

\subsection{Introduction}

In transition metal catalysis, the property of a complex can be affected by the coordination of ligand to the metal center. Redox non-innocent ligands, which can engage in a ping-pong mechanism by easily being oxidized or reduced by one or more electrons, can have important effects on the redox states of the transition metal center upon coordination. These ligands are capable of stabilizing metal ions with unusual oxidation states through modification of the electrochemical potentials, and act as an electron-reservoirs which allow the transition metal to maintain its most common or stable oxidation state in multielectron transformations by donating or accepting the electron densities. ${ }^{139-141} \mathrm{O}$-aminophenol, an archetypal example of a redox noninnocent ligand, has been used widely paired with numerous transition-metal catalysts. This ligand can accommodate three stable oxidation states once deprotonated, $o$-aminophenolate, $o$ iminosemiquinoate and $o$-iminobenzoquinone as shown in Scheme 4.1. Metal complexes with one and two electron reduced forms in $o$-aminophenol type ligands have been intensively reported by multiple research groups. ${ }^{142-146}$

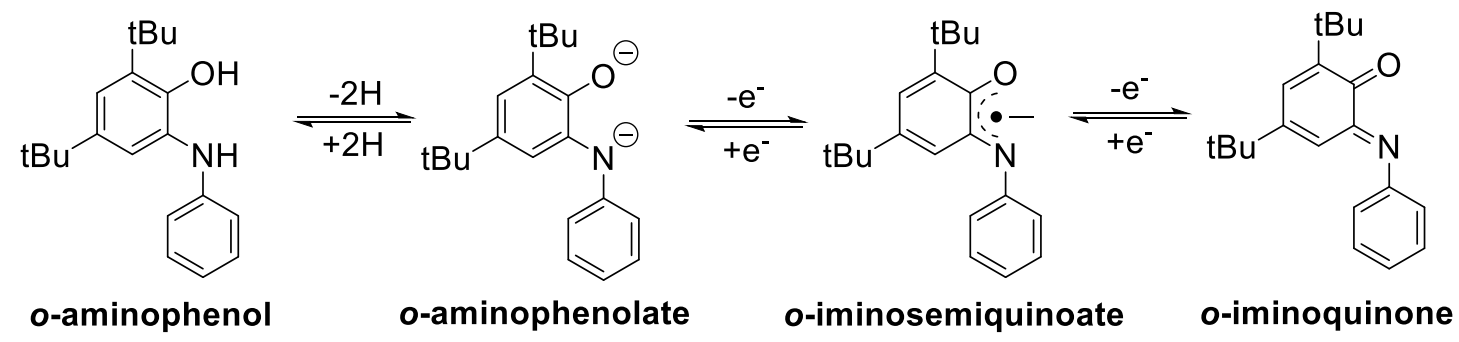

Scheme 4.1. Oxidation states of the bidentate $o$-aminophenol as a redox-active ligand

Among the types of redox non-innocent ligands, extensive studies have focused on 3,5-ditert-butyl substituted $o$-aminophenol ligands. The increased electron-donating property of tertbutyl groups enables the deprotonated ligand to stabilize the complex with high oxidation states 
efficiently. Also, these substituents play a critical role in facilitating the oxidation of the ligand while suppressing its oxidative decomposition by lowering the oxidation potential of the ligand. ${ }^{147}$ With the increasing interest of pairing 3,5-di-tert-butyl-o-aminophenol with transition-metal catalysts, great efforts have been made on the synthesis and studies of such complexes with a wide range of transition metals, such as iron complexes, ${ }^{148}$ uranium complexes, ${ }^{149}$ platinum complexes, ${ }^{150}$ and zirconium complexes. ${ }^{151}$

While the $2^{\text {nd }}$ and $3^{\text {rd }}$ row late transition metals have a well-established two-electron oxidation state changes in catalysis, first-row base metals don't necessarily undergo the same transformations due to their preference for the single-electron redox changes, for example, $\mathrm{Co}^{\mathrm{II}} / \mathrm{Co}^{\mathrm{III}}$ couples. In this regard, the combined behavior of a base metal and a redox non-innocent ligand may facilitate $2 \mathrm{e}^{-}$transformations resembling those of noble metals without compromising to the high energy redox-states for oxidizing the metal by two electrons. ${ }^{141}$ The Wieghardt group has made significant contributions in elucidating the electronic structure and the coordination chemistry of redox non-innocent ligands involving catechol, $o$-aminophenol and $o$ phenylenediamine. ${ }^{69}, 70,152-156$ These works have provided valuable insights towards the understanding of how the ligands bind to the metal center and interact with the metal in different oxidation states. $\mathrm{Co}^{\mathrm{III}}$ complexes consisting of 3,5-di-tert-butyl-o-aminophenol ligands were amongst those of the most studied by this group. A few examples of these metal complexes are illustrated in Figure 4.1. Regardless of the coordination environment of these structures, most of the well-defined $\mathrm{Co}^{\mathrm{III}}$ complexes exclusively contain $o$-aminophenol ligands with bulky aromatic substitution on each NH moiety, ${ }^{55,70,145}$ a comprehensive study on a cobalt complex bearing $o$ aminophenol ligands with unsubstituted $\mathrm{NH}_{2}$ groups has yet to be reported.
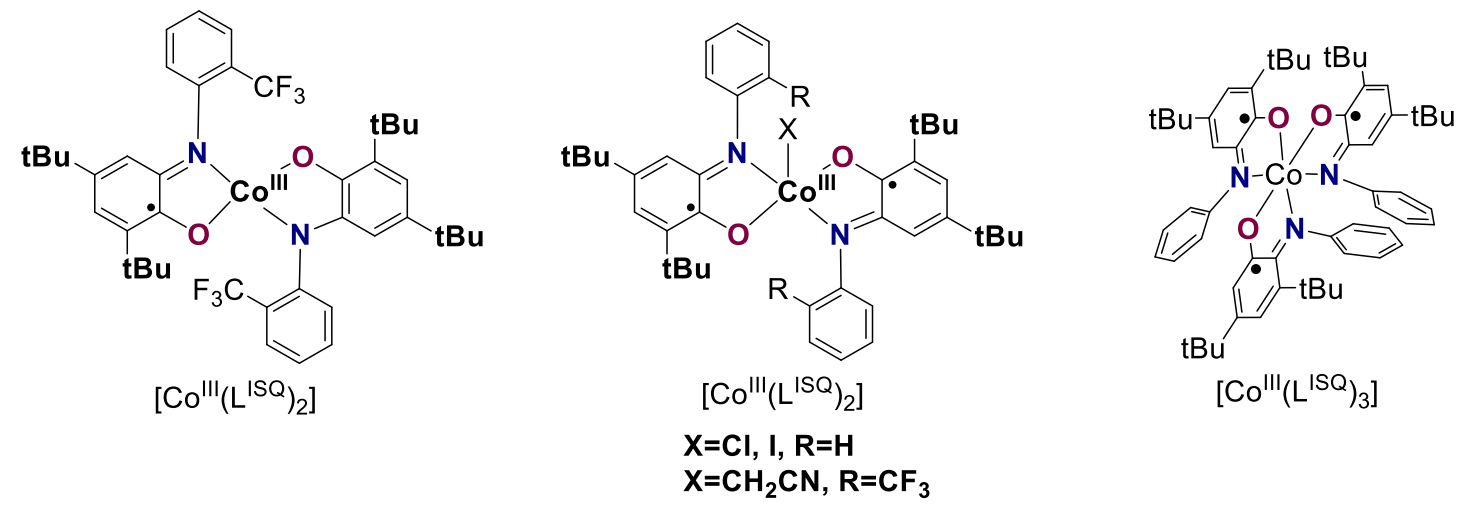

Figure 4.1. Selected examples for cobalt complexes with 3,5-di-tert-butyl-o-aminophenols. 
In these extensively studied $\mathrm{Co}^{\mathrm{III}}$ complexes the ligand radical anions were assigned. Upon oxidation, the metal center remained $\mathrm{Co}^{\mathrm{III}}$ while the ligands engaged in the redox changes when coordinated to the metal, resembling the oxidative transformation mediated by noble metals. A few decades prior to these findings, Gary and co-workers had demonstrated that square planner cobalt and nickel complexes with dithiolene ligands were best described as metal (II) species with two ligand radical anions, rather than the assumed metal with +4 oxidation states and ligands with $-2 .{ }^{157,158}$ Due to the presence of the extended network of $\pi$ bonds, these redox non-innocent ligands not only allow themselves to stabilize the radical species but also promote reversible reactions with the metal center, when the formation of radicals are involved. ${ }^{159}$ These carbon-centered ligand radicals were not only determined in cobalt complexes, they were also frequently reported in the structural elucidation of other metal complexes such as $\mathrm{Ni}^{\mathrm{II}},{ }^{160} \mathrm{Cu}^{\mathrm{II}},{ }^{145,156} \mathrm{Pd}^{\mathrm{II}},{ }^{145,} 154$ and $\mathrm{Fe}^{\mathrm{III}} 69$, 155 when the same 3,5-di-tert-butyl-o-aminophenol ligand was employed.

Despite all the notable advances in assigning the true electronic structure of these transition metal complexes involving redox non-innocent ligands, reactivity studies using these metal complexes with radicals on the supporting ligands as catalysts are still underrepresented. Wieghardt and co-workers reported the first examples where redox-active ligands in the metal complexes effectively engaged in $\mathrm{C}-\mathrm{H}$ bond activations. ${ }^{161}$ The work was inspired by enzymatic reactions of galactose oxidase, which performs the two-electron oxidation of alcohols to aldehydes. Using $\mathrm{Cu}^{\mathrm{II}}$ and $\mathrm{Zn}^{\mathrm{II}}$ complexes of a tetradentate redox non-innocent ligand, primary alcohols could effectively be oxidized to aldehydes with the reduction of $\mathrm{O}_{2}$ to $\mathrm{H}_{2} \mathrm{O}_{2}$ (Scheme 4.2). Under aerobic conditions, the single electron oxidized complex (a) underwent a stoichiometric oxidation of the primary alcohol and gave rise to complex (b). Through a rate-determining HAA step and electron transfer, the corresponding aldehyde was generated along with the doubly protonated, singleelectron reduced species (d), which immediately regenerated complex (a) in the presence of molecular oxygen to complete the cycle. 


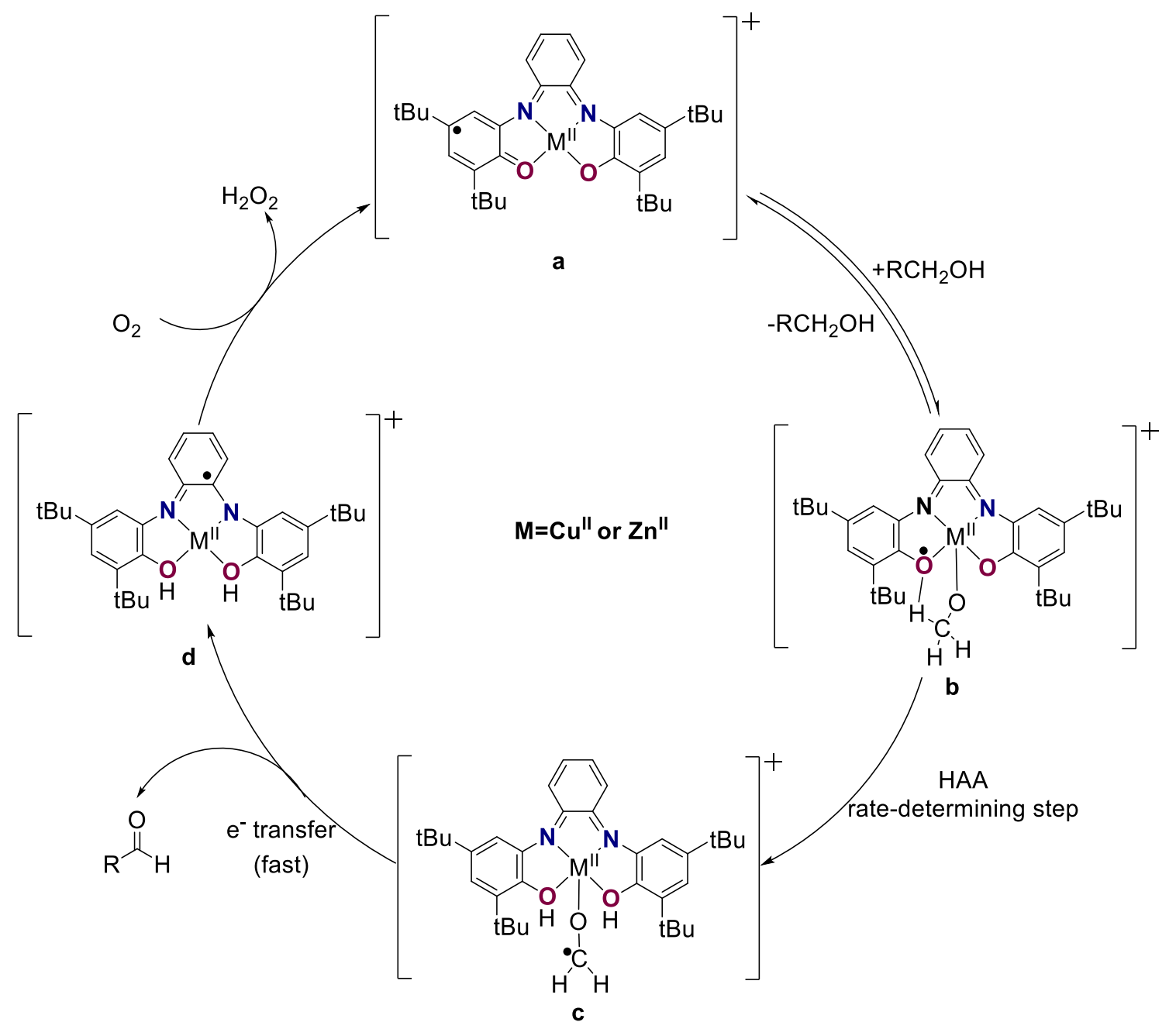

Scheme 4.2. Proposed mechanism for the catalytic oxidation of primary alcohols by dioxygen employing complexes of a tetradentate redox non-innocent ligand.

Although this revolutionary work had shed a lot of light on the later studies of the primary alcohol oxidation reactions using well-characterized metal complexes bearing aminophenolderived redox non-innocent ligands, ${ }^{162,} 163$ implications for cobalt complexes containing redoxactive aminophenolate-type ligand in catalysis are still quite limited. To date, the only wellestablished work demonstrating the reactivity of cobalt aminophenolate complexes was reported by the Soper group, ${ }^{71}$ where a square planner $\mathrm{Co}^{\mathrm{III}}$ complex was capable of catalyzing a Negishilike cross-coupling reaction of an alkyl halide with an organozinc reagent (Scheme 4.3). The starting $\mathrm{Co}^{\mathrm{III}}$ complex had two bidentate amidophenolato ligands coordinating to the metal center in the anionic aminophenolate form. This complex demonstrated a very unique reactivity to behave 
as a nucleophile and react towards the alkylhalide, affording the square pyramidal alkyl complex in quantitative yield. While the cobalt remained the same oxidation state during the oxidative addition, the electrons required for this transformation were provided by the amidophenolato ligands, both of which were oxidized to $o$-iminosemiquinoate $\left(\mathrm{sq}^{-}\right)$oxidation state. Upon treatment of the alkyl complex with zinc bromide, ethyl benzene was observed as a result of $\mathrm{C}$-C bond formation. The starting $\mathrm{Co}^{\mathrm{III}}$ complex with square planer geometry was regenerated.

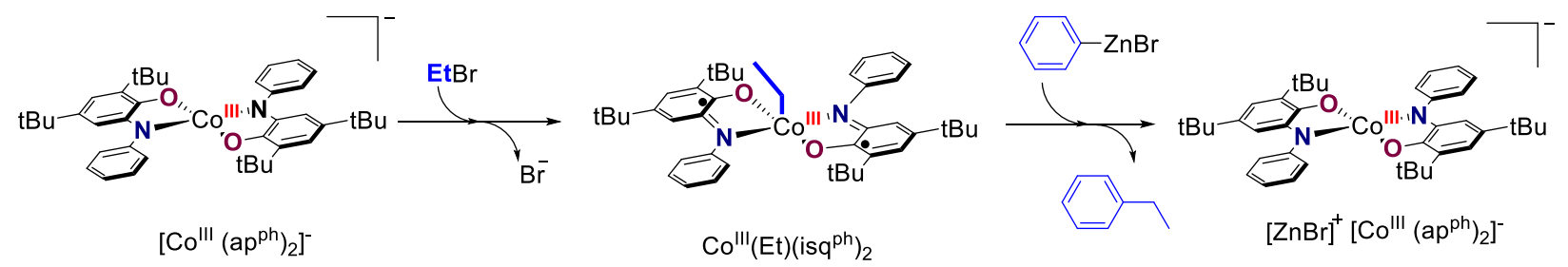

Scheme 4.3. Negishi-type cross-coupling reaction of alkyl halides with organozinc reagents by Co ${ }^{\text {III }}$ bis $(o$-amidophenolato) complex.

In this regard, the work in this chapter strives to deepen the understanding of cobalt complexes bearing redox non-innocent aminophenolate ligands, especially their engagement in the oxidative cyclization reactions with bis-nucleophiles through $\mathrm{O}_{2}$ activation. To date, the cobalt complexes reported in this chapter are the first examples of well-characterized $\mathrm{Co}^{\mathrm{II}}$ and $\mathrm{Co}^{\mathrm{III}}$ species bearing redox-active 3,5-di-tert-butyl-o-aminophenol ligand without $\mathrm{NH}_{2}$ substitutions. Notably, the bulky N-substitutions on the most commonly used aminophenol-derived ligands play a critical role in stabilizing Co complexes in the presence of $\mathrm{O}_{2}$. The Paine research group recently reported a biomimetic six-coordinate Fe(II) complex capable of oxidizing 2-amino-4-tertbutylphenol to picolinic acid in the presence of $\mathrm{O}_{2}$ (Scheme 4.4), ${ }^{164}$ which resembles the activity of the dioxygenase metalloenzymes ${ }^{165}$ that are able to catalyze the ring cleavage of numerous organic substrates. This finding suggests that to sustain the stability of carbon-centered ligand radicals against oxidative ring opening reactions in the presence of $\mathrm{O}_{2}$, both $N$-substitutions and protective tert-butyl groups at the backbone of aminophenol are necessary. 
(a) Oxidative Ring Ceavage of 2-Amino-4-tert-Butylphenol to the Picolinic Acid by Fe Complex

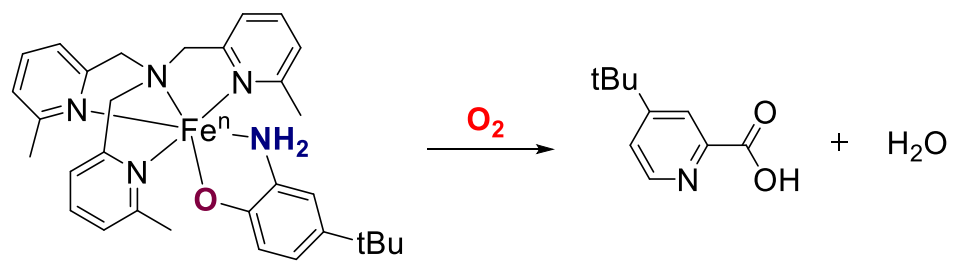

(b) Proposed Mechanism
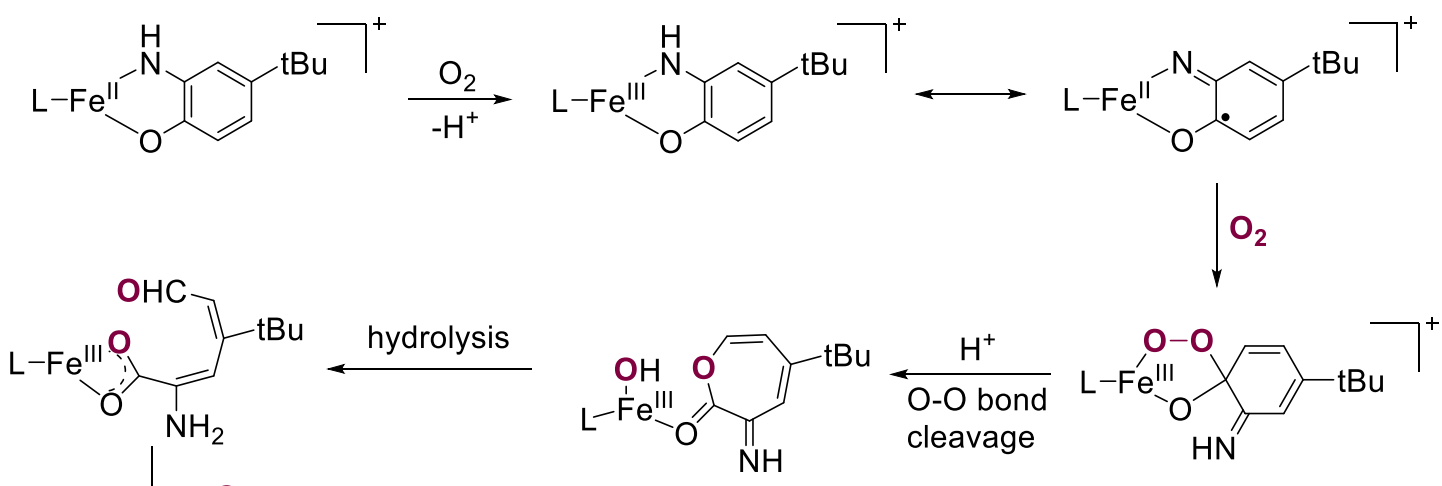

$-\mathrm{H}_{2} \mathrm{O}$
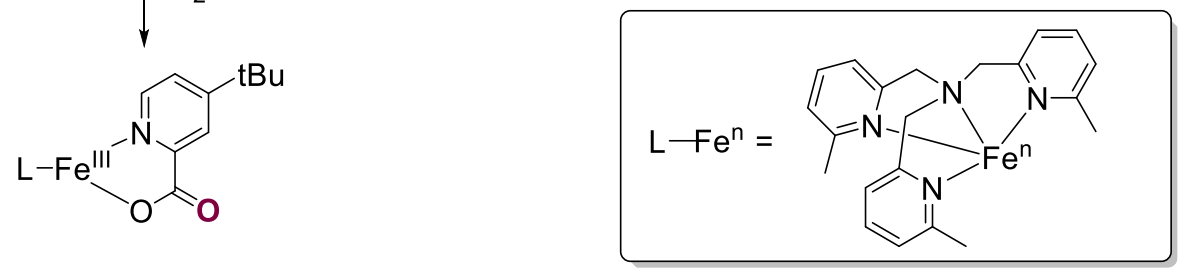

Scheme 4.4. Proposed mechanism for oxidative ring cleavage of 2-amino-4-tert-butylphenol to the picolinic acid in the presence of $\mathrm{O}_{2}$.

As a continuation of our previous mechanistic investigations on the oxidative cyclization reactions with bis-nucleophiles, these extremely challenging complexes were further tested in the model reaction developed in chapter 2 for their ability to effectively mediate aerobic oxidative cyclization reactions as potential active intermediates. Beyond the above investigations, this work expands on the currently limited understanding of first-row base metal species from the structure elucidation to the implementation in the organic transformations.

\subsection{Results}

4.2.1. Synthesis of $\mathrm{Co}^{\mathrm{II}}$ complex bearing 2-amino-4,6-ditert-butyl phenol ligands Co ${ }^{\mathrm{II}}$ (2amino-4,6-tert-butylphenolate)2(2-amino-4,6-tert-butylphenol)2 
Initially, several attempts to isolate the cobalt complex containing the unsubstituted 2amino-4-nitrophenol ligands were unsuccessful. Mixtures of products were obtained due to the solubility issues associated with the starting materials and the products. Consequently, the efficacy of 2-amino-4,6-di-tertbutyl phenol was tested in the standard conditions for aerobic oxidative cyclization developed in Chapter 2 (Scheme 4.5), where the desired product 3w was generated with an isolated yield of $78 \%$. Based on the positive results, the 2-amino-4,6-di-tertbutyl phenol was selected as the ligand of choice to synthesize and isolate the cobalt complexes.

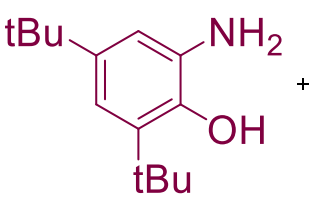

$1 w$

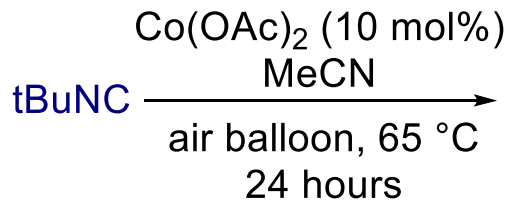

$\mathbf{2 a}$

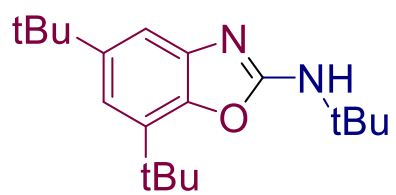

$3 w, 78 \%$

Scheme 4.5. Cobalt-catalyzed oxidative coupling of 2-amino-4,6-di-tert-butyl phenol and tertbutyl isonitrile under the standard reaction conditions.

The synthesis of the Co ${ }^{\mathrm{II}}$ complex was performed under a rigorously inert atmosphere using acetonitrile as the solvent. Triethylamine was introduced as a base to deprotonate the ligand. $\mathrm{CoCl}_{2}$ was chosen as the cobalt source for its greater solubility compared to $\mathrm{Co}(\mathrm{OAc})_{2}$. When 2-amino4,6-di-tert-butylphenol was employed as a ligand, we were delightful to find that under the reaction conditions shown in Scheme 4.6, a cobalt complex with a unique coordinating environment was formed in acetonitrile, regardless of the ratio between the metal and the ligand. These results are in contrast to the observations in most other studies, where the corresponding complexes were formed based on the stoichiometry of the ligands introduced; ${ }^{70,145}$ however, the ligands presented in those studies all used bulky $N$-substitutions as detailed in the introduction, which may help to stabilize the 1:2 and 1:3 complexes in solution. In this work, the monomeric cobalt complex was obtained in optimal yield when a 1:4 metal to ligand ratio was employed. A microcrystalline solid was generated with a golden sheen. Based on the extent of acetonitrile solvation, the color of the solid varied from beige to faint greyish green in different batches of synthesis. 

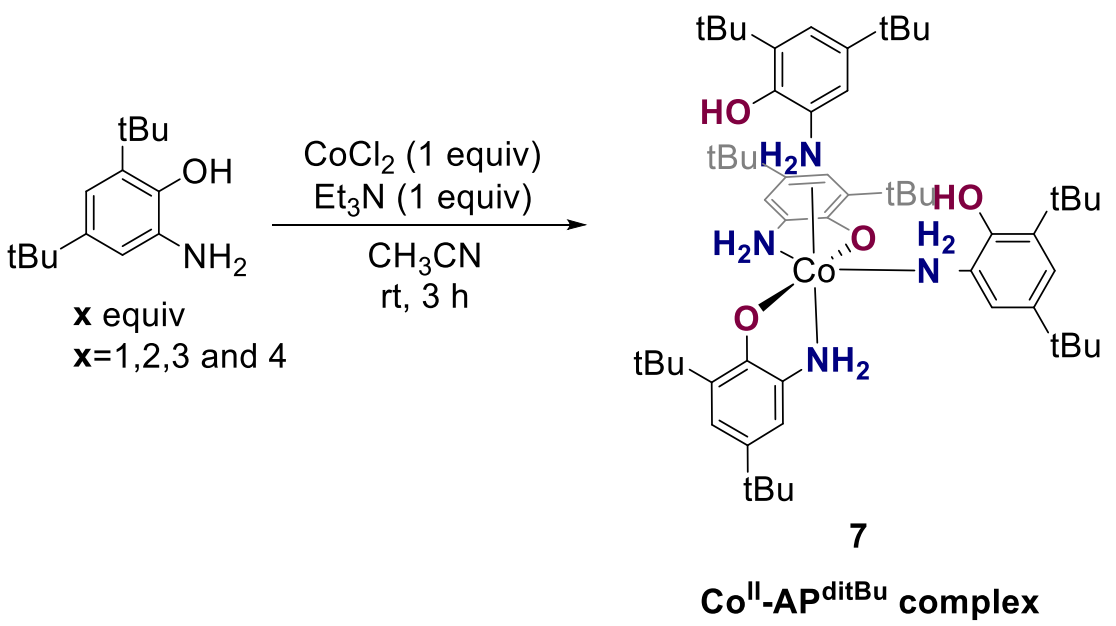

\begin{tabular}{ccc}
\hline Entry & M:L Ratio & \% Yield \\
\hline 1 & $1: 1$ & 43 \\
2 & $1: 2$ & 54 \\
3 & $1: 3$ & 70 \\
4 & $1: 4$ & 93 \\
\hline
\end{tabular}

Scheme 4.6. Synthesis and condition optimization of $\mathrm{Co}^{\mathrm{II}}$-AP ${ }^{\mathrm{ditBu}}$ complex $\mathrm{Co}^{\mathrm{II}}(2$-amino-4,6-tertbutylphenolate $)_{2}(2 \text {-amino-4,6-tert-butylphenol })_{2}$ by varying metal to ligand ratio.

${ }^{1} \mathrm{H}-\mathrm{NMR}$ spectroscopy could not confirm the structure of the Co ${ }^{\mathrm{II}}$ complex $\mathbf{7}$ due to its paramagnetic nature. Single crystals, suitable for X-ray diffraction studies, were acquired by slow evaporation of the mixture under anaerobic conditions upon reaction completion. X-ray crystallography elucidation indicated the space group $\operatorname{Im} \overline{3}$ of the resulting cubic light-yellow single crystal. A unique coordinating environment of the $\mathrm{Co}^{\mathrm{II}}$ complex is determined as shown in Figure 4.2, which consists of two monodentate aminophenol ligands cis to each other and two bidendate aminophenolate ligands, binding through the octahedral geometry. 


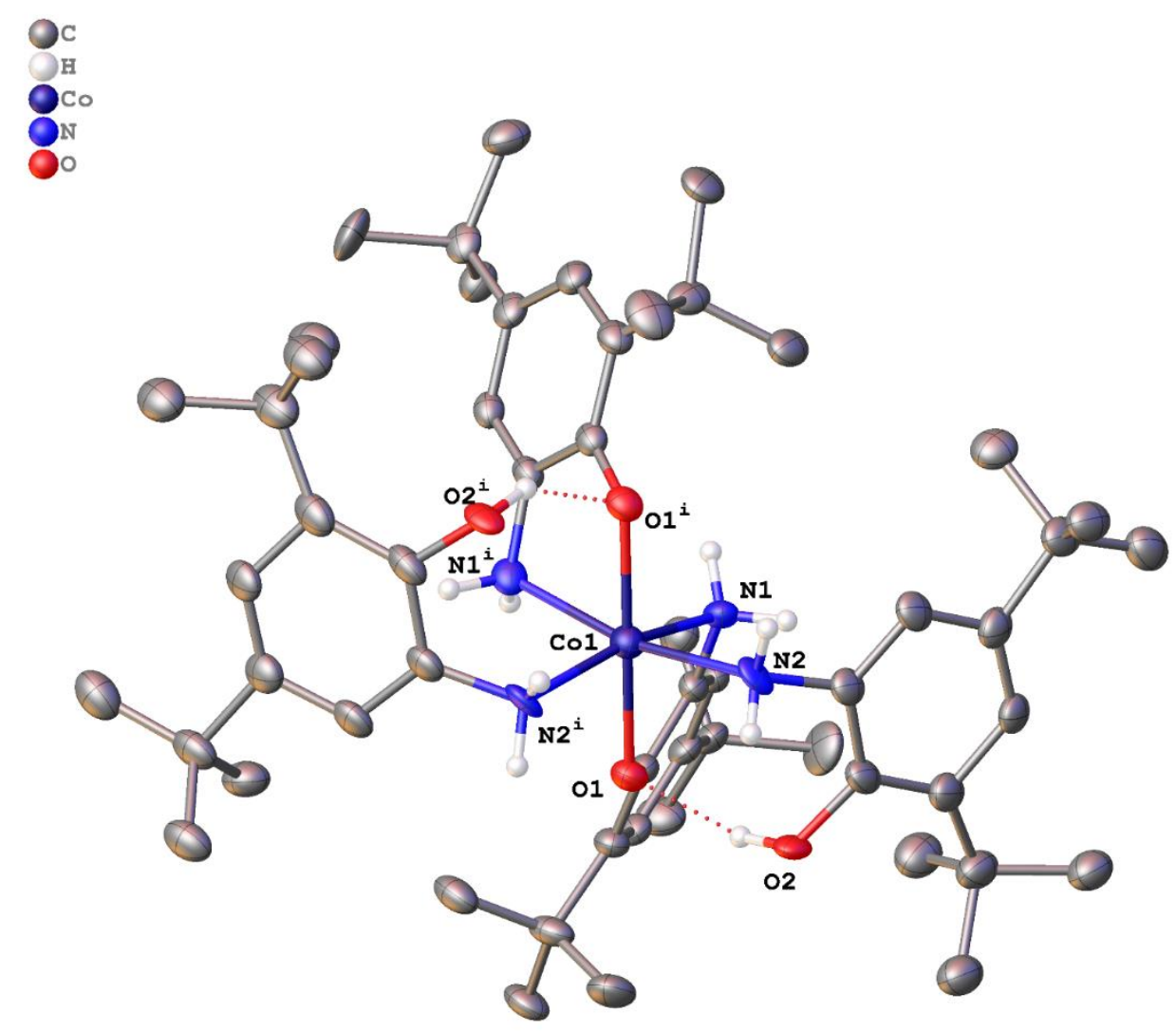

Figure 4.2. The structure of $\mathrm{Co}$ (2-amino-4,6-tert-butylphenolate $)_{2}$ (2-amino-4,6-tert-butylphenol $)_{2}$. All non-hydrogen atoms are dawn as $40 \%$ thermal probability ellipsoids. All hydrogen atoms except those on heteroatoms are omitted for clarity.

\subsubsection{Synthesis of $\mathrm{Co}^{\mathrm{III}}$ complex bearing 2-amino-4,6-di-tert-butyl phenol ligands $\mathrm{Co}_{2}{ }^{\mathrm{III}}(2-$ amino-4,6-tert-butylphenolate) 2 (2-amino-4,6-tert-butylphenol)( $\mu$-2-amido-4,6-tert- butylphenolate) 2}

The synthesis of the $\mathrm{Co}^{\mathrm{III}}$ complex bearing the same 2-amino-4,6-di-tert-butyl phenol was initially attempted by the homogenous aqueous synthesis employing air as the source of oxidant. Under the ambient atmosphere, numerous trials led to the generation of a mixture of products, which was difficult to purify due to the superior solubility of the products in most polar organic solvents or the mixed solvents. In these experiments, $\mathrm{CoCl}_{2}$ was treated with two or three equivalents of the 2-amino-4,6-di-tert-butylphenol ligands along with the same equivalents of bases. The reactions were carried out under either room temperature or reflux conditions in the presence of air, but no cobalt species shown in Scheme 4.7 were isolated as pure substances. The 
mixture of the products was extremely soluble in most organic solvents. The lack of bulky Nsubstitution on the aminophenolate ligand may also contribute to the instability of the formed product in solution when the reactions were carried out under an aerobic atmosphere. These observations were in accordance with similar discoveries by other research groups, that ligands such as catecholate and diamines usually would be unstable in solution when they are bound to metal centers, due to their distinctive ability to form radical species. ${ }^{159}$

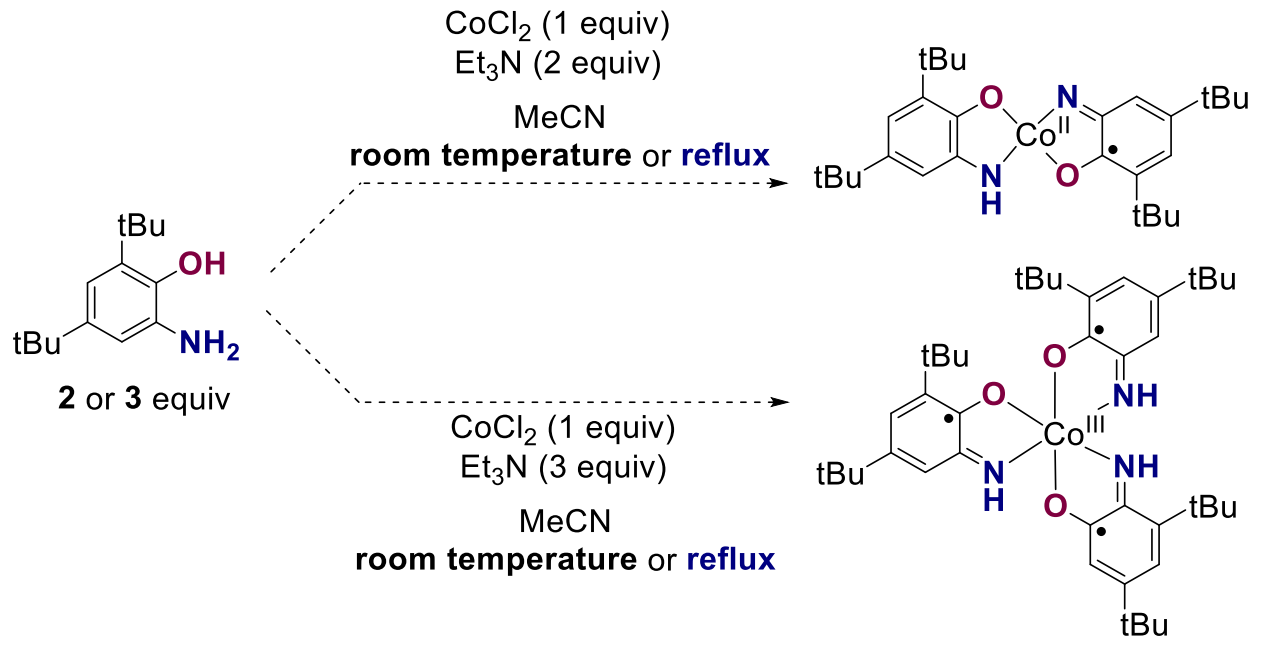

Scheme 4.7. Attempted synthesis of $\mathrm{Co}^{\mathrm{III}}-\mathrm{AP}^{\mathrm{ditBu}}$ complex in the aqueous medium under ambient atmosphere. Conditions: $\mathrm{CoCl}_{2}$ (1equiv), 2-amino-4,6-di-tert-butylphenol (2 or 3 equivs), triethylamine ( 2 or 3 equivs), acetonitrile. These reactions were carried out under ambient atmosphere either at room temperature or reflux conditions.

In one of Wieghart's studies, it was disclosed that when a comparable type of redox-active ligand 2-amino-4,6-di-tert-butyl thiophenol was employed in the synthesis of $\mathrm{Co}^{\mathrm{II}}$ complexes, solid state oxidation was observed immediately upon the exposure of $\mathrm{Co}^{\mathrm{II}}$ complex to the air, as indicated by the color change (Scheme 4.8). Inspired by this discovery, a small batch of $\mathrm{Co}^{\mathrm{II}}$ $\mathrm{AP}^{\mathrm{ditBu}}$ was taken out of the glovebox for testing of solid-state oxidation. An instant color change was observed from light grey to shinny dark violet when the compound was exposed to air, demonstrating the efficiency of solid-based oxidation to isolate the $\mathrm{Co}^{\mathrm{III}}$-aminophenolate complexes in this study. 

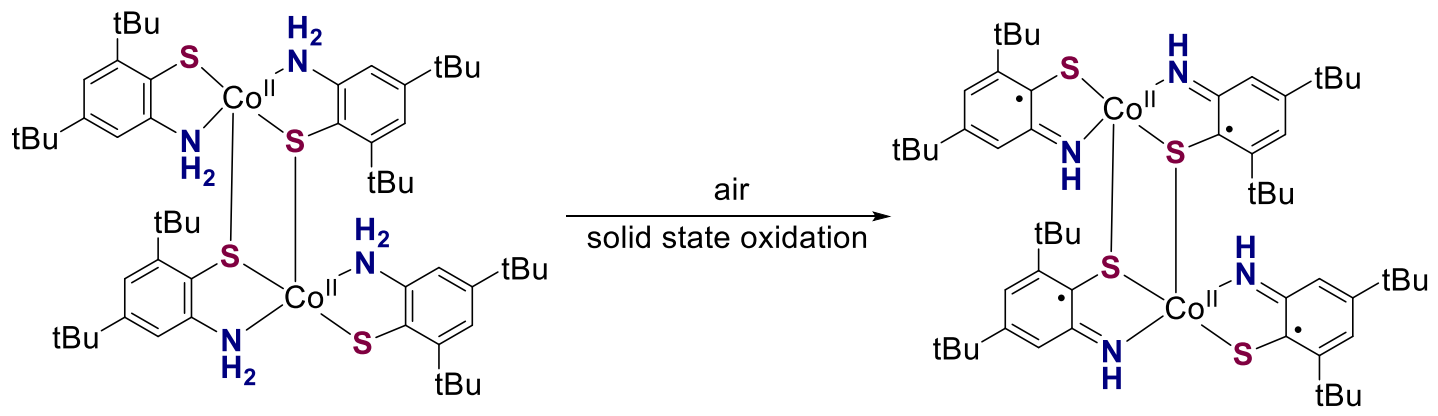

Scheme 4.8. Solid state oxidation observed by Wieghart group for the oxidation of the Co ${ }^{\mathrm{II}}$ complex $\left[\mathrm{Co}^{\mathrm{II}}\left(\mathrm{LS}^{\mathrm{AP}}\right)_{2}\right]_{2} \cdot 2 \mathrm{CH}_{3} \mathrm{CN}$ in the presence of air $\left(\mathrm{LS}^{\mathrm{AP}}=\right.$ 2-amino-4,6-di-tertbutylthiophenol).

Subsequently, we concentrated our efforts on the characterization of this oxidized compound. From our observations, the degree of solvation affected the rate at which oxidation of the $\mathrm{Co}^{\mathrm{II}}-\mathrm{AP}^{\mathrm{ditBu}}$ complex occurred. The presence of the solvent led to a slower rate of oxidation, whereas, the oxidation occurred in a few hours in the solid state. Elemental analysis confirmed the identity of the oxidized species to be a 3:1 ligand: metal complex, such as a monomeric complex $8 \mathbf{a}$ or $8 \mathbf{b}$ with three ligands coordinating to one cobalt center, as illustrated in the Scheme 4.9.

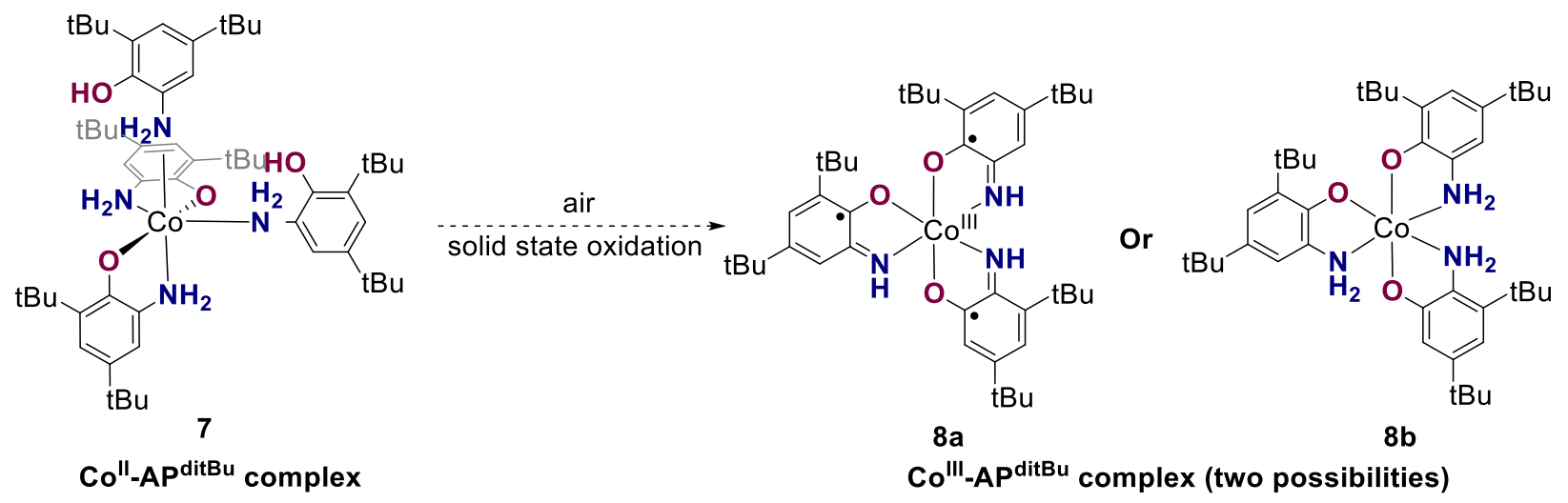

Scheme 4.9. Solid-state oxidation of metal complex $\mathrm{Co}^{\mathrm{II}}(2 \text {-amino-4,6-tert-butylphenolate })_{2}(2-$ amino-4,6-tert-butylphenol) $)_{2}$ under air.

A violet plate-shaped single crystal was able to be obtained by slow diffusion of pentane into dichloromethane dissolved with $\mathrm{Co}^{\mathrm{III}}-\mathrm{AP}^{\mathrm{ditBu}}$ complex under the rigorously anaerobic atmosphere and submitted to X-ray diffraction. The structure of the crystal was elucidated as a dimeric metal complex with the space group $P 21 / n$. Each cobalt center possesses three 
aminophenol-derived ligands with distinct coordinating environments (Figure 4.3), a neutral aminophenol ligand, a monoanionic aminophenolate ligand, and a bridging aminophenolate ligand connecting two cobalt centers via the $\mathrm{NH}$ group. Although the structure of this $\mathrm{Co}^{\mathrm{III}}-\mathrm{AP}^{\mathrm{ditBu}}$ complex revealed a dimeric species rather than monomeric as proposed, it is consistent with the elemental analysis of the compound collected from the solid-state oxidation.

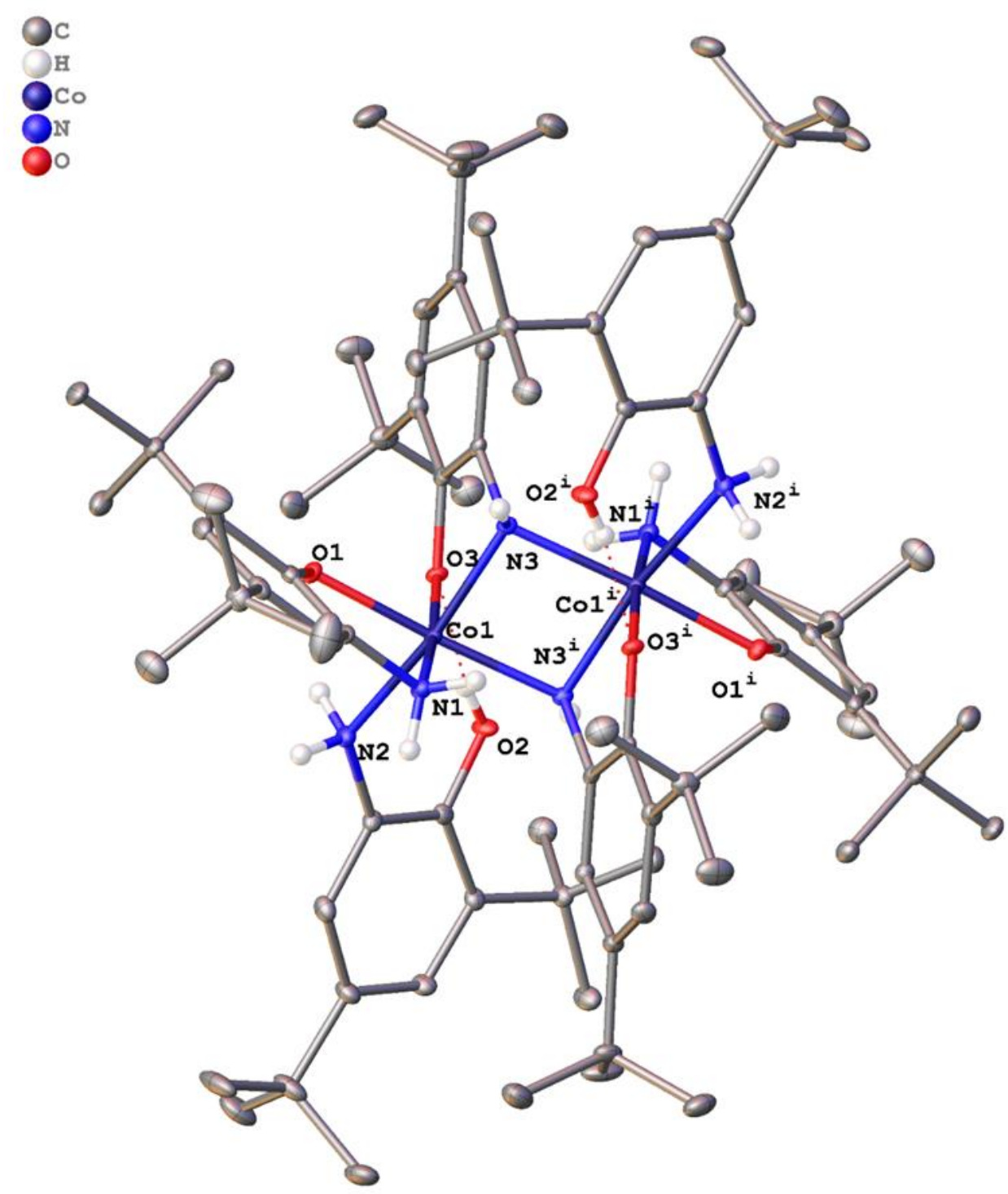

Figure 4.3. The structure of $\mathrm{Co}_{2}$ (2-amino-4,6-tert-butylphenolate) 2 (2-amino-4,6-tertbutylphenol)( $\mu$-2-amido-4,6-tert-butylphenolate) 2 . All non-hydrogen atoms are drawn as 50\% thermal probability ellipsoids. All hydrogen atoms except those on heteroatoms are omitted for clarity. 


\subsubsection{Evaluations of the Electronic Properties of $\mathrm{Co}^{\mathrm{II}}$-APditBu (7) and $\mathrm{Co}^{\mathrm{III}}$-APditBu Complexes}

\subsubsection{UV-Visible Spectroscopy}

The electronic properties of both $\mathrm{Co}^{\mathrm{II}}-\mathrm{AP}^{\mathrm{ditBu}}(7)$ and $\mathrm{Co}^{\mathrm{III}}-\mathrm{AP}^{\mathrm{ditBu}}(\mathbf{8})$ were evaluated by UV-visible spectroscopy (Figure 4.4). The electronic spectrum of complex (7) measured in $\mathrm{CH}_{2} \mathrm{Cl}_{2}$ displayed no intense absorption maxima above $450 \mathrm{~nm}$, suggesting that the ligands coordinated to the metal center are aromatic, in accordance with the X-ray structure. The electronic spectrum of $\mathrm{Co}^{\mathrm{III}}-\mathrm{AP}^{\mathrm{ditBu}}(\mathbf{8})$ presented two intense absorption maxima in $\mathrm{CH}_{2} \mathrm{Cl}_{2}$ solution around $550 \mathrm{~nm}\left(\varepsilon=3.6 \times 10^{3} \mathrm{M}^{-1} \mathrm{~cm}^{-1}\right)$ and $783 \mathrm{~nm}\left(\varepsilon=7.5 \times 10^{2} \mathrm{M}^{-1} \mathrm{~cm}^{-1}\right)$, which were absent for the $\mathrm{Co}^{\mathrm{II}}$ complex, indicating that a ligand to metal charge transfer may be involved. Although the X-ray crystal structure of this $\mathrm{Co}^{\mathrm{III}}$ compound showed aromatic coordinating ligands of 2-amino-4-6-ditert-butyl phenolate, in solution this compound may have radicals residing on the ligands, as suggested by the structure of $\mathbf{8 a}$. A series $\mathrm{Co}^{\mathrm{III}}$ complexes reported by Weighardt and co-workers consisting of $\mathrm{N}$-substituted iminosemiquinoate $\left(\mathrm{sq}^{-}\right)$ligands ${ }^{70}$ presented the most intense absorption maxima around $695 \mathrm{~nm}\left(\varepsilon=1.87 \times 10^{4} \mathrm{M}^{-1} \mathrm{~cm}^{-1}\right)$ and $884 \mathrm{~nm}\left(\varepsilon=1.03 \times 10^{4} \mathrm{M}^{-1} \mathrm{~cm}^{-1}\right)$. Compared to these observations, the much weaker absorption maxima of our $\mathrm{Co}^{\mathrm{III}}$ complex may be attributed to the low concentration of the cobalt species involving the ligand centered radical. Because our isolated species doesn't contain the N-substitution for stabilization in solution, the majority of these ligand-centered radicals are possibly delocalized and tautomerized and turn the ligand into aromatic aminophenolate coordinating to the metal center. 


\section{Co"-APditBu Complex}
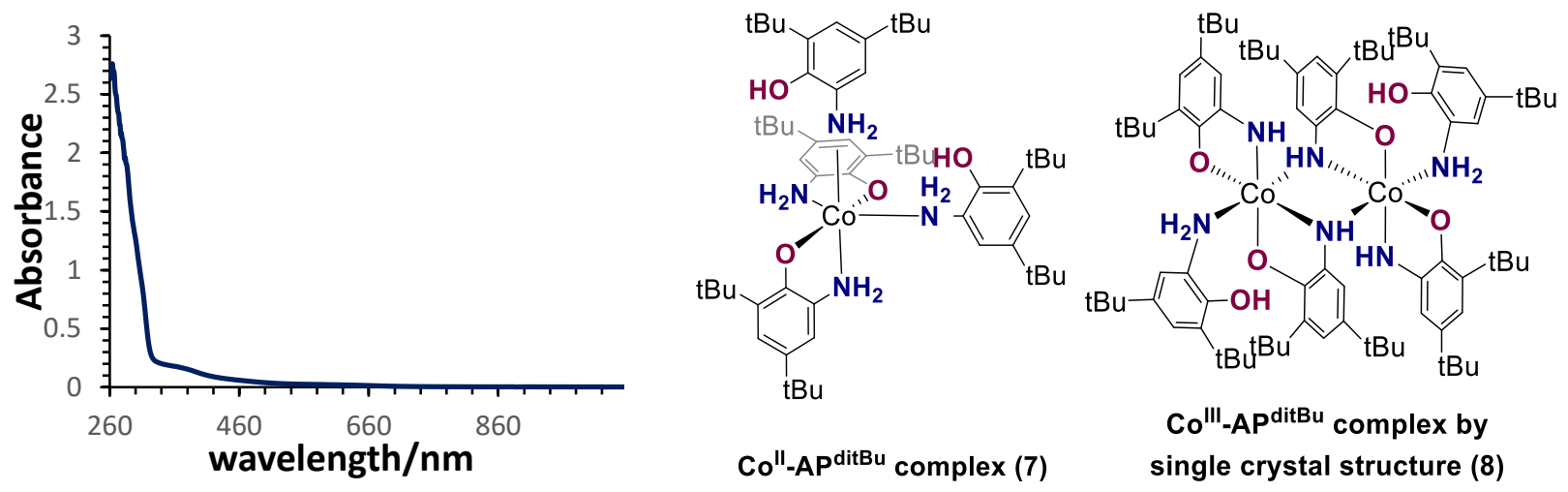

\section{Co'II-APditBu Complex}

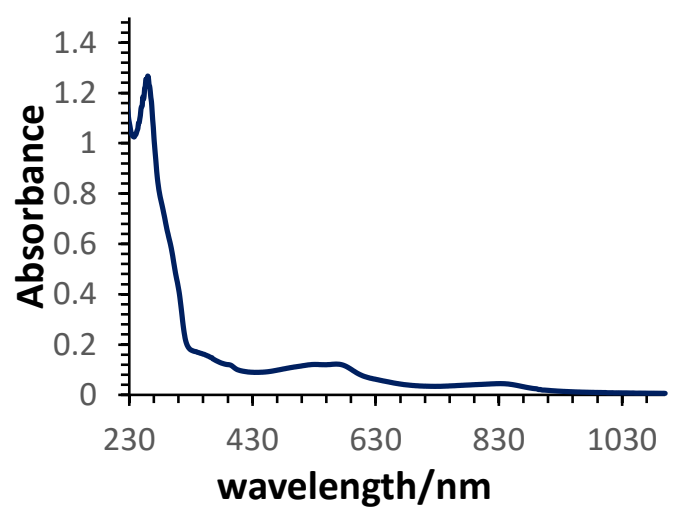

single crystal structure (8)

\section{(Concentrated)}

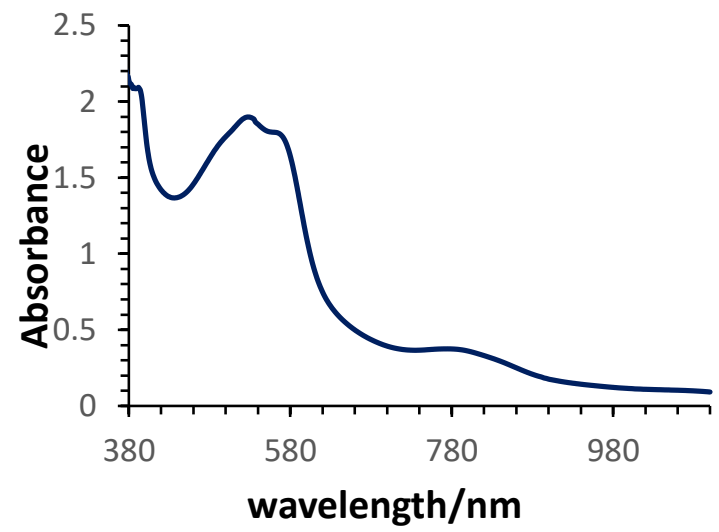

Figure 4.4. UV-visible spectroscopy of $\mathrm{Co}^{\mathrm{II}}$ - $\mathrm{AP}^{\mathrm{ditBu}}$ complex (7) and $\mathrm{Co}^{\mathrm{III}}-\mathrm{AP}^{\mathrm{ditBu}}$ complex (8). Top: Spectrum for $\mathrm{Co}^{\mathrm{II}}$-AP ${ }^{\mathrm{ditBu}}$ complex 7. Concentration: $1.1 \times 10^{-4} \mathrm{M}$ in $\mathrm{CH}_{2} \mathrm{Cl}_{2}$. Bottom left: Spectrum for $\mathrm{Co}^{\mathrm{III}}-\mathrm{AP}^{\mathrm{ditBu}}$ complex 8. Concentration: $5.0 \times 10^{-5} \mathrm{M}$ in $\mathrm{CH}_{2} \mathrm{Cl}_{2}$. Bottom right: Spectrum for $\mathrm{Co}^{\mathrm{III}}$-AP ${ }^{\mathrm{ditBu}}$ complex 8. Concentration: $5.0 \times 10^{-4} \mathrm{M}$ in $\mathrm{CH}_{2} \mathrm{Cl}_{2}$. All the above measurements were completed under $\mathrm{N}_{2}$ atmosphere.

\subsubsection{Cyclic Voltammetry}

We further investigated both $\mathrm{Co}^{\mathrm{II}}-\mathrm{AP}^{\mathrm{ditBu}}(\mathbf{7})$ and $\mathrm{Co}^{\mathrm{III}}-\mathrm{AP}^{\mathrm{ditBu}}(\mathbf{8})$ complexes by cyclic voltammetry. $\mathrm{Co}^{\mathrm{II}}-\mathrm{AP}^{\mathrm{ditBu}}$ complex 7 displayed a significant redox event at $\mathrm{E}_{1 / 2}=0.145 \mathrm{~V}$. Based on the $\left|\mathrm{E}_{\mathrm{pa}}-\mathrm{E}_{\mathrm{pc}}\right|$ values with different scan rates in comparison to ferrocene, this redox process for $\mathrm{Co}^{\mathrm{II}}$ complex is reversible. Additionally, the compound also exhibited a few irreversible oxidation and reduction events around $+1.0 \mathrm{~V}$ and $-0.8 \mathrm{~V}$. Compared to the $\mathrm{Co}^{\mathrm{II}}$ species, $\mathrm{Co}^{\mathrm{III}}-\mathrm{AP}^{\mathrm{ditBu}}$ 
complex 8 presented a significant different behavior under anaerobic atmosphere. The oxidation and reduction processes were completely irreversible when a higher potential $(>0 \mathrm{~V})$ was applied at the starting point. The complex showed a redox behavior highly similar to the $\mathrm{Co}^{\mathrm{II}}$ complex 7 with a lower applied potential, albeit a narrower window was observed. The redox events of this $\mathrm{Co}^{\mathrm{III}}$ species are quite different from those in the literature. In a study of a $\mathrm{Co}^{\mathrm{III}}$ complex consisting of tridentate benzoxazole amidophenoxide ligands, ${ }^{143}$ four redox couples were observed at $\mathrm{E}_{1 / 2}$ at $-0.67 \mathrm{~V},-0.20 \mathrm{~V},+0.28 \mathrm{~V}$, and $+0.84 \mathrm{~V}$ respectively. As both oxidation and reduction of this $\mathrm{Co}^{\mathrm{III}}$ were suggested as ligand-centered behaviors, we speculate that an irreversible decomposition occurred to our $\mathrm{Co}^{\mathrm{III}}$ complex $\mathbf{8}$ due to a lack of stabilizing $N$-substitutions.
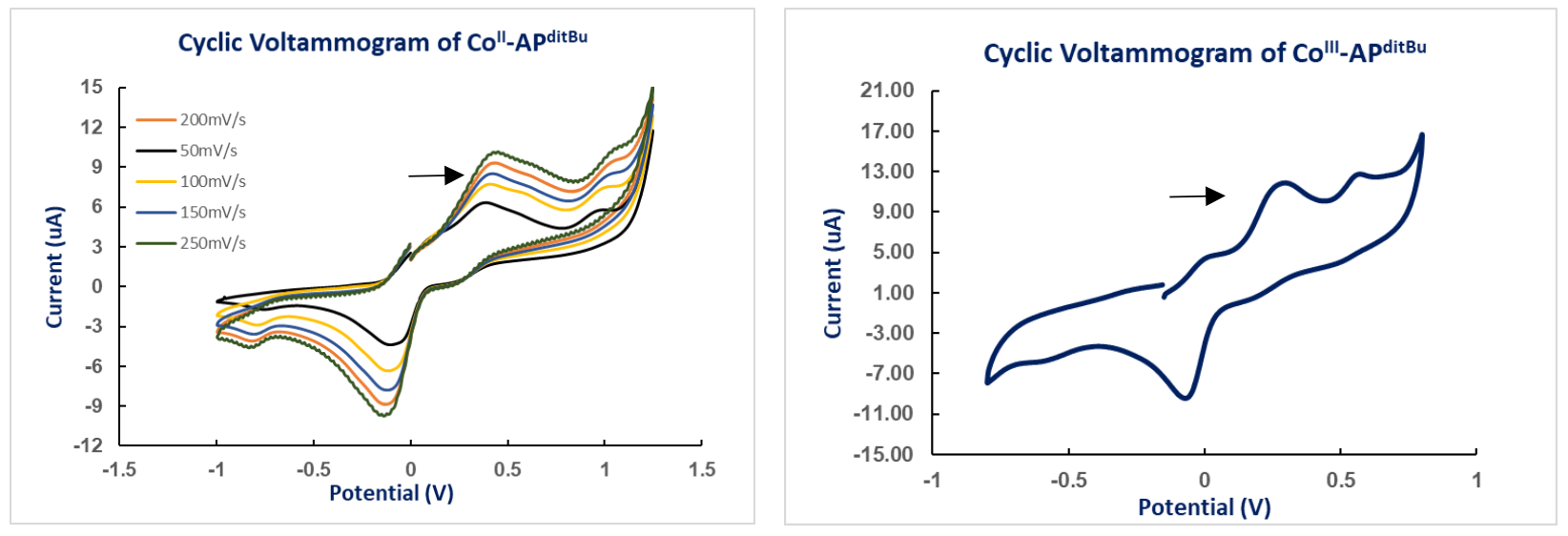

Figure 4.5. Cyclic voltammograms of $\mathrm{Co}^{\mathrm{II}}-\mathrm{AP}^{\mathrm{ditBu}}$ (7) and $\mathrm{Co}^{\mathrm{III}}$-AP ${ }^{\mathrm{ditBu}}$ (8). Left: Voltammograms of $\mathrm{Co}^{\mathrm{II}}-\mathrm{AP}^{\mathrm{ditBu}}$ (7). Conditions: $10 \mathrm{mM}$ complex, $0.10 \mathrm{M}\left[\mathrm{nBu}_{4} \mathrm{~N}\right]^{+}[\mathrm{PF} 6]^{-}$, scan rate 50, 100, 150, 200, $250 \mathrm{mV} \cdot \mathrm{s}^{-1}$, DMSO solution, $298 \mathrm{~K}$. Right: Voltammograms of Co $\mathrm{Co}^{\mathrm{III}}$-AP $\mathrm{P}^{\mathrm{ditBu}}$ (8). Conditions: $10 \mathrm{mM}$ complex, $\left.0.10 \mathrm{M}_{[\mathrm{nBu}} \mathrm{N}^{+}\right]^{+}[\mathrm{PF} 6]^{-}$, scan rate $100 \mathrm{mV} \cdot \mathrm{s}^{-1}$, DMSO solution, $298 \mathrm{~K}$. All of experiments were done under $\mathrm{N}_{2}$ atmosphere inside a glovebox.

\subsubsection{EPR Measurements (New section added)}

Both $\mathrm{Co}^{\mathrm{II}}-\mathrm{AP}^{\mathrm{ditBu}}$ complex (7) and $\mathrm{Co}^{\mathrm{III}}-\mathrm{AP}^{\mathrm{ditBu}}$ complex (8) were submitted to EPR measurements for the potential presence of ligand-centered radicals (Figure 4.6). Under $\mathrm{N}_{2}$ atmosphere, $\mathrm{Co}^{\mathrm{II}}$ exhibited no signals at $77 \mathrm{~K}$. When air was introduced into the tube, the sample was immediately sealed and frozen in liquid $\mathrm{N}_{2}$ for measurements. Intense signals were observed, suggesting radicals were generated in situ followed air oxidation (Figure 4.6 left). The signal of $\mathrm{Co}^{\mathrm{II}}$ complex upon air oxidation was calculated with a $g$ value equals to 2.001. A radical coupled to a nucleus was found with a nuclear spin of $7 / 2$ and an isotropic hyperfine coupling constant of 
28.1 Gauss. This hyperfine coupling constant was in a good agreement with a phenoxyl radical coupled to a cobalt ion previously reported from a $\mathrm{Co}^{\mathrm{III}}$ salen intermediate generated upon introducing the molecular oxygen. ${ }^{47}$ Our results combined with the literature precedence highlighted that a phenoxyl radical, or a carbon-centered ligand radical may exist in our system as a result of air oxidation. Compared to the species generated upon aerobic oxidation of $\mathrm{Co}^{\mathrm{II}}$, the signals observed for $\mathrm{Co}^{\mathrm{III}}$-AP ${ }^{\mathrm{ditBu}}$ complex (8) were a lot weaker and broader, probably due to the slow rotation of a frozen sample (Figure 4.6 right). Similarly, a $g$ value was calculated for these signals as 2.001. The spectrum of this complex also featured a coupling to one nucleus with a nuclear spin of 7/2 and an isotropic hyperfine coupling constant of 25.0 Gauss. The weak signals may also be attributed to a partial existence of the ligand-centered radicals. We performed the simulations for both $\mathrm{Co}^{\mathrm{II}}$ and $\mathrm{Co}^{\mathrm{III}}$ complexes by employing the parameters mentioned above. Simulating those parameters for $\mathrm{Co}^{\mathrm{II}}-\mathrm{AP}^{\mathrm{ditBu}}$ complex (7) recapitulated the line positions very well. As for $\mathrm{Co}^{\mathrm{II}}-\mathrm{AP}^{\mathrm{ditBu}}$ complex (8), the simulation fit the positions of the main features of the experimental spectrum very well especially on the low-field side (Simulated spectra not included).
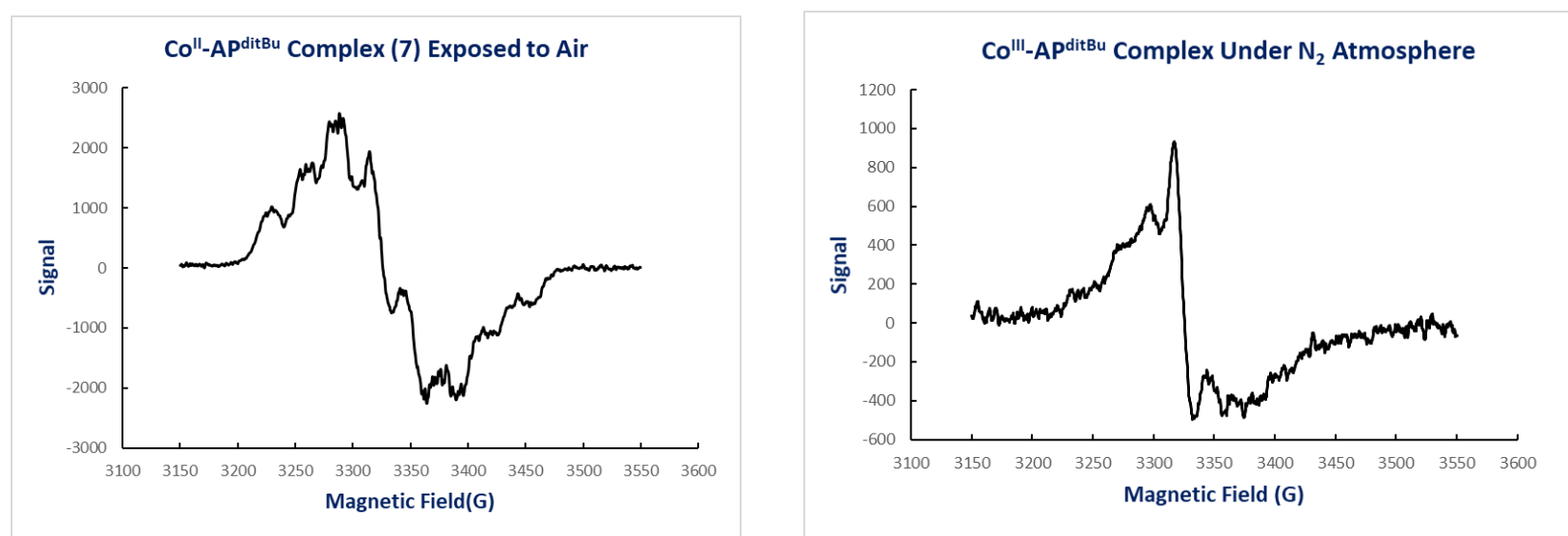

Figure 4.6. EPR spectra for $\mathrm{Co}^{\mathrm{II}}-\mathrm{AP}^{\mathrm{ditBu}}$ complex (7) and $\mathrm{Co}^{\mathrm{III}}$-AP ${ }^{\mathrm{ditBu}}$ complex (8). Left: EPR spectrum of $\mathrm{Co}^{\mathrm{II}}$-AP $\mathrm{AP}^{\mathrm{ditBu}}$ complex (7) exposed to air. Concentration: $1 \mathrm{mM}$ cobalt complex in dichloromethane. The sample was prepared inside a $\mathrm{N}_{2}$ filled glovebox. The spectrum was taken immediately after the sample was exposed to air then frozen in liquid $\mathrm{N}_{2}$. Spectrum measured at 77K. Right: EPR spectrum of $\mathrm{Co}^{\mathrm{III}}-\mathrm{AP}^{\mathrm{ditBu}}$ (8). Concentration: $1 \mathrm{mM}$ cobalt complex in dichloromethane. The sample was prepared inside a $\mathrm{N}_{2}$ filled glovebox and properly sealed. The spectrum was taken under $\mathrm{N}_{2}$ at $77 \mathrm{~K}$. 


\subsubsection{Aerobic Oxidation of $\mathrm{Co}^{\mathrm{II}}(2$-amino-4,6-tert-butylphenolate) 2 (2-amino-4,6-tert- butylphenol)2 in solution}

Next, the oxidation behavior of the isolated $\mathrm{Co}^{\mathrm{II}}$ complex $\mathbf{7}$ in solution was investigated. A sample of the $\mathrm{Co}^{\mathrm{II}}$ complex and dimethyl sulfone as an internal standard were placed in a J. Young NMR tube, then air was introduced into the headspace of the same tube. A 1:1 mixture of deuterated DMSO and chloroform was employed as the solvent system due to the extreme difference in polarity between the low-valent $\mathrm{Co}^{\mathrm{II}}$ complex and the oxidized intermediate. The insitu oxidation was monitored with ${ }^{1} \mathrm{H}$ NMR spectroscopy. Upon oxidation, we observed the ligand dissociation shown in the Figure 4.7, which was accompanied with the generation of a diamagnetic intermediate. The presence of an internal standard confirmed that the oxidation of the low-valent $\mathrm{Co}^{\mathrm{II}}-\mathrm{AP}^{\mathrm{ditBu}}$ to the intermediate accomplished within a few hours. The spectrum indicated an asymmetric structure for the diamagnetic intermediate, which includes 6 distinct aromatic protons and 6 different tert-butyl groups from the oxidized cobalt intermediate along with 6 exchangeable protons associated with $\mathrm{NH}$ group. Also found were the protons belonging to the dissociated 2-amino-4,6-di-tertbutyl ligand, and the ratio between the two species was exactly 1:1 according to the calculation based on the internal standard in solution.

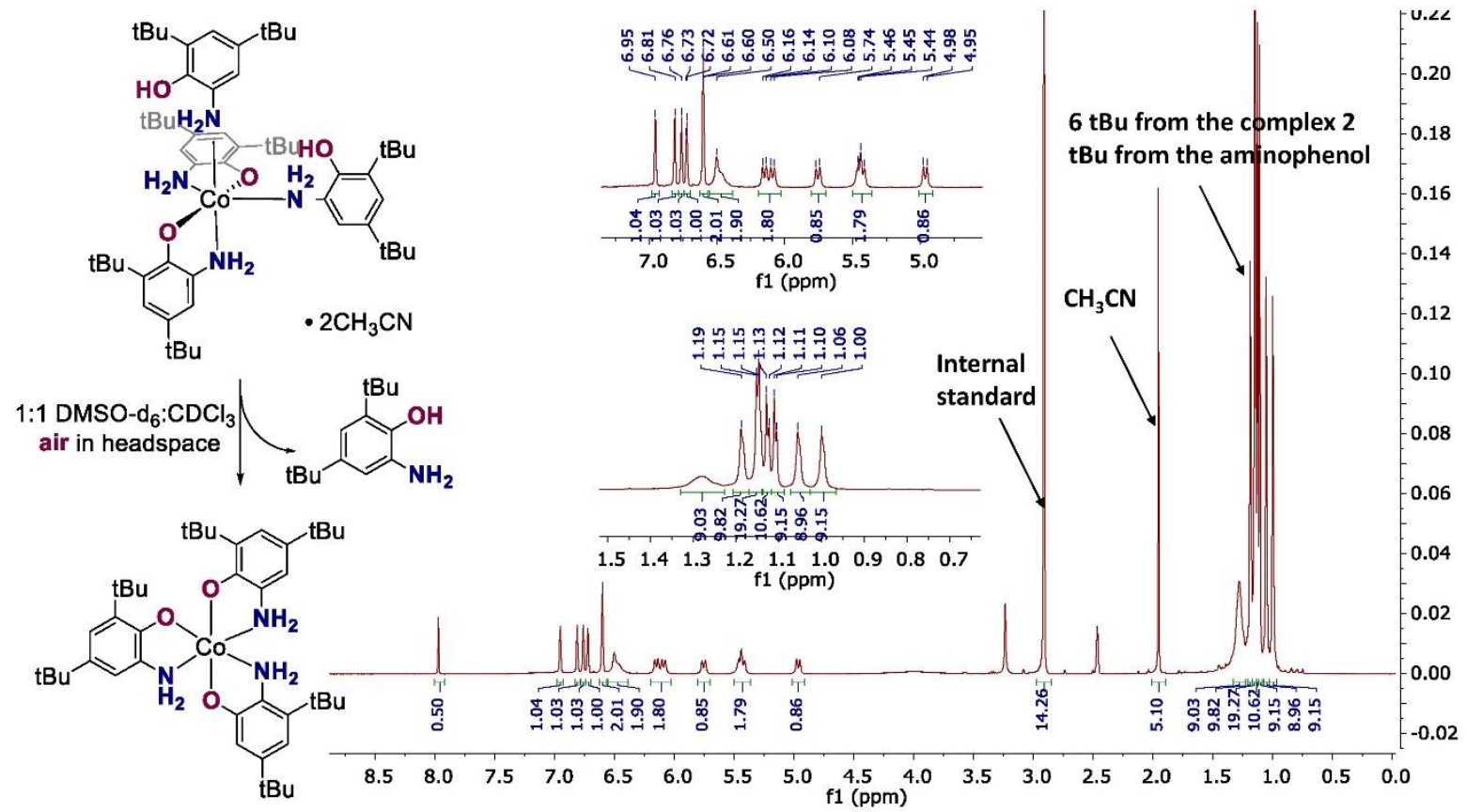

Figure 4.7. Aerobic oxidation of the $\mathrm{Co}^{\mathrm{II}}-\mathrm{AP}^{\mathrm{ditBu}}$ complex with dissociation of a ligand monitored by ${ }^{1} \mathrm{H}$ NMR spectroscopy. 
The exchangeability of NH protons associated with the diamagnetic cobalt intermediate was further confirmed by the in-situ deuterium-exchange experiment (Figure 4.8). The peaks between $6.5 \mathrm{ppm}$ and $5.0 \mathrm{ppm}$ all disappeared when the same sample was treated with a few drops of $\mathrm{D}_{2} \mathrm{O}$.

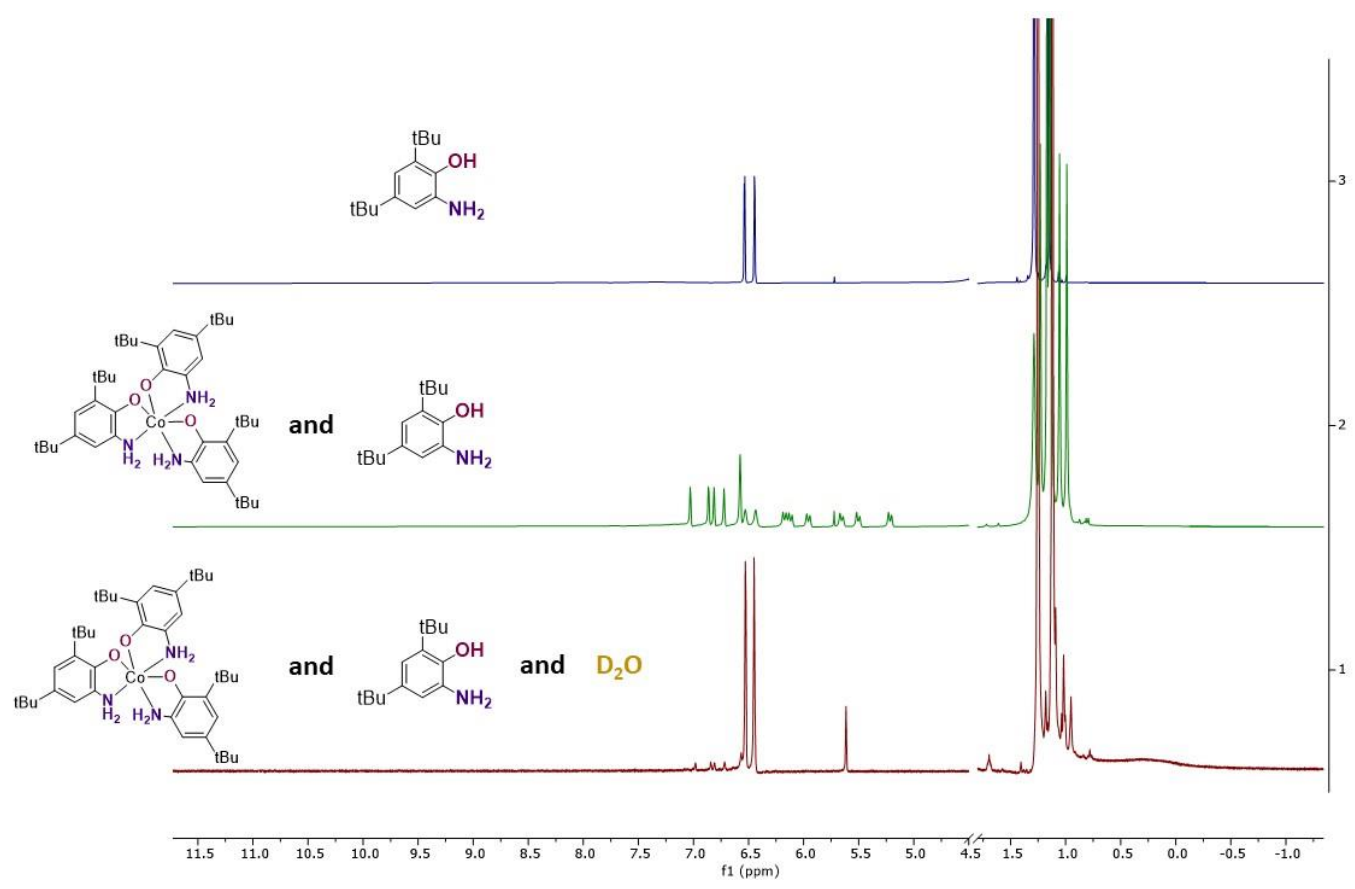

Figure 4.8. Deuterium exchange experiment of the oxidized cobalt intermediate. Standard spectrum of the ligand was included for reference.

\subsubsection{Reactivity of $\mathrm{Co}^{\mathrm{II}}$ and Co ${ }^{\mathrm{III}}$ Complexes in the Standard Aerobic Oxidative Coupling Systems}

4.2.5.1. Catalytic and Stoichiometric Reactivity of $\mathrm{Co}^{\mathrm{II}}-\mathrm{AP}^{\mathrm{ditBu}}$ complex (7) in the Oxidative Cyclization Reactions

In order to test for the catalytic competency of the isolated $\mathrm{Co}^{\mathrm{II}}$ complex 7 , the $\mathrm{Co}^{\mathrm{II}}(2-$ amino-4,6-tert-butylphenolate) ${ }_{2}(2 \text {-amino-4,6-tert-butylphenol })_{2}, \quad 10 \mathrm{~mol} \%$ of catalyst was employed in the experiments shown in Scheme 4.10. In the first control experiment (a), 2-amino4,6-di-tert-butyl phenol was employed as both the substrate and the ligand for the Co ${ }^{\text {II }}$ complex. The reaction was carried out in acetonitrile for 24 hours with air as the source of stoichiometric 
oxidant and delivered exclusively the desired benzoxazole $\mathbf{3 w}$ in $90 \%$ yield. However, the formation of two distinct benzoxazoles were observed in the control experiment (b) when unsubstituted 2-aminophenol was used as a substrate. With the same reaction conditions, product 3a from the oxidative cyclization with 2-amionphenol was observed with 55\% yield along with the other product 3w in 32\% yield, which derived from 2-amino-4,6-di-tert-butyl phenolate ligand for the $\mathrm{Co}^{\mathrm{II}}$ complex. These experiments demonstrated 1) the isolated $\mathrm{Co}^{\mathrm{II}}-\mathrm{AP}^{\mathrm{ditBu}}$ complex is catalytically competent; 2) the ligand 2-amino-4,6-di-tertbutyl phenol can dissociate from the cobalt center in solution and engage in the oxidative cyclization reactions with the isocyanide.

(a)<smiles>CC(C)(C)c1cc(N)c(O)c(C(C)(C)C)c1</smiles>

(b)

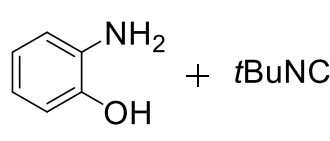

Co"-AP complex
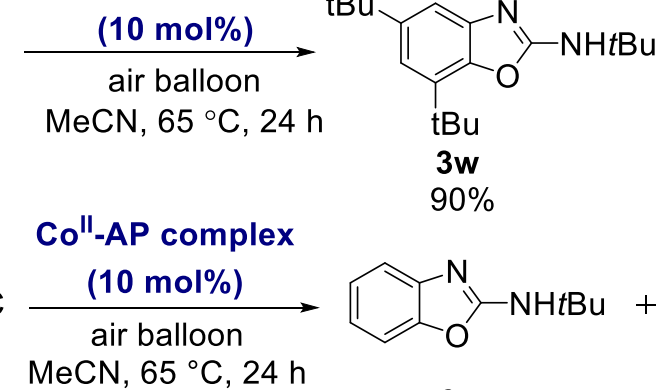

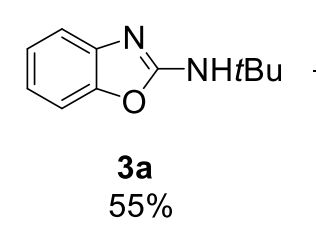

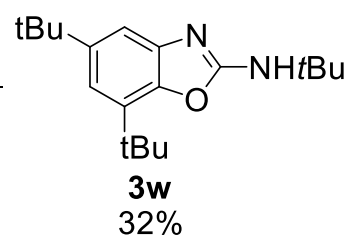

Scheme 4.10. Catalytic control experiments of $\mathrm{Co}^{\mathrm{II}}-\mathrm{AP}^{\mathrm{ditBu}}$ complex (7) in the aerobic oxidative cyclization reactions.

The experiment was repeated using stoichiometric amounts of $\mathrm{Co}^{\mathrm{II}}$ complex (7) under an anaerobic atmosphere shown in the Scheme 4.11. In this case, product 3w was not observed from the oxidative cyclization. We attribute this observation to the incompetency of the low valent $\mathrm{Co}^{\mathrm{II}}$ for this transformation, which is in agreement with the findings in Chapter 2. In a stoichiometric control experiment where 1 equiv of $\mathrm{Co}(\mathrm{OAc})_{2}$ was employed to mediate the oxidative cyclization of 2-aminophenol and tert-butyl isocyanide under inert atmoshphere, only $10 \%$ of the desired product was generated. This result reconfirmed the requirement of an oxidant to initiate the cyclization reactions and stoichiometric amount of $\mathrm{Co}^{\mathrm{II}}$ is insufficient in this transformation. 


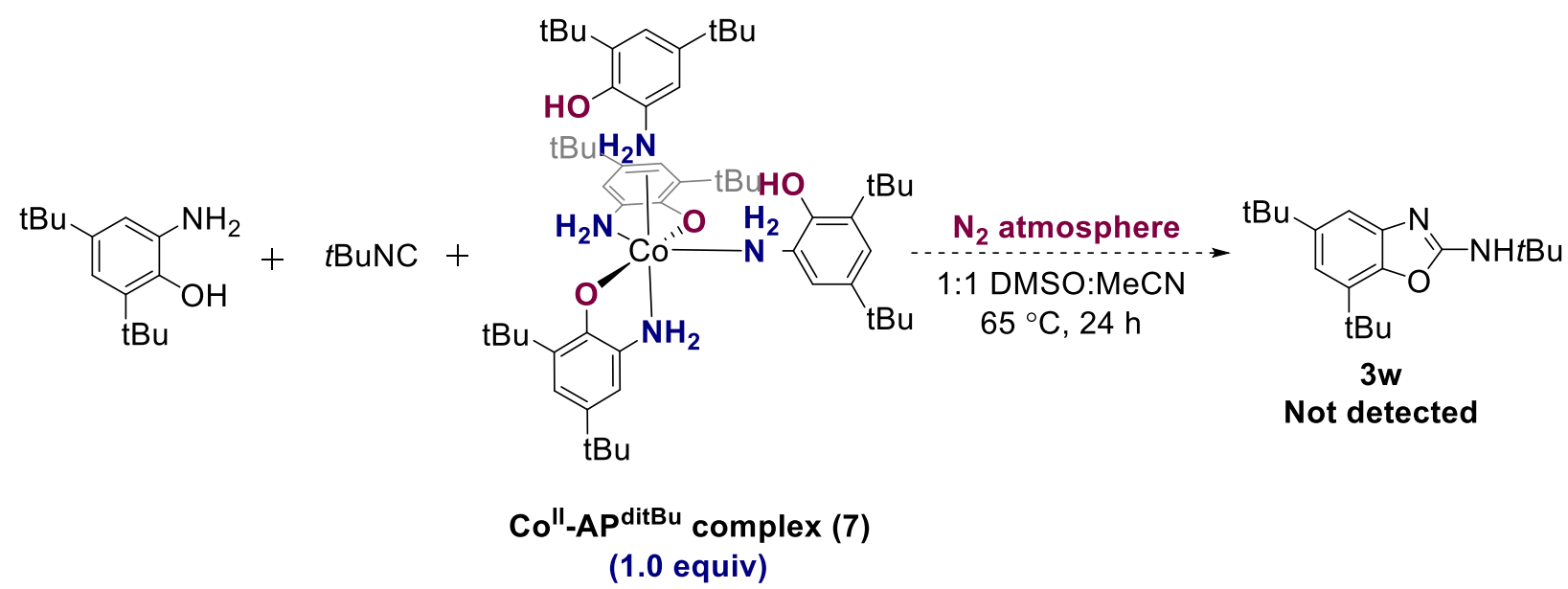

Scheme 4.11. Stoichiometric control experiments of $\mathrm{Co}^{\mathrm{II}}-\mathrm{AP}^{\mathrm{ditBu}}$ complex (7) under anaerobic reaction conditions.

\subsubsection{Catalytic and Stoichiometric Reactivity of $\mathrm{Co}^{\mathrm{III}}$ Complex (8) in the Oxidative Cyclization} Reactions

The reactivity of the $\mathrm{Co}^{\mathrm{III}}-\mathrm{AP}^{\mathrm{ditBu}}$ Complex $(\mathbf{8})$ in both catalytic and stoichiometric reaction systems was also evaluated. Catalytic competency of this compound was initially investigated under the aerobic reaction conditions (Scheme 4.12). When 2-amino-4,6-di-tert-butylphenol was employed as a substrate under the standard condition, only $43 \%$ of the compound $\mathbf{3 w}$ was generated as the major product. In the cross-over control experiment shown in Scheme 4.12b, unsubstituted $o$-aminophenol was employed to couple with tert-butyl isocyanide and generated 3a in 55\% yield as the only product. This distinct observation compared to the catalytic control with $\mathrm{Co}^{\mathrm{II}}$ complex 7 demonstrated a significantly different behavior of the $\mathrm{Co}^{\mathrm{III}}$ complex in terms of the ligand dissociation. When the tert-butyl isocyanide is replaced with cyclohexyl isocyanide in the standard reaction, the desired product $\mathbf{3 x}$ was generated in 53\% yield. While in these three catalytic reactions the yields are moderate compared to the reactivity of $\mathrm{Co}^{\mathrm{II}}$, these results still demonstrate the catalytic competency of the $\mathrm{Co}^{\mathrm{III}}$ complex with $4 \sim 5$ turnovers, albeit the reaction pathway might be completely different. The slightly diminished yields could be attributed to the slow ligand dissociation and reassociation for $\mathrm{Co}^{\mathrm{III}}$ complex in the presence of $\mathrm{O}_{2}$. Upon dissociation, the 2amino-4,6-di-tert-butylphenol ligand may be decomposed via an oxidative ring opening pathway as described in the introduction section, which explains the reason that in control experiment (b), the formation of the cross-over product was not observed. 
(a) Standard Reaction Condition

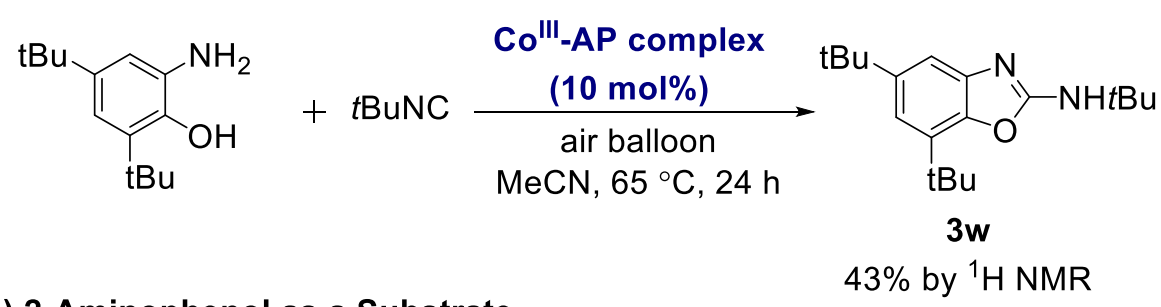

(b) 2-Aminophenol as a Substrate

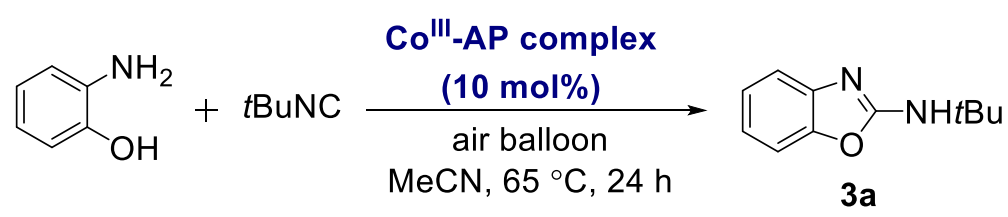

(c) Cyclohexyl Isocyanide as a Substrate

$55 \%$ by ${ }^{1} \mathrm{H}$ NMR

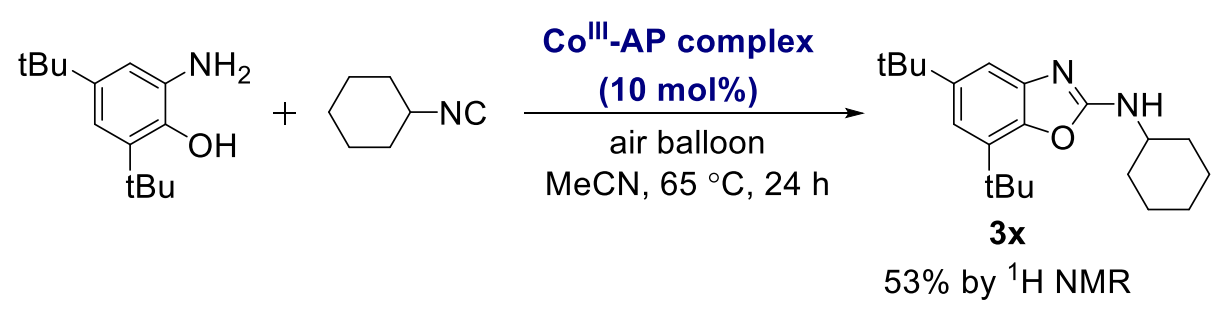

Scheme 4.12. Catalytic control experiments of $\mathrm{Co}^{\mathrm{III}}-\mathrm{AP}^{\mathrm{ditBu}}$ complex (8) under aerobic oxidative cyclization conditions.

The stoichiometric reactivity of the $\mathrm{Co}^{\mathrm{III}}$ was also evaluated. Control experiments were carried out by standard Schlenk line operation under both $\mathrm{N}_{2}$ and $\mathrm{O}_{2}$ atmosphere with 1 equivalent of the coupling partner, tert-butyl isocyanide (Scheme 4.13). As no desired product 3w was observed in either case, the reaction vessel was reinvestigated to reduce the potential loss of the volatile isocyanide through the Schlenk line. When the same reaction was carried out in a pressure tube under inert atmosphere, $\mathbf{3}$ w was still not detected. Of note, the three control experiments, regardless of the aerobic or anaerobic conditions, gave very comparable results. While no expected product was generated, these reactions yielded identical mixtures as indicated by ${ }^{1} \mathrm{H}$ NMR spectroscopy. These species may be related to one or multiple unknown cobalt complexes bearing 2-amino-4,6-di-tert-butylphenol derived ligands, as illustrated by multiple tert-butyl groups in the aliphatic range. Under such reaction conditions, cyclized product of $\mathbf{3} \mathbf{w}$ not being observed may be attributed to 1) slow rate of ligand dissociation from the cobalt metal center and 2) the 
concentration of tert-butyl isocyanide is too low to trap any phenoxyl radical and then form the cyclized products.
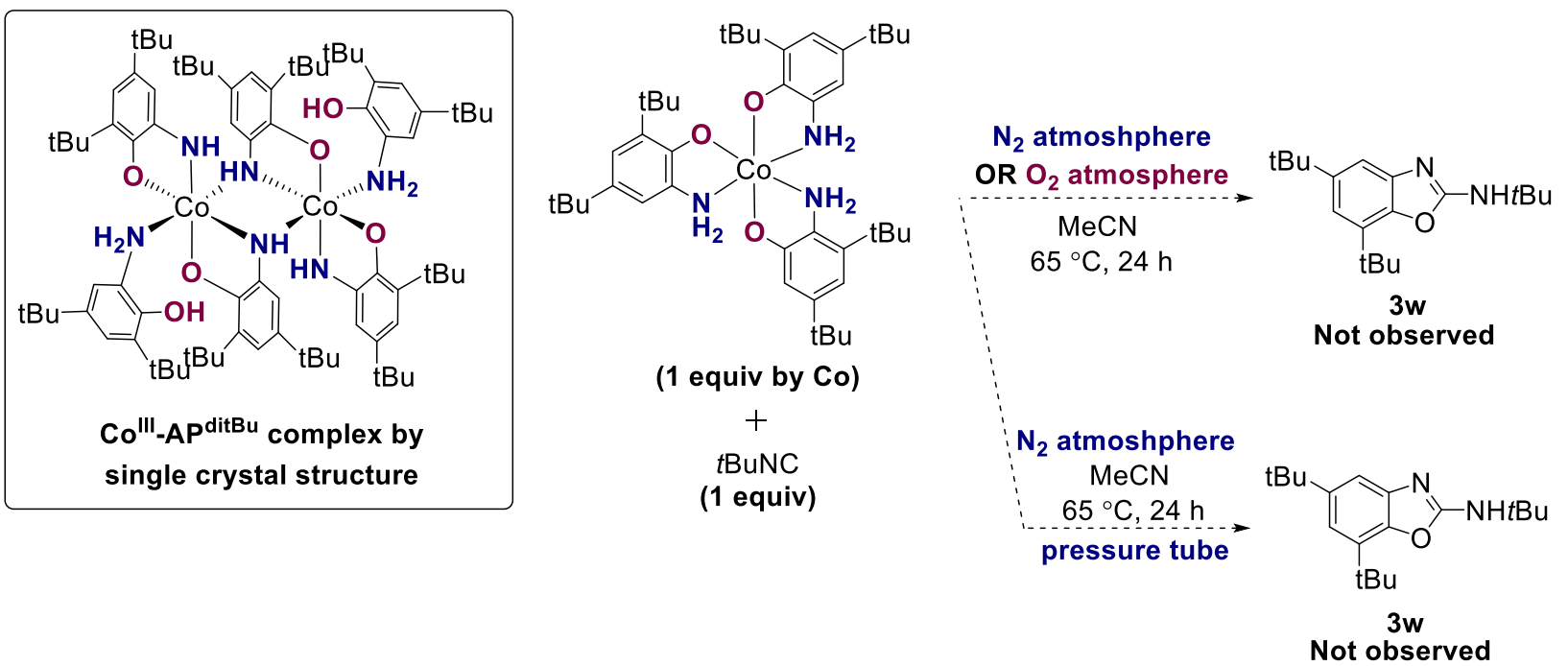

Scheme 4.13. Stoichiometric control experiments with $\mathrm{Co}^{\mathrm{III}}-\mathrm{AP}^{\mathrm{ditBu}}$ complex (8) under both aerobic and anaerobic atmosphere.

Moving forward, the ability of $\mathrm{Co}^{\mathrm{III}}$ complex in mediating the oxidative cyclization reactions under anaerobic atmosphere was also investigated. Both 2-amino-4,6-di-tert-butylphenol and tert-butyl isocyanide were present in this set of experiments with the catalyst loading as the only variation under the $\mathrm{N}_{2}$ atmosphere (Scheme 4.14). It was interesting to find that the yields of the desired product $\mathbf{3 w}$ in this transformation were nearly proportional to the loading of the $\mathrm{Co}^{\mathrm{III}}$ catalyst (8). The reactions carried out with $0.5,0.7$ and 1.0 equivalent of $\mathrm{Co}^{\mathrm{III}}$ catalyst afforded the product with the yields $42 \%, 64 \%$ and $93 \%$ respectively. These results indicated $\mathrm{Co}^{\mathrm{III}}$ might be the active species in mediating the oxidative cyclization reactions. Combined with the results from the above control experiments in the absence of 2-amino-4,6-di-tertbutyl phenol substrate (Scheme 4.13), it was assumed that the dissociated ligand from the $\mathrm{Co}^{\mathrm{III}}$ complex is not able to reversibly bind to the cobalt center, therefore, in the case where no aminophenol substrate was present, a new cobalt complex from ligand exchange will not be formed thus cannot undergo the transition-metal mediated interaction with tert-butyl isocyanide to form the cyclized product. Unfortunately, the fate of the dissociated ligand cannot be confirmed at the current stage, although some type of decomposition is highly suspected. 


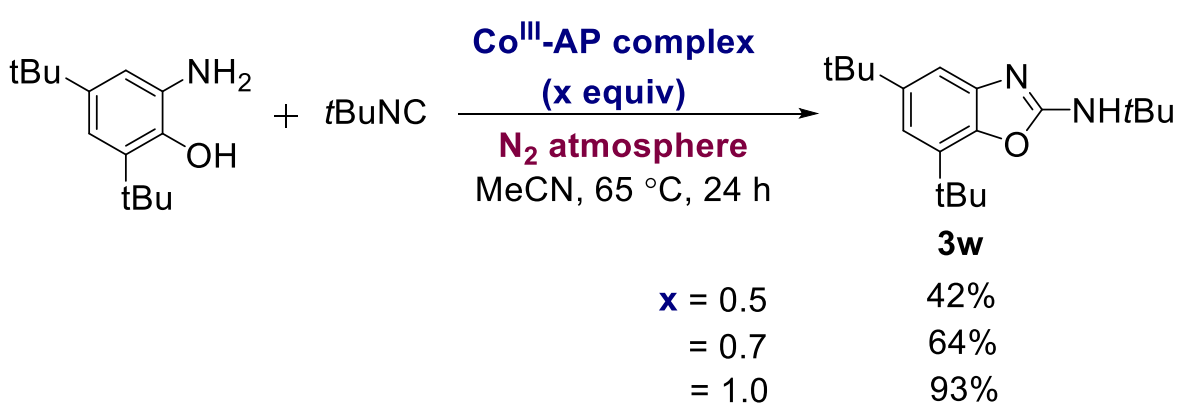

Scheme 4.14. Reactivity of $\mathrm{Co}^{\mathrm{III}}-\mathrm{AP}^{\mathrm{ditBu}}$ complex in oxidative cyclization reactions under $\mathrm{N}_{2}$ atmosphere.

\subsection{Conclusive Summary}

In summary, the work in this chapter is focused on the synthesis and reactivity studies of cobalt complexes bearing bisnucleophile-derived ligands as potentially active intermediates for aerobic oxidative cyclization transformations developed in the previous two chapters. 2-amino4,6-di-tert-butyl phenol was employed as a model ligand in the metal complex synthesis for solubility and stability considerations. Two unprecedented cobalt complexes were isolated with unique coordinating environments, $\mathrm{Co}^{\mathrm{II}}(2$-amino-4,6-tert-butylphenolate) 2 (2-amino-4,6-tertbutylphenol $)_{2}$ and $\mathrm{Co}_{2}{ }_{2}{ }^{\mathrm{III}}$ (2-amino-4,6-tert-butylphenolate) $)_{2}$ (2-amino-4,6-tert-butylphenol)( $\mu$-2amido-4,6-tert-butylphenolate)2. To date, these two compounds are the first examples of welldefined cobalt complexes that bear ortho-aminophenol ligands with unsubstituted $\mathrm{NH}_{2}$ groups. Notably, the bulky $N$-substitutions on the most commonly used aminophenol-derived ligands play a critical role in stabilizing cobalt complexes in the presence of $\mathrm{O}_{2}$. Preliminary studies on their abilities to mediate oxidative cyclization reactions have demonstrated the catalytic and stoichiometric competencies of both the $\mathrm{Co}^{\mathrm{II}}$ and $\mathrm{Co}^{\mathrm{III}}$ complexes. Both complexes are capable of participating in $\mathrm{O}_{2}$ activation. Under the catalytic reaction conditions, the ligand on $\mathrm{Co}^{\mathrm{II}}$ complex can reversibly bind to the metal center and engage in the aerobic oxidative cyclization. The interaction of the ligand with the metal center in these $\mathrm{Co}^{\mathrm{III}}$ complexes is irreversible upon $\mathrm{O}_{2}$ activation, as suggested by cross-over experiments in the context. In this regard, the $\mathrm{Co}^{\mathrm{II}}$ and the $\mathrm{Co}^{\mathrm{III}}$ complexes mediate the reaction via different pathways. Although the fate of the dissociated aminophenol ligands is still not clear at the current stage, these data combined support our earlier proposed mechanistic pathways in Chapter 2. Our study convinced the dual functionality of the 
bis-nucleophile as both a substrate and a redox-active ligand. The isolated complexes bearing 2amino-4,6-di-tert-butylphenol ligand are capable of activating molecular oxygen and mediating the oxidative cyclization reactions. We believe these studies on the cobalt complexes derived from our reaction system will shed a light on deeper insights for future relevant works.

\subsection{Experimental Section}

\subsubsection{General Considerations}

${ }^{1} \mathrm{H}$, and ${ }^{13} \mathrm{C}\left\{{ }^{1} \mathrm{H}\right\}$ NMR spectra were recorded on an Agilent $400 \mathrm{MHz}$ spectrometer or a JEOL $400 \mathrm{MHz}$ spectrometer. Chemical shifts are given in parts per million and referenced to the residual solvent signal; ${ }^{135}$ all coupling constants are reported in Hz. High resolution mass spectra were obtained on a Thermo Finnigan Linear Trapping Quadrupole mass spectrometer. IR spectra were recorded on a PerkinElmer (Spectrum 100) FT-IR spectrometer. Column chromatography was performed using Silicycle SiliaFlash P60 silica gel.

Dry solvents were taken from a solvent system which passes the solvent through a column of activated molecular sieves. All deuterated solvents were purchased from Cambridge Isotope Laboratories. All other chemicals were purchased from commercial sources and used without further purification unless otherwise noted. Air to fill air balloons was obtained from a house compressed air system. $\mathrm{O}_{2}$ used in control reactions was purchased from Airgas. Both air and $\mathrm{O}_{2}$ sources were used as received without drying tubes or additional precautions to remove trace water. IR spectra were recorded on a Perkin Elmer (Spectrum 100) FT-IR spectrometer. High resolution mass spectra were obtained on a Thermofisher Scientific Q Exactive Mass Spectrometer. Elemental analyses were performed by Atlantic Microlab, Inc., Norcross, GA.

\subsubsection{Synthesis of 2-amino-4,6-di-tert-butyl phenol ligand}

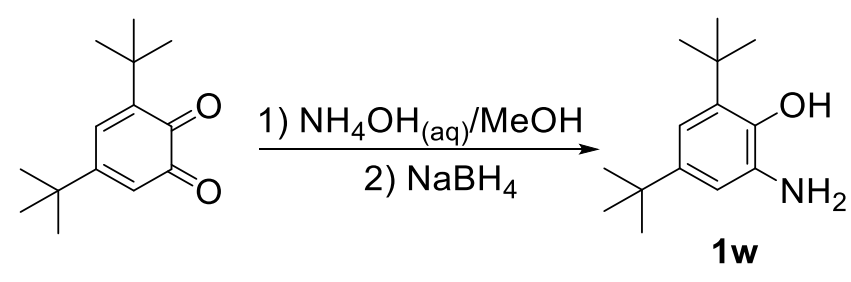


The synthesis was based on the modified literature procedure. ${ }^{166}$ In a $500 \mathrm{~mL}$ round bottom flask, 3,5-di-tertbutyl-1,2-benzoquinone (7.91g, $35.9 \mathrm{mmol}, 1.0$ equiv) was dissolved in a mixture of methanol and concentrated ammonium hydroxide $(200 \mathrm{~mL} / 80 \mathrm{~mL})$ and stirred for $10 \mathrm{~min}$. Upon dissolution, sodium borohydride (3.23g, $85.4 \mathrm{mmol}$, 2.2. equiv) was added as solid portion by portion over a period of $60 \mathrm{~min}$. The mixture was allowed to stir at room temperature for another 1 hour. Upon completion, the reaction mixture was quenched by pouring slowly into $1 \mathrm{~L}$ of ice water, then exacted three times with ethyl acetate $(3 \times 150 \mathrm{~mL})$. The combined organic phase was washed with brine, separated, dried over anhydrous sodium sulfate and filtered. The solvent was removed via the rotary evaporation to yield the crude compound. High purity 2-amino-4,6-ditertbutyl phenol $\mathbf{1 w}$ was generated by repetitive washing and decant with hexane, giving the desired product as a pale-yellow powder (5.65g, $25.5 \mathrm{mmol}, 71 \%)$. Elemental Analysis: calculated $\mathrm{C}_{14} \mathrm{H}_{23} \mathrm{NO}, \mathrm{C}: 75.97$; H: 10.47; N: 6.33; found: C: 76.18; H: 10.58; N: 6.32. ${ }^{1} \mathrm{H}-\mathrm{NMR}$ (400 MHz, DMSO-D $) \delta 6.54(\mathrm{~d}, \mathrm{~J}=2.3 \mathrm{~Hz}, 1 \mathrm{H}), 6.44$ (d, J = 2.3 Hz, 1H), 4.41 (s, 2H), 1.29 (s, 9H), 1.15 (s, 9H).

\subsubsection{Synthesis of 5,7-di-tert-butyl-2-(tert-butylamino)benzoxazole (3w) by Aerobic Oxidative Cyclization Reaction}

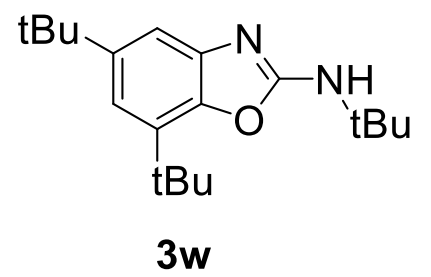

2-amino-4,6-di-tertbutyl phenol $(66.4 \mathrm{mg}, 0.300 \mathrm{mmol})$ and cobalt(II) acetate $(5.31 \mathrm{mg}$, $0.0300 \mathrm{mmol}$ ) were combined in a 6-inch test tube inside a $\mathrm{N}_{2}$ filled glovebox, and dissolved in dry $\mathrm{CH}_{3} \mathrm{CN}$ (3 mL). tert-Butyl isocyanide $(35.2 \mu \mathrm{L}, 0.300 \mathrm{mmol})$ was added to the same test tube after which it was sealed with a septum and removed from the glovebox. The reaction mixture was then stirred in an oil bath at $65{ }^{\circ} \mathrm{C}$ for 24 hours with an air balloon attached to a syringe with a needle inserted through the septum. Upon completion, the reaction mixture was cooled to room temperature and filtered through a Pasteur pipette silica gel plug and washed with ethyl acetate $(\sim 15 \mathrm{~mL})$. The resulting filtrate was concentrated by rotary evaporation and the resulting solid was 
purified by silica column flash chromatography (gradient elution from the pure hexanes to hexane: ethyl acetate $=8: 1, R_{\mathrm{f}}=0.4$ in 5:1 hexanes : ethyl acetate), to give the title compound as a light pink microcrystalline solid in $78 \%$ yield $(70.9 \mathrm{mg}, 0.234 \mathrm{mmol}) .{ }^{1} \mathrm{H}-\mathrm{NMR}\left(400 \mathrm{MHz}, \mathrm{CDCl}_{3}\right) \delta$ $7.30(\mathrm{~s}, 1 \mathrm{H}), 6.98(\mathrm{~s}, 1 \mathrm{H}), 5.33(\mathrm{~s}, 1 \mathrm{H}), 1.51$ (s, 9H), 1.44 (s, 11H), 1.34 (s, 10H). ${ }^{13} \mathrm{C}-\mathrm{NMR}(100$ $\left.\mathrm{MHz}, \mathrm{CDCl}_{3}\right) \delta 160.87,146.71,144.09,143.11,131.77,115.21,111.43,51.97,35.05,34.20,32.00$, 30.10, 29.43. FTIR (ATR, $\mathrm{cm}^{-1}$ ): 3156 (w), $3056(\mathrm{w}), 2960$ (m), $2868(\mathrm{w}), 1666(\mathrm{~s}), 1616(\mathrm{~m})$, 1589 (s), 1492 (m), 1409 (s), 1362 (s), 1302 (m), 1265 (w), 1047.59 (s), 1016 (s), 981 (w), 919 (s), $854(\mathrm{~s}), 736(\mathrm{~s}), 661(\mathrm{~m}), 612(\mathrm{w})$.

\subsubsection{Synthesis of $\mathrm{Co}^{\mathrm{II}}$-AP ${ }^{\mathrm{ditBu}}$ Complex $\mathrm{Co}^{\mathrm{II}}$ (2-amino-4,6-tert-butylphenolate)2(2-amino-} 4,6-tert-butylphenol) 2 and $\mathrm{Co}^{\mathrm{III}}$-AP ${ }^{\mathrm{ditBu}} \mathrm{Complex} \mathrm{Co}_{2}{ }^{\mathrm{III}}$ (2-amino-4,6-tert-butylphenolate) 2 (2amino-4,6-tert-butylphenol)( $\mu$-2-amido-4,6-tert-butylphenolate) ${ }_{2}$
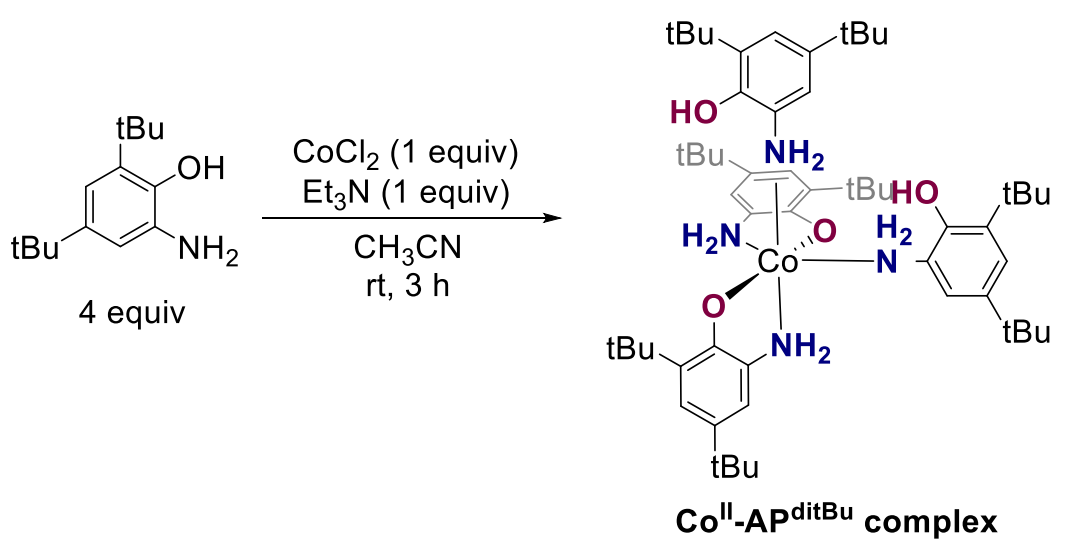

In a $\mathrm{N}_{2}$-filled glovebox, a $50 \mathrm{~mL}$ Erlenmeyer flask equipped with a stir bar was charged with 2-amino-4,6-di-tert-butyl phenol ligand ( $885.4 \mathrm{mg}, 4.0 \mathrm{mmol}, 1.0$ equiv) and anhydrous cobalt (II) chloride (128.8mg, $1.0 \mathrm{mmol}, 1$ equiv) in dry acetonitrile $(40 \mathrm{~mL})$. The resulting mixture was allowed to stir at room temperature for 10 mins to yield a persistent dark green color. It was then filtered and the filtrate was transferred into another clean $50 \mathrm{ml}$ Erlenmeyer flask. Triethylamine (404.8 mg, $4.0 \mathrm{mmol}$, 4.0 equiv) pre-diluted with $2 \mathrm{~mL}$ acetonitrile was added dropwise into the filtrate and the mixture was stirred under room temperature for another three hours. Upon completion, beige to light grey precipitate crushed out from the solution, leaving the solution a 
violet supernatant. The precipitate was filtered, washed a couple of times with dry acetonitrile under vacuum to generate the desired $\mathrm{Co}^{\mathrm{II}}$ complex with up to $93 \%$ yield. The complex was further dried under high vacuum to remove excess solvent that binding around, leading to slight color change to light greyish green with a golden sheen. Elemental Analysis: calculated $\mathrm{C}_{56} \mathrm{H}_{90} \mathrm{CoN}_{4} \mathrm{O}_{4} \cdot 2 \mathrm{CH}_{3} \mathrm{CN}, \mathrm{C}: 70.35 ; \mathrm{H}: 9.45 ; \mathrm{N}: 8.20$; found, C: 70.13; H: 9.52; N: 7.94.

Solid-state oxidation to $\mathrm{Co}^{\mathrm{III}}$ : The dry $\mathrm{Co}^{\mathrm{II}}-\mathrm{AP}^{\mathrm{ditBu}}$ complex was exposed to air up to 12 hours, yielding the corresponding $\mathrm{Co}^{\mathrm{III}}-\mathrm{AP}^{\mathrm{ditBu}}$ as microcrystalline dark violet solid with a golden sheen. Elemental Analysis: calculated $\mathrm{C}_{42} \mathrm{H}_{66} \mathrm{CoN}_{3} \mathrm{O}_{3}, \mathrm{C}: 70.07 ; \mathrm{H}: 9.24 ; \mathrm{N}: 5.84$; found, $\mathrm{C}$ : 70.33; $\mathrm{H}$ : $9.08 ; \mathrm{N}: 5.70$.

\subsubsection{Reactivity Studies of Co ${ }^{\mathrm{II}}$-APditBu Complex (7) and Co ${ }^{\mathrm{II}}$-APditBu Complex (8) Synthetic Procedure for Catalytic Experiment with Co ${ }^{\mathrm{II}}$-APditBu Complex (7)}

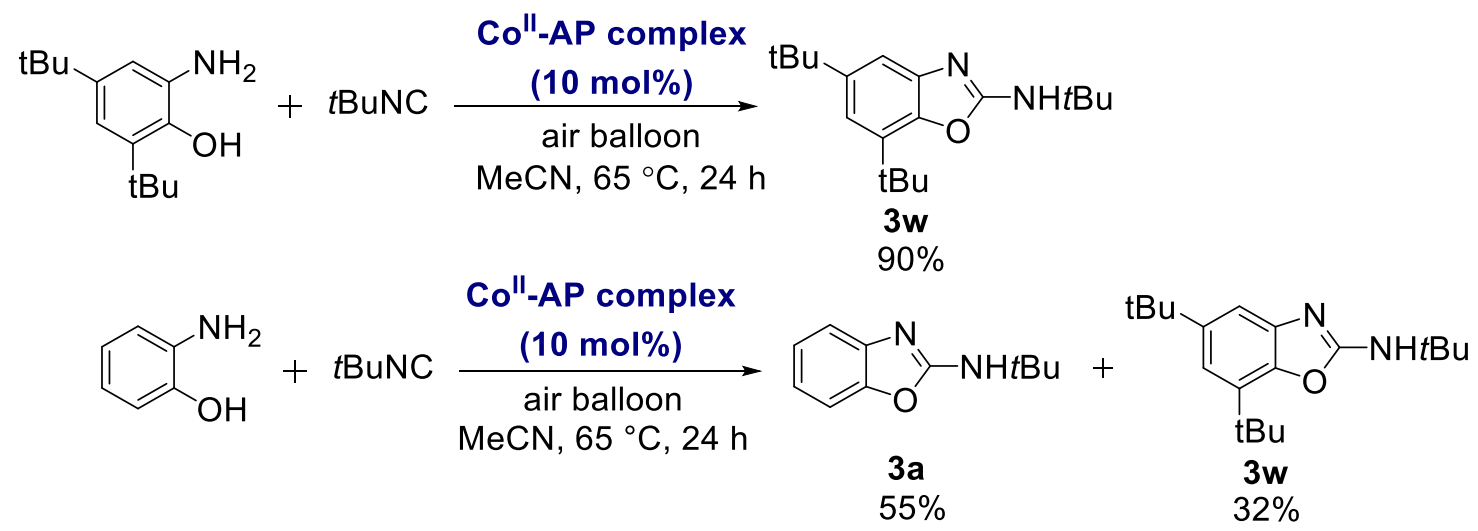

In a 6-inch test tube inside a $\mathrm{N}_{2}$ filled glovebox, $\mathrm{Co}^{\mathrm{II}}-\mathrm{AP}^{\mathrm{ditBu}}$ complex (7) $(28.27 \mathrm{mg}, 0.03$ mmol, 0.1 equiv) and 2-amino-4,6-di-tert-butyl phenol $(66.40 \mathrm{mg}, 0.3 \mathrm{mmol}, 1.0$ equiv) or 2aminophenol (32.74mg, $0.3 \mathrm{mmol}, 1.0$ equiv) were combined and dissolved in in dry $\mathrm{CH}_{3} \mathrm{CN}$ (3 $\mathrm{mL})$. tert-Butyl isocyanide $(35.2 \mu \mathrm{L}, 0.300 \mathrm{mmol})$ was added to the same test tube before it was sealed with a septum and removed from the glovebox. The reaction mixture was stirred in an oil bath at $65{ }^{\circ} \mathrm{C}$ for 24 hours with an air balloon attached to a syringe with a needle inserted through the septum. Upon completion, the reaction mixture was cooled to room temperature, partitioned into $30 \mathrm{~mL}$ ethyl acetate and stirred with $100 \mathrm{~mL}$ of $1.0 \mathrm{M}$ EDTA solution for 1 hour. The resulting 
mixture was separated, and the aqueous layer was washed another two times with ethyl acetate $(2 \times 30 \mathrm{~mL})$. The combined organic phase was washed again with saturated sodium chloride solution, separated, dried over anhydrous sodium sulfate, filtered, concentrated to $10 \mathrm{~mL}$ solution, and eventually passed through a Pasteur pipette silica gel plug. The resulting filtrate was concentrated by rotary evaporation to yield the crude product. The crude yield was determined by ${ }^{1} \mathrm{H}$ NMR spectroscopy with dimethylsulfone $(0.0300 \mathrm{mg}, 0.0318 \mathrm{mmol})$ as the internal standard.

\section{Synthetic Procedure for Stoichiometric Control Experiments of Co ${ }^{\mathrm{II}}$-APditBu ${ }^{\mathrm{d}}$ complex (7) under Anaerobic Reaction Conditions}

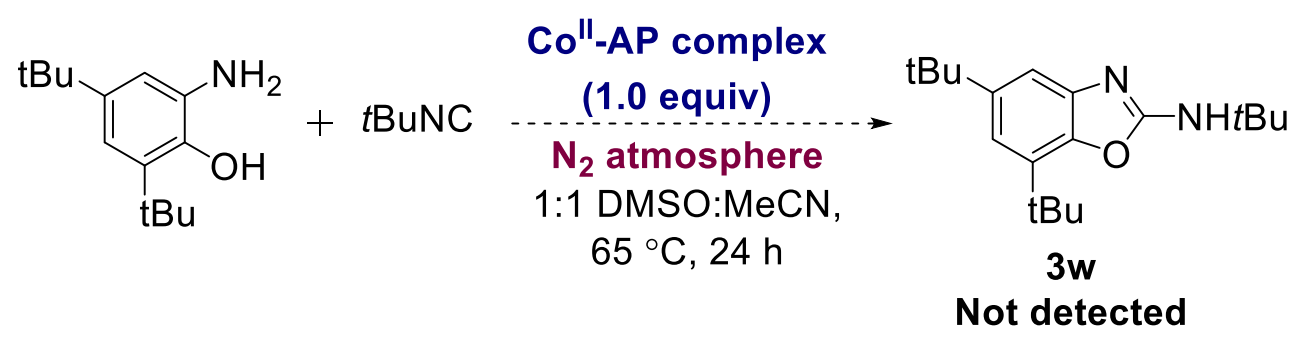

In a $20 \mathrm{~mL}$ pressure tube inside a $\mathrm{N}_{2}$ filled glovebox, $\mathrm{Co}^{\mathrm{II}}-\mathrm{AP}^{\mathrm{ditBu}}$ complex (7) $(188.5 \mathrm{mg}$, $0.2 \mathrm{mmol}, 1.0$ equiv) and 2-amino-4,6-di-tert-butyl phenol (44.27mg, $0.2 \mathrm{mmol}, 1.0$ equiv) were combined and dissolved in $5 \mathrm{~mL}$ mixture of dry $\mathrm{CH}_{3} \mathrm{CN}$ and DMSO (1:1). tert-Butyl isocyanide ( $23.5 \mu \mathrm{L}, 0.2 \mathrm{mmol}, 1.0$ equiv) was added to the same pressure tube before it was sealed and removed from the glovebox. The reaction mixture was stirred in an oil bath at $65^{\circ} \mathrm{C}$ for 24 hours under $\mathrm{N}_{2}$. Upon completion, the reaction mixture was cooled to room temperature, then $\mathrm{CH}_{3} \mathrm{CN}$ was removed via rotary evaporation. The resulting mixture in DMSO was partitioned into $30 \mathrm{~mL}$ ethyl acetate and stirred with $100 \mathrm{~mL}$ of $1.0 \mathrm{M}$ EDTA solution for 1 hour. The resulting mixture was separated, and the aqueous layer was washed twice with ethyl acetate $(2 \times 30 \mathrm{~mL})$. The combined organic phase was washed again with saturated sodium chloride solution, separated, dried over anhydrous sodium sulfate, filtered, concentrated to $10 \mathrm{~mL}$ solution, and eventually passed through a Pasteur pipette silica gel plug. The resulting filtrate was concentrated by rotary evaporation to yield the crude product as a brown solid. No desired product was generated during this reaction by ${ }^{1} \mathrm{H}$ NMR spectroscopy. 


\section{Synthetic Procedure for Catalytic Reactivity of $\mathrm{Co}^{\mathrm{III}}$-APditBu Complex (8) in the Oxidative}

Cyclization Reactions

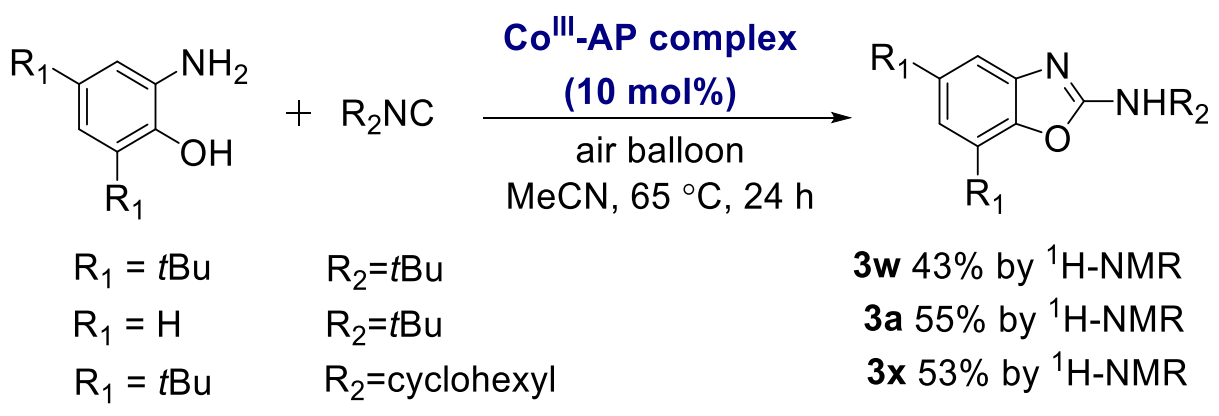

Representative procedure for the synthesis of $3 \mathrm{w}$ : In a 6-inch test tube inside a $\mathrm{N}_{2}$ filled glovebox, $\mathrm{Co}^{\mathrm{III}}$-AP ${ }^{\mathrm{ditBu}}$ complex (8) $(21.6 \mathrm{mg}, 0.03 \mathrm{mmol}, 0.1$ equiv) and 2-amino-4,6-di-tert-butyl phenol (66.40 mg, $0.3 \mathrm{mmol}, 1.0$ equiv) were combined and dissolved in $5 \mathrm{~mL}$ mixture of dry $\mathrm{CH}_{3} \mathrm{CN}$. tert-Butyl isocyanide $(35.2 \mu \mathrm{L}, 0.3 \mathrm{mmol}$ ) was added to the same test tube before it was sealed with a septum and removed from the glovebox. The reaction mixture was stirred in an oil bath at $65^{\circ} \mathrm{C}$ for 24 hours with an air balloon attached to a syringe with a needle inserted through the septum. Upon completion, the reaction mixture was cooled to room temperature, partitioned into $30 \mathrm{~mL}$ ethyl acetate and stirred with $100 \mathrm{~mL}$ of 1.0M EDTA solution for 1 hour. The resulting mixture was separated, and the aqueous layer was washed twice with ethyl acetate $(2 \times 30 \mathrm{~mL})$. The combined organic phase was extracted again with saturated sodium chloride solution, separated, dried over anhydrous sodium sulfate, filtered, concentrated to $10 \mathrm{~mL}$ solution, and eventually passed through a Pasteur pipette silica gel plug. The resulting filtrate was concentrated by rotary evaporation to yield the crude product which was later quantified using ${ }^{1} \mathrm{H}-\mathrm{NMR}$ spectroscopy with dimethyl sulfone $(0.0300 \mathrm{mg}, 0.0318 \mathrm{mmol})$ internal standard.

Synthesis of 3a: In a 6-inch test tube inside a $\mathrm{N}_{2}$ filled glovebox, $\mathrm{Co}^{\mathrm{III}}$-AP ${ }^{\mathrm{ditBu}}$ complex (8) (21.6 $\mathrm{mg}, 0.03 \mathrm{mmol}, 0.1$ equiv) and 2-aminophenol (32.74 mg, $0.3 \mathrm{mmol}, 1.0$ equiv) were combined and dissolved in $5 \mathrm{~mL}$ mixture of dry $\mathrm{CH}_{3} \mathrm{CN}$. tert-Butyl isocyanide $(35.2 \mu \mathrm{L}, 0.3 \mathrm{mmol})$ was added to the same test tube before it was sealed with a septum and removed from the glovebox. The rest of procedures follow the synthesis of $\mathbf{3 w}$.

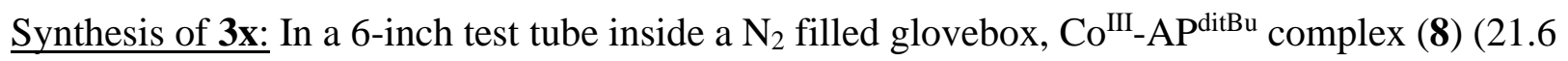
$\mathrm{mg}, 0.03 \mathrm{mmol}, 0.1$ equiv) and 2-amino-4,6-di-tert-butyl phenol ( $66.40 \mathrm{mg}, 0.3 \mathrm{mmol}, 1.0$ equiv) 
were combined and dissolved in $5 \mathrm{~mL}$ mixture of dry $\mathrm{CH}_{3} \mathrm{CN}$. Cyclohexyl isocyanide $(37.3 \mu \mathrm{L}$, $0.3 \mathrm{mmol}$ ) was added to the same test tube before it was sealed with a septum and removed from the glovebox. The rest of procedures follow the synthesis of $\mathbf{3 w}$.

\section{Synthetic Procedure for Stoichiometric Reactivity of Co ${ }^{\mathrm{III}}-\mathrm{AP}^{\mathrm{ditBu}}$ Complex (8) in the Oxidative Cyclization Reactions}

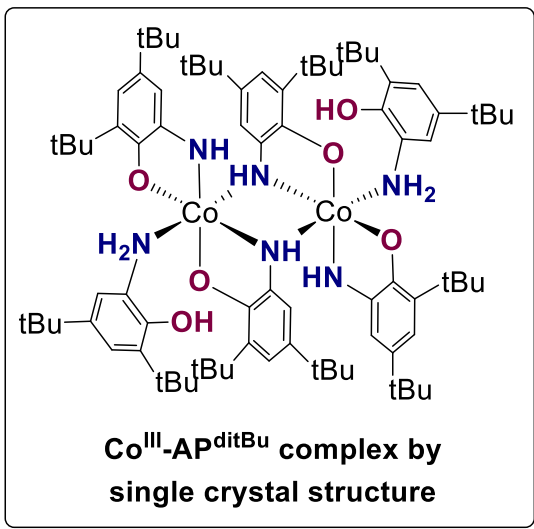

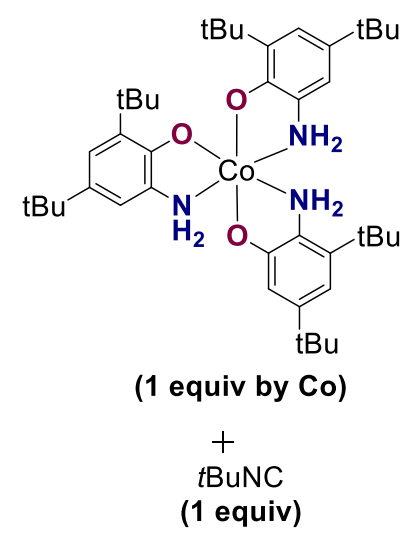

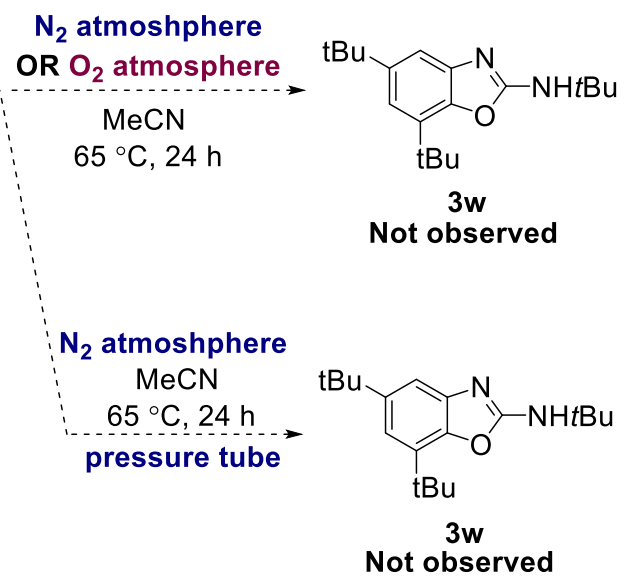

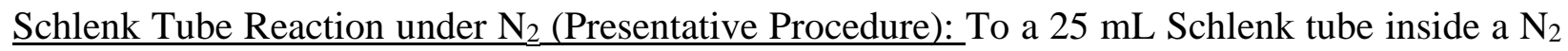
filled glovebox, $\mathrm{Co}^{\mathrm{III}}-\mathrm{AP}^{\mathrm{ditBu}}$ complex $(\mathbf{8})(71.9 \mathrm{mg}, 0.1 \mathrm{mmol}, 1.0$ equiv) was dissolved in $5 \mathrm{~mL}$ of dry $\mathrm{CH}_{3} \mathrm{CN}$. tert-Butyl isocyanide $(11.8 \mu \mathrm{L}, 0.1 \mathrm{mmol})$ was added to the same Schlenk tube before it was sealed with a septum and removed from the glovebox. The tube was connected to the Schlenk line via the side arm, and tubing was evacuated and backfilled with $\mathrm{N}_{2}$ three times before the valve on the side arm was opened. The reaction mixture was stirred in an oil bath at $65{ }^{\circ} \mathrm{C}$ for 24 hours under $\mathrm{N}_{2}$ atmosphere. Upon completion, the reaction mixture was cooled to room temperature, partitioned into $30 \mathrm{~mL}$ ethyl acetate and stirred with $100 \mathrm{~mL}$ of 1.0M EDTA solution for 1 hour. The resulting mixture was separated, and the aqueous layer was washed twice with ethyl acetate $(2 \times 30 \mathrm{~mL})$. The combined organic phase was extracted again with saturated sodium chloride solution, separated, dried over anhydrous sodium sulfate, filtered, concentrated to $10 \mathrm{~mL}$ solution, and eventually passed through a Pasteur pipette silica gel plug. The resulting filtrate was concentrated by rotary evaporation to yield the crude product which was later quantified using ${ }^{1} \mathrm{H}$ NMR spectroscopy with dimethyl sulfone $(0.0300 \mathrm{mg}, 0.0318 \mathrm{mmol})$ internal standard. 
$\underline{\text { Schlenk Tube Reaction under } \mathrm{O}_{2}}:$ In a $25 \mathrm{~mL}$ Schlenk tube, Co ${ }^{\mathrm{III}}-\mathrm{AP}^{\mathrm{ditBu}}$ complex (8) (71.9 mg, $0.1 \mathrm{mmol}, 1.0$ equiv) was added. The tube was sealed with a septum and was connected to the Schlenk line via the side arm. The tube was then evacuated and backfilled with $\mathrm{O}_{2}$ by inserting a $\mathrm{O}_{2}$ balloon through the septum for three times. Under $\mathrm{O}_{2}$ atmosphere, $5 \mathrm{~mL}$ of dry $\mathrm{CH}_{3} \mathrm{CN}$ was added to dissolve the $\mathrm{Co}^{\mathrm{III}}$ complex, followed by adding the tert-Butyl isocyanide $(11.8 \mu \mathrm{L}, 0.1$ mmol) into the same Schlenk tube. With a $\mathrm{O}_{2}$ balloon attached to a syringe with a needle inserted through the septum, the reaction mixture was stirred in an oil bath at $65{ }^{\circ} \mathrm{C}$ for 24 hours. The rest procedures follow the above Schlenk Tube Reaction under $\mathrm{N}_{2}$ (Presentative Procedure).

Pressure Tube Reaction under $\mathrm{N}_{2}$ : In a $20 \mathrm{~mL}$ pressure tube inside a $\mathrm{N}_{2}$ filled glovebox, Co ${ }^{\text {III }}$ $\mathrm{AP}^{\mathrm{ditBu}}$ complex (8) $(71.9 \mathrm{mg}, 0.1 \mathrm{mmol}, 1.0$ equiv) was added and dissolved in $5 \mathrm{~mL}$ of dry $\mathrm{CH}_{3} \mathrm{CN}$. tert-Butyl isocyanide $(11.8 \mu \mathrm{L}, 0.1 \mathrm{mmol}, 1.0$ equiv) was added to the same pressure tube before it was sealed and removed from the glovebox. The reaction mixture was stirred in an oil bath at $65{ }^{\circ} \mathrm{C}$ for 24 hours under $\mathrm{N}_{2}$. The rest procedures follow the above Schlenk Tube Reaction $\underline{\text { under } \mathrm{N}_{2}}$ (Presentative Procedure).

Synthetic Procedure for Stoichiometric Reactivity of Co ${ }^{\mathrm{III}}-\mathrm{AP}^{\mathrm{ditBu}}$ Complex (8) in the Presence of Both Aminophenol and Isonitrile Substrates<smiles>CC(C)(C)Nc1nc2cc(C(C)(C)C)cc(C(C)(C)C)c2o1</smiles>
$0.2 \mathrm{mmol}$
$0.2 \mathrm{mmol}$
$93 \%$ by ${ }^{1}$ HNMR
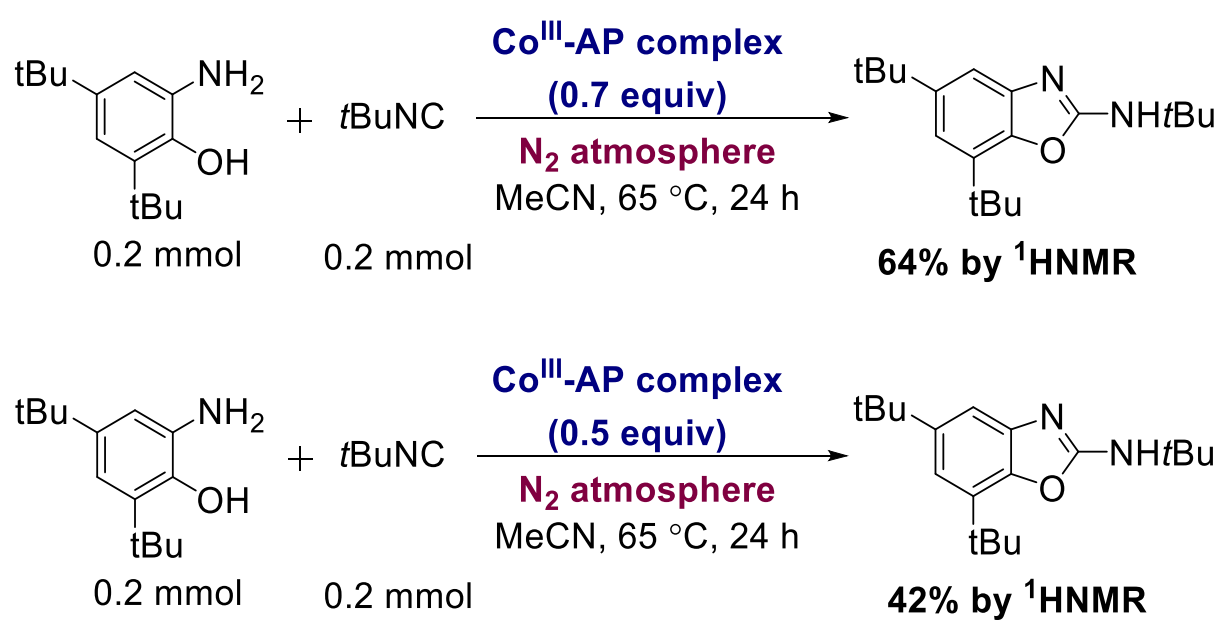
Representative Procedure: In a $20 \mathrm{~mL}$ pressure tube inside a $\mathrm{N}_{2}$ filled glovebox, $\mathrm{Co}^{\mathrm{III}}-\mathrm{AP}^{\mathrm{ditBu}}$ complex (8) (144.0 mg, 0.02 mmol, 1.0 equiv) and 2-amino-4,6-di-tert-butyl phenol (44.27mg, 0.2 mmol, 1.0 equiv) were combined and dissolved in $5 \mathrm{~mL}$ of dry $\mathrm{CH}_{3} \mathrm{CN}$. tert-Butyl isocyanide ( $23.5 \mu \mathrm{L}, 0.2 \mathrm{mmol}, 1.0$ equiv) was added to the same pressure tube before it was sealed and removed from the glovebox. The reaction mixture was stirred in an oil bath at $65{ }^{\circ} \mathrm{C}$ for 24 hours under $\mathrm{N}_{2}$. Upon completion, the reaction mixture was cooled to room temperature, then was partitioned into $30 \mathrm{~mL}$ ethyl acetate and stirred with $100 \mathrm{~mL}$ of $1.0 \mathrm{M}$ EDTA solution for 1 hour. The resulting mixture was separated, and the aqueous layer was extracted twice with ethyl acetate $(2 \times 30 \mathrm{~mL})$. The combined organic phase was washed again with saturated sodium chloride solution, separated, dried over anhydrous sodium sulfate, filtered, concentrated to $10 \mathrm{~mL}$ solution, and eventually passed through a Pasteur pipette silica gel plug. The resulting filtrate was concentrated by rotary evaporation to yield the crude product, which was quantified by ${ }^{1} \mathrm{H}$ NMR spectroscopy using dimethyl sulfone $(0.0300 \mathrm{mg}, 0.0318 \mathrm{mmol})$ internal standard.

\subsubsection{Crystallography Data}

4.4.6.1. Description of the X-ray Structural Analysis of $\mathrm{Co}^{\mathrm{II}}$-AP ${ }^{\mathrm{ditBu}}$ Complex (7)

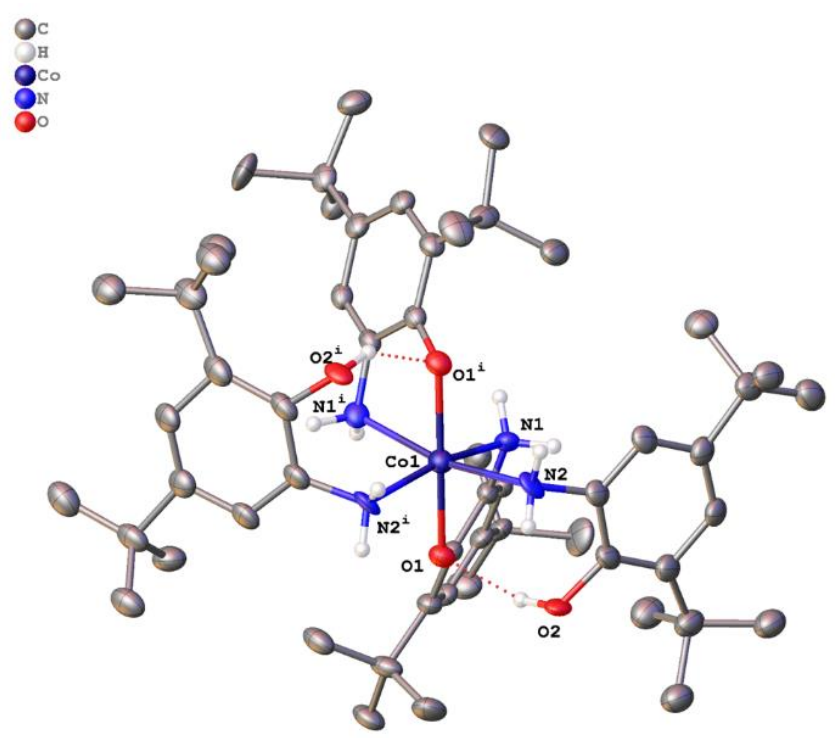

A green-yellow block shaped crystal measuring $0.34 \mathrm{~mm} \times 0.30 \mathrm{~mm} \times 0.17 \mathrm{~mm}$ was selected under paratone oil using a MiTeGen Micromount and mounted at 100(1) K to a D8- 
Venture diffractometer equipped with a Mo sealed tube X-ray source, a Triumph monochromator, and a Photon CMOS area detector. The unit cell was determined from reflections harvested with a signal to noise ratio $(\mathrm{I} / \sigma)$ of at least 8 from a series of $3 \omega$ scans of $6^{\circ}$ with $0.5^{\circ}$ frames using APEX3. ${ }^{1}$ The data were collected to a resolution of $0.81 \AA$ using $4 \omega$ scans.

The data were integrated using SAINT and corrected for absorption using SADABS. ${ }^{2}$ The systematic absences and E-statistics of the data were consistent with the space group $\operatorname{Im} \overline{3}$. The structure was solved using the intrinsic phasing routine of SHELXT. ${ }^{3}$ The non-hydrogen atoms were located from a Fourier difference map of the electron density and anisotropically refined using the least-squares algorithm of SHELXL. ${ }^{4}$ The carbon-based hydrogen atoms were then placed in calculated positions and refined with riding thermal parameters.

The asymmetric unit consists of one half molecule of $\operatorname{Co}$ (2-amino-4,6-tertbutylphenolate $)_{2}(2 \text {-amino-4,6-tert-butylphenol })_{2}$ (Figures 1 - 2). The molecule resides on a crystallographic 2-fold axis and a crystallographic mirror plane. The 2-fold axis is a true symmetry element of the molecule and passes through the following points: the midpoint of $\mathrm{N} 2$ and $\mathrm{N} 2{ }^{\mathrm{i}}$; Co1; and the midpoint of $\mathrm{N} 1$ and $\mathrm{N} 1{ }^{\mathrm{i}}$. The molecule is disordered over the mirror plane.

Phenol ligand O2 shows additional positional disorder (major component: 27.8(6)\%). Geometry and thermal parameter restraints were used to ensure a chemically reasonable and computationally stable refinement.

There was an additional solvent molecule located in the crystal structure. Despite numerous attempts to model this solvent, a computationally stable refinement was not possible. The SQUEEZE algorithm of PLATON was used to correct for the solvent electron density. PLATON calculated that the solvent accessible voids in the structure had a volume of $3077 \mathrm{~A}^{3}(16.2 \%$ of the unit cell volume) and consisted of 864 electrons/unit cell. This is consistent with approximately 3 molecules of $\mathrm{MeCN}$ per molecule of $\mathrm{Co}(2$-amino-4,6-tert-butylphenolate)2(2-amino-4,6-tertbutylphenol $)_{2}$ in the structure.

The final structure consisted of 461 parameters refined against 3347 independent reflections, giving refinement residuals of $\mathrm{R}_{1}=0.0524$ (based off $F^{2}$ for $I>2 \sigma$ ) and $\mathrm{wR}_{2}=0.1617$ (based of $F^{2}$ for all reflections). The final difference Fourier map was featureless. 


\section{References:}

1. Bruker-AXS (2016). APEX 3 version 2016.9-0. Madison, Wisconsin, USA

2. (a) Bruker-AXS (2015). SAINT V8.37A. Madison, Wisconsin, USA. (b) Krause, L.; HerbstIrmer, R.; Sheldrick, G.; Stalke, D. J. Appl. Crystallogr. 2015, 48, 3-10.

3. Sheldrick, G. M., Acta Crystallogr. A 2015, A71, 3-8.

4. (a) Sheldrick, G. M., Acta Crystallogr. C 2015, C71, 3-8.; (b) Dolomanov, O. V.; Bourhis, L. J.; Gildea, R. J.; Howard, J. A. K.; Puschmann, H., J. Appl. Crystallogr. 2009, 42, 339-341.

Table 4.1. Crystal data and structure refinement for $\mathrm{Co}^{\mathrm{II}}-\mathrm{AP}^{\mathrm{ditBu}}$ Complex (7).

\begin{tabular}{|c|c|}
\hline Identification code & $\mathrm{Co}^{\mathrm{II}}-\mathrm{AP}^{\mathrm{ditBu}}$ Complex (7) \\
\hline Empirical formula & $\mathrm{C}_{56} \mathrm{H}_{90} \mathrm{CoN}_{4} \mathrm{O}_{4}$ \\
\hline Formula weight & 942.24 \\
\hline Temperature/K & 100.0 \\
\hline Crystal system & cubic \\
\hline Space group & Im-3 \\
\hline $\mathrm{a} / \AA$ & $26.692(3)$ \\
\hline $\mathrm{b} / \AA$ & $26.692(3)$ \\
\hline $\mathrm{c} / \AA$ & $26.692(3)$ \\
\hline$\alpha /^{\circ}$ & 90 \\
\hline$\beta /{ }^{\circ}$ & 90 \\
\hline$\gamma /{ }^{\circ}$ & 90 \\
\hline Volume $/ \AA^{3}$ & $19018(7)$ \\
\hline $\mathrm{Z}$ & 12 \\
\hline$\rho_{\text {calc }} \mathrm{g} / \mathrm{cm}^{3}$ & 0.987 \\
\hline
\end{tabular}




\begin{tabular}{ll}
$\mu / \mathrm{mm}^{-1}$ & 0.310 \\
$\mathrm{~F}(000)$ & 6156.0 \\
Crystal size $/ \mathrm{mm}^{3}$ & $0.34 \times 0.3 \times 0.17$ \\
Radiation & $\mathrm{MoK} \alpha(\lambda=0.71073)$ \\
$2 \Theta$ range for data collection ${ }^{\circ}$ & 6.106 to 52.046 \\
Index ranges & $-32 \leq \mathrm{h} \leq 32,-32 \leq \mathrm{k} \leq 32,-32 \leq 1 \leq 32$ \\
Reflections collected & 231435 \\
Independent reflections & $3347\left[\mathrm{R}_{\text {int }}=0.0988, \mathrm{R}_{\text {sigma }}=0.0146\right]$ \\
Data/restraints/parameters & $3347 / 573 / 461$ \\
Goodness-of-fit on $\mathrm{F}^{2}$ & 1.181 \\
Final R indexes $[\mathrm{I}>=2 \sigma(\mathrm{I})]$ & $\mathrm{R}_{1}=0.0524, \mathrm{wR}_{2}=0.1322$ \\
Final R indexes [all data] & $\mathrm{R}_{1}=0.0757, \mathrm{wR}_{2}=0.1617$ \\
\hline Largest diff. peak/hole $/ \mathrm{e} \AA^{-3}$ & $0.42 /-0.27$
\end{tabular}

Table 4.2. Fractional atomic coordinates $\left(\times 10^{4}\right)$ and equivalent isotropic displacement parameters $\left(\AA^{2} \times 10^{3}\right)$ for $\mathrm{Co}^{\mathrm{II}}-\mathrm{AP}^{\mathrm{ditBu}}$ Complex (7). $\mathrm{U}_{\mathrm{eq}}$ is defined as $1 / 3$ of of the trace of the orthogonalised $\mathrm{U}_{\mathrm{IJ}}$ tensor.

\begin{tabular}{|c|c|c|c|c|}
\hline \multicolumn{2}{|c|}{ Atom $x$} & $y$ & $z$ & $\mathbf{U}(\mathbf{e q})$ \\
\hline Co1 & 5000 & $8024.6(2)$ & 5000 & $31.9(2)$ \\
\hline $\mathrm{O} 1$ & $5176.3(11)$ & $8053.1(11)$ & $4277.8(11)$ & $33.3(7)$ \\
\hline N1 & $5550.0(11)$ & $8619.1(11)$ & $4994(5)$ & $31.7(8)$ \\
\hline
\end{tabular}




\begin{tabular}{|c|c|c|c|c|}
\hline $\mathrm{C} 1$ & $5541.7(15)$ & $8821.7(17)$ & $4504.3(15)$ & 29.2(9) \\
\hline $\mathrm{C} 2$ & $5328.7(15)$ & $8508.2(16)$ & $4144.0(15)$ & 29.0(9) \\
\hline $\mathrm{C} 3$ & $5296.8(16)$ & 8689.6(18) & $3650.7(15)$ & $33.5(10)$ \\
\hline $\mathrm{C} 4$ & $5483.3(16)$ & $9157.4(18)$ & $3555.2(16)$ & $33.6(10)$ \\
\hline C5 & $5700.5(18)$ & $9461(2)$ & 3908.1(19) & $33.0(11)$ \\
\hline C6 & $5722.4(15)$ & $9280.2(17)$ & 4386.1(15) & $30.0(9)$ \\
\hline $\mathrm{C} 7$ & $5040(8)$ & $8375.5(17)$ & $3249.1(14)$ & $40(2)$ \\
\hline $\mathrm{C} 8$ & $4505(2)$ & $8289(2)$ & $3392.4(18)$ & $46.6(13)$ \\
\hline $\mathrm{C} 9$ & $5314(2)$ & $7883(2)$ & $3180(2)$ & $56.2(15)$ \\
\hline $\mathrm{C} 10$ & $5055(10)$ & $8642(2)$ & $2741.4(15)$ & $48(3)$ \\
\hline $\mathrm{C} 11$ & $5915.5(14)$ & $9966(7)$ & $3790.5(15)$ & $36.4(17)$ \\
\hline $\mathrm{C} 12$ & $6484.8(15)$ & $9953(13)$ & $3841(2)$ & $58(4)$ \\
\hline C13 & $5795(2)$ & $10142.6(19)$ & $3258.6(18)$ & $49.9(16)$ \\
\hline C14 & $5716(2)$ & $10372(2)$ & $4145(2)$ & $40.2(12)$ \\
\hline $\mathrm{O} 2 \mathrm{~A}$ & $6010(8)$ & $7556(10)$ & $4141(5)$ & $44(3)$ \\
\hline $\mathrm{N} 2 \mathrm{~A}$ & $5534(5)$ & $7415(8)$ & 4952(13) & $40(3)$ \\
\hline $\mathrm{C} 15 \mathrm{~A}$ & $6039(6)$ & $7585(11)$ & 4979(10) & $37(2)$ \\
\hline $\mathrm{C} 16 \mathrm{~A}$ & $6279(10)$ & $7715(18)$ & $4528(9)$ & $41(3)$ \\
\hline $\mathrm{C} 17 \mathrm{~A}$ & $6772(9)$ & 7901(15) & $4508(7)$ & $44(2)$ \\
\hline C18A & $6975(10)$ & 7982(17) & 4983(9) & $40(2)$ \\
\hline C19A & $6751(9)$ & $7826(11)$ & $5413(7)$ & $38(2)$ \\
\hline
\end{tabular}




\begin{tabular}{|c|c|c|c|c|}
\hline \multicolumn{2}{|c|}{ C20A 6274(12) } & $7650(20)$ & $5418(10)$ & $39(3)$ \\
\hline \multicolumn{2}{|c|}{ C21A 7071(7) } & $8091(7)$ & $4052(6)$ & $51(2)$ \\
\hline \multicolumn{2}{|c|}{ C22A 7056(7) } & $8651(5)$ & $4034(6)$ & $60(3)$ \\
\hline \multicolumn{2}{|c|}{ C23A 6842(6) } & $7886(7)$ & $3572(5)$ & $52(3)$ \\
\hline \multicolumn{2}{|c|}{ C24A 7606(6) } & $7884(8)$ & $4082(7)$ & $61(3)$ \\
\hline \multicolumn{2}{|c|}{ C25A 6961(7) } & $7844(6)$ & $5940(6)$ & $40(2)$ \\
\hline \multicolumn{2}{|c|}{ С26A 6641(8) } & $8201(7)$ & $6265(7)$ & $48(3)$ \\
\hline \multicolumn{2}{|c|}{ C27A 6958(7) } & $7330(6)$ & $6191(6)$ & $47(3)$ \\
\hline \multicolumn{2}{|c|}{ C28A 7484(7) } & $8083(9)$ & $5928(8)$ & $45(3)$ \\
\hline & $5966(6)$ & $7497(7)$ & $4262(4)$ & $36(2)$ \\
\hline & $5562(4)$ & $7429(6)$ & $5170(6)$ & $35(2)$ \\
\hline C15 & $6066(5)$ & $7595(9)$ & $5128(5)$ & $34(2)$ \\
\hline C16 & $6263(9)$ & $7655(16)$ & $4641(6)$ & $40(2)$ \\
\hline C17 & $6741(8)$ & $7877(14)$ & $4542(7)$ & $44(2)$ \\
\hline C18 & 6998(8) & $7956(13)$ & 4992(8) & $39(2)$ \\
\hline C19 & $6793(8)$ & 7915(13) & $5448(7)$ & $40(2)$ \\
\hline $\mathrm{C} 20$ & $6333(7)$ & $7727(11)$ & $5538(6)$ & $38(3)$ \\
\hline C21 & $7026(7)$ & $8072(6)$ & $4079(6)$ & $52(2)$ \\
\hline $\mathrm{C} 22$ & $6814(6)$ & $8571(6)$ & $3905(5)$ & $59(3)$ \\
\hline C23 & $6997(6)$ & $7709(6)$ & $3645(5)$ & $56(3)$ \\
\hline C24 & $7598(6)$ & $8111(10)$ & $4161(9)$ & $54(3)$ \\
\hline
\end{tabular}




$\begin{array}{lllcr}\text { C25 } & 7030(7) & 8009(7) & 5957(7) & 46(3) \\ \text { C26 } & 6664(7) & 8381(6) & 6216(6) & 48(3) \\ \text { C27 } & 7050(7) & 7520(6) & 6255(6) & 49(3) \\ \text { C28 } & 7523(6) & 8281(6) & 5861(8) & 55(3)\end{array}$

Table 4.3. Anisotropic displacement parameters $\left(\AA^{2} \times 10^{3}\right)$ for $\mathrm{Co}^{\mathrm{II}}-\mathrm{AP}^{\mathrm{ditBu}}$ Complex (7). The anisotropic displacement factor exponent takes the form: $-2 \pi^{2}\left[h^{2} a^{* 2} U_{11}+2 h k a * b * U_{12}+\ldots\right]$.

\begin{tabular}{|c|c|c|c|c|c|c|}
\hline \multicolumn{2}{|c|}{ Atom U11 } & $\mathbf{U}_{22}$ & $\mathbf{U}_{33}$ & $\mathbf{U}_{23}$ & $\mathbf{U}_{13}$ & $\mathbf{U}_{12}$ \\
\hline Co1 & $31.4(3)$ & $37.5(4)$ & $26.8(3)$ & 0 & 0 & 0 \\
\hline $\mathrm{O} 1$ & $36.4(16)$ & $38.4(16)$ & $25.0(14)$ & $-4.3(12)$ & $-3.2(11)$ & $0.9(12)$ \\
\hline N1 & $31.8(13)$ & $38.5(17)$ & $24.9(15)$ & $-10(10)$ & $1(12)$ & $2.0(13)$ \\
\hline $\mathrm{C} 1$ & $24.7(19)$ & $40(2)$ & $22.5(19)$ & $-1.7(17)$ & $-2.5(16)$ & $4.9(17)$ \\
\hline $\mathrm{C} 2$ & $23.9(19)$ & $39(2)$ & $24(2)$ & $-3.6(17)$ & $1.7(15)$ & $4.3(17)$ \\
\hline $\mathrm{C} 3$ & $33(2)$ & $46(3)$ & $22(2)$ & $-5.3(18)$ & $-0.5(17)$ & $1.9(19)$ \\
\hline $\mathrm{C} 4$ & $29(2)$ & $46(3)$ & $26(2)$ & $-1.8(18)$ & $6.5(17)$ & $0.1(19)$ \\
\hline $\mathrm{C} 5$ & $25(2)$ & $44(3)$ & $29(3)$ & $-5(2)$ & $8(2)$ & $3(2)$ \\
\hline C6 & $23(2)$ & $41(3)$ & $26(2)$ & $-8.3(19)$ & $0.4(16)$ & $1.4(18)$ \\
\hline $\mathrm{C} 7$ & $50(6)$ & $49(2)$ & $22.0(15)$ & $-6.9(15)$ & $1(4)$ & $-14(6)$ \\
\hline $\mathrm{C} 8$ & $49(3)$ & $63(3)$ & $28(2)$ & $-2(2)$ & $-7(2)$ & $-17(3)$ \\
\hline C9 & $64(4)$ & $66(4)$ & $39(3)$ & $-23(3)$ & $-6(3)$ & $8(3)$ \\
\hline C10 & $54(9)$ & $69(3)$ & $22.5(17)$ & $-2.9(17)$ & $-10(4)$ & $-9(5)$ \\
\hline
\end{tabular}




\begin{tabular}{|c|c|c|c|c|c|}
\hline C11 27.9(16) & $47(5)$ & $33.7(17)$ & $-11(5)$ & $6.6(13)$ & $6(5)$ \\
\hline C12 28(2) & $68(11)$ & $77(3)$ & $0(6)$ & $13.2(19)$ & $-20(7)$ \\
\hline C13 56(3) & $58(4)$ & $35(2)$ & $3(2)$ & $10(2)$ & $-10(2)$ \\
\hline C14 35(3) & $45(3)$ & $41(3)$ & $-4(3)$ & $5(3)$ & $-5(2)$ \\
\hline $\mathrm{O} 2 \mathrm{~A} \quad 47(5)$ & $64(6)$ & $21(6)$ & $0(5)$ & $-5(5)$ & $17(4)$ \\
\hline $\mathrm{N} 2 \mathrm{~A} \quad 41(4)$ & $42(4)$ & $38(8)$ & $2(7)$ & $-7(7)$ & $1(4)$ \\
\hline C15A 35(4) & $40(3)$ & $36(6)$ & $3(6)$ & $-10(6)$ & $13(3)$ \\
\hline C16A40(4) & $53(5)$ & $31(5)$ & $-3(5)$ & $-10(5)$ & $19(4)$ \\
\hline C17A 37(4) & $56(4)$ & $39(4)$ & $-2(4)$ & $-10(4)$ & $18(4)$ \\
\hline C18A 28(4) & $51(5)$ & $40(4)$ & $2(6)$ & $-2(6)$ & $15(4)$ \\
\hline C19A 34(4) & $44(5)$ & $37(4)$ & $5(5)$ & $-6(5)$ & $20(4)$ \\
\hline C20A 38(5) & $41(5)$ & $38(6)$ & $9(5)$ & $-1(5)$ & $15(5)$ \\
\hline C21A48(4) & $68(4)$ & $38(4)$ & $-3(4)$ & $2(3)$ & $20(4)$ \\
\hline C22A 63(6) & $69(6)$ & $49(5)$ & $5(5)$ & $0(5)$ & $-1(6)$ \\
\hline C23A 53(6) & $64(6)$ & $38(5)$ & $0(5)$ & $6(5)$ & $15(5)$ \\
\hline C24A 53(5) & $83(7)$ & $46(6)$ & $-3(6)$ & $9(5)$ & $25(6)$ \\
\hline $\mathrm{C} 25 \mathrm{~A} 42(4)$ & $44(6)$ & $35(4)$ & $2(4)$ & $-4(3)$ & $13(4)$ \\
\hline C26A 50(5) & $53(8)$ & $40(5)$ & $3(6)$ & $-8(4)$ & $9(6)$ \\
\hline C27A 50(6) & $50(8)$ & $40(6)$ & $14(6)$ & $-15(5)$ & $9(6)$ \\
\hline C28A 54(6) & $47(7)$ & $34(5)$ & $6(6)$ & $-6(5)$ & $21(6)$ \\
\hline $41(4)$ & $54(5)$ & $13(5)$ & $-5(4)$ & $-1(4)$ & $11(3)$ \\
\hline
\end{tabular}




\begin{tabular}{|c|c|c|c|c|c|c|}
\hline $\mathrm{N} 2$ & $42(4)$ & $40(4)$ & $23(5)$ & $6(5)$ & $-19(4)$ & $5(3)$ \\
\hline C15 & $35(4)$ & $38(3)$ & $30(5)$ & $5(5)$ & $-8(4)$ & $12(3)$ \\
\hline C16 & $40(4)$ & $51(4)$ & $29(5)$ & $-4(5)$ & $-11(4)$ & $16(4)$ \\
\hline C17 & $38(4)$ & $57(4)$ & $38(4)$ & $-3(4)$ & $-7(4)$ & $20(4)$ \\
\hline C18 & $28(3)$ & $49(4)$ & $39(3)$ & $2(6)$ & $-4(6)$ & $17(3)$ \\
\hline C19 & $33(4)$ & $46(5)$ & $41(4)$ & $4(4)$ & $-2(4)$ & $15(4)$ \\
\hline C20 & $41(5)$ & $41(5)$ & $33(5)$ & $6(5)$ & $-11(4)$ & $13(4)$ \\
\hline C21 & $49(4)$ & $68(4)$ & $39(4)$ & $-4(4)$ & $1(3)$ & $22(4)$ \\
\hline $\mathrm{C} 22$ & $60(6)$ & $73(6)$ & $44(5)$ & $8(5)$ & $3(5)$ & $16(5)$ \\
\hline $\mathrm{C} 23$ & $56(6)$ & $70(7)$ & $42(5)$ & $-4(5)$ & $3(5)$ & $17(5)$ \\
\hline C24 & $51(6)$ & $68(7)$ & $42(6)$ & $-3(6)$ & $6(5)$ & $13(6)$ \\
\hline $\mathrm{C} 25$ & $47(4)$ & $55(6)$ & $34(4)$ & $4(5)$ & $-7(4)$ & $21(5)$ \\
\hline C26 & $54(5)$ & $54(8)$ & $35(5)$ & $7(6)$ & 7(4) & $2(6)$ \\
\hline C27 & $56(6)$ & $55(7)$ & $37(5)$ & $2(5)$ & $-5(4)$ & $21(6)$ \\
\hline C28 & $55(6)$ & $60(8)$ & $49(6)$ & $-6(7)$ & $-13(5)$ & $15(6)$ \\
\hline
\end{tabular}

Table 4.4. Bond Lengths for $\mathrm{Co}^{\mathrm{II}}-\mathrm{AP}^{\mathrm{ditBu}}$ Complex (7).

$\begin{array}{llllll}\text { Atom Atom } & \text { Length/A } & \text { Atom } & \text { Atom } & \text { Length/A } \\ \text { Co1 } \mathrm{O} 1 & 1.986(3) & \mathrm{C} 17 \mathrm{~A} & \mathrm{C} 21 \mathrm{~A} & 1.539(17) \\ \mathrm{Co} 1 \mathrm{~N} 1 & 2.162(3) & \mathrm{C} 18 \mathrm{~A} & \mathrm{C} 19 \mathrm{~A} & 1.360(17) \\ \mathrm{Co} 1 \mathrm{~N} 2 \mathrm{~A} & 2.17(2) & \mathrm{C} 19 \mathrm{~A} & \mathrm{C} 20 \mathrm{~A} & 1.355(16) \\ \mathrm{Co} 1 \mathrm{~N} 2 & 2.231(15) & \mathrm{C} 19 \mathrm{~A} & \mathrm{C} 25 \mathrm{~A} & 1.516(17)\end{array}$




\begin{tabular}{|c|c|c|c|c|c|}
\hline $\mathrm{O} 1$ & $\mathrm{C} 2$ & $1.330(5)$ & $\mathrm{C} 21 \mathrm{~A}$ & $\mathrm{C} 22 \mathrm{~A}$ & $1.498(17)$ \\
\hline N1 & $\mathrm{C} 1$ & $1.415(14)$ & C21A & $\mathrm{C} 23 \mathrm{~A}$ & $1.521(16)$ \\
\hline $\mathrm{C} 1$ & $\mathrm{C} 2$ & $1.396(6)$ & C21A & $\mathrm{C} 24 \mathrm{~A}$ & $1.532(16)$ \\
\hline $\mathrm{C} 1$ & C6 & $1.353(6)$ & $\mathrm{C} 25 \mathrm{~A}$ & C26A & $1.547(14)$ \\
\hline $\mathrm{C} 2$ & $\mathrm{C} 3$ & $1.405(6)$ & $\mathrm{C} 25 \mathrm{~A}$ & C27A & $1.526(14)$ \\
\hline $\mathrm{C} 3$ & $\mathrm{C} 4$ & $1.368(6)$ & $\mathrm{C} 25 \mathrm{~A}$ & C28A & $1.535(16)$ \\
\hline $\mathrm{C} 3$ & $\mathrm{C} 7$ & $1.523(11)$ & $\mathrm{O} 2$ & $\mathrm{C} 16$ & $1.351(14)$ \\
\hline $\mathrm{C} 4$ & C5 & $1.371(7)$ & N2 & $\mathrm{C} 15$ & $1.420(10)$ \\
\hline $\mathrm{C} 5$ & C6 & $1.365(6)$ & C15 & C16 & $1.413(14)$ \\
\hline $\mathrm{C} 5$ & C11 & $1.497(18)$ & C15 & $\mathrm{C} 20$ & $1.353(13)$ \\
\hline $\mathrm{C} 7$ & $\mathrm{C} 8$ & $1.498(19)$ & C16 & $\mathrm{C} 17$ & $1.432(15)$ \\
\hline $\mathrm{C} 7$ & C9 & $1.515(12)$ & C17 & C18 & $1.398(16)$ \\
\hline $\mathrm{C} 7$ & $\mathrm{C} 10$ & $1.531(6)$ & $\mathrm{C} 17$ & $\mathrm{C} 21$ & $1.544(17)$ \\
\hline C11 & C12 & $1.526(6)$ & C18 & C19 & $1.342(16)$ \\
\hline $\mathrm{C} 11$ & C13 & $1.531(8)$ & C19 & $\mathrm{C} 20$ & $1.348(15)$ \\
\hline C11 & C14 & $1.536(14)$ & C19 & $\mathrm{C} 25$ & $1.518(18)$ \\
\hline $\mathrm{O} 2 \mathrm{~A}$ & C16A & $1.328(17)$ & $\mathrm{C} 21$ & $\mathrm{C} 22$ & $1.521(17)$ \\
\hline $\mathrm{N} 2 \mathrm{~A}$ & $\mathrm{C} 15 \mathrm{~A}$ & $1.424(12)$ & $\mathrm{C} 21$ & $\mathrm{C} 23$ & $1.512(15)$ \\
\hline $\mathrm{C} 15 \mathrm{~A}$ & C16A & $1.407(16)$ & $\mathrm{C} 21$ & $\mathrm{C} 24$ & $1.545(16)$ \\
\hline $\mathrm{C} 15 \mathrm{~A}$ & C $20 \mathrm{~A}$ & $1.341(16)$ & $\mathrm{C} 25$ & $\mathrm{C} 26$ & $1.554(16)$ \\
\hline $\mathrm{C} 16 \mathrm{~A}$ & C17A & $1.410(16)$ & $\mathrm{C} 25$ & $\mathrm{C} 27$ & $1.529(15)$ \\
\hline
\end{tabular}


$\begin{array}{lllll}\mathrm{C} 17 \mathrm{AC} 18 \mathrm{~A} & 1.394(17) & \mathrm{C} 25 & \mathrm{C} 28 & 1.525(18)\end{array}$

Table 4.5. Bond angles for $\mathrm{Co}^{\mathrm{II}}-\mathrm{AP}^{\mathrm{ditBu}}$ complex (7).

\begin{tabular}{|c|c|c|c|c|c|c|}
\hline \multicolumn{4}{|c|}{ Atom Atom Atom Angle ${ }^{\circ}$} & \multirow{2}{*}{$\begin{array}{l}\text { Atom Atom } \\
\text { C20AC19A }\end{array}$} & \multirow{2}{*}{$\begin{array}{l}\text { Atom } \\
\text { C18A }\end{array}$} & \multirow{2}{*}{$\begin{array}{l}\text { Angle } /^{\circ} \\
121.8(16)\end{array}$} \\
\hline $\mathrm{O} 1$ & Col & $\mathrm{N} 1$ & $78.7(4)$ & & & \\
\hline $\mathrm{O} 1$ & Co1 & $\mathrm{N} 2$ & $93.7(4)$ & C20AC19A & $\mathrm{C} 25 \mathrm{~A}$ & $110.4(16)$ \\
\hline N1 & Co1 & $\mathrm{N} 2$ & 93.9(3) & C15AC20A & C19A & $118.5(17)$ \\
\hline $\mathrm{C} 2$ & $\mathrm{O} 1$ & Co1 & $111.6(2)$ & $\mathrm{C} 22 \mathrm{AC} 21 \mathrm{~A}$ & C17A & $109.8(18)$ \\
\hline $\mathrm{C} 1$ & N1 & Co1 & 106.1(5) & $\mathrm{C} 22 \mathrm{AC} 21 \mathrm{~A}$ & $\mathrm{C} 23 \mathrm{~A}$ & $108.8(13)$ \\
\hline $\mathrm{C} 2$ & $\mathrm{C} 1$ & N1 & 114.4(4) & $\mathrm{C} 22 \mathrm{AC} 21 \mathrm{~A}$ & $\mathrm{C} 24 \mathrm{~A}$ & $112.7(15)$ \\
\hline C6 & $\mathrm{C} 1$ & N1 & $123.8(4)$ & $\mathrm{C} 23 \mathrm{AC} 21 \mathrm{~A}$ & C17A & $109.9(14)$ \\
\hline C6 & $\mathrm{C} 1$ & $\mathrm{C} 2$ & $121.8(4)$ & $\mathrm{C} 23 \mathrm{AC} 21 \mathrm{~A}$ & $\mathrm{C} 24 \mathrm{~A}$ & $106.9(14)$ \\
\hline $\mathrm{O} 1$ & $\mathrm{C} 2$ & $\mathrm{C} 1$ & 119.1(4) & $\mathrm{C} 24 \mathrm{AC} 21 \mathrm{~A}$ & C17A & $108.8(16)$ \\
\hline $\mathrm{O} 1$ & $\mathrm{C} 2$ & $\mathrm{C} 3$ & $123.2(4)$ & C19AC25A & C26A & $109.5(14)$ \\
\hline $\mathrm{C} 1$ & $\mathrm{C} 2$ & C3 & $117.6(4)$ & C19AC25A & C27A & $112.2(13)$ \\
\hline $\mathrm{C} 2$ & $\mathrm{C} 3$ & C7 & $119.8(4)$ & C19AC25A & $\mathrm{C} 28 \mathrm{~A}$ & $109.3(13)$ \\
\hline $\mathrm{C} 4$ & $\mathrm{C} 3$ & $\mathrm{C} 2$ & $117.8(4)$ & C27AC25A & C26A & $107.7(11)$ \\
\hline $\mathrm{C} 4$ & $\mathrm{C} 3$ & $\mathrm{C} 7$ & $122.3(4)$ & C27AC25A & C28A & $112.8(12)$ \\
\hline $\mathrm{C} 3$ & $\mathrm{C} 4$ & C5 & 124.4(4) & $\mathrm{C} 28 \mathrm{AC} 25 \mathrm{~A}$ & $\mathrm{C} 26 \mathrm{~A}$ & $104.9(13)$ \\
\hline $\mathrm{C} 4$ & $\mathrm{C} 5$ & $\mathrm{C} 11$ & $123.4(4)$ & $\mathrm{C} 15 \quad \mathrm{~N} 2$ & Co1 & $113.5(13)$ \\
\hline C6 & $\mathrm{C} 5$ & $\mathrm{C} 4$ & $116.8(5)$ & C16 C15 & $\mathrm{N} 2$ & $117.4(11)$ \\
\hline C6 & $\mathrm{C} 5$ & $\mathrm{C} 11$ & $119.8(5)$ & $\mathrm{C} 20 \quad \mathrm{C} 15$ & $\mathrm{~N} 2$ & $121.1(11)$ \\
\hline
\end{tabular}




\begin{tabular}{|c|c|c|c|c|c|c|c|}
\hline $\mathrm{C} 1$ & C6 & C5 & $121.5(4)$ & $\mathrm{C} 20$ & C15 & C16 & $121.3(10)$ \\
\hline $\mathrm{C} 3$ & $\mathrm{C} 7$ & $\mathrm{C} 10$ & $110.9(8)$ & $\mathrm{O} 2$ & C16 & $\mathrm{C} 15$ & $115.8(11)$ \\
\hline C8 & C7 & $\mathrm{C} 3$ & $109.5(6)$ & $\mathrm{O} 2$ & C16 & $\mathrm{C} 17$ & $120.9(13)$ \\
\hline C8 & C7 & C9 & $110.9(7)$ & $\mathrm{C} 15$ & C16 & $\mathrm{C} 17$ & $123.2(13)$ \\
\hline C8 & $\mathrm{C} 7$ & $\mathrm{C} 10$ & $108.8(14)$ & C16 & $\mathrm{C} 17$ & $\mathrm{C} 21$ & $136.6(15)$ \\
\hline C9 & $\mathrm{C} 7$ & $\mathrm{C} 3$ & $110.3(11)$ & $\mathrm{C} 18$ & $\mathrm{C} 17$ & C16 & $110.1(12)$ \\
\hline C9 & C7 & $\mathrm{C} 10$ & $106.4(8)$ & $\mathrm{C} 18$ & C17 & $\mathrm{C} 21$ & $113.2(13)$ \\
\hline C5 & $\mathrm{C} 11$ & $\mathrm{C} 12$ & $110.1(15)$ & $\mathrm{C} 19$ & $\mathrm{C} 18$ & $\mathrm{C} 17$ & $124.5(12)$ \\
\hline C5 & $\mathrm{C} 11$ & $\mathrm{C} 13$ & $113.0(7)$ & $\mathrm{C} 18$ & C19 & $\mathrm{C} 20$ & $124.4(14)$ \\
\hline $\mathrm{C} 5$ & $\mathrm{C} 11$ & $\mathrm{C} 14$ & $111.9(5)$ & $\mathrm{C} 18$ & C19 & $\mathrm{C} 25$ & $128.9(14)$ \\
\hline $\mathrm{C} 12$ & $\mathrm{C} 11$ & $\mathrm{C} 13$ & $107.4(6)$ & $\mathrm{C} 20$ & C19 & $\mathrm{C} 25$ & $106.4(14)$ \\
\hline $\mathrm{C} 12$ & $\mathrm{C} 11$ & $\mathrm{C} 14$ & $107.9(12)$ & $\mathrm{C} 19$ & $\mathrm{C} 20$ & $\mathrm{C} 15$ & $115.6(13)$ \\
\hline $\mathrm{C} 13$ & $\mathrm{C} 11$ & $\mathrm{C} 14$ & $106.3(10)$ & $\mathrm{C} 17$ & $\mathrm{C} 21$ & $\mathrm{C} 24$ & $113.3(14)$ \\
\hline $\mathrm{C} 15 \mathrm{~A}$ & $\mathrm{~N} 2 \mathrm{~A}$ & Co1 & $112.4(16)$ & $\mathrm{C} 22$ & $\mathrm{C} 21$ & $\mathrm{C} 17$ & $110.8(17)$ \\
\hline C16A & $\mathrm{C} 15 \mathrm{~A}$ & $\mathrm{AN} 2 \mathrm{~A}$ & $117.8(18)$ & $\mathrm{C} 22$ & $\mathrm{C} 21$ & $\mathrm{C} 24$ & $110.5(15)$ \\
\hline $\mathrm{C} 20 \mathrm{~A}$ & $\mathrm{C} 15 \mathrm{~A}$ & $\mathrm{AN} 2 \mathrm{~A}$ & $122(2)$ & $\mathrm{C} 23$ & $\mathrm{C} 21$ & $\mathrm{C} 17$ & $111.9(15)$ \\
\hline $\mathrm{C} 20 \mathrm{~A}$ & $\mathrm{C} 15 \mathrm{~A}$ & AC16A & $120.0(12)$ & $\mathrm{C} 23$ & $\mathrm{C} 21$ & $\mathrm{C} 22$ & $108.0(13)$ \\
\hline $\mathrm{O} 2 \mathrm{~A}$ & C16A & AC15A & $109.9(16)$ & $\mathrm{C} 23$ & $\mathrm{C} 21$ & $\mathrm{C} 24$ & $101.8(14)$ \\
\hline $\mathrm{O} 2 \mathrm{~A}$ & C16A & $\mathrm{AC} 17 \mathrm{~A}$ & $126.0(19)$ & C19 & $\mathrm{C} 25$ & $\mathrm{C} 26$ & $104.0(16)$ \\
\hline $\mathrm{C} 15 \mathrm{~A}$ & $\mathrm{C} 16 \mathrm{~A}$ & $\mathrm{AC} 17 \mathrm{~A}$ & $123.1(15)$ & C19 & $\mathrm{C} 25$ & $\mathrm{C} 27$ & $109.8(16)$ \\
\hline $\mathrm{C} 16 \mathrm{~A}$ & $\mathrm{C} 17 \mathrm{~A}$ & $\mathrm{AC} 21 \mathrm{~A}$ & 129.1(16) & $\mathrm{C} 19$ & $\mathrm{C} 25$ & $\mathrm{C} 28$ & $106.8(13)$ \\
\hline
\end{tabular}




$\begin{array}{lllll}\text { C18AC17AC16A 112.5(15) } & \text { C27 } & \text { C25 } & \text { C26 } & 109.6(12) \\ \text { C18AC17AC21A 117.8(16) } & \text { C28 } & \text { C25 } & \text { C26 } & 108.2(13) \\ \text { C19AC18A C17A 123.3(15) } & \text { C28 } & \text { C25 } & \text { C27 } & 117.6(14)\end{array}$

C18A C19A C25A 127.7(16)

Table 4.6. Hydrogen atom coordinates $\left(\AA \times 10^{4}\right)$ and isotropic displacement parameters $\left(\AA^{2} \times 10^{3}\right)$ for $\mathrm{Co}^{\mathrm{II}}-\mathrm{AP}^{\mathrm{ditBu}}$ Complex (7).

\begin{tabular}{|c|c|c|c|c|}
\hline Atom & $x$ & $y$ & $z$ & $\mathbf{U}(\mathbf{e q})$ \\
\hline H1A & 5470 & 8858 & 5224 & 38 \\
\hline H1B & 5859 & 8496 & 5067 & 38 \\
\hline H4 & 5461 & 9280 & 3222 & 40 \\
\hline H6 & 5868 & 9481 & 4641 & 36 \\
\hline H8A & 4491 & 8123 & 3720 & 70 \\
\hline H8B & 4343 & 8077 & 3140 & 70 \\
\hline $\mathrm{H} 8 \mathrm{C}$ & 4329 & 8611 & 3411 & 70 \\
\hline H9A & 5668 & 7948 & 3108 & 84 \\
\hline H9B & 5164 & 7698 & 2900 & 84 \\
\hline H9C & 5286 & 7683 & 3487 & 84 \\
\hline H10A & 4877 & 8962 & 2766 & 73 \\
\hline H10B & 4894 & 8431 & 2488 & 73 \\
\hline $\mathrm{H} 10 \mathrm{C}$ & 5404 & 8703 & 2645 & 73 \\
\hline
\end{tabular}




\begin{tabular}{|c|c|c|c|c|}
\hline $\mathrm{H} 12 \mathrm{~A}$ & 6575 & 9897 & 4193 & 86 \\
\hline H12B & 6625 & 10273 & 3729 & 86 \\
\hline $\mathrm{H} 12 \mathrm{C}$ & 6620 & 9681 & 3635 & 86 \\
\hline H13A & 5953 & 9917 & 3016 & 75 \\
\hline H13B & 5923 & 10483 & 3211 & 75 \\
\hline $\mathrm{H} 13 \mathrm{C}$ & 5431 & 10141 & 3209 & 75 \\
\hline H14A & 5351 & 10395 & 4111 & 60 \\
\hline H14B & 5867 & 10695 & 4059 & 60 \\
\hline $\mathrm{H} 14 \mathrm{C}$ & 5801 & 10285 & 4492 & 60 \\
\hline $\mathrm{H} 2 \mathrm{AA}$ & 5475 & 7196 & 5206 & 48 \\
\hline $\mathrm{H} 2 \mathrm{AB}$ & 5487 & 7249 & 4657 & 48 \\
\hline H18A & 7285 & 8155 & 5007 & 48 \\
\hline $\mathrm{H} 20 \mathrm{~A}$ & 6112 & 7575 & 5725 & 46 \\
\hline $\mathrm{H} 22 \mathrm{~A}$ & 6711 & 8766 & 4084 & 90 \\
\hline $\mathrm{H} 22 \mathrm{~B}$ & 7177 & 8767 & 3708 & 90 \\
\hline $\mathrm{H} 22 \mathrm{C}$ & 7270 & 8788 & 4300 & 90 \\
\hline $\mathrm{H} 23 \mathrm{~A}$ & 6809 & 7521 & 3598 & 78 \\
\hline $\mathrm{H} 23 \mathrm{~B}$ & 7059 & 7969 & 3288 & 78 \\
\hline $\mathrm{H} 23 \mathrm{C}$ & 6510 & 8035 & 3521 & 78 \\
\hline $\mathrm{H} 24 \mathrm{~A}$ & 7764 & 8000 & 4393 & 91 \\
\hline $\mathrm{H} 24 \mathrm{~B}$ & 7800 & 8004 & 3794 & 91 \\
\hline
\end{tabular}




\begin{tabular}{|c|c|c|c|c|}
\hline $\mathrm{H} 24 \mathrm{C}$ & 7596 & 7517 & 4080 & 91 \\
\hline $\mathrm{H} 26 \mathrm{~A}$ & 6635 & 8534 & 6111 & 71 \\
\hline H26B & 6786 & 8224 & 6601 & 71 \\
\hline $\mathrm{H} 26 \mathrm{C}$ & 6298 & 8071 & 6288 & 71 \\
\hline $\mathrm{H} 27 \mathrm{~A}$ & 6611 & 7218 & 6236 & 70 \\
\hline H27B & 7122 & 7353 & 6519 & 70 \\
\hline $\mathrm{H} 27 \mathrm{C}$ & 7138 & 7090 & 5981 & 70 \\
\hline $\mathrm{H} 28 \mathrm{~A}$ & 7675 & 7945 & 5647 & 67 \\
\hline $\mathrm{H} 28 \mathrm{~B}$ & 7659 & 8010 & 6243 & 67 \\
\hline $\mathrm{H} 28 \mathrm{C}$ & 7451 & 8446 & 5888 & 67 \\
\hline $\mathrm{H} 2 \mathrm{~B}$ & 5558 & 7178 & 4956 & 42 \\
\hline $\mathrm{H} 2 \mathrm{C}$ & 5540 & 7313 & 5479 & 42 \\
\hline H18 & 7342 & 8046 & 4972 & 46 \\
\hline $\mathrm{H} 20$ & 6204 & 7689 & 5868 & 46 \\
\hline $\mathrm{H} 22 \mathrm{D}$ & 6464 & 8528 & 3806 & 88 \\
\hline $\mathrm{H} 22 \mathrm{E}$ & 7009 & 8694 & 3619 & 88 \\
\hline $\mathrm{H} 22 \mathrm{~F}$ & 6834 & 8814 & 4180 & 88 \\
\hline $\mathrm{H} 23 \mathrm{D}$ & 7193 & 7409 & 3723 & 84 \\
\hline $\mathrm{H} 23 \mathrm{E}$ & 7132 & 7868 & 3343 & 84 \\
\hline $\mathrm{H} 23 \mathrm{~F}$ & 6647 & 7615 & 3587 & 84 \\
\hline $\mathrm{H} 24 \mathrm{D}$ & 7668 & 8376 & 4405 & \\
\hline
\end{tabular}




\begin{tabular}{lllll} 
H24E & 7762 & 8191 & 3843 & 81 \\
H24F & 7726 & 7791 & 4288 & 81 \\
H26D & 6622 & 8678 & 6004 & 72 \\
H26E & 6802 & 8481 & 6541 & 72 \\
H26F & 6339 & 8218 & 6265 & 72 \\
H27D & 6708 & 7403 & 6321 & 74 \\
H27E & 7223 & 7578 & 6573 & 74 \\
H27F & 7231 & 7266 & 6061 & 74 \\
H28D & 7756 & 8055 & 5690 & 82 \\
H28E & 7668 & 8387 & 6181 & 82 \\
H28F & 7461 & 8575 & 5650 & $51(16)$ \\
H2A & $5740(20)$ & $7760(20)$ & $4170(20)$ & \\
\hline & & & & \\
\hline
\end{tabular}

Table 4.7. Atomic occupancy for $\mathrm{Co}^{\mathrm{II}}-\mathrm{AP}^{\mathrm{ditBu}}$ complex (7).

$\begin{array}{cccccc}\text { Atom } & \text { Occupancy } & \text { Atom } & \text { Occupancy } & \text { Atom } & \text { Occupancy } \\ \text { O1 } & 0.5 & \mathrm{~N} 1 & 0.5 & \mathrm{H} 1 \mathrm{~A} & 0.5 \\ \mathrm{H} 1 \mathrm{~B} & 0.5 & \mathrm{C} 1 & 0.5 & \mathrm{C} 2 & 0.5 \\ \mathrm{C} 3 & 0.5 & \mathrm{C} 4 & 0.5 & \mathrm{H} 4 & 0.5 \\ \mathrm{C} 5 & 0.5 & \mathrm{C} 6 & 0.5 & \mathrm{H} 6 & 0.5 \\ \mathrm{C} 7 & 0.5 & \mathrm{C} 8 & 0.5 & \mathrm{H} 8 \mathrm{~A} & 0.5 \\ \mathrm{H} 8 \mathrm{~B} & 0.5 & \mathrm{H} 8 \mathrm{C} & 0.5 & \mathrm{C} 9 & 0.5\end{array}$




\begin{tabular}{|c|c|c|c|c|}
\hline H9A 0.5 & H9B & 0.5 & $\mathrm{H} 9 \mathrm{C}$ & 0.5 \\
\hline C10 0.5 & H10A & 0.5 & H10B & 0.5 \\
\hline H10C 0.5 & C11 & 0.5 & $\mathrm{C} 12$ & 0.5 \\
\hline H12A 0.5 & H12B & 0.5 & $\mathrm{H} 12 \mathrm{C}$ & 0.5 \\
\hline C13 0.5 & H13A & 0.5 & H13B & 0.5 \\
\hline H13C 0.5 & C14 & 0.5 & H14A & 0.5 \\
\hline H14B 0.5 & $\mathrm{H} 14 \mathrm{C}$ & 0.5 & $\mathrm{O} 2 \mathrm{~A}$ & $0.222(6)$ \\
\hline $\mathrm{N} 2 \mathrm{~A} \quad 0.222(6)$ & $\mathrm{H} 2 \mathrm{AA}$ & $0.222(6)$ & $\mathrm{H} 2 \mathrm{AB}$ & $0.222(6)$ \\
\hline C15A 0.222(6) & C16A & $0.222(6)$ & C17A & $0.222(6)$ \\
\hline C18A 0.222(6) & H18A & $0.222(6)$ & C19A & $0.222(6)$ \\
\hline C20A 0.222(6) & $\mathrm{H} 20 \mathrm{~A}$ & $0.222(6)$ & C21A & $0.222(6)$ \\
\hline C22A $0.222(6)$ & $\mathrm{H} 22 \mathrm{~A}$ & $0.222(6)$ & $\mathrm{H} 22 \mathrm{~B}$ & $0.222(6)$ \\
\hline $\mathrm{H} 22 \mathrm{C} 0.222(6)$ & $\mathrm{C} 23 \mathrm{~A}$ & $0.222(6)$ & $\mathrm{H} 23 \mathrm{~A}$ & $0.222(6)$ \\
\hline $\mathrm{H} 23 \mathrm{~B} 0.222(6)$ & $\mathrm{H} 23 \mathrm{C}$ & $0.222(6)$ & $\mathrm{C} 24 \mathrm{~A}$ & $0.222(6)$ \\
\hline $\mathrm{H} 24 \mathrm{~A} 0.222(6)$ & $\mathrm{H} 24 \mathrm{~B}$ & $0.222(6)$ & $\mathrm{H} 24 \mathrm{C}$ & $0.222(6)$ \\
\hline C25A 0.222(6) & C26A & $0.222(6)$ & $\mathrm{H} 26 \mathrm{~A}$ & $0.222(6)$ \\
\hline H26B 0.222(6) & $\mathrm{H} 26 \mathrm{C}$ & $0.222(6)$ & C27A & $0.222(6)$ \\
\hline $\mathrm{H} 27 \mathrm{~A} 0.222(6)$ & $\mathrm{H} 27 \mathrm{~B}$ & $0.222(6)$ & $\mathrm{H} 27 \mathrm{C}$ & $0.222(6)$ \\
\hline C28A $0.222(6)$ & $\mathrm{H} 28 \mathrm{~A}$ & $0.222(6)$ & $\mathrm{H} 28 \mathrm{~B}$ & $0.222(6)$ \\
\hline $\mathrm{H} 28 \mathrm{C} 0.222(6)$ & $\mathrm{O} 2$ & $0.278(6)$ & N2 & $0.278(6)$ \\
\hline $\mathrm{H} 2 \mathrm{~B} \quad 0.278(6)$ & $\mathrm{H} 2 \mathrm{C}$ & $0.278(6)$ & $\mathrm{C} 15$ & $0.278(6)$ \\
\hline
\end{tabular}




\begin{tabular}{|c|c|c|c|c|c|}
\hline C16 & $0.278(6)$ & $\mathrm{C} 17$ & $0.278(6)$ & $\mathrm{C} 18$ & $0.278(6)$ \\
\hline H18 & $0.278(6)$ & C19 & $0.278(6)$ & $\mathrm{C} 20$ & $0.278(6)$ \\
\hline H20 & $0.278(6)$ & $\mathrm{C} 21$ & $0.278(6)$ & $\mathrm{C} 22$ & $0.278(6)$ \\
\hline $\mathrm{H} 22 \mathrm{D}$ & $0.278(6)$ & $\mathrm{H} 22 \mathrm{E}$ & $0.278(6)$ & $\mathrm{H} 22 \mathrm{~F}$ & $0.278(6)$ \\
\hline C23 & $0.278(6)$ & $\mathrm{H} 23 \mathrm{D}$ & $0.278(6)$ & $\mathrm{H} 23 \mathrm{E}$ & $0.278(6)$ \\
\hline $\mathrm{H} 23 \mathrm{~F}$ & $0.278(6)$ & $\mathrm{C} 24$ & $0.278(6)$ & $\mathrm{H} 24 \mathrm{D}$ & $0.278(6)$ \\
\hline $\mathrm{H} 24 \mathrm{E}$ & $0.278(6)$ & $\mathrm{H} 24 \mathrm{~F}$ & $0.278(6)$ & $\mathrm{C} 25$ & $0.278(6)$ \\
\hline C26 & $0.278(6)$ & $\mathrm{H} 26 \mathrm{D}$ & $0.278(6)$ & $\mathrm{H} 26 \mathrm{E}$ & $0.278(6)$ \\
\hline $\mathrm{H} 26 \mathrm{~F}$ & $0.278(6)$ & $\mathrm{C} 27$ & $0.278(6)$ & $\mathrm{H} 27 \mathrm{D}$ & $0.278(6)$ \\
\hline $\mathrm{H} 27 \mathrm{E}$ & $0.278(6)$ & $\mathrm{H} 27 \mathrm{~F}$ & $0.278(6)$ & $\mathrm{C} 28$ & $0.278(6)$ \\
\hline H28D & $0.278(6)$ & $\mathrm{H} 28 \mathrm{E}$ & $0.278(6)$ & $\mathrm{H} 28 \mathrm{~F}$ & $0.278(6)$ \\
\hline
\end{tabular}

4.4.6.2. Description of the X-ray Structural Analysis of $\mathrm{Co}^{\mathrm{III}}$-AP ${ }^{\mathrm{ditBu}}$ Complex (8) 


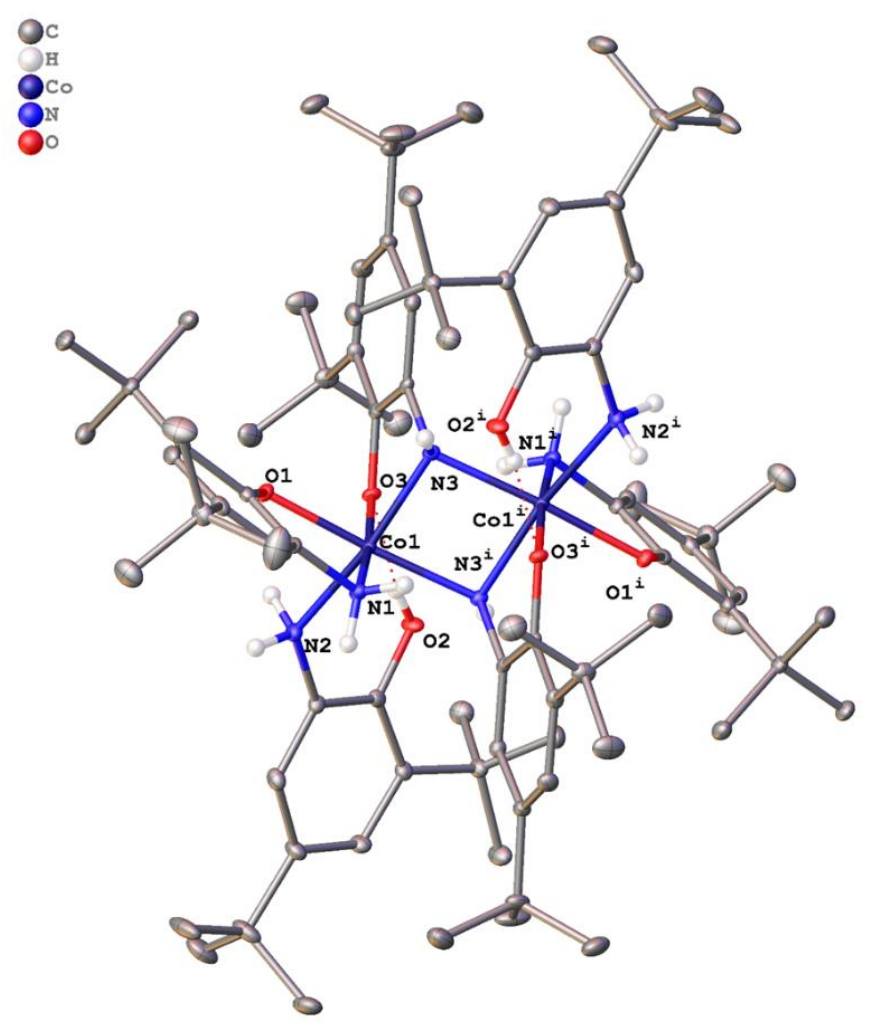

A green-yellow plate shaped crystal measuring $0.357 \mathrm{~mm}$ x $0.279 \mathrm{~mm}$ x $0.066 \mathrm{~mm}$ was selected under paratone oil using a MiTeGen Micromount and mounted at 100(1) K to a D8Venture diffractometer equipped with a Mo sealed tube X-ray source, a Triumph monochromator, and a Photon CMOS area detector. The unit cell was determined from reflections harvested with a signal to noise ratio $(\mathrm{I} / \sigma)$ of at least 8 from a series of $3 \omega$ scans of $6^{\circ}$ with $0.5^{\circ}$ frames using APEX3. ${ }^{1}$ The data were collected to a resolution of $0.77 \AA$ using $4 \omega$ scans.

The data were integrated using SAINT and corrected for absorption using SADABS. ${ }^{2}$ The systematic absences and E-statistics of the data were uniquely consistent with the space group $P 2{ }_{1} / n$. The structure was solved using the intrinsic phasing routine of SHELXT. ${ }^{3}$ The nonhydrogen atoms were located from a Fourier difference map of the electron density and anisotropically refined using the least-squares algorithm of SHELXL. ${ }^{4}$ The carbon-based hydrogen atoms were then placed in calculated positions and refined with riding thermal parameters. All hydrogen atoms on heteroatoms were located from the Fourier difference map. Their positions were allowed to refine freely and their thermal parameters were constrained to be 1.5 times the thermal parameter of their parent atom. 
The asymmetric unit consists of one half molecule $\mathrm{Co}_{2}$ (2-amino-4,6-tertbutylphenolate $)_{2}$ (2-amino-4,6-tert-butylphenol)( $\mu$-2-amido-4,6-tert-butylphenolate $)_{2}$ and one molecule of dichloromethane (Figures 1 and 2). The dimer resides on a crystallographic inversion center. Tert-butyl group C36 was disordered over two positions (major component: 85.6(4)\%). The dichloromethane is also disordered over two positions (major component: 54(3)\%). Geometry and thermal parameter restraints were used to ensure a chemically reasonable and computationally stable refinement.

The final structure consisted of 564 parameters refined against 10161 independent reflections, giving refinement residuals of $\mathrm{R}_{1}=0.0380$ (based off $F^{2}$ for $I>2 \sigma$ ) and $\mathrm{wR}_{2}=0.0896$ (based of $F^{2}$ for all reflections). The final difference Fourier map was featureless.

\section{References}

1. Bruker-AXS (2016). APEX 3 version 2016.9-0. Madison, Wisconsin, USA

2. (a) Bruker-AXS (2015). SAINT V8.37A. Madison, Wisconsin, USA. (b) ) Krause, L.; HerbstIrmer, R.; Sheldrick, G.; Stalke, D. J. Appl. Crystallogr. 2015, 48, 3-10.

3. Sheldrick, G. M., Acta Crystallogr. A 2015, A71, 3-8.

4. (a) Sheldrick, G. M., Acta Crystallogr. C 2015, C71, 3-8.; (b) Dolomanov, O. V.; Bourhis, L. J.; Gildea, R. J.; Howard, J. A. K.; Puschmann, H., J. Appl. Crystallogr. 2009, 42, 339-341.

Table 4.8. Crystal data and structure refinement for $\mathrm{Co}^{\mathrm{III}}-\mathrm{AP}^{\mathrm{ditBu}}$ Complex (8).

Identification code

Empirical formula

Formula weight

Temperature/K

Crystal system
Co ${ }^{\text {III }}-\mathrm{AP}^{\mathrm{ditBu}}$ Complex (8)

$\mathrm{C}_{86} \mathrm{H}_{136} \mathrm{Cl}_{4} \mathrm{Co}_{2} \mathrm{~N}_{6} \mathrm{O}_{6}$

1609.66

100(1)

monoclinic 
Space group

$\mathrm{a} / \AA$

$\mathrm{b} / \AA$

$\mathrm{c} / \AA$

$\alpha /^{\circ}$

$\beta /{ }^{\circ}$

$\gamma /{ }^{\circ}$

Volume $/ \AA^{3}$

Z

$\rho_{\text {calc }} \mathrm{g} / \mathrm{cm}^{3}$

$\mu / \mathrm{mm}^{-1}$

$\mathrm{F}(000)$

Crystal size/mm $\mathrm{m}^{3}$

Radiation

$2 \Theta$ range for data collection/ ${ }^{\circ}$

Index ranges

Reflections collected

Independent reflections

Data/restraints/parameters

Goodness-of-fit on $\mathrm{F}^{2}$
$\mathrm{P} 2{ }_{1} / \mathrm{n}$

15.0642(4)

$20.4722(5)$

15.7982(4)

90

115.1256(13)

90

4411.1(2)

2

1.212

0.549

1728.0

$0.357 \times 0.279 \times 0.066$

$\operatorname{MoK} \alpha(\lambda=0.71073)$

5.772 to 55.102

$-19 \leq \mathrm{h} \leq 19,-26 \leq \mathrm{k} \leq 26,-20 \leq 1 \leq$

20

56144

$10161\left[\mathrm{R}_{\text {int }}=0.0580, \mathrm{R}_{\text {sigma }}=\right.$ 0.0389]

$10161 / 259 / 564$

1.022 
Final R indexes $[\mathrm{I}>=2 \sigma(\mathrm{I})]$

$\mathrm{R}_{1}=0.0380, \mathrm{wR}_{2}=0.0812$

Final R indexes [all data]

$\mathrm{R}_{1}=0.0573, \mathrm{wR}_{2}=0.0896$

Largest diff. peak/hole / e $\AA^{-3}$

$0.47 /-0.65$

Table 4.9. Fractional atomic coordinates $\left(\times 10^{4}\right)$ and equivalent isotropic displacement parameters $\left(\AA^{2} \times 10^{3}\right)$ for $\mathrm{Co}^{\mathrm{III}}-\mathrm{AP}^{\mathrm{ditBu}}$ complex (8). $\mathrm{U}_{\text {eq }}$ is defined as $1 / 3$ of of the trace of the orthogonalised UIJ tensor.

$\begin{array}{lllll}\text { Atom } & \boldsymbol{x} & \boldsymbol{y} & \boldsymbol{U} & \mathbf{U}(\mathbf{e q}) \\ \mathrm{C} 1 & 4877.3(2) & 698.6(2) & 5011.0(2) & 8.50(6) \\ \mathrm{O} 1 & 3933.5(8) & 1263.1(6) & 5152.5(8) & 10.9(2) \\ \mathrm{O} 2 & 7311.3(9) & 845.7(6) & 6410.6(9) & 13.7(3) \\ \mathrm{O} 3 & 5578.1(8) & 665.9(6) & 6340.9(8) & 10.1(2) \\ \mathrm{N} 1 & 4052.5(10) & 755.4(8) & 3681.4(10) & 11.1(3) \\ \mathrm{N} 2 & 5633.3(11) & 1553.5(7) & 5131.8(12) & 12.3(3) \\ \mathrm{N} 3 & 4226.8(10) & -66.8(7) & 5164.5(10) & 9.0(3) \\ \mathrm{C} 1 & 3113.5(12) & 1033.6(8) & 3556.1(12) & 11.2(3) \\ \mathrm{C} 2 & 3111.0(12) & 1294.9(8) & 4368.2(12) & 11.0(3) \\ \mathrm{C} 3 & 2218.3(12) & 1576.1(8) & 4306.3(12) & 11.7(3) \\ \mathrm{C} 4 & 1425.0(12) & 1570.7(8) & 3432.4(13) & 13.2(3) \\ \mathrm{C} 5 & 1431.1(13) & 1294.1(9) & 2621.3(13) & 14.1(4) \\ \mathrm{C} 6 & 2305.7(13) & 1019.1(8) & 2700.2(12) & 12.7(3) \\ \mathrm{C} 7 & 528.1(13) & 1326.4(9) & 1675.8(13) & 16.5(4)\end{array}$




\begin{tabular}{|c|c|c|c|c|}
\hline $\mathrm{C} 8$ & $-417.0(14)$ & $1205.3(12)$ & 1795.1(16) & $29.3(5)$ \\
\hline C9 & $486.5(15)$ & 2013.5(10) & $1272.6(15)$ & $25.4(5)$ \\
\hline C10 & $579.0(17)$ & $825.6(12)$ & $983.8(16)$ & $36.0(6)$ \\
\hline $\mathrm{C} 11$ & 2154.2(12) & $1851.2(8)$ & $5181.9(12)$ & $12.4(3)$ \\
\hline C12 & $1134.5(13)$ & 2128.7(9) & $4967.7(14)$ & $16.9(4)$ \\
\hline C13 & $2367.4(14)$ & 1300.1(9) & $5909.0(13)$ & $16.6(4)$ \\
\hline C14 & 2904.4(14) & 2401.8(9) & $5604.0(14)$ & $17.8(4)$ \\
\hline $\mathrm{C} 15$ & $4238.8(12)$ & $-8.4(8)$ & 6078.6(11) & $9.6(3)$ \\
\hline C16 & 4995.0(12) & $382.6(8)$ & $6700.4(12)$ & $10.2(3)$ \\
\hline $\mathrm{C} 17$ & $5136.6(13)$ & $445.7(9)$ & $7634.4(12)$ & $12.7(3)$ \\
\hline $\mathrm{C} 18$ & $4452.2(13)$ & $130.2(9)$ & $7875.9(13)$ & $15.1(4)$ \\
\hline C19 & $3662.5(13)$ & $-232.7(8)$ & $7254.0(13)$ & $12.9(3)$ \\
\hline $\mathrm{C} 20$ & $3572.4(12)$ & $-312.3(8)$ & $6343.5(12)$ & $11.0(3)$ \\
\hline $\mathrm{C} 21$ & 2943.3(14) & $-554.2(9)$ & 7588.1(13) & $17.5(4)$ \\
\hline $\mathrm{C} 22$ & $1988.5(15)$ & $-754.2(12)$ & $6764.3(15)$ & $27.6(5)$ \\
\hline $\mathrm{C} 23$ & 2668.7(16) & $-73.9(10)$ & $8185.7(15)$ & $24.5(4)$ \\
\hline $\mathrm{C} 24$ & $3433.9(17)$ & $-1158.2(10)$ & 8172.1(16) & $27.7(5)$ \\
\hline $\mathrm{C} 25$ & 5996.7(13) & $839.2(9)$ & 8346.0(13) & $16.3(4)$ \\
\hline $\mathrm{C} 26$ & $5959.6(16)$ & $877.8(11)$ & $9300.5(14)$ & $24.7(4)$ \\
\hline $\mathrm{C} 27$ & 6969.6(14) & $509.8(11)$ & $8496.1(14)$ & $22.9(4)$ \\
\hline $\mathrm{C} 28$ & $5970.3(15)$ & $1543.7(9)$ & $7996.6(14)$ & $21.3(4)$ \\
\hline
\end{tabular}




\begin{tabular}{|c|c|c|c|c|}
\hline C29 & $6613.9(12)$ & $1655.5(8)$ & $5193.3(12)$ & $11.7(3)$ \\
\hline C30 & 7399.1(12) & $1281.6(8)$ & $5797.1(12)$ & $11.3(3)$ \\
\hline C31 & $8328.5(12)$ & $1346.8(8)$ & $5784.0(12)$ & $11.8(3)$ \\
\hline $\mathrm{C} 32$ & $8435.5(13)$ & $1844.8(9)$ & $5231.7(13)$ & $14.3(4)$ \\
\hline C33 & 7674.7(13) & $2255.9(9)$ & $4668.2(13)$ & $16.0(4)$ \\
\hline C34 & $6752.5(13)$ & 2138.9(9) & 4639.1(13) & $14.9(4)$ \\
\hline C35 & 7868.2(14) & $2828.4(10)$ & $4136.2(15)$ & $23.8(4)$ \\
\hline C39 & $9171.7(12)$ & $875.6(9)$ & 6341.6(13) & $13.4(3)$ \\
\hline $\mathrm{C} 40$ & $9487.6(13)$ & $939.7(10)$ & 7397.7(13) & $18.4(4)$ \\
\hline $\mathrm{C} 41$ & $8851.9(14)$ & 166.2(9) & $6029.7(14)$ & $17.4(4)$ \\
\hline $\mathrm{C} 42$ & $10076.7(13)$ & $1008.5(10)$ & $6158.0(14)$ & $19.8(4)$ \\
\hline C36 & 8371.3(18) & 2573.1(12) & $3505.3(18)$ & $25.5(6)$ \\
\hline C37 & 6934.6(19) & $3171.0(15)$ & $3490(2)$ & $32.2(7)$ \\
\hline C38 & $8565(2)$ & $3308.2(12)$ & $4835(2)$ & $31.3(7)$ \\
\hline $\mathrm{C} 36 \mathrm{~A}$ & $8813(13)$ & 2979(9) & $4347(14)$ & $40(3)$ \\
\hline C37A & $7081(15)$ & $2868(11)$ & $3220(15)$ & $42(3)$ \\
\hline C38A & $7533(14)$ & $3520(9)$ & $4693(13)$ & $40(3)$ \\
\hline $\mathrm{Cl} 1$ & 3942(4) & $2856(2)$ & $3846(3)$ & $23.5(9)$ \\
\hline $\mathrm{Cl} 2$ & 4049(7) & 2107(3) & $2327(5)$ & $42.1(12)$ \\
\hline $\mathrm{C} 43$ & $3246(9)$ & 2591(6) & 2708(9) & $23.7(17)$ \\
\hline Cl1A & $3850(7)$ & 2835(3) & $3717(8)$ & $51.9(16)$ \\
\hline
\end{tabular}




$\begin{array}{lllll}\mathrm{Cl} 2 \mathrm{~A} & 4266(9) & 2048(5) & 2407(5) & 53.9(17) \\ \mathrm{C} 43 \mathrm{~A} & 3415(11) & 2492(8) & 2591(11) & 28(3)\end{array}$

Table 4.10. Anisotropic displacement parameters $\left(\AA^{2} \times 10^{3}\right)$ for $\mathrm{Co}^{\mathrm{III}}$-AP ${ }^{\mathrm{ditBu}}$ complex (8). The anisotropic displacement factor exponent takes the form: $-2 \pi^{2}\left[h^{2} a^{* 2} U_{11}+2 h k a * b * U_{12}+\ldots\right]$.

\begin{tabular}{|c|c|c|c|c|c|c|}
\hline Atom & $\mathrm{U}_{11}$ & $\mathrm{U}_{22}$ & $\mathbf{U}_{33}$ & $\mathbf{U}_{23}$ & $\mathrm{U}_{13}$ & $\mathrm{U}_{12}$ \\
\hline Co1 & $6.49(10)$ & $10.11(11)$ & $8.86(11)$ & $0.30(9)$ & $3.21(8)$ & $0.60(9)$ \\
\hline $\mathrm{O} 1$ & $7.4(5)$ & 13.1(6) & $11.6(6)$ & $-0.8(5)$ & $3.5(5)$ & $1.6(5)$ \\
\hline $\mathrm{O} 2$ & $7.1(6)$ & 18.2(7) & $15.7(6)$ & $5.0(5)$ & $4.9(5)$ & $-0.2(5)$ \\
\hline $\mathrm{O} 3$ & $8.8(5)$ & $14.1(6)$ & $8.2(6)$ & $0.1(5)$ & $4.5(5)$ & $-0.4(5)$ \\
\hline N1 & $9.3(7)$ & $13.5(7)$ & $10.7(7)$ & $1.8(6)$ & $4.5(6)$ & $2.1(6)$ \\
\hline N2 & $9.4(7)$ & $12.0(7)$ & $15.6(8)$ & $1.4(6)$ & $5.3(6)$ & $1.6(6)$ \\
\hline N3 & $5.9(6)$ & $12.2(7)$ & $7.5(6)$ & $-0.1(6)$ & $1.5(6)$ & $-0.5(5)$ \\
\hline $\mathrm{C} 1$ & $8.3(8)$ & $10.2(8)$ & $16.3(9)$ & $2.3(7)$ & $6.4(7)$ & $1.7(6)$ \\
\hline $\mathrm{C} 2$ & $9.1(8)$ & $9.3(8)$ & $15.0(8)$ & $2.2(7)$ & $5.6(7)$ & $-0.4(6)$ \\
\hline C3 & $10.8(8)$ & $9.5(8)$ & 16.4(9) & $2.1(7)$ & $7.2(7)$ & $1.2(6)$ \\
\hline $\mathrm{C} 4$ & $8.7(8)$ & $12.2(8)$ & 18.9(9) & $3.0(7)$ & $6.1(7)$ & $2.7(7)$ \\
\hline $\mathrm{C} 5$ & $10.5(8)$ & $11.6(8)$ & 17.2(9) & $4.3(7)$ & $3.0(7)$ & $0.0(7)$ \\
\hline C6 & $13.1(8)$ & $11.4(8)$ & $13.5(8)$ & $1.2(7)$ & $5.6(7)$ & $1.2(7)$ \\
\hline $\mathrm{C} 7$ & $11.3(8)$ & $17.2(9)$ & 16.1(9) & $2.3(7)$ & $1.0(7)$ & $1.9(7)$ \\
\hline $\mathrm{C} 8$ & $11.7(9)$ & 41.1(13) & $26.9(11)$ & $8.5(10)$ & $0.3(8)$ & $-5.1(9)$ \\
\hline
\end{tabular}




\begin{tabular}{|c|c|c|c|c|c|c|}
\hline C9 & $19.5(10)$ & $25.6(11)$ & $22.8(10)$ & $8.4(9)$ & $1.1(8)$ & $0.8(8)$ \\
\hline $\mathrm{C} 10$ & $24.8(11)$ & $40.1(14)$ & $25.5(12)$ & $-12.8(10)$ & $-6.4(9)$ & $10.5(10)$ \\
\hline C11 & $10.2(8)$ & $12.7(8)$ & $15.9(9)$ & $1.3(7)$ & $7.0(7)$ & $1.9(7)$ \\
\hline $\mathrm{C} 12$ & $13.9(8)$ & $17.5(9)$ & $22.8(10)$ & $2.7(8)$ & $11.0(8)$ & $5.1(7)$ \\
\hline C13 & $16.6(9)$ & 17.7(9) & $18.4(9)$ & $3.7(7)$ & $10.2(8)$ & $4.5(7)$ \\
\hline C14 & $17.3(9)$ & $16.0(9)$ & $22.9(10)$ & $-4.2(8)$ & $11.2(8)$ & $-1.1(7)$ \\
\hline $\mathrm{C} 15$ & $10.4(8)$ & $10.4(7)$ & $8.6(7)$ & $1.5(6)$ & $4.6(6)$ & $3.8(6)$ \\
\hline C16 & $8.7(7)$ & $10.5(8)$ & $12.1(8)$ & $2.2(6)$ & $5.0(7)$ & $2.9(6)$ \\
\hline $\mathrm{C} 17$ & $14.2(8)$ & $12.2(8)$ & $10.4(8)$ & $0.1(7)$ & $3.9(7)$ & $1.5(7)$ \\
\hline C18 & $18.5(9)$ & $16.7(9)$ & $11.0(8)$ & $0.1(7)$ & $7.2(7)$ & $0.0(7)$ \\
\hline C19 & $15.1(8)$ & $11.8(8)$ & $14.5(8)$ & $2.3(7)$ & $9.0(7)$ & $1.0(7)$ \\
\hline $\mathrm{C} 20$ & $10.0(8)$ & 11.1(8) & $11.3(8)$ & $-0.5(6)$ & $3.7(7)$ & $0.5(6)$ \\
\hline $\mathrm{C} 21$ & 22.3(9) & 19.0(9) & $16.6(9)$ & $-1.9(7)$ & $13.7(8)$ & $-5.4(8)$ \\
\hline $\mathrm{C} 22$ & $24.3(10)$ & $41.0(13)$ & $23.8(11)$ & $-5.9(10)$ & $16.3(9)$ & $-15.7(10)$ \\
\hline $\mathrm{C} 23$ & $25.4(11)$ & $29.2(11)$ & $27.6(11)$ & $-5.7(9)$ & 19.8(9) & $-5.1(9)$ \\
\hline $\mathrm{C} 24$ & $39.6(12)$ & $20.7(10)$ & $31.1(12)$ & $4.2(9)$ & $22.9(10)$ & $-2.4(9)$ \\
\hline $\mathrm{C} 25$ & $16.0(9)$ & 20.3(9) & $11.2(8)$ & $-3.1(7)$ & $4.6(7)$ & $-3.6(7)$ \\
\hline $\mathrm{C} 26$ & $26.7(11)$ & $33.1(11)$ & $13.6(9)$ & $-6.9(8)$ & $8.1(8)$ & $-10.1(9)$ \\
\hline $\mathrm{C} 27$ & $15.3(9)$ & $31.8(11)$ & $16.9(9)$ & $-0.8(8)$ & $2.4(8)$ & $-0.4(8)$ \\
\hline $\mathrm{C} 28$ & $27.9(10)$ & $18.6(9)$ & $18.6(10)$ & $-6.8(8)$ & $11.0(8)$ & $-6.4(8)$ \\
\hline $\mathrm{C} 29$ & $8.6(8)$ & $10.9(8)$ & $15.1(8)$ & $-1.9(7)$ & $4.6(7)$ & $-0.9(6)$ \\
\hline
\end{tabular}




\begin{tabular}{|c|c|c|c|c|c|c|}
\hline $\mathrm{C} 30$ & $12.0(8)$ & $10.0(8)$ & $11.3(8)$ & $-1.8(6)$ & $4.4(7)$ & $-1.9(7)$ \\
\hline C31 & $9.9(8)$ & $10.7(8)$ & $12.9(8)$ & $-1.3(6)$ & $3.0(7)$ & $-1.4(6)$ \\
\hline C32 & $9.3(8)$ & 16.1(9) & $16.5(9)$ & $1.3(7)$ & $4.6(7)$ & $-2.0(7)$ \\
\hline C33 & $13.5(8)$ & $13.0(8)$ & $20.4(9)$ & $4.3(7)$ & $6.1(7)$ & $-1.7(7)$ \\
\hline C34 & $10.9(8)$ & $12.3(8)$ & $18.0(9)$ & $2.3(7)$ & $2.7(7)$ & $1.2(7)$ \\
\hline C35 & $17.6(9)$ & $20.4(10)$ & $28.6(11)$ & $12.7(9)$ & $5.3(9)$ & $-3.5(8)$ \\
\hline C39 & $9.4(8)$ & $13.6(8)$ & $16.4(9)$ & $3.1(7)$ & $4.8(7)$ & $1.6(7)$ \\
\hline $\mathrm{C} 40$ & $12.5(8)$ & $22.3(9)$ & $16.5(9)$ & $2.3(8)$ & $2.3(7)$ & $0.9(7)$ \\
\hline C41 & $16.5(9)$ & $13.0(9)$ & $22.3(10)$ & $1.8(7)$ & $7.9(8)$ & $2.9(7)$ \\
\hline $\mathrm{C} 42$ & $11.5(8)$ & $21.3(10)$ & $26.5(10)$ & $7.8(8)$ & $8.1(8)$ & $3.3(7)$ \\
\hline C36 & $23.5(12)$ & $29.0(13)$ & $29.0(13)$ & $13.5(11)$ & $15.8(11)$ & $1.8(10)$ \\
\hline $\mathrm{C} 37$ & $18.9(12)$ & $30.0(15)$ & $48.2(18)$ & $26.8(14)$ & $14.6(12)$ & $4.5(11)$ \\
\hline C38 & $37.5(15)$ & $20.6(12)$ & $34.1(15)$ & $5.0(11)$ & $13.6(12)$ & $-11.7(11)$ \\
\hline C36A & $39(5)$ & $43(6)$ & $50(6)$ & $28(5)$ & $31(5)$ & $9(5)$ \\
\hline C37A & $44(7)$ & $43(7)$ & $49(7)$ & $27(6)$ & $31(6)$ & $15(6)$ \\
\hline C38A & $53(6)$ & $35(6)$ & $46(6)$ & $13(6)$ & $33(5)$ & $4(6)$ \\
\hline $\mathrm{Cl1}$ & $24.9(11)$ & $26.2(13)$ & $15.1(11)$ & $2.1(9)$ & $4.5(7)$ & $0.9(7)$ \\
\hline $\mathrm{Cl} 2$ & $82(3)$ & $24.5(11)$ & $33.5(17)$ & $-0.7(12)$ & $38(2)$ & $-10.8(16)$ \\
\hline $\mathrm{C} 43$ & $21(4)$ & 21(3) & $25(3)$ & $3(2)$ & $6(2)$ & $3(2)$ \\
\hline Cl1A & $44(2)$ & $62(3)$ & $50(3)$ & $30.9(19)$ & $20(2)$ & $5.3(17)$ \\
\hline $\mathrm{Cl} 2 \mathrm{~A}$ & $66(3)$ & $47(3)$ & $35.2(13)$ & $11.0(14)$ & $9.2(17)$ & $-22(2)$ \\
\hline
\end{tabular}


$\begin{array}{lllllll}\mathrm{C} 43 \mathrm{~A} & 20(5) & 27(5) & 27(4) & 13(4) & -1(3) & -5(4)\end{array}$

Table 4.11. Bond lengths for $\mathrm{Co}^{\mathrm{III}}-\mathrm{AP}^{\mathrm{ditBu}}$ complex (8).

\begin{tabular}{|c|c|c|c|c|c|}
\hline Atom & Atom & Length/Å & Atom & Atom & Length/Å \\
\hline Co1 & $\mathrm{Co}^{1}{ }^{1}$ & $2.8861(5)$ & $\mathrm{C} 17$ & $\mathrm{C} 25$ & $1.534(2)$ \\
\hline Co1 & $\mathrm{O} 1$ & $1.9176(12)$ & C18 & C19 & $1.393(3)$ \\
\hline Col & $\mathrm{O} 3$ & $1.9104(12)$ & C19 & $\mathrm{C} 20$ & $1.396(2)$ \\
\hline Co1 & N1 & $1.9373(15)$ & C19 & $\mathrm{C} 21$ & $1.540(2)$ \\
\hline Co1 & N2 & $2.0524(15)$ & $\mathrm{C} 21$ & $\mathrm{C} 22$ & $1.530(3)$ \\
\hline Co1 & N3 & $1.9172(14)$ & $\mathrm{C} 21$ & $\mathrm{C} 23$ & $1.537(3)$ \\
\hline Co1 & $\mathrm{N} 3^{1}$ & $1.9719(14)$ & $\mathrm{C} 21$ & $\mathrm{C} 24$ & $1.532(3)$ \\
\hline $\mathrm{O} 1$ & $\mathrm{C} 2$ & $1.331(2)$ & $\mathrm{C} 25$ & $\mathrm{C} 26$ & $1.534(3)$ \\
\hline $\mathrm{O} 2$ & $\mathrm{C} 30$ & $1.365(2)$ & $\mathrm{C} 25$ & $\mathrm{C} 27$ & $1.538(3)$ \\
\hline $\mathrm{O} 3$ & $\mathrm{C} 16$ & $1.362(2)$ & $\mathrm{C} 25$ & $\mathrm{C} 28$ & $1.539(3)$ \\
\hline $\mathrm{N} 1$ & $\mathrm{C} 1$ & $1.458(2)$ & $\mathrm{C} 29$ & C30 & $1.392(2)$ \\
\hline $\mathrm{N} 2$ & $\mathrm{C} 29$ & $1.454(2)$ & $\mathrm{C} 29$ & C34 & $1.395(2)$ \\
\hline N3 & $\mathrm{Co}^{1}{ }^{1}$ & $1.9720(14)$ & C30 & C31 & $1.415(2)$ \\
\hline N3 & $\mathrm{C} 15$ & $1.441(2)$ & C31 & C32 & $1.395(2)$ \\
\hline $\mathrm{C} 1$ & $\mathrm{C} 2$ & $1.392(2)$ & C31 & C39 & $1.539(2)$ \\
\hline $\mathrm{C} 1$ & C6 & $1.383(2)$ & $\mathrm{C} 32$ & C33 & $1.396(3)$ \\
\hline $\mathrm{C} 2$ & $\mathrm{C} 3$ & $1.428(2)$ & C33 & C34 & $1.391(2)$ \\
\hline
\end{tabular}




\begin{tabular}{|c|c|c|c|c|c|}
\hline $\mathrm{C} 3$ & $\mathrm{C} 4$ & $1.390(2)$ & C33 & C35 & $1.541(2)$ \\
\hline $\mathrm{C} 3$ & $\mathrm{C} 11$ & $1.534(2)$ & C35 & C36 & $1.576(3)$ \\
\hline $\mathrm{C} 4$ & C5 & $1.405(3)$ & C35 & $\mathrm{C} 37$ & $1.514(3)$ \\
\hline $\mathrm{C} 5$ & C6 & $1.389(2)$ & C35 & C38 & $1.517(3)$ \\
\hline C5 & $\mathrm{C} 7$ & $1.536(2)$ & C35 & C36A & $1.353(17)$ \\
\hline $\mathrm{C} 7$ & $\mathrm{C} 8$ & $1.534(3)$ & C35 & C37A & $1.43(2)$ \\
\hline $\mathrm{C} 7$ & C9 & $1.534(3)$ & $\mathrm{C} 35$ & C38A & $1.846(18)$ \\
\hline $\mathrm{C} 7$ & $\mathrm{C} 10$ & $1.524(3)$ & C39 & $\mathrm{C} 40$ & $1.534(3)$ \\
\hline C11 & $\mathrm{C} 12$ & $1.535(2)$ & C39 & $\mathrm{C} 41$ & $1.544(2)$ \\
\hline C11 & $\mathrm{C} 13$ & $1.543(2)$ & C39 & $\mathrm{C} 42$ & $1.534(2)$ \\
\hline $\mathrm{C} 11$ & $\mathrm{C} 14$ & $1.534(2)$ & Cl1 & $\mathrm{C} 43$ & $1.739(13)$ \\
\hline C15 & $\mathrm{C} 16$ & $1.398(2)$ & $\mathrm{Cl} 2$ & $\mathrm{C} 43$ & $1.851(11)$ \\
\hline C15 & $\mathrm{C} 20$ & $1.388(2)$ & Cl1A & $\mathrm{C} 43 \mathrm{~A}$ & $1.759(15)$ \\
\hline C16 & $\mathrm{C} 17$ & $1.404(2)$ & $\mathrm{Cl} 2 \mathrm{~A}$ & $\mathrm{C} 43 \mathrm{~A}$ & $1.694(14)$ \\
\hline $\mathrm{C} 17$ & C18 & $1.400(2)$ & & & \\
\hline
\end{tabular}

Table 4.12. Bond angles for $\mathrm{Co}^{\mathrm{III}}-\mathrm{AP}^{\mathrm{ditBu}}$ complex (8).

$\begin{array}{llllllll}\text { Atom } & \text { Atom } & \begin{array}{l}\text { Ato } \\ \text { m }\end{array} & \text { Angle } /^{\circ} & \text { Atom Atom } & \text { Atom } & \text { Angle } /^{\circ} \\ \text { O1 } & \text { Co1 } & \text { Co1 }{ }^{1} & 134.73(4) & \text { O3 } & \text { C16 } & \text { C15 } & 115.36(15) \\ \text { O1 } & \text { Co1 } & \text { N1 } & 85.65(6) & \text { O3 } & \text { C16 } & \text { C17 } & 124.20(15) \\ \text { O1 } & \text { Co1 } & \text { N2 } & 83.39(6) & \text { C15 } & \text { C16 } & \text { C17 } & 120.40(15)\end{array}$




\begin{tabular}{|c|c|c|c|c|c|c|c|}
\hline $\mathrm{O} 1$ & Co1 & $\mathrm{N} 3^{1}$ & $175.75(6)$ & C16 & $\mathrm{C} 17$ & $\mathrm{C} 25$ & $121.49(16)$ \\
\hline $\mathrm{O} 3$ & Co1 & $\mathrm{Co} 1^{1}$ & $87.98(4)$ & C18 & C17 & C16 & $116.30(16)$ \\
\hline $\mathrm{O} 3$ & Co1 & $\mathrm{O} 1$ & $89.07(5)$ & $\mathrm{C} 18$ & $\mathrm{C} 17$ & $\mathrm{C} 25$ & $122.21(16)$ \\
\hline $\mathrm{O} 3$ & Co1 & $\mathrm{N} 1$ & $174.29(6)$ & C19 & $\mathrm{C} 18$ & $\mathrm{C} 17$ & $124.14(17)$ \\
\hline $\mathrm{O} 3$ & Co1 & $\mathrm{N} 2$ & $84.37(6)$ & $\mathrm{C} 18$ & C19 & $\mathrm{C} 20$ & $118.00(16)$ \\
\hline $\mathrm{O} 3$ & Co1 & $\mathrm{N} 3^{1}$ & $92.30(5)$ & C18 & C19 & $\mathrm{C} 21$ & $120.05(16)$ \\
\hline $\mathrm{O} 3$ & Co1 & N3 & $84.59(6)$ & $\mathrm{C} 20$ & C19 & $\mathrm{C} 21$ & 121.91(16) \\
\hline N1 & Co1 & $\mathrm{Co} 1^{1}$ & $94.19(5)$ & $\mathrm{C} 15$ & $\mathrm{C} 20$ & C19 & $119.48(16)$ \\
\hline N1 & Co1 & N2 & $97.16(7)$ & $\mathrm{C} 22$ & $\mathrm{C} 21$ & C19 & $111.53(15)$ \\
\hline N1 & Co1 & $\mathrm{N} 3^{1}$ & $92.82(6)$ & $\mathrm{C} 22$ & $\mathrm{C} 21$ & $\mathrm{C} 23$ & $107.02(17)$ \\
\hline N2 & Co1 & $\mathrm{Co}^{1}$ & $141.03(4)$ & $\mathrm{C} 22$ & $\mathrm{C} 21$ & $\mathrm{C} 24$ & $109.59(17)$ \\
\hline N3 & Co1 & $\mathrm{Co}^{1}{ }^{1}$ & $42.83(4)$ & $\mathrm{C} 23$ & $\mathrm{C} 21$ & C19 & $110.43(15)$ \\
\hline $\mathrm{N} 3^{1}$ & Co1 & $\mathrm{Co}^{1}{ }^{1}$ & $41.37(4)$ & $\mathrm{C} 24$ & $\mathrm{C} 21$ & C19 & $108.77(16)$ \\
\hline N3 & Co1 & $\mathrm{O} 1$ & $91.93(6)$ & $\mathrm{C} 24$ & $\mathrm{C} 21$ & $\mathrm{C} 23$ & $109.48(17)$ \\
\hline N3 & Co1 & N1 & $93.40(6)$ & $\mathrm{C} 17$ & $\mathrm{C} 25$ & $\mathrm{C} 26$ & $112.04(15)$ \\
\hline N3 & Co1 & $\mathrm{N} 2$ & $168.07(6)$ & $\mathrm{C} 17$ & $\mathrm{C} 25$ & $\mathrm{C} 27$ & $109.62(15)$ \\
\hline $\mathrm{N} 3^{1}$ & Co1 & $\mathrm{N} 2$ & $100.75(6)$ & $\mathrm{C} 17$ & $\mathrm{C} 25$ & $\mathrm{C} 28$ & $110.12(15)$ \\
\hline N3 & Co1 & $\mathrm{N} 3^{1}$ & $84.20(6)$ & $\mathrm{C} 26$ & $\mathrm{C} 25$ & $\mathrm{C} 27$ & $107.52(16)$ \\
\hline $\mathrm{C} 2$ & $\mathrm{O} 1$ & Co1 & $111.36(10)$ & $\mathrm{C} 26$ & $\mathrm{C} 25$ & $\mathrm{C} 28$ & $107.34(16)$ \\
\hline C16 & $\mathrm{O} 3$ & Co1 & $108.70(10)$ & $\mathrm{C} 27$ & $\mathrm{C} 25$ & $\mathrm{C} 28$ & $110.13(16)$ \\
\hline $\mathrm{C} 1$ & N1 & Co1 & $108.02(11)$ & C30 & $\mathrm{C} 29$ & $\mathrm{~N} 2$ & $120.71(16)$ \\
\hline
\end{tabular}




\begin{tabular}{|c|c|c|c|c|c|c|c|}
\hline $\mathrm{C} 29$ & N2 & Co1 & $129.54(11)$ & $\mathrm{C} 30$ & C29 & C34 & $120.69(16)$ \\
\hline Co1 & N3 & $\mathrm{Co} 1^{1}$ & $95.81(6)$ & C34 & $\mathrm{C} 29$ & $\mathrm{~N} 2$ & $118.60(15)$ \\
\hline C15 & N3 & $\mathrm{Co}^{1}{ }^{1}$ & $118.49(11)$ & $\mathrm{O} 2$ & C30 & C29 & $122.41(15)$ \\
\hline C15 & N3 & Co1 & $105.62(11)$ & $\mathrm{O} 2$ & C30 & C 31 & $117.84(15)$ \\
\hline $\mathrm{C} 2$ & $\mathrm{C} 1$ & N1 & $114.02(15)$ & $\mathrm{C} 29$ & C 30 & $\mathrm{C} 31$ & $119.75(16)$ \\
\hline C6 & $\mathrm{C} 1$ & $\mathrm{~N} 1$ & $121.63(15)$ & C30 & C31 & C39 & $120.89(15)$ \\
\hline C6 & $\mathrm{C} 1$ & $\mathrm{C} 2$ & $124.33(15)$ & C32 & C31 & C30 & $117.13(16)$ \\
\hline $\mathrm{O} 1$ & $\mathrm{C} 2$ & $\mathrm{C} 1$ & $118.28(15)$ & C32 & C31 & C39 & $121.97(15)$ \\
\hline $\mathrm{O} 1$ & $\mathrm{C} 2$ & $\mathrm{C} 3$ & $124.12(16)$ & C31 & C32 & $\mathrm{C} 33$ & 123.91(16) \\
\hline $\mathrm{C} 1$ & $\mathrm{C} 2$ & $\mathrm{C} 3$ & $117.59(16)$ & C32 & C33 & C35 & $120.82(16)$ \\
\hline $\mathrm{C} 2$ & $\mathrm{C} 3$ & C11 & $120.30(15)$ & C34 & C33 & C32 & $117.09(16)$ \\
\hline $\mathrm{C} 4$ & $\mathrm{C} 3$ & $\mathrm{C} 2$ & $116.89(16)$ & C34 & C33 & C35 & $122.04(16)$ \\
\hline $\mathrm{C} 4$ & $\mathrm{C} 3$ & C11 & $122.80(15)$ & C33 & C34 & $\mathrm{C} 29$ & $121.00(16)$ \\
\hline C3 & $\mathrm{C} 4$ & $\mathrm{C} 5$ & $124.98(16)$ & C33 & C35 & C36 & $110.24(17)$ \\
\hline $\mathrm{C} 4$ & C5 & C7 & $121.58(16)$ & C33 & C35 & C38A & $99.8(5)$ \\
\hline C6 & $\mathrm{C} 5$ & $\mathrm{C} 4$ & 117.07(16) & C37 & C35 & C33 & $112.54(17)$ \\
\hline C6 & C5 & C7 & $121.27(17)$ & C37 & C35 & C36 & $106.6(2)$ \\
\hline $\mathrm{C} 1$ & C6 & $\mathrm{C} 5$ & $119.10(17)$ & C37 & C35 & C38 & $110.4(2)$ \\
\hline $\mathrm{C} 8$ & C7 & C5 & $111.00(16)$ & C 38 & C35 & C33 & 109.17(18) \\
\hline C8 & C7 & C9 & 108.83(16) & C38 & C35 & C36 & 107.77(19) \\
\hline C9 & C7 & $\mathrm{C} 5$ & $107.84(15)$ & C36 & C35 & C33 & $117.5(7)$ \\
\hline
\end{tabular}




$\begin{array}{llllllll}\mathrm{C} 10 & \mathrm{C} 7 & \mathrm{C} 5 & 112.03(15) & \mathrm{C} 36 \mathrm{C} 35 & \mathrm{C} 37 \mathrm{~A} & 124.7(11) \\ \mathrm{C} 10 & \mathrm{C} 7 & \mathrm{C} 8 & 108.14(18) & \mathrm{C} 36 \mathrm{~A} 35 & \mathrm{C} 38 \mathrm{~A} & 100.4(11) \\ \mathrm{C} 10 & \mathrm{C} 7 & \mathrm{C} 9 & 108.94(18) & \mathrm{C} 37 \mathrm{~A} \text { C35 } & \mathrm{C} 33 & 109.1(8) \\ \mathrm{C} 3 & \mathrm{C} 11 & \mathrm{C} 12 & 112.18(15) & \mathrm{C} 37 \mathrm{~A} \text { C35 } & \mathrm{C} 38 \mathrm{~A} & 99.3(11) \\ \mathrm{C} 3 & \mathrm{C} 11 & \mathrm{C} 13 & 109.26(14) & \mathrm{C} 31 & \mathrm{C} 39 & \mathrm{C} 41 & 109.70(14) \\ \mathrm{C} 12 & \mathrm{C} 11 & \mathrm{C} 13 & 107.89(14) & \mathrm{C} 40 & \mathrm{C} 39 & \mathrm{C} 31 & 111.62(15) \\ \mathrm{C} 14 & \mathrm{C} 11 & \mathrm{C} 3 & 110.18(14) & \mathrm{C} 40 & \mathrm{C} 39 & \mathrm{C} 41 & 109.78(15) \\ \mathrm{C} 14 & \mathrm{C} 11 & \mathrm{C} 12 & 107.91(14) & \mathrm{C} 42 & \mathrm{C} 39 & \mathrm{C} 31 & 111.36(15) \\ \mathrm{C} 14 & \mathrm{C} 11 & \mathrm{C} 13 & 109.36(15) & \mathrm{C} 42 & \mathrm{C} 39 & \mathrm{C} 40 & 107.47(15) \\ \mathrm{C} 16 & \mathrm{C} 15 & \mathrm{~N} 3 & 114.30(15) & \mathrm{C} 42 & \mathrm{C} 39 & \mathrm{C} 41 & 106.76(15) \\ \mathrm{C} 20 & \mathrm{C} 15 & \mathrm{~N} 3 & 124.18(15) & \mathrm{C} 11 & \mathrm{C} 43 & \mathrm{Cl} 2 & 108.2(7) \\ \mathrm{C} 20 & \mathrm{C} 15 & \mathrm{C} 16 & 121.52(15) & \mathrm{C} 12 \mathrm{C} 43 \mathrm{~A} & \mathrm{C} 11 \mathrm{~A} & 113.8(9)\end{array}$

Table 4.13. Torsion angles for $\mathrm{Co}^{\mathrm{III}}-\mathrm{AP}^{\mathrm{ditBu}}$ complex $(\mathbf{8})$.
$\begin{array}{llllllllll}\text { A } & \text { B } & \text { C } & \text { D } & \text { Angle }^{\circ} & \text { A } & \text { B } & \text { C } & \text { D } & \text { Angle }^{\circ}\end{array}$
$\begin{array}{llllllll}\text { Co1 } & \text { O1 } & \text { C2 } & \text { C1 } & -11.35(18) & \text { C15 C16 C17 } & \text { C25 } & 176.39(16)\end{array}$
$\begin{array}{llllllll}\text { Co1 } & \text { O1 } & \text { C2 } & \text { C3 } & 168.08(13) & \text { C16 C15 C20 } & \text { C19 } & -0.7(3)\end{array}$
$\begin{array}{llllllll}\text { Co1 } & \text { O3 } & \text { C16 } & \text { C15 } & \text { 21.72(17) } & \text { C16 C17 C18 } & \text { C19 } & 0.1(3)\end{array}$
$\begin{array}{llllllll}\text { Co1 O3 } & \text { C16 } & \text { C17 } & -160.52(14) & \text { C16 C17 C25 } & \text { C26 } & 176.09(17)\end{array}$
$\begin{array}{llllllll}\text { Co1 N1 } & \text { C1 } & \text { C2 } & 11.58(18) & \text { C16 C17 C25 } & \text { C27 } & -64.6(2)\end{array}$
$\begin{array}{lllllll}\text { Co1 N1 C1 C6 } & -167.20(14) & \text { C16 C17 C25 } & \text { C28 } & \text { 56.7(2) }\end{array}$
$\begin{array}{llllllll}\text { Co1 } & \text { N2 } & \text { C29 } & \text { C30 } & -46.8(2) & \text { C17 C18 C19 } & \text { C20 } & 3.1(3)\end{array}$ 


\begin{tabular}{|c|c|c|c|c|c|c|c|}
\hline Co1 & N2 & $\mathrm{C} 29$ & C34 & $133.63(15)$ & C17 C18 C19 & $\mathrm{C} 21$ & $-179.26(17)$ \\
\hline $\mathrm{Co}^{1}$ & N3 & C15 & $\mathrm{C} 16$ & $81.09(16)$ & $\mathrm{C} 18 \mathrm{C} 17 \mathrm{C} 25$ & $\mathrm{C} 26$ & $-4.0(2)$ \\
\hline Co1 & N3 & C15 & C16 & $-24.65(16)$ & $\mathrm{C} 18 \mathrm{C} 17 \mathrm{C} 25$ & $\mathrm{C} 27$ & $115.30(19)$ \\
\hline Co1 & N3 & C15 & $\mathrm{C} 20$ & $155.87(14)$ & $\mathrm{C} 18 \mathrm{C} 17 \mathrm{C} 25$ & $\mathrm{C} 28$ & $-123.38(18)$ \\
\hline $\mathrm{Co} 1^{1}$ & N3 & C15 & $\mathrm{C} 20$ & $-98.39(17)$ & $\mathrm{C} 18 \mathrm{C} 19 \mathrm{C} 20$ & C15 & $-2.7(2)$ \\
\hline $\mathrm{O} 1$ & $\mathrm{C} 2$ & $\mathrm{C} 3$ & $\mathrm{C} 4$ & $179.95(16)$ & $\mathrm{C} 18 \mathrm{C} 19 \mathrm{C} 21$ & $\mathrm{C} 22$ & $163.48(17)$ \\
\hline $\mathrm{O} 1$ & $\mathrm{C} 2$ & $\mathrm{C} 3$ & $\mathrm{C} 11$ & $-1.6(3)$ & $\mathrm{C} 18 \mathrm{C} 19 \mathrm{C} 21$ & $\mathrm{C} 23$ & $44.6(2)$ \\
\hline $\mathrm{O} 2$ & $\mathrm{C} 30$ & C31 & C32 & $-172.94(16)$ & $\mathrm{C} 18 \mathrm{C} 19 \mathrm{C} 21$ & $\mathrm{C} 24$ & $-75.5(2)$ \\
\hline $\mathrm{O} 2$ & C30 & C31 & C39 & $8.4(2)$ & C20 C15 C16 & $\mathrm{O} 3$ & $-178.19(15)$ \\
\hline $\mathrm{O} 3$ & C16 & C17 & $\mathrm{C} 18$ & $178.80(15)$ & C20 C15 C16 & C17 & $4.0(3)$ \\
\hline $\mathrm{O} 3$ & C16 & C17 & $\mathrm{C} 25$ & $-1.3(3)$ & $\mathrm{C} 20 \mathrm{C} 19 \mathrm{C} 21$ & $\mathrm{C} 22$ & $-19.0(2)$ \\
\hline N1 & $\mathrm{C} 1$ & $\mathrm{C} 2$ & $\mathrm{O} 1$ & $-0.4(2)$ & C20 C19 C21 & $\mathrm{C} 23$ & $-137.82(18)$ \\
\hline N1 & $\mathrm{C} 1$ & $\mathrm{C} 2$ & $\mathrm{C} 3$ & $-179.87(15)$ & C20 C19 C21 & $\mathrm{C} 24$ & $102.0(2)$ \\
\hline N1 & $\mathrm{C} 1$ & C6 & C5 & $-179.74(16)$ & C21 C19 C20 & C15 & $179.68(16)$ \\
\hline N2 & C29 & C30 & $\mathrm{O} 2$ & $-5.6(3)$ & $\mathrm{C} 25 \mathrm{C} 17 \mathrm{C} 18$ & C19 & $-179.87(17)$ \\
\hline N2 & $\mathrm{C} 29$ & C30 & C31 & $174.20(16)$ & $\mathrm{C} 29 \mathrm{C} 30 \mathrm{C} 31$ & C32 & $7.2(2)$ \\
\hline N2 & $\mathrm{C} 29$ & C34 & C33 & $-179.81(17)$ & C 29 C 30 C 31 & C39 & $-171.46(16)$ \\
\hline N3 & C15 & C16 & $\mathrm{O} 3$ & $2.3(2)$ & C30 C29 C34 & C33 & $0.6(3)$ \\
\hline N3 & C15 & C16 & $\mathrm{C} 17$ & $-175.54(15)$ & C30 C31 C32 & C33 & $-3.0(3)$ \\
\hline N3 & $\mathrm{C} 15$ & $\mathrm{C} 20$ & C19 & $178.76(15)$ & C30 C31 C39 & $\mathrm{C} 40$ & $-64.4(2)$ \\
\hline C1 & $\mathrm{C} 2$ & C3 & $\mathrm{C} 4$ & $-0.6(2)$ & C30 C31 C39 & C41 & $57.5(2)$ \\
\hline
\end{tabular}




\begin{tabular}{|c|c|c|c|c|c|c|c|}
\hline $\mathrm{C} 1$ & $\mathrm{C} 2$ & $\mathrm{C} 3$ & $\mathrm{C} 11$ & $177.85(15)$ & C30 C31 C39 & C42 & $175.50(16)$ \\
\hline $\mathrm{C} 2$ & $\mathrm{C} 1$ & C6 & $\mathrm{C} 5$ & $1.6(3)$ & C 31 C 32 C 33 & C34 & $-2.4(3)$ \\
\hline $\mathrm{C} 2$ & C3 & $\mathrm{C} 4$ & C5 & $2.0(3)$ & C 31 C 32 C 33 & C35 & $175.29(18)$ \\
\hline $\mathrm{C} 2$ & C3 & C11 & $\mathrm{C} 12$ & $-179.84(15)$ & C 32 C 31 C 39 & $\mathrm{C} 40$ & $116.98(19)$ \\
\hline $\mathrm{C} 2$ & $\mathrm{C} 3$ & C11 & $\mathrm{C} 13$ & $-60.3(2)$ & C32 C31 C39 & $\mathrm{C} 41$ & $-121.11(18)$ \\
\hline $\mathrm{C} 2$ & $\mathrm{C} 3$ & C11 & C14 & $59.9(2)$ & C32 C31 C39 & $\mathrm{C} 42$ & $-3.1(2)$ \\
\hline C3 & $\mathrm{C} 4$ & $\mathrm{C} 5$ & C6 & $-1.5(3)$ & C32 C33 C34 & $\mathrm{C} 29$ & $3.6(3)$ \\
\hline C3 & $\mathrm{C} 4$ & $\mathrm{C} 5$ & $\mathrm{C} 7$ & $-178.29(16)$ & C 32 C 33 C 35 & C36 & $55.3(2)$ \\
\hline $\mathrm{C} 4$ & C3 & C11 & $\mathrm{C} 12$ & $-1.5(2)$ & C32 C33 C35 & C37 & $174.2(2)$ \\
\hline $\mathrm{C} 4$ & $\mathrm{C} 3$ & $\mathrm{C} 11$ & $\mathrm{C} 13$ & $118.12(18)$ & C32 C33 C35 & $\mathrm{C} 38$ & $-62.9(3)$ \\
\hline $\mathrm{C} 4$ & $\mathrm{C} 3$ & C11 & C14 & $-121.70(18)$ & C32 C33 C35 & C $36 \mathrm{~A}$ & $-10.1(11)$ \\
\hline $\mathrm{C} 4$ & C5 & C6 & $\mathrm{C} 1$ & $-0.3(2)$ & C32 C33 C35 & C37A & $139.2(10)$ \\
\hline $\mathrm{C} 4$ & C5 & $\mathrm{C} 7$ & $\mathrm{C} 8$ & $-41.0(2)$ & C32 C33 C35 & C $38 \mathrm{~A}$ & $-117.3(7)$ \\
\hline $\mathrm{C} 4$ & $\mathrm{C} 5$ & C7 & C9 & $78.2(2)$ & C 34 C 29 C 30 & $\mathrm{O} 2$ & $173.95(16)$ \\
\hline $\mathrm{C} 4$ & $\mathrm{C} 5$ & $\mathrm{C} 7$ & $\mathrm{C} 10$ & $-161.97(19)$ & $\mathrm{C} 34 \mathrm{C} 29 \mathrm{C} 30$ & $\mathrm{C} 31$ & $-6.2(3)$ \\
\hline C6 & $\mathrm{C} 1$ & $\mathrm{C} 2$ & $\mathrm{O} 1$ & $178.34(16)$ & C34 C33 C35 & C36 & $-127.2(2)$ \\
\hline C6 & $\mathrm{C} 1$ & $\mathrm{C} 2$ & $\mathrm{C} 3$ & $-1.1(3)$ & C34 C33 C35 & C37 & $-8.3(3)$ \\
\hline C6 & C5 & C7 & C8 & $142.40(18)$ & C34 C33 C35 & C38 & $114.7(2)$ \\
\hline C6 & $\mathrm{C} 5$ & $\mathrm{C} 7$ & C9 & $-98.5(2)$ & C34 C33 C35 & C36A & $167.5(10)$ \\
\hline C6 & C5 & $\mathrm{C} 7$ & $\mathrm{C} 10$ & $21.4(3)$ & C34 C33 C35 & $\mathrm{C} 37 \mathrm{~A}$ & $-43.2(10)$ \\
\hline$C_{7}$ & C5 & C6 & $\mathrm{C} 1$ & $176.49(16)$ & C34 C33 C35 & $\mathrm{C} 38 \mathrm{~A}$ & $60.3(7)$ \\
\hline
\end{tabular}




\section{$\begin{array}{llllllll}\text { C11 } & \text { C3 } & \text { C4 } & \text { C5 } & -176.45(16) & \text { C35 C33 C34 } & \text { C29 } & -174.03(18)\end{array}$ \\ C15 C16 C17 C18 $\quad-3.5(2) \quad$ C39 C31 C32 $\quad$ C33 175.71(17)}

Table 4.14. Hydrogen atom coordinates $\left(\AA \times 10^{4}\right)$ and isotropic displacement parameters $\left(\AA^{2} \times 10^{3}\right)$ for $\mathrm{Co}^{\mathrm{III}}-\mathrm{AP}^{\mathrm{ditBu}}$ complex $(\mathbf{8})$.

\begin{tabular}{|c|c|c|c|c|}
\hline Atom & $x$ & $y$ & $z$ & $\mathrm{U}(\mathrm{eq})$ \\
\hline $\mathrm{H} 2$ & 6844(18) & $837(12)$ & $6415(17)$ & 21 \\
\hline H1A & $3975(16)$ & $372(12)$ & $3472(15)$ & 17 \\
\hline H1B & $4292(16)$ & $970(11)$ & $3367(15)$ & 17 \\
\hline $\mathrm{H} 2 \mathrm{~A}$ & $5607(16)$ & $1649(11)$ & $5643(16)$ & 18 \\
\hline $\mathrm{H} 2 \mathrm{~B}$ & $5235(16)$ & $1827(11)$ & $4716(16)$ & 18 \\
\hline $\mathrm{H} 3$ & $3631(16)$ & $-130(10)$ & $4748(15)$ & 13 \\
\hline $\mathrm{H} 4$ & 834 & 1769 & 3380 & 16 \\
\hline H6 & 2348 & 824 & 2173 & 15 \\
\hline $\mathrm{H} 8 \mathrm{~A}$ & -376 & 781 & 2097 & 44 \\
\hline H8B & -978 & 1206 & 1181 & 44 \\
\hline $\mathrm{H} 8 \mathrm{C}$ & -501 & 1551 & 2184 & 44 \\
\hline H9A & 457 & 2339 & 1715 & 38 \\
\hline H9B & -98 & 2052 & 679 & 38 \\
\hline $\mathrm{H} 9 \mathrm{C}$ & 1074 & 2088 & 1167 & 38 \\
\hline $\mathrm{H} 10 \mathrm{~A}$ & 1135 & 927 & 839 & 54 \\
\hline H10B & -30 & 840 & 408 & 54 \\
\hline
\end{tabular}




\begin{tabular}{|c|c|c|c|}
\hline $\mathrm{H} 10 \mathrm{C}$ & 664 & 388 & 1259 \\
\hline $\mathrm{H} 12 \mathrm{~A}$ & 985 & 2484 & 4512 \\
\hline H12B & 1125 & 2296 & 5545 \\
\hline $\mathrm{H} 12 \mathrm{C}$ & 643 & 1783 & 4709 \\
\hline H13A & 1891 & 947 & 5639 \\
\hline H13B & 2315 & 1472 & 6465 \\
\hline $\mathrm{H} 13 \mathrm{C}$ & 3031 & 1131 & 6085 \\
\hline $\mathrm{H} 14 \mathrm{~A}$ & 3567 & 2230 & 5781 \\
\hline H14B & 2853 & 2576 & 6159 \\
\hline $\mathrm{H} 14 \mathrm{C}$ & 2773 & 2751 & 5142 \\
\hline H18 & 4531 & 166 & 8504 \\
\hline $\mathrm{H} 20$ & 3059 & -572 & 5909 \\
\hline $\mathrm{H} 22 \mathrm{~A}$ & 1699 & -373 & 6368 \\
\hline $\mathrm{H} 22 \mathrm{~B}$ & 1529 & -925 & 7000 \\
\hline $\mathrm{H} 22 \mathrm{C}$ & 2126 & -1092 & 6397 \\
\hline $\mathrm{H} 23 \mathrm{~A}$ & 3257 & 41 & 8747 \\
\hline H23B & 2188 & -278 & 8369 \\
\hline $\mathrm{H} 23 \mathrm{C}$ & 2385 & 322 & 7822 \\
\hline $\mathrm{H} 24 \mathrm{~A}$ & 3587 & -1472 & 7784 \\
\hline $\mathrm{H} 24 \mathrm{~B}$ & 2988 & -1361 & 8401 \\
\hline $\mathrm{H} 24 \mathrm{C}$ & 4041 & -1028 & 8704 \\
\hline
\end{tabular}




\begin{tabular}{|c|c|c|c|c|}
\hline H26A & 5346 & 1087 & 9228 & 37 \\
\hline H26B & 6517 & 1134 & 9732 & 37 \\
\hline $\mathrm{H} 26 \mathrm{C}$ & 5991 & 436 & 9551 & 37 \\
\hline $\mathrm{H} 27 \mathrm{~A}$ & 6983 & 64 & 8728 & 34 \\
\hline H27B & 7518 & 760 & 8954 & 34 \\
\hline $\mathrm{H} 27 \mathrm{C}$ & 7028 & 495 & 7902 & 34 \\
\hline $\mathrm{H} 28 \mathrm{~A}$ & 6032 & 1538 & 7404 & 32 \\
\hline $\mathrm{H} 28 \mathrm{~B}$ & 6515 & 1793 & 8461 & 32 \\
\hline $\mathrm{H} 28 \mathrm{C}$ & 5347 & 1749 & 7902 & 32 \\
\hline H32 & 9064 & 1908 & 5240 & 17 \\
\hline H34 & 6209 & 2392 & 4236 & 18 \\
\hline $\mathrm{H} 40 \mathrm{~A}$ & 8931 & 837 & 7542 & 28 \\
\hline $\mathrm{H} 40 \mathrm{~B}$ & 9707 & 1388 & 7595 & 28 \\
\hline $\mathrm{H} 40 \mathrm{C}$ & 10026 & 636 & 7731 & 28 \\
\hline $\mathrm{H} 41 \mathrm{~A}$ & 8316 & 45 & 6194 & 26 \\
\hline H41B & 9408 & -128 & 6345 & 26 \\
\hline $\mathrm{H} 41 \mathrm{C}$ & 8629 & 131 & 5351 & 26 \\
\hline $\mathrm{H} 42 \mathrm{~A}$ & 10596 & 697 & 6513 & 30 \\
\hline $\mathrm{H} 42 \mathrm{~B}$ & 10310 & 1454 & 6354 & 30 \\
\hline $\mathrm{H} 42 \mathrm{C}$ & 9903 & 959 & 5489 & 30 \\
\hline H36A & 8983 & 2348 & 3897 & 38 \\
\hline
\end{tabular}




\begin{tabular}{|c|c|c|c|c|}
\hline H36B & 8514 & 2943 & 3190 & 38 \\
\hline H36C & 7929 & 2269 & 3037 & 38 \\
\hline H37A & 6486 & 2854 & 3052 & 48 \\
\hline H37B & 7091 & 3513 & 3141 & 48 \\
\hline $\mathrm{H} 37 \mathrm{C}$ & 6622 & 3368 & 3860 & 48 \\
\hline $\mathrm{H} 38 \mathrm{~A}$ & 8269 & 3475 & 5238 & 47 \\
\hline H38B & 8692 & 3673 & 4500 & 47 \\
\hline $\mathrm{H} 38 \mathrm{C}$ & 9183 & 3087 & 5219 & 47 \\
\hline H36D & 9110 & 2627 & 4134 & 60 \\
\hline $\mathrm{H} 36 \mathrm{E}$ & 9175 & 3031 & 5025 & 60 \\
\hline $\mathrm{H} 36 \mathrm{~F}$ & 8840 & 3387 & 4036 & 60 \\
\hline H37D & 7116 & 2496 & 2845 & 63 \\
\hline $\mathrm{H} 37 \mathrm{E}$ & 7134 & 3276 & 2920 & 63 \\
\hline $\mathrm{H} 37 \mathrm{~F}$ & 6453 & 2858 & 3268 & 63 \\
\hline $\mathrm{H} 38 \mathrm{D}$ & 6849 & 3474 & 4596 & 61 \\
\hline $\mathrm{H} 38 \mathrm{E}$ & 7612 & 3931 & 4413 & 61 \\
\hline $\mathrm{H} 38 \mathrm{~F}$ & 7960 & 3523 & 5364 & 61 \\
\hline $\mathrm{H} 43 \mathrm{~A}$ & 2976 & 2971 & 2289 & 28 \\
\hline $\mathrm{H} 43 \mathrm{~B}$ & 2692 & 2319 & 2684 & 28 \\
\hline $\mathrm{H} 43 \mathrm{C}$ & 2847 & 2208 & 2490 & 34 \\
\hline $\mathrm{H} 43 \mathrm{D}$ & 3182 & 2849 & 2124 & 34 \\
\hline
\end{tabular}


Table 4.15. Atomic occupancy for $\mathrm{Co}^{\mathrm{III}}-\mathrm{AP}^{\mathrm{ditBu}}$ complex (8).

$\begin{array}{llllll}\text { Atom } & \text { Occupancy } & \text { Atom } & \text { Occupancy } & \text { Atom } & \text { Occupancy } \\ \text { C36 } & 0.856(4) & \text { H36A } & 0.856(4) & \text { H36B } & 0.856(4) \\ \text { H36C } & 0.856(4) & \text { C37 } & 0.856(4) & \text { H37A } & 0.856(4) \\ \text { H37B } & 0.856(4) & \text { H37C } & 0.856(4) & \text { C38 } & 0.856(4) \\ \text { H38A } & 0.856(4) & \text { H38B } & 0.856(4) & \text { H38C } & 0.856(4) \\ \text { C36A } & 0.144(4) & \text { H36D } & 0.144(4) & \text { H36E } & 0.144(4) \\ \text { H36F } & 0.144(4) & \text { C37A } & 0.144(4) & \text { H37D } & 0.144(4) \\ \text { H37E } & 0.144(4) & \text { H37F } & 0.144(4) & \text { C38A } & 0.144(4) \\ \text { H38D } & 0.144(4) & \text { H38E } & 0.144(4) & \text { H38F } & 0.144(4) \\ \text { Cl1 } & 0.54(3) & \text { Cl2 } & 0.54(3) & \text { C43 } & 0.54(3) \\ \text { H43A } & 0.54(3) & \text { H43B } & 0.54(3) & \text { Cl1A } & 0.46(3) \\ \text { Cl2A } & 0.46(3) & \text { C43A } & 0.46(3) & \text { H43C } & 0.46(3) \\ \text { H43D } & 0.46(3) & & & & \end{array}$




\section{References:}

1. Constable, D. J. C.; Dunn, P. J.; Hayler, J. D.; Humphrey, G. R.; Leazer, J. J. L.; Linderman, R. J.; Lorenz, K.; Manley, J.; Pearlman, B. A.; Wells, A.; Zaks, A.; Zhang, T. Y., Key green chemistry research areas-a perspective from pharmaceutical manufacturers. Green Chem. 2007, 9 (5), 411-420.

2. Punniyamurthy, T.; Velusamy, S.; Iqbal, J., Recent advances in transition metal catalyzed oxidation of organic substrates with molecular oxygen. Chem Rev 2005, 105 (6), 2329-63.

3. Sigman, M. S.; Schultz, M. J., The renaissance of palladium(II)-catalyzed oxidation chemistry. Org Biomol Chem 2004, 2 (18), 2551-4.

4. Stahl, S. S., Palladium oxidase catalysis: selective oxidation of organic chemicals by direct dioxygen-coupled turnover. Angew Chem Int Ed Engl 2004, 43 (26), 3400-20.

5. $\quad$ Shi, Z.; Zhang, C.; Tang, C.; Jiao, N., Recent advances in transition-metal catalyzed reactions using molecular oxygen as the oxidant. Chem Soc Rev 2012, 41 (8), 3381-430.

6. Urgoitia, G.; SanMartin, R.; Herrero, M.; Domínguez, E., Recent Advances in Homogeneous Metal-Catalyzed Aerobic C-H Oxidation of Benzylic Compounds. Catalysts 2018, 8 (12).

7. Ho, W. C.; Chung, K.; Ingram, A. J.; Waymouth, R. M., Pd-Catalyzed Aerobic Oxidation Reactions: Strategies To Increase Catalyst Lifetimes. J Am Chem Soc 2018, 140 (2), 748-757.

8. Wang, D.; Weinstein, A. B.; White, P. B.; Stahl, S. S., Ligand-Promoted PalladiumCatalyzed Aerobic Oxidation Reactions. Chem Rev 2018, 118 (5), 2636-2679.

9. Trammell, R.; Rajabimoghadam, K.; Garcia-Bosch, I., Copper-Promoted Functionalization of Organic Molecules: from Biologically Relevant $\mathrm{Cu} / \mathrm{O}_{2}$ Model Systems to Organometallic Transformations. Chem Rev 2019, 119 (4), 2954-3031.

10. Shigeru, I.; Teruaki, M., A New Method for Preparation of Alcohols from Olefins with Molecular Oxygen and Phenylsilane by the Use of Bis(acetylacetonato)cobalt(II). Chemistry Letters 1989, 18 (6), 1071-1074.

11. Isayama, S.; Mukaiyama, T., Novel method for the preparation of triethylsilyl peroxides from olefins by the reaction with molecular oxygen and triethylsilane catalyzed by bis(1,3diketonato)cobalt(II). Chemistry Letters 1989, 18 (4), 573-576.

12. Inoki, S.; Mukaiyama, T., A convenient method for the stereoselective preparation of trans(2-hydroxymethyl)tetrahydrofurans by the oxidative cyclization of 5-hydroxy-1-alkenes with molecular oxygen catalyzed by cobalt(II) complex. Chemistry Letters 1990, (1), 67-70.

13. Faisca Phillips, A. M.; Pombeiro, A. J. L.; Kopylovich, M. N., Recent Advances in Cascade Reactions Initiated by Alcohol Oxidation. ChemCatChem 2017, 9 (2), 217-246.

14. Palmer, C.; Morra, N. A.; Stevens, A. C.; Bajtos, B.; Machin, B. P.; Pagenkopf, B. L., Increased yields and simplified purification with a second-generation cobalt catalyst for the oxidative formation of trans-THF rings. Org Lett 2009, 11 (24), 5614-7.

15. Schuch, D.; Fries, P.; Donges, M.; Menendez Perez, B.; Hartung, J., Reductive and brominative termination of alkenol cyclization in aerobic cobalt-catalyzed reactions. J Am Chem Soc 2009, 131 (36), 12918-20.

16. Fries, P.; Muller, M. K.; Hartung, J., An aerobic oxidation/homolytic substitution-cascade for stereoselective methylsulfanyl-cyclization of 4-pentenols. Org Biomol Chem 2013, 11 (16), 2630-7. 
17. Ishii, Y.; Nakayama, K.; Takeno, M.; Sakaguchi, S.; Iwahama, T.; Nishiyama, Y., Novel Catalysis by N-Hydroxyphthalimide in the Oxidation of Organic Substrates by Molecular Oxygen. J. Org. Chem. 1995, 60 (13), 3934-3935.

18. Ishii, Y.; Iwahama, T.; Sakaguchi, S.; Nakayama, K.; Nishiyama, Y., Alkane Oxidation with Molecular Oxygen Using a New Efficient Catalytic System: N-Hydroxyphthalimide (NHPI) Combined with Co(acac)n (n=2 or 3) $\dagger$. J. Org. Chem. 1996, 61 (14), 4520-4526.

19. Yoshino, Y.; Hayashi, Y.; Iwahama, T.; Sakaguchi, S.; Ishii, Y., Catalytic Oxidation of Alkylbenzenes with Molecular Oxygen under Normal Pressure and Temperature by NHydroxyphthalimide Combined with $\mathrm{Co}(\mathrm{OAc})_{2}$. J. Org. Chem. 1997, 62 (20), 6810-6813.

20. Patil, R. D.; Fuchs, B.; Taha, N.; Sasson, Y., Solvent-free and Selective Autooxidation of Alkylbenzenes Catalyzed by Co/NHPI under Phase Transfer Conditions. ChemistrySelect 2016, 1 (13), 3791-3796.

21. Melone, L.; Prosperini, S.; Ercole, G.; Pastori, N.; Punta, C., Is it possible to implement $\mathrm{N}$-hydroxyphthalimide homogeneous catalysis for industrial applications? A case study of cumene aerobic oxidation. Journal of Chemical Technology \& Biotechnology 2014, 89 (9), 1370-1378.

22. Baciocchi, E.; Gerini, M. F.; Lanzalunga, O., Reactivity of phthalimide N-oxyl radical (PINO) toward the phenolic O-H bond. A kinetic study. J Org Chem 2004, 69 (25), 8963-6.

23. Hruszkewycz, D. P.; Miles, K. C.; Thiel, O. R.; Stahl, S. S., Co/NHPI-mediated aerobic oxygenation of benzylic C-H bonds in pharmaceutically relevant molecules. Chem Sci 2017, 8 (2), 1282-1287.

24. Huang, J. K.; Wong, Y. C.; Kao, T. T.; Tseng, C. T.; Shia, K. S., Cobalt(II)-Catalyzed Aerobic Oxidation of Terminal-Capped Alkynyl alpha-Cyano Alkanone Systems. An OxygenMediated Radical Chain Reaction. J Org Chem 2016, 81 (22), 10759-10768.

25. Tokuichi, T., Nebenvalenzringverbindungen. IV. Über einige innerkomplexe Kobaltsalze der Oxyaldimine. Bull. Chem. Soc. Jpn 1938, 13 (2), 252-260.

26. Niederhoffer, E. C.; Timmons, J. H.; Martell, A. E., Thermodynamics of oxygen binding in natural and synthetic dioxygen complexes. Chem. Rev. 1984, 84 (2), 137-203.

27. Bozell, J. J.; Hames, B. R.; Dimmel, D. R., Cobalt-Schiff Base Complex Catalyzed Oxidation of Para-Substituted Phenolics. Preparation of Benzoquinones. J. Org. Chem. 1995, 60 (8), 2398-2404.

28. Chen, D.; Martell, A. E., Dioxygen affinities of synthetic cobalt Schiff base complexes. Inorg Chem 1987, 26 (7), 1026-1030.

29. Cedeno, D.; Bozell, J. J., Catalytic oxidation of para-substituted phenols with cobalt-Schiff base complexes $/ \mathrm{O}_{2}$ - selective conversion of syringyl and guaiacyl lignin models to benzoquinones. Tetrahedron Letters 2012, 53 (19), 2380-2383.

30. Biannic, B.; Bozell, J. J., Efficient cobalt-catalyzed oxidative conversion of lignin models to benzoquinones. Org Lett 2013, 15 (11), 2730-3.

31. Cooper, C. J.; Alam, S.; Nziko, V. d. P. N.; Johnston, R. C.; Ivanov, A. S.; Mou, Z.; Turpin, D. B.; Rudie, A. W.; Elder, T. J.; Bozell, J. J.; Parks, J. M., Co(salen)-Catalyzed Oxidation of Lignin Models to Form Benzoquinones and Benzaldehydes: A Computational and Experimental Study. ACS Sustainable Chemistry \& Engineering 2020, 8 (18), 7225-7234.

32. Zombeck, A.; Drago, R. S.; Corden, B. B.; Gaul, J. H., Activation of molecular oxygen. Kinetic studies of the oxidation of hindered phenols with cobalt-dioxygen complexes. J Am Chem Soc 1981, 103 (25), 7580-7585. 
33. Anson, C. W.; Ghosh, S.; Hammes-Schiffer, S.; Stahl, S. S., Co(salophen)-Catalyzed Aerobic Oxidation of $p$-Hydroquinone: Mechanism and Implications for Aerobic Oxidation Catalysis. J Am Chem Soc 2016, 138 (12), 4186-93.

34. Baeckvall, J.-E.; Hopkins, R. B.; Grennberg, H.; Mader, M.; Awasthi, A. K., Multistep electron transfer in palladium-catalyzed aerobic oxidations via a metal macrocycle quinone system. J Am Chem Soc 1990, 112 (13), 5160-5166.

35. Morandi, B.; Wickens, Z. K.; Grubbs, R. H., Practical and general palladium-catalyzed synthesis of ketones from internal olefins. Angew Chem Int Ed Engl 2013, 52 (10), 2944-8.

36. Gigant, N.; Backvall, J. E., Aerobic double dehydrogenative cross coupling between cyclic saturated ketones and simple arenes. Chemistry 2014, 20 (20), 5890-4.

37. Piera, J.; Backvall, J. E., Catalytic oxidation of organic substrates by molecular oxygen and hydrogen peroxide by multistep electron transfer--a biomimetic approach. Angew Chem Int Ed Engl 2008, 47 (19), 3506-23.

38. Purse, B. W.; Tran, L. H.; Piera, J.; Akermark, B.; Backvall, J. E., Synthesis of new hybrid hydroquinone/cobalt Schiff base catalysts: efficient electron-transfer mediators in aerobic oxidation. Chemistry 2008, 14 (25), 7500-3.

39. Reiss, H.; Shalit, H.; Vershinin, V.; More, N. Y.; Forckosh, H.; Pappo, D., Cobalt(II)[salen]-Catalyzed Selective Aerobic Oxidative Cross-Coupling between Electron-Rich Phenols and 2-Naphthols. J Org Chem 2019, 84 (12), 7950-7960.

40. Habaue, S.; Aoyagi, H.; Murakami, S.; Higashimura, H., Asymmetric oxidative coupling polymerization of dihydroxynaphthalene derivatives with cobalt-salen complexes. Polymer Bulletin 2007, 59 (3), 303-310.

41. Haikarainen, A.; Sipilä, J.; Pietikäinen, P.; Pajunenband, A.; Mutikainen, I., Salen Complexes with Bulky Substituents as UsefulTools for Biomimetic Phenol Oxidation Research. Bioorganic \& Medicinal Chemistry 2001, 9, 1633-1638.

42. Campbell, A. N.; Stahl, S. S., Overcoming the "oxidant problem": strategies to use O2 as the oxidant in organometallic $\mathrm{C}-\mathrm{H}$ oxidation reactions catalyzed by $\mathrm{Pd}$ (and $\mathrm{Cu}$ ). Acc Chem Res 2012, 45 (6), 851-63.

43. Wu, W.; Jiang, H., Palladium-catalyzed oxidation of unsaturated hydrocarbons using molecular oxygen. Acc Chem Res 2012, 45 (10), 1736-48.

44. Wendlandt, A. E.; Suess, A. M.; Stahl, S. S., Copper-catalyzed aerobic oxidative C-H functionalizations: trends and mechanistic insights. Angew Chem Int Ed Engl 2011, 50 (47), 11062-87.

45. Allen, S. E.; Walvoord, R. R.; Padilla-Salinas, R.; Kozlowski, M. C., Aerobic coppercatalyzed organic reactions. Chem Rev 2013, 113 (8), 6234-458.

46. Jain, S. L.; Sain, B., An unconventional cobalt-catalyzed aerobic oxidation of tertiary nitrogen compounds to N-oxides. Angew Chem Int Ed Engl 2003, 42 (11), 1265-7.

47. Vinck, E.; Murphy, D. M.; Fallis, I. A.; Strevens, R. R.; Van Doorslaer, S., Formation of a cobalt(III)-phenoxyl radical complex by acetic acid promoted aerobic oxidation of a Co(II)salen complex. Inorg Chem 2010, 49 (5), 2083-92.

48. Fries, P.; Halter, D.; Kleinschek, A.; Hartung, J., Functionalized tetrahydrofurans from alkenols and olefins/alkynes via aerobic oxidation-radical addition cascades. J Am Chem Soc 2011, 133 (11), 3906-12.

49. Xu, P.; Zhu, T.-H.; Wei, T.-Q.; Wang, S.-Y.; Ji, S.-J., Co(acac) $)_{2} / \mathrm{O}_{2}$-catalyzed oxidative isocyanide insertion with 2-vinylanilines: efficient synthesis of 2-aminoquinolines. RSC Advances 2016, 6 (39), 32467-32470. 
50. Dey, S. K.; Mukherjee, A., Catechol oxidase and phenoxazinone synthase: Biomimetic functional models and mechanistic studies. Coordination Chemistry Reviews 2016, 310, 80-115.

51. Mitra, M.; Raghavaiah, P.; Ghosh, R., A mononuclear cobalt(III) complex and its catecholase activity. New Journal of Chemistry 2015, 39 (1), 200-205.

52. $\quad$ Simandi, T. M.; May, Z.; Szigyarto, I. C.; Simandi, L. I., Hydrogen atom vs electron transfer in catecholase-mimetic oxidations by superoxometal complexes. Deuterium kinetic isotope effects. Dalton Trans 2005, (2), 365-8.

53. Poddel'sky, A. I.; Cherkasov, V. K.; Fukin, G. K.; Bubnov, M. P.; Abakumova, L. G.; Abakumov, G. A., New four- and five-coordinated complexes of cobalt with sterically hindered o-iminobenzoquinone ligands: synthesis and structure. Inorganica Chimica Acta 2004, 357 (12), 3632-3640.

54. $\quad$ Chakrabarty, S.; Choudhary, S.; Doshi, A.; Liu, F. Q.; Mohan, R.; Ravindra, M. P.; Shah, D.; Yang, X.; Fleming, F. F., Catalytic Isonitrile Insertions and Condensations Initiated by RNC-X Complexation. Adv Synth Catal 2014, 356 (10), 2135-2196.

55. Bill, E.; Bothe, E.; Chaudhuri, P.; Chlopek, K.; Herebian, D.; Kokatam, S.; Ray, K.; Weyhermuller, T.; Neese, F.; Wieghardt, K., Molecular and electronic structure of four- and fivecoordinate cobalt complexes containing two $o$-phenylenediamine- or two $o$-aminophenol-type ligands at various oxidation levels: an experimental, density functional, and correlated ab initio study. Chemistry 2005, 11 (1), 204-24.

56. Smith, A. L.; Clapp, L. A.; Hardcastle, K. I.; Soper, J. D., Redox-active ligand-mediated $\mathrm{Co}-\mathrm{Cl}$ bond-forming reactions at reducing square planar cobalt(III) centers. Polyhedron 2010, 29 (1), 164-169.

57. Vlaar, T.; Cioc, R. C.; Mampuys, P.; Maes, B. U.; Orru, R. V.; Ruijter, E., Sustainable synthesis of diverse privileged heterocycles by palladium-catalyzed aerobic oxidative isocyanide insertion. Angew Chem Int Ed Engl 2012, 51 (52), 13058-61.

58. Zhu, T.-H.; Xu, X.-P.; Cao, J.-J.; Wei, T.-Q.; Wang, S.-Y.; Ji, S.-J., Cobalt(II)-Catalyzed Isocyanide Insertion Reaction with Amines under Ultrasonic Conditions: A Divergent Synthesis of Ureas, Thioureas and Azaheterocycles. Advanced Synthesis \& Catalysis 2014, 356 (2-3), 509518.

59. Leardini, R.; Nanni, D.; Zanardi, G., Radical addition to isonitriles: a route to polyfunctionalized alkenes through a novel three-component radical cascade reaction. $\mathrm{J}$ Org Chem 2000, 65 (9), 2763-72.

60. Blanksby, S. J.; Ellison, G. B., Bond dissociation energies of organic molecules. Acc Chem Res 2003, 36 (4), 255-63.

61. Liu, B.; Yin, M.; Gao, H.; Wu, W.; Jiang, H., Synthesis of 2-aminobenzoxazoles and 3aminobenzoxazines via palladium-catalyzed aerobic oxidation of $o$-aminophenols with isocyanides. J Org Chem 2013, 78 (7), 3009-20.

62. Nahakpam, L.; Chipem, F. A.; Chingakham, B. S.; Laitonjam, W. S., Diacetoxyiodobenzene assisted $\mathrm{C}-\mathrm{O}$ bond formation via sequential acylation and deacylation process: synthesis of benzoxazole amides and their mechanistic study by DFT. Org Biomol Chem 2016, 14 (32), 7735-45.

63. Sharma, V. B.; Jain, S. L.; Sain, B., Cobalt (II) Schiff base catalyzed aerobic oxidation of secondary alcohols to ketones. Journal of Molecular Catalysis A: Chemical 2004, 212 (1-2), 5559. 
64. Yang, W. C.; Wei, K.; Sun, X.; Zhu, J.; Wu, L., Cascade C(sp $\left.{ }^{3}\right)-S$ Bond Cleavage and Imidoyl C-S Formation: Radical Cyclization of 2-Isocyanoaryl Thioethers toward 2-Substituted Benzothiazoles. Org Lett 2018, 20 (10), 3144-3147.

65. Bitzer, J.; Große, T.; Wang, L.; Lang, S.; Beil, W.; Zeeck., New Aminophenoxazinones from a Marine Halomonas sp.: Fermentation, Structure Elucidation, and Biological Activity. $J$ Antibiot 2006, 59, 86-92.

66. Simándi, L. I.; Barna, T.; Németh, S., Kinetics and mechanism of the cobaloxime(II)catalysed oxidation of 2-aminophenol by dioxygen. A phenoxazinone synthase model involving free-radical intermediates. J. Chem. Soc., Dalton Trans. 1996, 473-478.

67. El-Khalafy, S. H.; Hassanein, M., Oxidation of 2-aminophenol with molecular oxygen and hydrogen peroxide catalyzed by water soluble metalloporphyrins. Journal of Molecular Catalysis A: Chemical 2012, 363-364, 148-152.

68. Kaizer, J.; Csonka, R.; Speier, G., TEMPO-initiated oxidation of 2-aminophenol to 2aminophenoxazin-3-one. J. Mol. Catal. A: Chem. 2002, 180 (1-2), 91-96.

69. Chun, H.; Verani, C. N.; Chaudhuri, P.; Bothe, E.; Bill, E.; Weyhermuller, T.; Wieghardt, K., Molecular and electronic structure of octahedral o-aminophenolato and oiminobenzosemiquinonato complexes of $\mathrm{V}(\mathrm{V}), \mathrm{Cr}(\mathrm{III}), \mathrm{Fe}(\mathrm{III})$, and $\mathrm{Co}(\mathrm{III})$. Experimental determination of oxidation levels of ligands and metal ions. Inorg Chem 2001, 40 (17), 4157-66.

70. Herebian, D.; Ghosh, P.; Chun, H.; Bothe, E.; Weyhermüller, T.; Wieghardt., K., Cobalt(II)/(III) Complexes Containing $o$-Iminothiobenzosemiquinonato(1-) and $o$ Iminobenzosemiquinonato(1-) $\pi$-Radical Ligands. Eur. J. Inorg. Chem. 2002, 2002 (8), 19571967.

71. Smith, A. L.; Hardcastle, K. I.; Soper, J. D., Redox-active ligand-mediated oxidative addition and reductive elimination at square planar cobalt(III): multielectron reactions for crosscoupling. J Am Chem Soc 2010, 132 (41), 14358-60.

72. Maity, S.; Kundu, S.; Bera, S.; Weyhermüller, T.; Ghosh, P., Mixed-Valence $o^{-}$ Iminobenzoquinone and $o$-Iminobenzosemiquinonate Anion Radical Complexes of Cobalt: Valence Tautomerism. European Journal of Inorganic Chemistry 2016, 2016 (22), 3680-3690.

73. Fukuda, O.; Sakaguchi, S.; Ishii, Y., Preparation of Hydroperoxides by NHydroxyphthalimide-Catalyzed Aerobic Oxidation of Alkylbenzenes and Hydroaromatic Compounds and Its Application. Adv Synth Catal 2001, 343 (8), 809-813.

74. Adams, D. M.; Noodleman, L., Hendrickson, D. N., Density Functional Study of the Valence-Tautomeric Interconversion Low-Spin $\left[\mathrm{Co}^{\mathrm{III}}(\mathrm{SQ})(\mathrm{Cat})(\mathrm{phen})\right] \leftrightarrow$ High-Spin $\left[\mathrm{Co}^{\mathrm{II}}(\mathrm{SQ})_{2}\right.$ (phen)]. Inorg. Chem. 1997, 36, 3966-3984.

75. Evangelio, E.; Ruiz-Molina, D., Valence Tautomerism: New Challenges for Electroactive Ligands. European Journal of Inorganic Chemistry 2005, 2005 (15), 2957-2971.

76. Gottlieb, H. E.; Kotlyar, V.; Nudelman, A. NMR Chemical Shifts of Common Laboratory Solvents as Trace Impurities. J. Org. Chem. 1997, 62 (21), 7512-7515.

77. Cioffi, C. L.; Lansing, J. J.; Yuksel, H., Synthesis of 2-aminobenzoxazoles using tetramethyl orthocarbonate or 1,1-dichlorodiphenoxymethane. J Org Chem 2010, 75 (22), 7942-5. 78. Zhu, T. H.; Wang, S. Y.; Wang, G. N.; Ji, S. J., Cobalt-catalyzed oxidative isocyanide insertion to amine-based bisnucleophiles: diverse synthesis of substituted 2-aminobenzimidazoles, 2-aminobenzothiazoles, and 2-aminobenzoxazoles. Chemistry 2013, 19 (19), 5850-3.

79. Cho, S. H.; Kim, J. Y.; Lee, S. Y.; Chang, S., Silver-mediated direct amination of benzoxazoles: tuning the amino group source from formamides to parent amines. Angew Chem Int Ed Engl 2009, 48 (48), 9127-30. 
80. Wang, G.-N.; Zhu, T.-H.; Wang, S.-Y.; Wei, T.-Q.; Ji, S.-J., $\mathrm{NiCl}_{2}$-catalyzed cascade reaction of isocyanides with functionalized anilines. Tetrahedron 2014, 70 (43), 8079-8083.

81. Yella, R.; Patel, B. K, One-Pot Synthesis of Five and Six Membered N, O, S-Heterocycles Using a Ditribromide Reagent. J. Comb. Chem. 2010, 12, 754-763.

82. Yadav, V. K.; Srivastava, V. P.; Yadav, L. D. S., Iodide catalyzed synthesis of 2aminobenzoxazoles via oxidative cyclodesulfurization of phenolic thioureas with hydrogen peroxide. Tetrahedron Letters 2018, 59 (3), 252-255.

83. Murata, Y.; Matsumoto, N.; Miyata, M.; Kitamura, Y.; Kakusawa, N.; Matsumura, M.; Yasuike, S., One-pot reaction for the synthesis of $N$-substituted 2-aminobenzoxazoles using triphenylbismuth dichloride as cyclodesulfurization reagent. Journal of Organometallic Chemistry 2018, 859, 18-23.

84. Khatik, G. L.; Dube, N.; Pal, A.; Nair, V. A., Highly Efficient One-Pot Synthesis of 2Aminobenzoxazoles Using Triflic Acid as a Cyclodesulfurizing Reagent. Synthetic Communications 2011, 41 (17), 2631-2639.

85. Bitzer, J.; Grosse, T.; Wang, L.; Lang, S.; Beil, W.; Zeeck, A., New aminophenoxazinones from a marine Halomonas sp.: fermentation, structure elucidation, and biological activity. J Antibiot (Tokyo) 2006, 59 (2), 86-92.

86. Beaulieu, C.; Wang, Z.; Denis, D.; Greig, G.; Lamontagne, S.; O'Neill, G.; Slipetz, D.; Wang, J., Benzimidazoles as new potent and selective DP antagonists for the treatment of allergic rhinitis. Bioorg Med Chem Lett 2004, 14 (12), 3195-9.

87. Madsen, P.; Knudsen, L. B.; Wiberg, F. C.; Carr, R. D. Discovery and Structure-Activity Relationship of the First Non-Peptide Competitive Human Glucagon Receptor Antagonists. J. Med. Chem. 1998, 41, 5150-5157.

88. Palmer, B. D.; Kraker, A. J., Hartl, B. G.; Panopoulos, A. D.; Panek, R. L.; Batley, B. L.; Lu, G. H.; Trumpp-Kallmeyer, S.; Hollis Showalter, H. D. and Denny, W. A., Structure-Activity Relationships for 5-Substituted 1-Phenylbenzimidazoles as Selective Inhibitors of the PlateletDerived Growth Factor Receptor. 1999, (42), 2373-2382.

89. Sørensen, U. S.; Strøbæk, D.; Christophersen, P.; Hougaard, C.; Jensen, M. L.; Nielsen, E. Ø. Synthesis and Structure-Activity Relationship Studies of 2-(N-Substituted)aminobenzimidazoles as Potent Negative Gating Modulators of Small Conductance $\mathrm{Ca}^{2+}$ Activated K ${ }^{+}$Channels. J. Med. Chem. 2008, 51, 7625-7634.

90. Morningstar, M. L.; Roth, T.; Farnsworth, D. W.; Smith, M. K.; Watson, K.; Buckheit, R. W.; Jr., K. D.; Zhang, W.; Arnold, E.; Julias, J. G.; Hughes, S. H.; Michejda, C. J. Synthesis, Biological Activity, and Crystal Structure of Potent Nonnucleoside Inhibitors of HIV-1 Reverse Transcriptase That Retain Activity against Mutant Forms of the Enzyme. J. Med. Chem. 2007, 50, 4003-4015.

91. Janssens, F.; Torremans, J.; Janssen, M.; Stokbroekx, R. A.; Luyckx, M.; Janssen, P. A. J. New Antihistaminic N-Heterocyclic 4-Piperidinamines. 1. Synthesis and Antihistaminic Activity of JV-(4-Piperidinyl)-lfT-benzimidazol-2-amines. J. Med. Chem. 1985, 28, 1925-1933.

92. Valdez, J.; Cedillo, R.; Hernández-Campos, A.; Yépez, L.; Hernández-Luis, F.; NavarreteVázquez, G.; Tapia, A.; Cortés, R. Hernándezc M.; and Castillo, R. Synthesis and Antiparasitic Activity of $1 H$-Benzimidazole Derivatives. Bioorganic \& Medicinal Chemistry Letters 2002, 12, 2221-2224.

93. Snow, R. J.; Cardozo, M. G.; Morwick, T. M.; Busacca, C. A.; Dong, Y.; Eckner, R. J.; Jacober, S.; Jakes, S.; Kapadia, S.; Lukas, S.; Panzenbeck, M.; Peet, G. W.; Peterson, J. D.; Prokopowicz. A. S., Sellati, R.; Tolbert, R. M.; Tschantz, M. A. and Moss, N. Discovery of 2- 
Phenylamino-imidazo[4,5-h]isoquinolin-9-ones: A New Class of Inhibitors of Lck Kinase. J. Med. Chem. 2002, 45, 3394-3405.

94. Zhong, M.; Bui, M.; Shen, W.; Baskaran, S.; Allen, D. A.; Elling, R. A.; Flanagan, W. M.; Fung, A. D.; Hanan, E. J.; Harris, S. O.; Heumann, S. A.; Hoch, U.; Ivy, S. N.; Jacobs, J. W.; Lam, S.; Lee, H.; McDowell, R. S.; Oslob, J. D.; Purkey, H. E.; Romanowski, M. J.; Silverman, J. A.; Tangonan, B. T.; Taverna, P.; Yang, W.; Yoburn, J. C.; Yu, C. H.; Zimmerman, K. M.; O'Brien, T.; Lew, W., 2-Aminobenzimidazoles as potent Aurora kinase inhibitors. Bioorg Med Chem Lett 2009, 19 (17), 5158-61.

95. Kling, A.; Backfisch, G.; Delzer, J.; Geneste, H.; Graef, C.; Hornberger, W.; Lange, U. E. W.; Lauterbach, A.; Seitz, W.; Subkowski, T., Design and synthesis of 1,5- and 2,5-substituted tetrahydrobenzazepinones as novel potent and selective integrin $\alpha \mathrm{V} \beta 3$ antagonists. Bioorganic \& Medicinal Chemistry 2003, 11 (7), 1319-1341.

96. Mukhopadhyay, T.; Sasaki, J.-i.; Ramesh, R.; Roth, J. A. Mebendazole Elicits a Potent Antitumor Effect on Human Cancer Cell Lines Both in Vitro and in Vivo. Clin Cancer. Res. 2002, 8, 2963-2969.

97. Chong, C. R.; Chen, X.; Shi, L.; Liu, J. O.; Sullivan, D. J., Jr. A clinical drug library screen identifies astemizole as an antimalarial agent. Nat Chem Biol 2006, 2 (8), 415-6.

98. Bonfanti, J.-F.; Doublet, F.; Fortin, J.; Lacrampe, J.; Guillemont, J.; Muller, P.; Queguiner, L.; Arnoult. E., Gevers, T.; Janssens, P.; Szel, H.; Willebrords, R.; Timmerman, P.; Wuyts, K.; Janssens, F.; Sommen, C.; Wigerinck, P.; and Andries, K. Selection of a Respiratory Syncytial Virus Fusion Inhibitor Clinical Candidate, Part 1: Improving the Pharmacokinetic Profile Using the Structure-Property Relationship. J. Med. Chem. 2007, 50, 4572-4584.

99. Hasegawa, M.; Nishigaki, N.; Washio, Y.; Kano, K.; Harris, P. A.; Sato, H.; Mori, I.; West, R. I.; Shibahara, M.; Toyoda, H.; Wang, L.; Nolte, R. T.; Veal, J. M.; Cheung, M. Discovery of Novel Benzimidazoles as Potent Inhibitors of TIE-2 and VEGFR-2 Tyrosine Kinase Receptors. J. Med. Chem. 2007, 50, 4453-4470.

100. Charton, J.; Girault-Mizzi, S.; Debreu-Fontaine, M. A.; Foufelle, F.; Hainault, I.; BizotEspiard, J. G.; Caignard, D. H.; Sergheraert, C., Synthesis and biological evaluation of benzimidazole derivatives as potent AMP-activated protein kinase activators. Bioorg Med Chem 2006, 14 (13), 4490-518.

101. Danneberg, F.; Ghidini, A.; Dogandzhiyski, P.; Kalden, E.; Stromberg, R.; Gobel, M. W., Sequence-specific RNA cleavage by PNA conjugates of the metal-free artificial ribonuclease tris(2-aminobenzimidazole). Beilstein J Org Chem 2015, 11, 493-8.

102. Carpenter, R. D.; DeBerdt, P. B.; Lam, K. S.; Kurth, M. J. Carbodiimide-Based Benzimidazole Library Method. J. Comb. Chem. 2006, 8, 907-914.

103. Walchshofer, N.; Delabre-Defayolle, I.; Paris, J.; Petavy, A. F. In Vitro Morphological Damage Induced by a New Benzimidazole Prodrug in Echinococcus multiocularis Metacestodes. J. Pharm. Sci. 1990, 79, 606-608.

104. Scheffer, U.; Strick, A.; Ludwig, V.; Peter, S.; Kalden, E.; Göbel, M. W. Metal-Free Catalysts for the Hydrolysis of RNA Derived from Guanidines, 2-Aminopyridines, and 2Aminobenzimidazoles. J Am Chem Soc 2005, 127, 2211-2217.

105. J Perkins, J. J.; Zartman, A. E.; Meissner, R. S. Synthesis of 2(Alkylamino)benzimidazoles. Tetrahedron Letters 1999, 40, 1103-1106.

106. Hamley, P.; Tinker, A. C. 1,2-Diaminobenzimidazoles: Selective Inhibitors of Nitric Oxide Synthase Derived From Aminoguanidine. Bioorganic \& Medicinal Chemistry Letters 1995, 5, 1573-1576. 
107. Gudmundsson, K. S.; Tidwell, J.; Lippa, N.; Koszalka, G. W.; Draanen, N. v.; Ptak, R. G.; Drach, J. C.; Townsend, L. B. Synthesis and Antiviral Evaluation of Halogenated â-D- and L-Erythrofuranosylbenzimidazoles. J. Med. Chem. 2000, 43, 2464-2472.

108. Murphy, D. B., Carbonimidoyl Dihalides as Organic Intermediates. I. The Preparation of 2-Aryl Aminobenzimidazoles. J. Org. Chem. 1964, 29, 1613-1615.

109. Carpenter, R. D.; Kurth, M. J., A rapid and efficient route to benzazole heterocycles. Nat Protoc 2010, 5 (11), 1731-6.

110. Phakhodee, W.; Duangkamol, C.; Wiriya, N.; Pattarawarapan, M., Ultrasound-assisted synthesis of substituted 2-aminobenzimidazoles, 2-aminobenzoxazoles, and related heterocycles. Tetrahedron Letters 2016, 57 (47), 5290-5293.

111. Wang, Z.; Zhao, Q.; Hou, J.; Yu, W.; Chang, J., Iodine-mediated direct synthesis of multifunctional 2-aminobenzimidazoles from $N$-substituted $o$-diaminoarenes and isothiocyanates. Tetrahedron 2018, 74 (19), 2324-2329.

112. Chanda, K.; Maiti, B.; Chung, W.-S.; Sun, C.-M., Novel approach towards 2-substituted aminobenzimidazoles on imidazolium ion tag under focused microwave irradiation. Tetrahedron 2011, 67 (34), 6214-6220.

113. Heinelt, U.; Schultheis, D.; Jäger, S.; Lindenmaier, M.; Pollex, A.; Beckmann, H. S. g., A convenient method for the synthesis of 2-amino substituted aza-heterocycles from N, $\mathrm{N}^{\prime}$ disubstituted thioureas using TsCl/NaOH. Tetrahedron 2004, 60 (44), 9883-9888.

114. Cee, V. J.; Downing, N. S., A one-pot method for the synthesis of 2-aminobenzimidazoles and related heterocycles. Tetrahedron Letters 2006, 47 (22), 3747-3750.

115. Clark, P. R.; Williams, G. D.; Tomkinson, N. C. O., Copper-catalysed C-H functionalisation gives access to 2-aminobenzimidazoles. Org Biomol Chem 2019, 17 (34), 7943 7955.

116. Wang, X.-j.; Zhang, L.; Xu, Y.; Krishnamurthy, D.; Senanayake, C. H., A practical synthesis of 2-(N-substituted)-aminobenzimidazoles utilizing $\mathrm{CuCl}$-promoted intramolecular cyclization of N-(2-aminoaryl)thioureas. Tetrahedron Letters 2004, 45 (38), 7167-7170.

117. Wang, F.; Cai, S.; Liao, Q.; Xi, C., A protocol to 2-aminobenzimidazoles via coppercatalyzed cascade addition and cyclization of o-haloanilines and carbodiimides. J Org Chem 2011, 76 (9), 3174-80.

118. Yin, J.; Zhao, M. M.; Huffman, M. A.; McNamara, J. M. Pd-Catalyzed N-Arylation of Heteroarylamines. Org Lett 2002, 4, 3481-3484.

119. Devine, W. G.; Diaz-Gonzalez, R.; Ceballos-Perez, G.; Rojas, D.; Satoh, T.; Tear, W.; Ranade, R. M.; Barros-Alvarez, X.; Hol, W. G.; Buckner, F. S.; Navarro, M.; Pollastri, M. P., From Cells to Mice to Target: Characterization of NEU-1053 (SB-443342) and Its Analogues for Treatment of Human African Trypanosomiasis. ACS Infect Dis 2017, 3 (3), 225-236.

120. Martin, M. W.; Newcomb, J.; Nunes, J. J.; Boucher, C.; Chai, L.; Epstein, L. F.; Faust, T.; Flores, S.; Gallant, P.; Gore, A.; Gu, Y.; Hsieh, F.; Huang, X.; Kim, J. L.; Middleton, S.; Morgenstern, K.; Oliveira-dos-Santos, A.; Patel, V. F.; Powers, D.; Rose, P.; Tudor, Y.; Turci, S. M.; Welcher, A. A.; Zack, D.; Zhao, H.; Zhu, L.; Zhu, X.; Ghiron, C.; Ermann, M.; Johnston, D.; Saluste, C. G., Structure-based design of novel 2-amino-6-phenylpyrimido[5',4':5,6]pyrimido[1,2-a]benzimidazol-5(6H)-ones as potent and orally active inhibitors of lymphocyte specific kinase (Lck): synthesis, SAR, and in vivo anti-inflammatory activity. $J$ Med Chem 2008, 51 (6), 1637-48. 
121. Barrett, 1. C.; Kerr, M. A. The High-Pressure SNAr Reaction of N-p-Fluorobenzyl-2chlorobenzimidazole With Amines; An Approach to Norastemizole and Analogues. Tetrahedron Letters 1999, 40, 2439-2442.

122. Saha, P.; Ramana, T.; Purkait, N.; Ali, M. A.; Paul, R.; Punniyamurthy, T., Ligand-free copper-catalyzed synthesis of substituted benzimidazoles, 2-aminobenzimidazoles, 2aminobenzothiazoles, and benzoxazoles. J Org Chem 2009, 74 (22), 8719-25.

123. Deng, X.; McAllister, H.; Mani, N. S., CuI-catalyzed amination of arylhalides with guanidines or amidines: a facile synthesis of 1-H-2-substituted benzimidazoles. J Org Chem 2009, 74 (15), 5742-5.

124. Chi, Y.; Zhang, W. X.; Xi, Z., Oxidant-switchable selective synthesis of 2aminobenzimidazoles via $\mathrm{C}-\mathrm{H}$ amination/acetoxylation of guanidines. Org Lett 2014, 16 (24), 6274-7.

125. Zhu, T. S.; Chen, J. P.; Xu, M. H., Rhodium-catalyzed enantioselective addition to unsymmetrical alpha-diketones: tandem one-pot synthesis of optically active 3-tetrasubstituted isochroman derivatives. Chemistry 2013, 19 (3), 865-9.

126. Liu, J.; Hoover, J. M., Cobalt-Catalyzed Aerobic Oxidative Cyclization of 2Aminophenols with Isonitriles: 2-Aminophenol Enabled $\mathrm{O}_{2}$ Activation by Cobalt(II). Org Lett 2019, 21 (12), 4510-4514.

127. Pitzer, L.; Schafers, F.; Glorius, F., Rapid Assessment of the Reaction-Condition-Based Sensitivity of Chemical Transformations. Angew Chem Int Ed Engl 2019, 58 (25), 8572-8576.

128. Ravindranathan, T.; Wakharkar, R. D.; Landge, A. B., Synthesis of Mebendazole and Enviroxime. Acylation of 2-Amino-5-Benzoylbenzimidazole. Organic Preparations and Procedures International 1987, 19 (1), 9-16.

129. Ravindranathan, T.; Wakharkar, R. D.; Landge, A. B., Preparation of 2-Chloro- and 2Amino-5-Benzoylbenzimidazoles. Organic Preparations and Procedures International 1986, 18 (2), 95-98.

130. Pal, S., Chapter 4 : Synthesis of other Isocoumarin derivatives. In Isocoumarin, Thiaisocoumarin and Phosphaisocoumarin : natural occurrences, synthetic approaches and pharmaceutical applications, Elsevier Science: 2019; pp 109-151.

131. Marco-Contelles, J.; Pérez-Mayoral, E.; Ballesteros, P., 11.05 - Bicyclic 5-5 Systems with One Bridgehead (Ring Junction) Nitrogen Atom: Three Extra Heteroatoms 2:1. In Comprehensive Heterocyclic Chemistry III, ScienceDirect: 2008; pp 199-305.

132. Wamhoff, H.; Richardt, G.; Stölben, S., Iminophosphoranes: Versatile Tools in Heterocyclic Synthesis. In Advances in Heterocyclic Chemistry, 1995; Vol. 64, pp 159-249.

133. Ke, F.; Zhang, P.; Lin, C.; Lin, X.; Xu, J.; Zhou, X., Synthesis of benzimidazoles by $\mathrm{CuI}$-catalyzed three-component reaction of 2-haloaniline, ammonia and aldehyde in water. Org Biomol Chem 2018, 16 (43), 8090-8094.

134. Kalas, S.; Patil, S.; Jadhav, V., Synthesis and Characterization of Impurities of an BroadSpectrum Anthelmintic Drug, Albendazole. Chemical Science Transactions 2016, 5 (1), 79-86.

135. Fulmer, G. R.; Miller, A. J. M.; Sherden, N. H.; Gottlieb, H. E.; Nudelman, A.; Stoltz, B. M.; Bercaw, J. E.; Goldberg, K. I., NMR Chemical Shifts of Trace Impurities: Common Laboratory Solvents, Organics, and Gases in Deuterated Solvents Relevant to the Organometallic Chemist. Organometallics 2010, 29 (9), 2176-2179.

136. Zhu, J.; Wu, C. F.; Li, X.; Wu, G. S.; Xie, S.; Hu, Q. N.; Deng, Z.; Zhu, M. X.; Luo, H. R.; Hong, X., Synthesis, biological evaluation and molecular modeling of substituted 2- 
aminobenzimidazoles as novel inhibitors of acetylcholinesterase and butyrylcholinesterase. Bioorg Med Chem 2013, 21 (14), 4218-24.

137. Xie, Y.; Zhang, F.; Li, J.; Shi, X., Novel Synthesis of 2-Aminobenzimidazoles from Isoselenocyanates. Synlett 2010, 2010 (06), 901-904.

138. Quast, H.; Ross, K.-H.; Philipp, G.; Hagedorn, M.; Hahn, H.; Banert, K., Syntheses and ${ }^{15} \mathrm{~N}$ NMR Spectra of Iminodiaziridines - Ring-Expansions of 1-Aryl-3-iminodiaziridines to $1 \mathrm{H}$ and 3aH-Benzimidazoles, 2H-Indazoles, and 5H-Dibenzo[d,f][1,3]diazepines. European Journal of Organic Chemistry 2009, 2009 (23), 3940-3952.

139. Lyaskovskyy, V.; de Bruin, B., Redox Non-Innocent Ligands: Versatile New Tools to Control Catalytic Reactions. ACS Catalysis 2012, 2 (2), 270-279.

140. Butschke, B.; Fillman, K. L.; Bendikov, T.; Shimon, L. J.; Diskin-Posner, Y.; Leitus, G.; Gorelsky, S. I.; Neidig, M. L.; Milstein, D., How Innocent are Potentially Redox NonInnocent Ligands? Electronic Structure and Metal Oxidation States in Iron-PNN Complexes as a Representative Case Study. Inorg Chem 2015, 54 (10), 4909-26.

141. Broere, D. L.; Plessius, R.; van der Vlugt, J. I., New avenues for ligand-mediated processes--expanding metal reactivity by the use of redox-active catechol, $o$-aminophenol and $o$ phenylenediamine ligands. Chem Soc Rev 2015, 44 (19), 6886-915.

142. Alaji, Z.; Safaei, E.; Chiang, L.; Clarke, R. M.; Mu, C.; Storr, T., A Copper Complex of a Noninnocent Iminophenol-Amidopyridine Hybrid Ligand: Synthesis, Characterization, and Aerobic Alcohol Oxidation. European Journal of Inorganic Chemistry 2014, 2014 (35), 60666074.

143. Safaei, E.; Balaghi, S. E.; Chiang, L.; Clarke, R. M.; Martelino, D.; Webb, M. I.; Wong, E. W. Y.; Savard, D.; Walsby, C. J.; Storr, T., Stabilization of different redox levels of a tridentate benzoxazole amidophenoxide ligand when bound to Co(III) or V(V). Dalton Trans 2019, 48 (35), 13326-13336.

144. Alaji, Z.; Safaei, E.; Yi, H.; Cong, H.; Wojtczak, A.; Lei, A., Redox active ligand and metal cooperation for $\mathrm{C}\left(\mathrm{sp}^{2}\right)-\mathrm{H}$ oxidation: extension of the galactose oxidase mechanism in watermediated amide formation. Dalton Trans 2018, 47 (43), 15293-15297.

145. Chaudhuri, P.; Verani, C. N.; Bill, E.; Bothe, E.; Weyhermuller, T.; Wieghardt, K., Electronic structure of bis(o-iminobenzosemiquinonato)metal complexes $(\mathrm{Cu}, \mathrm{Ni}, \mathrm{Pd})$. The art of establishing physical oxidation states in transition-metal complexes containing radical ligands. $J$ Am Chem Soc 2001, 123 (10), 2213-23.

146. Leconte, N.; Moutet, J.; Constantin, T.; Molton, F.; Philouze, C.; Thomas, F., Coordination Chemistry of the Redox Non-Innocent Ligand Bis(2-amino-3,5-di-tertbutylphenyl)amine with Group 10 Metal Ions (Ni, Pd, Pt). European Journal of Inorganic Chemistry 2018, 2018 (16), 1752-1761.

147. Nasibipour, M.; Safaei, E.; Masoumpour, M. S.; Wojtczak, A., Ancillary ligand electroactivity effects towards phenyl acetylene homocoupling reaction by a nickel(ii) complex of a noninnocent O-amino phenol ligand: a mechanistic insight. RSC Advances 2020, 10 (41), 2417624189.

148. Metzinger, R.; Demeshko, S.; Limberg, C., A Novel Pentadentate Redox-Active Ligand and Its Iron(III) Complexes: Electronic Structures and O2Reactivity. Chemistry - A European Journal 2014, 20 (16), 4721-4735.

149. Matson, E. M.; Franke, S. M.; Anderson, N. H.; Cook, T. D.; Fanwick, P. E.; Bart, S. C., Radical Reductive Elimination from Tetrabenzyluranium Mediated by an Iminoquinone Ligand. Organometallics 2014, 33 (8), 1964-1971. 
150. Boyer, J. L.; Cundari, T. R.; DeYonker, N. J.; Rauchfuss, T. B.; Wilson, S. R., Redox activation of alkene ligands in platinum complexes with non-innocent ligands. Inorg Chem 2009, 48 (2), 638-45.

151. Blackmore, K. J.; Ziller, J. W.; Heyduk, A. F., "Oxidative addition" to a Zirconium(IV) redox-active ligand complex. Inorg Chem 2005, 44 (16), 5559-61.

152. Herebian, D.; Bothe, E.; Bill, E.; Weyhermuller, T.; Wieghardt, K., Experimental evidence for the noninnocence of o-aminothiophenolates: coordination chemistry of oiminothionebenzosemiquinonate(1-) pi-radicals with Ni(II), $\mathrm{Pd}(\mathrm{II}), \mathrm{Pt}(\mathrm{II})$. J Am Chem Soc 2001, 123 (41), 10012-23.

153. Chun, H.; Bill, E.; Bothe, E.; Weyhermuller, T.; Wieghardt, K., Octahedral (ciscyclam)iron(III) complexes with $\mathrm{O}, \mathrm{N}$-coordinated o-iminosemiquinonate(1-) pi radicals and oimidophenolate(2-) anions. Inorg Chem 2002, 41 (20), 5091-9.

154. Sun, X.; Chun, H.; Hildenbrand, K.; Bothe, E.; Weyhermuller, T.; Neese, F.; Wieghardt, K., o-Iminobenzosemiquinonato(1-) and o-amidophenolato(2-) complexes of palladium(II) and platinum(II): a combined experimental and density functional theoretical study. Inorg Chem 2002, 41 (16), 4295-303.

155. Chun, H.; Bill, E.; Weyhermuller, T.; Wieghardt, K., $S=(3) /(2)<==S=(1) /(2)$ spin crossover behavior in five-coordinate halido- and pseudohalido-bis(oiminobenzosemiquinonato)iron(III) complexes. Inorg Chem 2003, 42 (18), 5612-20.

156. Min, K. S.; Weyhermuller, T.; Bothe, E.; Wieghardt, K., Tetradentate bis(oiminobenzosemiquinonate(1-)) $\pi$ radical ligands and their o-aminophenolate(1-) derivatives in complexes of nickel(II), palladium(II), and copper(II). Inorg Chem 2004, 43 (9), 2922-31.

157. Gray, H. B.; Williams, R.; Bernal, I.; Billig, E. A Spin-Free Square Planar Cobaltous Complex. J. Am. Chem. Soc. 1962, 84 (18), 3596-3597.

158. Billig, E.; Williams, R.; Bernal, I.; Waters, J. H.; Gray, H. B. The Electronic Structures of Square-Planar Metal Complexes. II. The Complexes of Maleonitriledithiolate with Copper(II), Nickel(II), Palladium(II), and Platinum(II). Inorg. Chem. 1963, 3 (5), 663-666.

159. Chirik, P. J.; Wieghardt, K., Chemistry. Radical ligands confer nobility on base-metal catalysts. Science 2010, 327 (5967), 794-5.

160. Bachler, V.; Olbrich, G.; Neese, F.; Wieghardt, K., Theoretical evidence for the singlet diradical character of square planar nickel complexes containing two o-semiquinonato type ligands. Inorg Chem 2002, 41 (16), 4179-93.

161. Chaudhuri, P.; Hess, M.; Muller, J.; Hildenbrand, K.; Bill, E.; Weyhermuller, T.; Wieghardt, K., Aerobic oxidation of primary alcohols (including methanol) by copper(II)- and zinc(II)-phenoxyl radical catalysts. Journal of the American Chemical Society 1999, 121 (41), 9599-9610.

162. Boyer, J. L.; Rochford, J.; Tsai, M.-K.; Muckerman, J. T.; Fujita, E., Ruthenium complexes with non-innocent ligands: Electron distribution and implications for catalysis. Coordination Chemistry Reviews 2010, 254 (3-4), 309-330.

163. Balaghi, S. E.; Safaei, E.; Chiang, L.; Wong, E. W.; Savard, D.; Clarke, R. M.; Storr, T., Synthesis, characterization and catalytic activity of copper(II) complexes containing a redoxactive benzoxazole iminosemiquinone ligand. Dalton Trans 2013, 42 (19), 6829-39.

164. Chakraborty, B.; Paine, T. K., Aromatic ring cleavage of 2-amino-4-tert-butylphenol by a nonheme iron(II) complex: functional model of 2-aminophenol dioxygenases. Angew Chem Int Ed Engl 2013, 52 (3), 920-4. 
165. Costas, M.; Mehn, M. P.; Jensen, M. P.; Que, L., Jr., Dioxygen activation at mononuclear nonheme iron active sites: enzymes, models, and intermediates. Chem Rev 2004, 104 (2), 939-86. 166. Baltrun, M.; Watt, F. A.; Schoch, R.; Wolper, C.; Neuba, A. G.; Hohloch, S., A new bisphenolate mesoionic carbene ligand for early transition metal chemistry. Dalton Trans 2019, 48 (39), 14611-14625. 


\section{Appendix}

NMR Characterization of Aminobenzoxazoles and Aminobenzimidazoles 
${ }^{1} \mathrm{H}$ and ${ }^{13} \mathrm{C}$ NMR Spectra of 2-Aminobenzoxazoles

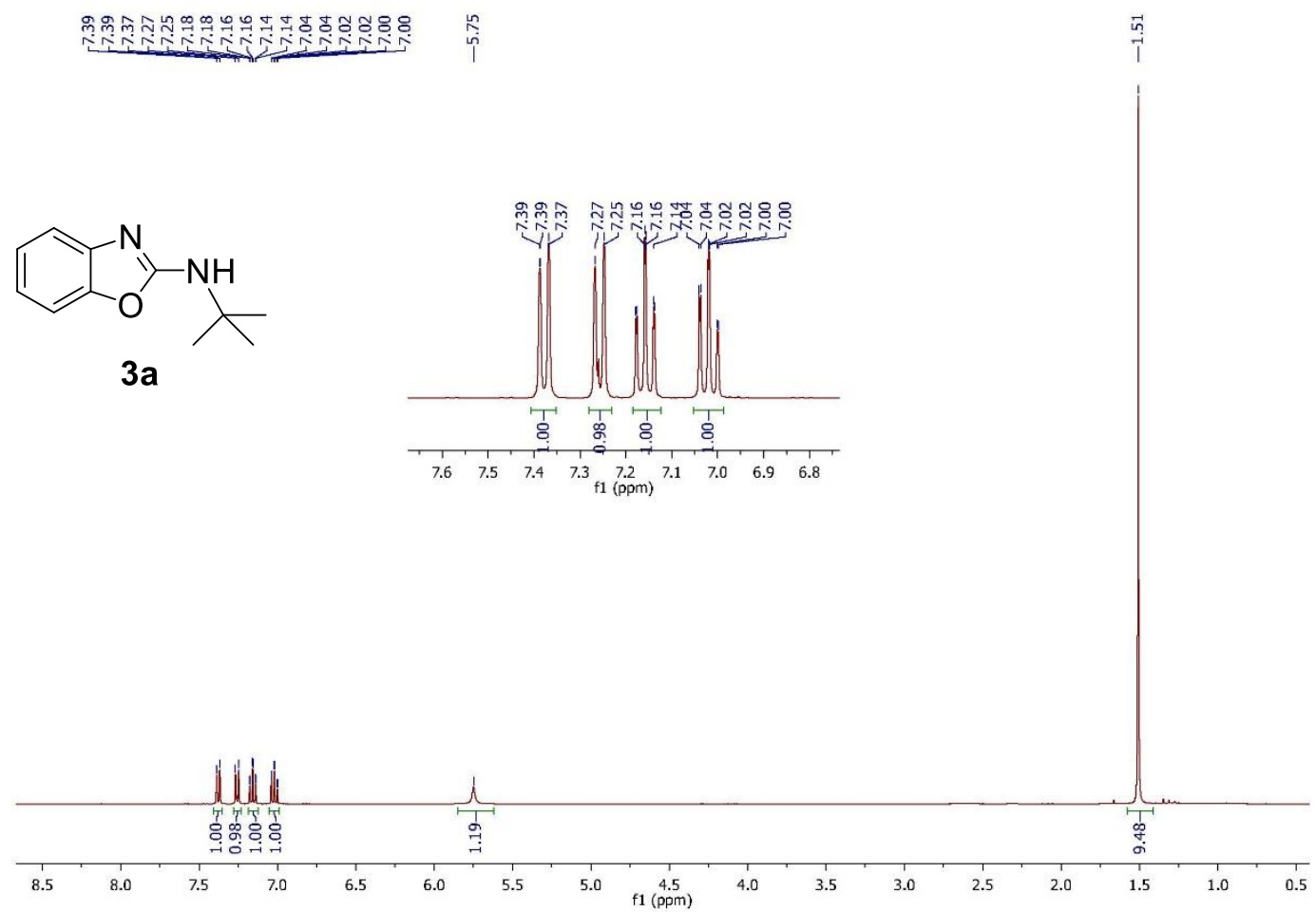

Figure A1. ${ }^{1} \mathrm{H}$ NMR spectrum of 2-(tert-butylamino)benzoxazole (3a) in $\mathrm{CDCl}_{3}$ at $400 \mathrm{MHz}$.

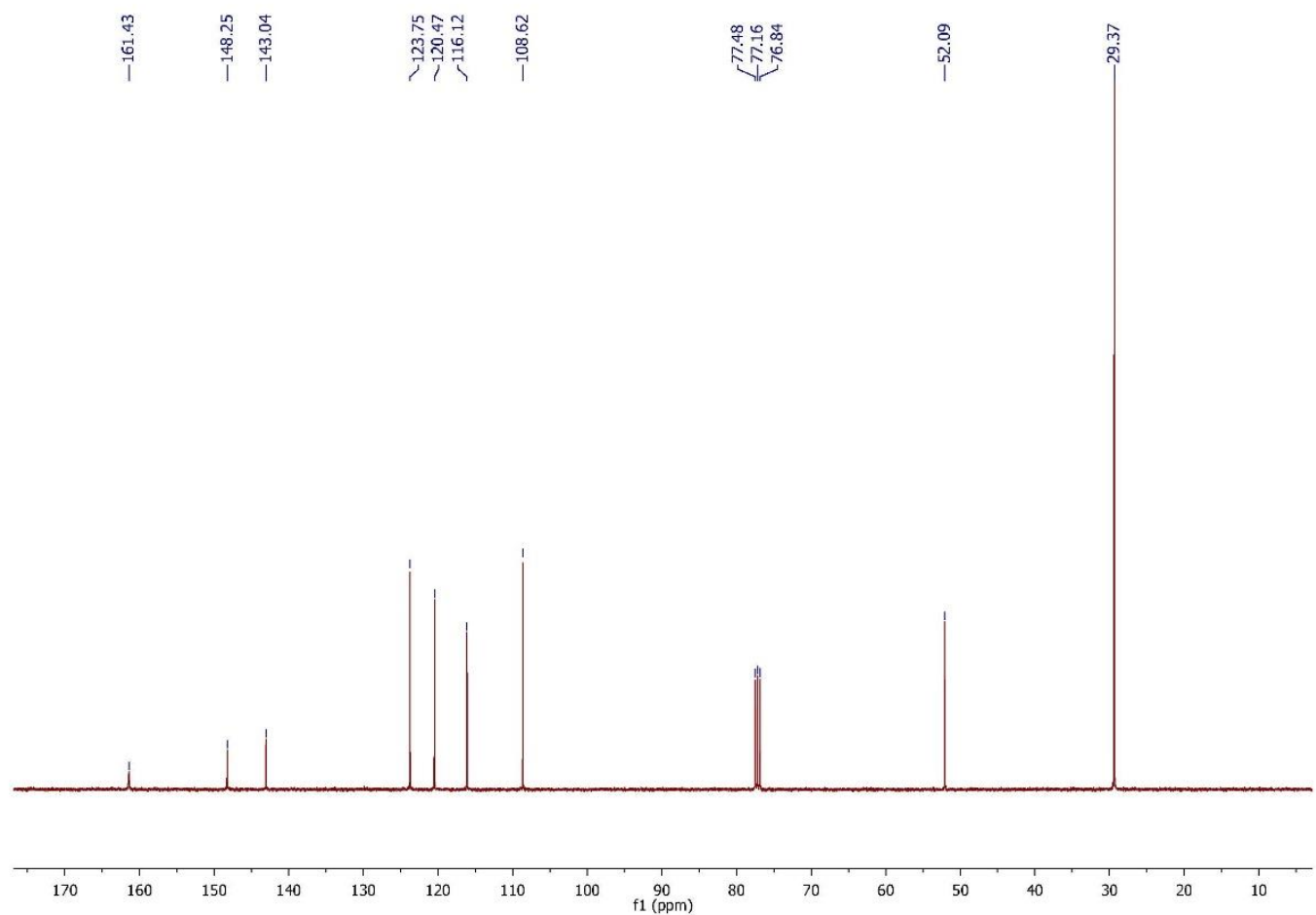

Figure A2. ${ }^{13} \mathrm{C}$ NMR spectrum of 2-(tert-butylamino)benzoxazole (3a) in $\mathrm{CDCl}_{3}$ at $100 \mathrm{MHz}$. 


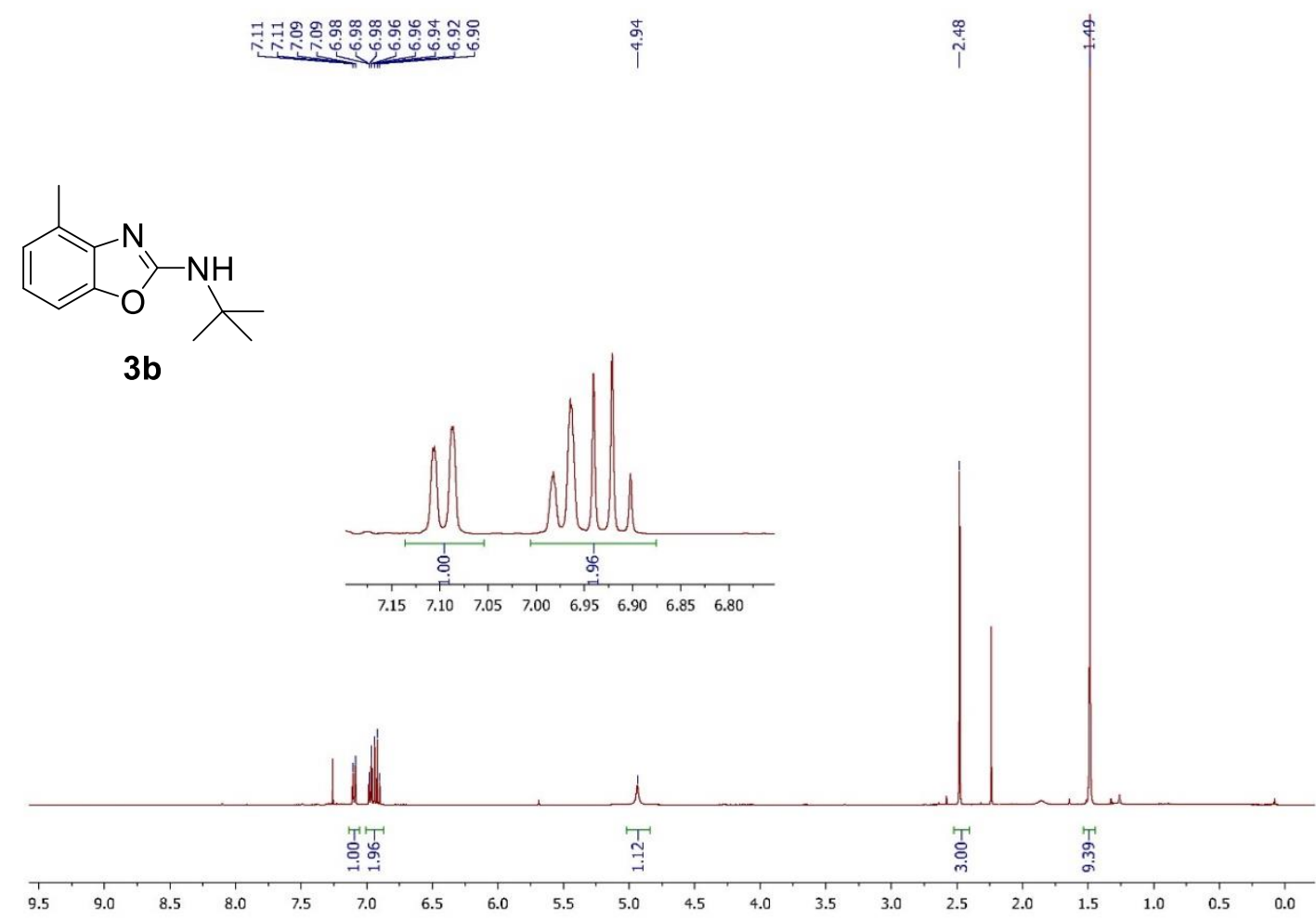

Figure A3. ${ }^{1} \mathrm{H}$ NMR spectrum of 4-methyl-2-(tert-butylamino)benzoxazole (3b) in $\mathrm{CDCl}_{3}$ at $400 \mathrm{MHz}$.

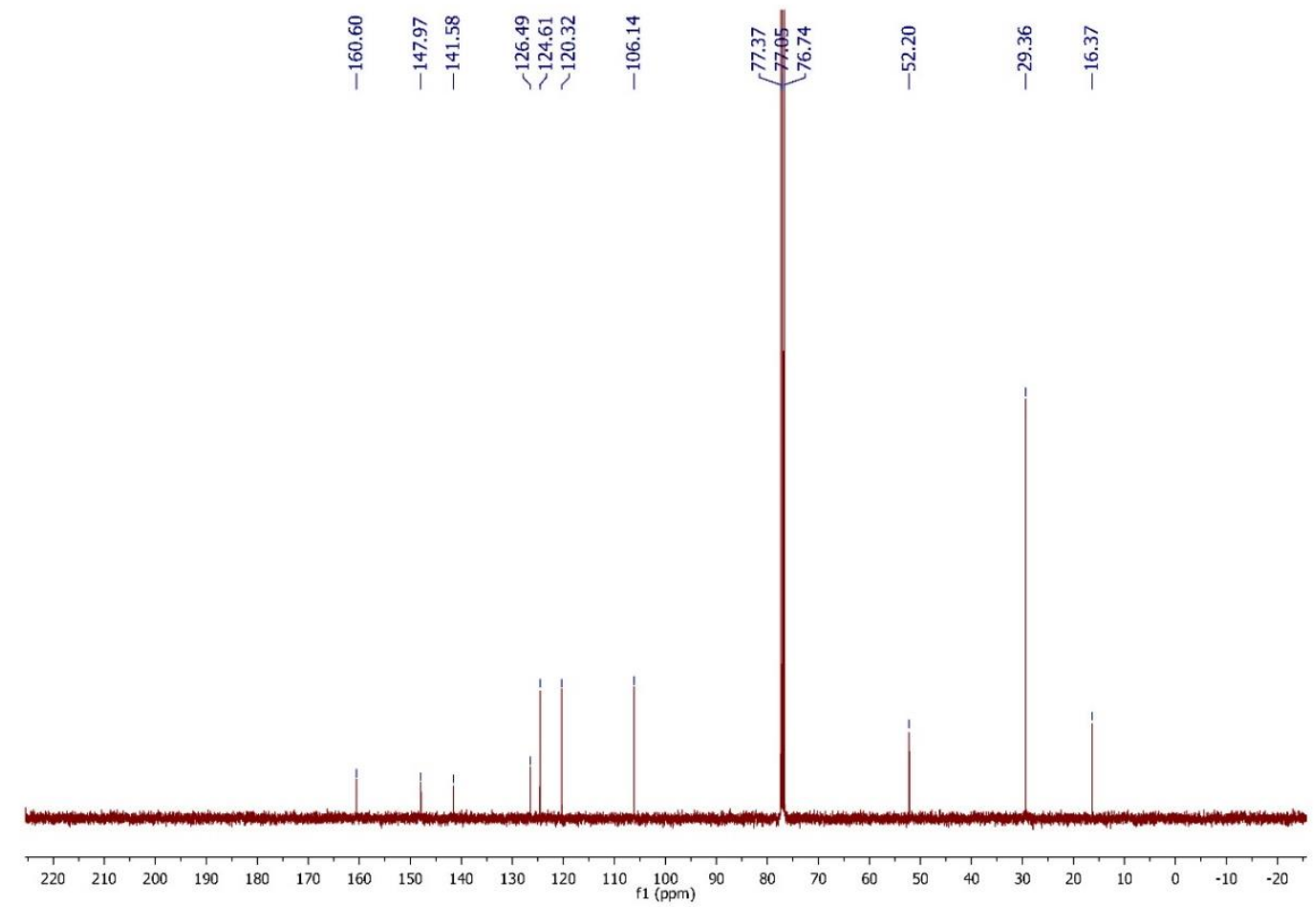

Figure A4. ${ }^{13} \mathrm{C}$ NMR spectrum of 4-methyl-2-(tert-butylamino)benzoxazole (3b) in $\mathrm{CDCl} 3$ at 100 MHz. 


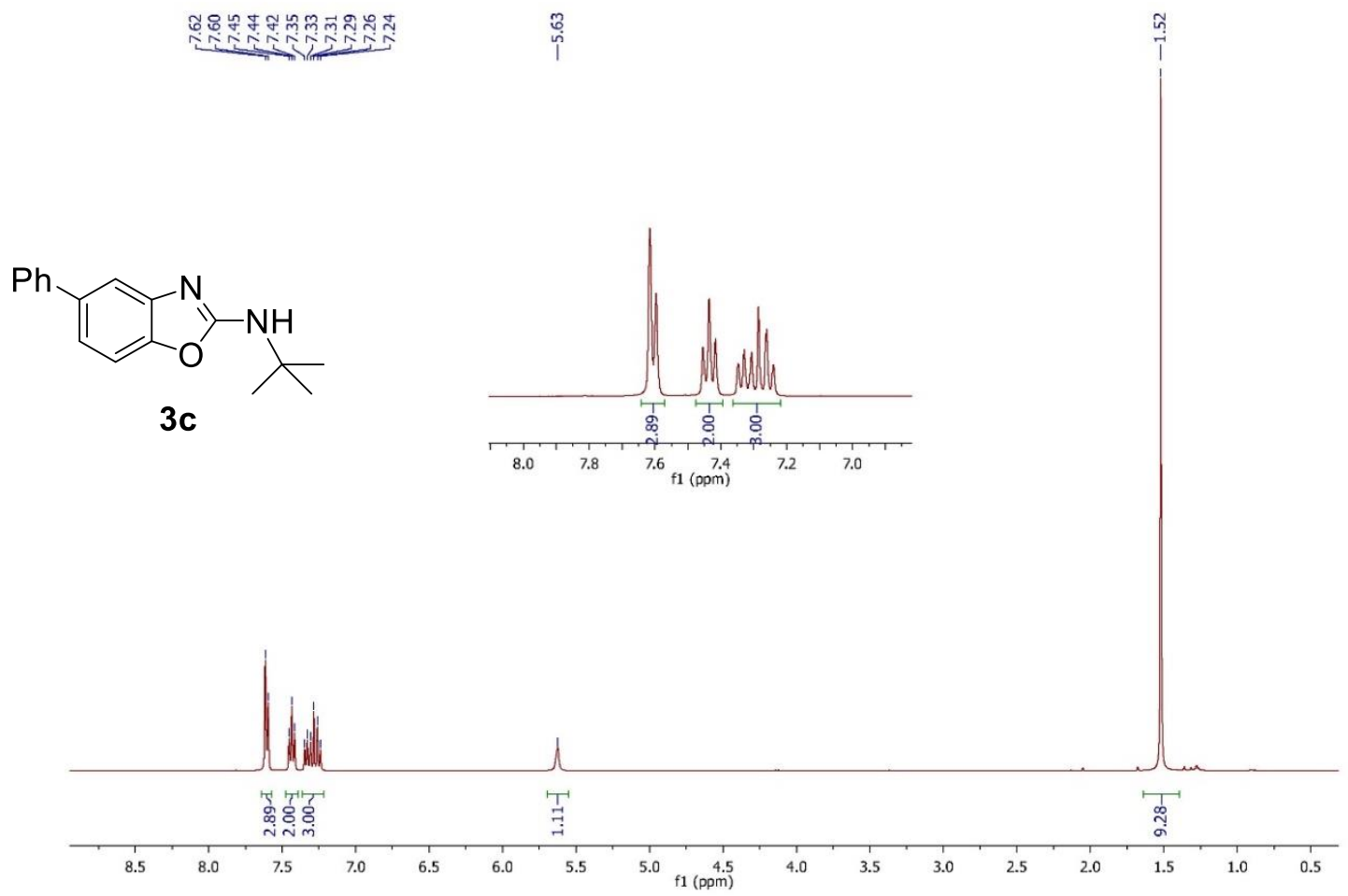

Figure A5. ${ }^{1} \mathrm{H}-\mathrm{NMR}$ spectrum of 5-phenyl-2-(tert-butylamino) benzoxazole (3c) in CDCl3 at 400 MHz.

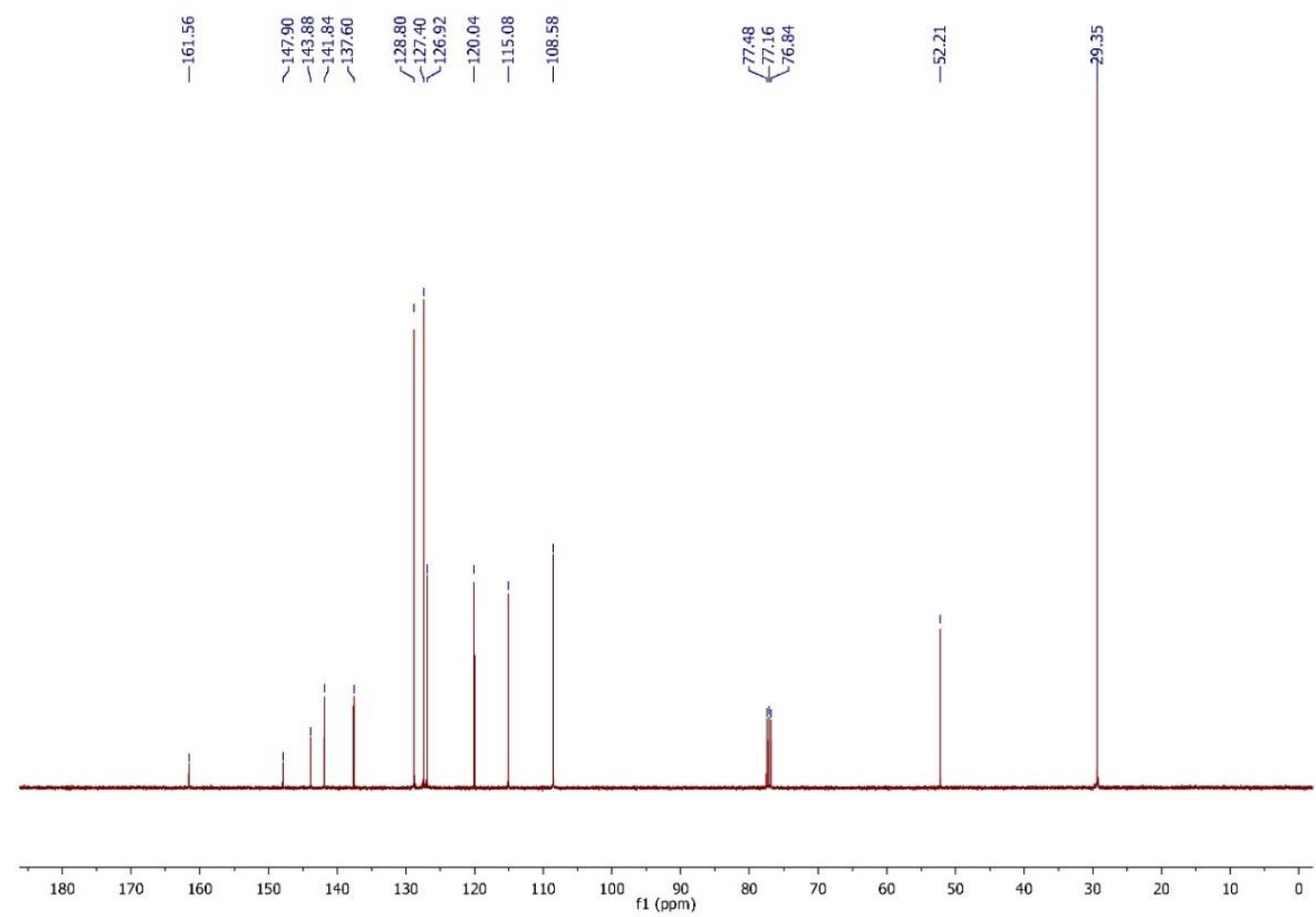

Figure A6. ${ }^{13} \mathrm{C}$ NMR spectrum of 5-phenyl-2-(tert-butylamino)benzoxazole (3c) in $\mathrm{CDCl} 3$ at $100 \mathrm{MHz}$. 


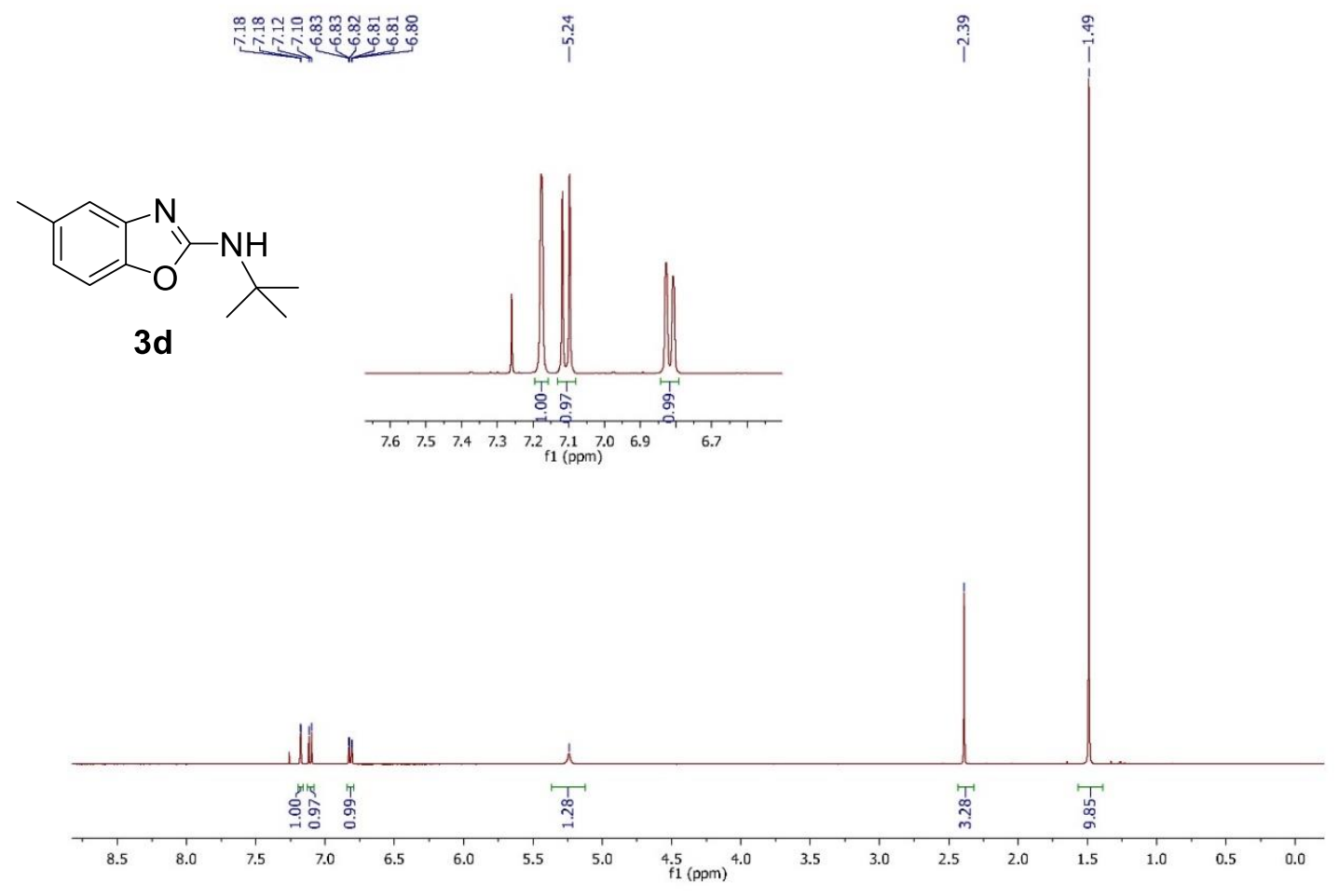

Figure A7. ${ }^{1} \mathrm{H}$ NMR spectrum of 5-methyl-2-(tert-butylamino)benzoxazole (3d) in $\mathrm{CDCl} 3$ at 400 MHz.

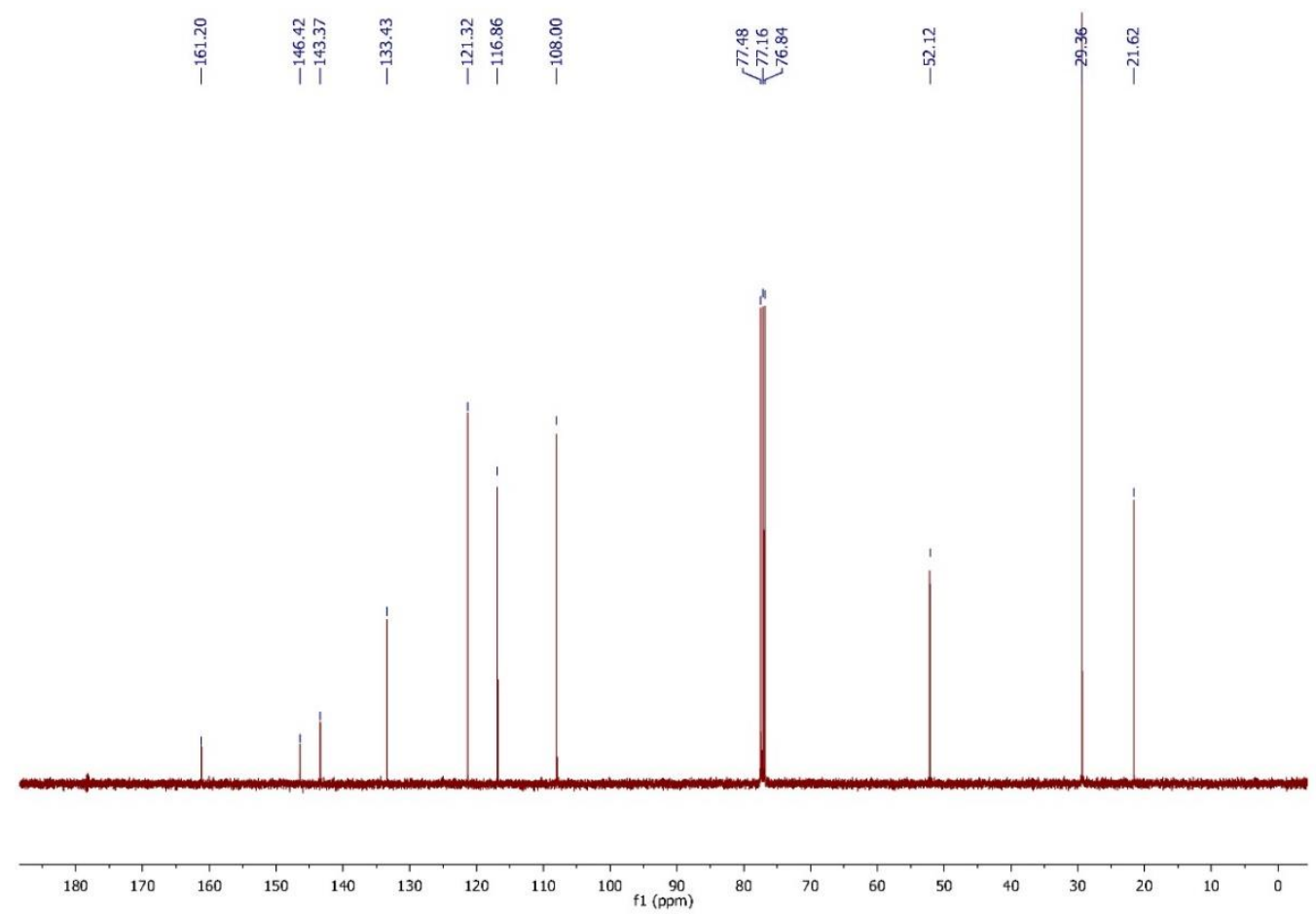

Figure A8. ${ }^{13} \mathrm{C}$ NMR spectrum of 5-methyl-2-(tert-butylamino) benzoxazole (3d) in CDCl3 at 100 MHz. 


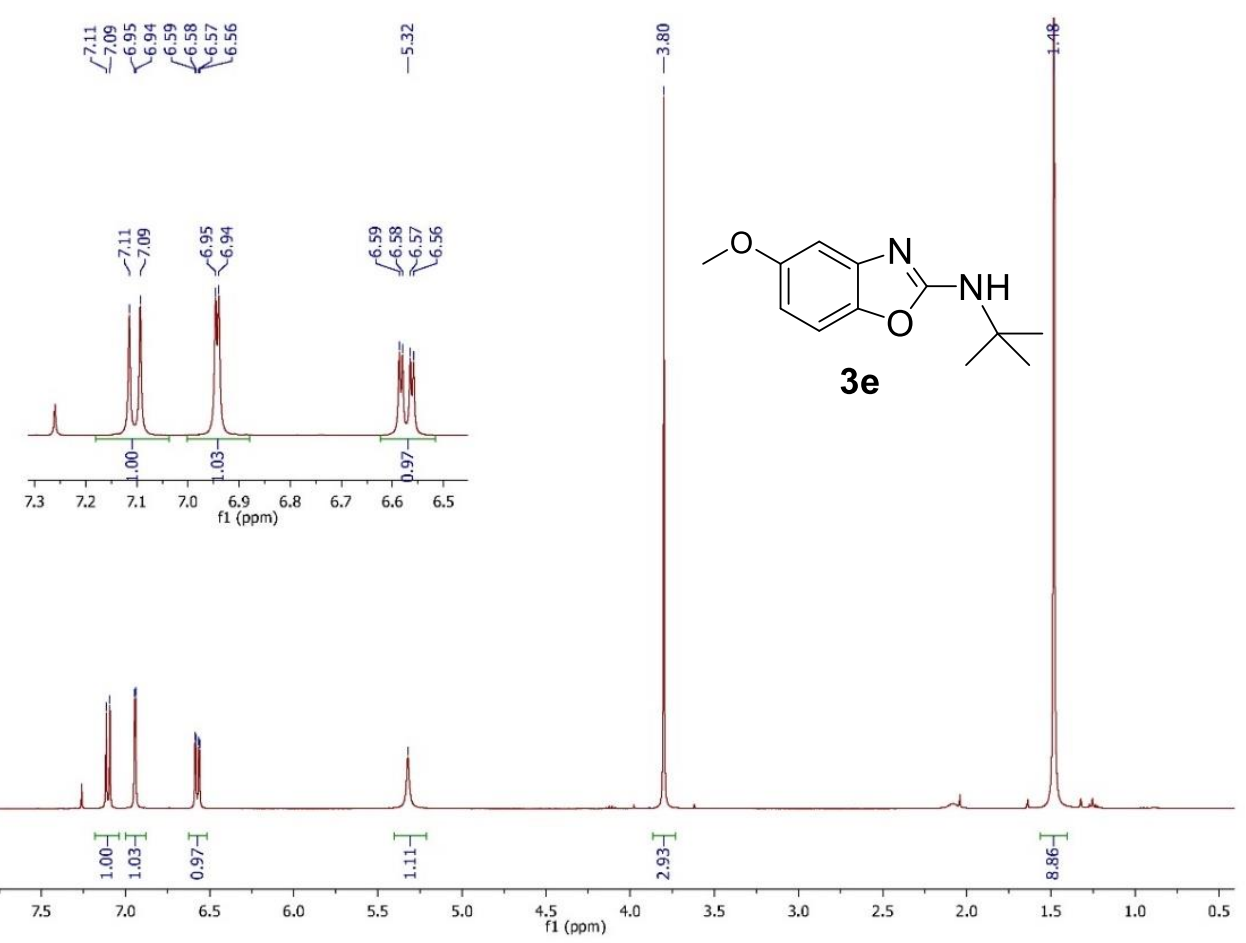

Figure A9. ${ }^{1} \mathrm{H}$ NMR spectrum of 5-methoxy-2-(tert-butylamino)benzoxazole (3e) in $\mathrm{CDCl}_{3}$ at $400 \mathrm{MHz}$.

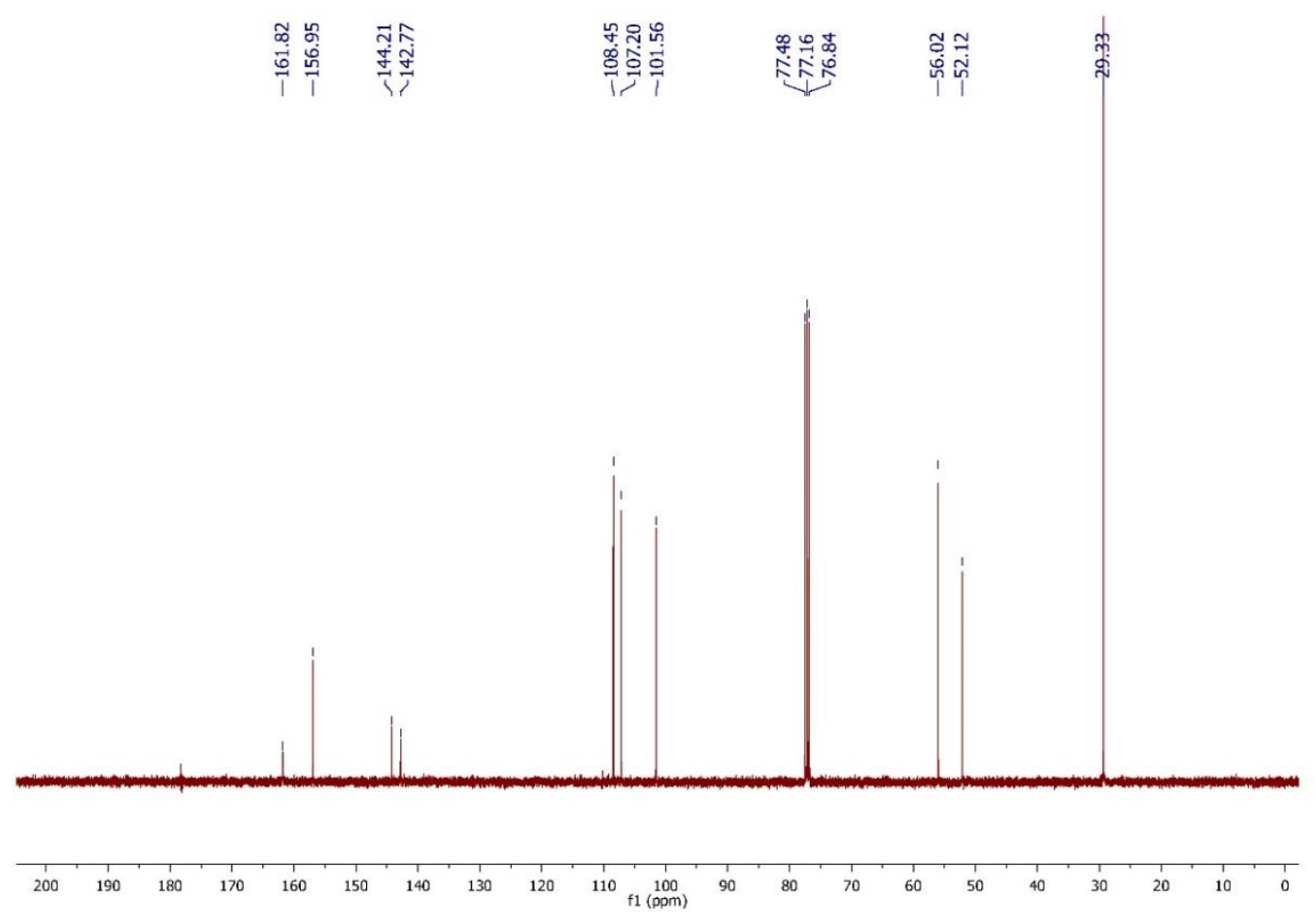

Figure A10. ${ }^{13} \mathrm{C}$ NMR spectrum of 5-methoxy-2-(tert-butylamino)benzoxazole (3e) in $\mathrm{CDCl}_{3}$ at 100 MHz. 


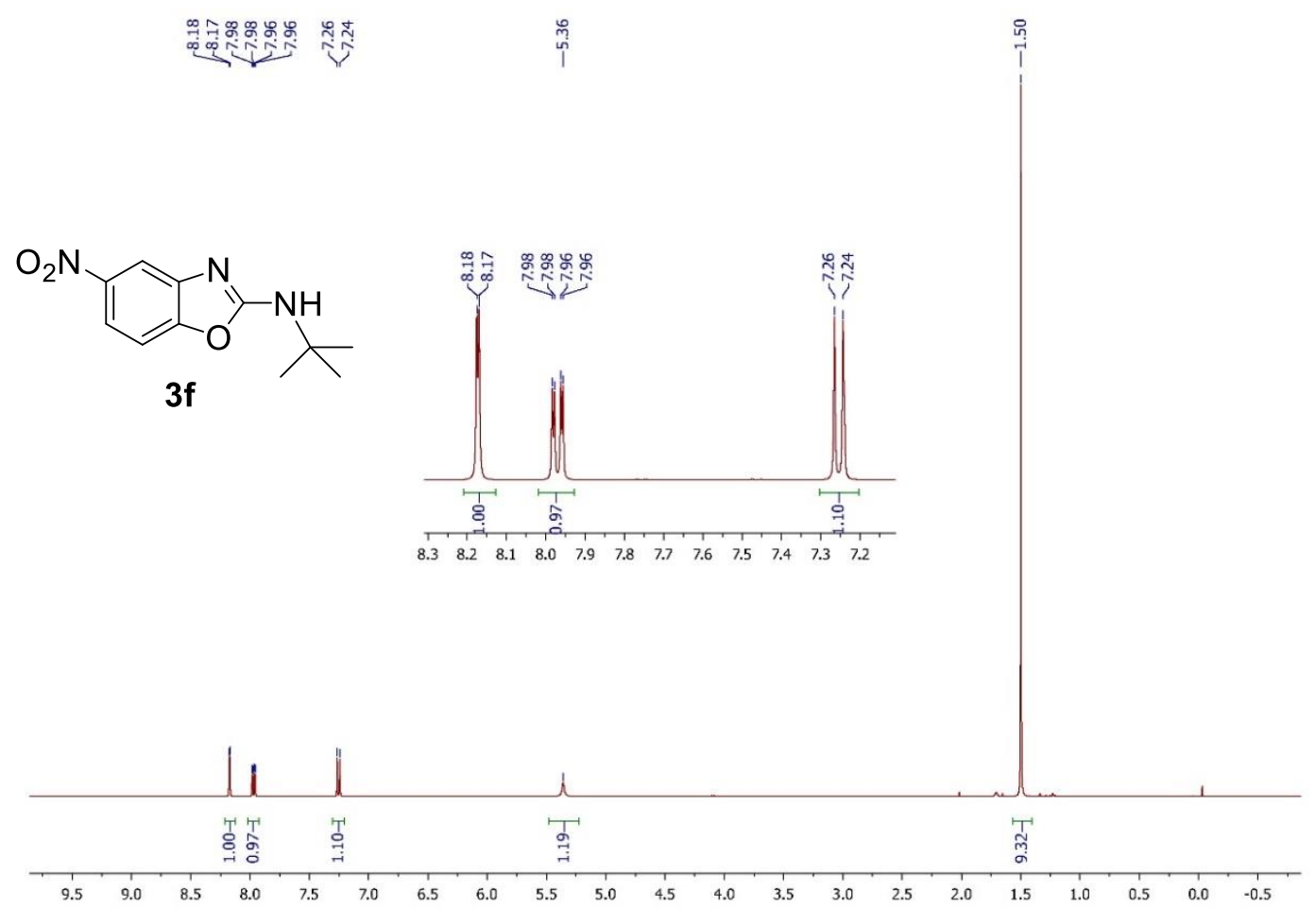

Figure A11. ${ }^{1} \mathrm{H}$ NMR spectrum of 5-nitro-2-(tert-butylamino)benzoxazole (3f) in $\mathrm{CDCl}_{3}$ at 400 MHz.

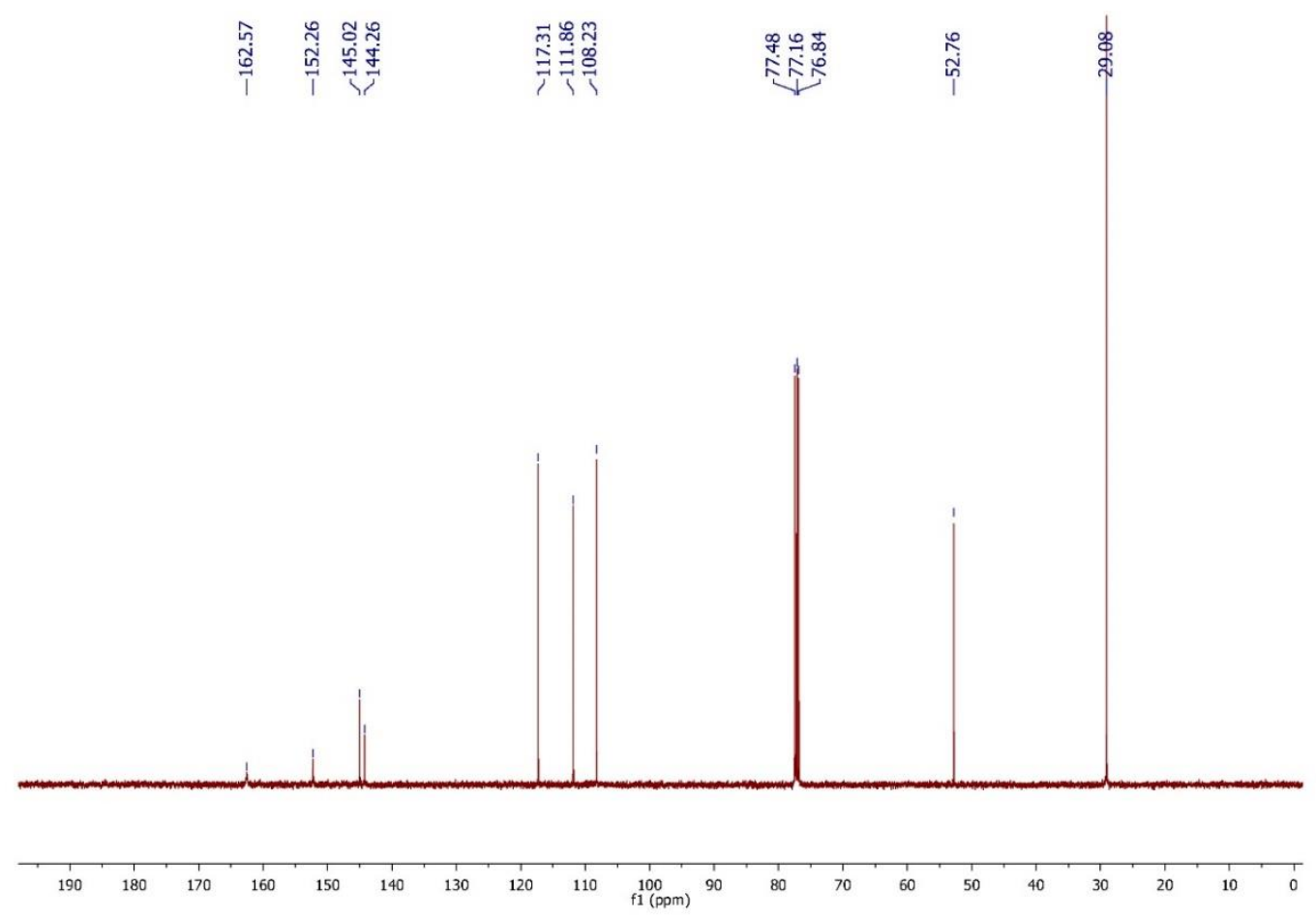

Figure A12. ${ }^{13} \mathrm{C}$ NMR spectrum of 5-nitro-2-(tert-butylamino)benzoxazole (3f) in CDCl3 at 100 MHz. 


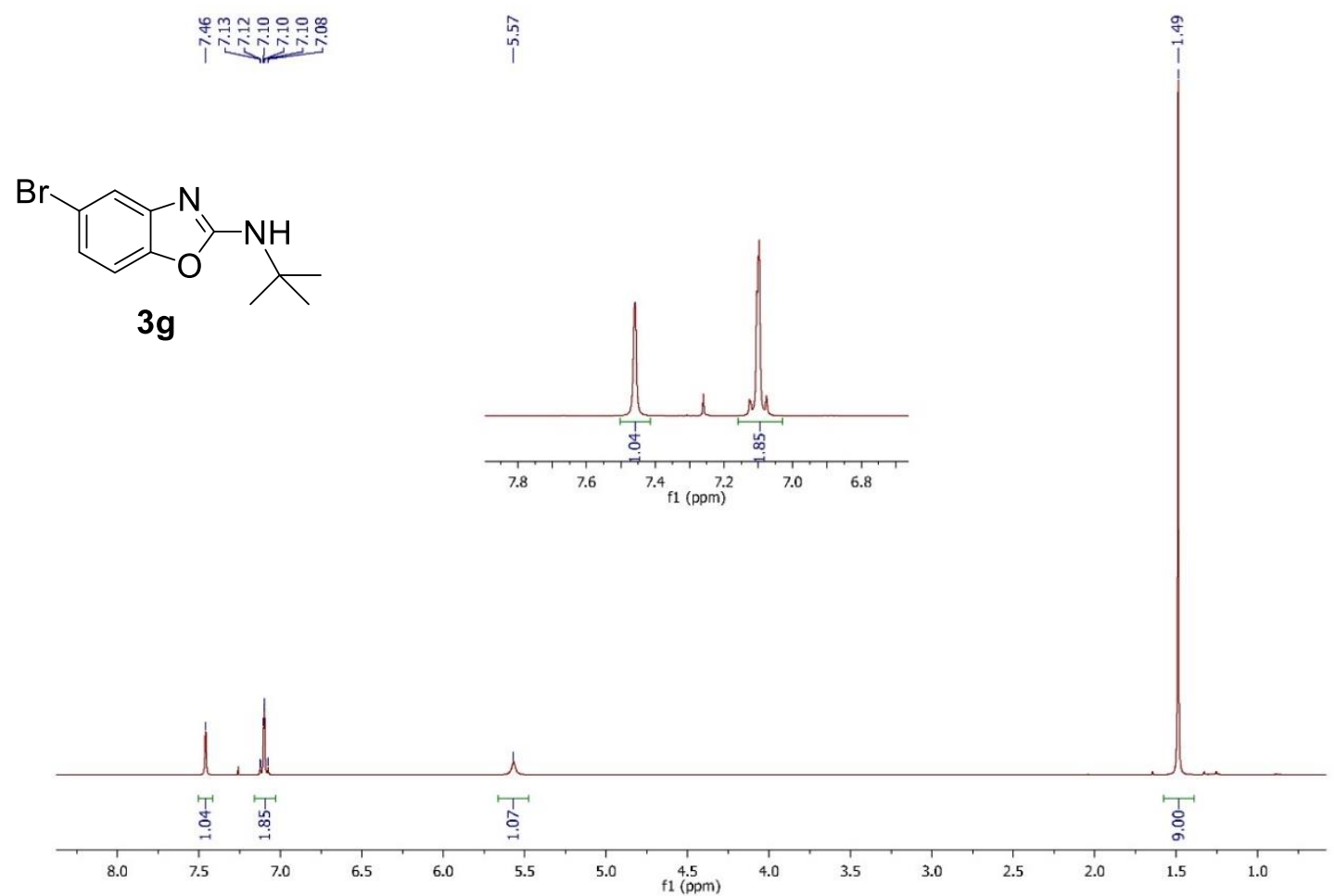

Figure A13. ${ }^{1} \mathrm{H}$ NMR spectrum of 5-bromo-2-(tert-butylamino)benzoxazole (3g) in $\mathrm{CDCl} 3$ at $400 \mathrm{MHz}$.

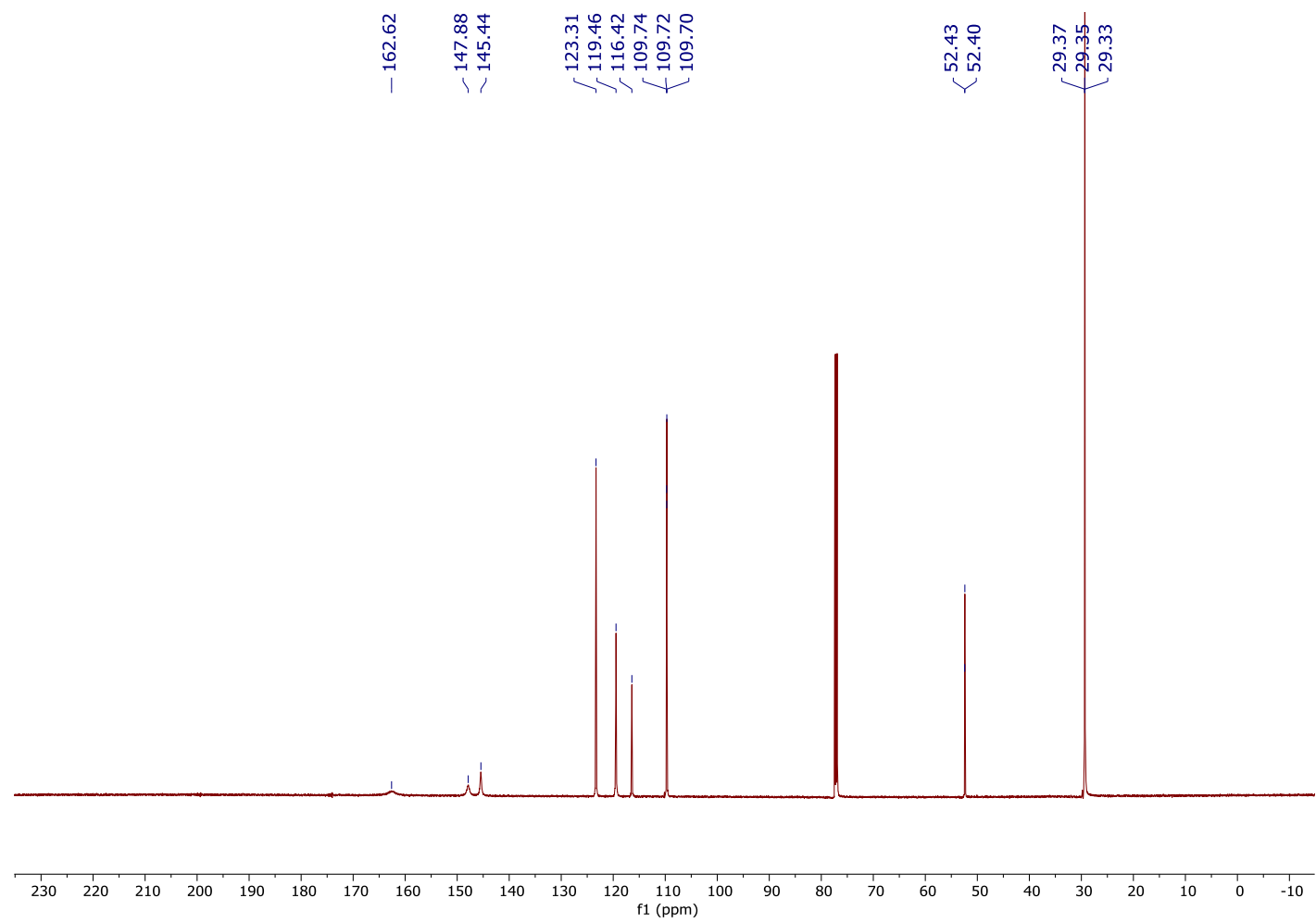

Figure A14. ${ }^{13} \mathrm{C}$ NMR spectrum of 5-bromo-2-(tert-butylamino)benzoxazole $(3 \mathrm{~g})$ in $\mathrm{CDCl} 3 \mathrm{at}$ $100 \mathrm{MHz}$. 


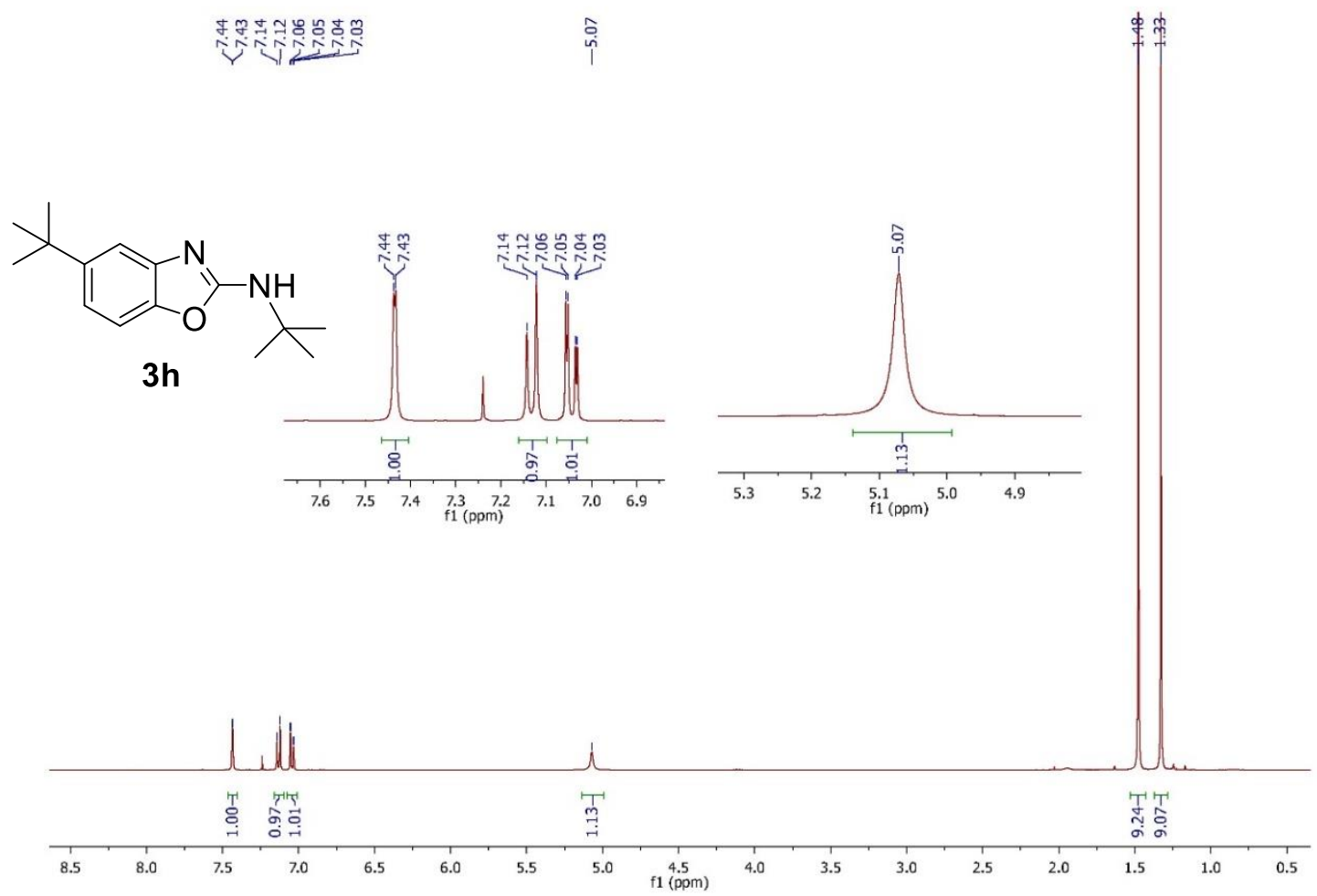

Figure A15. ${ }^{1} \mathrm{H}$ NMR spectrum of 5-tert-butyl-2-(tert-butylamino)benzoxazole (3h) in CDCl3 at 400 MHz.

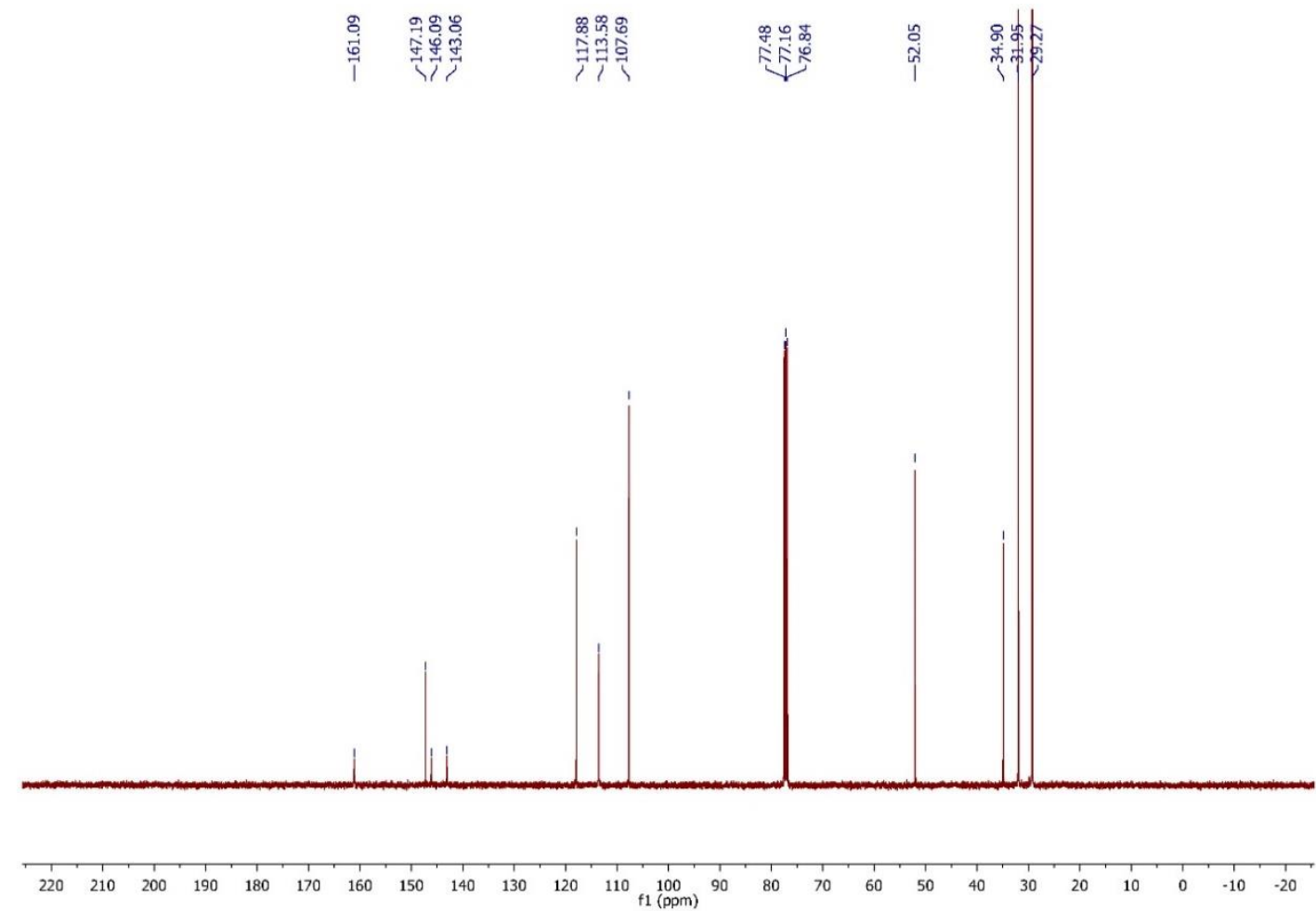

Figure A16. ${ }^{13} \mathrm{C}$ NMR spectrum of 5-tert-butyl-2-(tert-butylamino)benzoxazole (3h) in $\mathrm{CDCl} 3$ at $100 \mathrm{MHz}$. 


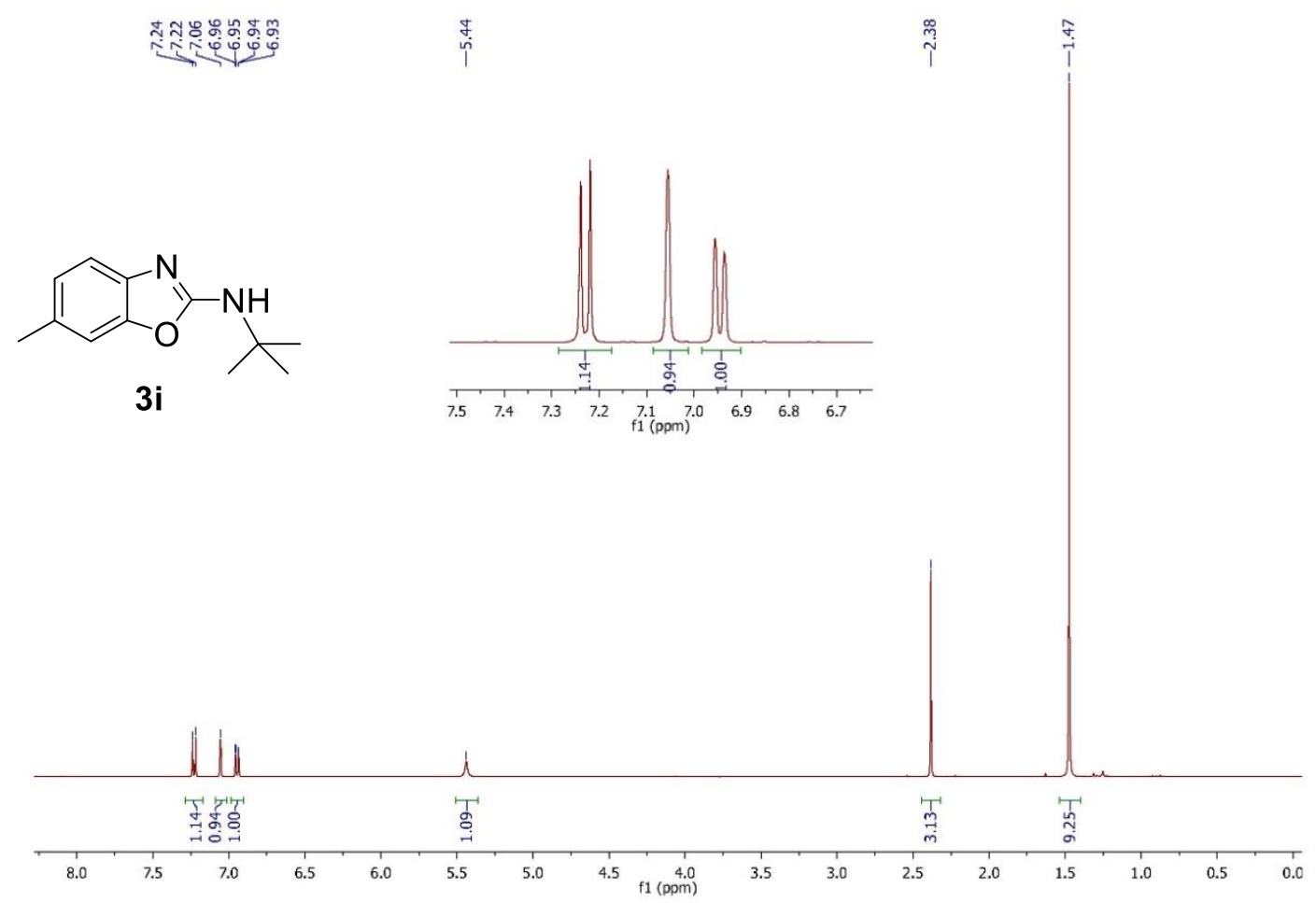

Figure A17. ${ }^{1} \mathrm{H}$ NMR spectrum of 6-methyl-2-(tert-butylamino)benzoxazole (3i) in $\mathrm{CDCl}_{3}$ at $400 \mathrm{MHz}$.

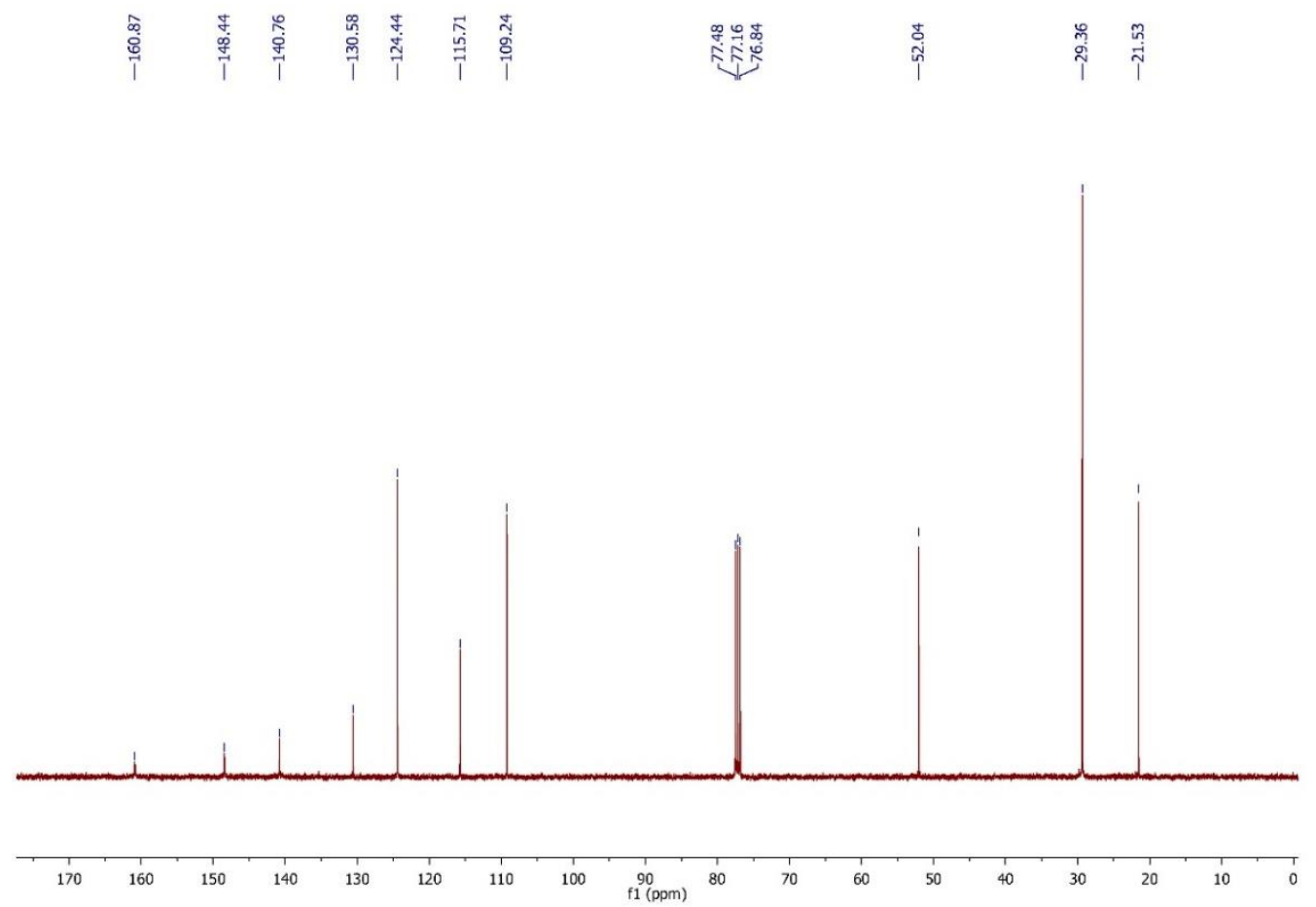

Figure A18. ${ }^{13} \mathrm{C}$ NMR spectrum of 6-methyl-2-(tert-butylamino) benzoxazole(3i) in $\mathrm{CDCl}_{3}$ at $100 \mathrm{MHz}$. 


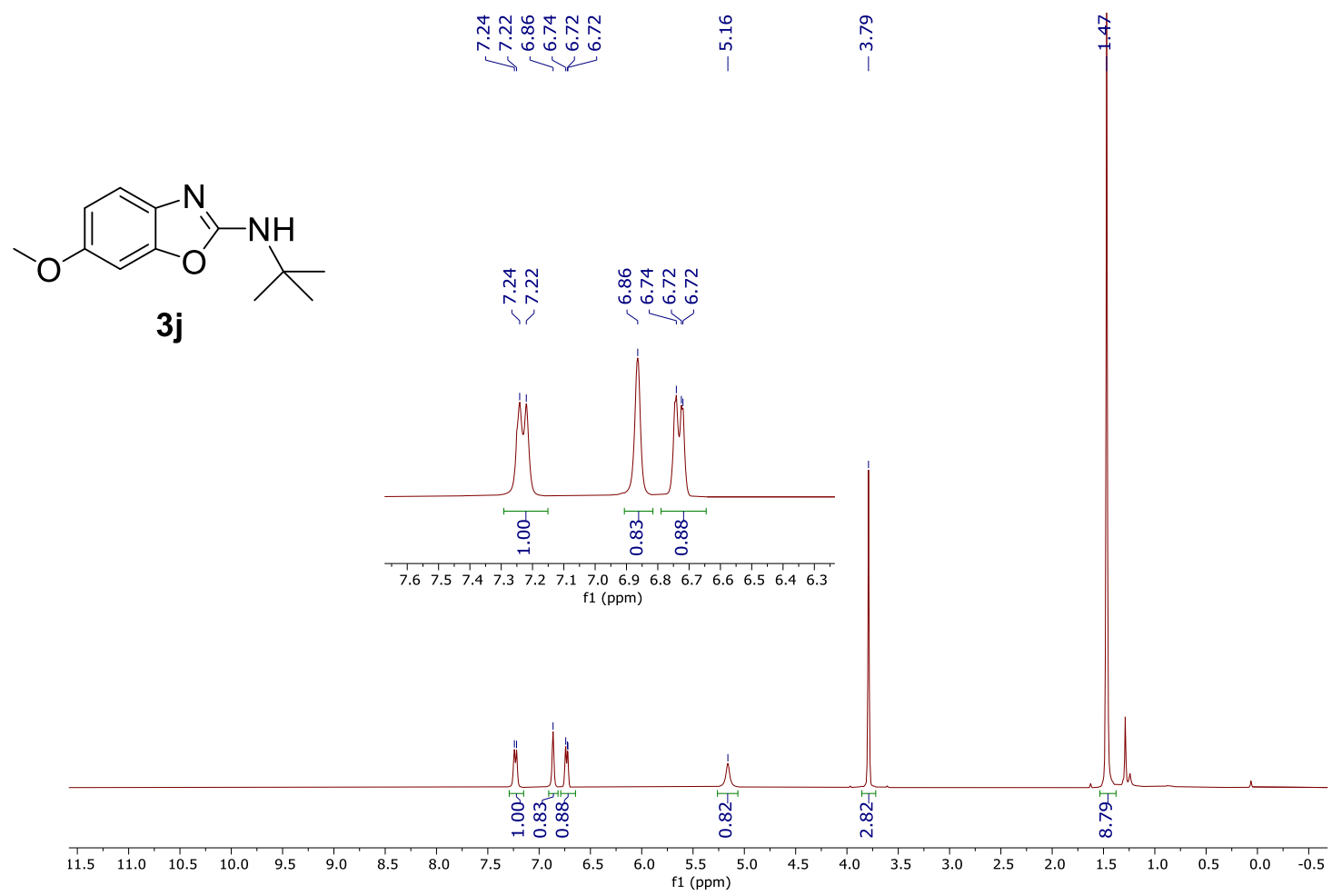

Figure A19. ${ }^{1} \mathrm{H}$ NMR spectrum of 6-methoxy-2-(tert-butylamino)benzoxazole $(3 \mathrm{j})$ in $\mathrm{CDCl}_{3}$ at $400 \mathrm{MHz}$.

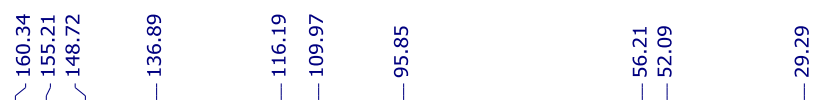

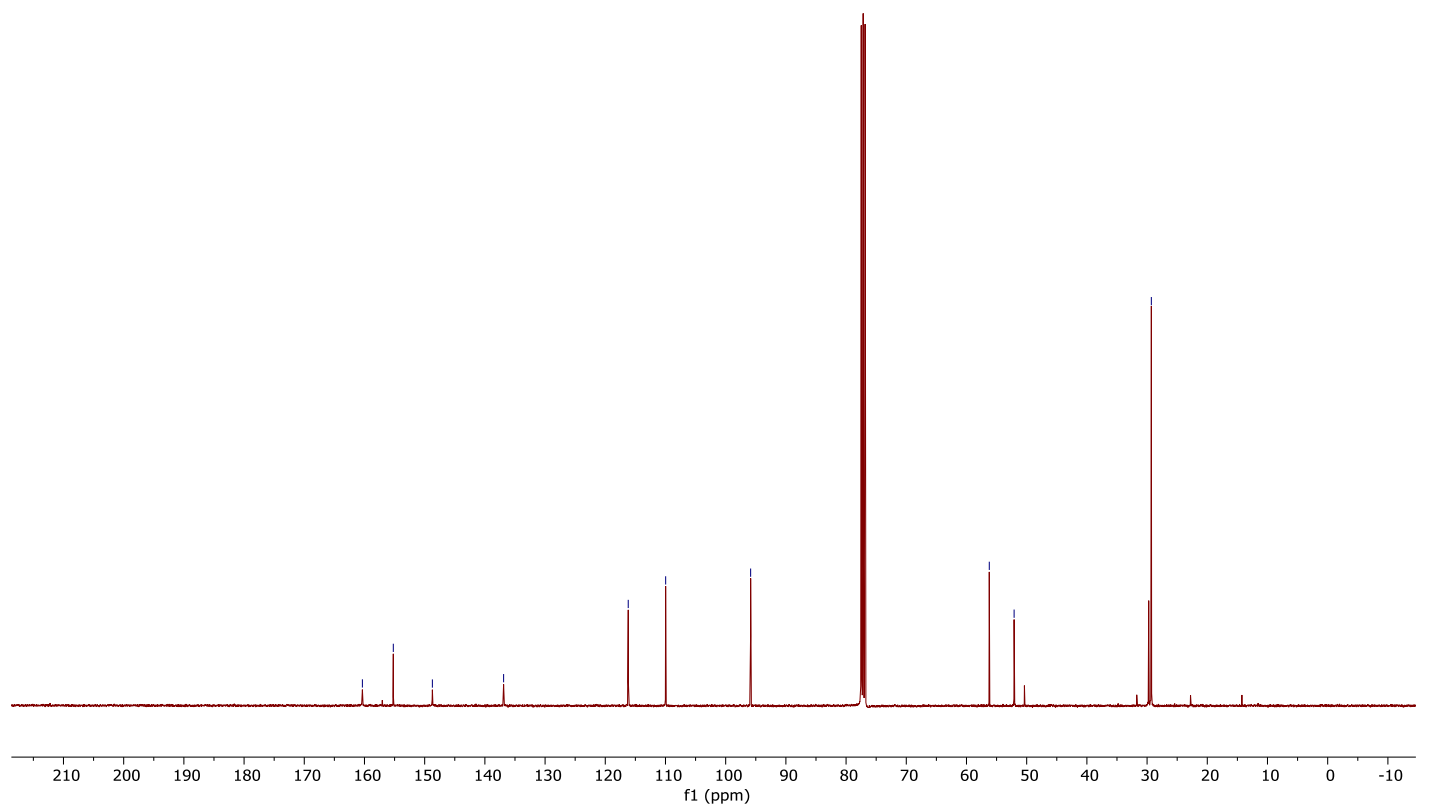

Figure A20. ${ }^{13} \mathrm{C}$ NMR spectrum of 6-methoxy-2-(tert-butylamino)benzoxazole (3j) in $\mathrm{CDCl}_{3}$ at 100 MHz. 


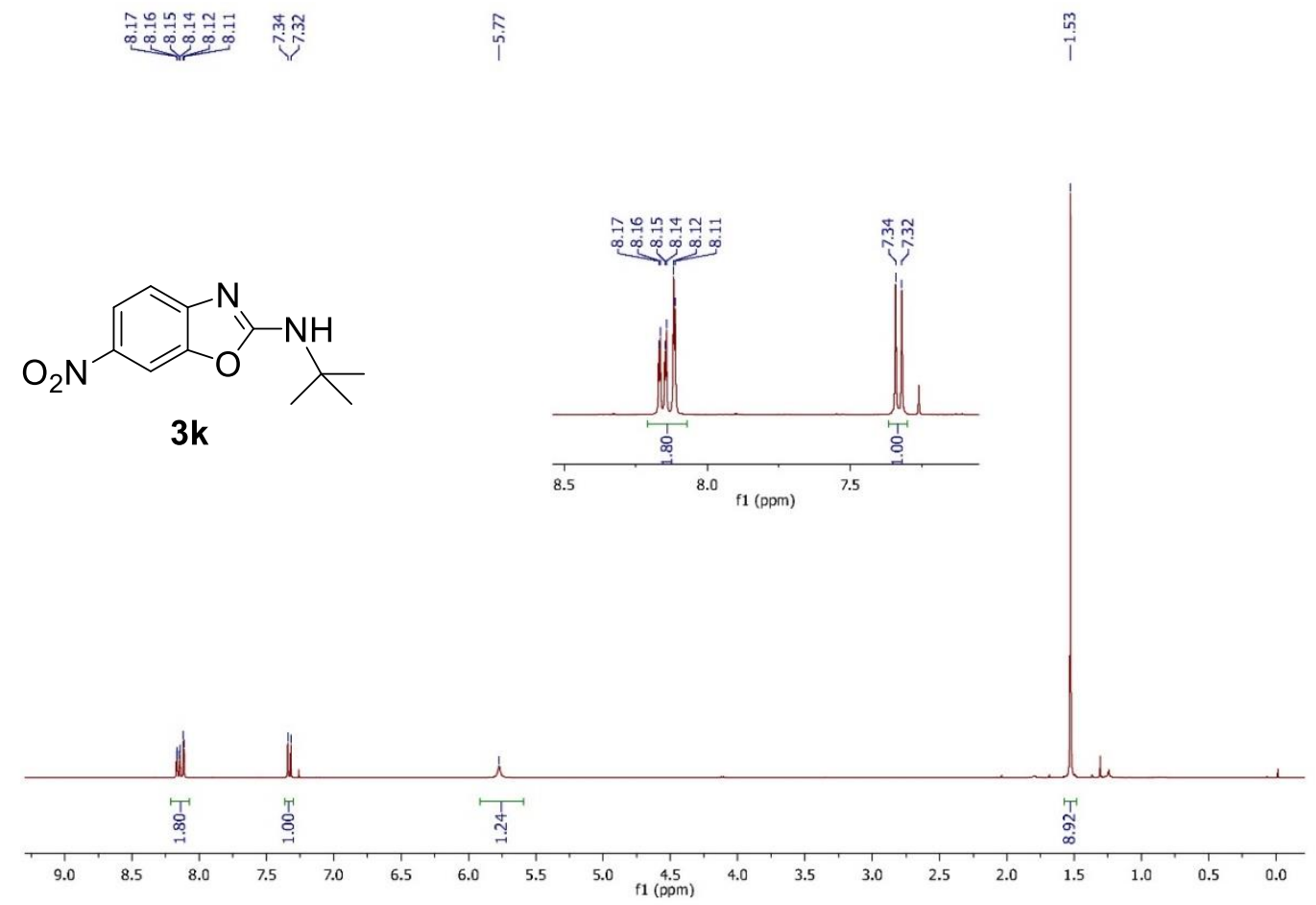

Figure A21. ${ }^{1} \mathrm{H}$ NMR spectrum of 6-nitro-2-(tert-butylamino)benzoxazole (3k) in $\mathrm{CDCl}_{3}$ at $400 \mathrm{MHz}$.

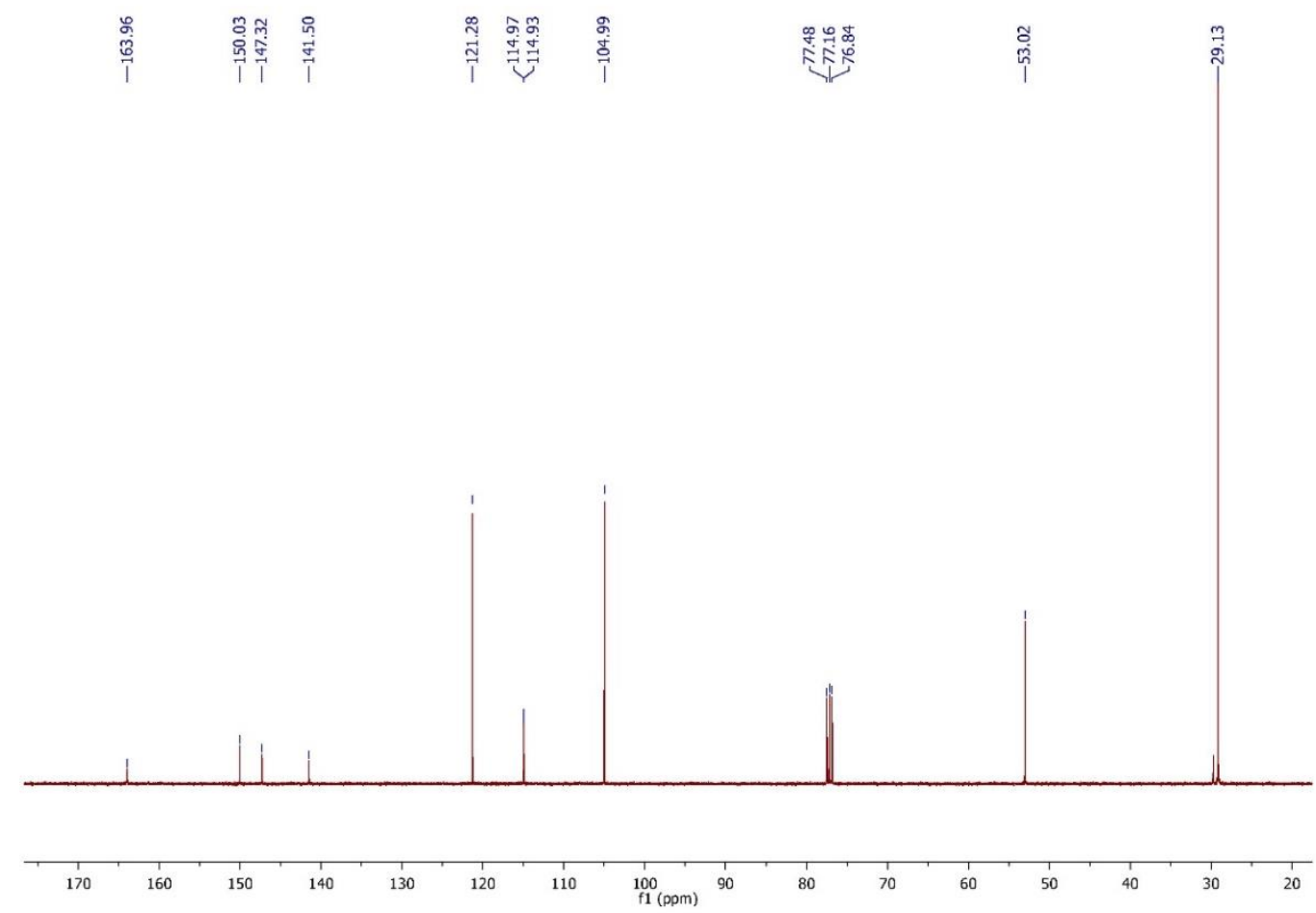

Figure A22. ${ }^{13} \mathrm{C}$ NMR spectrum of 6-nitro-2-(tert-butylamino)benzoxazole (3k) in $\mathrm{CDCl}_{3}$ at 100 MHz. 


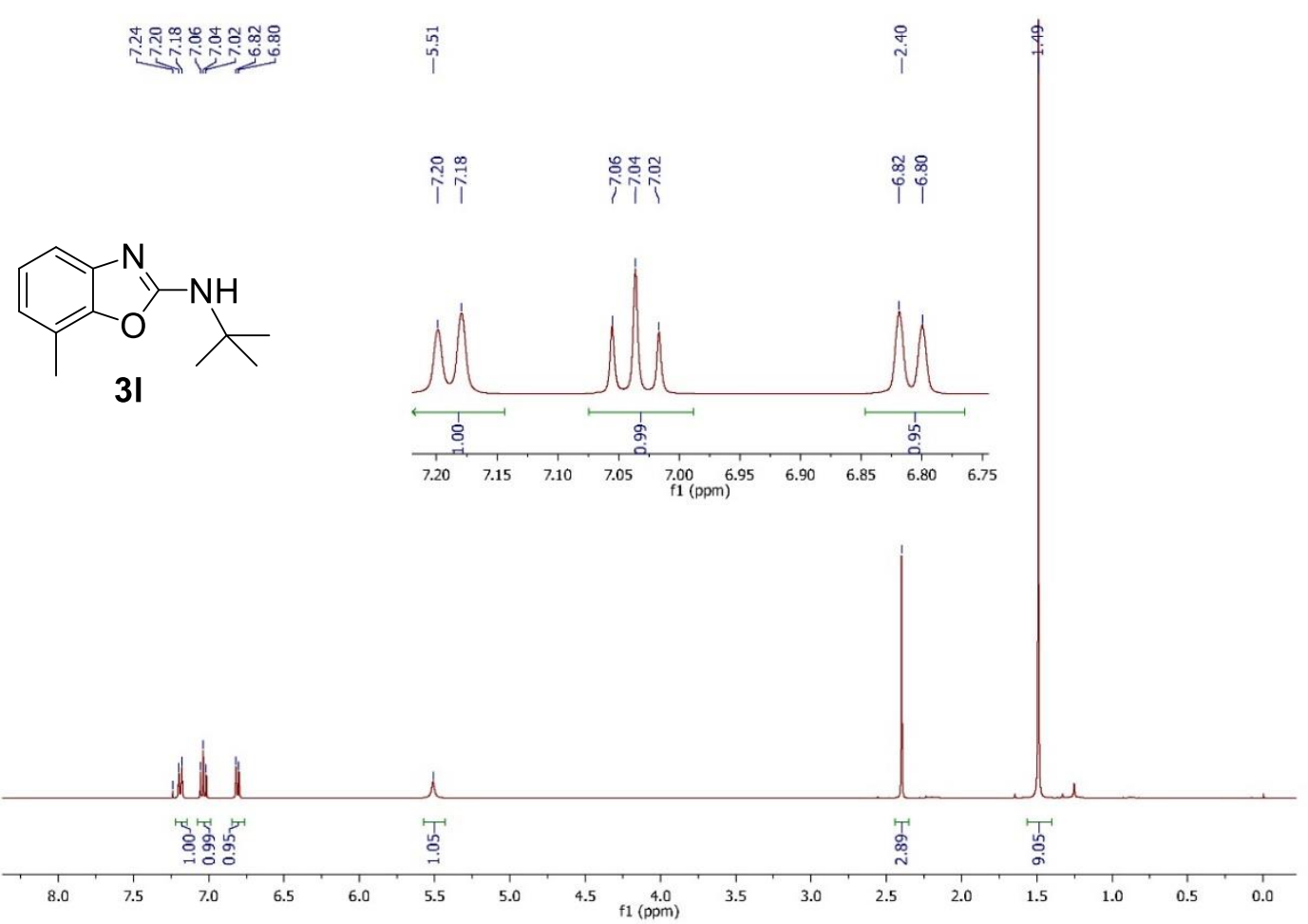

Figure A23. ${ }^{1} \mathrm{H}$ NMR spectrum of 7 -methyl-2-(tert-butylamino)benzoxazole (3I) in $\mathrm{CDCl}_{3}$ at 400 MHz.

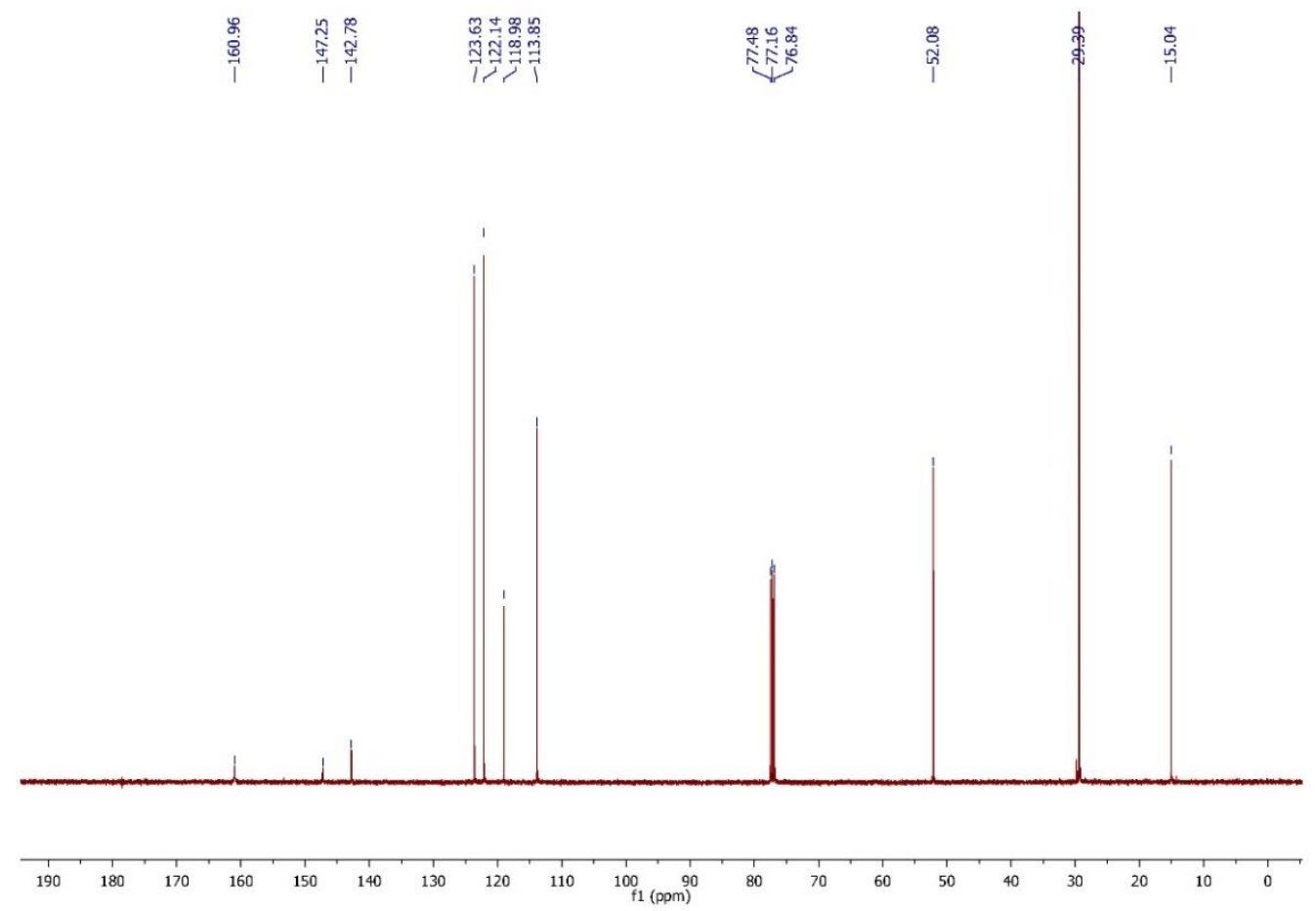

Figure A24. ${ }^{13} \mathrm{C}$ NMR spectrum of 7-methyl-2-(tert-butylamino)benzoxazole (31) in $\mathrm{CDCl}_{3}$ at $100 \mathrm{MHz}$. 


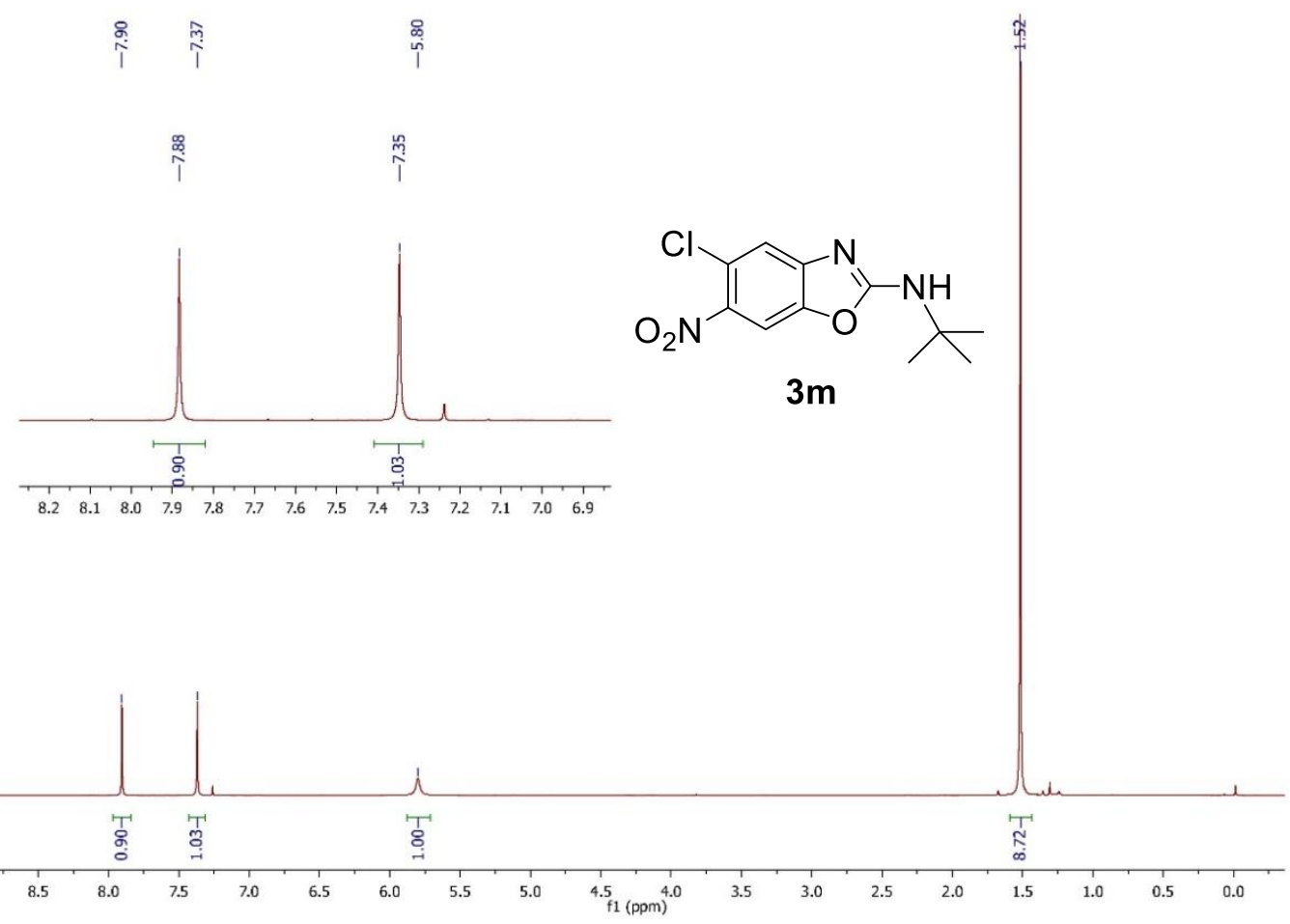

Figure A25. ${ }^{1} \mathrm{H}$ NMR spectrum of 6-nitro-5-chloro-2-(tert-butylamino)benzoxazole (3m) in $\mathrm{CDCl}_{3}$ at $400 \mathrm{MHz}$.

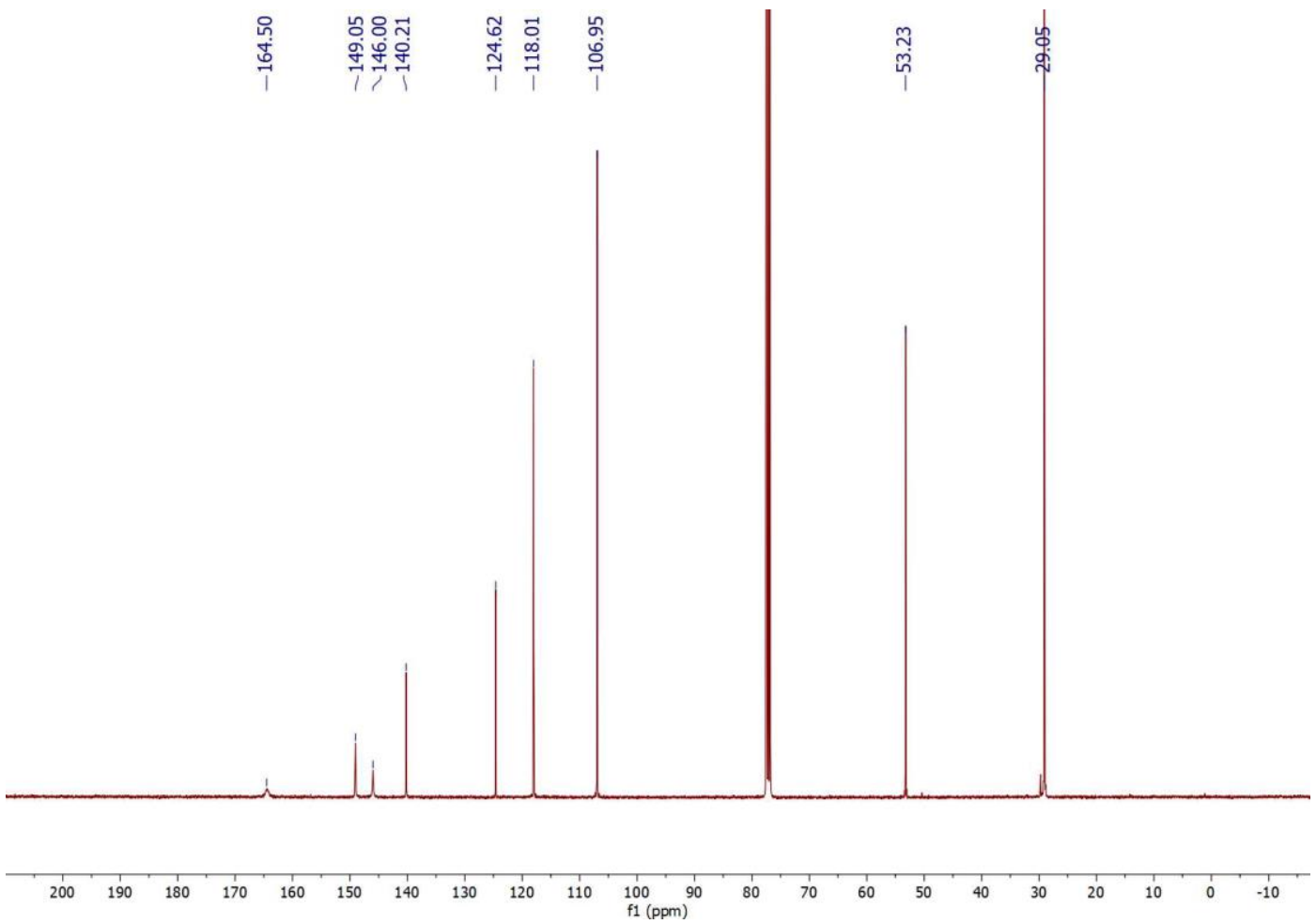

Figure A26. ${ }^{13} \mathrm{C}$ NMR spectrum of 6-nitro-5-chloro-2-(tert-butylamino)benzoxazole (3m) in $\mathrm{CDCl}_{3}$ at $100 \mathrm{MHz}$. 


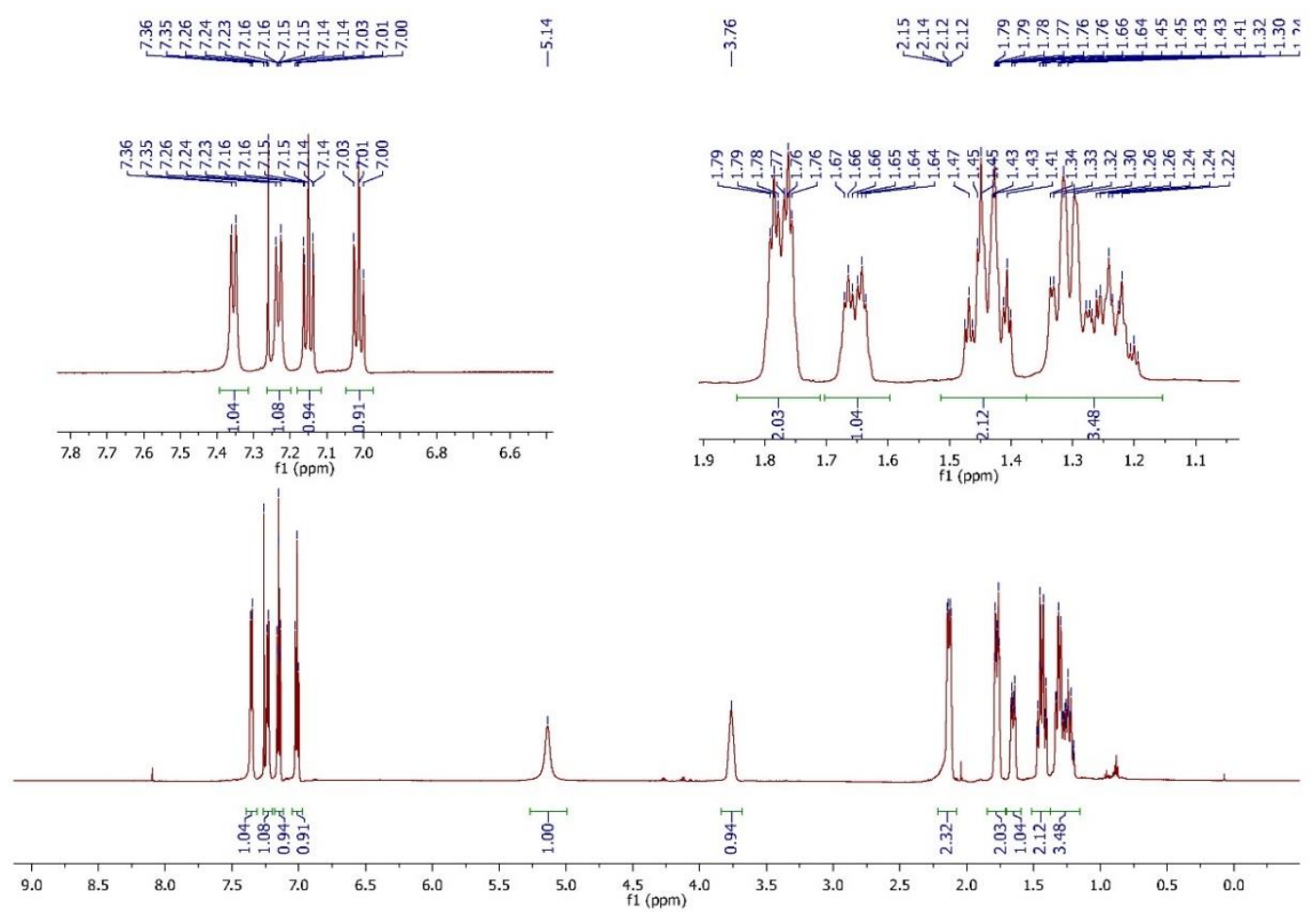

Figure A27. ${ }^{1} \mathrm{H}$ NMR spectrum of 2-(cyclohexylamino)benzoxazole (3n) in $\mathrm{CDCl}_{3}$ at $400 \mathrm{MHz}$.

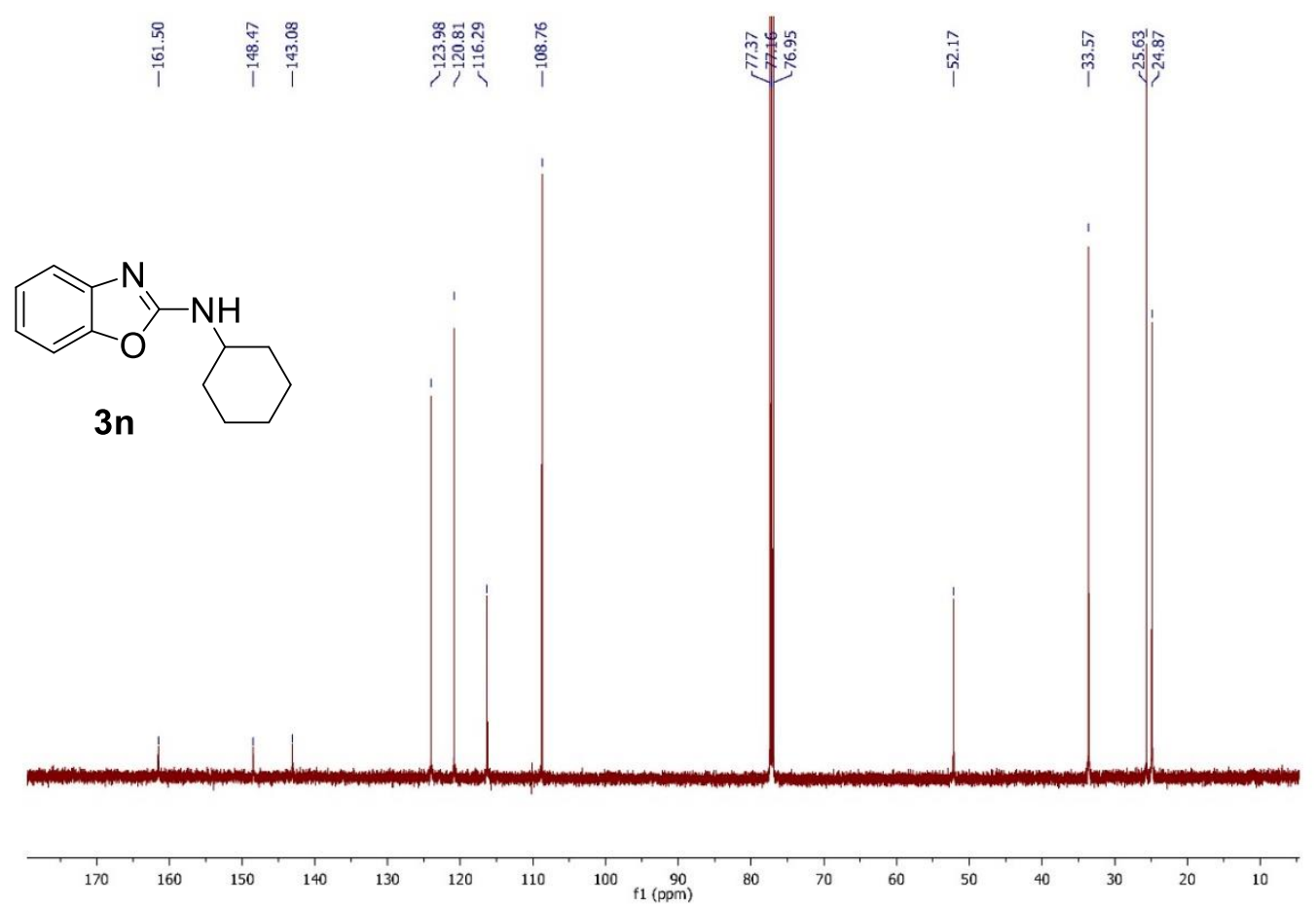

Figure A28. ${ }^{13} \mathrm{C}$ NMR spectrum of 2-(cyclohexylamino)benzoxazole (3n) in $\mathrm{CDCl}_{3}$ at 100 MHz. 

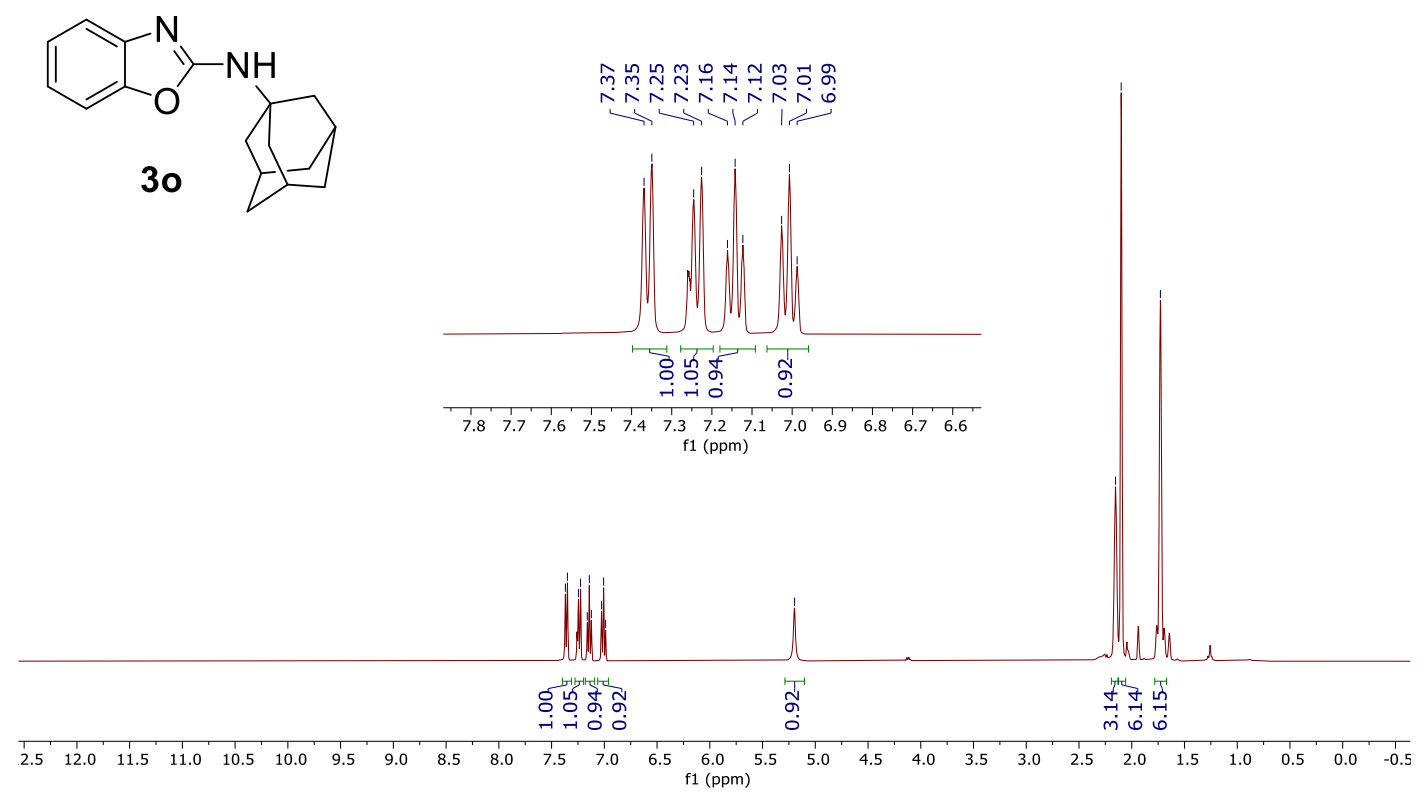

Figure A29. ${ }^{1} \mathrm{H}$ NMR spectrum of 2-(1-admantylamino)benzoxazole (3o) in $\mathrm{CDCl}_{3}$ at 400 MHz.

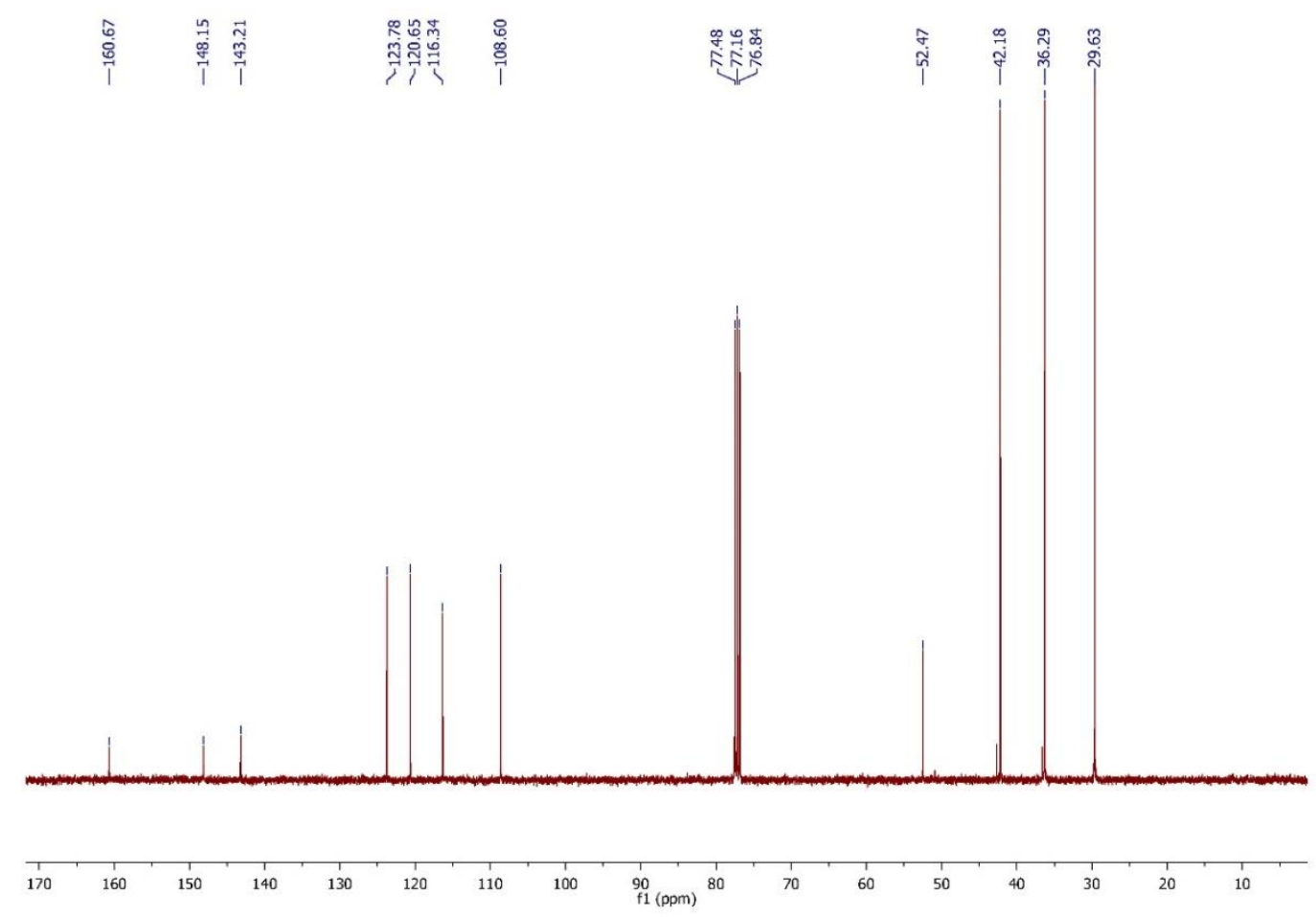

Figure A30. ${ }^{13} \mathrm{C}-\mathrm{NMR}$ spectrum of 2-(1-admantylamino)benzoxazole (3o) in $\mathrm{CDCl}_{3}$ at 100 MHz. 


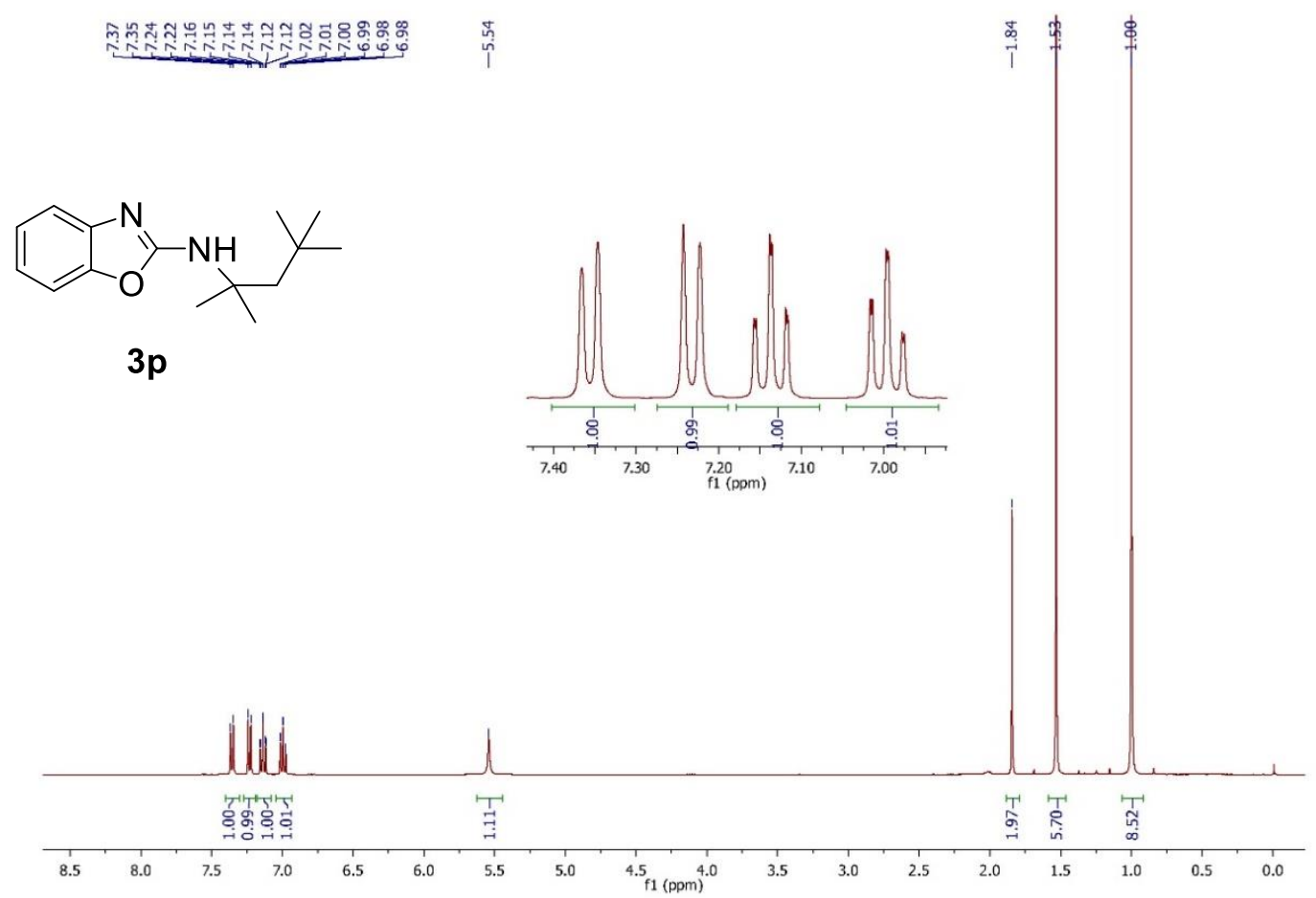

Figure A31. ${ }^{1} \mathrm{H}$ NMR spectrum of 2-(1,1,3,3-tetramethylbutylamino)benzoxazole (3p) in $\mathrm{CDCl}_{3}$ at $400 \mathrm{MHz}$.
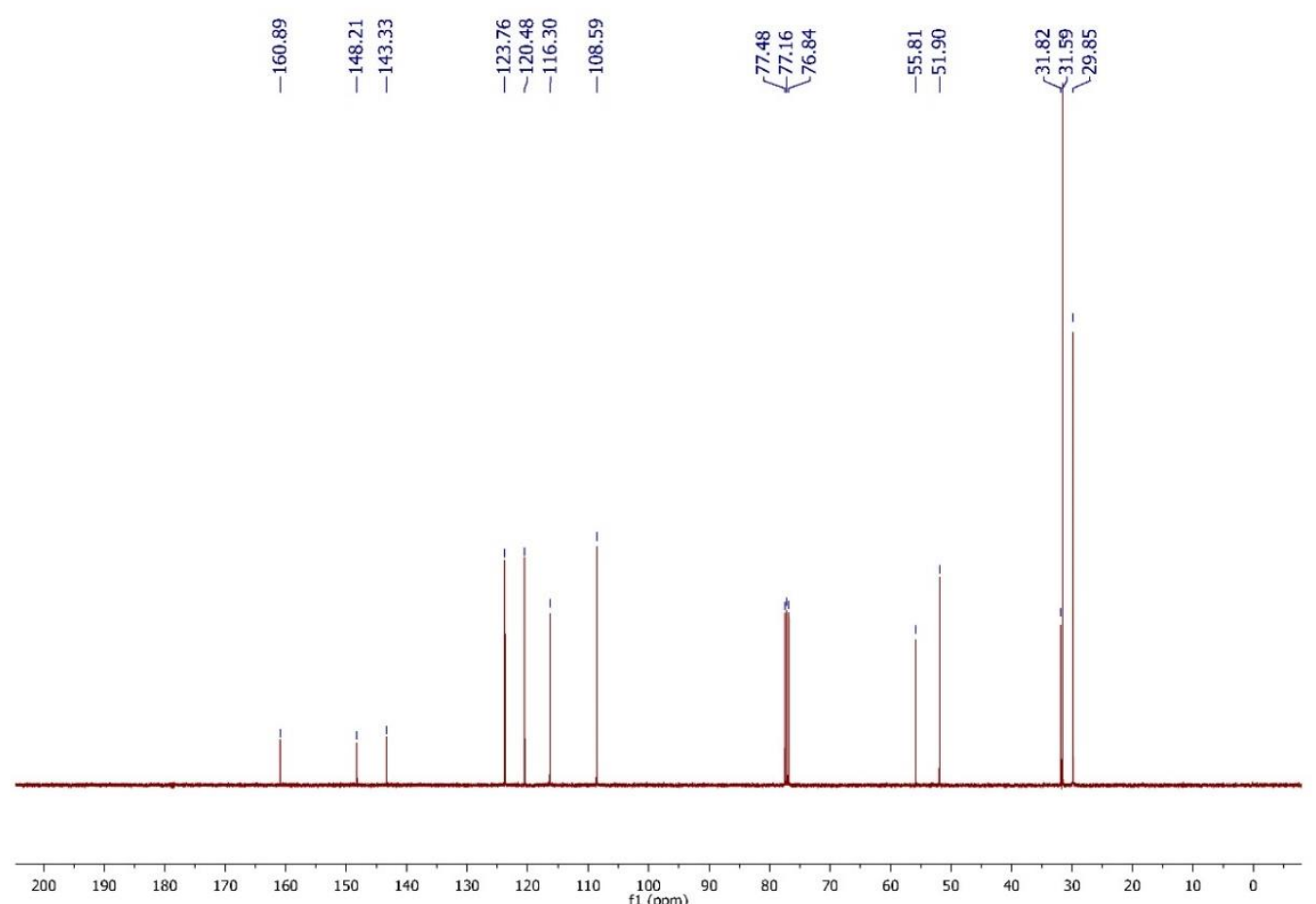

Figure A32. ${ }^{13} \mathrm{C}$ NMR spectrum of 2-(1,1,3,3-tetramethylbutylamino)benzoxazole (3p) in $\mathrm{CDCl}_{3}$ at $100 \mathrm{MHz}$. 

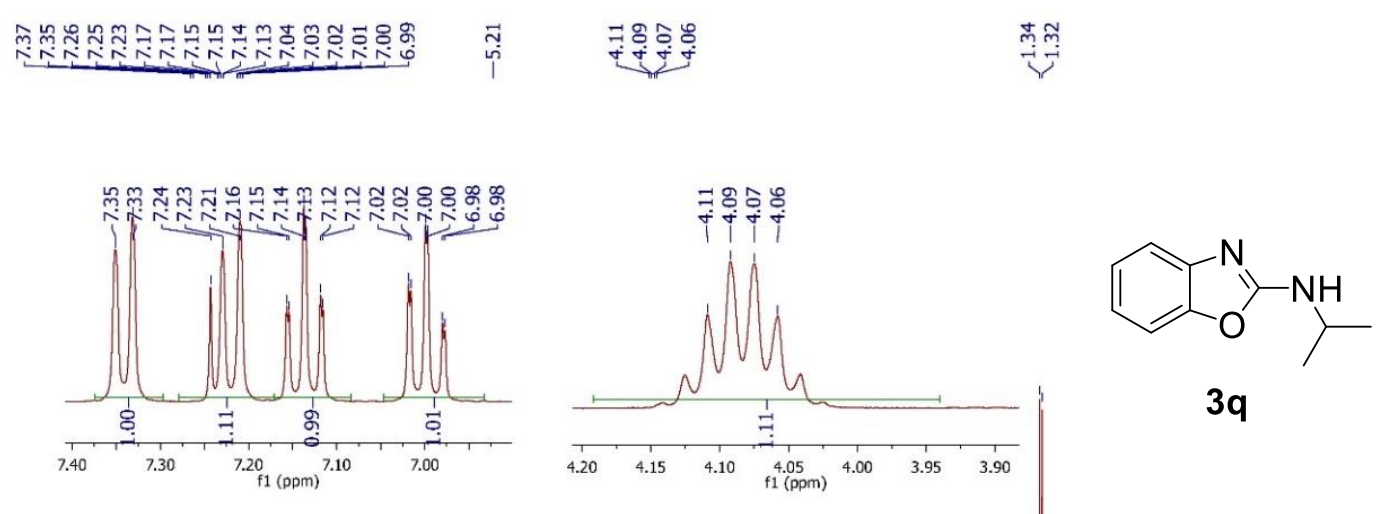

$3 q$

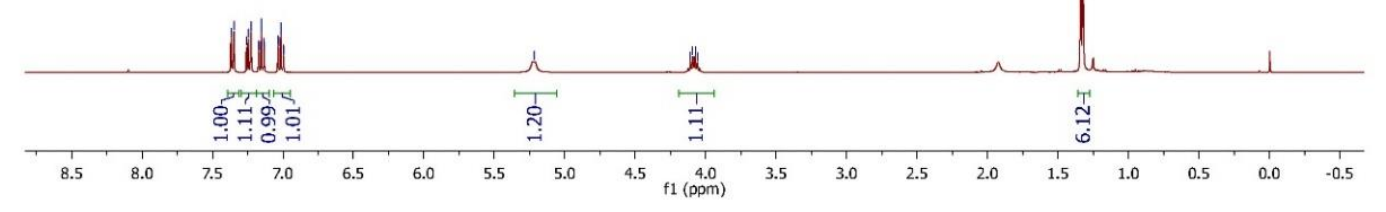

Figure A33. ${ }^{1} \mathrm{H}$ NMR spectrum of 2-(isopropylamino)benzoxazole (3q) in $\mathrm{CDCl}_{3}$ at $400 \mathrm{MHz}$.

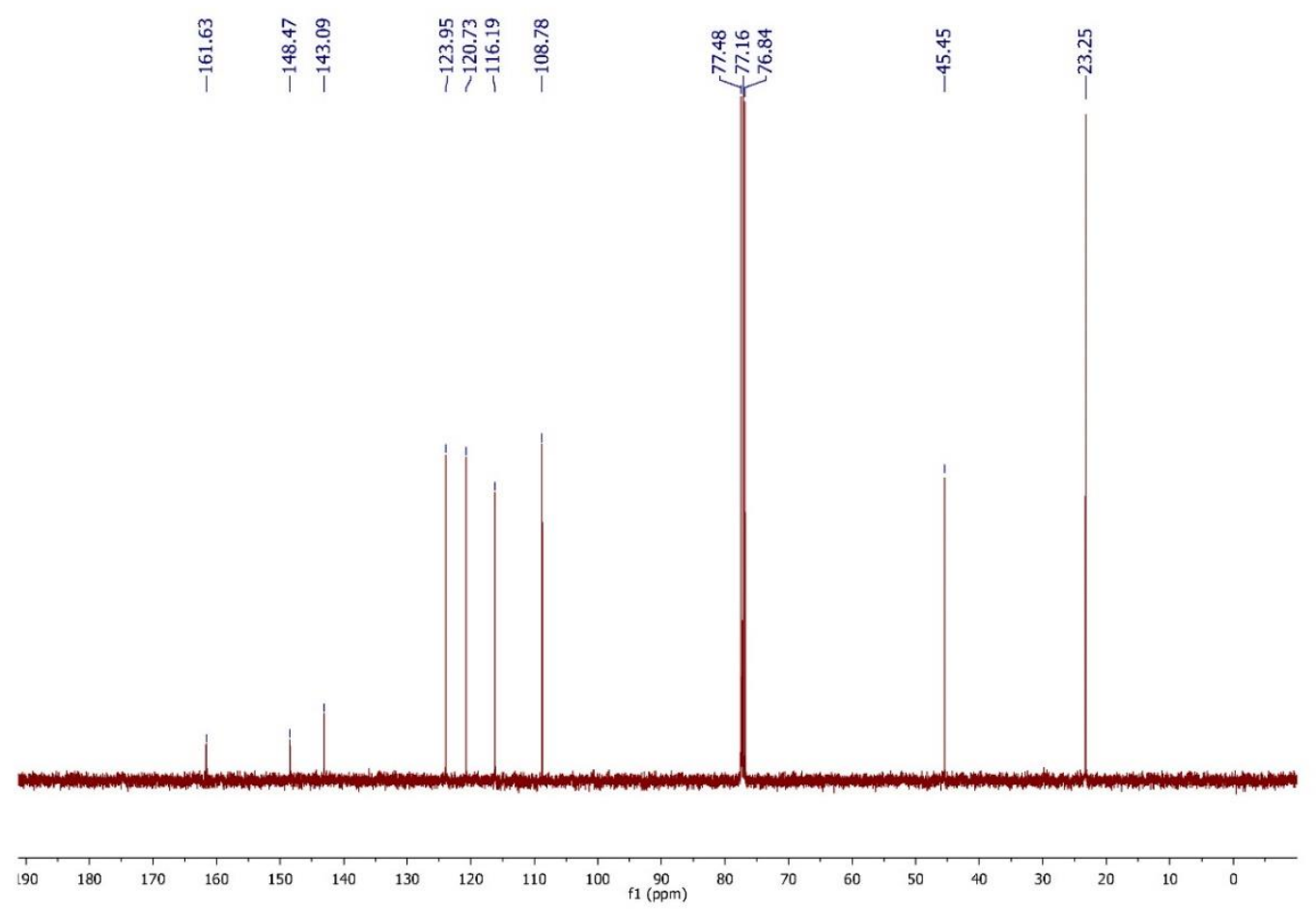

Figure A34. ${ }^{13} \mathrm{C}$ NMR spectrum of 2-(isopropylamino)benzoxazole (3q) in $\mathrm{CDCl}_{3}$ at $100 \mathrm{MHz}$. 


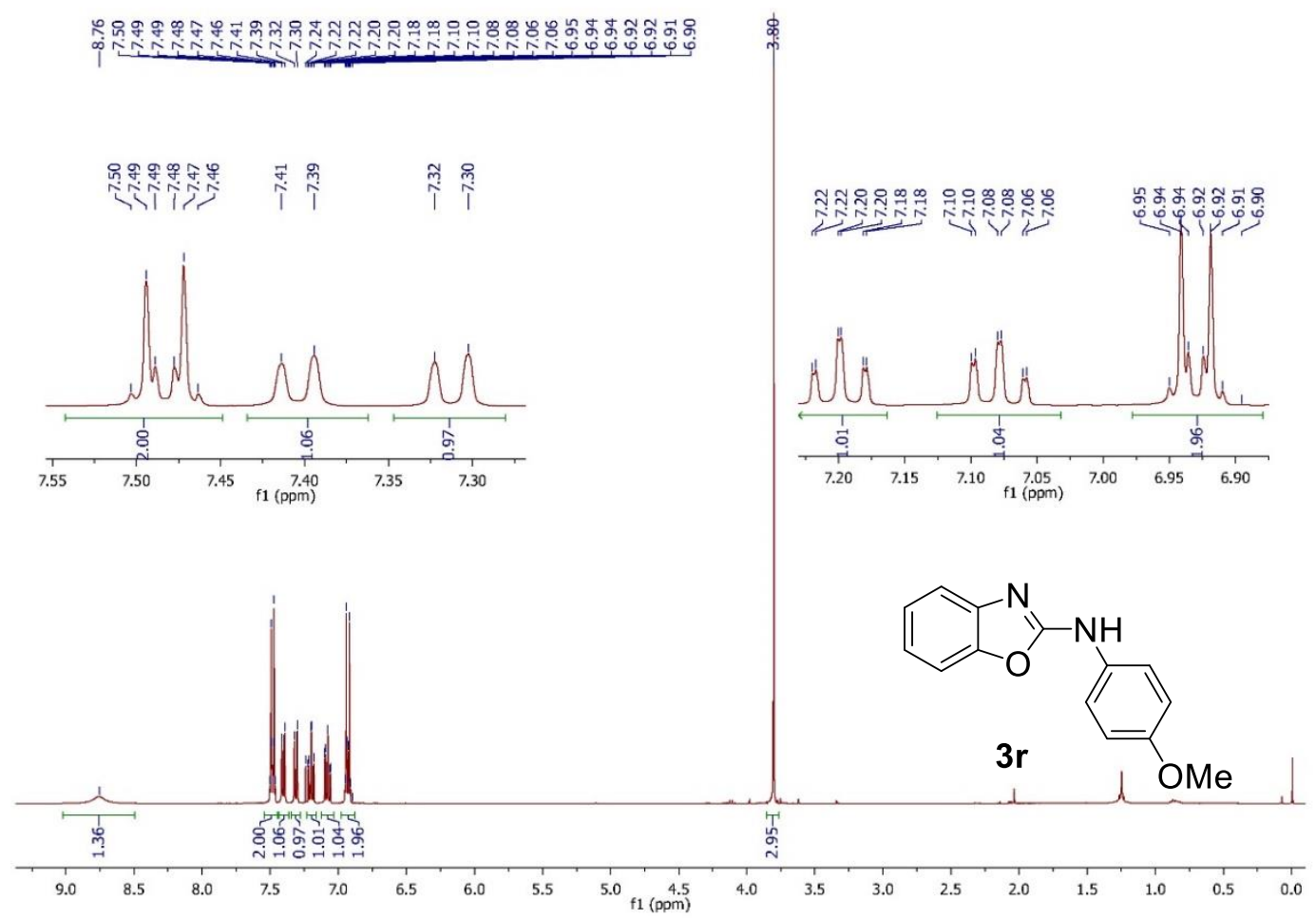

Figure A35. ${ }^{1} \mathrm{H}$ NMR spectrum of 2-(4-methoxyphenylamino)benzoxazole (3r) in $\mathrm{CDCl}_{3}$ at $400 \mathrm{MHz}$.

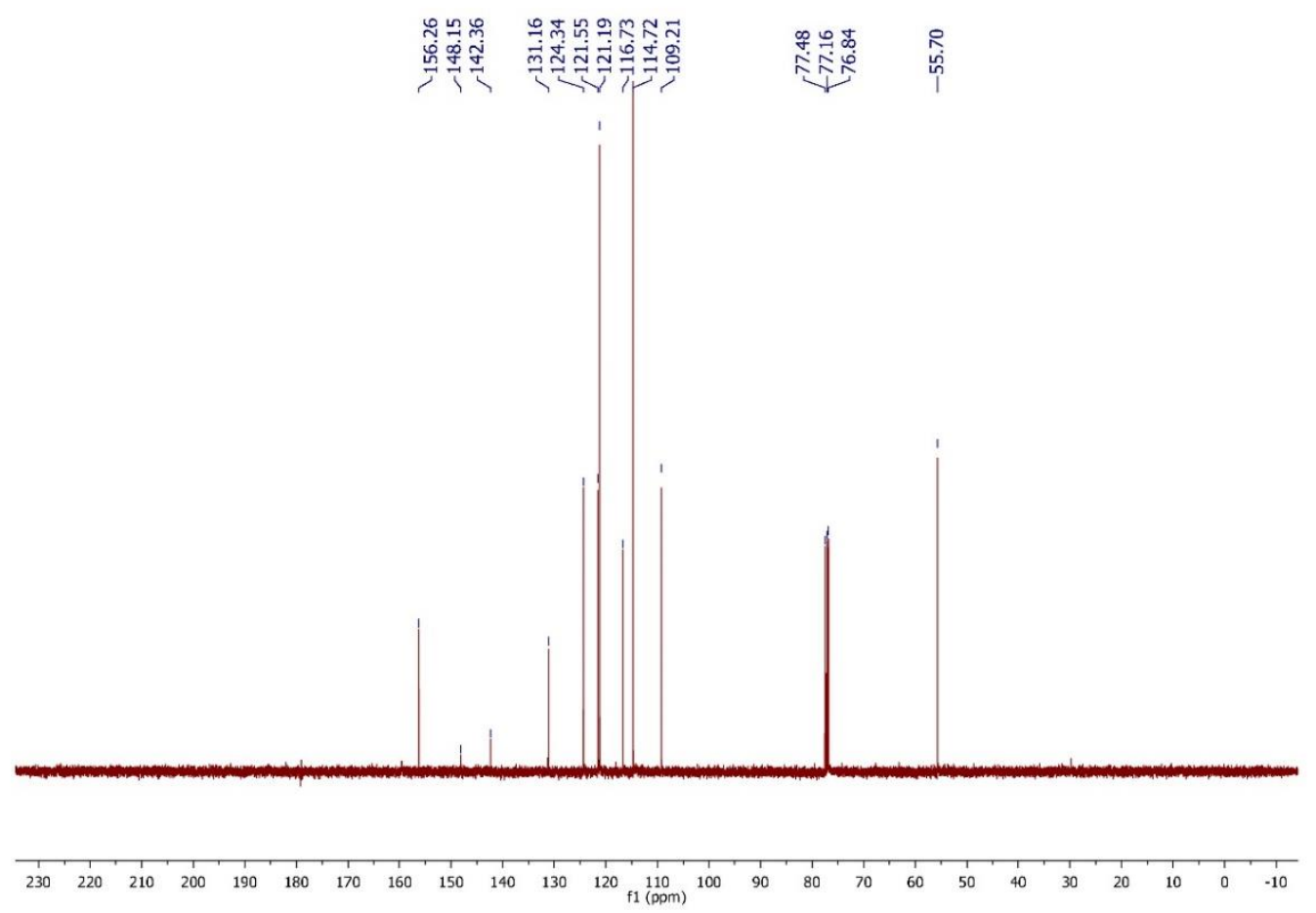

Figure A36. ${ }^{13} \mathrm{C}$ NMR spectrum of 2-(4-methoxyphenylamino)benzoxazole (3r) in $\mathrm{CDCl}_{3}$ at $100 \mathrm{MHz}$. 


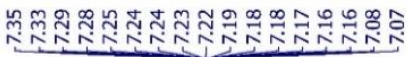

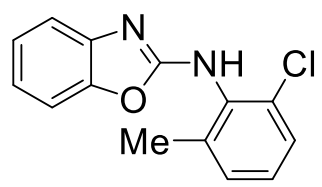

3s
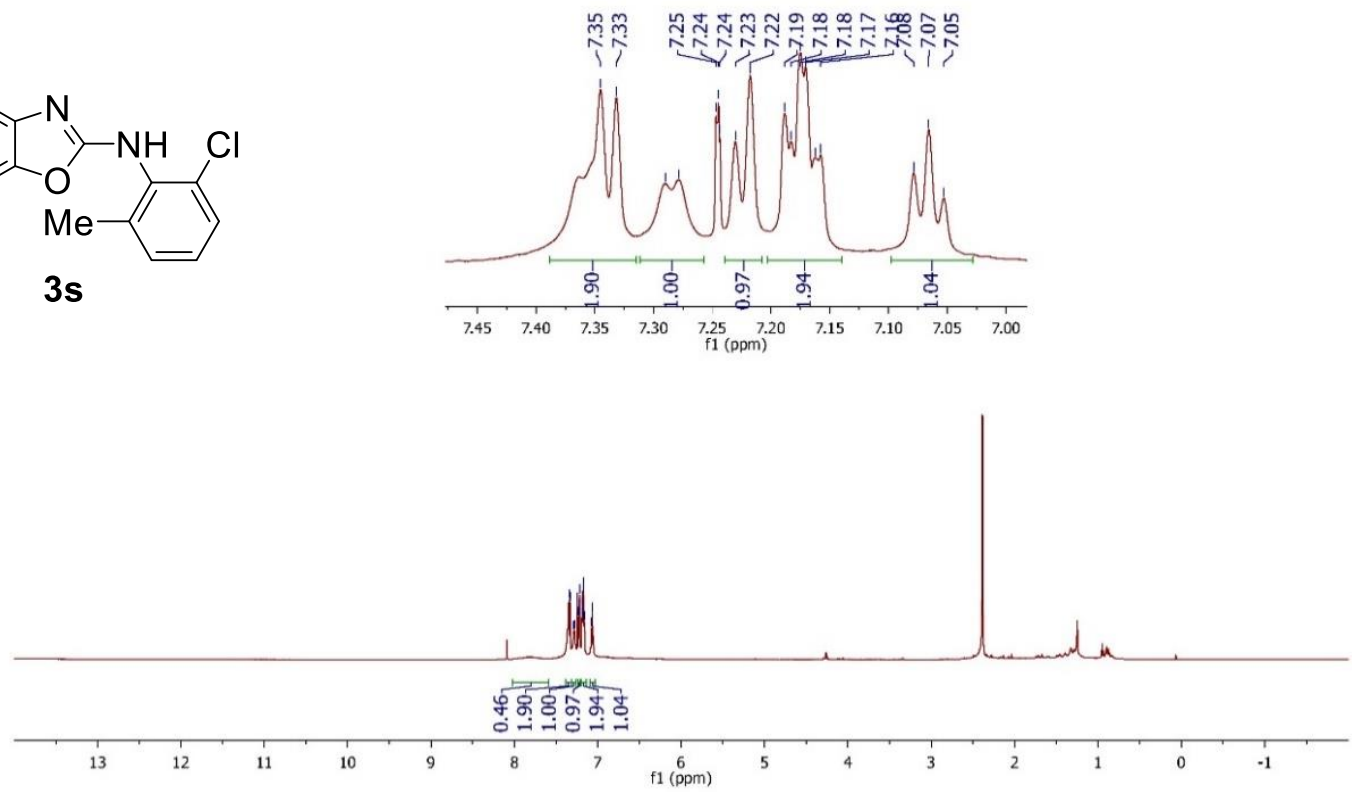

Figure A37. ${ }^{1} \mathrm{H}$ NMR spectrum of 2-(6-chloro-2-methylphenylamino)benzoxazole (3s) in $\mathrm{CDCl}_{3}$ at $400 \mathrm{MHz}$.
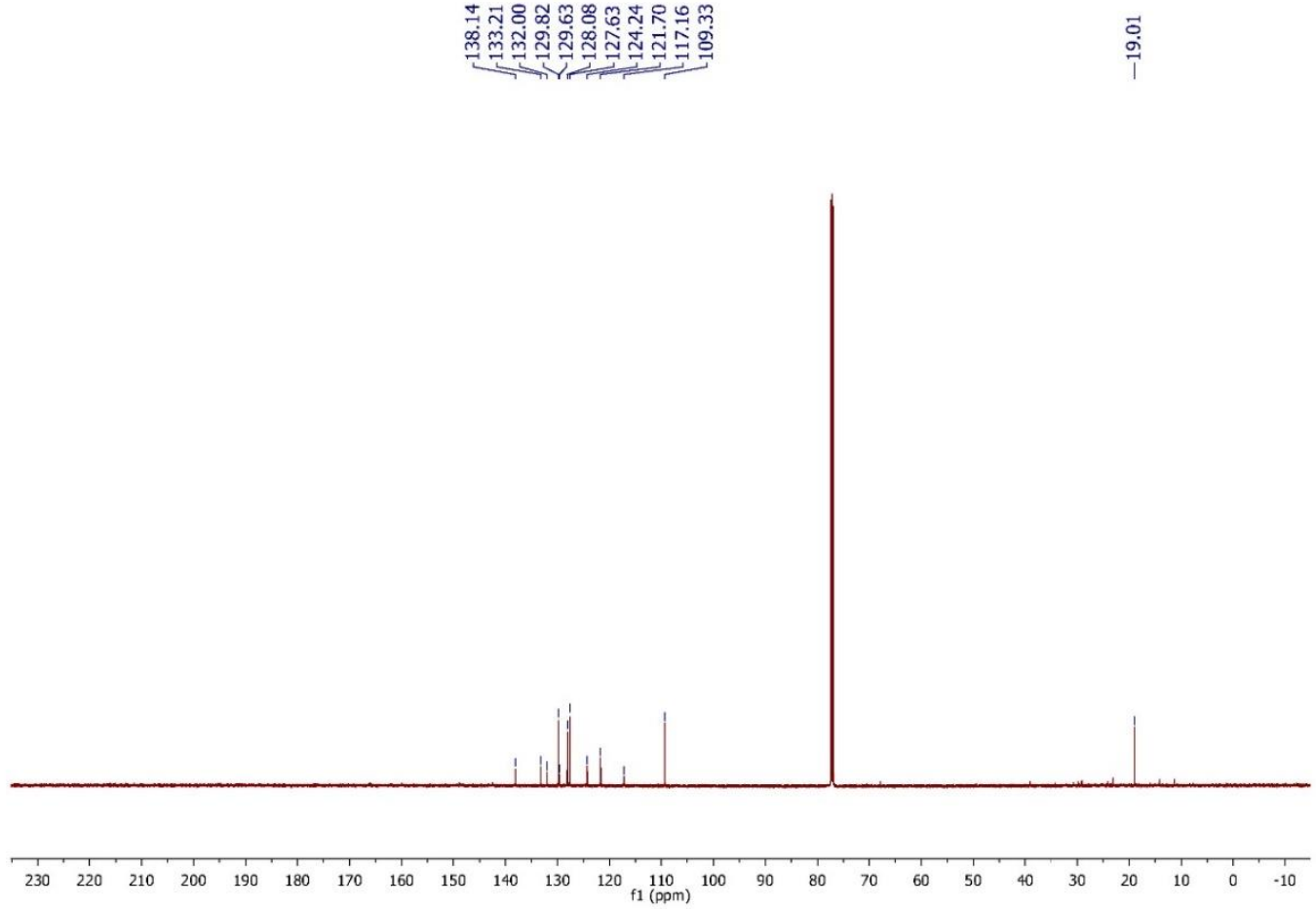

Figure A38. ${ }^{13} \mathrm{C}$ NMR spectrum of 2-(6-chloro-2-methylphenylamino)benzoxazole (3s) in $\mathrm{CDCl}_{3}$ at $100 \mathrm{MHz}$. 


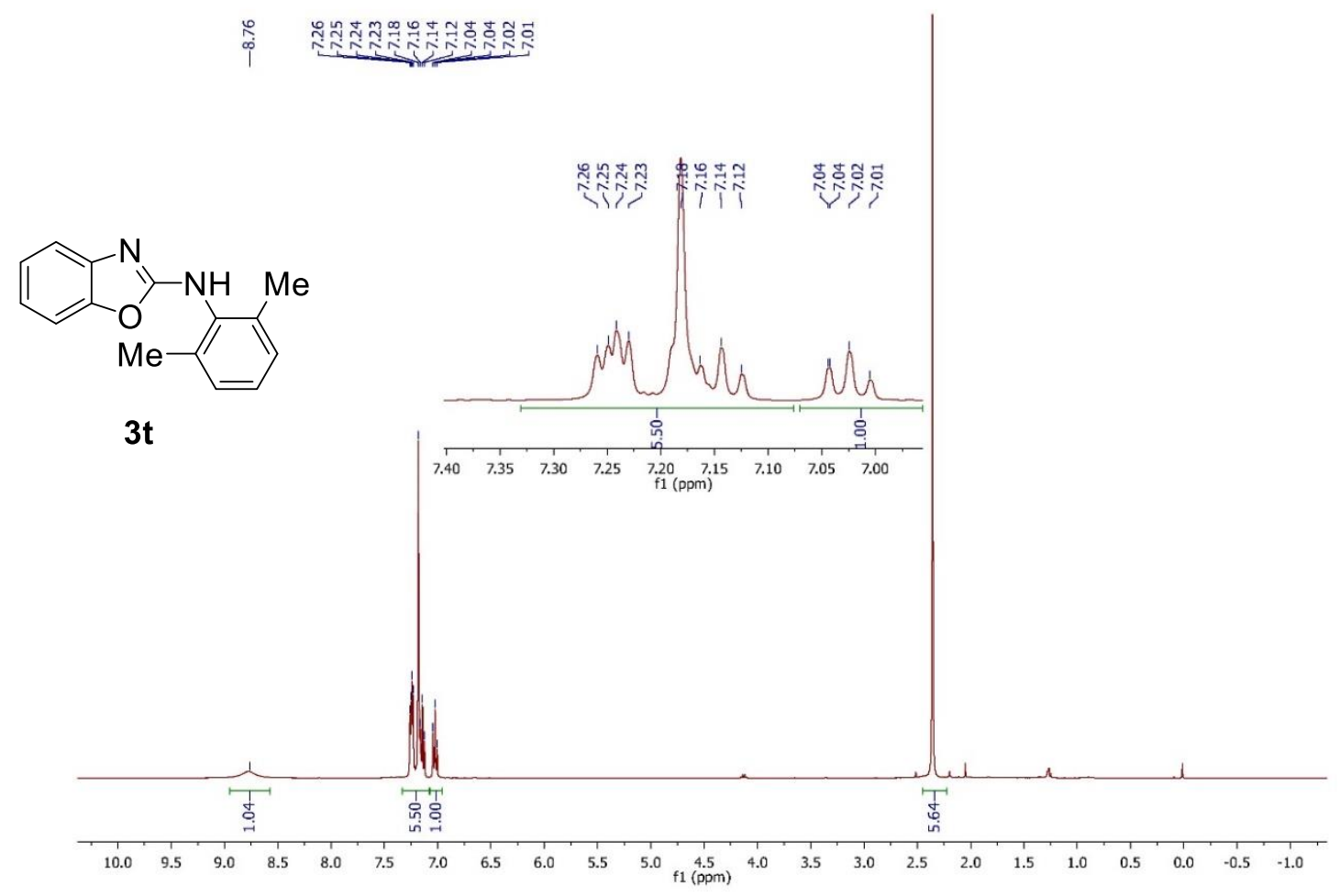

Figure A39. ${ }^{1} \mathrm{H}$ NMR spectrum of 2-(2,6-dimethylphenylamino)benzoxazole (3t) in $\mathrm{CDCl}_{3}$ at $400 \mathrm{MHz}$.
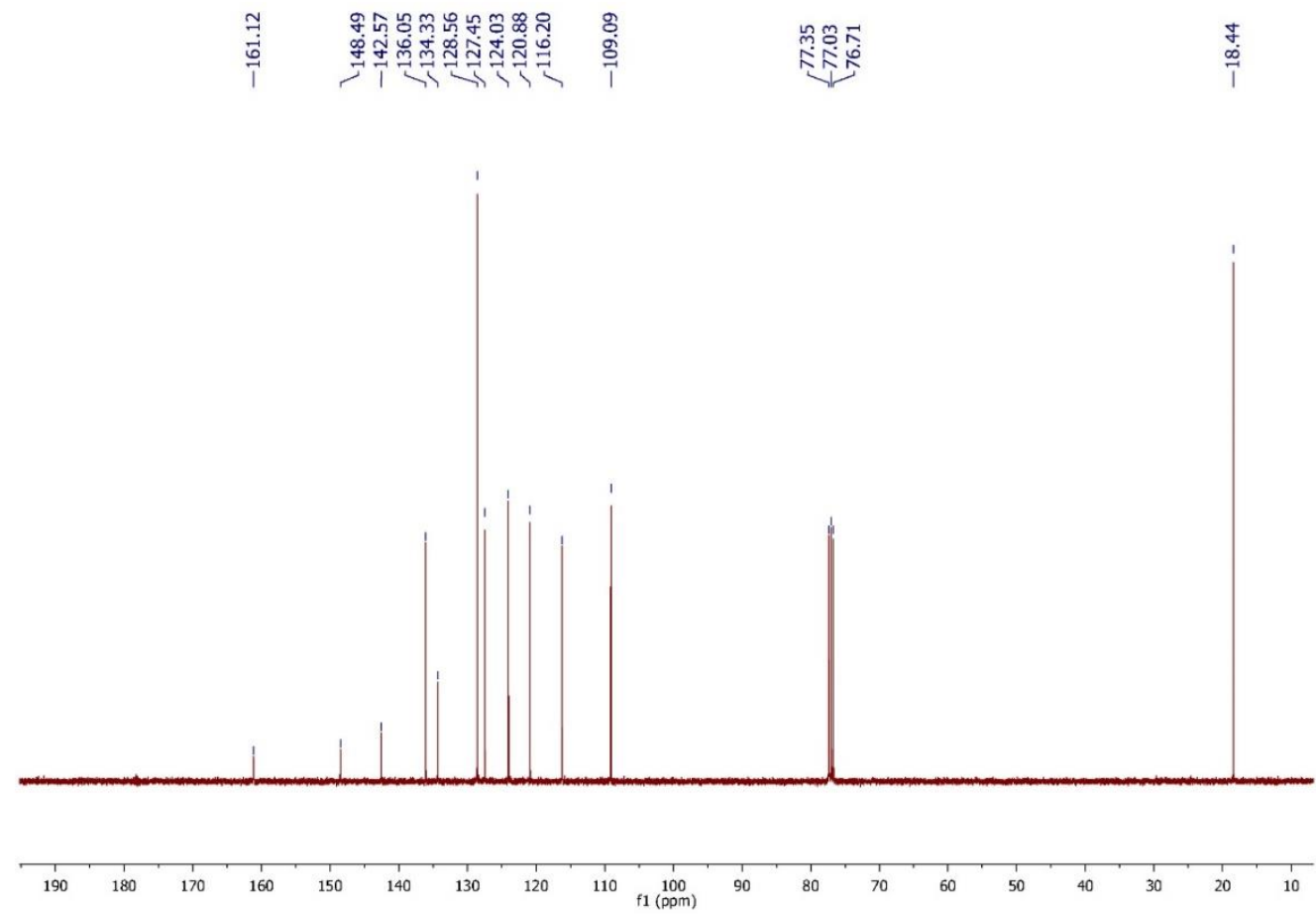

Figure A40. ${ }^{13} \mathrm{C}$ NMR spectrum of 2-(2,6-dimethylphenylamino)benzoxazole (3t) in $\mathrm{CDCl}_{3}$ at $100 \mathrm{MHz}$. 


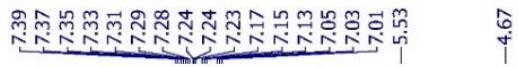
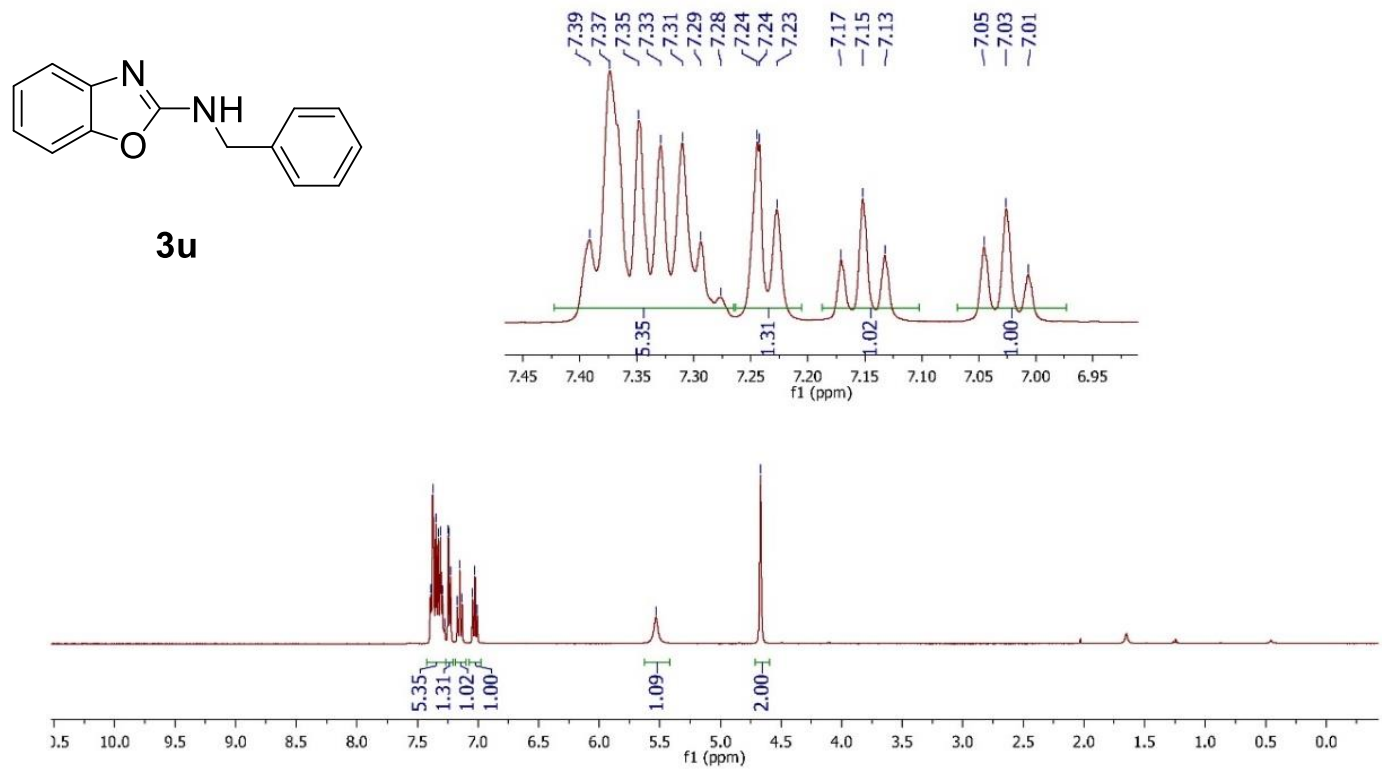

Figure A41. ${ }^{1} \mathrm{H}$ NMR spectrum of $N$-(phenylmethyl)-2-benzoxazolamine (3u) in $\mathrm{CDCl} 3$ at 400 MHz.

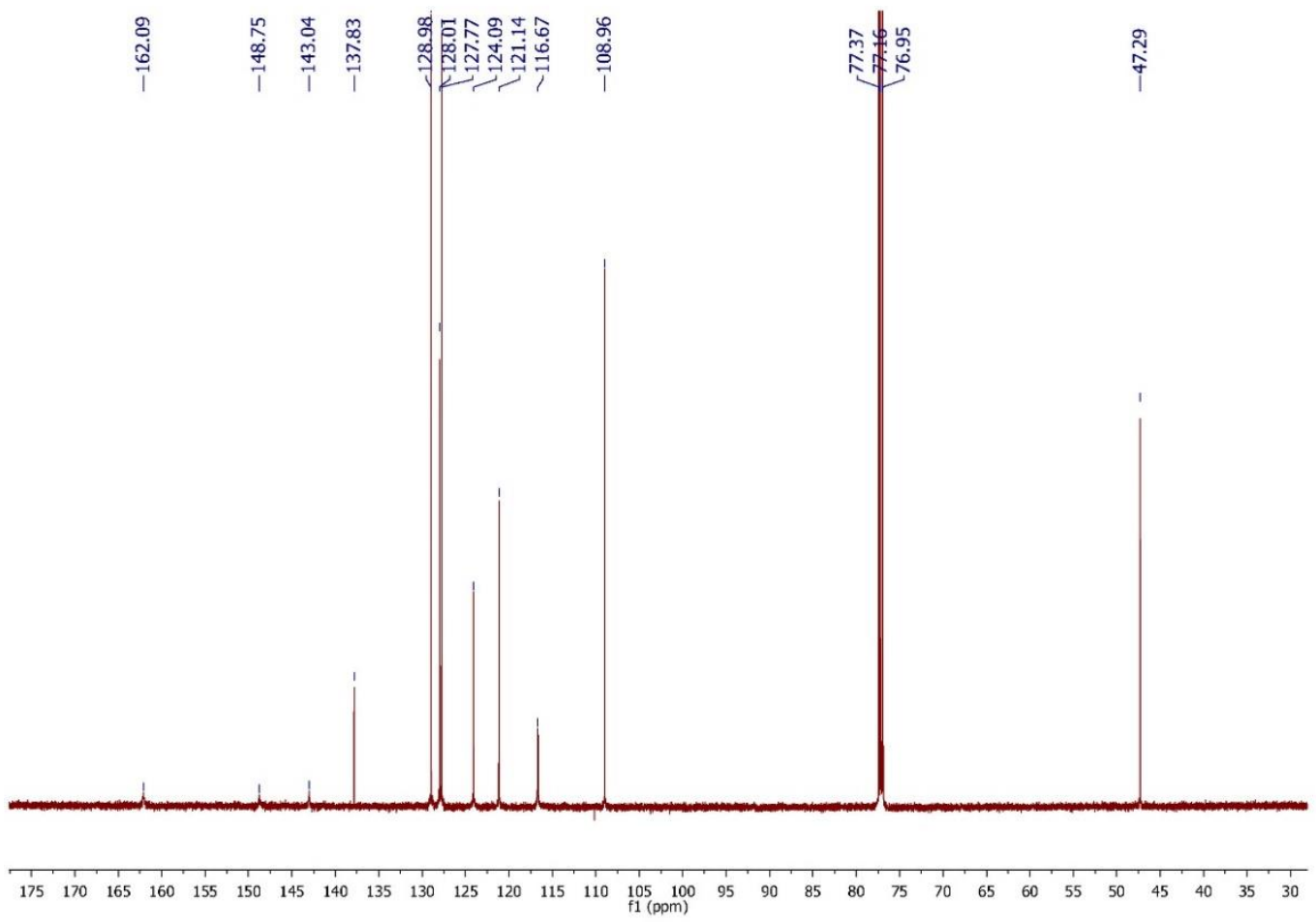

Figure A42. ${ }^{13} \mathrm{C}$ NMR spectrum of $N$-(phenylmethyl)-2-benzoxazolamine (3u) in $\mathrm{CDCl}_{3}$ at $100 \mathrm{MHz}$. 


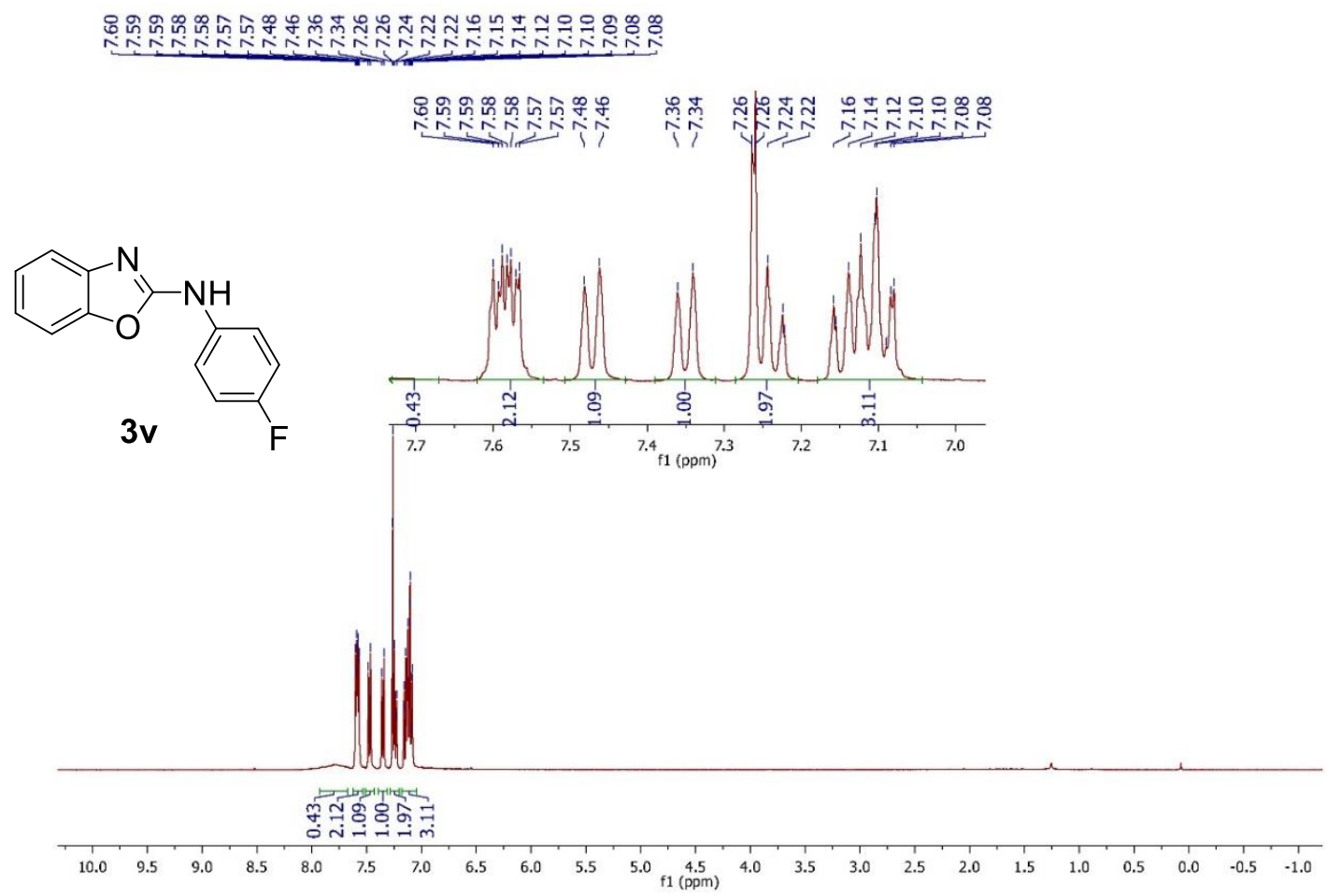

Figure A43. ${ }^{1} \mathrm{H}$ NMR spectrum of 2-(4-fluorophenylamino)benzoxazole (3v) in $\mathrm{CDCl}_{3}$ at 400 MHz.

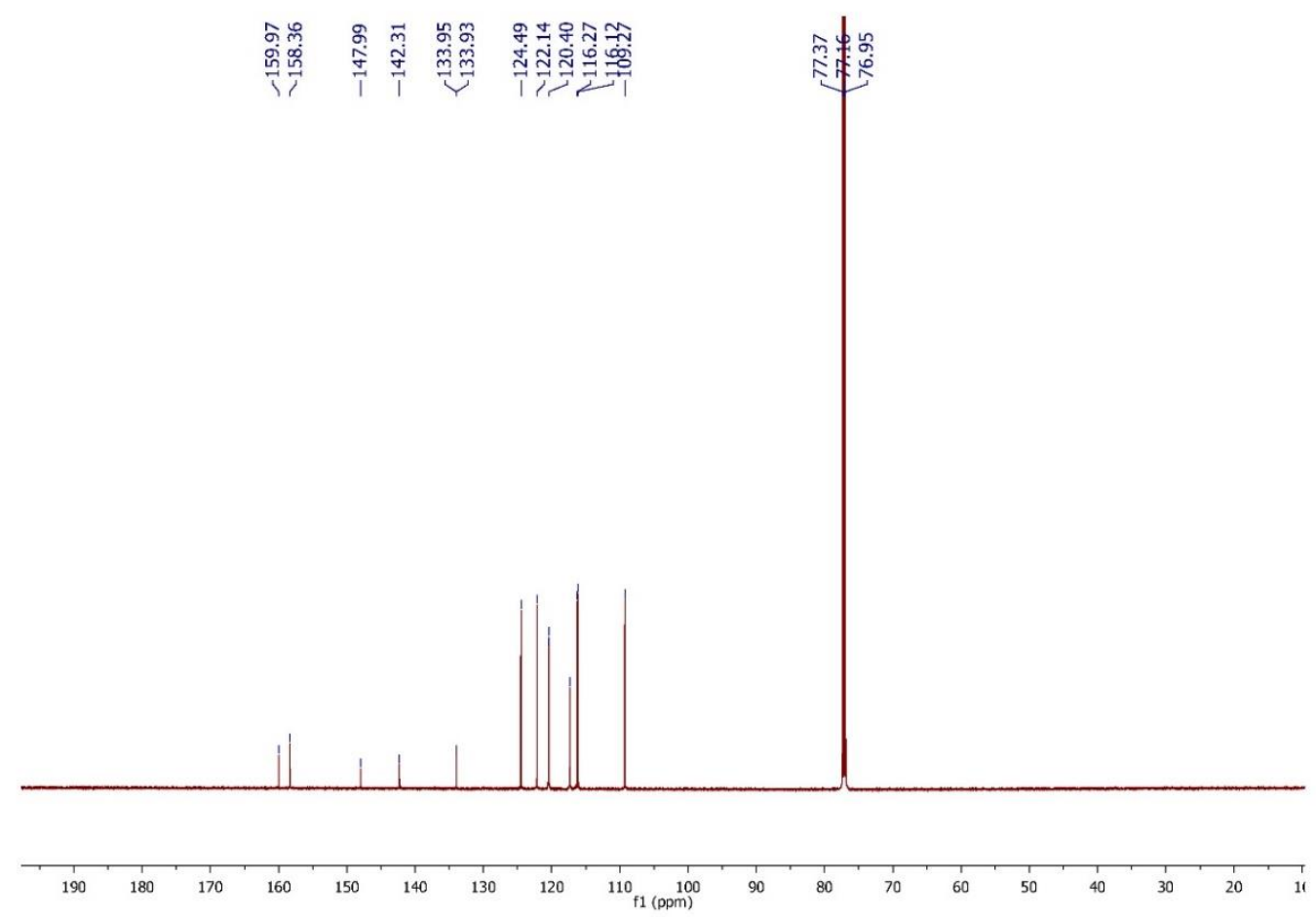

Figure A44. ${ }^{13} \mathrm{C}$ NMR spectrum of 2-(4-fluorophenylamino)benzoxazole (3v) in $\mathrm{CDCl}_{3}$ at $100 \mathrm{MHz}$. 


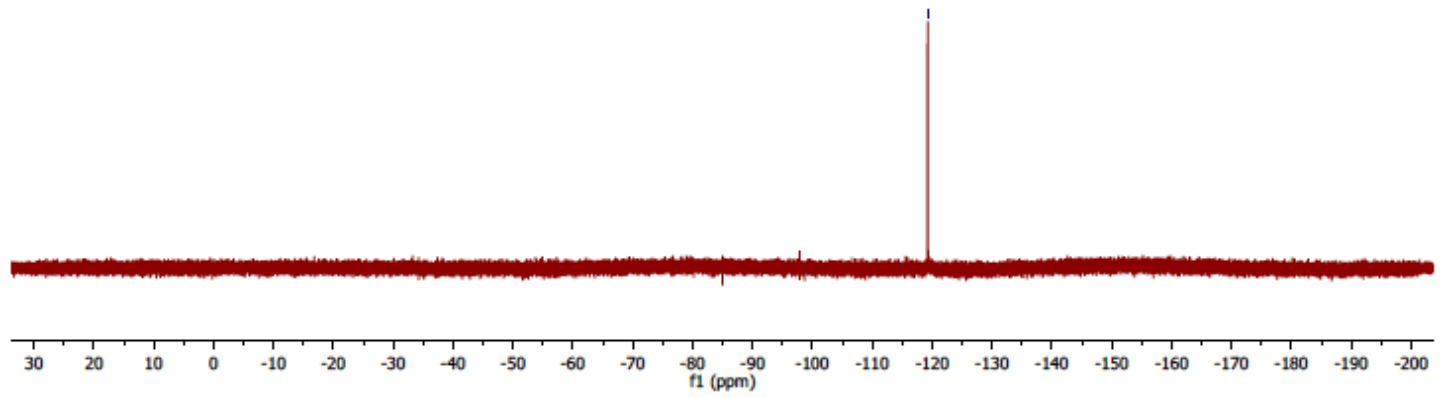

Figure A45. ${ }^{19} \mathrm{~F}$ NMR spectrum of 2-(4-fluorophenylamino)benzoxazole (3v) in $\mathrm{CDCl}_{3}$ at 376 MHz. 


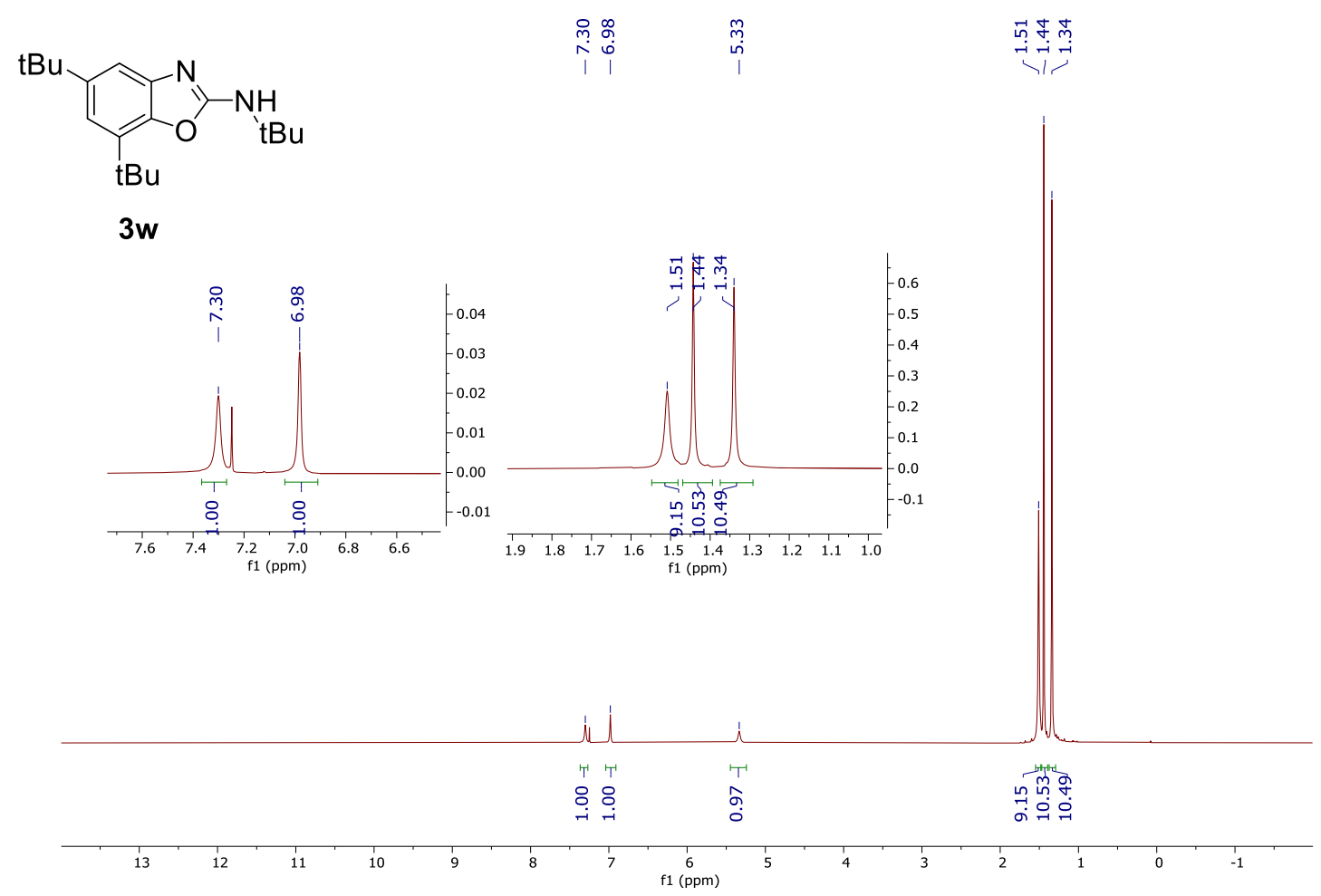

Figure A46. ${ }^{1} \mathrm{H}$ NMR spectrum of 5,7-di-tertbutyl -2-(tert-butylamino)benzoxazole (3w) in $\mathrm{CDCl}_{3}$ at $400 \mathrm{MHz}$.

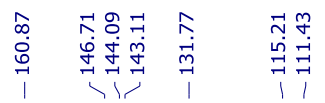

$\underset{1}{\stackrel{m}{m}}$
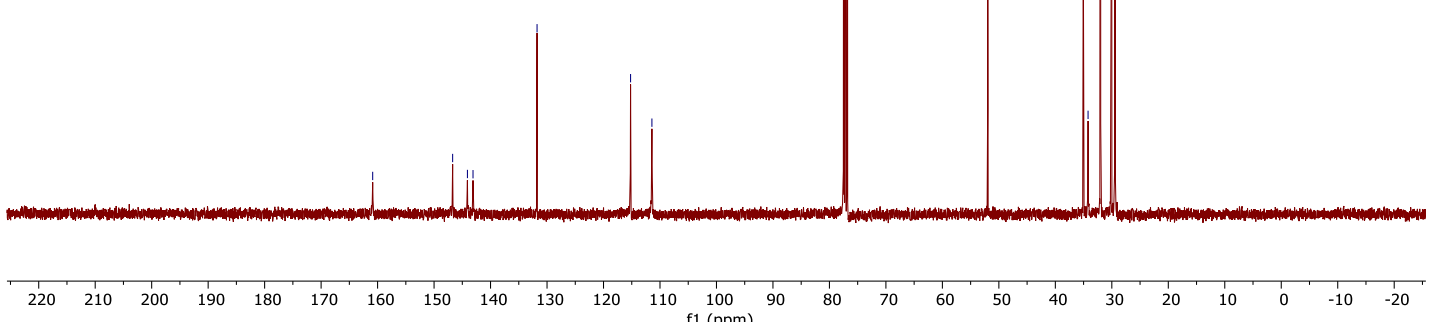

Figure A47. ${ }^{13} \mathrm{C}$ NMR spectrum of 5,7-di-tertbutyl -2-(tert-butylamino)benzoxazole (3w) in $\mathrm{CDCl}_{3}$ at $400 \mathrm{MHz}$. 
${ }^{1} \mathrm{H}$ and ${ }^{13} \mathrm{C}$ NMR Spectra of 2-Aminobenzimidazoles

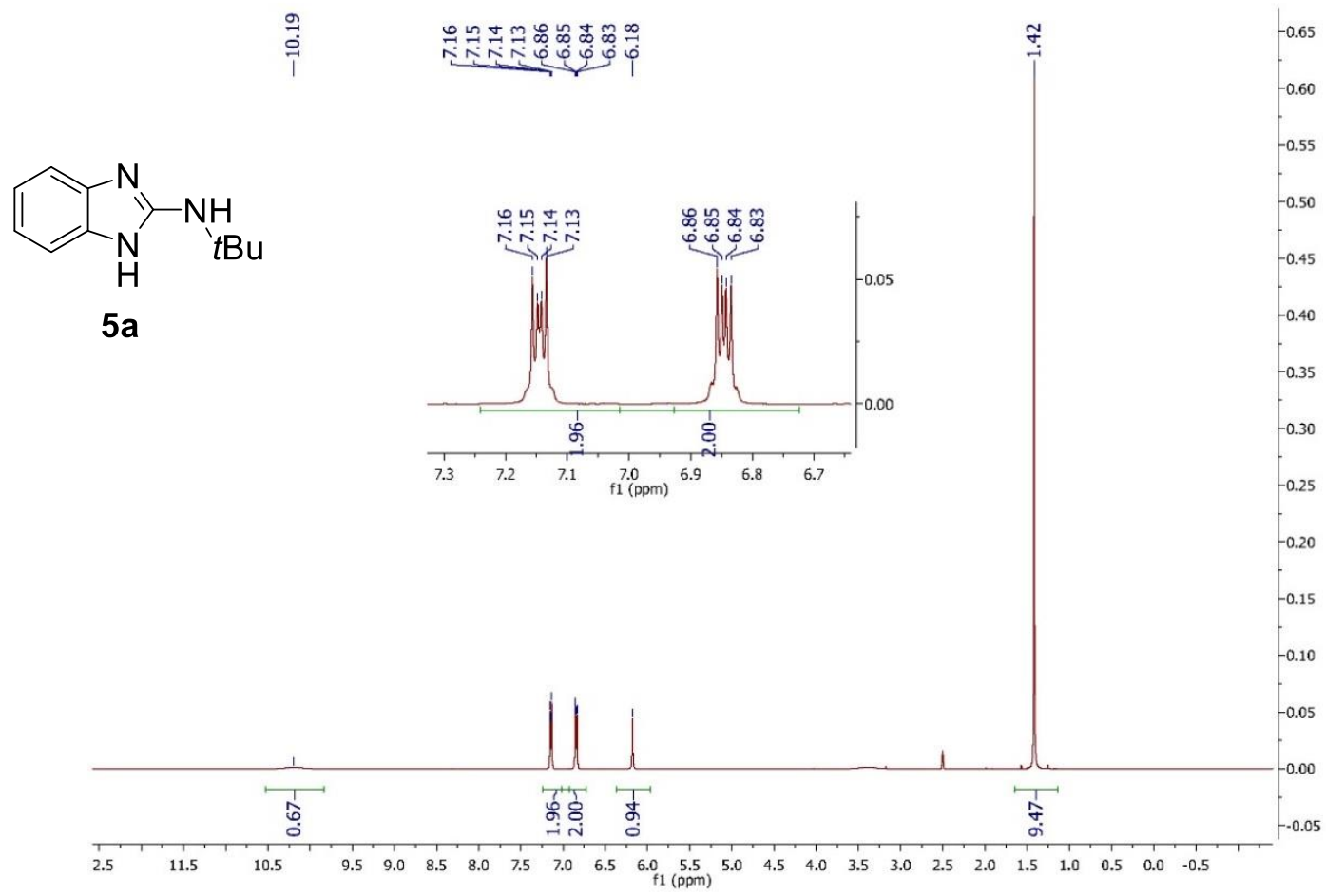

Figure A48. ${ }^{1} \mathrm{H}$ NMR spectrum of 2-(tert-butylamino)benzimidazole (5a) in DMSO-d6 at 400 MHz.

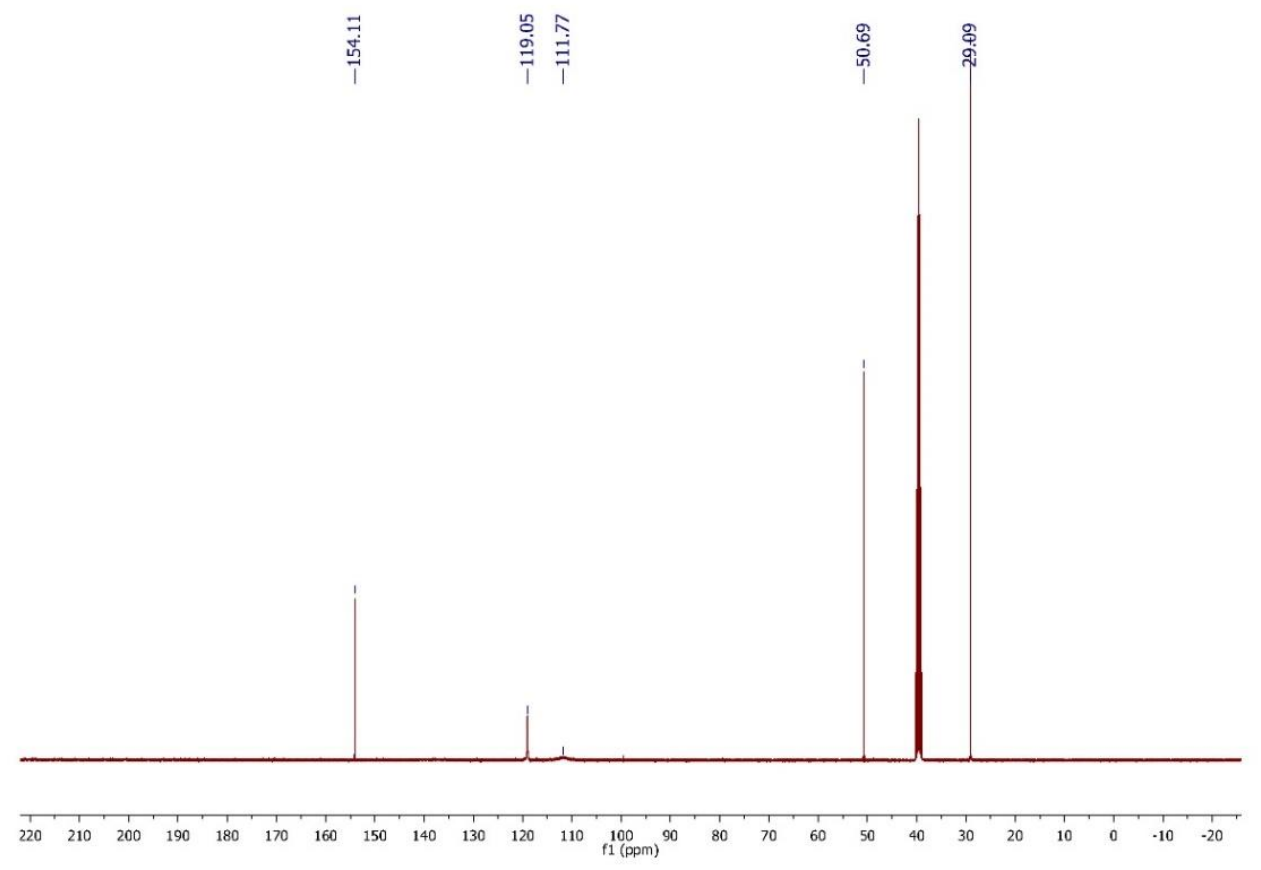

Figure A49. ${ }^{13} \mathrm{C}$ NMR spectrum of 2-(tert-butylamino)benzimidazole (5a) in DMSO-d6 at 100 MHz. 


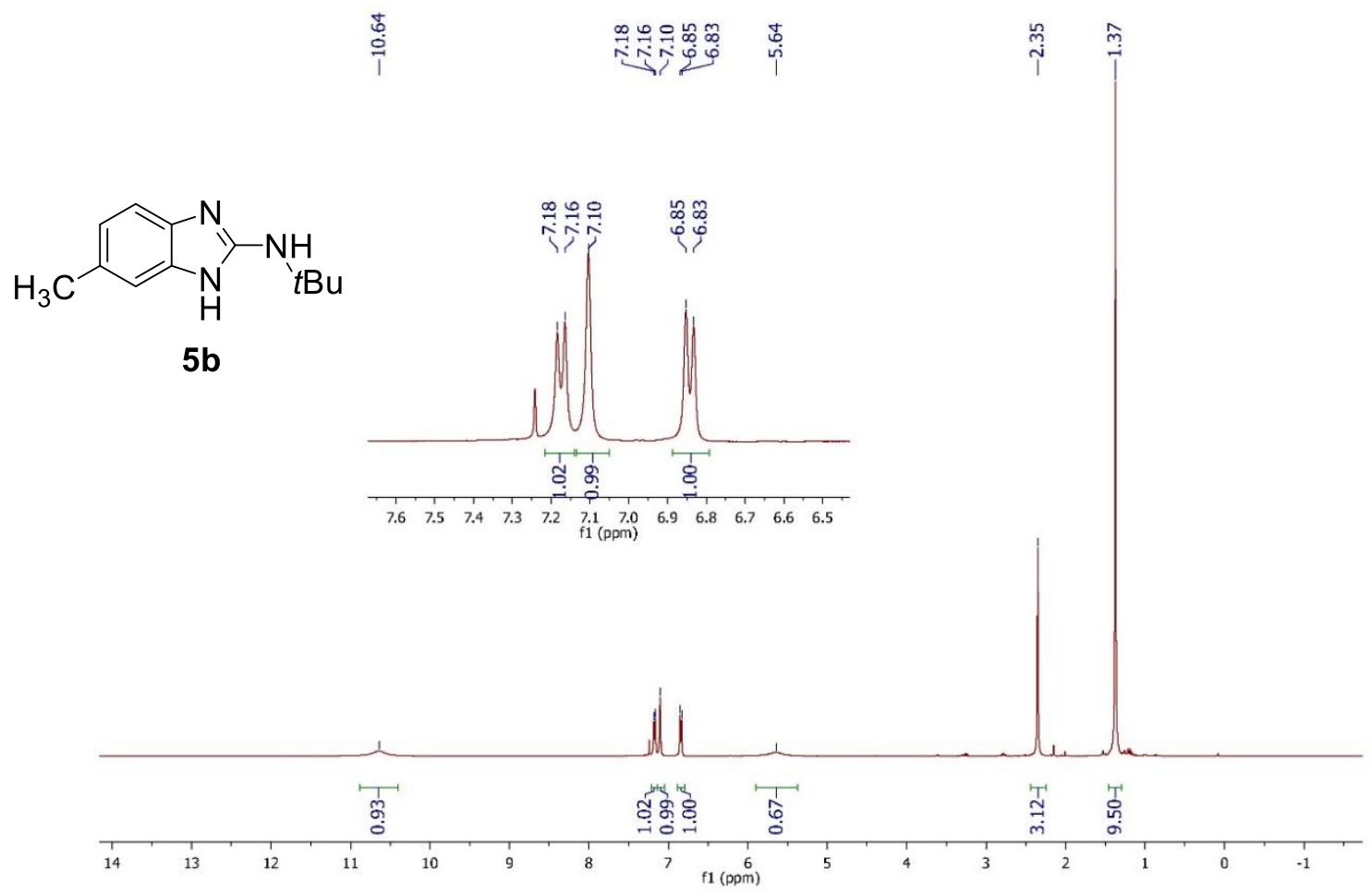

Figure A50. ${ }^{1} \mathrm{H}$ NMR spectrum of 2-(tert-butylamino)-5-methylbenzimidazole (5b) in $\mathrm{CDCl}_{3}$ at $400 \mathrm{MHz}$.

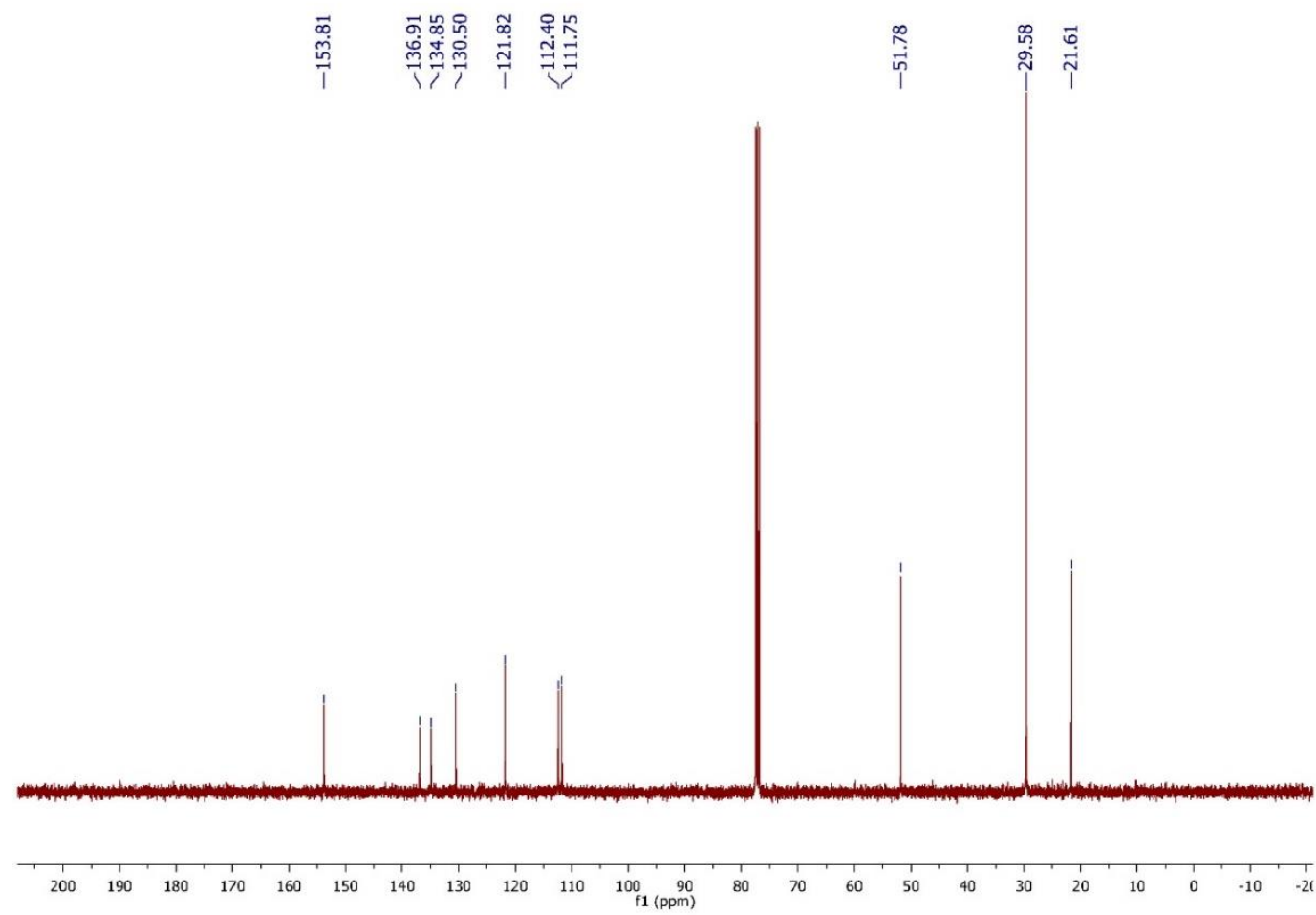

Figure A51. ${ }^{13} \mathrm{C}$ NMR spectrum of 2-(tert-butylamino) benzimidazole (5b) in $\mathrm{CDCl}_{3}$ at 100 MHz. 


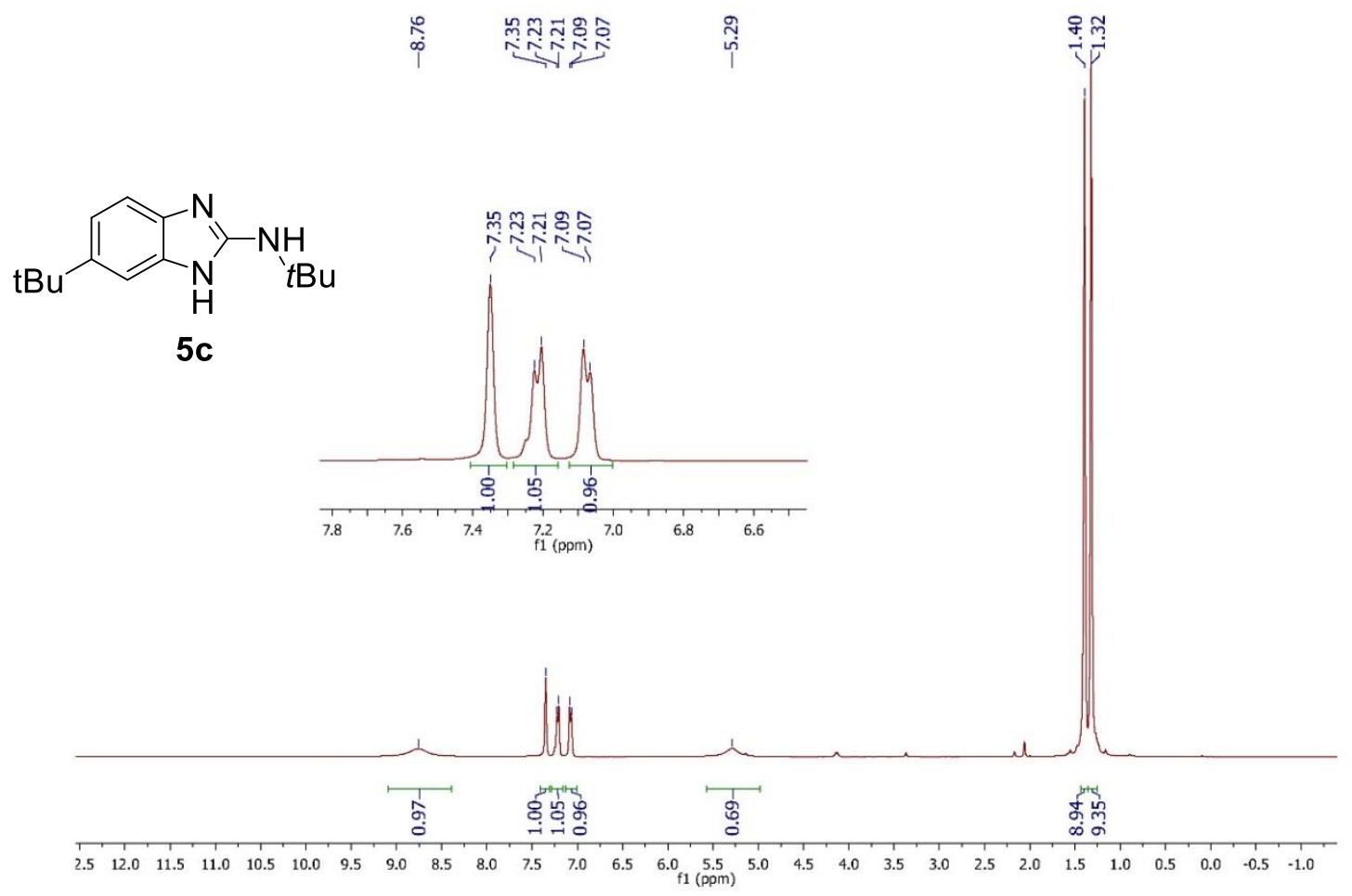

Figure A52. ${ }^{1} \mathrm{H}$ NMR spectrum of 2-(tert-butylamino)-5-tert-butylbenzimidazole (5c) in $\mathrm{CDCl}_{3}$ at $400 \mathrm{MHz}$.

\begin{tabular}{|c|c|c|c|}
\hline 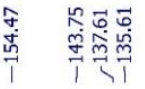 & 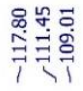 & 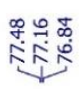 & in \\
\hline
\end{tabular}
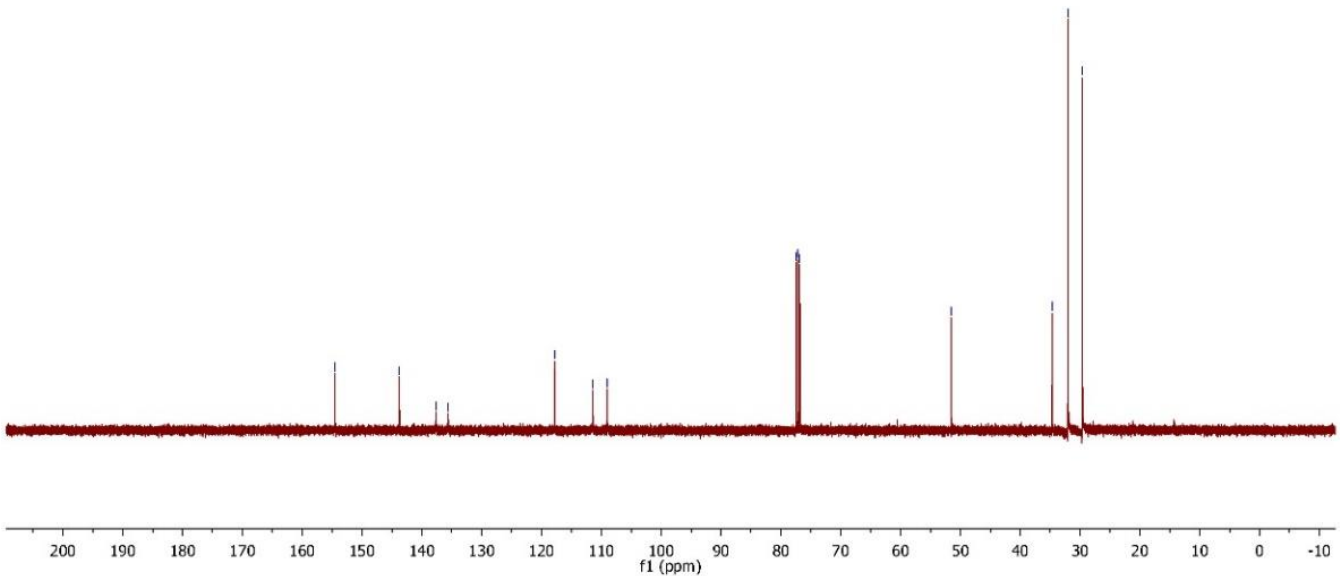

Figure A53. ${ }^{13} \mathrm{C}$ NMR spectrum of 2-(tert-butylamino)-5-tert-butylbenzimidazole (5c) in $\mathrm{CDCl}_{3}$ at $100 \mathrm{MHz}$. 


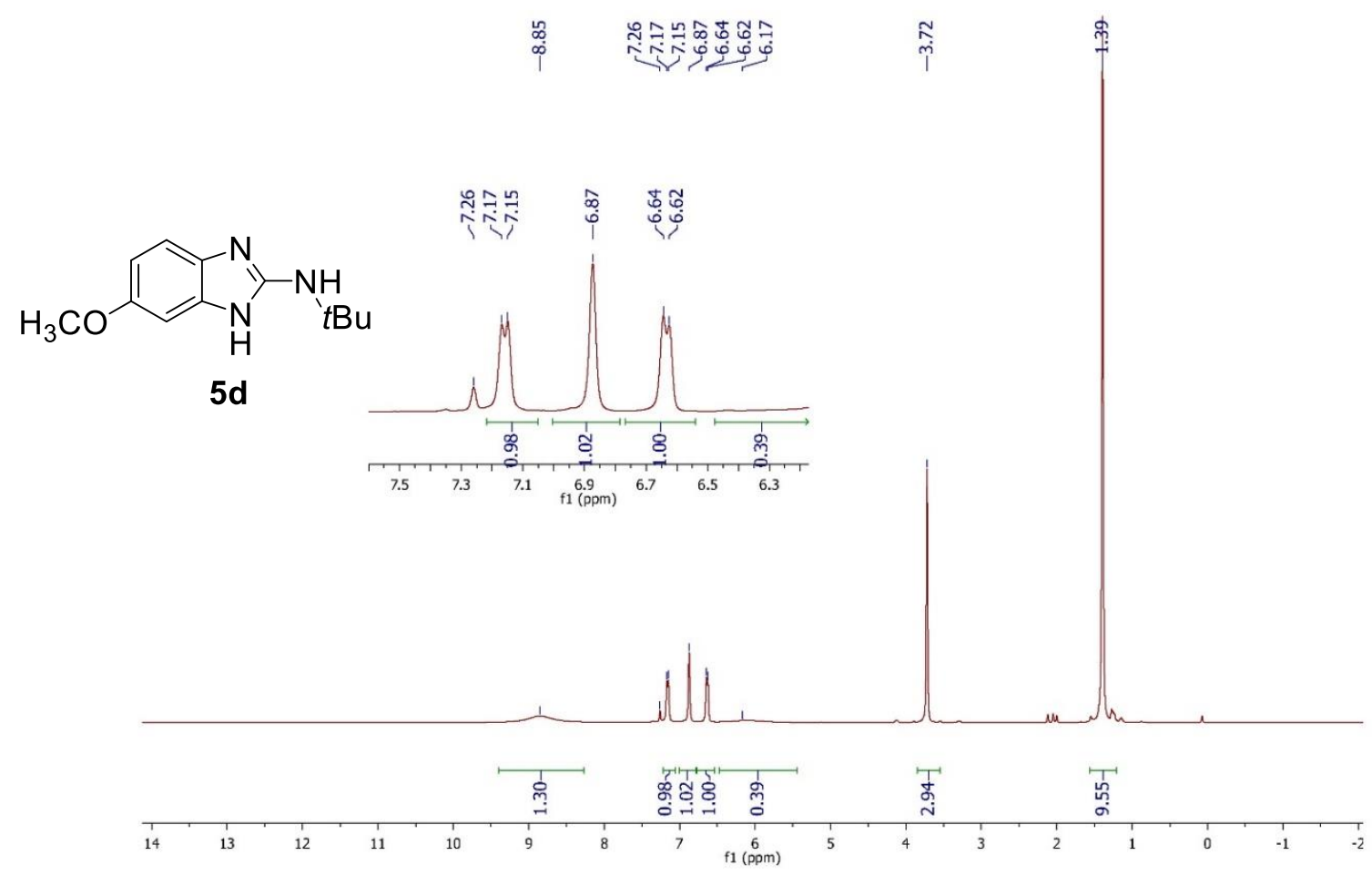

Figure A54. ${ }^{1} \mathrm{H}$ NMR spectrum of 2-(tert-butylamino)-5-methoxybutylbenzimidazole (5d) in CDCl3 at $400 \mathrm{MHz}$.

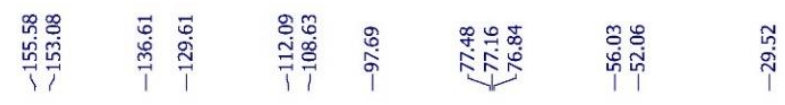
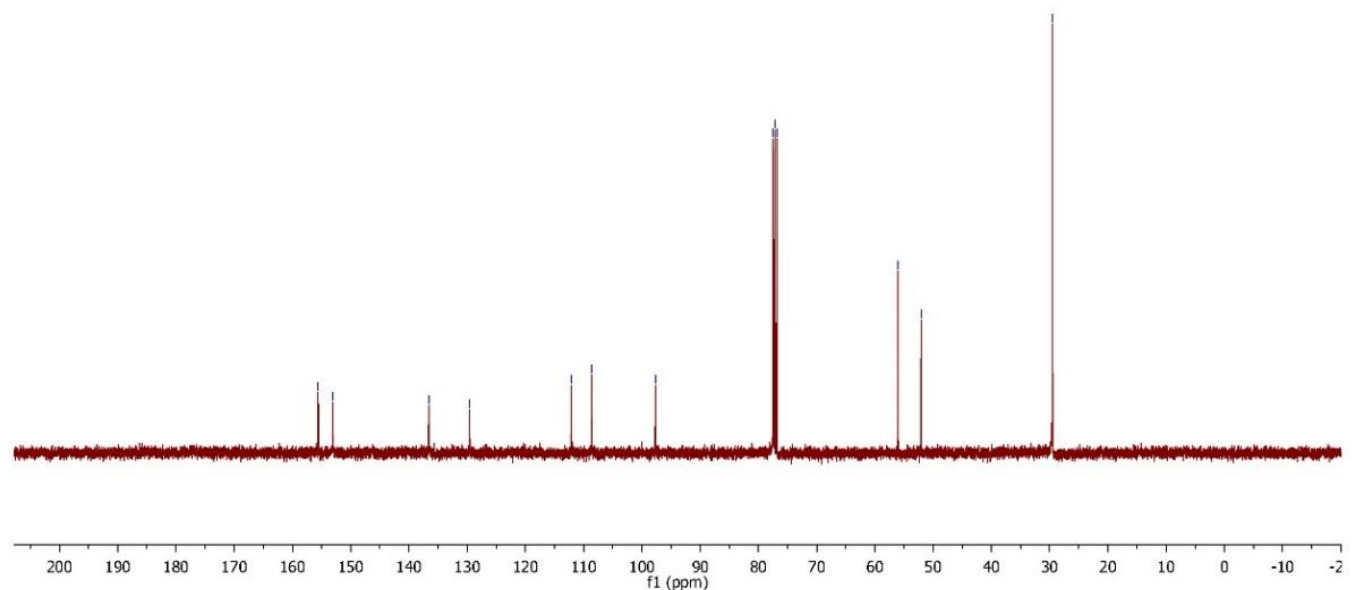

Figure A55. ${ }^{13} \mathrm{C}$ NMR spectrum of 2-(tert-butylamino)-5-methoxybenzimidazole (5d) in $\mathrm{CDCl} 3$ at $100 \mathrm{MHz}$. 


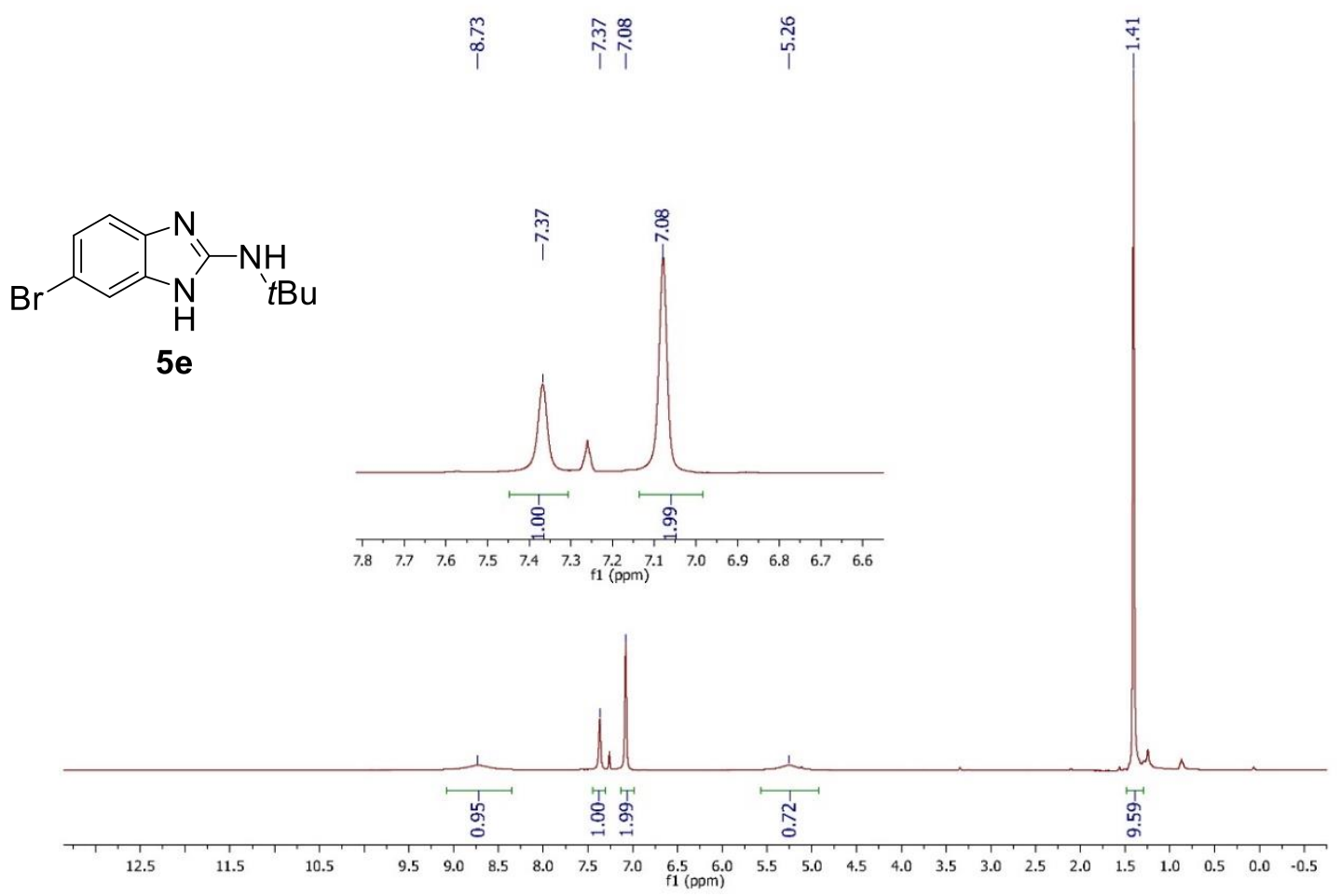

Figure A56. ${ }^{1} \mathrm{H}$ NMR spectrum of 2-(tert-butylamino)-5-bromobenzimidazole (5e) in CDCl3 at $400 \mathrm{MHz}$.
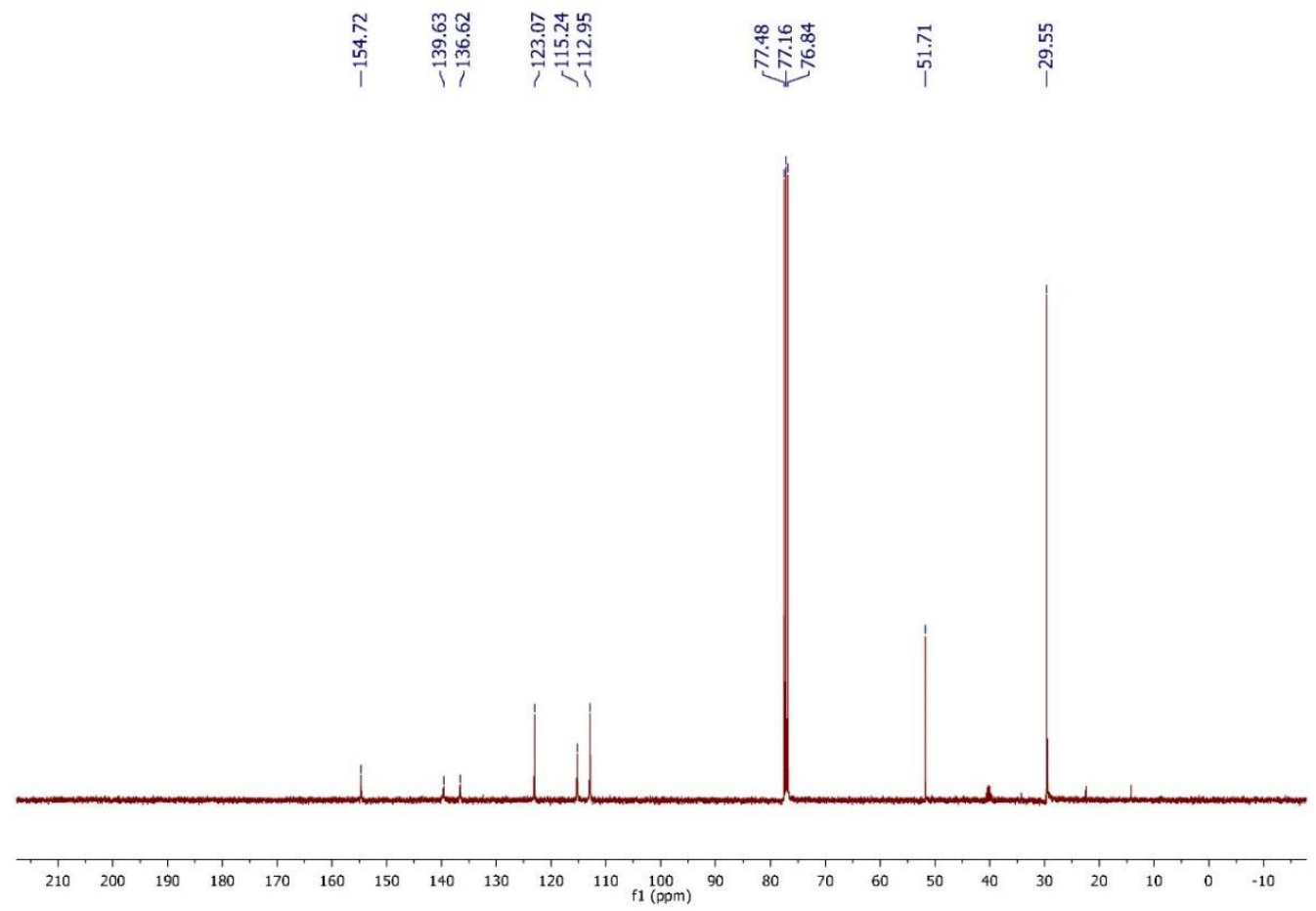

Figure A57. ${ }^{13} \mathrm{C}$ NMR spectrum of 2-(tert-butylamino)-5-bromobenzimidazole (5e) in CDCl3 at $100 \mathrm{MHz}$. 


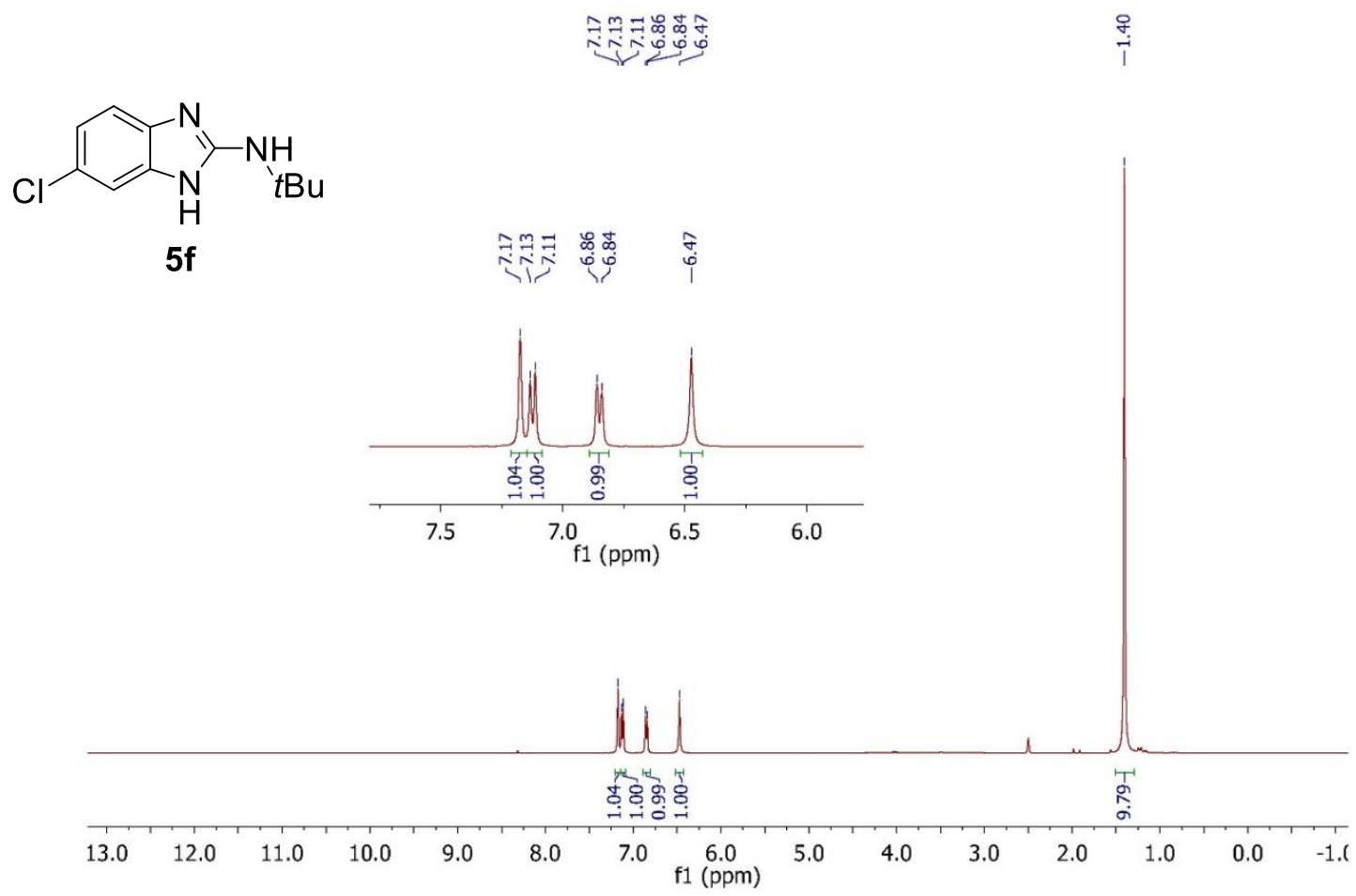

Figure A58. ${ }^{1} \mathrm{H}$ NMR spectrum of 2-(tert-butylamino)-5-chlorobenzimidazole (5f) in DMSO- $d_{6}$ at 400 MHz.

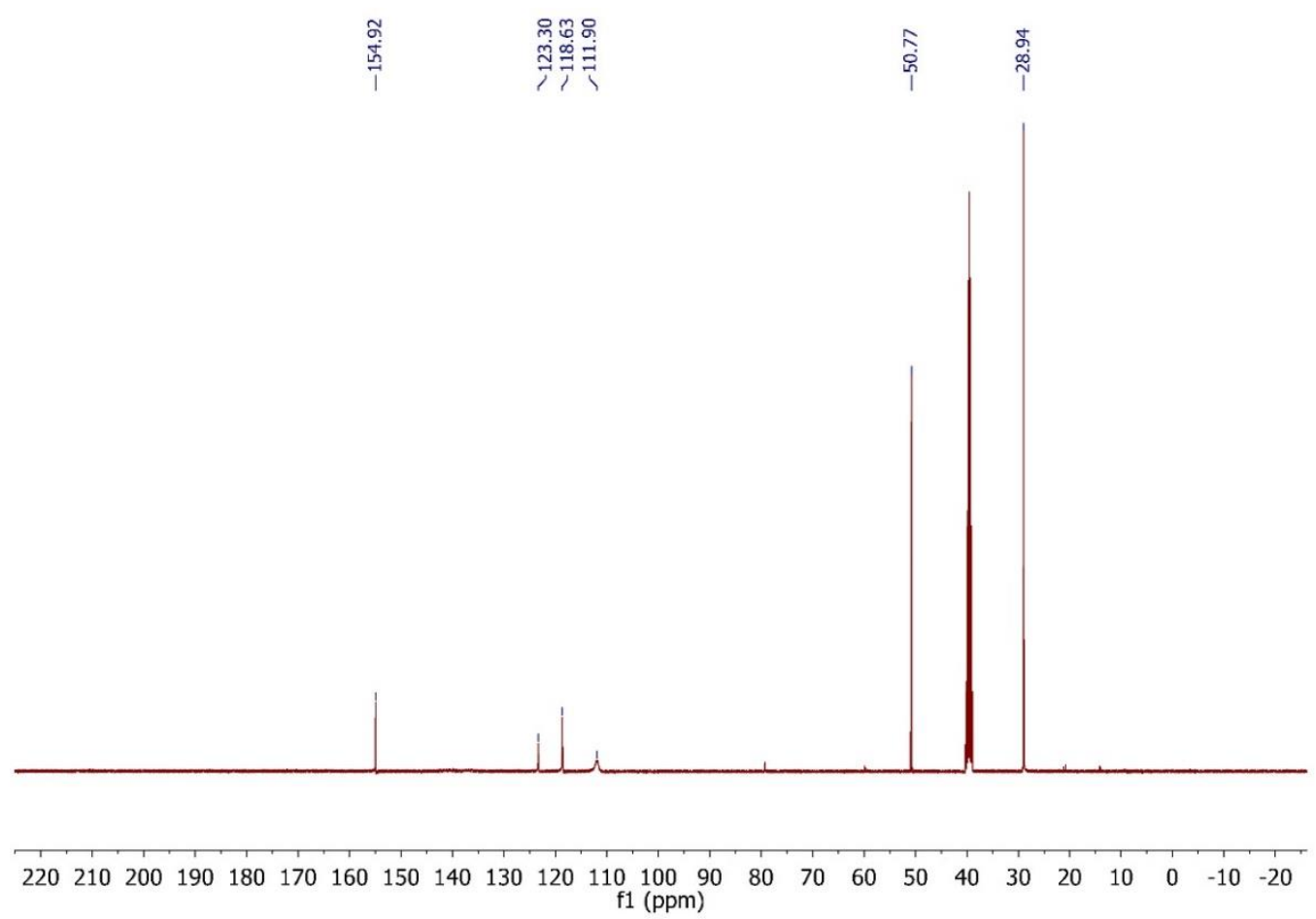

Figure A59. ${ }^{13} \mathrm{C}$ NMR spectrum of 2-(tert-butylamino)-5-chlorobenzimidazole (5f) in DMSO-d6 at $100 \mathrm{MHz}$. 


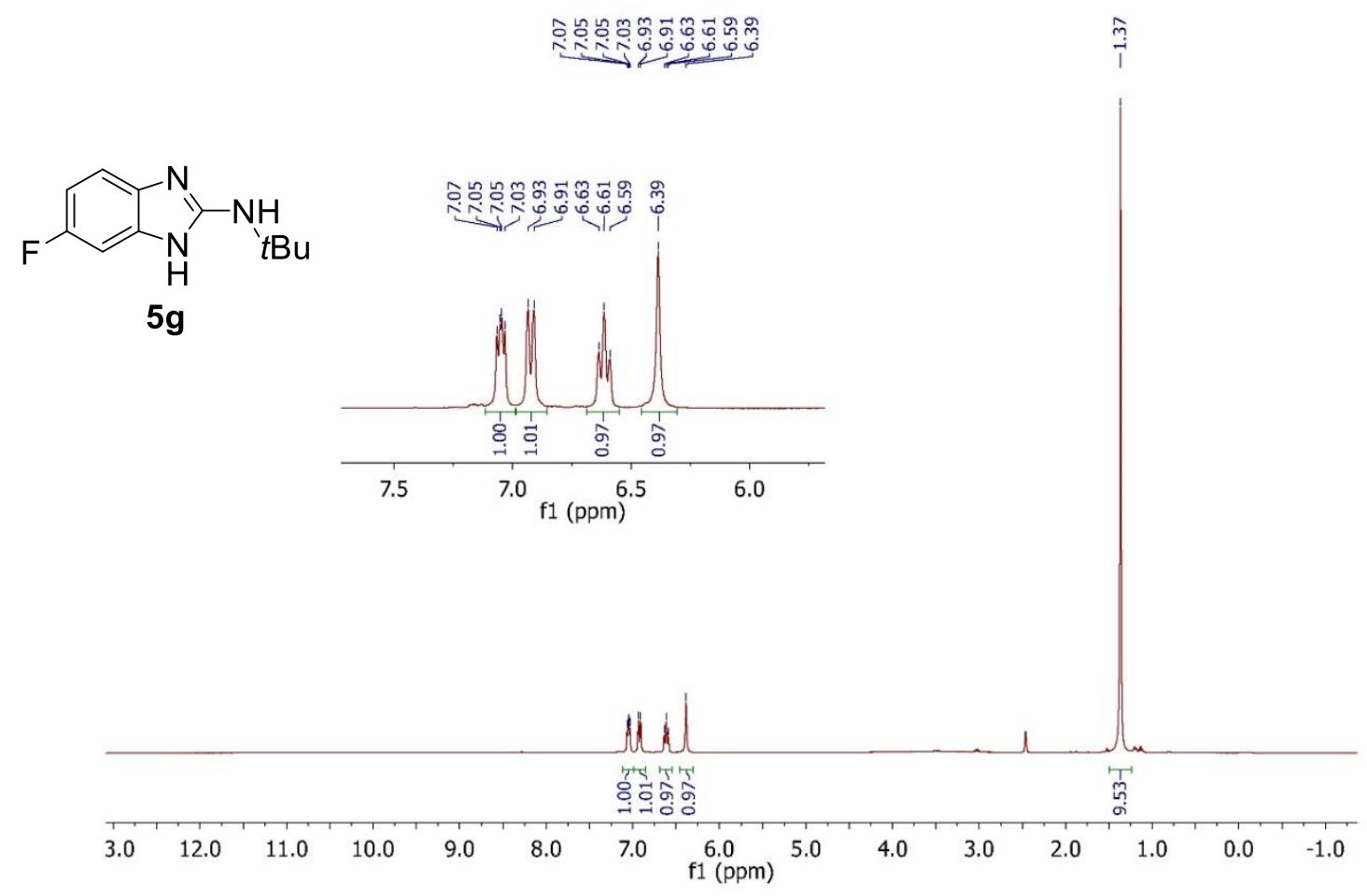

Figure A60. ${ }^{1} \mathrm{H}$ NMR spectrum of 2-(tert-butylamino)-5-fluorobenzimidazole (5g) in DMSO$d_{6}$ at 400 MHz.
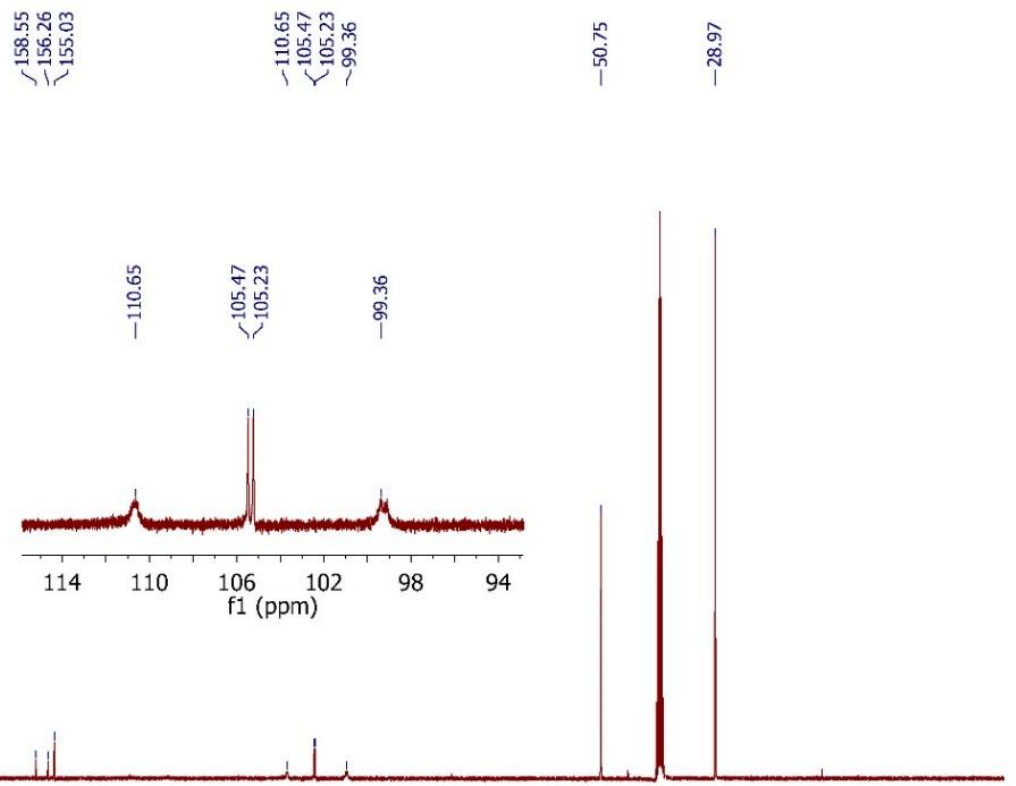

$\begin{array}{llllllllllllllllllllll}220 & 210 & 200 & 190 & 180 & 170 & 160 & 150 & 140 & 130 & 120 & 110 \\ \mathrm{f} 1 & 100 & 90 & 80 & 70 & 60 & 50 & 40 & 30 & 20 & 10 & 0 & -10 & -20\end{array}$

Figure A61. ${ }^{13} \mathrm{C}$ NMR spectrum of 2-(tert-butylamino)-5-fluorobenzimidazole (5g) in DMSO$d_{6}$ at 100 MHz. 


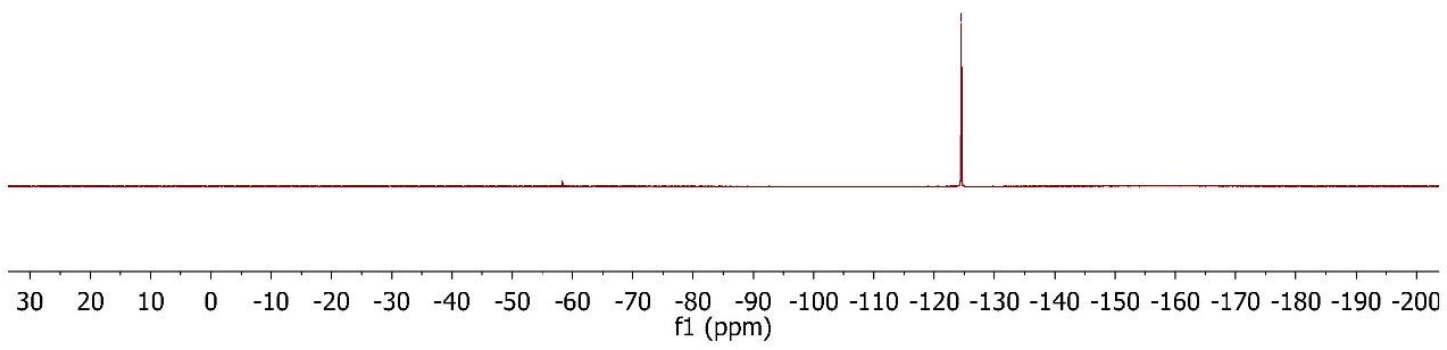

Figure A62. ${ }^{19}$ F NMR spectrum of 2-(tert-butylamino)-5-fluorobenzimidazole (5g) in DMSO$d_{6}$ at 376 MHz. 


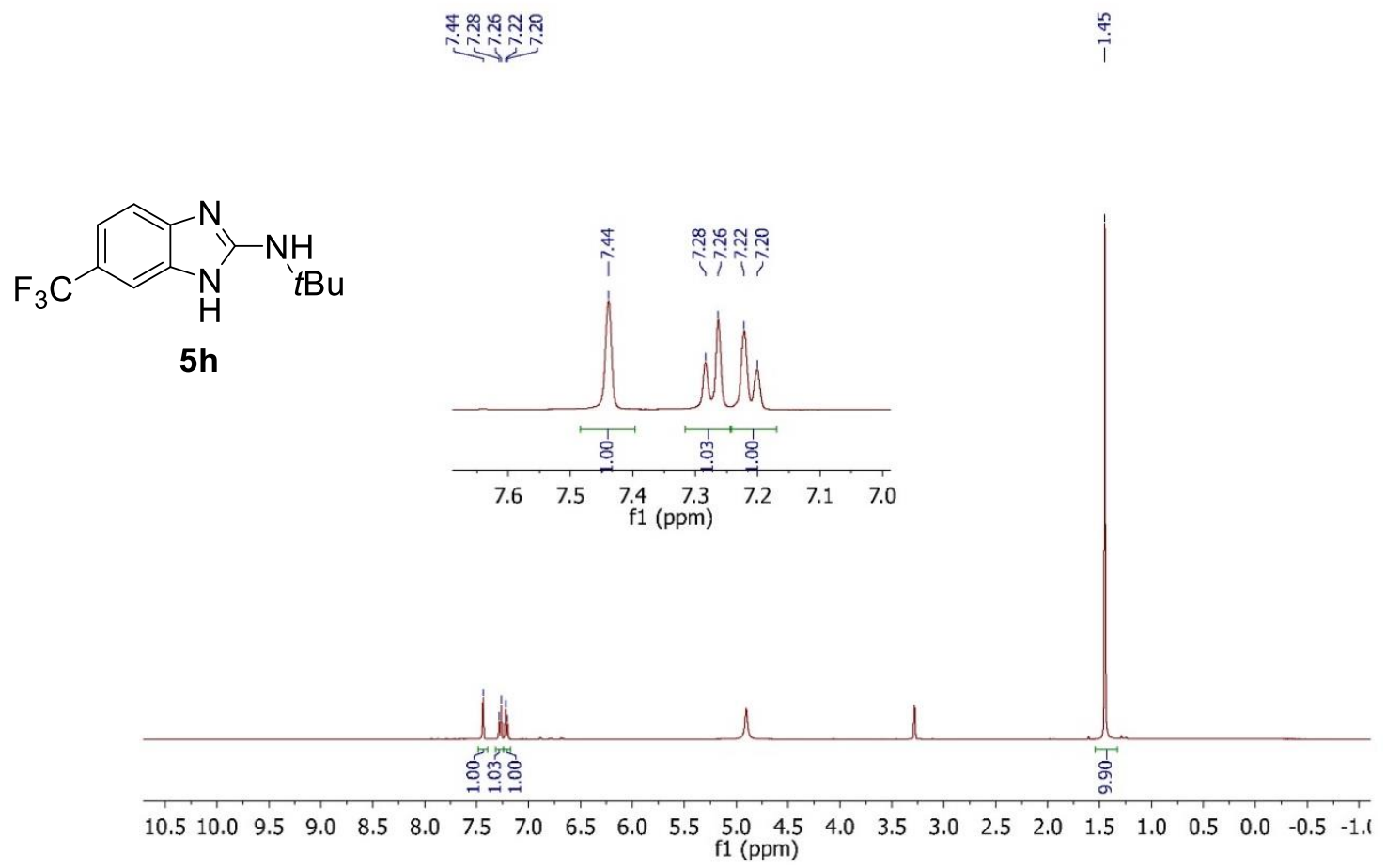

Figure A63. ${ }^{1} \mathrm{H}$ NMR spectrum of 2-(tert-butylamino)-5-trifluoromethylbenzimidazole (5h) in $\mathrm{CD}_{3} \mathrm{OD}$ at $400 \mathrm{MHz}$.

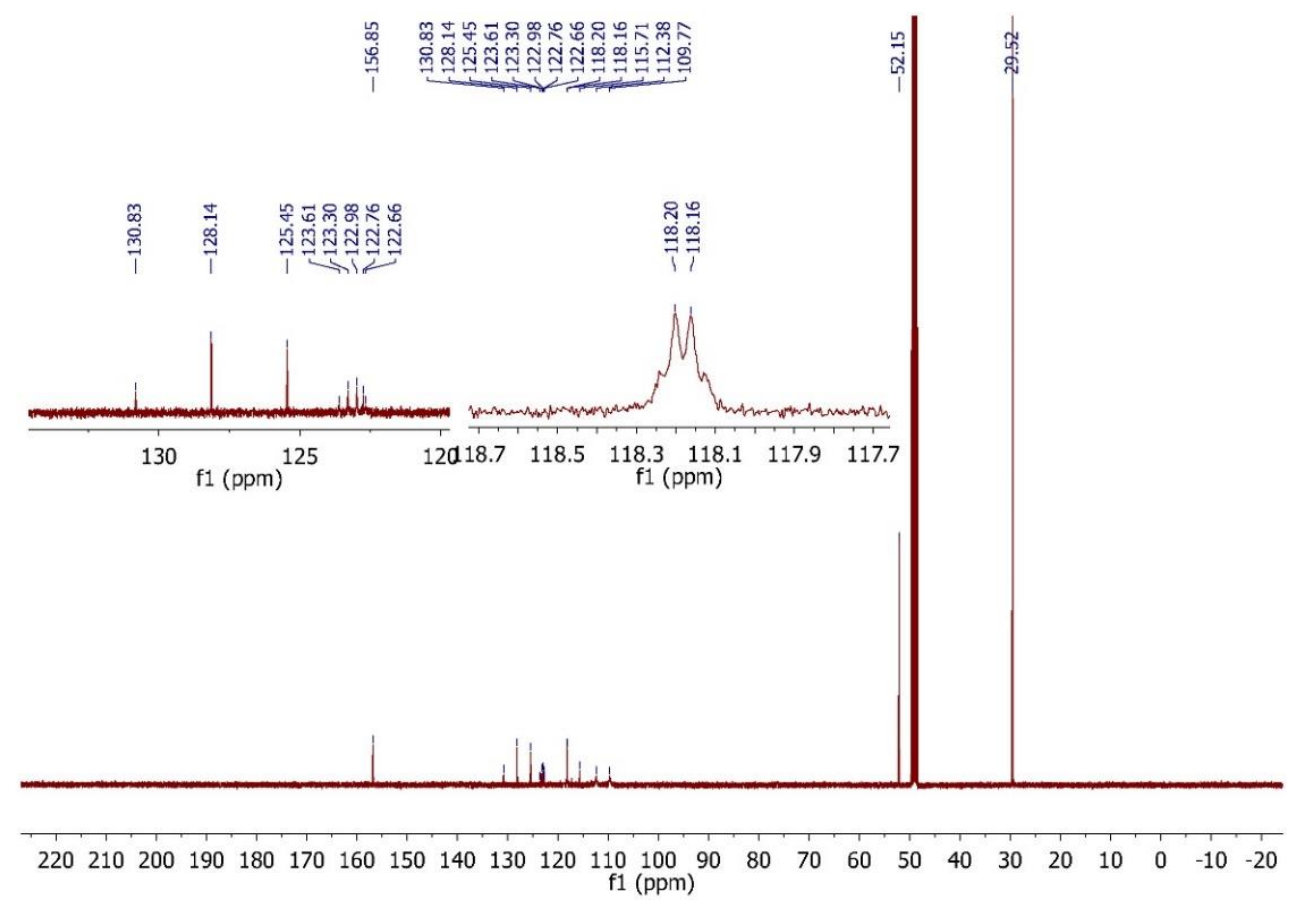

Figure A64. ${ }^{13} \mathrm{H}$ NMR spectrum of 2-(tert-butylamino)-5-trifluoromethylbenzimidazole (5h) in $\mathrm{CD}_{3} \mathrm{OD}$ at $100 \mathrm{MHz}$. 


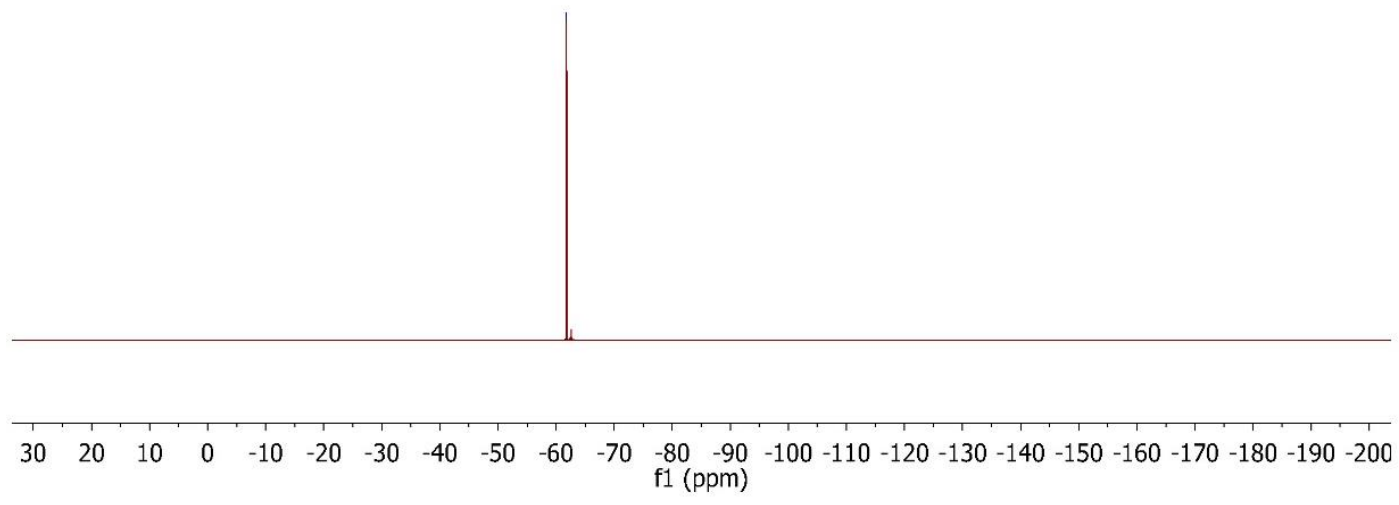

Figure A65. ${ }^{19} \mathrm{~F}$ NMR spectrum of 2-(tert-butylamino)-5-trifluoromethylbenzimidazole (5h) in $\mathrm{CD}_{3} \mathrm{OD}$ at $376 \mathrm{MHz}$. 


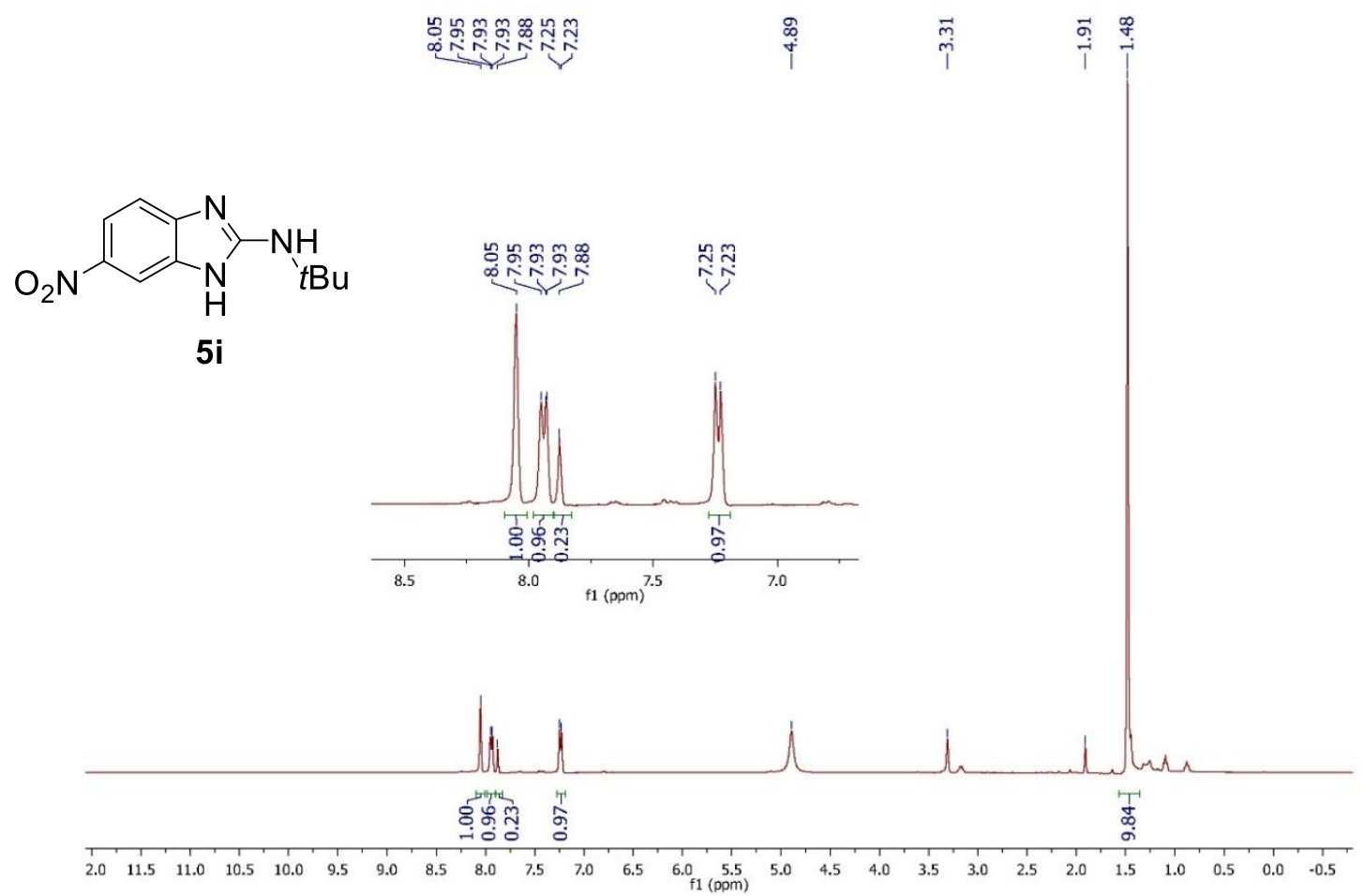

Figure A66. ${ }^{1} \mathrm{H}$ NMR spectrum of 2-(tert-butylamino)-5-nitrobenzimidazole (5i) in $\mathrm{CD}$-OD at $400 \mathrm{MHz}$.
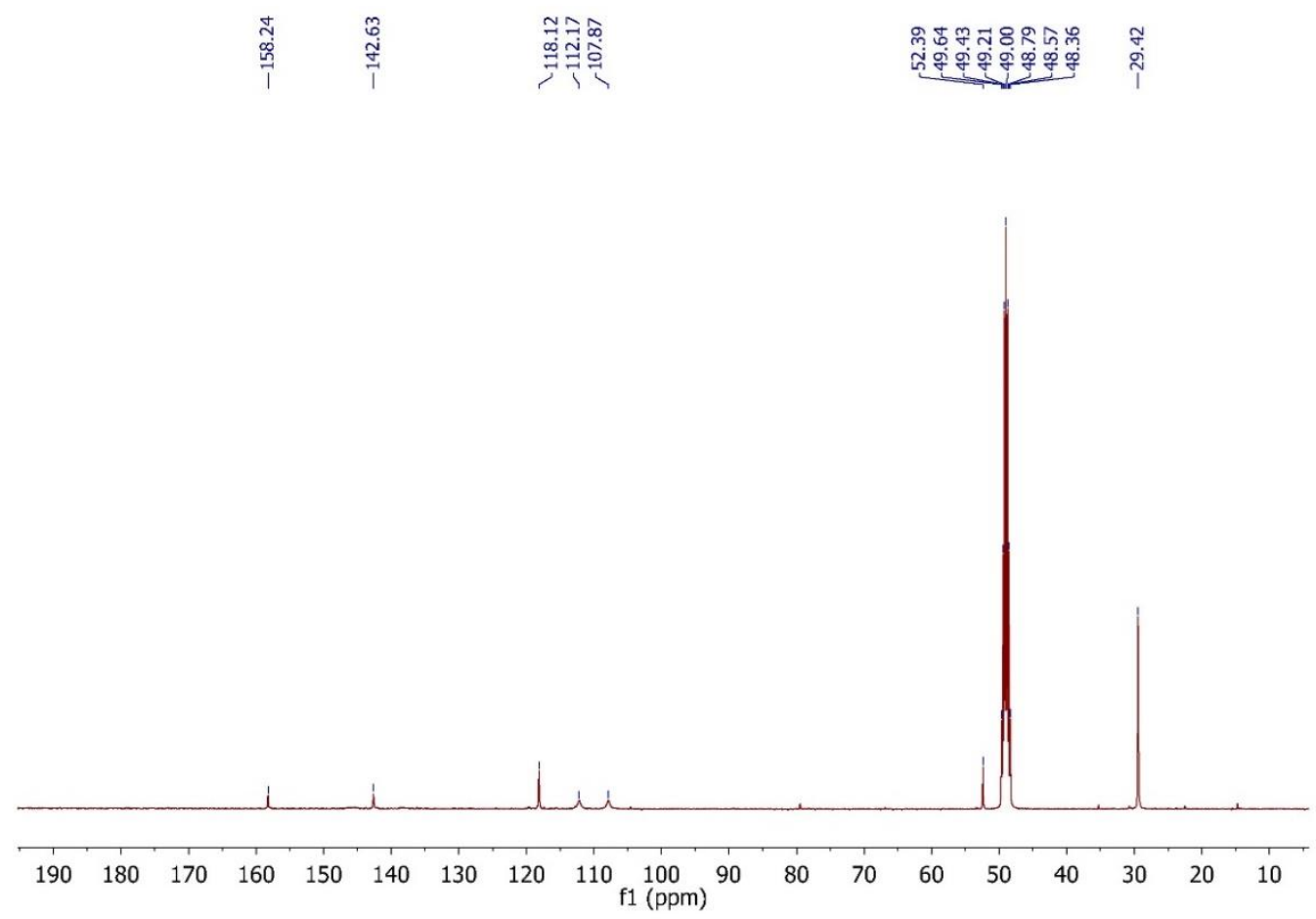

Figure A67. ${ }^{13} \mathrm{C}$ NMR spectrum of 2-(tert-butylamino)-5-nitrobenzimidazole (5i) in $\mathrm{CD}_{3} \mathrm{OD}$ at $100 \mathrm{MHz}$. 


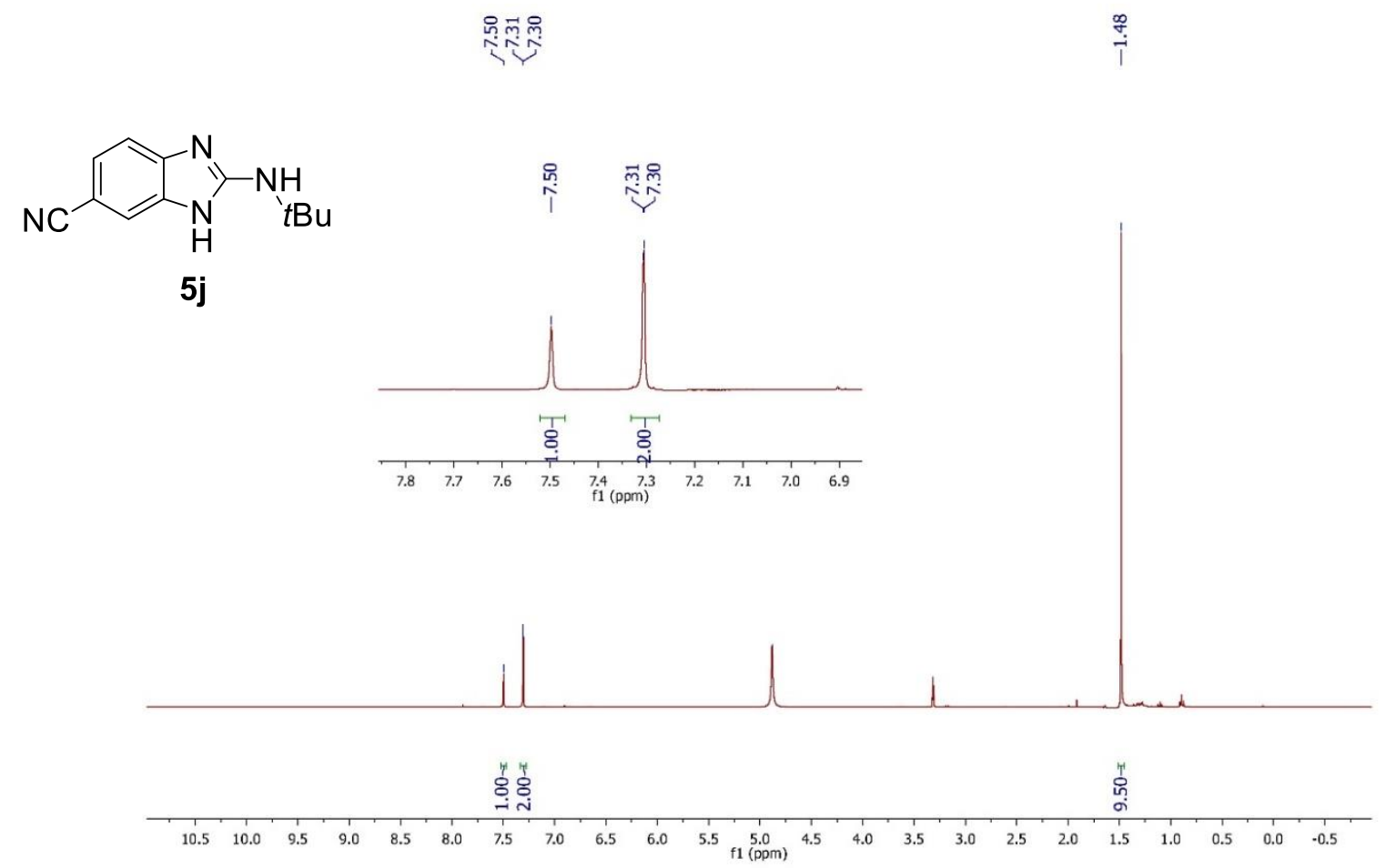

Figure A68. ${ }^{1} \mathrm{H}$ NMR spectrum of 2-(tert-butylamino)-5-cyanobenzimidazole (5j) in CD3OD at $400 \mathrm{MHz}$.

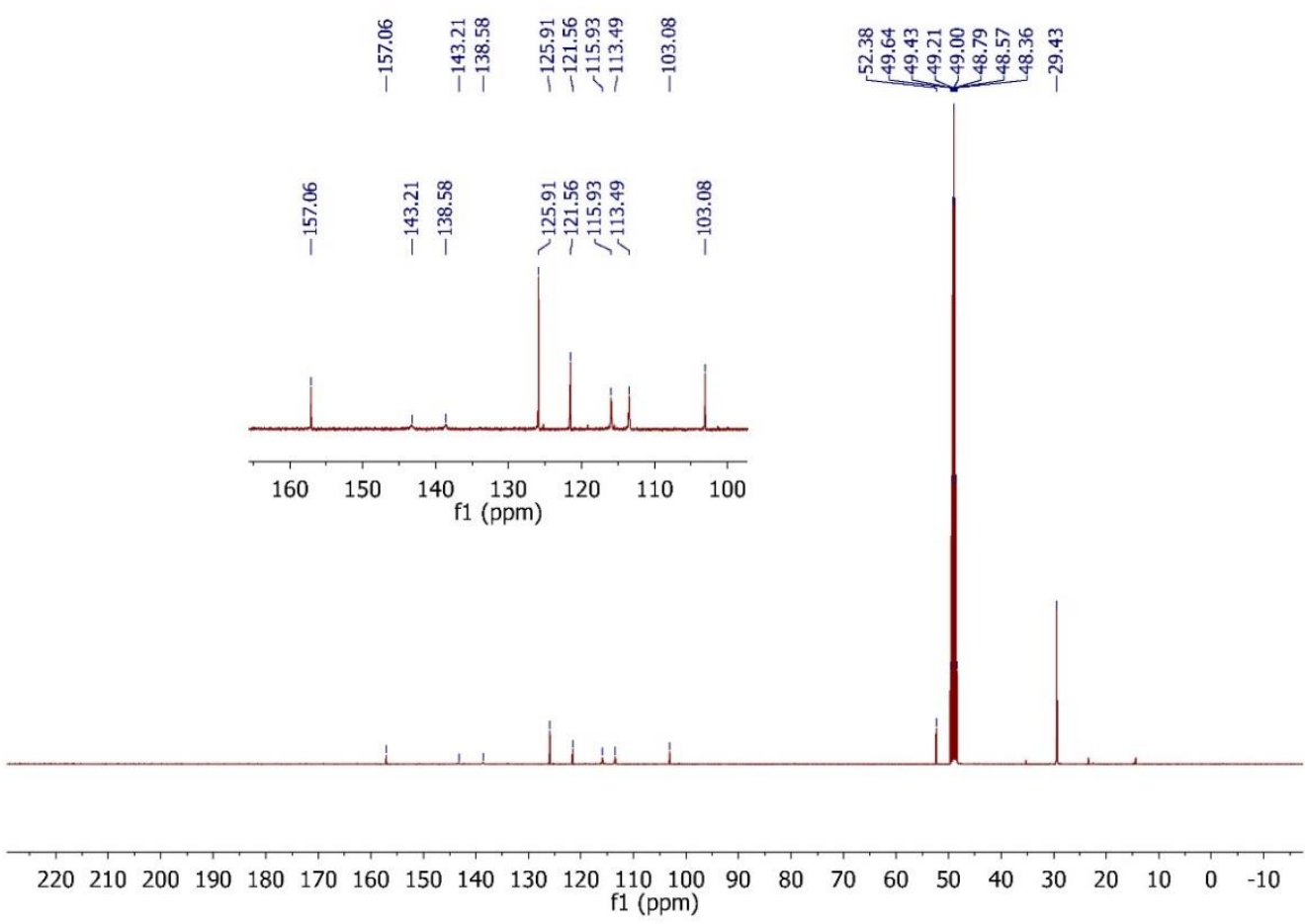

Figure A69. ${ }^{13} \mathrm{C}$ NMR spectrum of 2-(tert-butylamino)-5-cyanobenzimidazole (5j) in CD3OD at $100 \mathrm{MHz}$. 


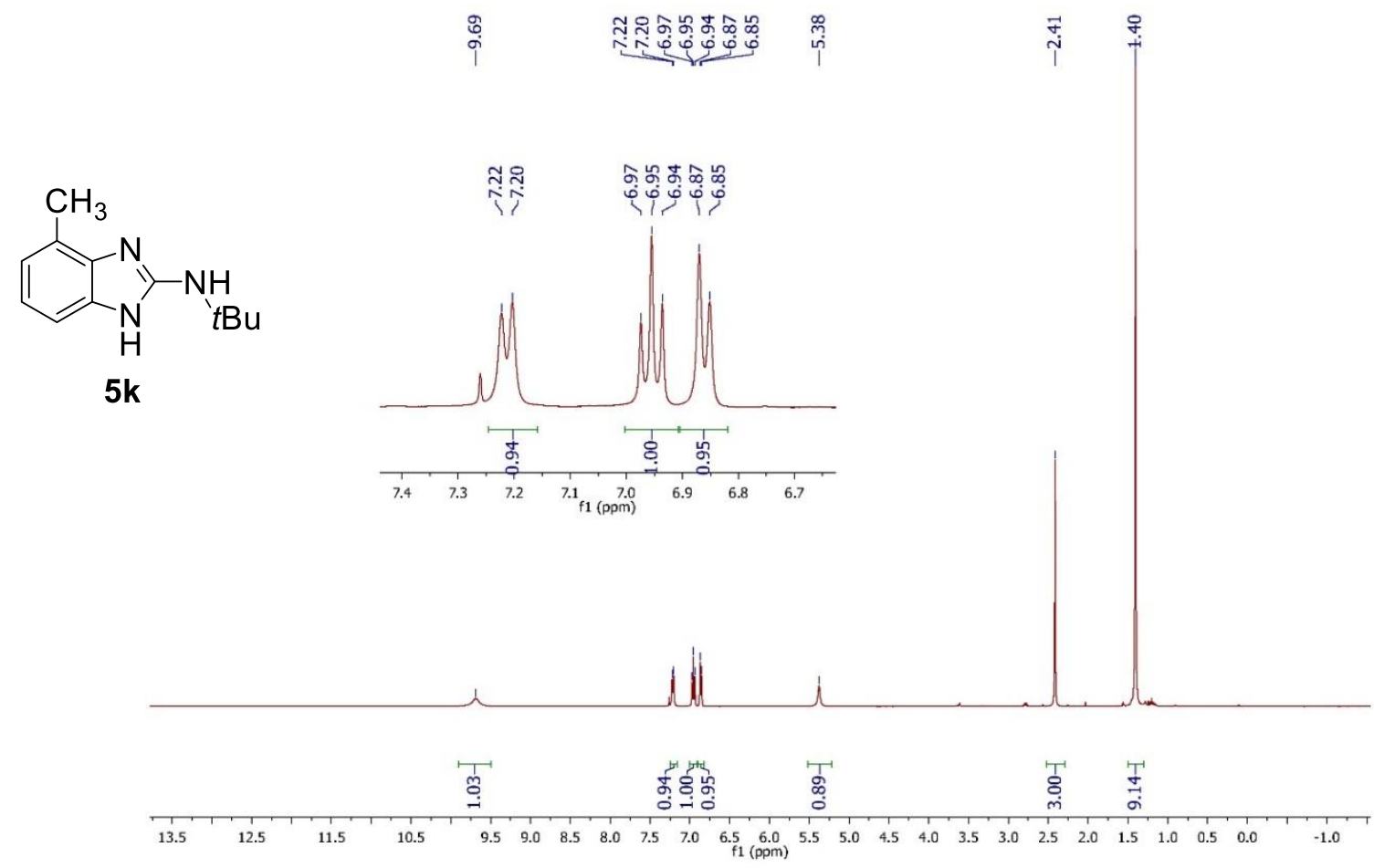

Figure A70. ${ }^{1} \mathrm{H}$ NMR spectrum of 2-(tert-butylamino)-7-methylbenzimidazole $(5 \mathrm{k})$ in $\mathrm{CDCl}_{3}$ at $400 \mathrm{MHz}$.
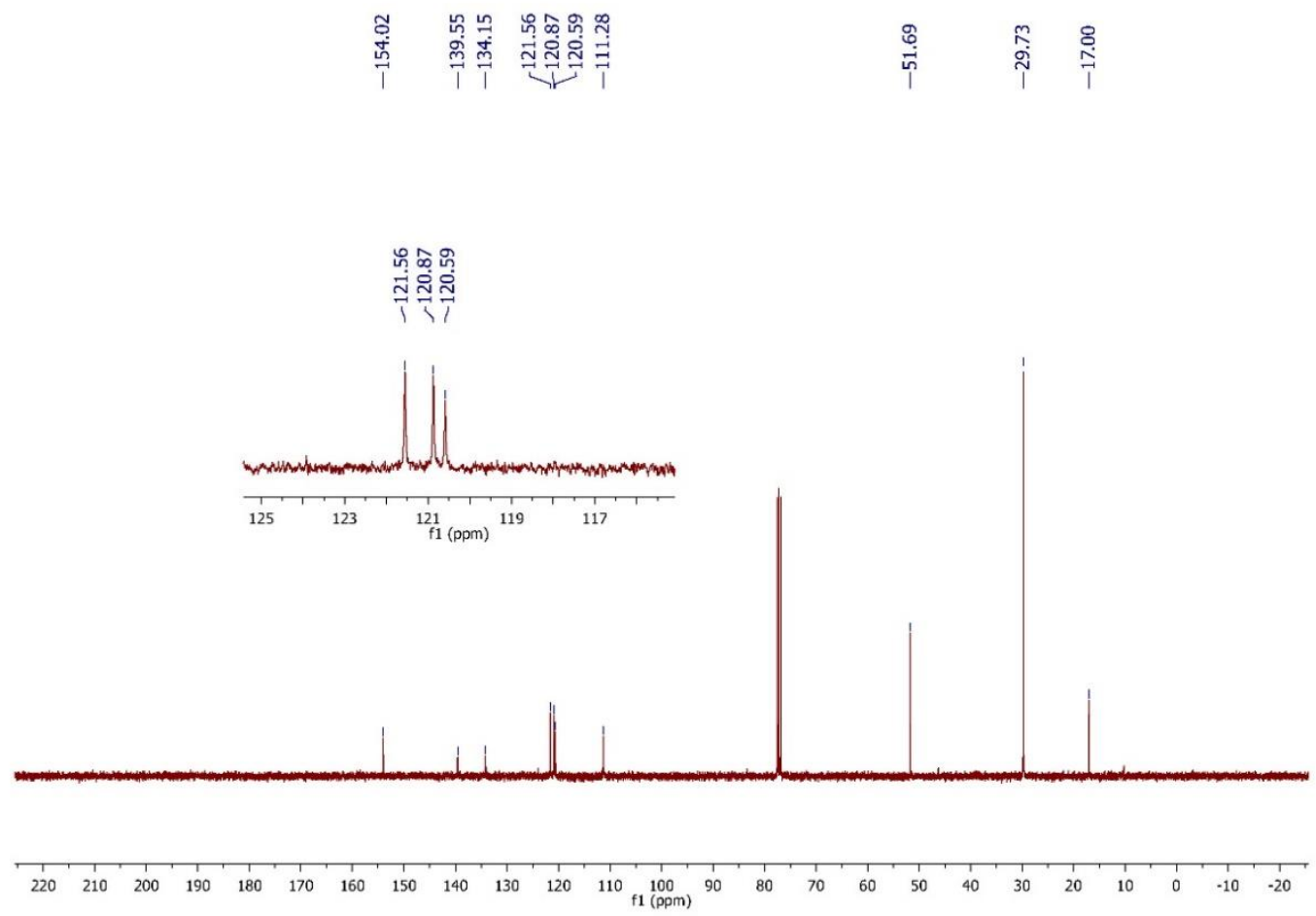

Figure A71. ${ }^{13} \mathrm{C}$ NMR spectrum of 2-(tert-butylamino)-7-methylbenzimidazole (5k) in CDCl3 at $100 \mathrm{MHz}$. 


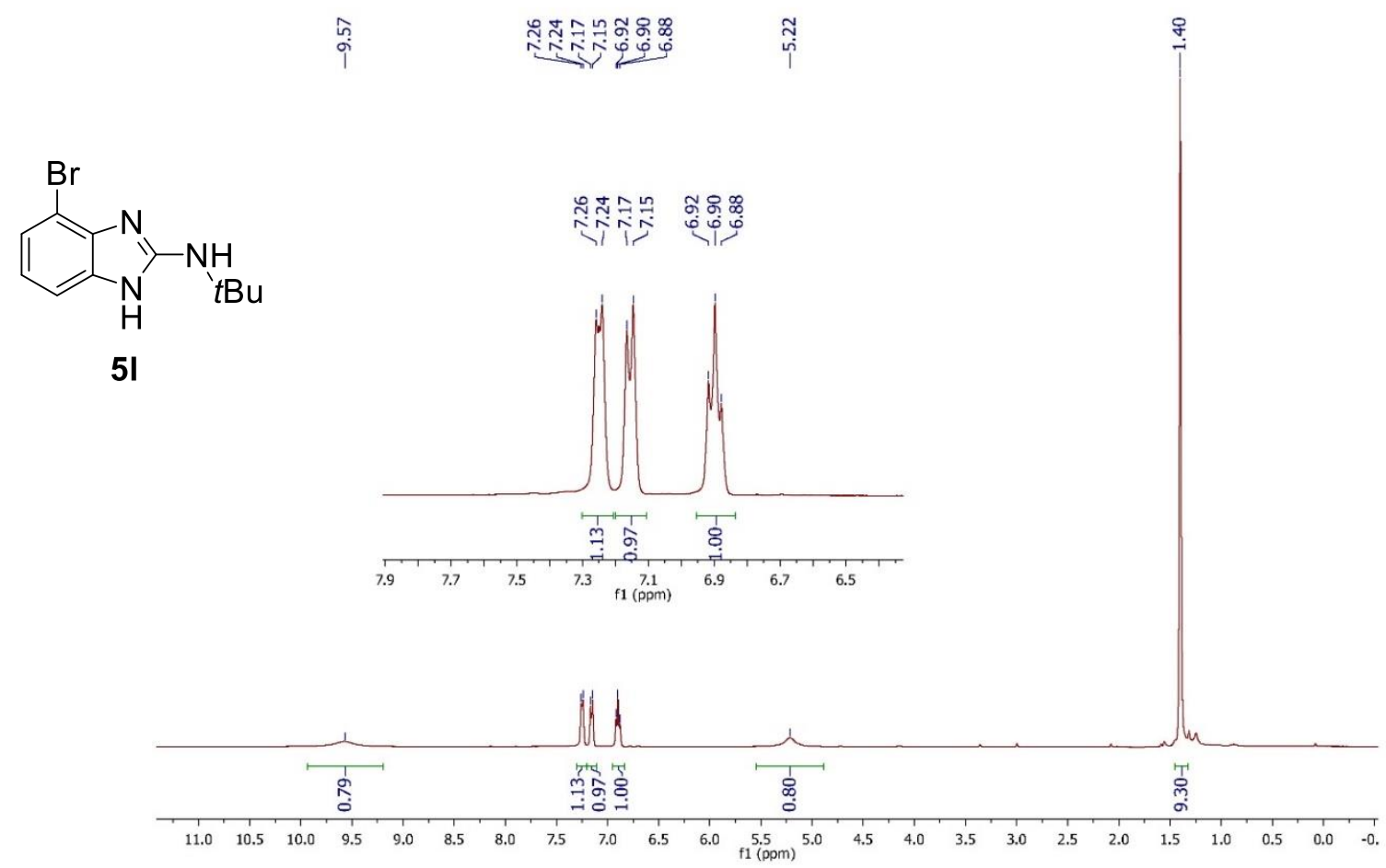

Figure A72. ${ }^{1} \mathrm{H}$ NMR spectrum of 2-(tert-butylamino)-7-bromobenzimidazole (5l) in $\mathrm{CDCl} 3$ at $400 \mathrm{MHz}$.

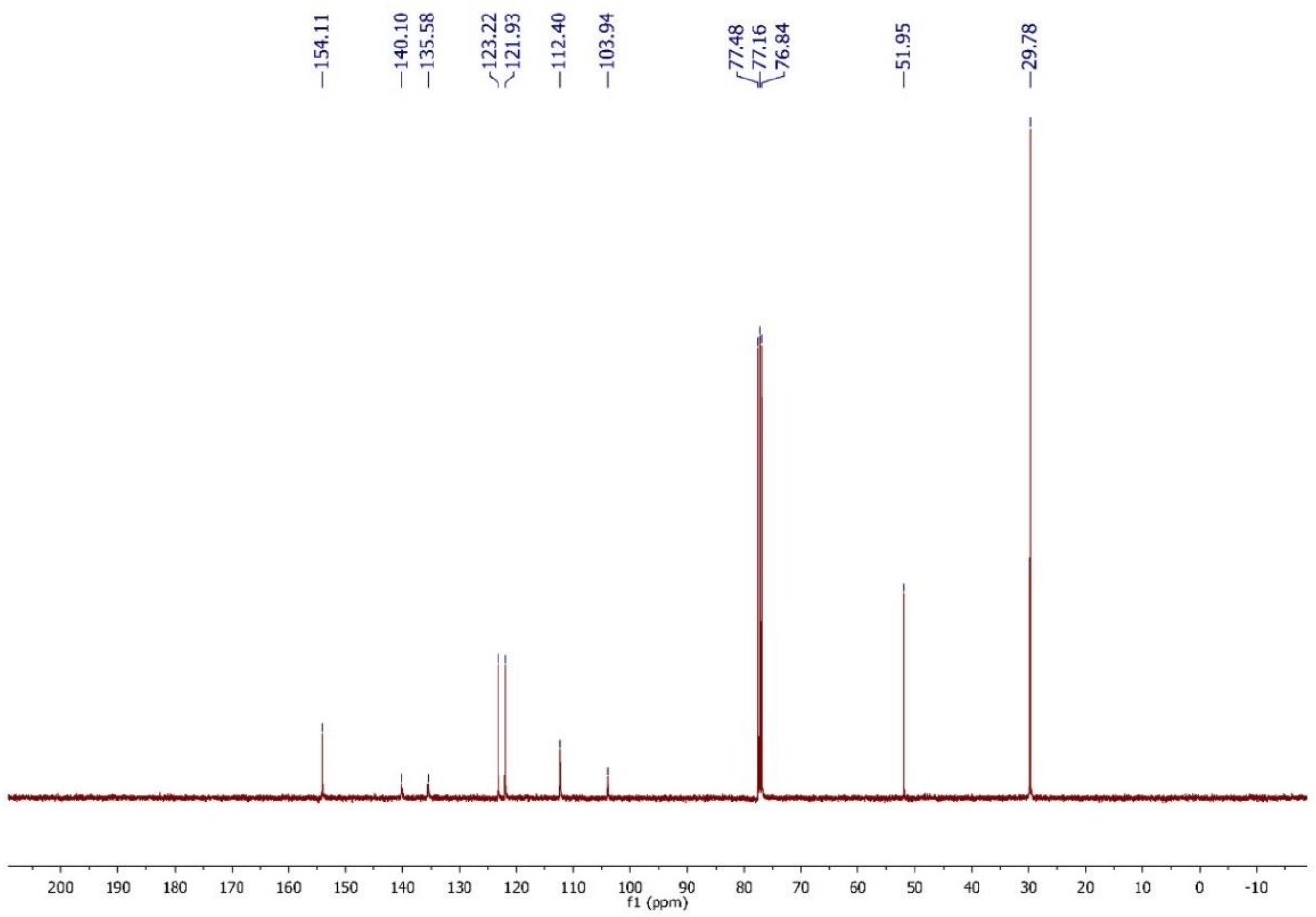

Figure A73. ${ }^{13} \mathrm{C}$ NMR spectrum of 2-(tert-butylamino)-7-bromobenzimidazole (5l) in $\mathrm{CDCl} 3$ at $100 \mathrm{MHz}$. 


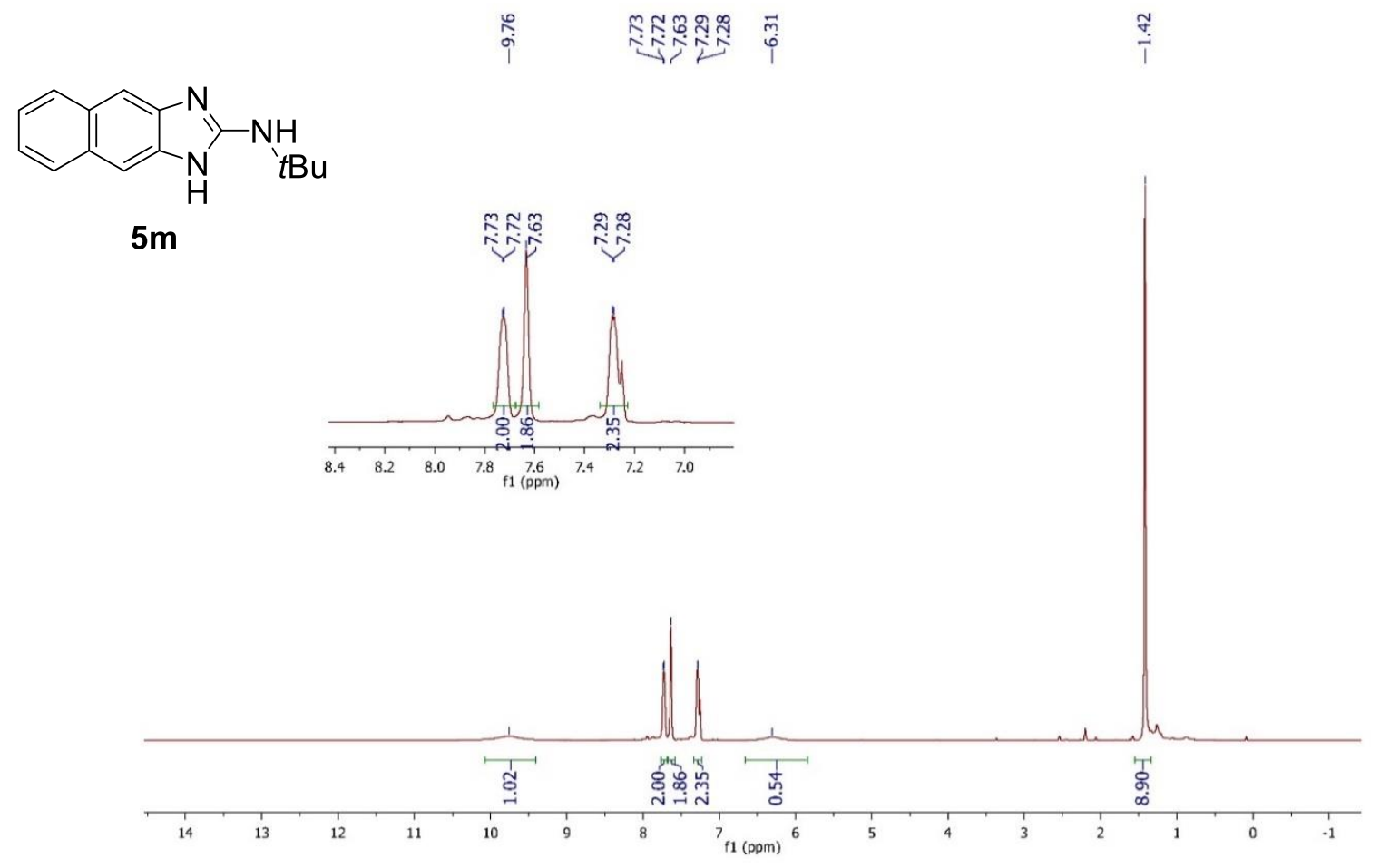

Figure A74. ${ }^{1} \mathrm{H}$ NMR spectrum of 2-(tert-butylamino)naphtho[2,3-d]imidazole (5m) in CDCl3 at $400 \mathrm{MHz}$.

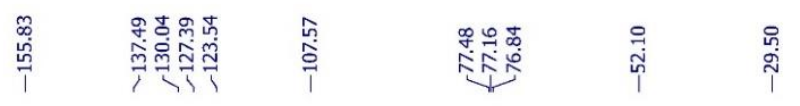

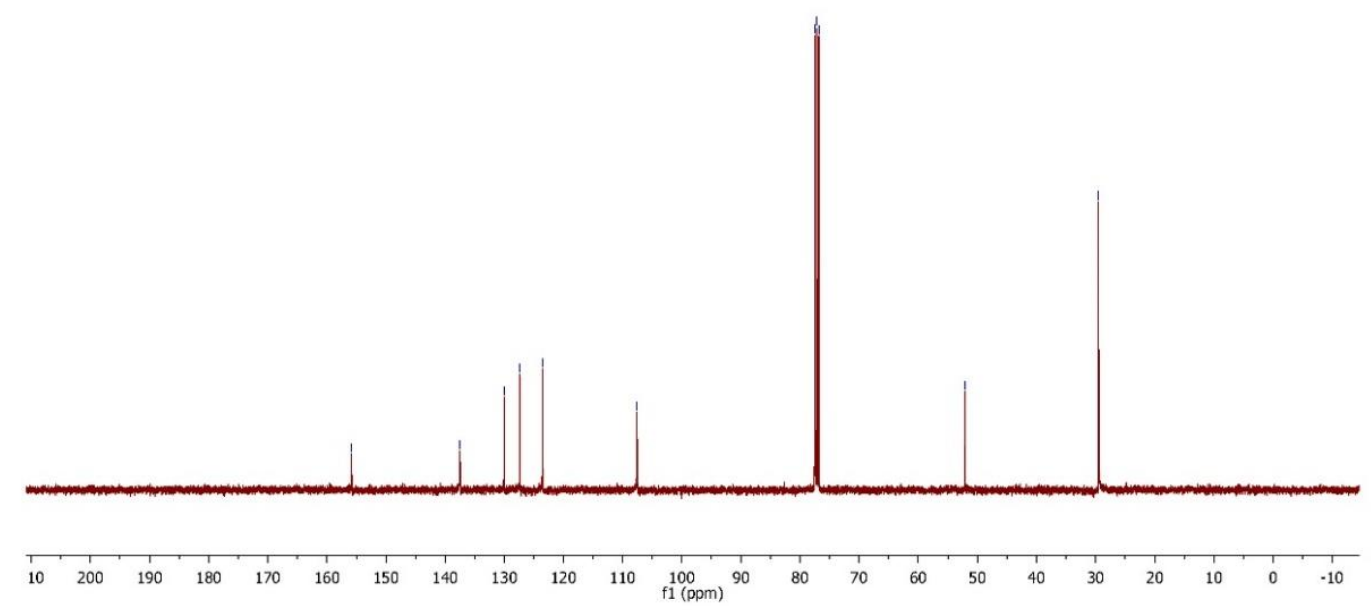

Figure A75. ${ }^{13} \mathrm{C}$ NMR spectrum of 2-(tert-butylamino)naphtho[2,3-d]imidazole (5m) in $\mathrm{CDCl}_{3}$ at $100 \mathrm{MHz}$. 

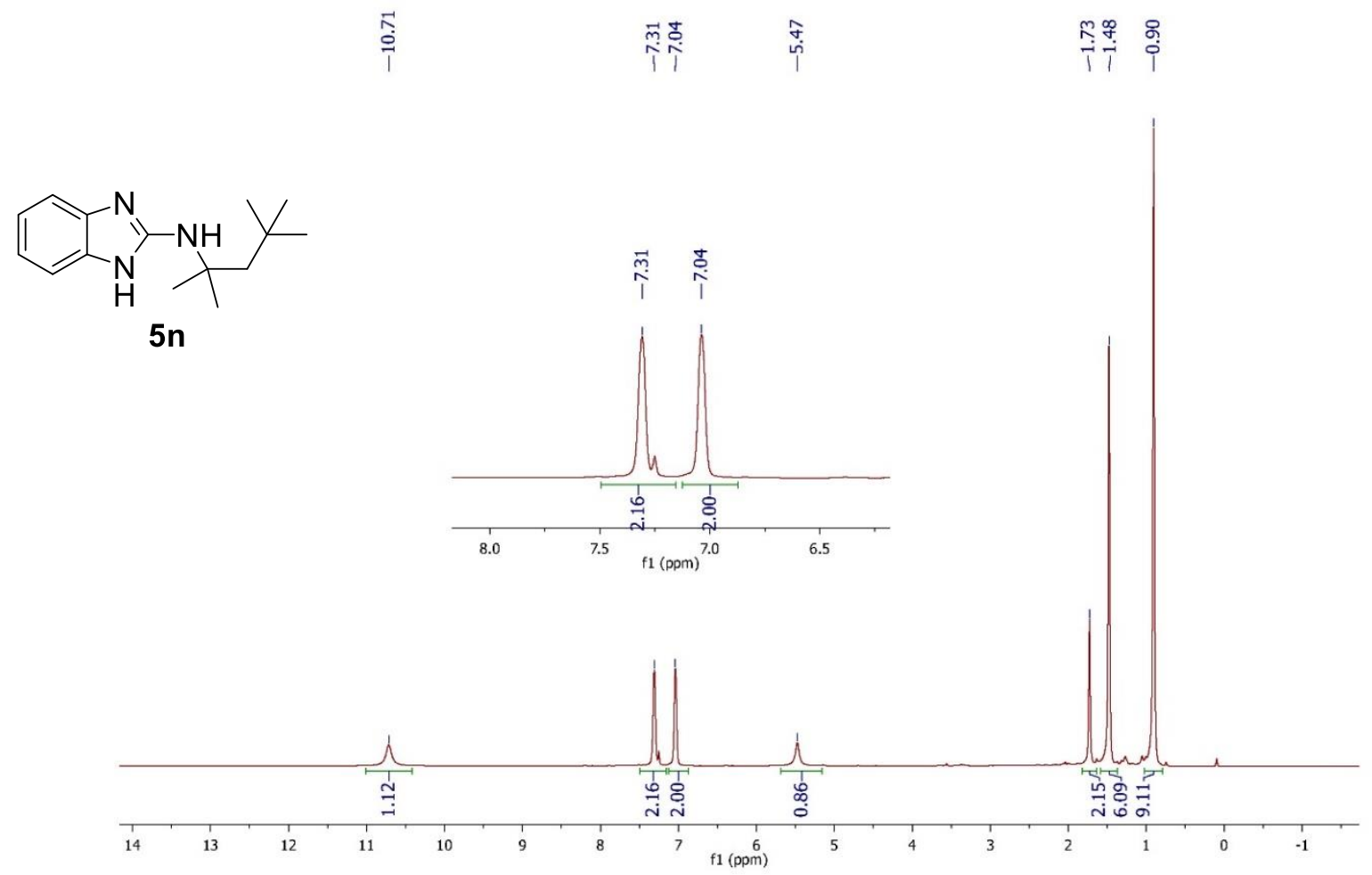

Figure A76. ${ }^{1} \mathrm{H}$ NMR spectrum of 2-(1,1,3,3-tetramethylbutylamino)benzimidazole (5n) in CDCl3 at 400 MHz.

\begin{tabular}{|c|c|c|c|c|c|}
\hline $\begin{array}{l}\vec{b} \\
\stackrel{n}{n} \\
\stackrel{T}{\mid}\end{array}$ & 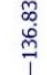 & 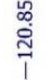 & 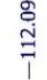 & 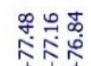 & 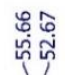 \\
\hline
\end{tabular}

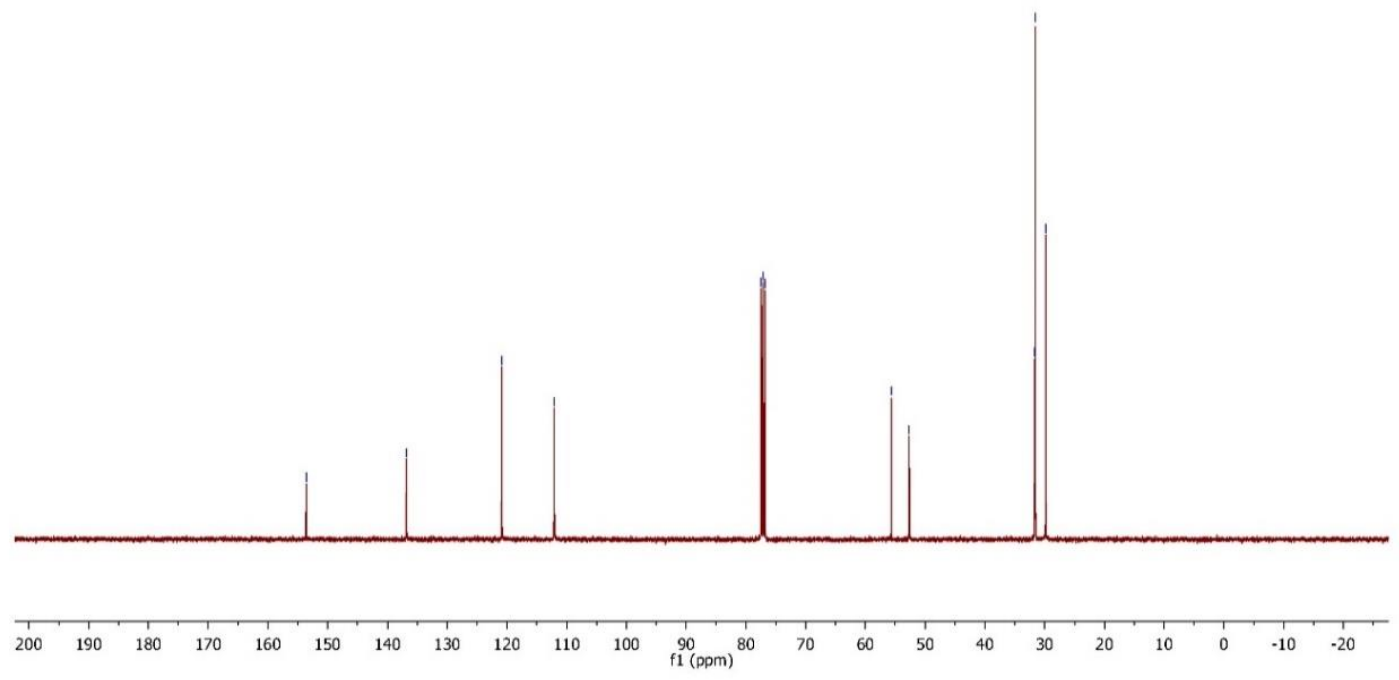

Figure A77. ${ }^{13} \mathrm{C}$ NMR spectrum of 2-(1,1,3,3-tetramethylbutylamino)benzimidazole (5n) in CDCl3 at $100 \mathrm{MHz}$. 


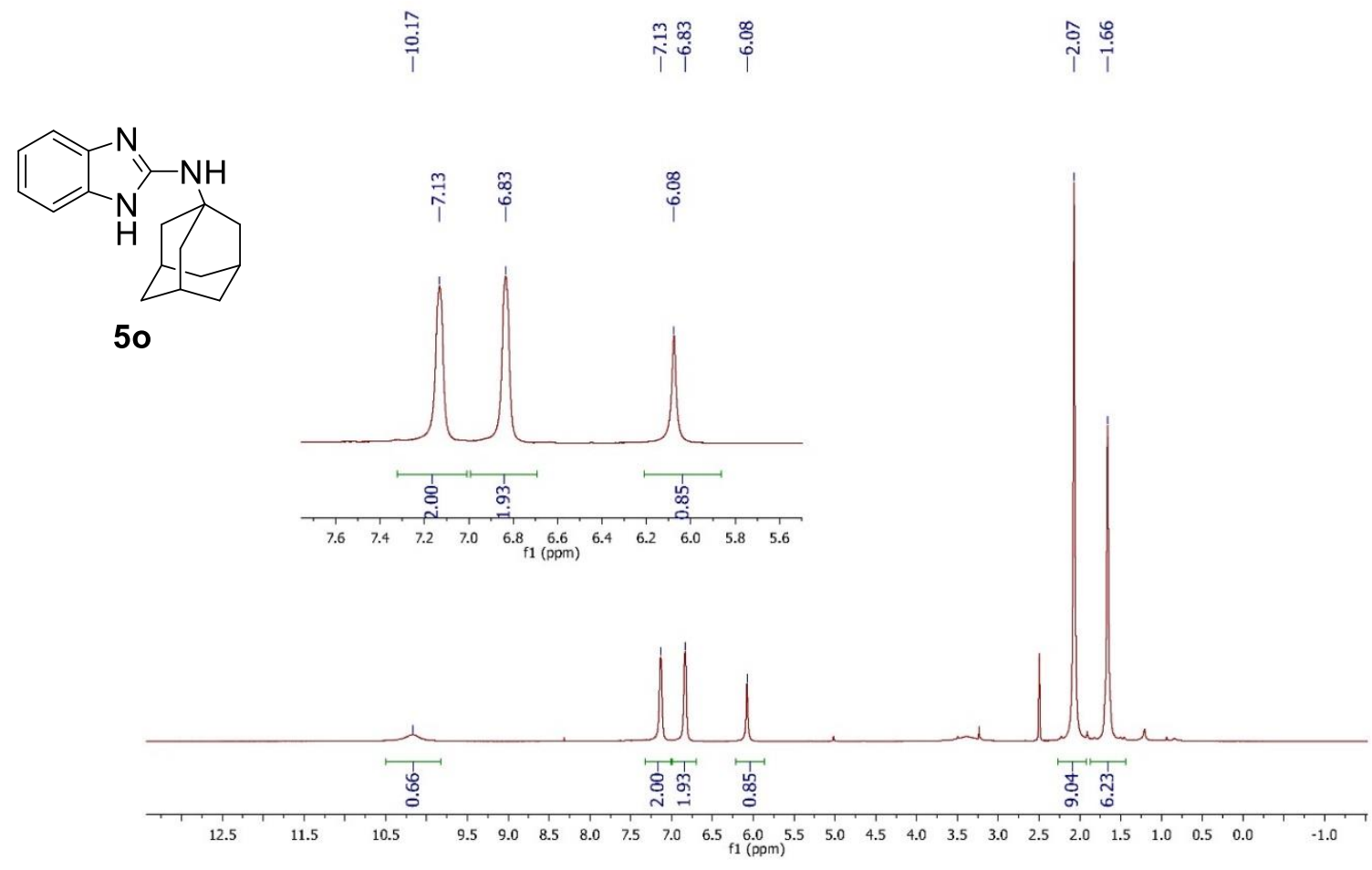

Figure A78. ${ }^{1} \mathrm{H}$ NMR spectrum of 2-(1-adamantylamino)benzimidazole (5o) in DMSO-d6 at 400 MHz.

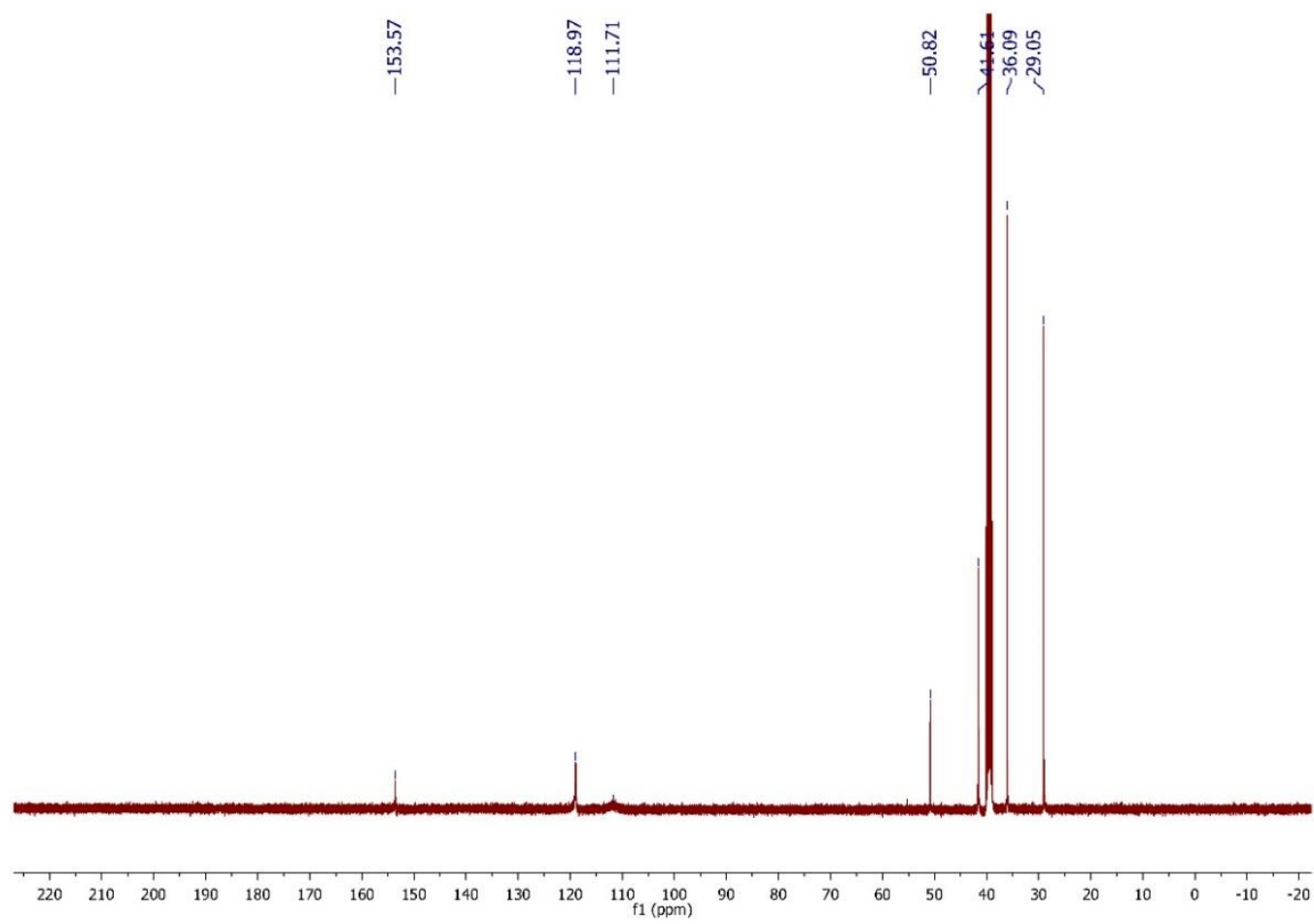

Figure A79. ${ }^{13} \mathrm{C}$ NMR spectrum of 2-(1-adamantylamino)benzimidazole (5o) in DMSO-d6 at $100 \mathrm{MHz}$. 

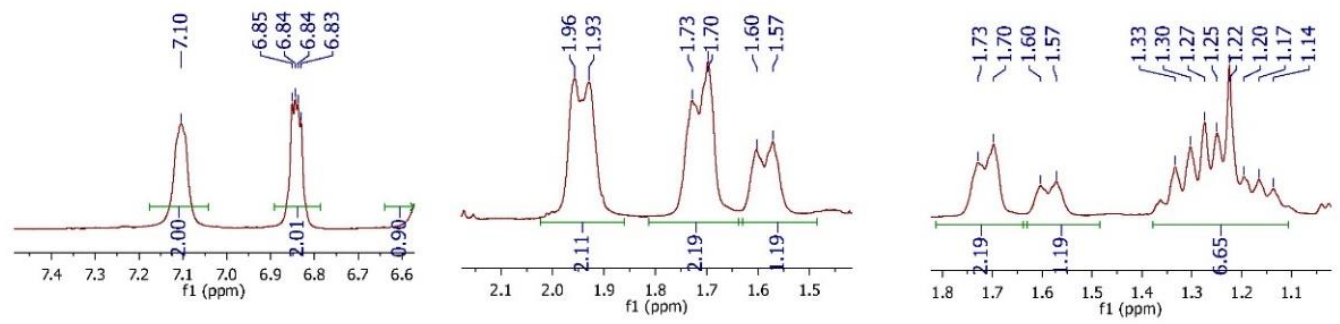<smiles>c1ccc2[nH]c(NC3CCCCC3)nc2c1</smiles>

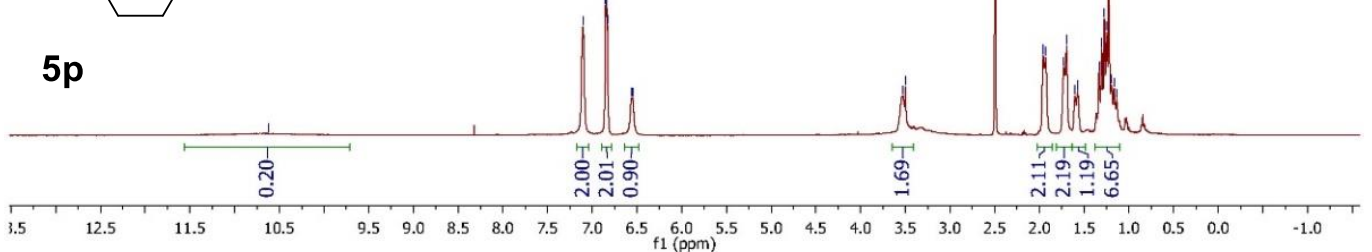

Figure A80. ${ }^{1} \mathrm{H}$ NMR spectrum of 2-(cyclohexylamino)benzimidazole (5p) in DMSO-d 6 at 400 MHz.

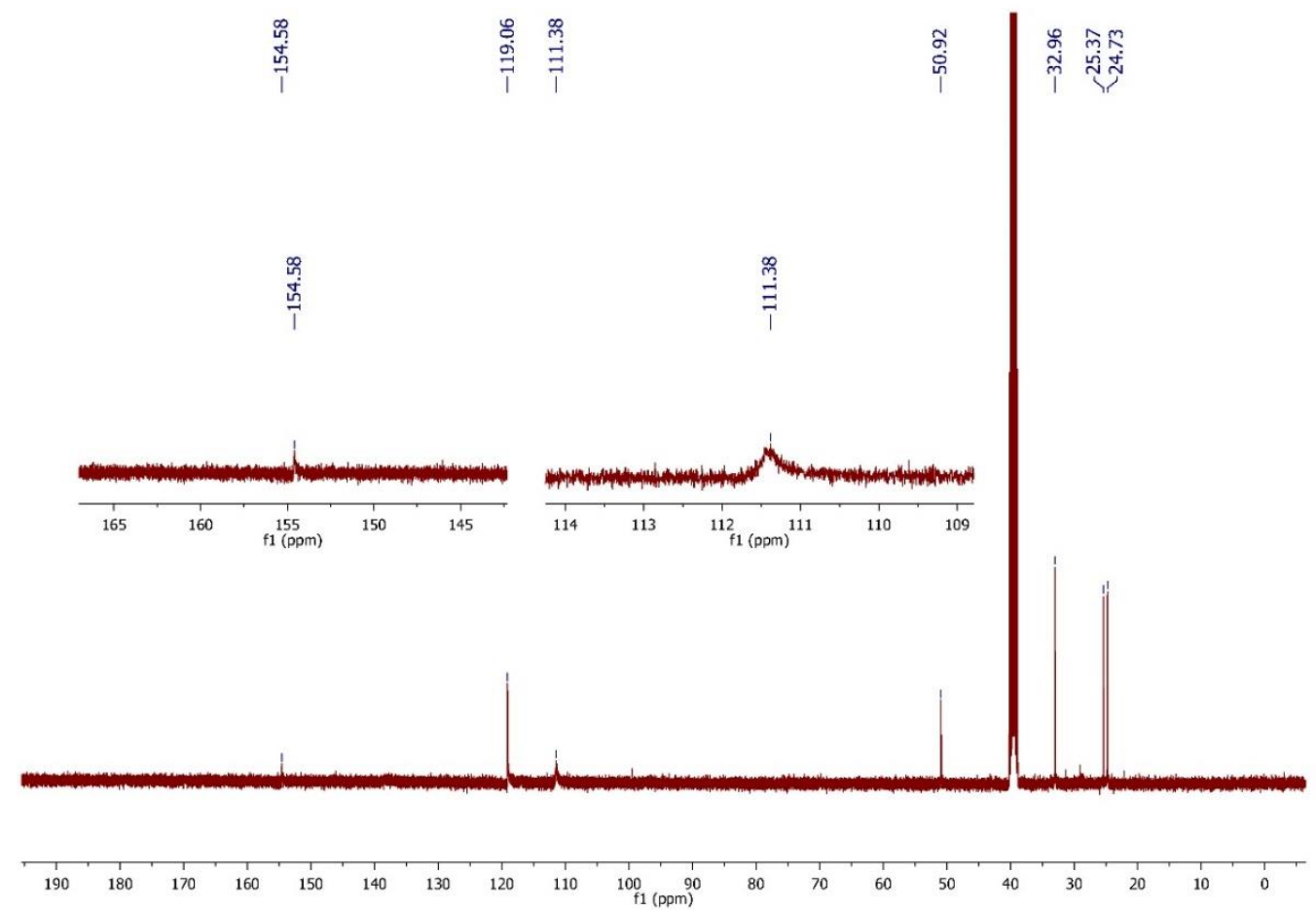

Figure A81. ${ }^{13} \mathrm{C}$ NMR spectrum of 2-(cyclohexylamino)benzimidazole (5p) in DMSO-d6 at $100 \mathrm{MHz}$. 
<smiles>Nc1nc2cc(C(=O)c3ccccc3)ccc2[nH]1</smiles>
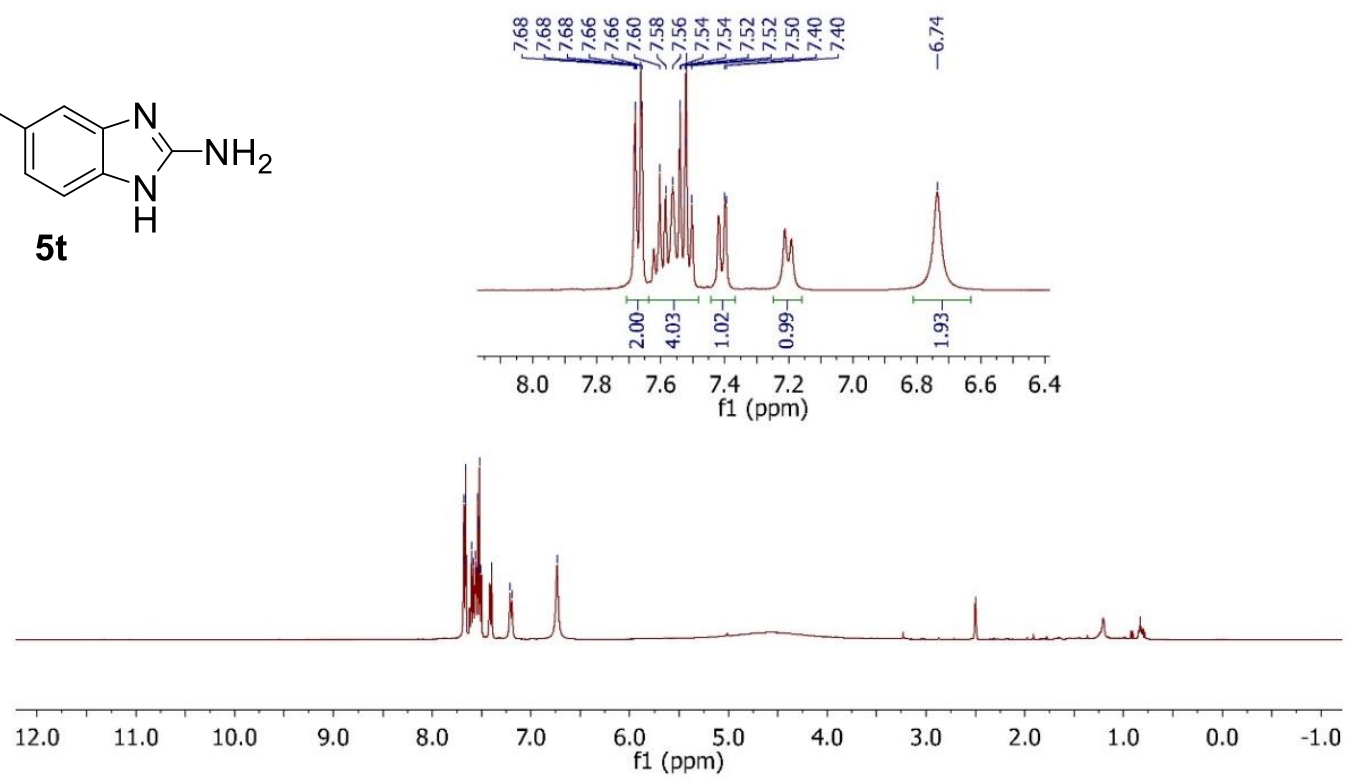

Figure A82. ${ }^{1} \mathrm{H}$ NMR spectrum of 2-amino-5-benzoyl-1H-benzimidazole (5t) in DMSO- $d 6$ at $400 \mathrm{MHz}$.
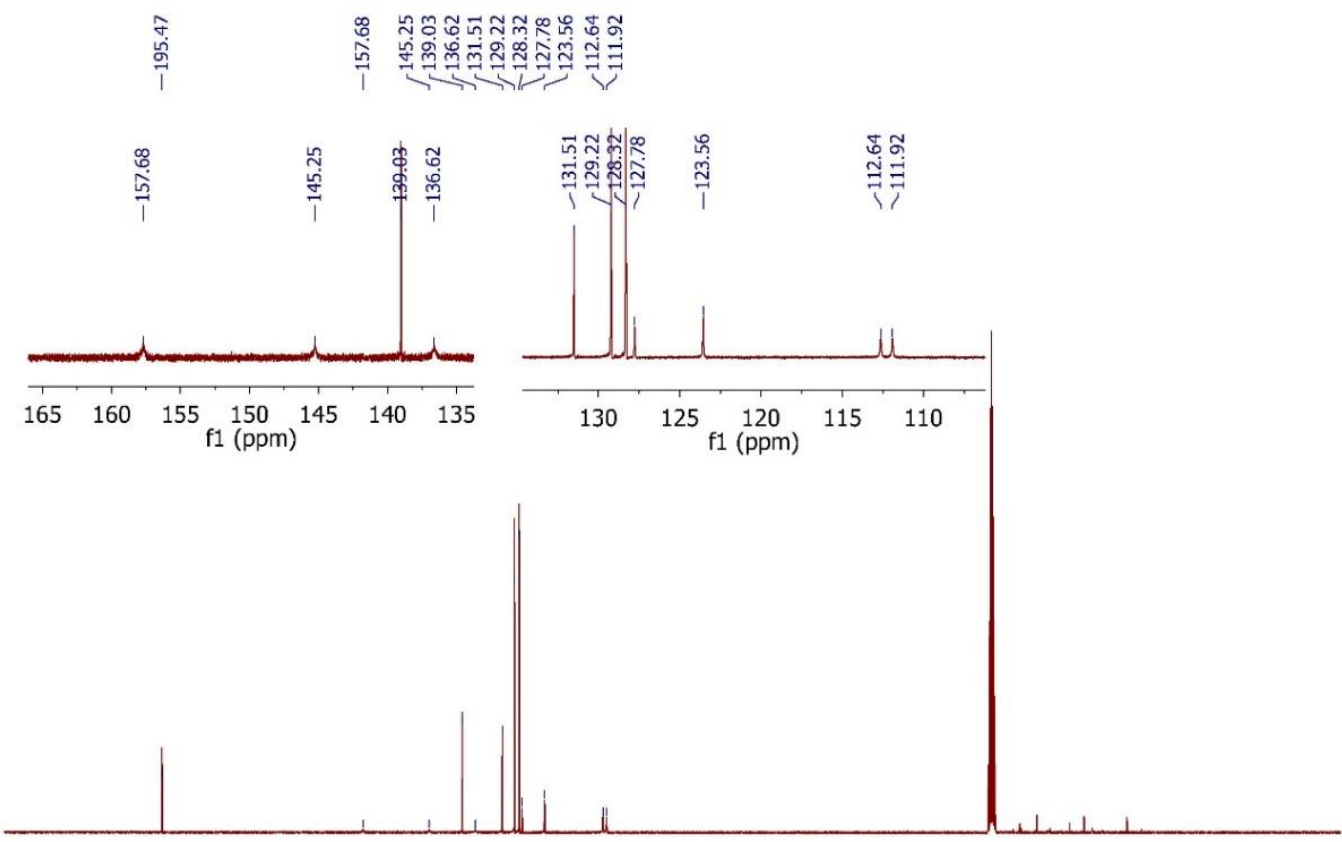

$\begin{array}{llllllllllllllllllllllllllll}220 & 210 & 200 & 190 & 180 & 170 & 160 & 150 & 140 & 130 & 120 & 110 & 100 & 90 & 80 & 70 & 60 & 50 & 40 & 30 & 20 & 10 & 0 & -10 & -20\end{array}$

Figure A83. ${ }^{13} \mathrm{C}$ NMR spectrum of 2-amino-5-benzoyl- $1 H$-benzimidazole (5t) in DMSO- $d 6$ at $100 \mathrm{MHz}$. 

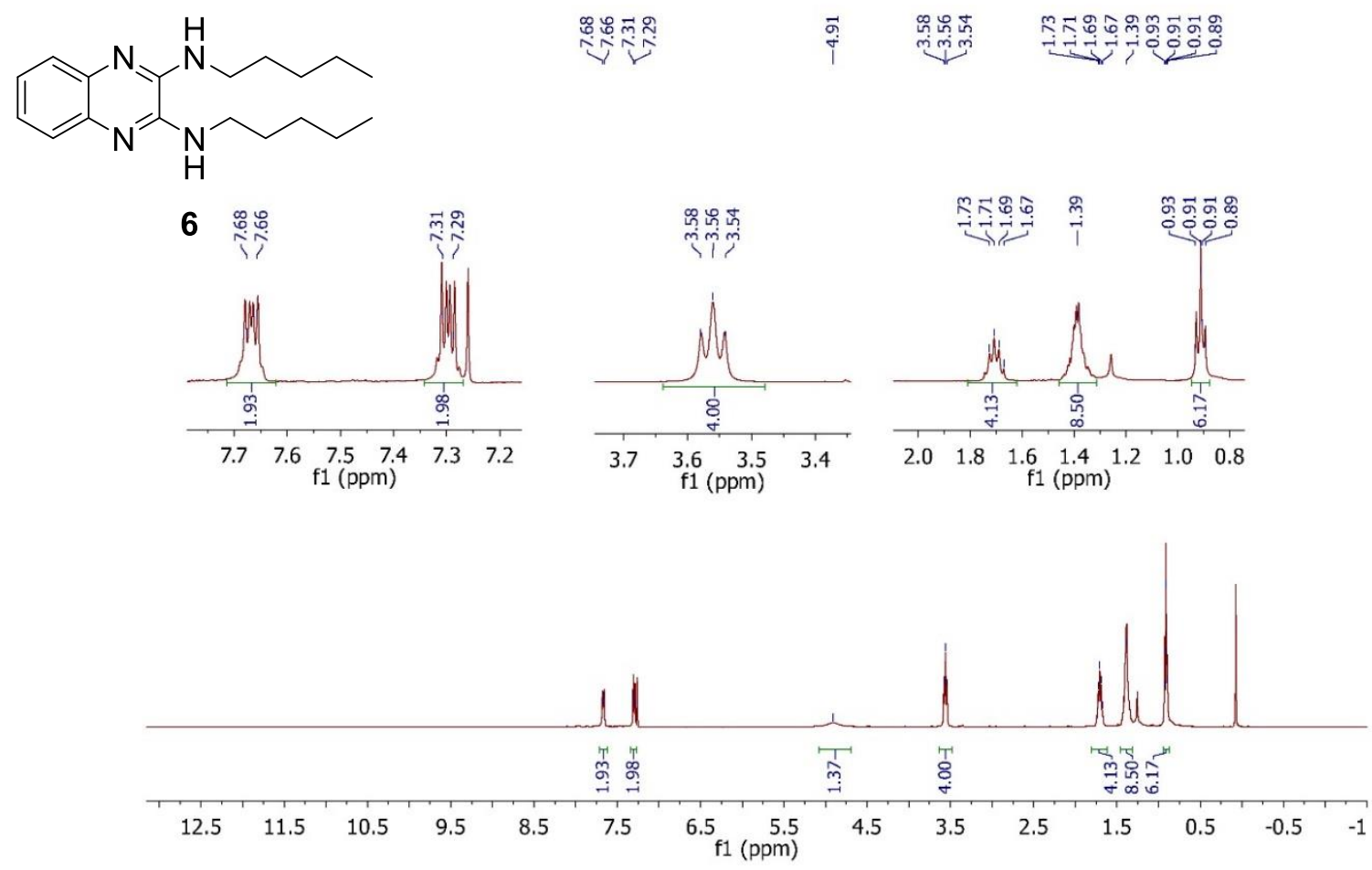

Figure A84. ${ }^{1} \mathrm{H}$ NMR spectrum of $N_{2}, N_{3}$-dipentylquinoxaline-2,3-diamine (6) in $\mathrm{CDCl}_{3}$ at 400 MHz.

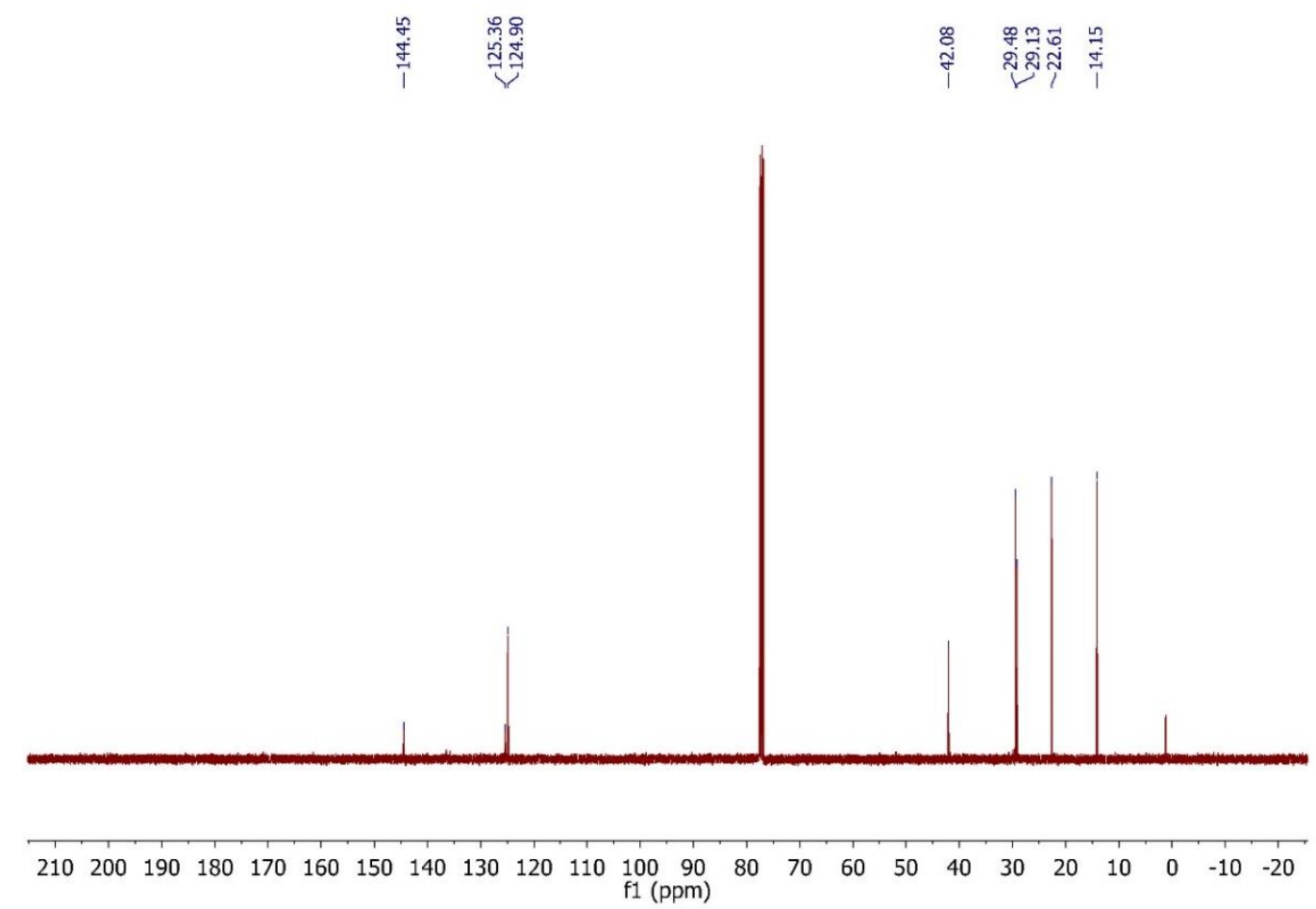

Figure A85. ${ }^{13} \mathrm{C}$ NMR spectrum of $\mathrm{N}_{2}, \mathrm{~N}_{3}$-dipentylquinoxaline-2,3-diamine (6) in $\mathrm{CDCl}_{3}$ at $100 \mathrm{MHz}$. 